\title{
Evaluating the Robustness of Metal-Organic Frameworks for Synthetic Chemistry
}

Zihao Wang, ${ }^{a}$ Arvin Bilegsaikhan, ${ }^{a}$ Ronald T. Jerozal, ${ }^{a}$ Tristan A. Pitt, Phillip J. Milner ${ }^{a, *}$

${ }^{a}$ Department of Chemistry and Chemical Biology, Cornell University, Ithaca, NY, 14850, United States

*pjm347@cornell.edu

Table of Contents.

Page.

1. General Procedures.

S2

2. Synthesis of organic linkers.

S3

3. Procedure for stability studies.

$\mathrm{S17}$

4. Synthesis, characterization, and stability assessment of MIL-100 (Fe).

S19

5. Synthesis, characterization, and stability assessment of MIL-100 (Cr).

S27

6. Synthesis, characterization, and stability assessment of MOF-808.

S35

7. Synthesis, characterization, and stability assessment of UiO-66.

S43

8. Synthesis, characterization, and stability assessment of UiO-67.

S51

9. Synthesis, characterization, and stability assessment of PCN-128.

S59

10. Synthesis, characterization, and stability assessment of MOF-74 (Mg).

S67

11. Synthesis, characterization, and stability assessment of MOF-74 (Ni).

S75

12. Synthesis, characterization, and stability assessment of $\mathrm{Niz}$ (m-dobdc).

S83

13. Synthesis, characterization, and stability assessment of $\mathrm{Mg}_{2}$ (dobpdc).

S91

14. Synthesis, characterization, and stability assessment of $\mathrm{Mg}_{2}(\mathrm{dotpdc}$ ).

S99

15. Synthesis, characterization, and stability assessment of ZIF-8.

16. Synthesis, characterization, and stability assessment of $\mathrm{Ni}_{2} \mathrm{Cl}_{2}(\mathrm{btdd})$.

17. Synthesis, characterization, and stability assessment of $\mathrm{Ni}_{3}(\mathrm{btp})_{2}$.

18. Synthesis, characterization, and stability assessment of $\mathrm{Zn}(\mathrm{bdp})$.

19. Synthesis, characterization, and stability assessment of $\mathrm{Ni}(\mathrm{bdp})$.

20. Synthesis, characterization, and stability assessment of $\mathrm{Fe}_{2}(\mathrm{bdp})_{3}$.

21. Comparison of Langmuir surface areas to literature values.

22. Additional stability tests for $\mathrm{Fe}_{2}(\mathrm{bdp}) 3$.

23. Additional stability tests for MOF-808.

24. Additional stability tests for MOF-74 (Ni).

25. Stability assessments of defect-rich UiO-66 and UiO-67.

26. References. 


\section{General Procedures.}

All reagents were purchased from commercial vendors and used without additional purification unless specified. All solvents were purchased from Fisher Scientific and used without additional purification unless specified. Degassed solvents were obtained by sparging with argon for $30 \mathrm{~min}$ and then passing the solvent through two columns of activated alumina before use. The metal salts $\mathrm{FeCl}_{2} \bullet 4 \mathrm{H}_{2} \mathrm{O}$ (99+\%, Fluka), $\mathrm{CrCl}_{3} \bullet 6 \mathrm{H}_{2} \mathrm{O}$ (96\%, Sigma Aldrich), $\mathrm{ZrCl}_{4}$ (99.5\%, Alfa Aesar), $\mathrm{ZrOCl}_{2} \cdot 8 \mathrm{H}_{2} \mathrm{O}$ (98+\%, Alfa Aesar), $\mathrm{Mg}\left(\mathrm{NO}_{3}\right)_{2} \cdot 6 \mathrm{H}_{2} \mathrm{O}$ (98-102\%, Alfa Aesar), $\mathrm{Ni}\left(\mathrm{NO}_{3}\right)_{2} \cdot 6 \mathrm{H}_{2} \mathrm{O}$ (98\%, Acros), $\mathrm{Zn}\left(\mathrm{NO}_{3}\right)_{2} \cdot 6 \mathrm{H}_{2} \mathrm{O}$ (98\%, Sigma Aldrich), $\mathrm{Ni}(\mathrm{OAc})_{2} \bullet 4 \mathrm{H}_{2} \mathrm{O}(98 \%$, Sigma Aldrich), $\mathrm{Zn}(\mathrm{OAc})_{2} \bullet 2 \mathrm{H}_{2} \mathrm{O}$ (J. T. Baker), $\mathrm{Fe}(\text { acac) })_{3}\left(99 \%\right.$, Sigma Aldrich), and $\mathrm{NiCl}_{2} \bullet 6 \mathrm{H}_{2} \mathrm{O}$ (99.95\%, Acros) were stored in desiccators when not in use. The metal salt $\mathrm{NiCl}_{2}$ (98\%, Sigma Aldrich) was stored in a nitrogen-filled glovebox when not in use. The linkers trimesic acid (98\%, Alfa Aesar), 2,5-dihydroxyterephthalic acid (97\%, Alfa Aesar), terephthalic acid (98\%, Sigma Aldrich), 4,4'-biphenyldicarboxylic acid (97\%, Oakwood Chemical), and 2-methylimidazole $(97 \%$, Fluka) were purchased from commercial vendors and used without additional purification. Surface area data were collected on either a Micromeritics ASAP 2020 or a Micromeritics 3-Flex gas sorption analyzer using ultrapure $\mathrm{N}_{2}(99.999 \%)$ and a liquid $\mathrm{N}_{2}$ bath. Laboratory powder Xray diffraction (PXRD) data were collected on a Rigaku Ultima IV diffractometer equipped with a $\mathrm{Cu} \mathrm{K} \alpha$ source $(\lambda=1.5406 \AA) .{ }^{1} \mathrm{H}$ NMR data were collected on a Bruker INOVA $500 \mathrm{MHZ}$ spectrometer and are referenced to residual solvent. Full widths at half maximum (FWHM) were determined using OriginPro. Infrared (IR) spectra were collected on a Bruker Tensor II IR spectrometer with a diamond Attenuated Total Reflectance (ATR) attachment. Scanning electron microscopy (SEM) images were taken at $2.0 \mathrm{kV}$ using a Zeiss Gemini 500 scanning electron microscope. The powder samples were immobilized on carbon tape mounted on an aluminum stub. The samples were blown using compressed air to remove excess material not stuck to the tape and then were coated with a gold/palladium layer. 


\section{Synthesis of organic linkers.}

\section{Synthesis of H4etbptc.}<smiles>c1ccc(C(=C(c2ccccc2)c2ccccc2)c2ccccc2)cc1</smiles><smiles>Brc1ccc(C(=C(c2ccc(Br)cc2)c2ccc(Br)cc2)c2ccc(Br)cc2)cc1</smiles>

This procedure is adapted from the literature. ${ }^{1}$ A $500 \mathrm{~mL}$ round bottom flask equipped with a stir bar was charged with tetraphenylethylene (9.96 g, $30.0 \mathrm{mmol}, 1.00$ equiv.) and $\mathrm{CH}_{2} \mathrm{Cl}_{2}(500 \mathrm{~mL})$. The reaction mixture was cooled while stirring to $0{ }^{\circ} \mathrm{C}$ using an ice water bath. Bromine $(18 \mathrm{~mL})$ was added dropwise using an addition funnel. The reaction mixture was allowed to warm to room temperature and stir at room temperature for $14 \mathrm{~h}$ open to the air (Caution! Release of gaseous $\mathrm{HBr})$. Water was added $(300 \mathrm{~mL})$, and the phases were separated. The aqueous layer was further extracted with $\mathrm{CH}_{2} \mathrm{Cl}_{2}(2 \times 200 \mathrm{~mL})$. The combined organic layers were washed with saturated aq. $\mathrm{Na}_{2} \mathrm{SO}_{3}(200 \mathrm{~mL})$, saturated aq. $\mathrm{Na}_{2} \mathrm{CO}_{3}(200 \mathrm{~mL})$, and brine $(200 \mathrm{~mL})$. The solution was dried over $\mathrm{Mg}_{2} \mathrm{SO}_{4}$, filtered, and concentrated to yield an off-white solid. This solid was triturated with hexanes $(50 \mathrm{~mL})$ and filtered, yielding tetrakis(4-bromophenyl)ethylene $(18.3 \mathrm{~g}, 94 \%)$ as a white solid. ${ }^{1} \mathrm{H}$ NMR (500 MHz, $\left.\mathrm{CDCl}_{3}\right): \delta 7.24(\mathrm{~d}, \mathrm{~J}=8.4 \mathrm{~Hz}, 8 \mathrm{H}), 6.82(\mathrm{~d}, \mathrm{~J}=8.5 \mathrm{~Hz}, 4 \mathrm{H}) \mathrm{ppm}$. This spectrum is consistent with that reported in the literature. ${ }^{2}$

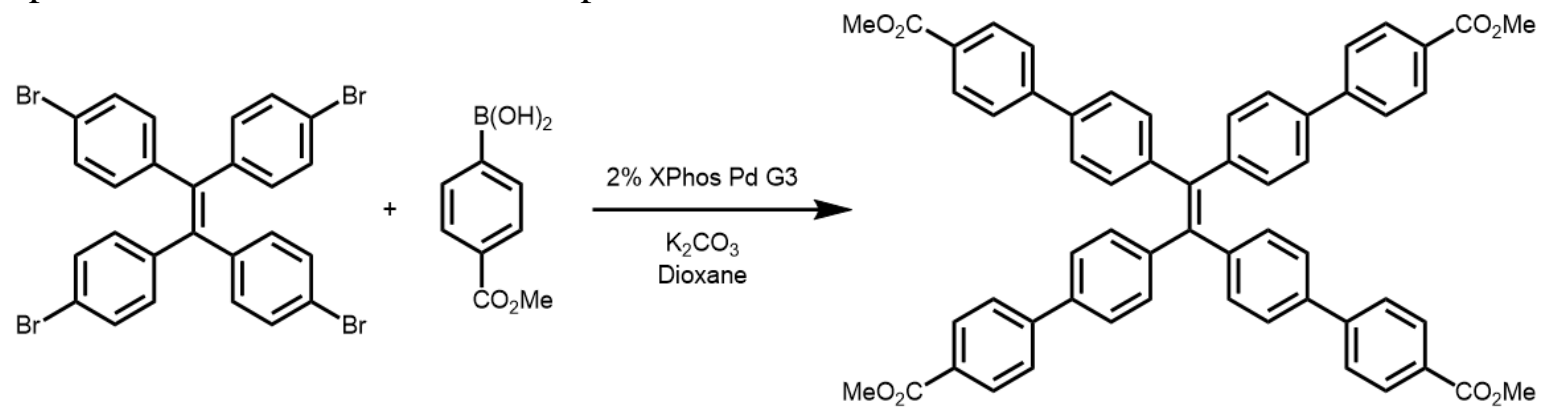

A $500 \mathrm{~mL}$ 3-neck round bottom flask equipped with a stir bar and reflux condenser was charged with tetrakis(4-bromophenyl)ethylene $(3.87 \mathrm{~g}, 6.00 \mathrm{mmol}, 1.00$ equiv.), methyl 4carboxylphenylboronic acid (4.77 g, $26.4 \mathrm{mmol}, 4.40$ equiv.), $\mathrm{K}_{2} \mathrm{CO}_{3}$ (6.63 g, $48.0 \mathrm{mmol}, 8.00$ equiv.), and XPhos Pd G3 (102 mg, $0.12 \mathrm{mmol}, 2 \%$ ). The flask was placed under high vacuum and back-filled with $\mathrm{N}_{2}$. This process was repeated a total of three times. Next, freshly degassed 1,4-dioxane $(90 \mathrm{~mL})$ was added, and the reaction mixture was vigorously stirred at reflux under $\mathrm{N}_{2}$ for $72 \mathrm{~h}$. At this time, the reaction mixture was allowed to cool to room temperature, and the 1,4-dioxane was removed in vacuo. Next, water $(200 \mathrm{~mL})$ was added and the heterogeneous mixture was filtered. The resulting solid was washed thoroughly with water $(200 \mathrm{~mL})$. The solid was dissolved in hot $\mathrm{CHCl}_{3}(500 \mathrm{~mL})$. The solution was filtered through a plug of celite, eluting with $\mathrm{CHCl}_{3}$. The solvent was removed in vacuo. The resulting solid was triturated with acetone, filtered, and washed with acetone $(20 \mathrm{~mL})$ and methanol $(20 \mathrm{~mL})$ to yield tetramethyl 4',4"',4"'",4"'"''-(ethene-1,1,2,2-tetrayl)tetrakis([1,1'-biphenyl]-4-carboxylate) as a yellow solid (4.36 g, 84\%). ${ }^{1} \mathrm{H}$ NMR (500 MHz, DMSO-d 6 ): $\delta 8.07$ (d, J = 8.4 Hz, 8H), 7.64 (d, J = 8.5 Hz, 
$8 \mathrm{H}), 7.45(\mathrm{~d}, \mathrm{~J}=8.4 \mathrm{~Hz}, 8 \mathrm{H}), 7.21(\mathrm{~d}, \mathrm{~J}=8.4 \mathrm{~Hz}, 8 \mathrm{H}) \mathrm{ppm}$. This spectrum is consistent with that reported in the literature. ${ }^{3}$<smiles>CC(=O)c1ccc(-c2ccc(C(=C(c3ccc(-c4ccc(C(=O)O)cc4)cc3)c3ccc(-c4ccc(C(=O)O)cc4)cc3)c3ccc(-c4ccc(C(=O)ON(C(C)=O)C(C)(C)O)cc4)cc3)cc2)cc1</smiles>

A $500 \mathrm{~mL}$ round bottom flask equipped with a stir bar and reflux condenser was charged with tetramethyl 4',4"',4"'",4"'"'-(ethene-1,1,2,2-tetrayl)tetrakis([1,1'-biphenyl]-4-carboxylate) (4.50 g, $5.16 \mathrm{mmol}, 1.00$ equiv.), freshly ground $\mathrm{NaOH}$ (20.6 g, $516 \mathrm{mmol}, 100$ equiv.), THF (150 mL), and methanol $(200 \mathrm{~mL})$. The reaction mixture was allowed to stir vigorously at reflux for $24 \mathrm{~h}$, at which time it was allowed to cool to room temperature and filtered. The resulting solid was washed thoroughly with THF $(100 \mathrm{~mL})$. The solid was transferred to a fresh $500 \mathrm{~mL}$ round bottom flask and suspended in water $(100 \mathrm{~mL})$. Concentrated $\mathrm{HCl}$ was added until the $\mathrm{pH}$ of the solution was less than 4 , leading to precipitation of a white solid from solution. The heterogeneous mixture was filtered, leading to a color change from white to yellow. The resulting yellow solid was washed thoroughly with water $(200 \mathrm{~mL})$ and ether $(200 \mathrm{~mL})$. Drying under high vacuum for $12 \mathrm{~h}$ yielded 4',4"',4"'",4"'"'-(ethene-1,1,2,2-tetrayl)tetrakis(([1,1'-biphenyl]-4-carboxylic acid)) as a bright yellow solid (H $\mathrm{H}_{4}$ etbptc, $\left.3.42 \mathrm{~g}, 82 \%\right) .{ }^{1} \mathrm{H}$ NMR $\left(500 \mathrm{MHz}, \mathrm{DMSO}-\mathrm{d}_{6}\right): \delta 7.96(\mathrm{~d}, \mathrm{~J}=8.2 \mathrm{~Hz}, 8 \mathrm{H})$, $7.77(\mathrm{~d}, \mathrm{~J}=8.1 \mathrm{~Hz}, 8 \mathrm{H}), 7.62(\mathrm{~d}, \mathrm{~J}=8.1 \mathrm{~Hz}, 8 \mathrm{H}), 7.19(\mathrm{~d}, \mathrm{~J}=8.1 \mathrm{~Hz}, 8 \mathrm{H}) \mathrm{ppm}$ (the carboxylic acid protons could not be readily observed). This spectrum is consistent with that reported in the literature. ${ }^{3}$

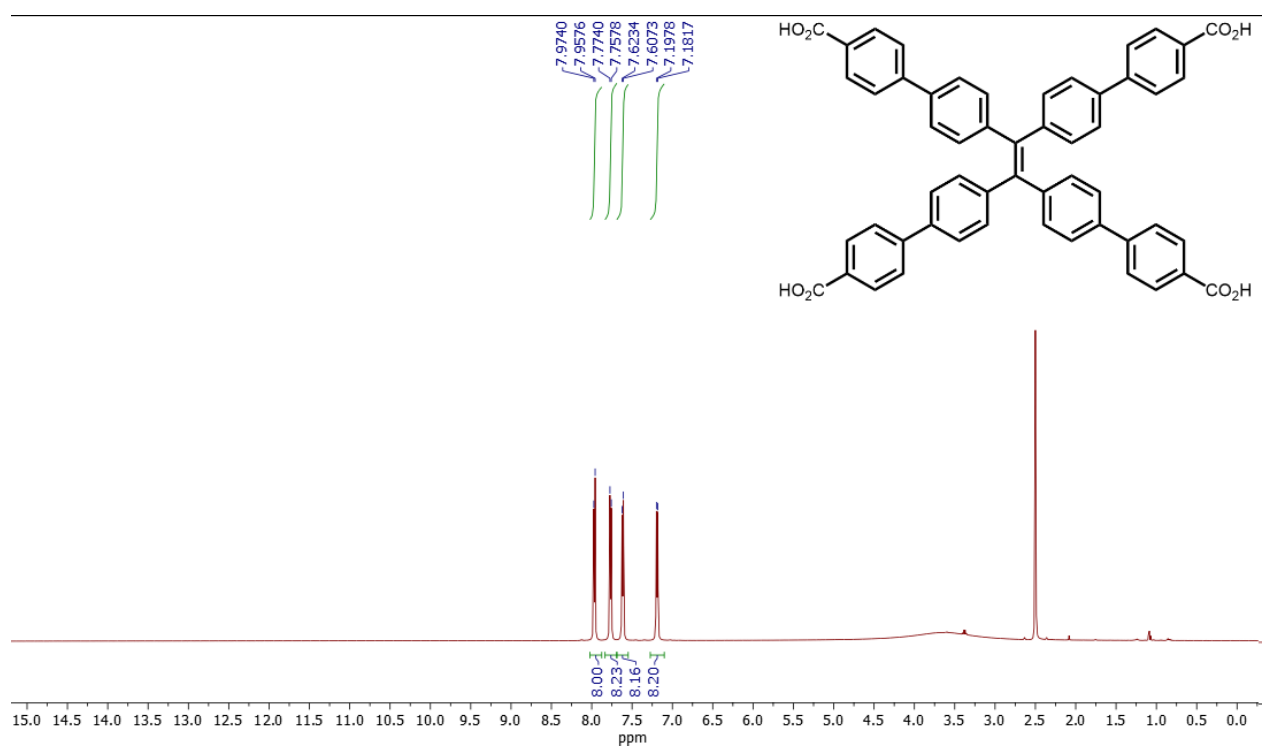

Figure S1. ${ }^{1} \mathrm{H}$ NMR spectrum $\left(500 \mathrm{MHz}, \mathrm{DMSO}-\mathrm{d}_{6}\right)$ of $\mathrm{H}_{4}$ etbptc used in this work. 
Synthesis of $\mathbf{H} 4 m$-dobdc.
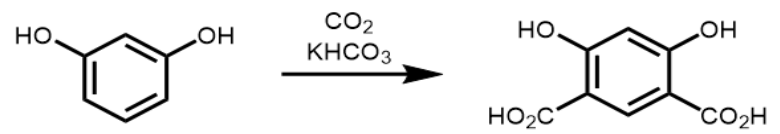

The $\mathrm{H}_{4} m$-dobdc used in this work was prepared according to the literature procedure. ${ }^{4}$ Resorcinol (5.00 g, $45.2 \mathrm{mmol}, 1.00$ equiv.) and $\mathrm{KHCO}_{3}(10.5 \mathrm{~g}, 105 \mathrm{mmol}, 2.32$ equiv.) were pulverized separately using a mortar and pestle and then thoroughly mixed together. The combined solids were sealed in a Parr reactor equipped with a pressure gauge. The Parr reactor was pressurized with $\mathrm{CO}_{2}$ to 25 bar at room temperature and then vented to the atmosphere. This process was repeated a total of three times. The Parr reactor was pressurized with $\mathrm{CO}_{2}$ to 25 bar at room temperature and sealed. The Parr reactor was then heated to $230{ }^{\circ} \mathrm{C}$ (as measured by an external thermocouple) in a sand bath for $18 \mathrm{~h}$ and then slowly cooled to room temperature. The pressure was vented and $1 \mathrm{~L}$ of water was added to the solid. The solid was broken up mechanically and then by sonication. The resulting suspension was filtered, and the filtrate was acidified with concentrated $\mathrm{HCl}$ until the $\mathrm{pH}$ of the solution was less than 1 , at which time a white solid precipitated from solution. The product was then collected by filtration and recrystallized from hot water. Filtration yielded 2,4-dihydroxybenzene-1,5-dicarboxylic acid ( $\mathrm{H}_{4} m$-dobdc, $\left.4.19 \mathrm{~g}, 47 \%\right)$ as a pale yellow solid. ${ }^{1} \mathrm{H}$ NMR (500 MHz, DMSO-d 6 ): $\delta 13.7 \mathrm{ppm}(\mathrm{br} \mathrm{s}, 2 \mathrm{H}), 12.0(\mathrm{br} \mathrm{s}, 2 \mathrm{H}$ ), $8.30 \mathrm{ppm}(\mathrm{s}, 1 \mathrm{H}), 6.41 \mathrm{ppm}(\mathrm{s}, 1 \mathrm{H})$. This spectrum is consistent with that reported in the literature. ${ }^{4}$

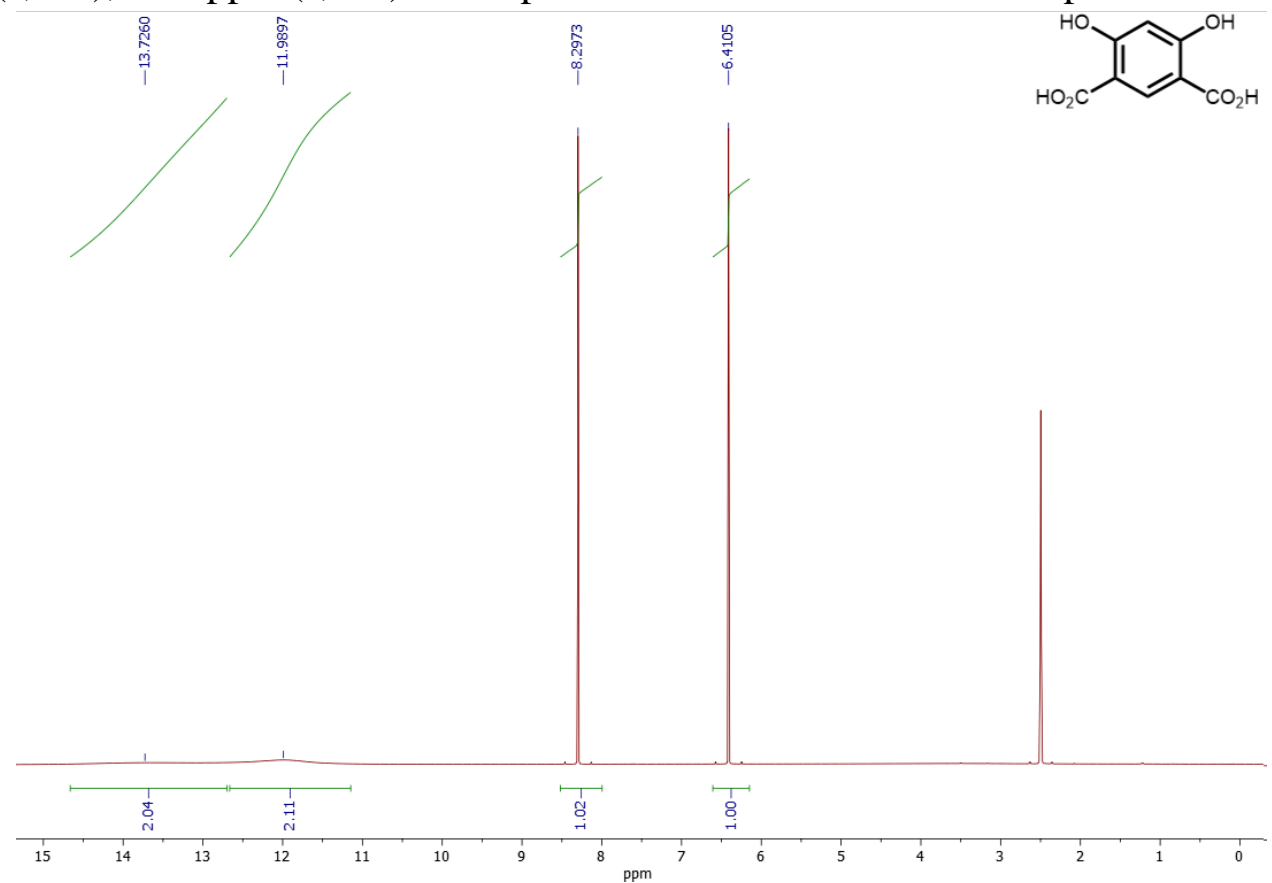

Figure S2. ${ }^{1} \mathrm{H}$ NMR spectrum (500 MHz, DMSO-d 6 ) of $\mathrm{H}_{4} m$-dobdc used in this work. 


\section{Synthesis of H4dobpdc.}

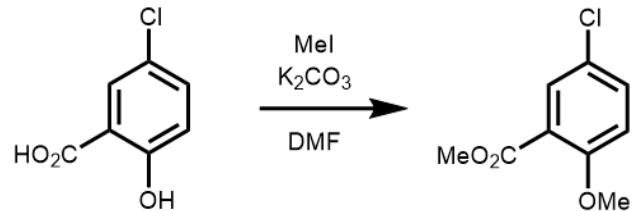

A $500 \mathrm{~mL}$ round bottom flask equipped with a stir bar was charged with 5-chlorosalicylic acid (10.4 g, 60.0 mmol, 1.00 equiv.), $\mathrm{K}_{2} \mathrm{CO}_{3}$ (33.2 g, $240 \mathrm{mmol}, 4.00$ equiv.), and $N, N-$ dimethylformamide $(120 \mathrm{~mL})$. Iodomethane $(11.2 \mathrm{~mL}, 180 \mathrm{mmol}, 3.00$ equiv.) was added, the flask was sealed with a septum, and the reaction mixture was allowed to stir vigorously at room temperature for $14 \mathrm{~h}$. At this time, water $(150 \mathrm{~mL})$ and ether $(250 \mathrm{~mL})$ were added, and the mixture was vigorously stirred until both phases were clear. The phases were separated, and the aqueous phase was extracted with ether $(2 \times 100 \mathrm{~mL})$. The combined organic extracts were washed with water $(5 \times 100 \mathrm{~mL})$ and brine $(100 \mathrm{~mL})$, dried over $\mathrm{Mg}_{2} \mathrm{SO}_{4}$, filtered, and concentrated in vacuo to yield methyl 5-chloro-2-methoxybenzoate $(8.95 \mathrm{~g}, 74 \%)$ as a pale yellow oil. ${ }^{1} \mathrm{H}$ NMR $(500$ $\left.\mathrm{MHz}_{\mathrm{CDCl}}\right): \delta 7.76(\mathrm{~d}, \mathrm{~J}=2.7 \mathrm{~Hz}, 1 \mathrm{H}), 7.41(\mathrm{dd}, \mathrm{J}=9.1,2.7 \mathrm{~Hz}, 1 \mathrm{H}), 6.91(\mathrm{~d}, \mathrm{~J}=9.0 \mathrm{~Hz}, 1 \mathrm{H})$, $3.89(\mathrm{~s}, 6 \mathrm{H}) \mathrm{ppm}$.

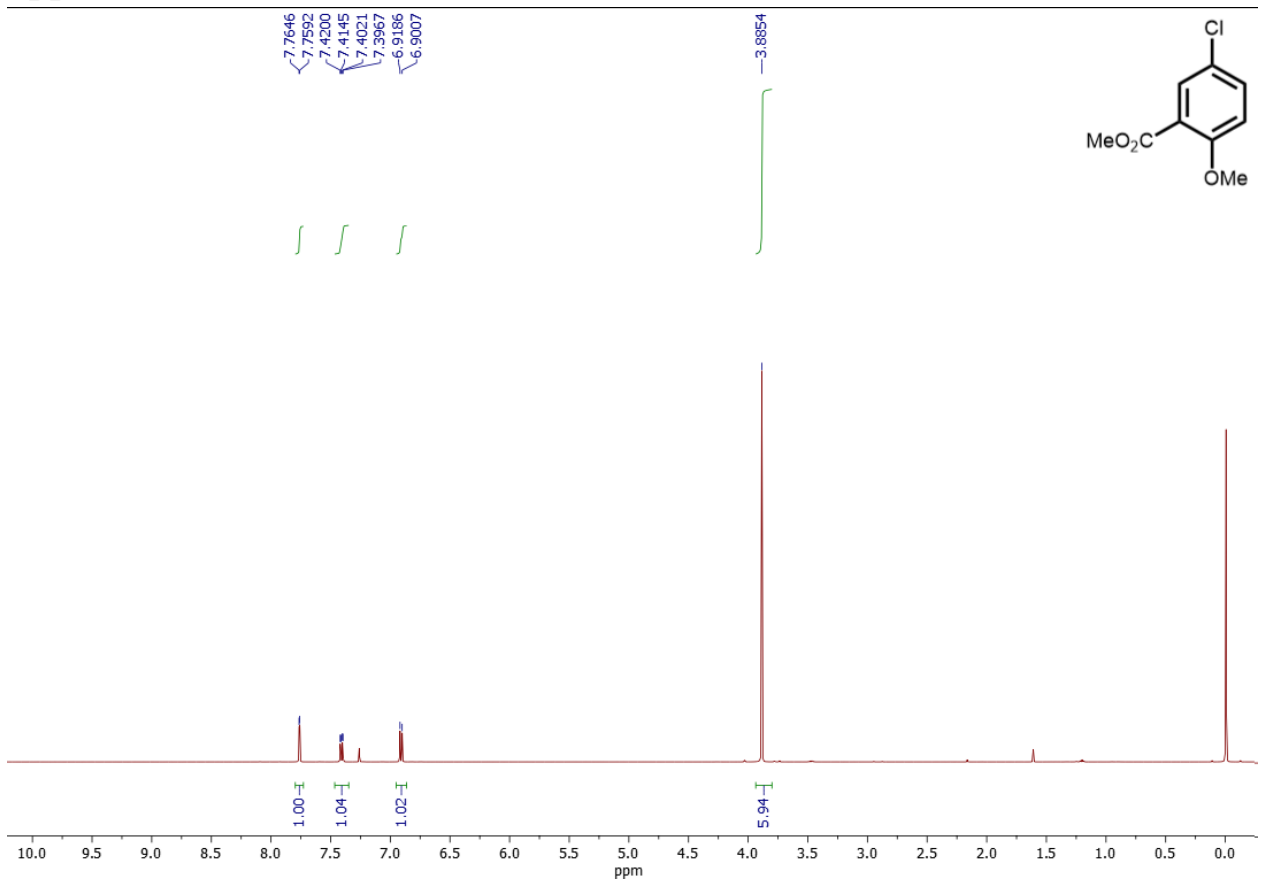

Figure S3. ${ }^{1} \mathrm{H}$ NMR spectrum $\left(500 \mathrm{MHz}, \mathrm{CDCl}_{3}\right)$ of methyl 5-chloro-2-methoxybenzoate.

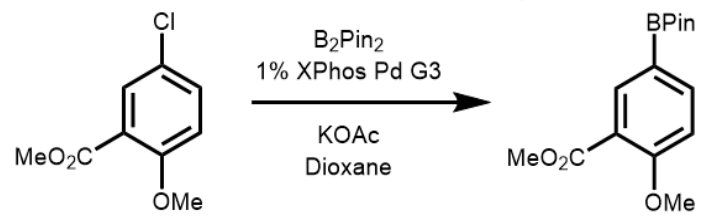

A $500 \mathrm{~mL} 3$-neck round bottom flask equipped with a stir bar and reflux condenser was charged with methyl 5-chloro-2-methoxybenzoate (5.74 g, $28.6 \mathrm{mmol}, 1.00$ equiv.), KOAc (8.42 g, 85.8 mmol, 3.00 equiv.), XPhos Pd G3 33 (242 mg, $0.29 \mathrm{mmol}, 1 \%$ ), and bis(pinacolato)diboron ( $8.00 \mathrm{~g}$, 31.5 mmol, 1.10 equiv.). The flask was placed under high vacuum and back-filled with $\mathrm{N}_{2}$. This 
process was repeated a total of three times. Next, freshly degassed 1,4-dioxane (60 mL) was added, and the reaction mixture was stirred at reflux under $\mathrm{N}_{2}$ for $24 \mathrm{~h}$. At this time, the reaction mixture was allowed to cool to room temperature and concentrated to yield a black solid. $\mathrm{CH}_{2} \mathrm{Cl}_{2}(200 \mathrm{~mL})$ and water $(200 \mathrm{~mL})$ were added, and the mixture was vigorously stirred for $5 \mathrm{~min}$ to dissolve all solids. The phases were separated, and the aqueous phase was further extracted with $\mathrm{CH}_{2} \mathrm{Cl}_{2}(2 \mathrm{x}$ $100 \mathrm{~mL})$. The combined organic extracts were washed with brine $(100 \mathrm{~mL})$, dried over $\mathrm{Mg}_{2} \mathrm{SO}_{4}$, and filtered through a short plug of celite, eluting with $\mathrm{CH}_{2} \mathrm{Cl}_{2}$. The solution was concentrated, and the resulting solid was triturated with hexanes and filtered, yielding methyl 5-(pinacalboryl)2-methoxybenzoate $(5.81 \mathrm{~g}, 70 \%)$ as a fluffy white solid. ${ }^{1} \mathrm{H} \mathrm{NMR}\left(500 \mathrm{MHz}, \mathrm{CDCl}_{3}\right): \delta 8.22(\mathrm{~d}$, $\mathrm{J}=1.8 \mathrm{~Hz}, 1 \mathrm{H}), 7.90(\mathrm{dd}, \mathrm{J}=8.3,1.7 \mathrm{~Hz}, 1 \mathrm{H}), 6.96(\mathrm{~d}, \mathrm{~J}=8.4 \mathrm{~Hz}, 1 \mathrm{H}), 3.92(\mathrm{~s}, 3 \mathrm{H}), 3.88(\mathrm{~s}, 3 \mathrm{H})$ ppm. This spectrum is consistent with that reported in the literature. ${ }^{5}$

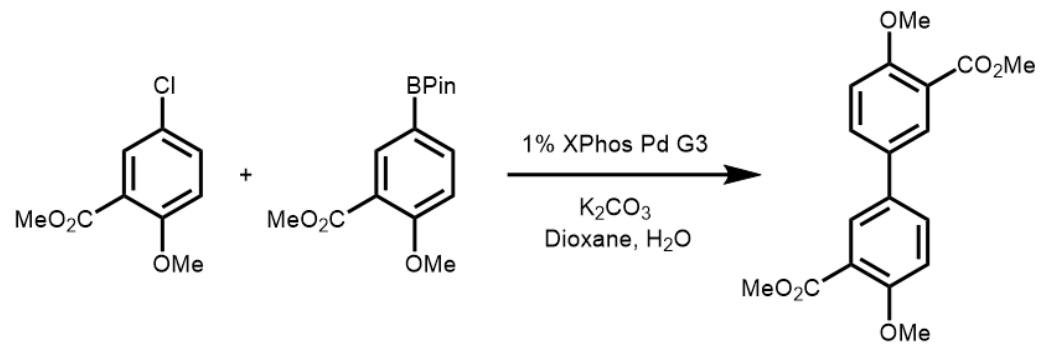

A $500 \mathrm{~mL}$ 3-neck round bottom flask equipped with a stir bar and reflux condenser was charged with methyl 5-chloro-2-methoxybenzoate (2.00 g, $10.0 \mathrm{mmol}, 1.00$ equiv.), 5-(pinacalboryl)-2methoxybenzoate (3.21 g, $11.0 \mathrm{mmol}, 1.10$ equiv.), $\mathrm{K}_{2} \mathrm{CO}_{3}$ (2.76 g, $20.0 \mathrm{mmol}, 2.00$ equiv.) and XPhos Pd G3 ${ }^{3}$ (85.0 mg, 0.1 Mmol, 1\%). The flask was placed under high vacuum and back-filled with $\mathrm{N}_{2}$. This process was repeated a total of three times. Next, freshly degassed 1,4-dioxane (20 $\mathrm{mL})$ and freshly degassed water $(10 \mathrm{~mL})$ were added, and the reaction mixture was stirred at reflux under $\mathrm{N}_{2}$ for $24 \mathrm{~h}$. At this time, the reaction mixture was poured into water ( $\left.200 \mathrm{~mL}\right)$, resulting in the precipitation of a gray solid from solution. The heterogeneous mixture was filtered, and the resulting solid was washed thoroughly with water $(100 \mathrm{~mL})$. The solid was dissolved in $\mathrm{CH}_{2} \mathrm{Cl}_{2}$ (250 mL), dried over $\mathrm{Mg}_{2} \mathrm{SO}_{4}$, and filtered through a short plug of celite, eluting with $\mathrm{CH}_{2} \mathrm{Cl}_{2}$. The solution was concentrated, and the resulting solid was triturated with methanol and filtered, yielding dimethyl 4,4'-dimethoxy-[1,1'-biphenyl]-3,3'-dicarboxylate (2.08 g, 63\%) as an off-white solid. ${ }^{1} \mathrm{H}$ NMR (500 MHz, DMSO-d 6 ): $\delta 7.86$ (d, J = 2.6 Hz, 2H), 7.82 (dd, J = 8.8, 2.6 Hz, 2H), $7.23(\mathrm{~d}, \mathrm{~J}=8.7 \mathrm{~Hz}, 2 \mathrm{H}) \mathrm{ppm}$. This spectrum is consistent with that reported in the literature. ${ }^{6}$

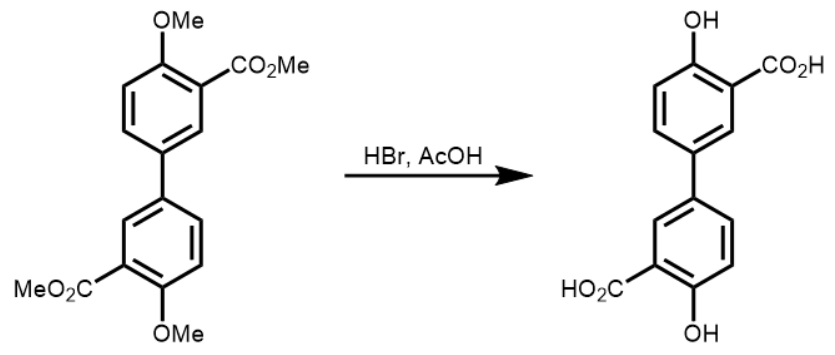

A $250 \mathrm{~mL}$ round bottom flask equipped with a stir bar and reflux condenser was charged with 4,4'dimethoxy-[1,1'-biphenyl]-3,3'-dicarboxylate (2.08 g, $6.30 \mathrm{mmol}, 1.00$ equiv.), concentrated $\mathrm{HBr}$ $(50 \mathrm{~mL})$, and glacial acetic acid $(50 \mathrm{~mL})$. The reaction mixture was allowed to stir vigorously at 
reflux for $48 \mathrm{~h}$. At this time, the reaction mixture was allowed to cool to room temperature and poured into water $(500 \mathrm{~mL})$, resulting in precipitation of a light brown solid from solution. The heterogeneous mixture was filtered, and the resulting solid was washed with water $(300 \mathrm{~mL})$ and ether (300 mL), yielding 4,4'-dihydroxy-[1,1'-biphenyl]-3,3'-dicarboxylic acid ( $\mathrm{H}_{4} \mathrm{dobpdc}, 1.50 \mathrm{~g}$, $87 \%$ ) as a light brown solid. ${ }^{1} \mathrm{H}$ NMR (500 MHz, DMSO-d $)$ : $\delta 14.1$ (bs, 2H), 11.3 (bs, 2H), 7.96 $(\mathrm{d}, \mathrm{J}=2.1 \mathrm{~Hz}, 2 \mathrm{H}), 7.78(\mathrm{dd}, \mathrm{J}=8.7,2.5 \mathrm{~Hz}, 2 \mathrm{H}), 7.04(\mathrm{~d}, \mathrm{~J}=8.6 \mathrm{~Hz}, 2 \mathrm{H}) \mathrm{ppm}$. This spectrum is consistent with that reported in the literature. ${ }^{7}$

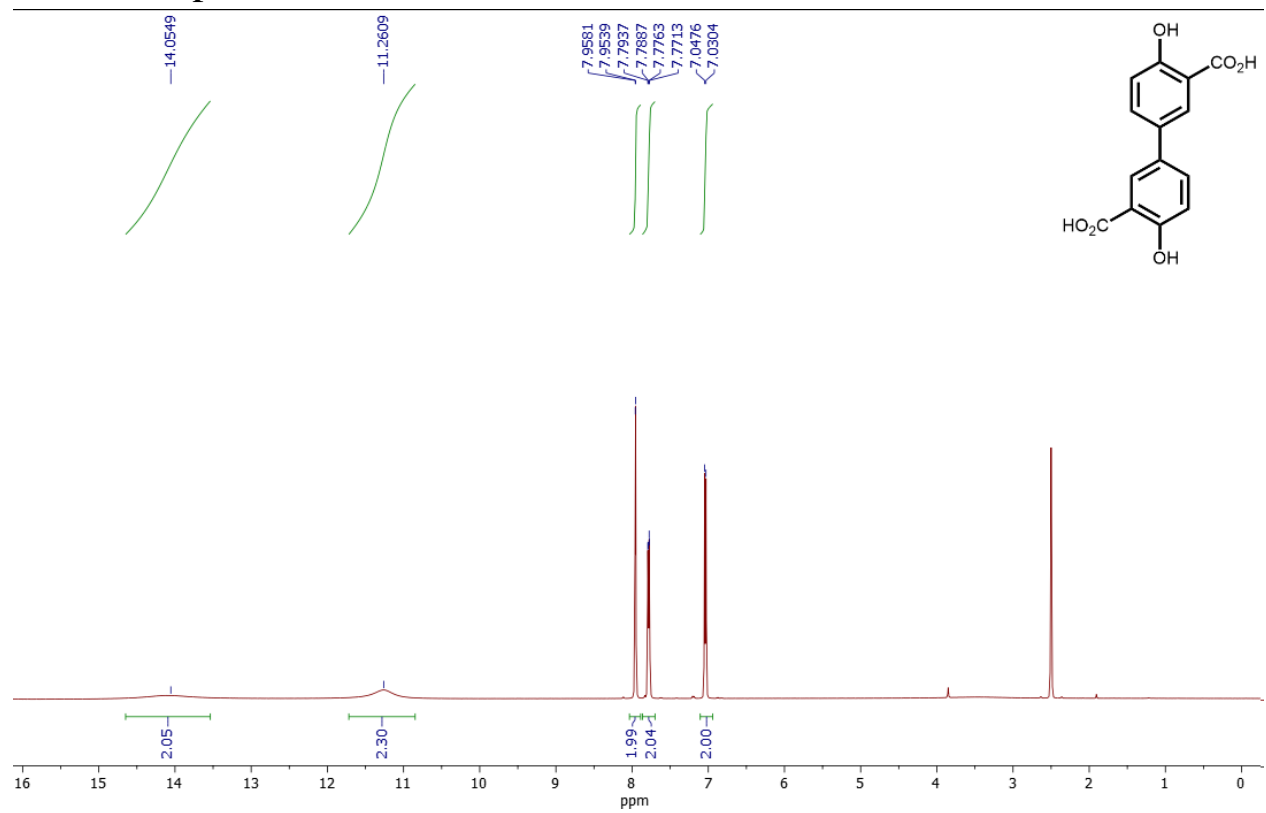

Figure S4. ${ }^{1} \mathrm{H}$ NMR spectrum (500 MHz, DMSO-d $)$ of $\mathrm{H}_{4}$ dobpdc used in this work.

\section{Synthesis of H4dotpdc.}

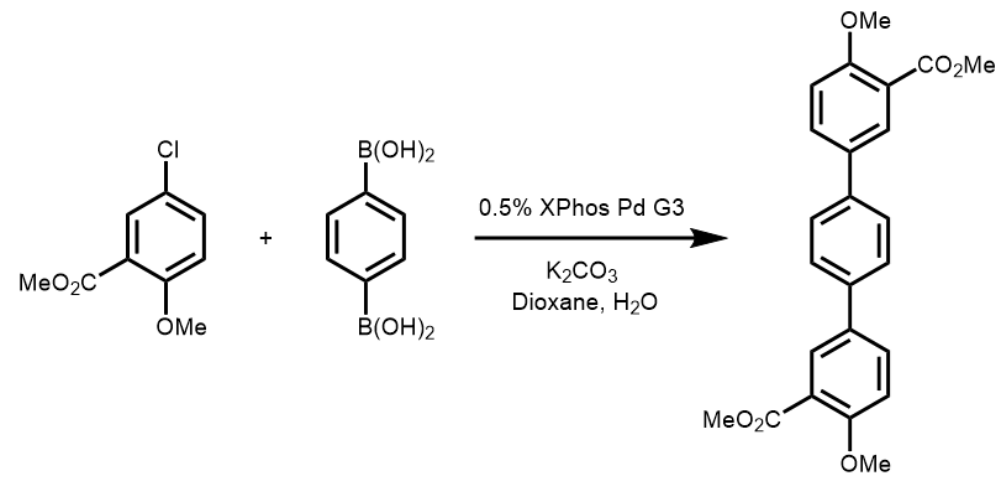

A $250 \mathrm{~mL}$ 3-neck round bottom flask equipped with a stir bar and reflux condenser was charged with benzene-1,4-diboronic acid (1.66 g, $10.0 \mathrm{mmol}, 1.00$ equiv.), methyl 5-chloro-2methoxybenzoate (4.41 g, $22.0 \mathrm{mmol}, 2.20$ equiv.), XPhos Pd G33 (42.3 mg, 0.05 mmol, 0.5\%), XPhos (23.8 mg, $0.05 \mathrm{mmol}, 0.5 \%$ ), and $\mathrm{K}_{2} \mathrm{CO}_{3}$ (5.52 g, $40.0 \mathrm{mmol}, 4.00$ equiv.). The flask was placed under high vacuum and back-filled with $\mathrm{N}_{2}$. This process was repeated a total of three times. Next, freshly degassed 1,4-dioxane (40 mL) and freshly degassed water (20 mL) were added, and the reaction mixture was stirred at reflux under $\mathrm{N}_{2}$ for $24 \mathrm{~h}$. At this time, the reaction mixture was 
poured into water $(200 \mathrm{~mL})$, resulting in the precipitation of a gray solid from solution. The heterogeneous mixture was filtered, and the resulting solid was washed thoroughly with water (100 $\mathrm{mL})$. The solid was dissolved in hot $\mathrm{CH}_{2} \mathrm{Cl}_{2}(300 \mathrm{~mL})$, dried over $\mathrm{Mg}_{2} \mathrm{SO}_{4}$, and filtered through a short plug of celite, eluting with $\mathrm{CH}_{2} \mathrm{Cl}_{2}$. The solution was concentrated, and the resulting solid was triturated with methanol and filtered, yielding dimethyl 4,4"-dimethoxy-[1,1':4',1"-terphenyl]3,3"-dicarboxylate $(1.65 \mathrm{~g}, 41 \%)$ as a white solid. ${ }^{1} \mathrm{H}$ NMR (500 MHz, DMSO-d $): \delta 8.08$ (d, J = $2.2 \mathrm{~Hz}, 2 \mathrm{H}), 7.74(\mathrm{dd}, \mathrm{J}=8.8,2.4 \mathrm{~Hz}, 2 \mathrm{H}), 7.64(\mathrm{~s}, 4 \mathrm{H}), 7.08(\mathrm{~d}, \mathrm{~J}=8.7 \mathrm{~Hz}, 2 \mathrm{H}) \mathrm{ppm}$. This spectrum is consistent with that reported in the literature. ${ }^{5}$

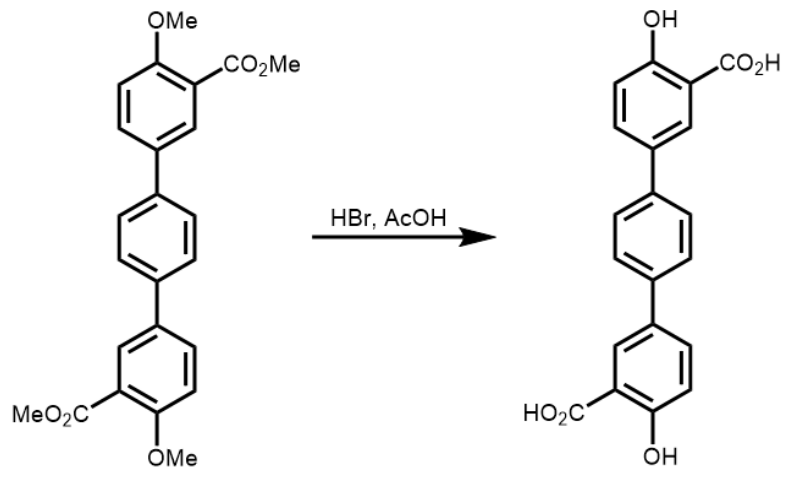

A $250 \mathrm{~mL}$ round bottom flask equipped with a stir bar and reflux condenser was charged with dimethyl 4,4"-dimethoxy-[1,1':4',1"-terphenyl]-3,3"-dicarboxylate (1.65 g, $4.06 \mathrm{mmol}, 1.00$ equiv.), concentrated $\mathrm{HBr}(75 \mathrm{~mL})$, and glacial acetic acid $(75 \mathrm{~mL})$. The reaction mixture was allowed to stir vigorously at reflux for $48 \mathrm{~h}$. At this time, the reaction mixture was allowed to cool to room temperature and poured into water $(500 \mathrm{~mL})$, resulting in precipitation of a white solid from solution. The heterogeneous mixture was filtered, and the resulting solid was washed with water $(300 \mathrm{~mL})$ and ether $(300 \mathrm{~mL})$, yielding 4,4"-dihydroxy-[1,1':4',1"-terphenyl]-3,3"dicarboxylic acid ( $\mathrm{H}_{4}$ dotpdc, $\left.1.29 \mathrm{~g}, 91 \%\right)$ as a white solid. ${ }^{1} \mathrm{H}$ NMR $\left(500 \mathrm{MHz}, \mathrm{DMSO}-\mathrm{d}_{6}\right): \delta$ 14.1 (bs, 2H), 11.3 (bs, 2H), 8.08 (d, J = 2.5 Hz, 2H), 7.89 (dd, J = 8.7, 2.5 Hz, 2H), 7.71 (s, 4H), $7.08(\mathrm{~d}, \mathrm{~J}=8.6 \mathrm{~Hz}, 2 \mathrm{H}) \mathrm{ppm}$. This spectrum is consistent with that reported in the literature. ${ }^{5}$ 


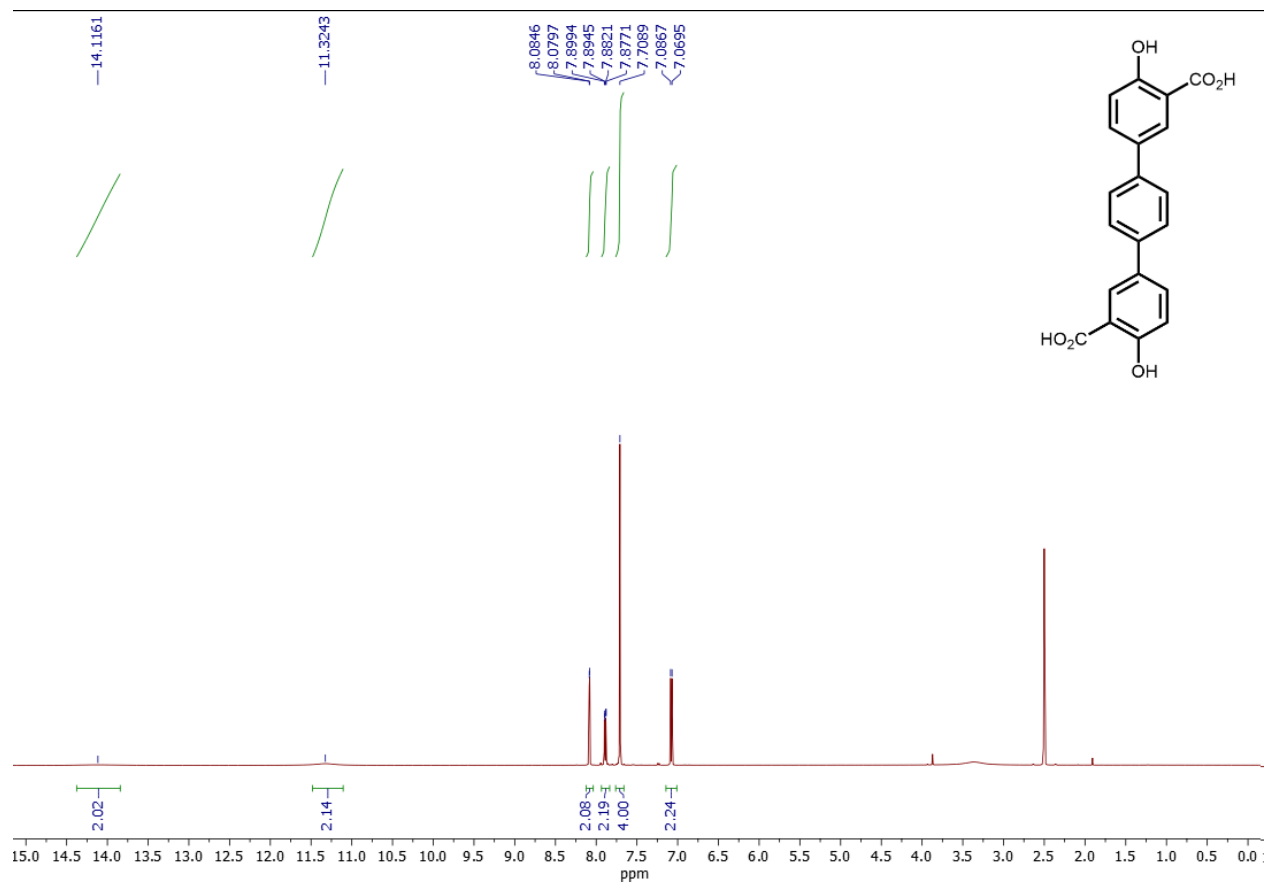

Figure S5. ${ }^{1} \mathrm{H}$ NMR spectrum ( $500 \mathrm{MHz}$, DMSO- $\mathrm{d}_{6}$ ) of $\mathrm{H}_{4}$ dotpdc used in this work.

Synthesis of $\mathrm{H}_{2}$ (btdd).

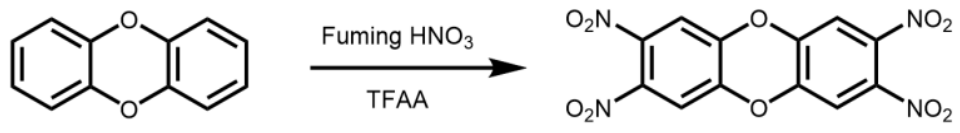

This procedure is adapted from the literature. ${ }^{8}$ A $50 \mathrm{~mL}$ round bottom flask equipped with a stir bar and reflux condenser was cooled to $0{ }^{\circ} \mathrm{C}$ using an ice water bath. Trifluoroacetic anhydride (3.6 mL) was added slowly at $0{ }^{\circ} \mathrm{C}$, followed by fuming nitric acid $(4.5 \mathrm{~mL})$. Next, dibenzo[b,e][1,4]dioxine $(1.09 \mathrm{~g}, 5.92 \mathrm{mmol}, 1.00$ equiv. $)$ was added portionwise over $10 \mathrm{~min}$ with vigorous stirring. The reaction mixture was warmed to room temperature, and then stirred at 65 ${ }^{\circ} \mathrm{C}$ for $1.5 \mathrm{~h}$. The reaction mixture was allowed to cool to room temperature and then poured into cold water $(100 \mathrm{~mL})$. The heterogeneous mixture was filtered, and the resulting solid was washed with water $(100 \mathrm{~mL})$. Drying under vacuum for $12 \mathrm{~h}$ yielded 2,3,7,8tetranitrodibenzo[b,e][1,4]dioxine $(1.83 \mathrm{~g}, 85 \%)$ as a bright yellow solid. ${ }^{1} \mathrm{H}$ NMR $(500 \mathrm{MHz}$, DMSO- $\left.\mathrm{d}_{6}\right): \delta 8.03(\mathrm{~s}, 4 \mathrm{H}) \mathrm{ppm}$. This spectrum is consistent with that reported in the literature. ${ }^{8}$<smiles>C[C@H](Cl)[C@H](C)Cl</smiles>

This procedure is adapted from the literature. ${ }^{9}$ A $250 \mathrm{~mL}$ round bottom flask equipped with a stir bar and reflux condenser was charged with 2,3,7,8-tetranitrodibenzo[b,e][1,4]dioxine (1.83 g, 5.02 mmol, 1.00 equiv.) and $6 \mathrm{M} \mathrm{HCl}(44 \mathrm{~mL})$. Sn powder (7.52 g, $63.7 \mathrm{mmol}, 12.7$ equiv.) was added portion-wise over $10 \mathrm{~min}$ with vigorous stirring. The reaction mixture was allowed to stir for 30 min at room temperature and then allowed to stir at reflux for $12 \mathrm{~h}$. The reaction mixture was allowed to cool to room temperature and filtered. The resulting solid was washed with $6 \mathrm{M} \mathrm{HCl}$ $(100 \mathrm{~mL})$, ethanol $(100 \mathrm{~mL})$, and diethyl ether $(100 \mathrm{~mL})$. Drying under vacuum for $12 \mathrm{~h}$ yielded 
dibenzo[b,e][1,4]dioxine-2,3,7,8-tetraamine hydrochloride $(3.91 \mathrm{~g}, 78 \%)$ as a green solid. ${ }^{1} \mathrm{H}$ NMR (500 MHz, DMSO- $\left.\mathrm{d}_{6}\right): \delta 6.61(\mathrm{bs}, 4 \mathrm{H}) \mathrm{ppm}$. This spectrum is consistent with that reported in the literature. ${ }^{9}$<smiles>CNc1cc2c(cc1NC)Oc1cc(NCl)c(N)cc1O2</smiles>

This procedure is adapted from the literature. ${ }^{8} \mathrm{~A} 100 \mathrm{~mL}$ round bottom flask equipped with a stir bar was charged with dibenzo[b,e][1,4]dioxine-2,3,7,8-tetraamine hydrochloride $(1.53 \mathrm{~g}, 6.25$ mmol, 1.00 equiv.), glacial acetic acid $(15 \mathrm{~mL})$, and water $(2 \mathrm{~mL})$. The flask was cooled to $0{ }^{\circ} \mathrm{C}$ using an ice water bath. Separately, $\mathrm{NaNO}_{2}(0.65 \mathrm{~g}, 9.38 \mathrm{mmol}, 1.50$ equiv.) was dissolved in water $(3 \mathrm{~mL})$. The $\mathrm{NaNO}_{2}$ solution was added dropwise to the substrate solution at $0{ }^{\circ} \mathrm{C}$. The reaction mixture was allowed to warm to room temperature and stir for $24 \mathrm{~h}$ at room temperature. Water $(100 \mathrm{~mL})$ was added, and the heterogeneous reaction mixture was filtered. The resulting brown solid was washed with water $(100 \mathrm{~mL})$ and methanol $(100 \mathrm{~mL})$. Drying under vacuum for $12 \mathrm{~h}$ yielded bis(1H-1,2,3-triazolo[4,5-b],[4',5'-i])dibenzo[1,4]dioxin) ( $\mathrm{H}_{2}$ btdd, $\left.1.31 \mathrm{~g}, 79 \%\right)$ as a brown solid. ${ }^{1} \mathrm{H}$ NMR (500 MHz, DMSO-d $)$ ): $\delta 15.6$ (bs, 2H), 7.63 (bs, 4H) ppm. This spectrum is consistent with that reported in the literature. ${ }^{8}$

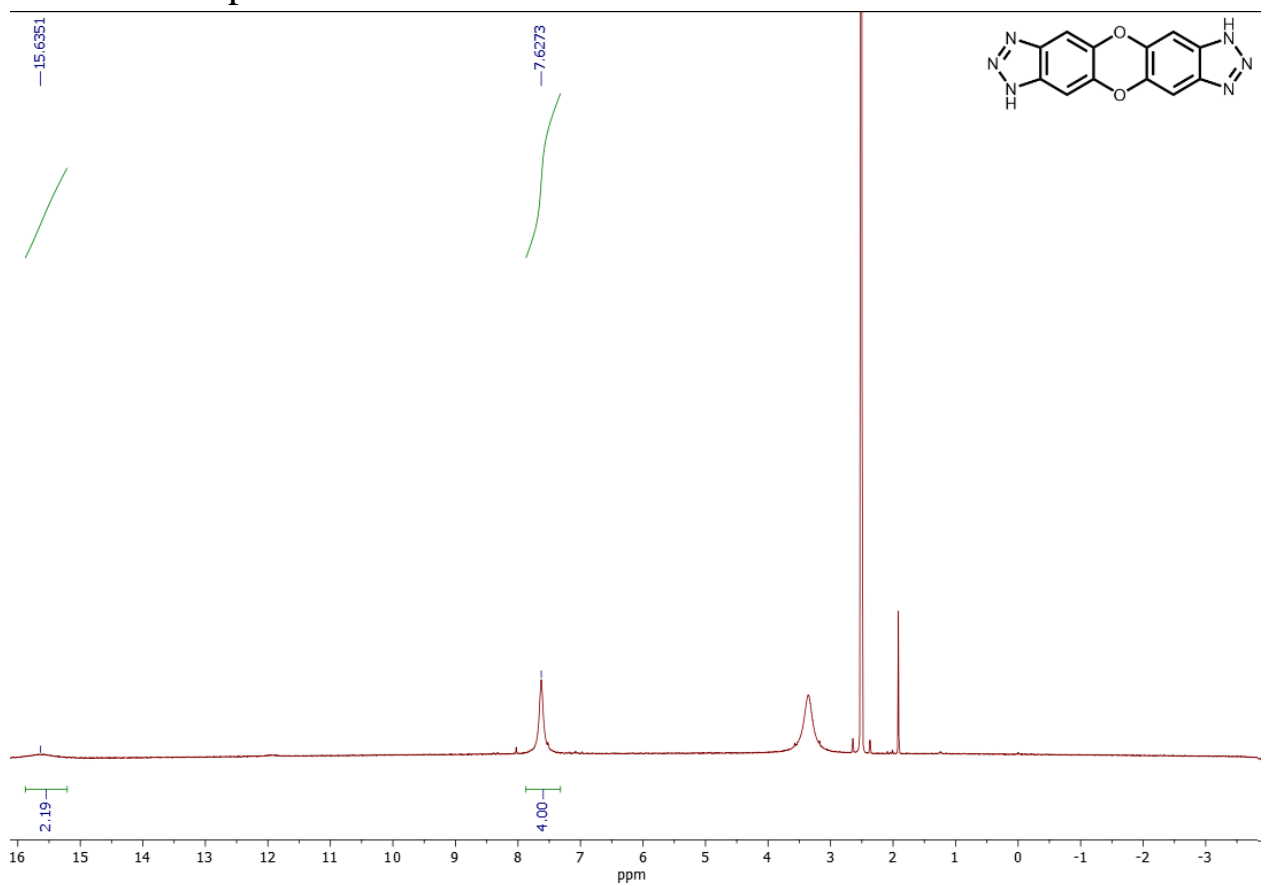

Figure S6. ${ }^{1} \mathrm{H}$ NMR spectrum $\left(500 \mathrm{MHz}, \mathrm{DMSO}-\mathrm{d}_{6}\right)$ of $\mathrm{H}_{2}$ btdd used in this work.

\section{Synthesis of $\mathrm{H}_{3}(\mathrm{btp})$.}<smiles>Brc1cn[nH]c1</smiles><smiles>O=S(=O)(O)n1cc(Br)cn1</smiles>

An oven dried $500 \mathrm{~mL}$ round bottom flask equipped with a stir bar was charged with 4-bromo- $1 \mathrm{H}$ pyrazole (10.0 g, $68.0 \mathrm{mmol}, 1.00$ equiv.). The flask was placed under high vacuum and back- 
filled with $\mathrm{N}_{2}$. This process was repeated a total of three times. Dry THF (250 mL) was added, and the flask was cooled to $0{ }^{\circ} \mathrm{C}$ using an ice water bath. Under a positive stream of $\mathrm{N}_{2}$ flowing through a vent needle, $\mathrm{NaH}$ (60\% dispersion in oil, $3.30 \mathrm{~g}, \sim 81.6 \mathrm{mmol}, \sim 1.20$ equiv.) was added portionwise at $0{ }^{\circ} \mathrm{C}$ over approximately $15 \mathrm{~min}$ (Caution: gas evolution!). After the addition of $\mathrm{NaH}$ was complete, the reaction mixture was allowed to stir at $0{ }^{\circ} \mathrm{C}$ for $1 \mathrm{~h}$. Under a positive stream of $\mathrm{N}_{2}$, trityl chloride (20.9 g, $74.8 \mathrm{mmol}, 1.10$ equiv.) was added portionwise over approximately $15 \mathrm{~min}$. The reaction mixture was allowed to warm to room temperature and stir at room temperature for $24 \mathrm{~h}$. At this time, water $(500 \mathrm{~mL})$ was added, leading to precipitation of a white solid from solution. The reaction mixture was filtered, and the solid was washed with water (200 $\mathrm{mL})$ and methanol $(200 \mathrm{~mL})$, yielding 4-bromo-1-trityl-1H-pyrazole $(26.3 \mathrm{~g}, 99 \%)$ as a fluffy white solid. This solid was used in subsequent transformations without additional purification.

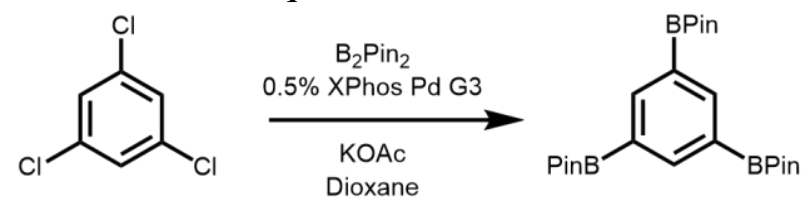

A $500 \mathrm{~mL} 3$-neck round bottom flask equipped with a stir bar and reflux condenser was charged with 1,3,5-trichlorobenzene (4.45 g, $30.0 \mathrm{mmol}, 1.00$ equiv.), bis(pinacolato)diboron ( $25.1 \mathrm{~g}, 99.0$ mmol, 3.30 equiv.), KOAc (26.5 g, 270 mmol, 9.00 equiv.), XPhos Pd G3 (127 mg, 0.15 mmol, $0.5 \%$ ), and XPhos (71.5 mg, $0.15 \mathrm{mmol}, 0.5 \%)$. The flask was placed under high vacuum and back-filled with $\mathrm{N}_{2}$. This process was repeated a total of three times. Freshly degassed 1,4-dioxane (80 $\mathrm{mL}$ ) was added, and the reaction mixture was allowed to stir at reflux for $24 \mathrm{~h}$ under $\mathrm{N}_{2}$. At this time, the reaction mixture was allowed to cool to room temperature and poured into water $(400 \mathrm{~mL})$, resulting in precipitation of a gray solid from solution. The heterogeneous mixture was filtered and washed with water $(200 \mathrm{~mL})$. The resulting solid was dissolved in $\mathrm{CHCl}_{3}(200 \mathrm{~mL})$ and filtered through celite, eluting with $\mathrm{CHCl}_{3}(300 \mathrm{~mL})$. The solution was concentrated in vacuo, and the resulting solid was triturated with cold methanol and filtered, yielding 1,3,5tris(pinacalboryl)benzene $(10.2 \mathrm{~g}, 75 \%)$ as an off-white solid. ${ }^{1} \mathrm{H} \mathrm{NMR}\left(500 \mathrm{MHz}, \mathrm{CDCl}_{3}\right): \delta 8.36$ (s, 3H), $1.33(\mathrm{~s}, 36 \mathrm{H}) \mathrm{ppm}$. 


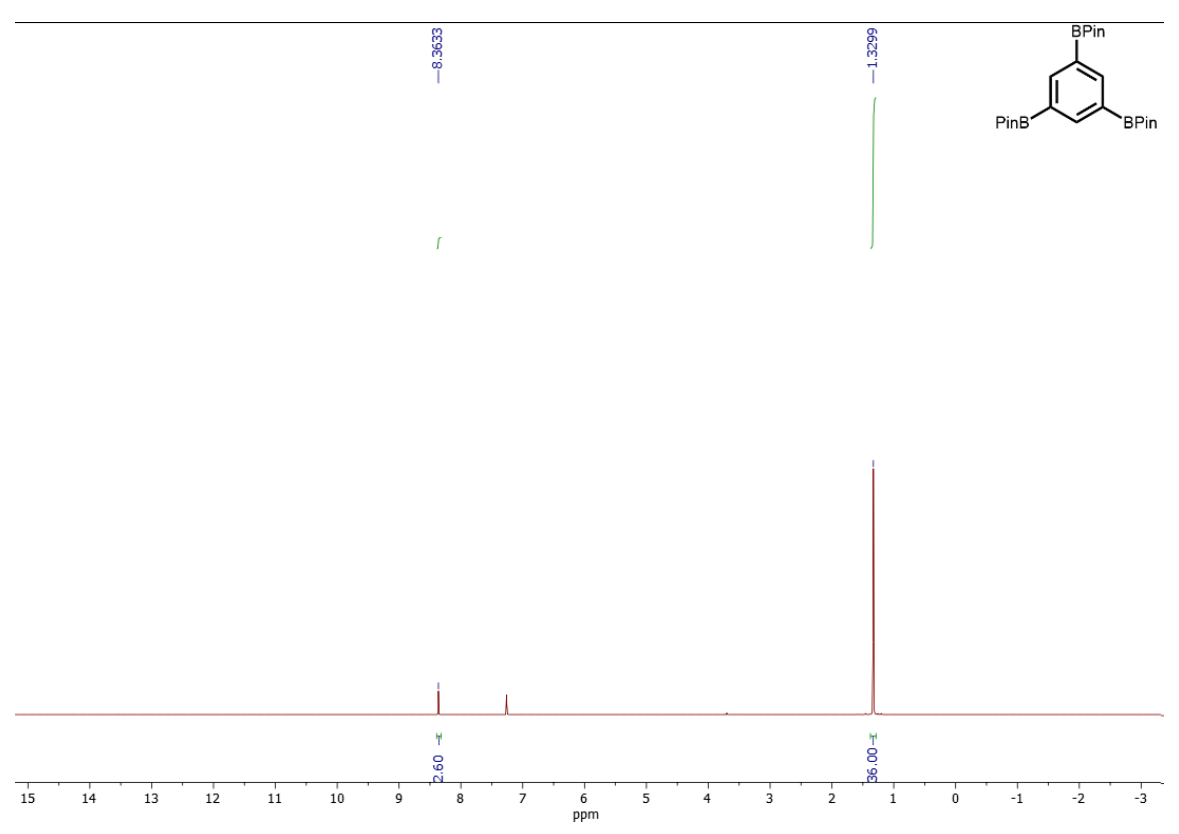

Figure S7. ${ }^{1} \mathrm{H}$ NMR spectrum (500 MHz, DMSO-d 6 ) of 1,3,5-tris(pinacalboryl)benzene used in this work.
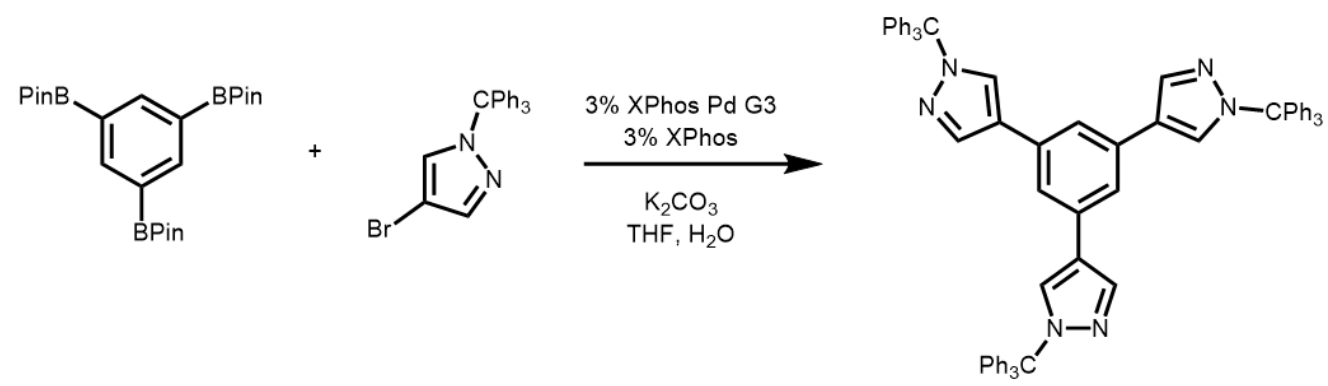

A $500 \mathrm{~mL}$ 3-neck round bottom flask equipped with a stir bar and reflux condenser was charged with 1,3,5-tris(pinacalboryl)benzene (7.30 g, $16.0 \mathrm{mmol}, 1.00$ equiv.), 4-bromo-1-trityl-1Hpyrazole (18.8 g, 48.0 mmol, 3.00 equiv.), XPhos Pd G3 (400 mg, 0.48 mmol, 3\%), XPhos (224 $\mathrm{mg}, 0.48 \mathrm{mmol}, 3 \%$ ), and potassium carbonate (13.2 g, $96.0 \mathrm{mmol}, 6.00$ equiv.). The flask was placed under high vacuum and then back-filled with nitrogen. This process was repeated a total of three times. Next, freshly degassed water $(96 \mathrm{~mL})$ and degassed THF $(48 \mathrm{~mL})$ were added under positive $\mathrm{N}_{2}$ pressure, and the reaction mixture was stirred at reflux under $\mathrm{N}_{2}$ for $14 \mathrm{~h}$. The reaction mixture was allowed to cool to room temperature and diluted with ethyl acetate $(200 \mathrm{~mL})$. The organic and aqueous phases were separated, and the aqueous phase was further extracted with ethyl acetate $(2 \times 100 \mathrm{~mL})$. The combined organic layers were washed with brine $(100 \mathrm{~mL})$, dried over $\mathrm{Mg}_{2} \mathrm{SO}_{4}$, and filtered through a plug of celite, eluting with ethyl acetate $(200 \mathrm{~mL})$. The solvent was removed in vacuo. The resulting white solid was triturated with cold methanol and filtered, yielding crude 1,3,5-tris(1-trityl-1H-pyrazol-4-yl)benzene (17.7 g) as an off-white solid. This solid was directly used in the next step without further purification. 

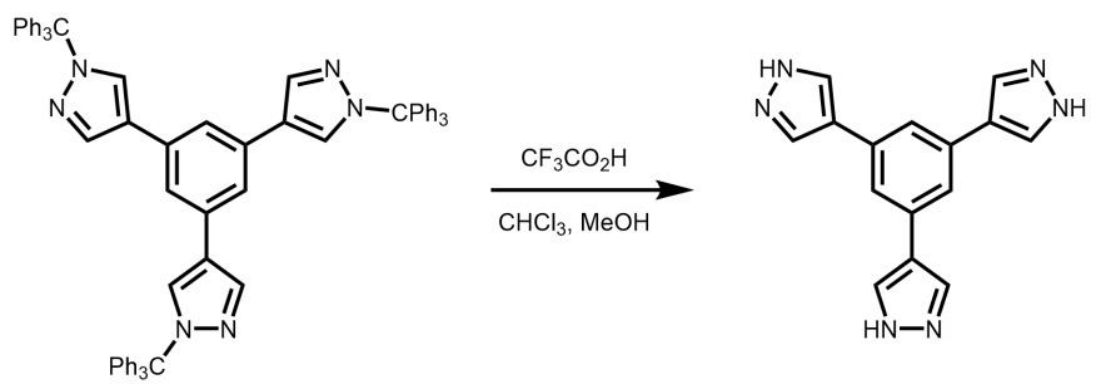

A $500 \mathrm{~mL}$ round bottom flask equipped with a stir bar and reflux condenser was charged with 1,3,5-tris(1-trityl-1H-pyrazol-4-yl)benzene (17.7 g, $17.7 \mathrm{mmol}, 1.00$ equiv.), trifluoroacetic acid $(150 \mathrm{~mL})$, chloroform $(150 \mathrm{~mL})$, and methanol $(50 \mathrm{~mL})$. The reaction mixture was allowed to stir at reflux for $24 \mathrm{~h}$. At this time, the reaction mixture was allowed to cool to room temperature. The solvent was removed under reduced pressure. Toluene $(100 \mathrm{~mL})$ was added and the mixture was filtered. The resulting solid was washed thoroughly with toluene $(100 \mathrm{~mL})$, chloroform $(100 \mathrm{~mL})$, methanol $(100 \mathrm{~mL})$, and diethyl ether $(100 \mathrm{~mL})$. The solid was suspended in water $(100 \mathrm{~mL})$ and solid $\mathrm{NaOH}$ was added until the $\mathrm{pH}$ of the solution was greater than 5 . The mixture was filtered, and the resulting solid was washed thoroughly with water $(250 \mathrm{~mL})$. The solid was then triturated with a hot 1:1 mixture of acetone and ethyl acetate $(100 \mathrm{~mL})$ and filtered. The resulting solid was washed with acetone $(100 \mathrm{~mL})$ and ethyl acetate $(100 \mathrm{~mL})$, yielding 1,3,5-tri $(1 H$-pyrazol-4yl)benzene ( $\mathrm{H}_{3} \mathrm{btp}, 4.56 \mathrm{~g}, 93 \%$ yield) as an off-white solid. ${ }^{1} \mathrm{H}$ NMR (500 MHz, DMSO-d 6 ): $\delta$ $12.92(\mathrm{~s}, 3 \mathrm{H}), 8.18(\mathrm{~s}, 6 \mathrm{H}), 7.68(\mathrm{~s}, 3 \mathrm{H}) \mathrm{ppm}$. This spectrum is consistent with that reported in the literature. ${ }^{10}$

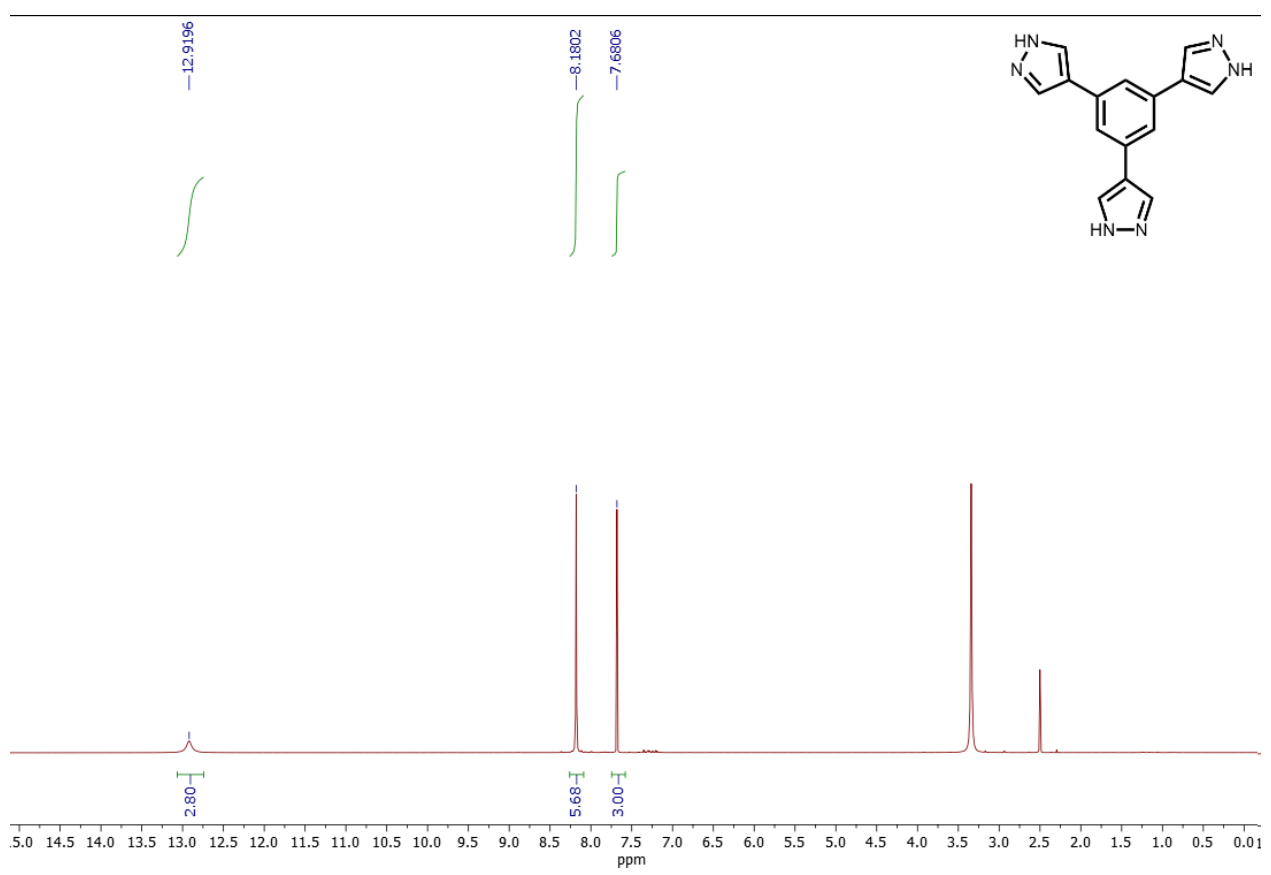

Figure S8. ${ }^{1} \mathrm{H}$ NMR spectrum (500 MHz, DMSO-d 6 ) of $\mathrm{H}_{3} b$ tp used in this work. 


\section{Synthesis of $\mathbf{H}_{2} b d p$.}

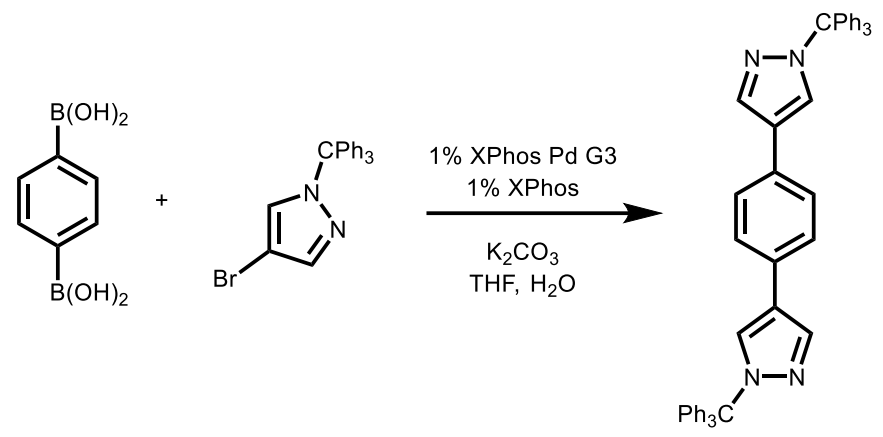

A $500 \mathrm{~mL}$ 3-neck round bottom flask equipped with a stir bar and reflux condenser was charged with benzene-1,4-diboronic acid (4.34 g, $26.2 \mathrm{mmol}, 1.00$ equiv.), 4-bromo-1-trityl-1H-pyrazole (20.4 g, 52.4 mmol, 2.00 equiv.), XPhos Pd G33 (0.22 g, 0.26 mmol, 1\%), XPhos (0.12 g, 0.26 mmol, $1 \%$ ), and $\mathrm{K}_{2} \mathrm{CO}_{3}$ (14.4 g, $104 \mathrm{mmol}, 4.00$ equiv.). The flask was placed under high vacuum and back-filled with nitrogen. This process was repeated a total of three times. Next, degassed water $(120 \mathrm{~mL})$ and THF $(80 \mathrm{~mL})$ were added under positive $\mathrm{N}_{2}$ pressure, and the reaction mixture was stirred at reflux under $\mathrm{N}_{2}$ for $36 \mathrm{~h}$. The reaction mixture was allowed to cool to room temperature, poured into water $(500 \mathrm{~mL})$, and filtered. The resulting pale yellow solid was washed thoroughly with water $(200 \mathrm{~mL})$, ethyl acetate $(200 \mathrm{~mL})$, and hexanes $(50 \mathrm{~mL})$, yielding 1,4-bis(1trityl-1H-pyrazol-4-yl)benzene (14.6 g, 80\%) as an off-white solid. ${ }^{1} \mathrm{H} \mathrm{NMR}\left(500 \mathrm{MHz}, \mathrm{CDCl}_{3}\right)$ : $\delta 7.92(\mathrm{~s}, 2 \mathrm{H}), 7.60(\mathrm{~s}, 2 \mathrm{H}), 7.37(\mathrm{~s}, 4 \mathrm{H}), 7.31-7.34(\mathrm{~m}, 18 \mathrm{H}), 7.18-7.22(\mathrm{~m}, 12 \mathrm{H}) \mathrm{ppm}$. This spectrum is consistent with that reported in the literature. ${ }^{11}$

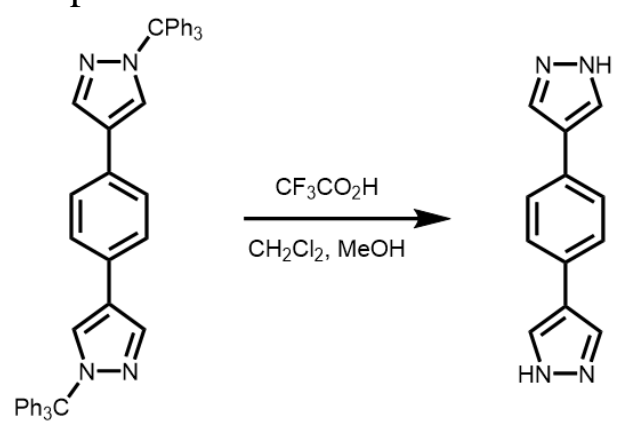

A 2 L round bottom flask equipped with a stir bar and reflux condenser was charged with 1,4bis(1-trityl-1H-pyrazol-4-yl)benzene (14.6 g, $21.0 \mathrm{mmol}, 1.00$ equiv.), methanol (300 mL), dichloromethane $(200 \mathrm{~mL})$, and trifluoroacetic acid $(200 \mathrm{~mL})$. The reaction mixture was allowed to stir at reflux for $48 \mathrm{~h}$. The reaction mixture was allowed to cool to room temperature and then to $0{ }^{\circ} \mathrm{C}$, resulting in precipitation of a white solid from solution. The mixture was filtered, and the resulting white solid was washed with toluene $(200 \mathrm{~mL})$ and THF $(200 \mathrm{~mL})$. The resulting solid was suspended in water $(200 \mathrm{~mL})$ and aq. $2 \mathrm{M} \mathrm{NaOH}$ was added slowly until the $\mathrm{pH}$ of the solution was greater than 5 . The heterogeneous mixture was filtered, and the resulting off-white solid was washed thoroughly with water $(200 \mathrm{~mL})$, THF $(100 \mathrm{~mL})$, and hexanes $(100 \mathrm{~mL})$. Drying under vacuum for $12 \mathrm{~h}$ yielded 1,4-di(1H-pyrazol-4-yl)benzene $\left(\mathrm{H}_{2} \mathrm{bdp}, 4.00 \mathrm{~g}, 91 \%\right)$ as a white solid. ${ }^{1} \mathrm{H}$ NMR (500 MHz, DMSO-d $)$ ): $\delta 12.9$ (bs, 2H), 8.05 (bs, 4H), 7.58 (s, 4H) ppm. This spectrum is consistent with that reported in the literature. ${ }^{11}$ 


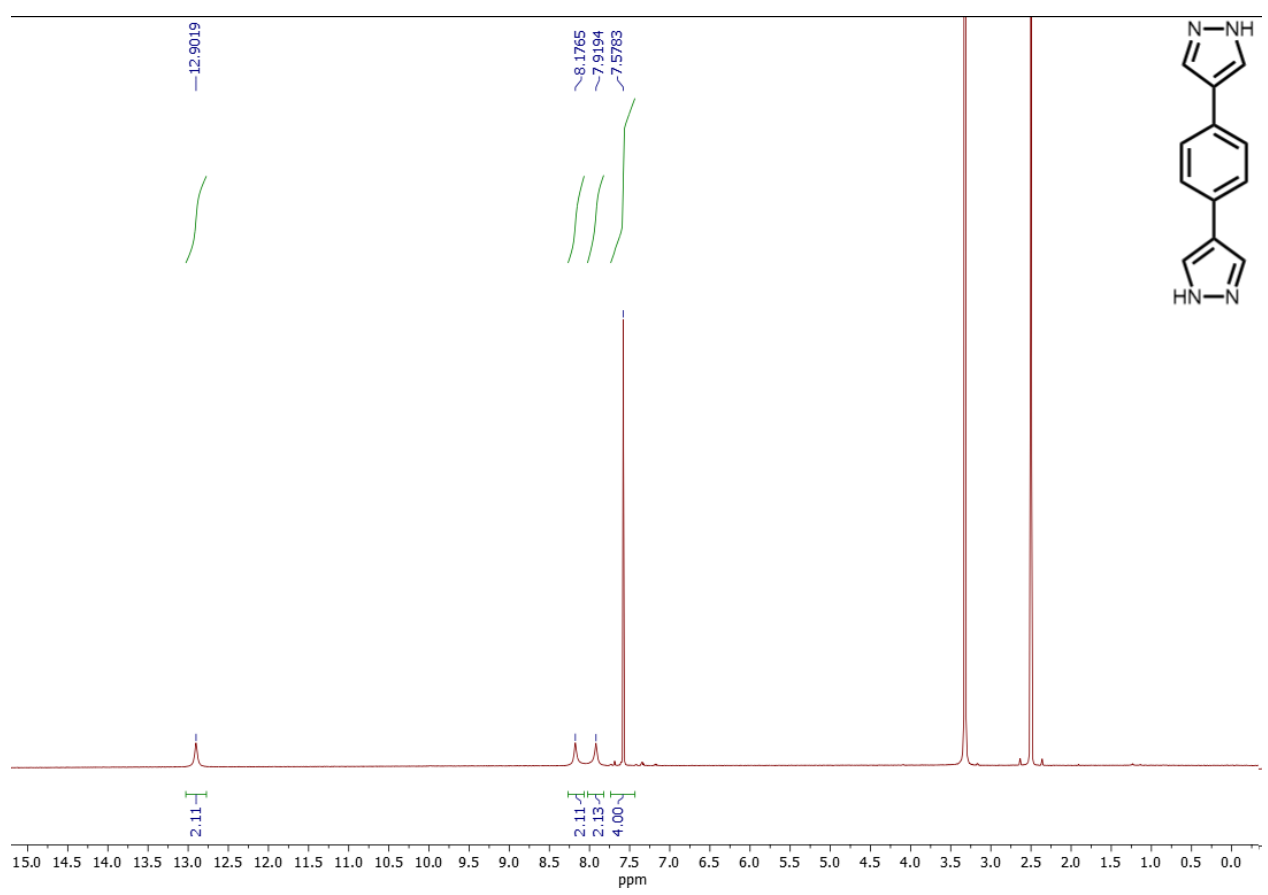

Figure S9. ${ }^{1} \mathrm{H}$ NMR spectrum (500 MHz, DMSO-d $\mathrm{d}_{6}$ ) of $\mathrm{H}_{2}$ bdp used in this work. 


\section{Procedures for stability studies.}

Stability assays were carried out by suspending $\sim 10 \mathrm{mg}$ of activated MOF (stored in a $\mathrm{N}_{2}$-filled glovebox) in $1.0 \mathrm{~mL}$ of the indicated solution for approximately $24 \mathrm{~h}$. After conclusion of the stability assay, the solution was filtered and the solid was rinsed with methanol $(\sim 10 \mathrm{~mL})$ before analysis by powder X-ray diffraction. Samples of the large-pore frameworks $\mathrm{Mg}_{2}$ (dobpdc), $\mathrm{Mg}_{2}$ (dotpdc), and PCN-128 were removed from suspension under methanol and filtered immediately prior to stability assays. For stability assays carried out under an atmosphere of air, 4 $\mathrm{mL}$ scintillation vials were used and the solution was added to the MOF open to air before the vial was capped. For stability assays carried out under an atmosphere of dry nitrogen, the MOF was added to a $15 \mathrm{~mL}$ screw-cap tube in a nitrogen-filled glovebox, and the tube was sealed and removed from the glovebox. An inlet needle of nitrogen was added, and the solution was added under a positive pressure of nitrogen. The cap was replaced with one that had not been punctured, and the suspension was allowed to stand under static nitrogen before being filtered in air.

Air stability tests were performed by placing samples into an oven that had been pre-heated to the indicated temperature.

Concentrated hydrochloric acid (37\%), aqueous $\mathrm{pH} 4$ buffer (potassium hydrogen phthalate, formaldehyde, methanol, and water), aqueous $\mathrm{pH} 7$ buffer (monopotassium phosphate, sodium hydroxide, water), and aqueous $\mathrm{pH} 10$ buffer (potassium hydroxide, potassium carbonate, potassium borate, water) were purchased from Fisher Scientific. Aqueous $\mathrm{pH} 1$ buffer was prepared by combining $50 \mathrm{ml}$ of aqueous $0.2 \mathrm{M} \mathrm{KCl}$ and $134 \mathrm{ml}$ of aqueous $0.2 \mathrm{M} \mathrm{HCl}$. Aqueous $\mathrm{pH} 13$ buffer was prepared by combining $50 \mathrm{~mL}$ of aqueous $0.2 \mathrm{M} \mathrm{KCl}$ and $132 \mathrm{~mL}$ of aqueous $0.2 \mathrm{M} \mathrm{NaOH}$. Several MOFs, including UiO-66, PCN-128, MOF-74 (Mg), $\mathrm{Mg}_{2}$ (dobpdc), and $\mathrm{Ni}_{2} \mathrm{Cl}_{2}$ (btdd) were found to undergo degradation in aqueous phosphate buffer $(\mathrm{pH}=7)$ even though they were relatively stable in deionized neutral water. This is likely due to the presence of phosphate in the buffer. As such, these MOFs were evaluated using an alternative buffer based on tris(hydroxymethyl)aminomethane (tris) as well. The stability of MOF-74 (Ni), which is stable in both deionized water and aqueous phosphate buffer $(\mathrm{pH}=7)$, was also assessed using tris buffer as a control. Aqueous tris buffer $(\mathrm{pH}=7)$ was prepared by dissolving $6.057 \mathrm{~g}$ of tris in $\mathrm{H}_{2} \mathrm{O}(40 \mathrm{~mL})$ in a $50 \mathrm{~mL}$ volumetric flask, adjusting the $\mathrm{pH}$ to 7 by dropwise addition of concentrated hydrochloric acid, and then diluting the solution to $50 \mathrm{~mL}$. Saturated aqueous sodium hydroxide was prepared immediately prior to use by suspending excess sodium hydroxide in water. The acetic acid assay was carried out using neat glacial acetic acid.

Solutions of hydrogen sulfide $\left(\mathrm{H}_{2} \mathrm{~S}\right)$ in tetrahydrofuran $(0.8 \mathrm{M})$, ammonia $\left(\mathrm{NH}_{3}\right)$ in methanol $(2.0 \mathrm{M})$, phenyl magnesium bromide $(\mathrm{PhMgBr})$ in tetrahydrofuran $(1.0 \mathrm{M})$, samarium iodide $\left(\mathrm{SmI}_{2}\right)$ in tetrahydrofuran $(0.1 \mathrm{M})$, lithium hexamethyldisilazide (LiHMDS) in toluene (1.0 M), tetrabutylammonium fluoride in THF $(1.0 \mathrm{M})$, and lithium borohydride $\left(\mathrm{LiBH}_{4}\right)$ in tetrahydrofuran $(2.0 \mathrm{M})$ were purchased from Sigma-Aldrich. The corresponding stability assays were carried out under an atmosphere of dry nitrogen. The solutions of lithium borohydride and ammonia were diluted with an equal volume of anhydrous, oxygen-free solvent to bring the final reagent 
concentration to $1.0 \mathrm{M}$. The filter flask for the $\mathrm{H}_{2} \mathrm{~S}$ assay was filled with bleach to quench unreacted $\mathrm{H}_{2} \mathrm{~S}$. The filter flask for the $\mathrm{PhMgBr}$ assay was filled with isopropanol to quench unreacted $\mathrm{PhMgBr}$.

Solutions of $n$-butylamine $\left(\mathrm{BuNH}_{2}\right)$ in tetrahydrofuran $(1.0 \mathrm{M})$, trimethylchlorosilane (TMSCl) in dichloromethane $(1.0 \mathrm{M})$, acetyl chloride $(\mathrm{MeCOCl})$ in dichloromethane $(1.0 \mathrm{M})$, bromine $\left(\mathrm{Br}_{2}\right)$ in dichloromethane $(1.0 \mathrm{M})$, iodine in dichloromethane (saturated), sulfuryl chloride in dichloromethane $(1.0 \mathrm{M}), m$-chloroperoxybenzoic acid (MCPBA) in dichloromethane (saturated), pyridinium chlorochromate (PCC) in dichloromethane (saturated), and dimethyl sulfate $\left(\mathrm{Me}_{2} \mathrm{SO}_{4}\right)$ in dichloromethane $(1.0 \mathrm{M})$ were prepared using commercially available reagents immediately prior to stability assays. The filter flask for the MCPBA and $\mathrm{Br}_{2}$ assays were filled with saturated aq. $\mathrm{NaHSO}_{3}$ to quench unreacted material. The filter flask for the $\mathrm{Me}_{2} \mathrm{SO}_{4}$ assay was filled with saturated aq. $\mathrm{NaHCO}_{3}$ to quench unreacted $\mathrm{Me}_{2} \mathrm{SO}_{4}$.

Solvent stability assays were carried out following the standard procedure using neat tetrahydrofuran (THF), methanol (MeOH), dichloromethane $\left(\mathrm{CH}_{2} \mathrm{Cl}_{2}\right)$, toluene (Tol), or deionized (DI) water. 


\section{Synthesis, characterization, and stability assessment of MIL-100 (Fe).}

Synthesis of MIL-100 (Fe). This procedure is adapted from the literature. ${ }^{12}$ A $250 \mathrm{~mL}$ roundbottom flask equipped with a stir bar was charged with trimesic acid (1.68 g, $8.00 \mathrm{mmol}, 1.00$ equiv.) and sodium hydroxide (912 $\mathrm{mg}, 22.8 \mathrm{mmol}, 2.85$ equiv.). Water ( $23 \mathrm{~mL}$ ) was added, the mixture was stirred vigorously and sonicated until completely homogeneous. Separately, $\mathrm{FeCl}_{2} \bullet 4 \mathrm{H}_{2} \mathrm{O}$ (2.26 g, $11.4 \mathrm{mmol}, 1.43$ equiv.) was dissolved in water $(97 \mathrm{~mL})$ in a $250 \mathrm{~mL}$ Erlenmeyer flask. The $\mathrm{FeCl}_{2} \bullet 4 \mathrm{H}_{2} \mathrm{O}$ solution was transferred to an addition funnel, which was affixed to the round-bottom flask containing the trimesic acid and sodium hydroxide solution. The $\mathrm{FeCl}_{2} \bullet 4 \mathrm{H}_{2} \mathrm{O}$ solution was added dropwise over the course of approximately $1 \mathrm{~h}$. The reaction mixture was allowed to stir gently $(500 \mathrm{rpm})$ at room temperature for $24 \mathrm{~h}$. At this time, the reaction mixture was filtered and the resulting dark brown solid was rinsed thoroughly with water ( 250 $\mathrm{mL})$. The solid was transferred to a $250 \mathrm{~mL}$ Pyrex jar and water $(200 \mathrm{~mL})$ was added. The jar was allowed to stand for $24 \mathrm{~h}$ at $70{ }^{\circ} \mathrm{C}$ in an oven, at which time the water was decanted and replaced with fresh water $(200 \mathrm{~mL})$. This procedure was repeated two additional times for a total of three hot water soaks. Next, the solid was filtered and soaked in $0.05 \mathrm{M} \mathrm{KF}$ in water $(200 \mathrm{~mL})$ for $24 \mathrm{~h}$ at room temperature following the same procedure. ${ }^{13}$ Last, the solid was filtered and soaked in ethanol $(200 \mathrm{~mL})$ for $24 \mathrm{~h}$ at $70{ }^{\circ} \mathrm{C}$ in an oven three total times following the same procedure. The solid was filtered to dryness and transferred to a Schlenk flask. The dark brown solid was activated under flowing $\mathrm{N}_{2}$ at $180{ }^{\circ} \mathrm{C}$ for $4 \mathrm{~h}$, followed by further activation under high vacuum (<100 mbar) at $180{ }^{\circ} \mathrm{C}$ for $24 \mathrm{~h}$. The Schlenk flask was transferred into a $\mathrm{N}_{2}$-filled glovebox, and the activated MIL-100 (Fe) was transferred into a $20 \mathrm{~mL}$ scintillation vial for long-term storage. A portion of the activated sample was transferred to a pre-tared Micromeritics sample tube equipped with a Sureseal. The tube was removed from the glovebox and the sample was further activated under high vacuum $(<10 \mu$ bar $)$ at $180{ }^{\circ} \mathrm{C}$ for $24 \mathrm{~h}$ prior to gas sorption measurements. 


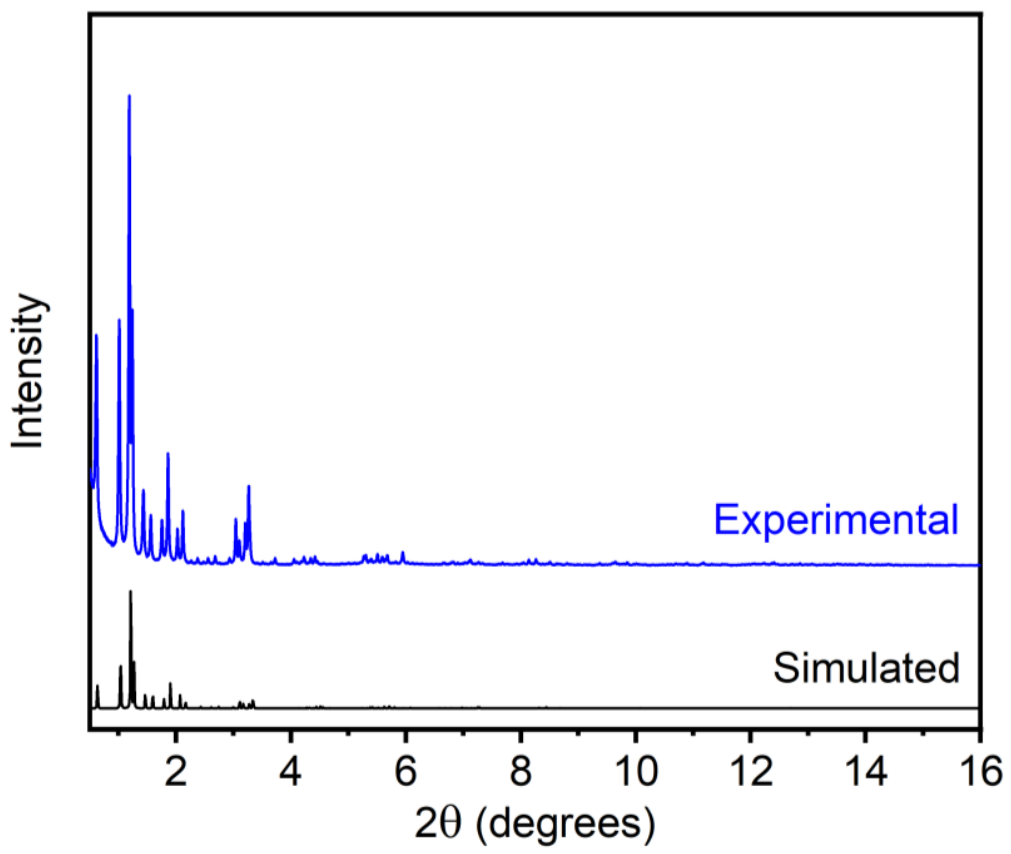

Figure S10. Synchrotron PXRD pattern $(\lambda=0.457897 \AA)$ of methanol-solvated MIL-100 (Fe). The simulated pattern based on the previously reported powder X-ray diffraction structure of MIL$100(\mathrm{Fe})$ is included for reference. ${ }^{14}$

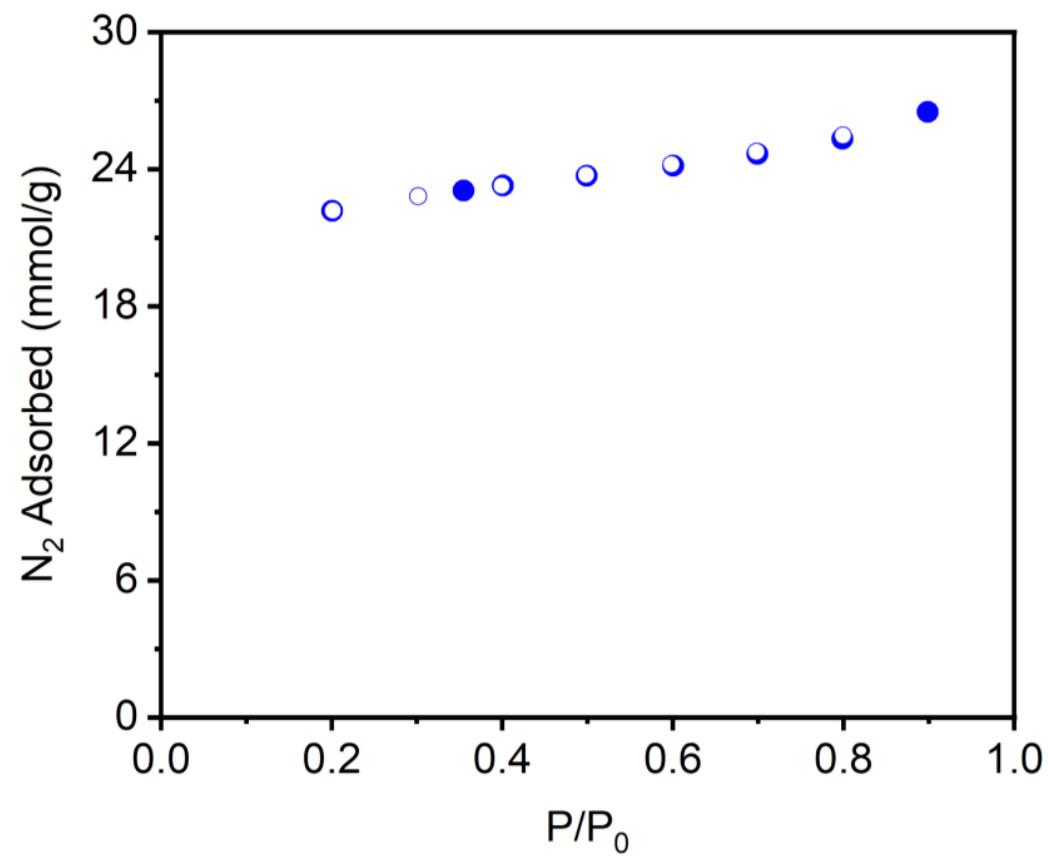

Figure S11. $77 \mathrm{~K} \mathrm{~N}_{2}$ adsorption (filled circles) and desorption (open circles) isotherm of activated MIL-100 (Fe). The Langmuir surface area determined from these data is $2387 \pm 15 \mathrm{~m}^{2} / \mathrm{g}$. 


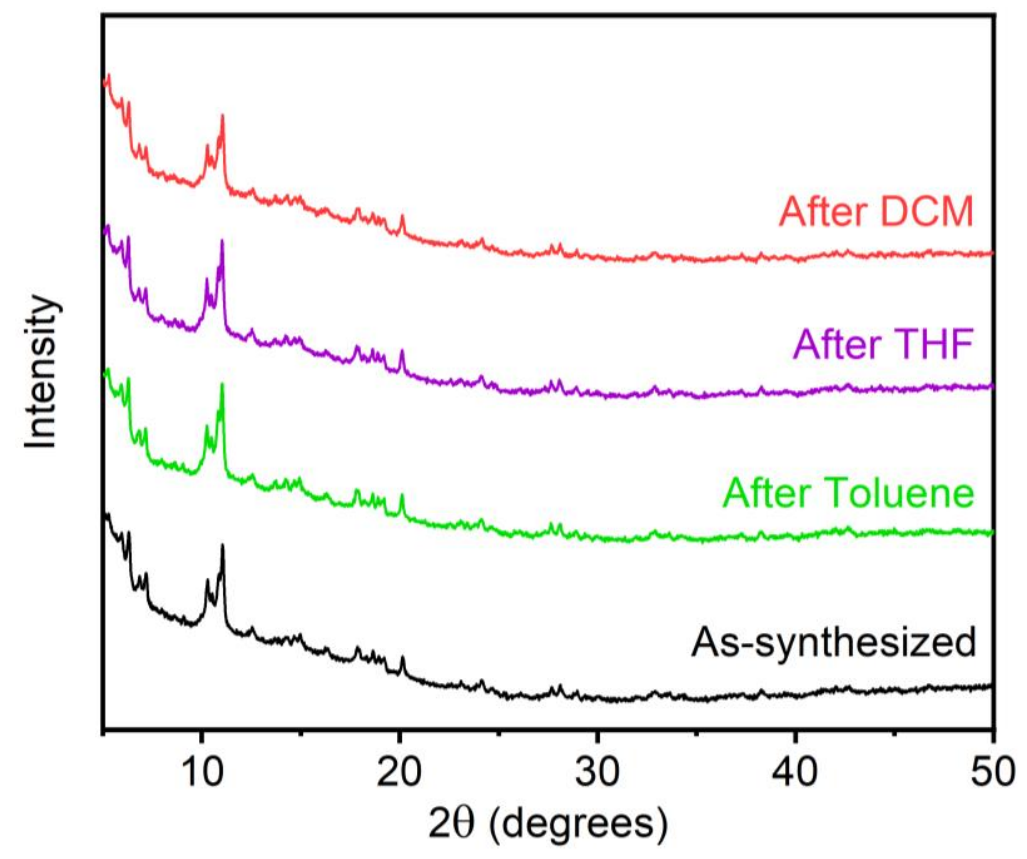

Figure S12. PXRD patterns $(\lambda=1.5406 \AA)$ of MIL-100 (Fe) upon exposure to various organic solvents. Note that MIL-100 (Fe) was soaked in water and ethanol during its synthesis as well. A reference pattern of as-synthesized MIL-100 $(\mathrm{Fe})$ is included.

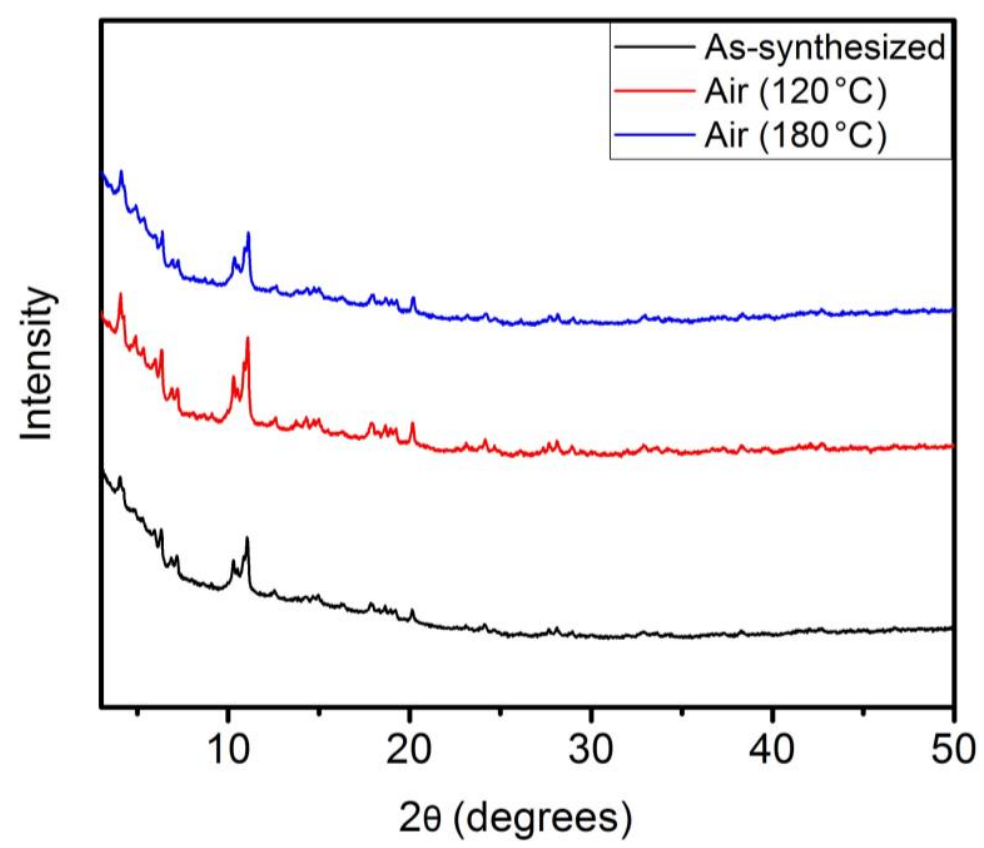

Figure S13. PXRD patterns $(\lambda=1.5406 \AA)$ of MIL-100 (Fe) upon standing at $120^{\circ} \mathrm{C}$ and $180{ }^{\circ} \mathrm{C}$ in air for $24 \mathrm{~h}$. A reference pattern of as-synthesized MIL-100 (Fe) is included. 


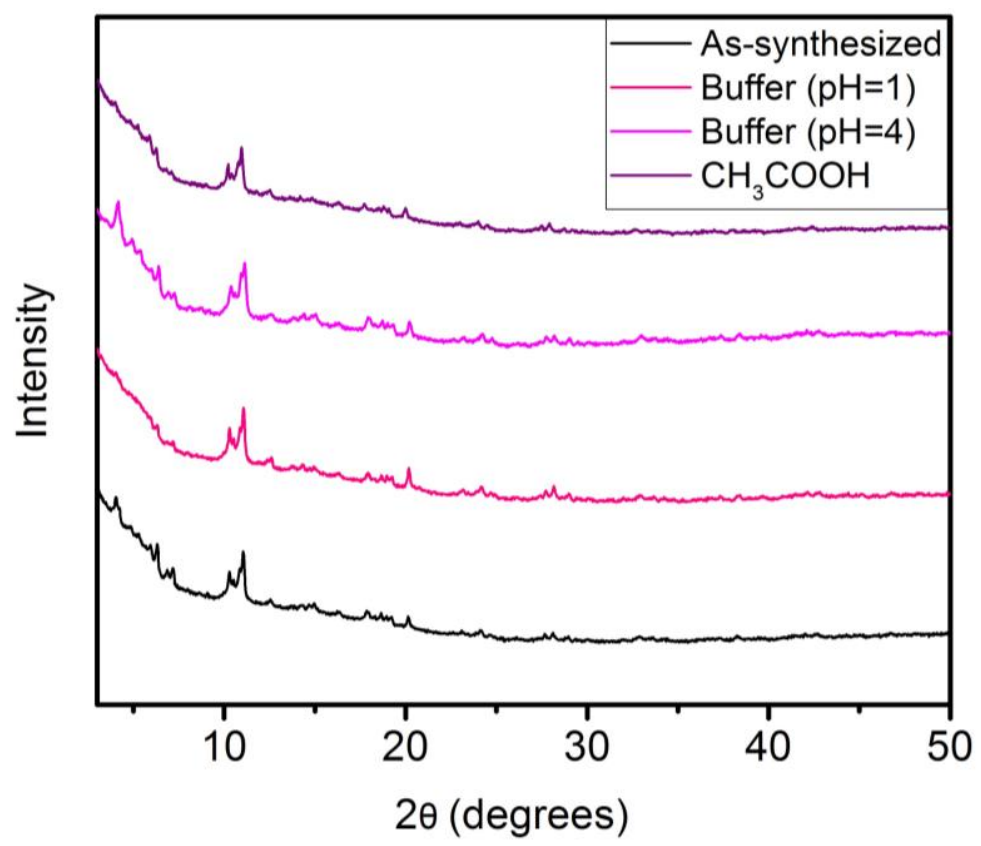

Figure S14. PXRD patterns $(\lambda=1.5406 \AA)$ of MIL-100 (Fe) upon exposure to acids. Exposure tests include aqueous solutions buffered at $\mathrm{pH} 1$ and $\mathrm{pH} 4$ and glacial acetic acid. A reference pattern of as-synthesized MIL-100 (Fe) is included.

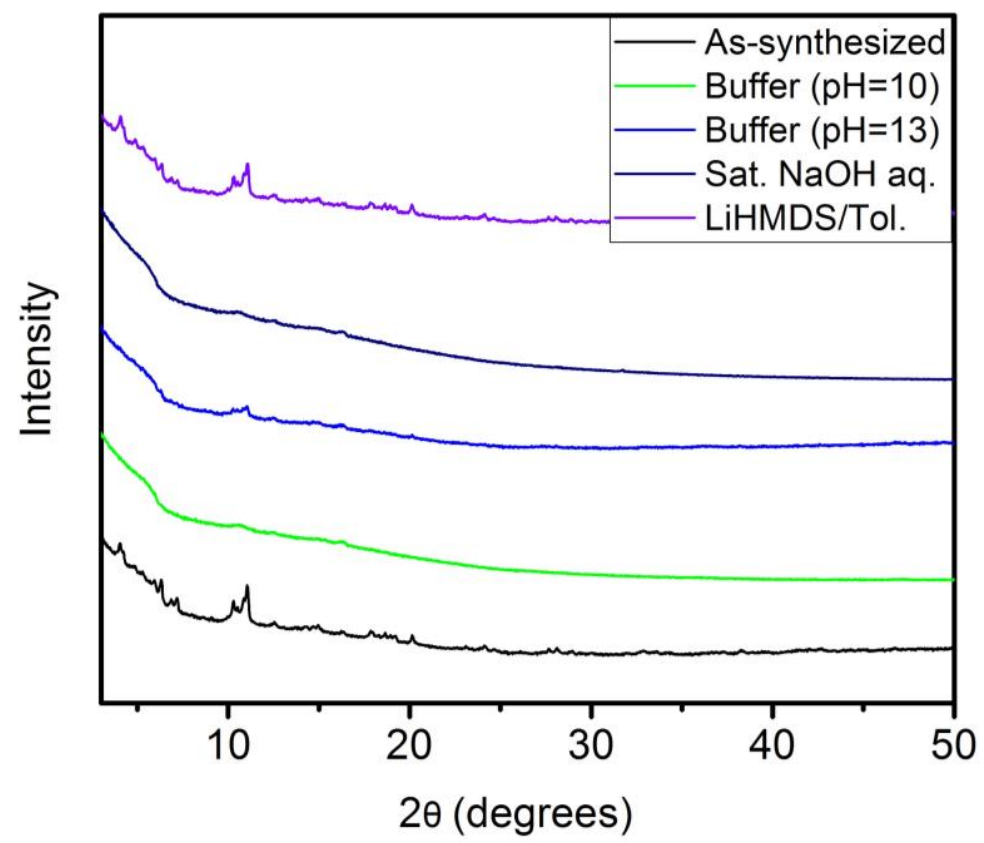

Figure S15. PXRD patterns $(\lambda=1.5406 \AA)$ of MIL-100 (Fe) upon exposure to bases. Exposure tests include aqueous solutions buffered at $\mathrm{pH} 10$ and $\mathrm{pH} 13$, saturated aqueous $\mathrm{NaOH}$, and $1.0 \mathrm{M}$ lithium hexamethyldisilazide (LiHMDS) in toluene. A reference pattern of as-synthesized MIL$100(\mathrm{Fe})$ is included. 


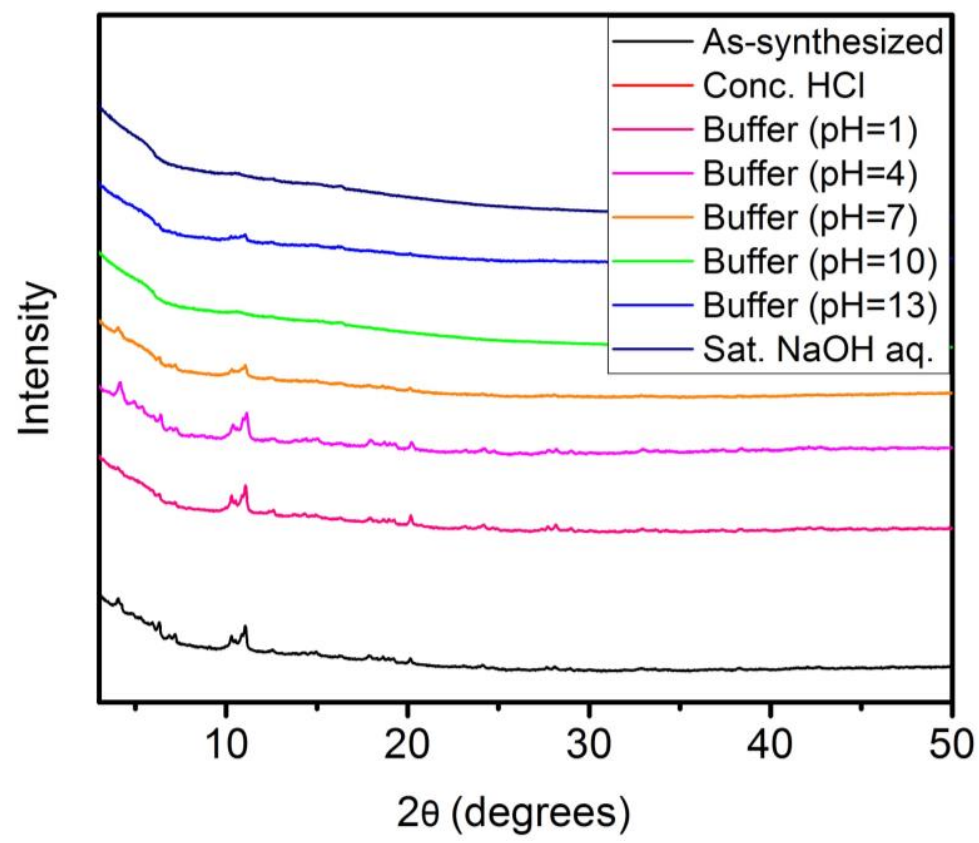

Figure S16. Summary of the PXRD patterns ( $\lambda=1.5406 \AA$ ) of MIL-100 (Fe) upon exposure to various aqueous conditions. No solid remained after exposure of MIL-100 (Fe) to concentrated $\mathrm{HCl}$. A reference pattern of as-synthesized MIL-100 (Fe) is included.

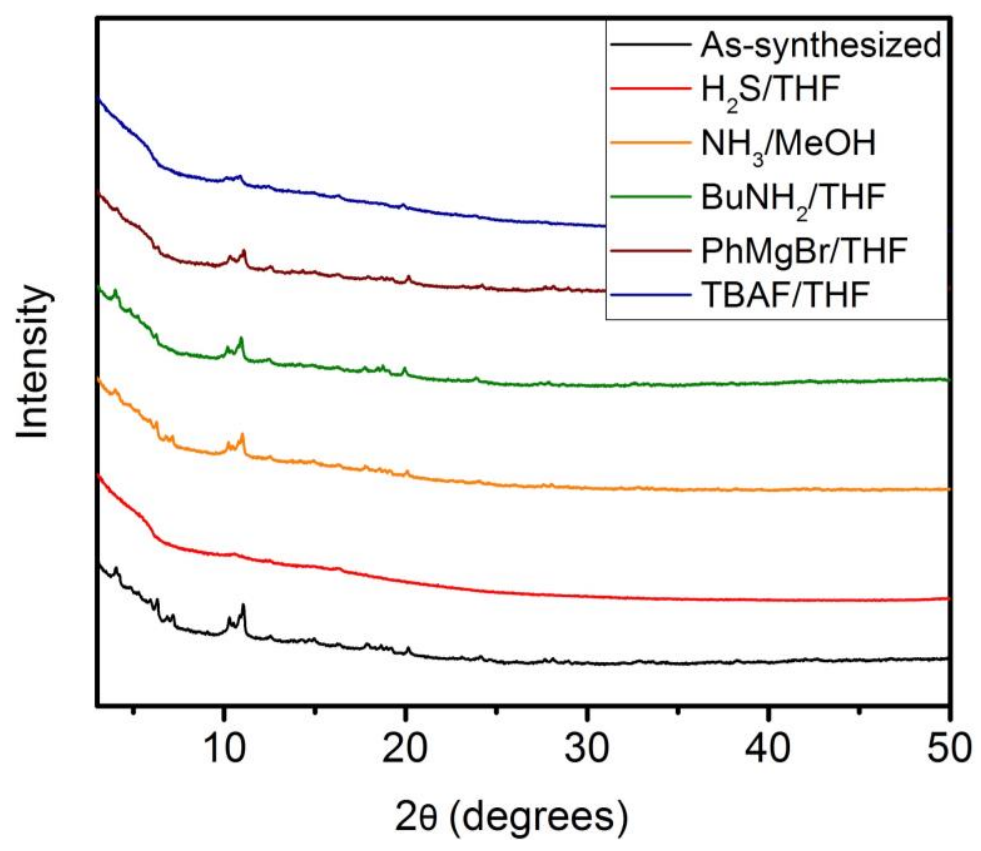

Figure S17. PXRD patterns $(\lambda=1.5406 \AA)$ of MIL-100 (Fe) upon exposure to nucleophiles. Exposure tests include $0.8 \mathrm{M}$ hydrogen sulfide in tetrahydrofuran, $1.0 \mathrm{M}$ ammonia in methanol, $1.0 \mathrm{M} n$-butylamine in tetrahydrofuran, $1.0 \mathrm{M} \mathrm{PhMgBr}$ in tetrahydrofuran, and $1.0 \mathrm{M}$ tetrabutylammonium fluoride (TBAF) in tetrahydrofuran. A reference pattern of as-synthesized MIL-100 (Fe) is included. 


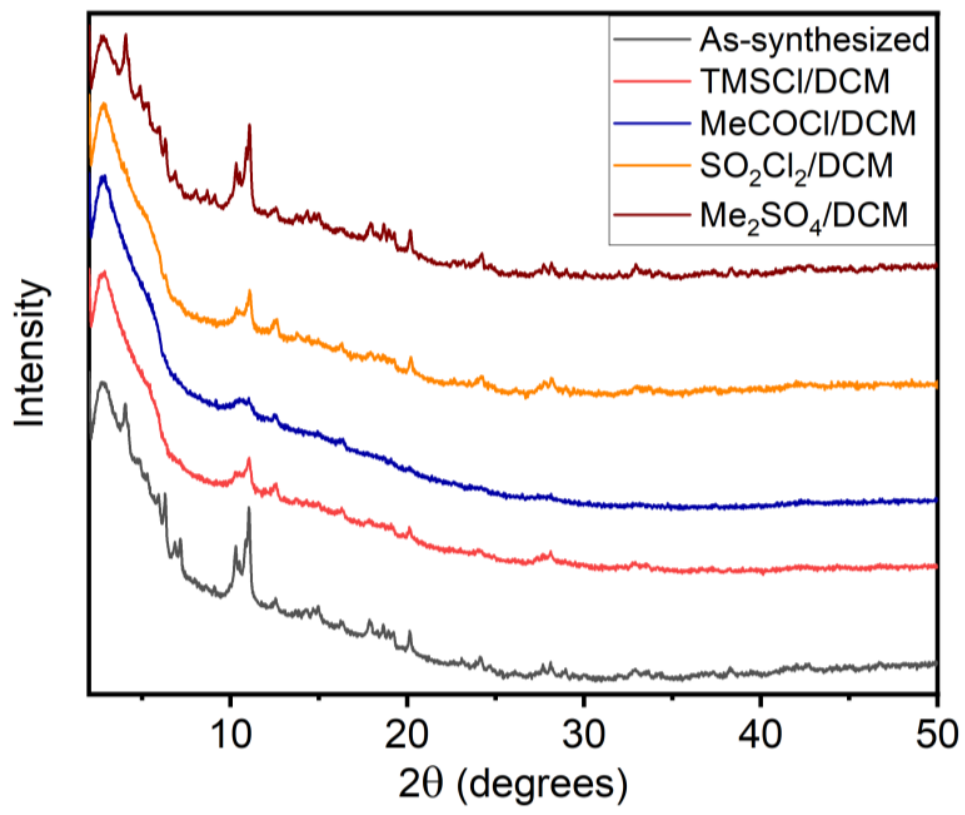

Figure S18. PXRD patterns $(\lambda=1.5406 \AA)$ of MIL-100 (Fe) upon exposure to electrophiles. Exposure tests include $1.0 \mathrm{M}$ chlorotrimethylsilane (TMSCl) in dichloromethane, $1.0 \mathrm{M}$ acetyl chloride in dichloromethane, $1.0 \mathrm{M}$ sulfuryl chloride in dichloromethane, and saturated dimethyl sulfate in dichloromethane. A reference pattern of as-synthesized MIL-100 (Fe) is included.

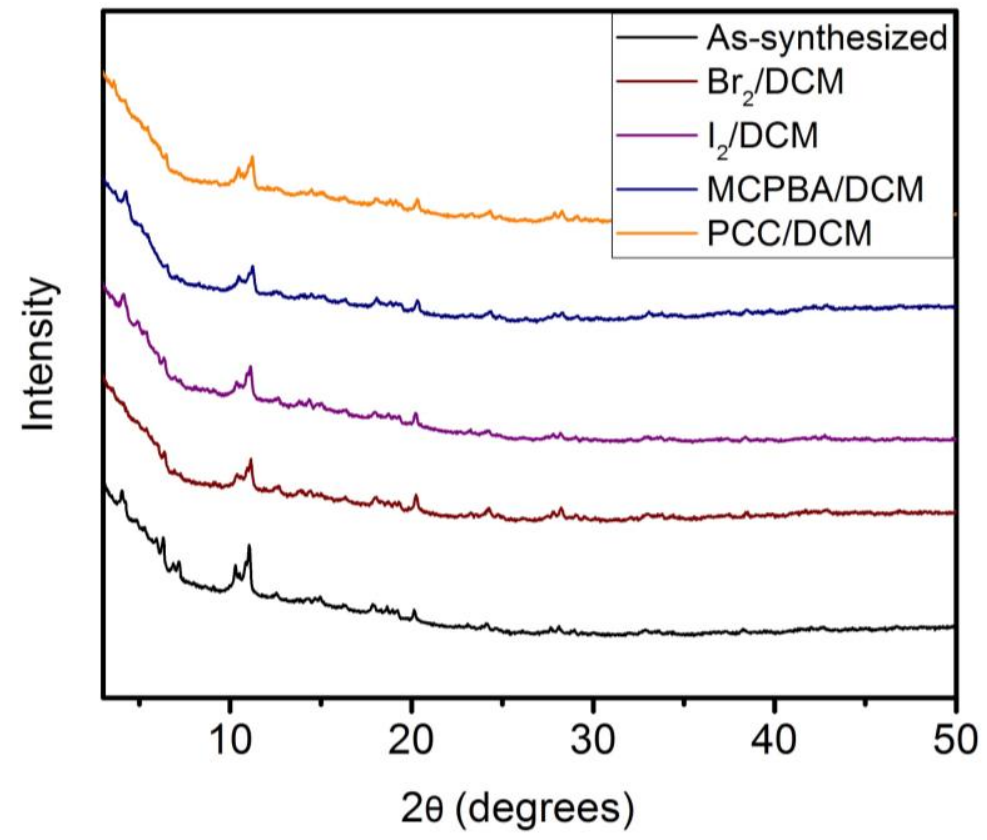

Figure S19. PXRD patterns ( $\lambda=1.5406 \AA$ ) of MIL-100 (Fe) upon exposure to oxidants. Exposure tests include $1.0 \mathrm{M}$ bromine in dichloromethane, saturated iodine in dichloromethane, saturated $m$-chloroperoxybenzoic acid (MCPBA) in dichloromethane, and saturated pyridinium chlorochromate (PCC) in dichloromethane. A reference pattern of as-synthesized MIL-100 (Fe) is included. 


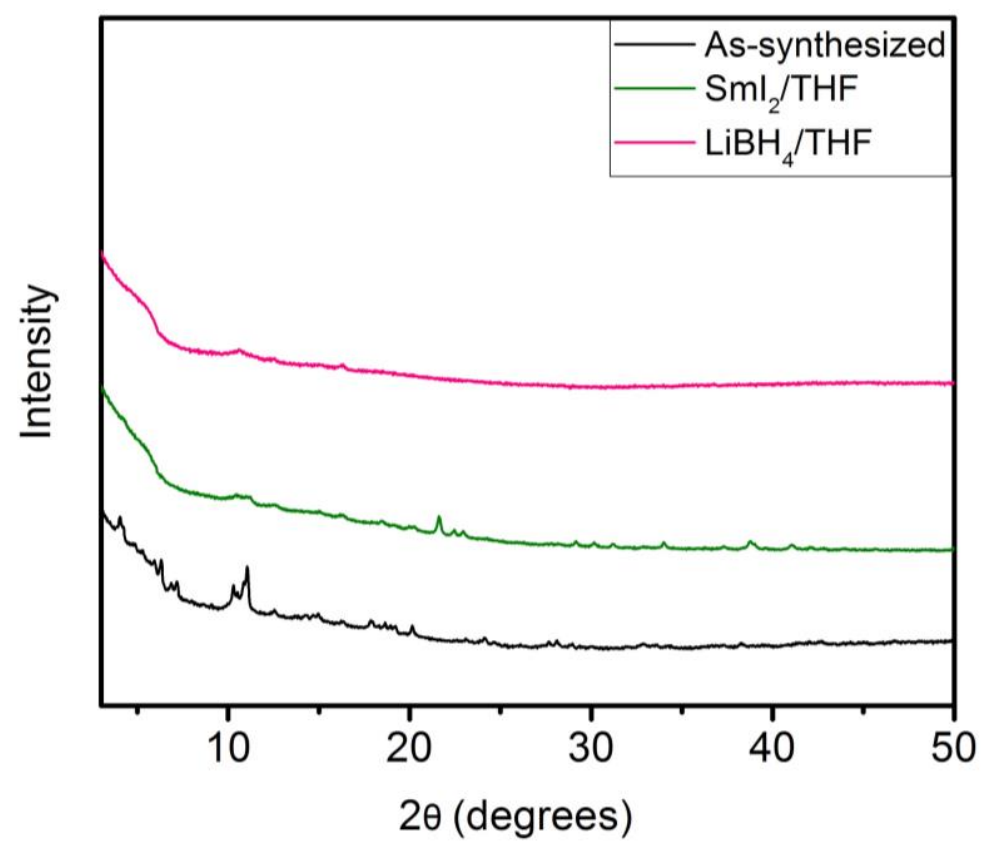

Figure S20. PXRD patterns $(\lambda=1.5406 \AA)$ of MIL-100 (Fe) upon exposure to reductants. Exposure tests include $0.1 \mathrm{M}$ samarium iodide in tetrahydrofuran and $1.0 \mathrm{M}$ lithium borohydride in tetrahydrofuran. A reference pattern of as-synthesized MIL-100 (Fe) is included. 
Table S1. Summary of changes in the full width at half maximum (FWHM) for the $2 \theta=11^{\circ}(\lambda=$ $1.5406 \AA$ ) reflection of MIL-100 (Fe) under a range of conditions.

\begin{tabular}{|c|c|c|c|c|c|}
\hline Condition & \multicolumn{2}{|c|}{ Result } & Condition & \multicolumn{2}{|c|}{ Result } \\
\hline \multirow{2}{*}{ Initial } & FWHM & 0.24468 & \multirow{2}{*}{ DI water } & FWHM & Wash $^{a}$ \\
\hline & $\%$ Change & - & & $\%$ Change & - \\
\hline \multirow{2}{*}{$120{ }^{\circ} \mathrm{C}$ Air } & FWHM & 0.26668 & \multirow{2}{*}{$\mathrm{BuNH}_{2} / \mathrm{THF}$} & FWHM & 0.25382 \\
\hline & $\%$ Change & 9 & & $\%$ Change & 4 \\
\hline \multirow{2}{*}{$180{ }^{\circ} \mathrm{C}$ Air } & FWHM & 0.26524 & \multirow{2}{*}{$\mathrm{PhMgBr} / \mathrm{THF}$} & FWHM & 0.16648 \\
\hline & $\%$ Change & 9 & & $\%$ Change & -32 \\
\hline \multirow{2}{*}{ Conc. $\mathrm{HCl}$} & FWHM & 0.00000 & \multirow{2}{*}{ TBAF/THF } & FWHM & 0.36212 \\
\hline & $\%$ Change & $x$ & & $\%$ Change & 48 \\
\hline \multirow{2}{*}{$\mathrm{pH}=1$ Buffer } & FWHM & 0.20056 & \multirow{2}{*}{$\mathrm{Me}_{3} \mathrm{SiCl} / \mathrm{CH}_{2} \mathrm{Cl}_{2}$} & FWHM & 0.17550 \\
\hline & $\%$ Change & -19 & & $\%$ Change & -29 \\
\hline \multirow{2}{*}{$\mathrm{pH}=4$ Buffer } & FWHM & 0.30091 & \multirow{2}{*}{$\mathrm{MeCOCl} / \mathrm{CH}_{2} \mathrm{Cl}_{2}$} & FWHM & 0.09959 \\
\hline & $\%$ Change & 23 & & $\%$ Change & $x$ \\
\hline \multirow{2}{*}{$\mathrm{pH}=7$ Buffer } & FWHM & 0.25527 & \multirow{2}{*}{$\mathrm{SO}_{2} \mathrm{Cl}_{2} / \mathrm{CH}_{2} \mathrm{Cl}_{2}$} & FWHM & 0.19047 \\
\hline & $\%$ Change & 5 & & $\%$ Change & -23 \\
\hline \multirow{2}{*}{$\mathrm{pH}=10$ Buffer } & FWHM & 0.00000 & \multirow{2}{*}{$\mathrm{Me}_{2} \mathrm{SO}_{4} / \mathrm{CH}_{2} \mathrm{Cl}_{2}$} & FWHM & 0.20291 \\
\hline & $\%$ Change & $x$ & & $\%$ Change & -17 \\
\hline \multirow{2}{*}{$\mathrm{pH}=13$ Buffer } & FWHM & 0.00000 & \multirow{2}{*}{$\mathrm{Br}_{2} / \mathrm{CH}_{2} \mathrm{Cl}_{2}$} & FWHM & 0.27996 \\
\hline & $\%$ Change & $x$ & & $\%$ Change & 15 \\
\hline \multirow{2}{*}{ Sat. $\mathrm{NaOH}$} & FWHM & 0.00000 & \multirow{2}{*}{$\mathrm{I}_{2} / \mathrm{CH}_{2} \mathrm{Cl}_{2}$} & FWHM & 0.27126 \\
\hline & $\%$ Change & $\times$ & & $\%$ Change & 11 \\
\hline \multirow{2}{*}{$\mathrm{CH}_{3} \mathrm{COOH}$} & FWHM & 0.26089 & \multirow{2}{*}{$\mathrm{MCPBA} / \mathrm{CH}_{2} \mathrm{Cl}_{2}$} & FWHM & 0.26632 \\
\hline & $\%$ Change & 7 & & $\%$ Change & 9 \\
\hline \multirow{2}{*}{ LiHMDS/Tol } & FWHM & 0.26781 & \multirow{2}{*}{$\mathrm{PCC} / \mathrm{CH}_{2} \mathrm{Cl}_{2}$} & FWHM & 0.25624 \\
\hline & $\%$ Change & 10 & & $\%$ Change & 5 \\
\hline \multirow{2}{*}{$\mathrm{H}_{2} \mathrm{~S} / \mathrm{THF}$} & FWHM & 0.00000 & \multirow{2}{*}{$\mathrm{SmI}_{2} / \mathrm{THF}$} & FWHM & 0.00000 \\
\hline & $\%$ Change & $\times$ & & $\%$ Change & $\times$ \\
\hline \multirow{2}{*}{$\mathrm{NH}_{3} / \mathrm{MeOH}$} & FWHM & 0.24867 & \multirow{2}{*}{$\mathrm{LiBH}_{4} / \mathrm{THF}$} & FWHM & 0.00000 \\
\hline & $\%$ Change & 2 & & $\%$ Change & $x$ \\
\hline
\end{tabular}

${ }^{a}$ Wash indicates the material was washed with water during its preparation. 


\section{Synthesis, characterization, and stability assessment of MIL-100 (Cr).}

Synthesis of MIL-100 $(\mathbf{C r})$. This procedure is adapted from the literature. ${ }^{15}$ Trimesic acid (1.68 g, $8.00 \mathrm{mmol}, 1.00$ equiv.) and $\mathrm{CrCl}_{3} \bullet 4 \mathrm{H}_{2} \mathrm{O}(4.26 \mathrm{mg}, 16.0 \mathrm{mmol}, 2.00$ equiv.) were added to a mortar and pestle and ground by hand for approximately $30 \mathrm{~min}$ at room temperature. The mixture was then transferred into a Teflon-lined autoclave and heated at $220^{\circ} \mathrm{C}$ in a preheated oven for 15 h. The resulting green solid was transferred to a $100 \mathrm{~mL}$ Pyrex jar and water $(90 \mathrm{~mL})$ was added. The jar was allowed to stand for 3 hours at $65^{\circ} \mathrm{C}$ in an oven, at which time the water was decanted and replaced with fresh water $(90 \mathrm{~mL})$. This procedure was repeated three additional times for a total of four hot water soaks. The solid was then filtered and soaked in anhydrous ethanol $(90 \mathrm{~mL})$ for $3 \mathrm{~h}$ at $65^{\circ} \mathrm{C}$ in an oven three total times following the same procedure. The solid was filtered to dryness and transferred to a $10 \mathrm{~mL}$ Schlenk flask. The green solid was activated under high vacuum ( $<50 \mathrm{mbar}$ ) at $150^{\circ} \mathrm{C}$ for $24 \mathrm{~h}$. The Schlenk flask was transferred into a $\mathrm{N}_{2}$-filled glovebox, and the activated MIL-100 (Cr) was transferred into a $20 \mathrm{~mL}$ scintillation vial for long-term storage. A portion of the activated sample was transferred to a pre-tared Micromeritics sample tube equipped with a Sureseal. The tube was removed from the glovebox and the sample was further activated under high vacuum $(<10 \mu \mathrm{bar})$ at $150^{\circ} \mathrm{C}$ for $24 \mathrm{~h}$ prior to gas sorption measurements. 


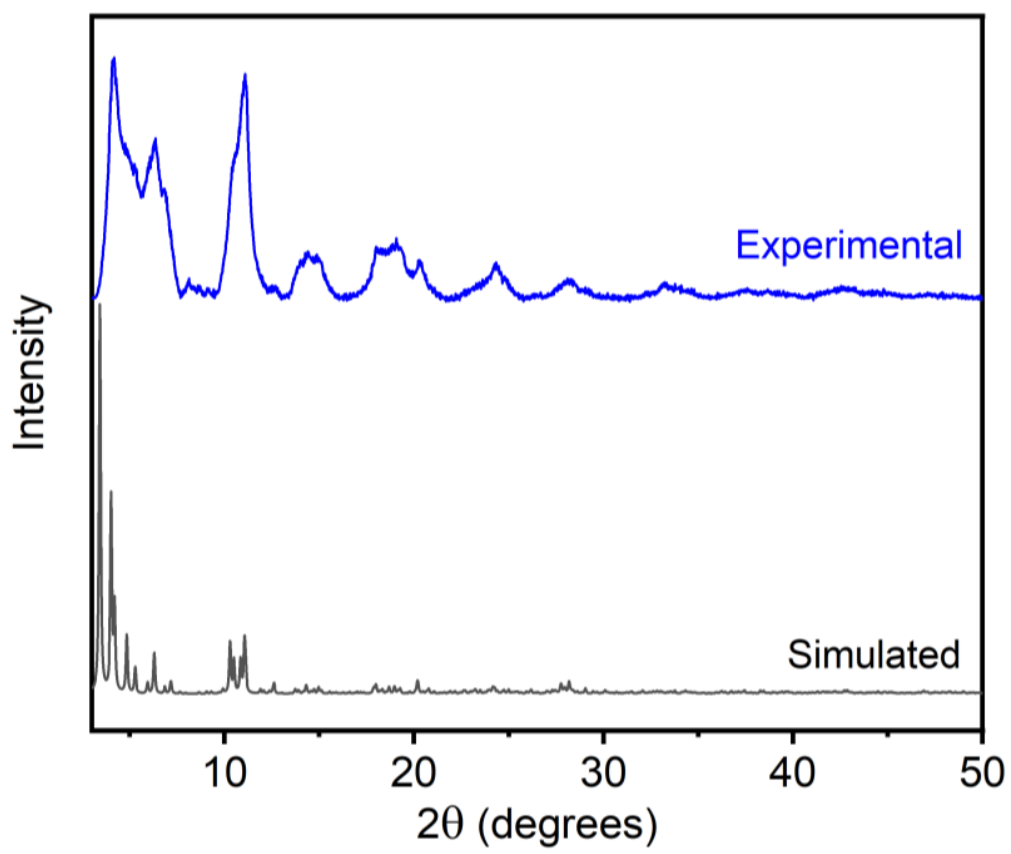

Figure S21. PXRD pattern $(\lambda=1.5406 \AA)$ of methanol-solvated MIL-100 (Cr). The simulated pattern based on the previously reported powder X-ray diffraction structure of MIL-100 (Cr) is included for reference. ${ }^{16}$ The experimental PXRD pattern of MIL-100 (Cr) was baseline corrected.

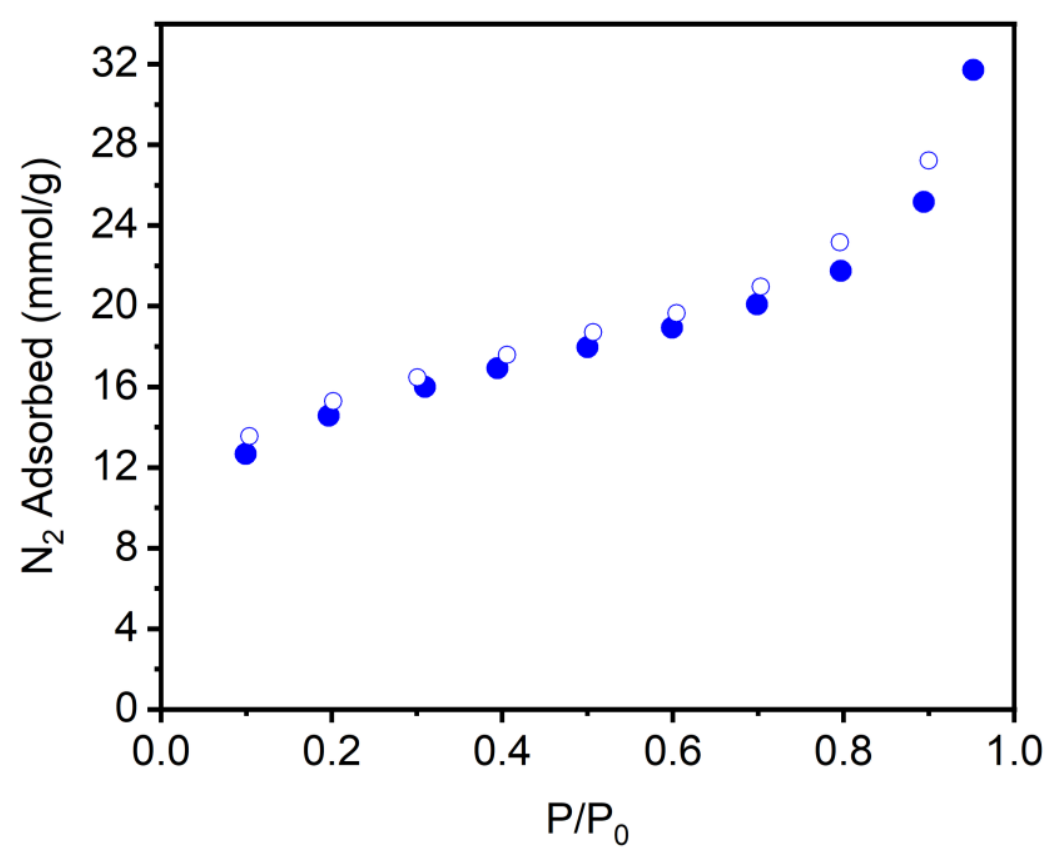

Figure S22. $77 \mathrm{~K} \mathrm{~N}_{2}$ adsorption (filled circles) and desorption (open circles) isotherm of activated MIL-100 (Cr). The Langmuir surface area determined from these data is $2449 \pm 100 \mathrm{~m}^{2} / \mathrm{g}$. 


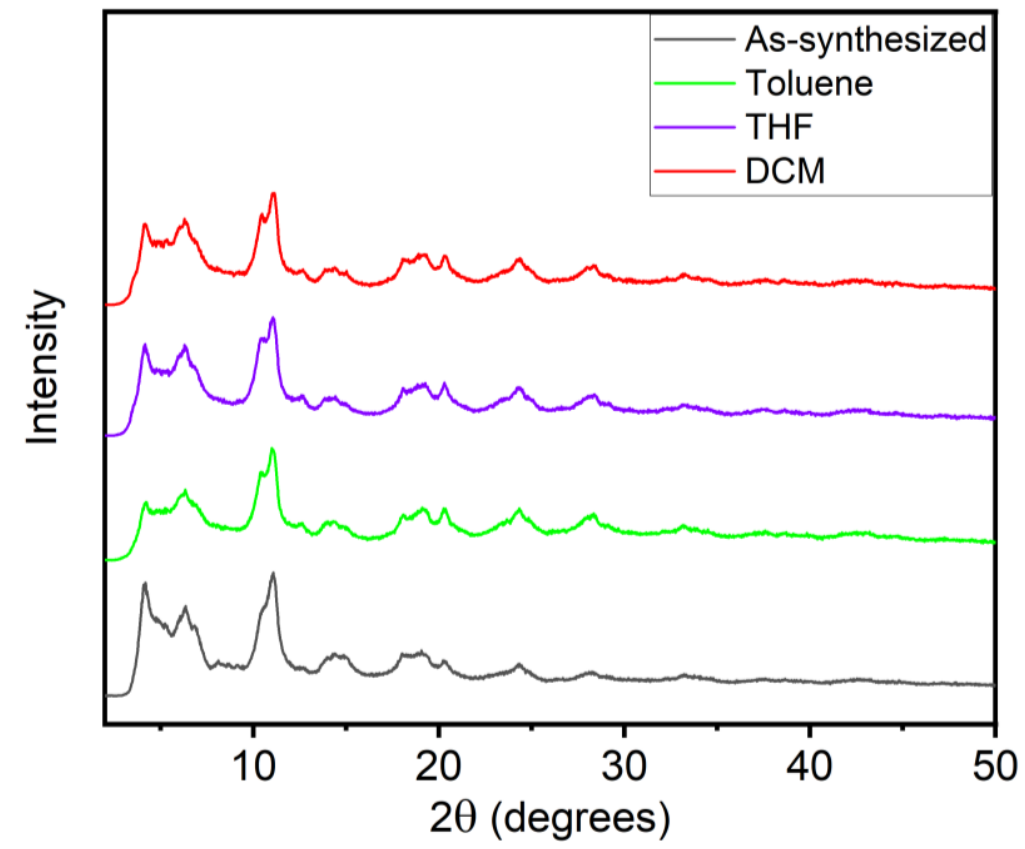

Figure S23. PXRD patterns $(\lambda=1.5406 \AA)$ of MIL-100 (Cr) upon exposure to various organic solvents. Note that MIL-100 (Cr) was soaked in water and ethanol during its synthesis as well. A reference pattern of as-synthesized MIL-100 (Cr) is included.

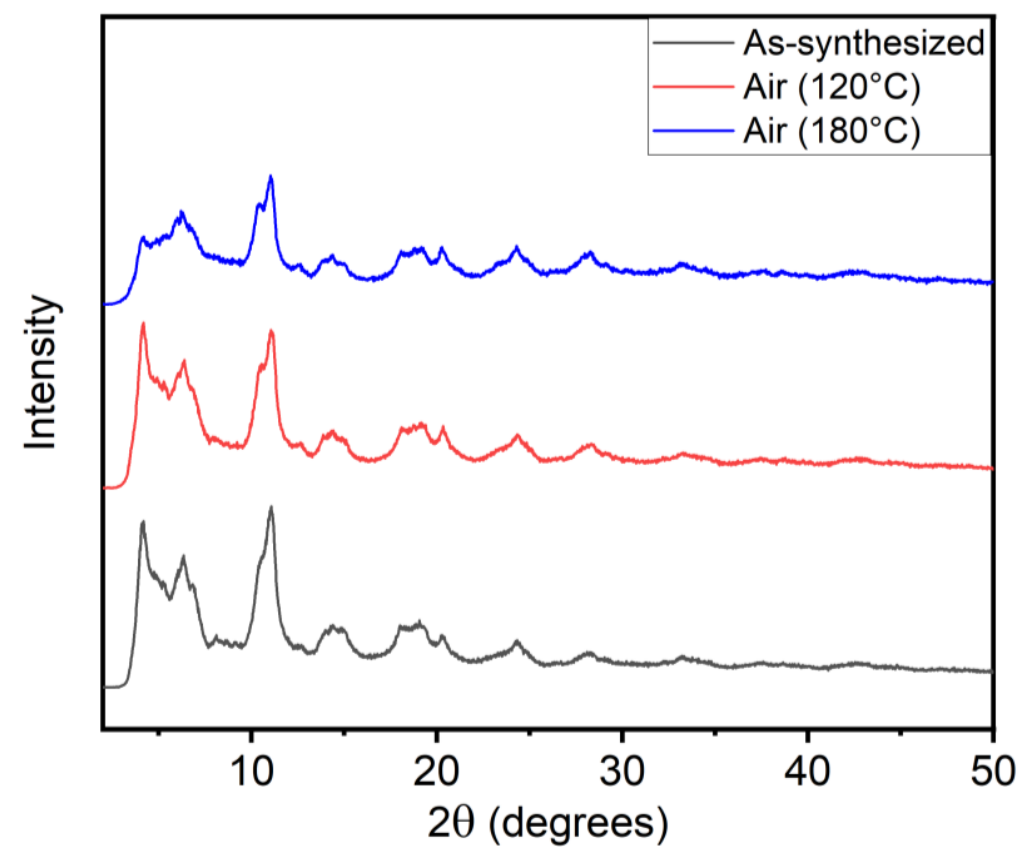

Figure S24. PXRD patterns ( $\lambda=1.5406 \AA)$ of MIL-100 (Cr) upon standing at $120{ }^{\circ} \mathrm{C}$ and $180^{\circ} \mathrm{C}$ in air for $24 \mathrm{~h}$. A reference pattern of as-synthesized MIL-100 (Cr) is included. 


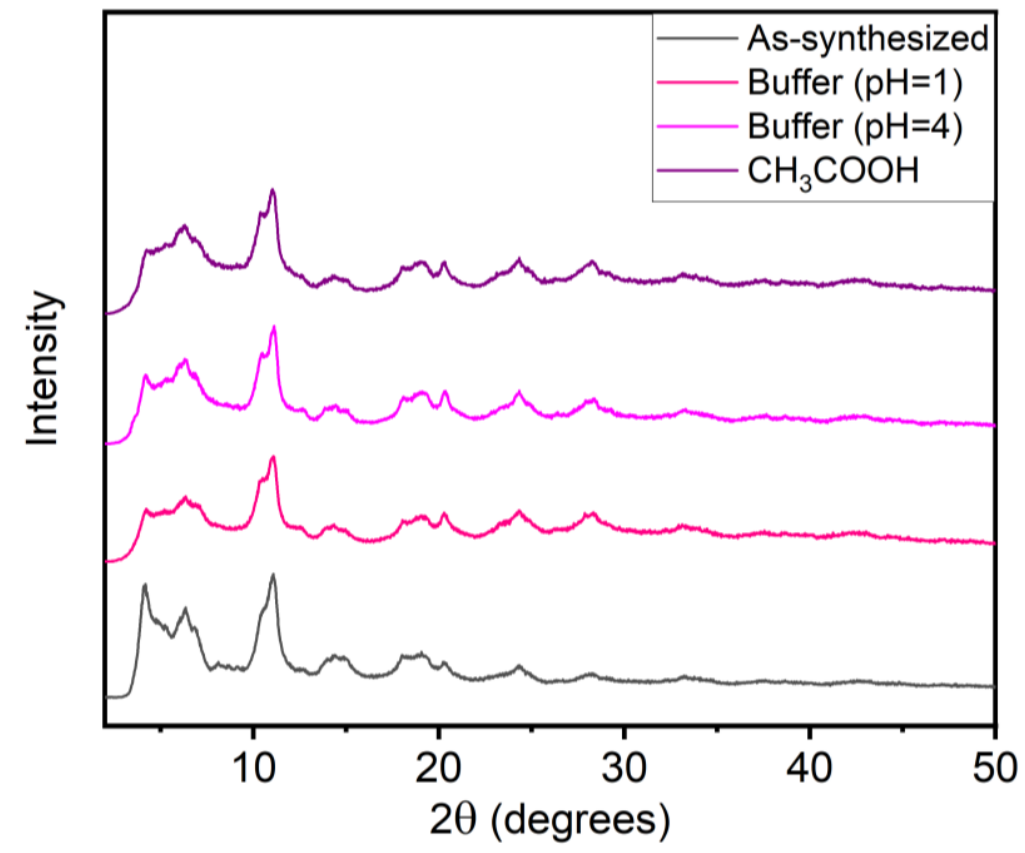

Figure S25. PXRD patterns $(\lambda=1.5406 \AA)$ of MIL-100 $(\mathrm{Cr})$ upon exposure to acids. Exposure tests include aqueous solutions buffered at $\mathrm{pH} 1$ and $\mathrm{pH} 4$ and glacial acetic acid. A reference pattern of as-synthesized MIL-100 (Cr) is included.

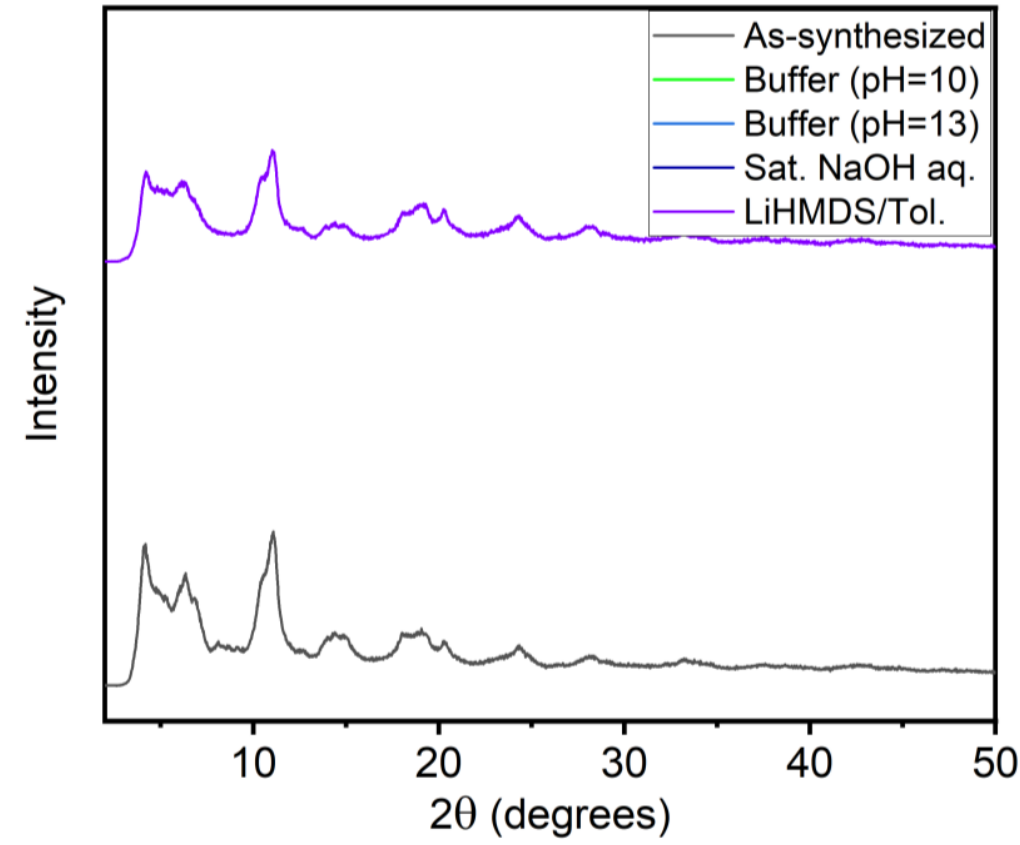

Figure S26. PXRD patterns ( $\lambda=1.5406 \AA$ ) of MIL-100 (Cr) upon exposure to bases. Exposure tests include aqueous solutions buffered at $\mathrm{pH} 10$ and $\mathrm{pH} 13$, saturated aqueous $\mathrm{NaOH}$, and $1.0 \mathrm{M}$ lithium hexamethyldisilazide (LiHMDS) in toluene. No solid remained after exposure of MIL-100 (Cr) to aqueous solutions buffered at $\mathrm{pH} 10$ and $\mathrm{pH} 13$ and to saturated aqueous $\mathrm{NaOH}$. A reference pattern of as-synthesized MIL-100 (Cr) is included. 


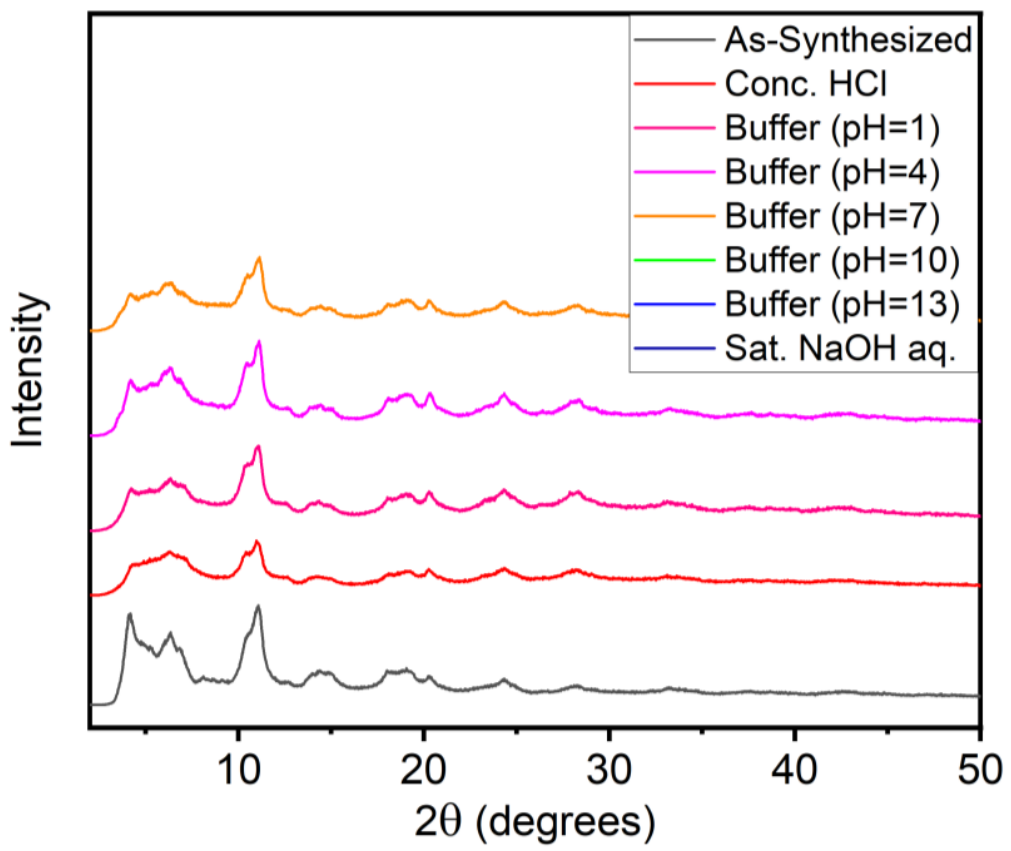

Figure S27. Summary of the PXRD patterns $(\lambda=1.5406 \AA)$ of MIL-100 (Cr) upon exposure to various aqueous conditions. No solid remained after exposure of MIL-100 (Cr) to aqueous solutions buffered at $\mathrm{pH} 10$ and $\mathrm{pH} 13$ and to saturated aqueous $\mathrm{NaOH}$. A reference pattern of assynthesized MIL-100 (Cr) is included.

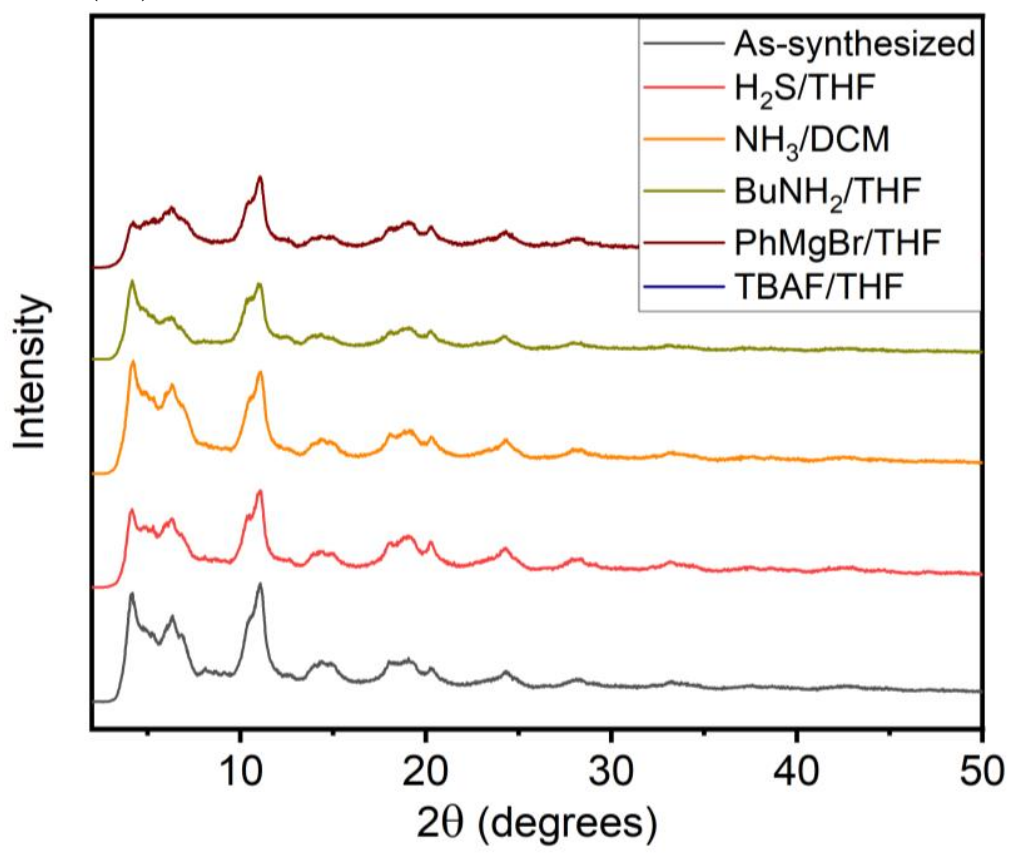

Figure S28. PXRD patterns $(\lambda=1.5406 \AA)$ of MIL-100 (Cr) upon exposure to nucleophiles. Exposure tests include $0.8 \mathrm{M}$ hydrogen sulfide in tetrahydrofuran, $1.0 \mathrm{M}$ ammonia in methanol, 1.0 $\mathrm{M} \mathrm{n}$-butylamine in tetrahydrofuran, $1.0 \mathrm{M} \mathrm{PhMgBr}$ in tetrahydrofuran, and $1.0 \mathrm{M}$ tetrabutylammonium fluoride (TBAF) in tetrahydrofuran. No solid remained after exposure of MIL-100 (Cr) to TBAF. A reference pattern of as-synthesized MIL-100 (Cr) is included. 


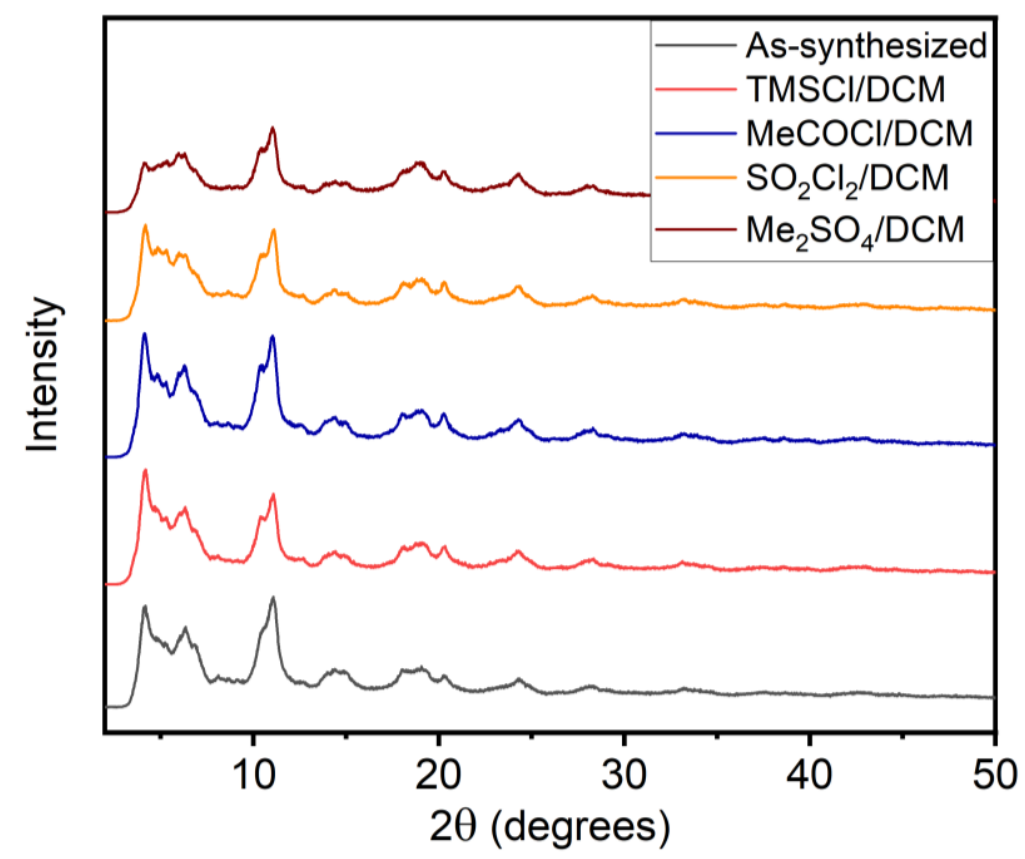

Figure S29. PXRD patterns $(\lambda=1.5406 \AA)$ of MIL-100 (Cr) upon exposure to electrophiles. Exposure tests include $1.0 \mathrm{M}$ chlorotrimethylsilane (TMSCl) in dichloromethane, $1.0 \mathrm{M}$ acetyl chloride in dichloromethane, $1.0 \mathrm{M}$ sulfuryl chloride in dichloromethane, and saturated dimethyl sulfate in dichloromethane. A reference pattern of as-synthesized MIL-100 (Cr) is included.

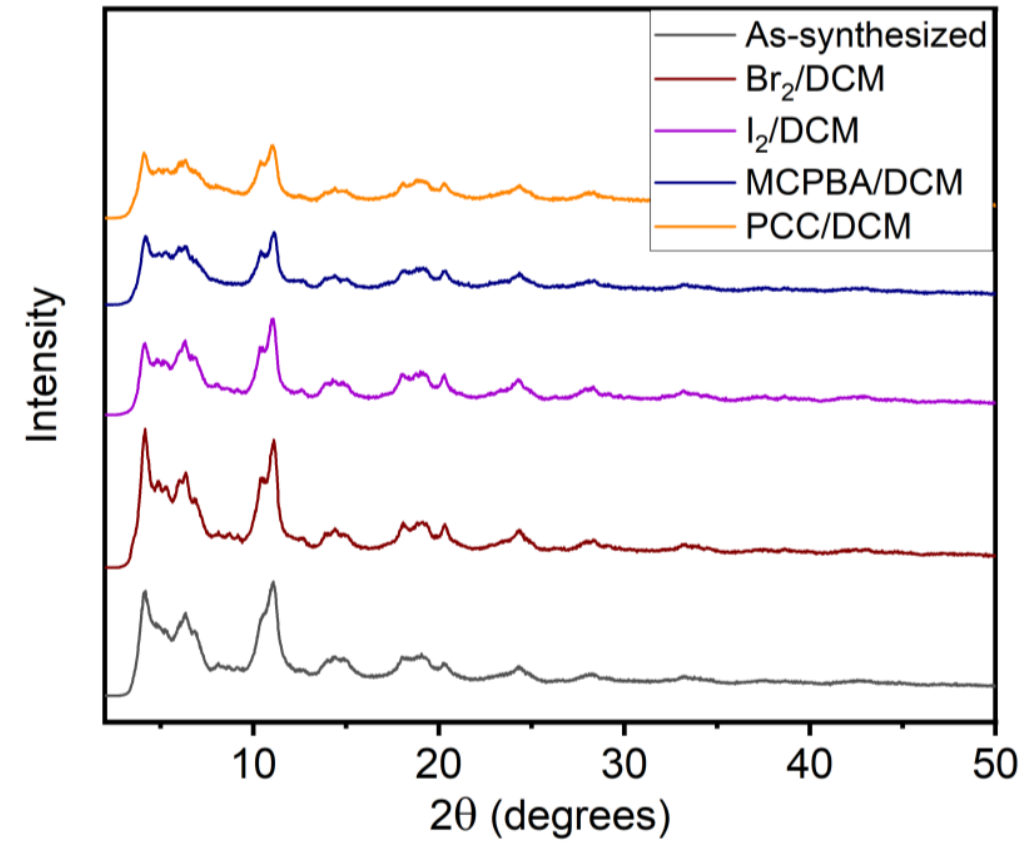

Figure S30. PXRD patterns $(\lambda=1.5406 \AA)$ of MIL-100 (Cr) upon exposure to oxidants. Exposure tests include $1.0 \mathrm{M}$ bromine in dichloromethane, saturated iodine in dichloromethane, saturated $m$-chloroperoxybenzoic acid (MCPBA) in dichloromethane, and saturated pyridinium chlorochromate (PCC) in dichloromethane. A reference pattern of as-synthesized MIL-100 (Cr) is included. 


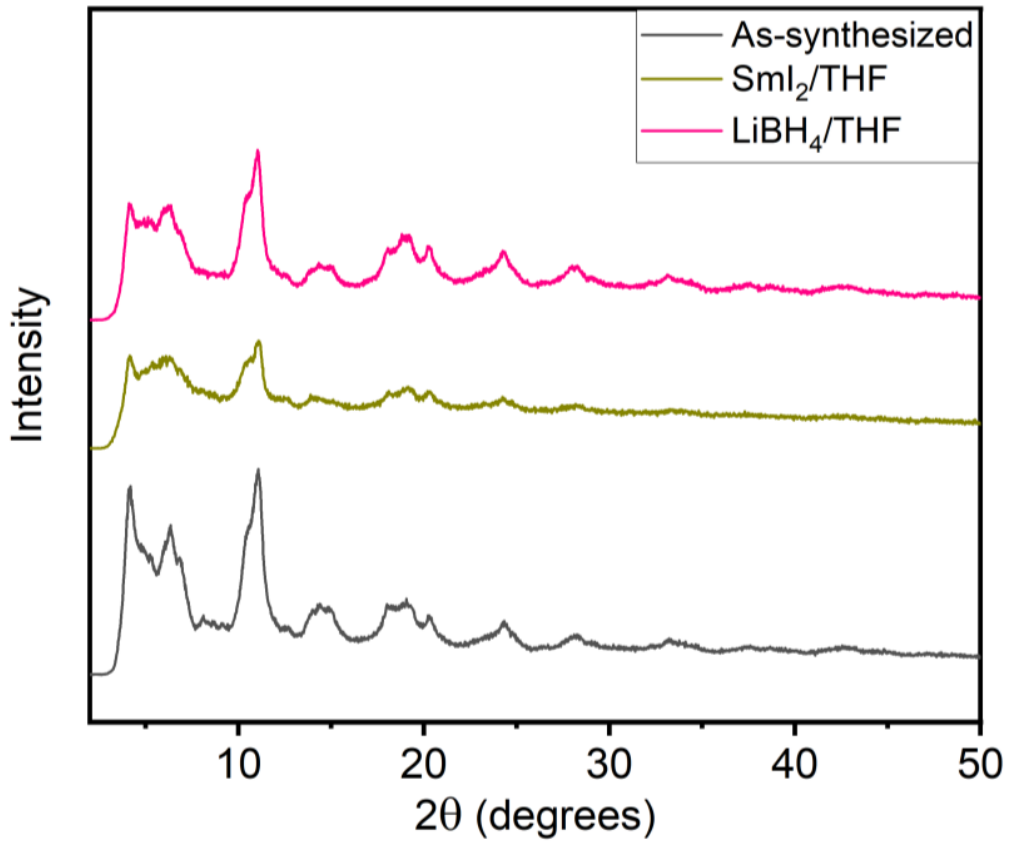

Figure S31. PXRD patterns $(\lambda=1.5406 \AA)$ of MIL-100 (Cr) upon exposure to reductants. Exposure tests include $0.1 \mathrm{M}$ samarium iodide in tetrahydrofuran and $1.0 \mathrm{M}$ lithium borohydride in tetrahydrofuran. A reference pattern of as-synthesized MIL-100 (Cr) is included. 
Table S2. Summary of changes in the full width at half maximum (FWHM) for the $2 \theta=11^{\circ}(\lambda=$ $1.5406 \AA$ ) reflection of MIL-100 (Cr) under a range of conditions.

\begin{tabular}{|c|c|c|c|c|c|}
\hline Condition & \multicolumn{2}{|c|}{ Result } & Condition & \multicolumn{2}{|c|}{ Result } \\
\hline \multirow{2}{*}{ Initial } & FWHM & 1.08264 & \multirow{2}{*}{ DI water } & FWHM & $\mathrm{Wash}^{a}$ \\
\hline & $\%$ Change & - & & $\%$ Change & - \\
\hline \multirow{2}{*}{$120^{\circ} \mathrm{C}$ Air } & FWHM & 1.18355 & \multirow{2}{*}{$\mathrm{BuNH}_{2} / \mathrm{THF}$} & FWHM & 1.22003 \\
\hline & $\%$ Change & 9 & & $\%$ Change & 13 \\
\hline \multirow{2}{*}{$180{ }^{\circ} \mathrm{C}$ Air } & FWHM & 1.21569 & \multirow{2}{*}{$\mathrm{PhMgBr} / \mathrm{THF}$} & FWHM & 1.10832 \\
\hline & $\%$ Change & 12 & & $\%$ Change & 2 \\
\hline \multirow{2}{*}{ Conc. $\mathrm{HCl}$} & FWHM & 1.15949 & \multirow{2}{*}{ TBAF/THF } & FWHM & 0.00000 \\
\hline & $\%$ Change & 7 & & $\%$ Change & $\times$ \\
\hline \multirow{2}{*}{$\mathrm{pH}=1$ Buffer } & FWHM & 1.16055 & \multirow{2}{*}{$\mathrm{Me}_{3} \mathrm{SiCl} / \mathrm{CH}_{2} \mathrm{Cl}_{2}$} & FWHM & 1.1501 \\
\hline & $\%$ Change & 7 & & $\%$ Change & 6 \\
\hline \multirow{2}{*}{$\mathrm{pH}=4$ Buffer } & FWHM & 1.15023 & \multirow{2}{*}{$\mathrm{MeCOCl} / \mathrm{CH}_{2} \mathrm{Cl}_{2}$} & FWHM & 1.15286 \\
\hline & $\%$ Change & 6 & & $\%$ Change & 7 \\
\hline \multirow{2}{*}{$\mathrm{pH}=7$ Buffer } & FWHM & 1.17449 & \multirow{2}{*}{$\mathrm{SO}_{2} \mathrm{Cl}_{2} / \mathrm{CH}_{2} \mathrm{Cl}_{2}$} & FWHM & 1.14368 \\
\hline & $\%$ Change & 9 & & $\%$ Change & 6 \\
\hline \multirow{2}{*}{$\mathrm{pH}=10$ Buffer } & FWHM & 0.00000 & \multirow{2}{*}{$\mathrm{Me}_{2} \mathrm{SO}_{4} / \mathrm{CH}_{2} \mathrm{Cl}_{2}$} & FWHM & 1.15741 \\
\hline & $\%$ Change & $\times$ & & $\%$ Change & 7 \\
\hline \multirow{2}{*}{$\mathrm{pH}=13$ Buffer } & FWHM & 0.00000 & \multirow{2}{*}{$\mathrm{Br}_{2} / \mathrm{CH}_{2} \mathrm{Cl}_{2}$} & FWHM & 1.14308 \\
\hline & $\%$ Change & $x$ & & $\%$ Change & 6 \\
\hline \multirow{2}{*}{ Sat. $\mathrm{NaOH}$} & FWHM & 0.00000 & \multirow{2}{*}{$\mathrm{I}_{2} / \mathrm{CH}_{2} \mathrm{Cl}_{2}$} & FWHM & 1.08901 \\
\hline & $\%$ Change & $x$ & & $\%$ Change & 1 \\
\hline \multirow{2}{*}{$\mathrm{CH}_{3} \mathrm{COOH}$} & FWHM & 1.14667 & \multirow{2}{*}{$\mathrm{MCPBA} / \mathrm{CH}_{2} \mathrm{Cl}_{2}$} & FWHM & 1.19128 \\
\hline & $\%$ Change & 6 & & $\%$ Change & 10 \\
\hline \multirow{2}{*}{ LiHMDS/Tol } & FWHM & 1.14342 & \multirow{2}{*}{$\mathrm{PCC} / \mathrm{CH}_{2} \mathrm{Cl}_{2}$} & FWHM & 1.16566 \\
\hline & $\%$ Change & 6 & & $\%$ Change & 8 \\
\hline \multirow{2}{*}{$\mathrm{H}_{2} \mathrm{~S} / \mathrm{THF}$} & FWHM & 1.14201 & \multirow{2}{*}{$\mathrm{SmI}_{2} / \mathrm{THF}$} & FWHM & 1.21693 \\
\hline & $\%$ Change & 6 & & $\%$ Change & 12 \\
\hline \multirow{2}{*}{$\mathrm{NH}_{3} / \mathrm{MeOH}$} & FWHM & 1.12508 & \multirow{2}{*}{$\mathrm{LiBH}_{4} / \mathrm{THF}$} & FWHM & 1.1447 \\
\hline & $\%$ Change & 4 & & $\%$ Change & 6 \\
\hline
\end{tabular}

${ }^{a}$ Wash indicates the material was washed with water during its preparation. 


\section{Synthesis, characterization, and stability assessment of MOF-808.}

Synthesis of MOF-808. This procedure is adapted from the literature. ${ }^{17}$ A $350 \mathrm{~mL}$ screwcap high-pressure reaction flask was charged with $\mathrm{ZrOCl}_{2} \bullet 8 \mathrm{H}_{2} \mathrm{O}(1.20 \mathrm{~g}, 3.72 \mathrm{mmol}, 1.00$ equiv.) and formic acid $(150 \mathrm{~mL})$. The mixture was sonicated for 30 minutes. Separately, trimesic acid $(0.83 \mathrm{~g}, 3.93 \mathrm{mmol}, 1.06$ equiv. $)$ was suspended in $N, N$-dimethylformamide $(150 \mathrm{~mL})$ in a $250 \mathrm{~mL}$ Erlenmeyer flask, and the mixture was sonicated for 30 minutes. The two solutions were combined, and the mixture was sonicated for an additional 30 minutes. The reaction vessel was sealed and transferred to an oven, which was then heated to $100{ }^{\circ} \mathrm{C}$. The reaction mixture was allowed to stand without stirring at $100{ }^{\circ} \mathrm{C}$ for $7 \mathrm{~d}$. At this time, the heterogeneous reaction mixture was allowed to cool to room temperature and filtered. The resulting white solid was transferred to a $250 \mathrm{~mL}$ Pyrex jar with $N, N$-dimethylformamide $(100 \mathrm{~mL})$. The jar was allowed to stand for $24 \mathrm{~h}$ at room temperature, at which time the $N, N$-dimethylformamide was decanted and replaced with fresh $N, N$-dimethylformamide $(100 \mathrm{~mL})$. This procedure was repeated two additional times for a total of three $\mathrm{N}, \mathrm{N}$-dimethylformamide soaks. Next, the solid was filtered and returned to the jar with fresh acetone $(100 \mathrm{~mL})$. The solid was soaked in acetone for $24 \mathrm{~h}$ at room temperature three total times following the same procedure as described above. Next, the solid was filtered and returned to the jar with fresh $\mathrm{CHCl}_{3}(100 \mathrm{~mL})$. The solid was soaked in $\mathrm{CHCl}_{3}$ for $24 \mathrm{~h}$ at $50^{\circ} \mathrm{C}$ three total times following the same procedure as described above. The resulting white solid was filtered and transferred to a Schlenk flask. The solid was activated under flowing $\mathrm{N}_{2}$ at $120{ }^{\circ} \mathrm{C}$ for $4 \mathrm{~h}$, followed by further activation under high vacuum ( $<100 \mathrm{mbar})$ at $120^{\circ} \mathrm{C}$ for $24 \mathrm{~h}$. The Schlenk flask was transferred into a $\mathrm{N}_{2}$-filled glovebox, and the activated MOF- 808 was transferred into a $20 \mathrm{~mL}$ scintillation vial for long-term storage. A portion of the activated sample was transferred to a pre-tared Micromeritics sample tube equipped with a Sureseal. The tube was removed from the glovebox and the sample was further activated under high vacuum $(<10 \mu \mathrm{bar})$ at $120^{\circ} \mathrm{C}$ for 24 $\mathrm{h}$ prior to gas sorption measurements.

A second batch of MOF-808 was prepared following the same procedure as above. This sample had a $77 \mathrm{~K} \mathrm{~N}_{2}$ Langmuir surface area of $1574 \pm 14 \mathrm{~m}^{2} / \mathrm{g}$ and was used for large scale stability studies (Supporting Information Section 22). 


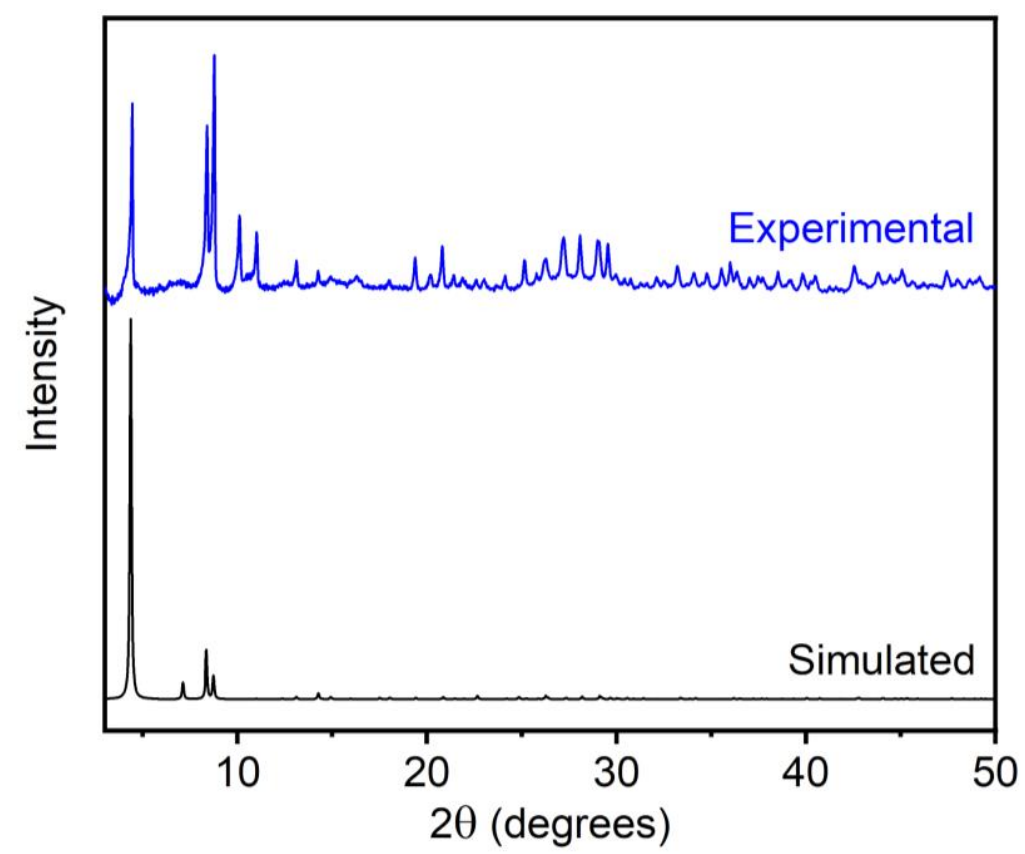

Figure S32. PXRD pattern $(\lambda=1.5406 \AA)$ of $\mathrm{CHCl}_{3}$-solvated MOF-808. The simulated pattern based on the previously reported, highly disordered single-crystal X-ray diffraction structure of MOF-808 is included for reference. ${ }^{17}$ The PXRD pattern of MOF-808 was baseline corrected.

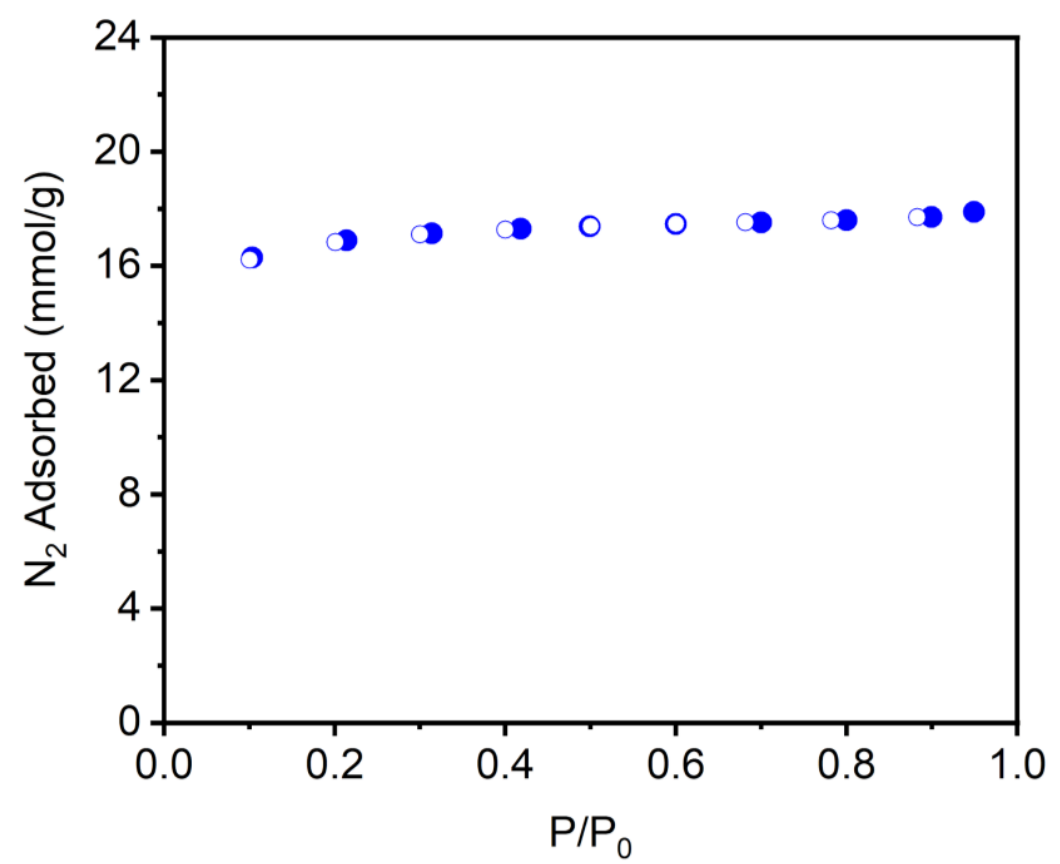

Figure S33. $77 \mathrm{~K} \mathrm{~N}_{2}$ adsorption (filled circles) and desorption (open circles) isotherm of activated MOF-808. The Langmuir surface area determined from these data is $1743 \pm 3 \mathrm{~m}^{2} / \mathrm{g}$. 


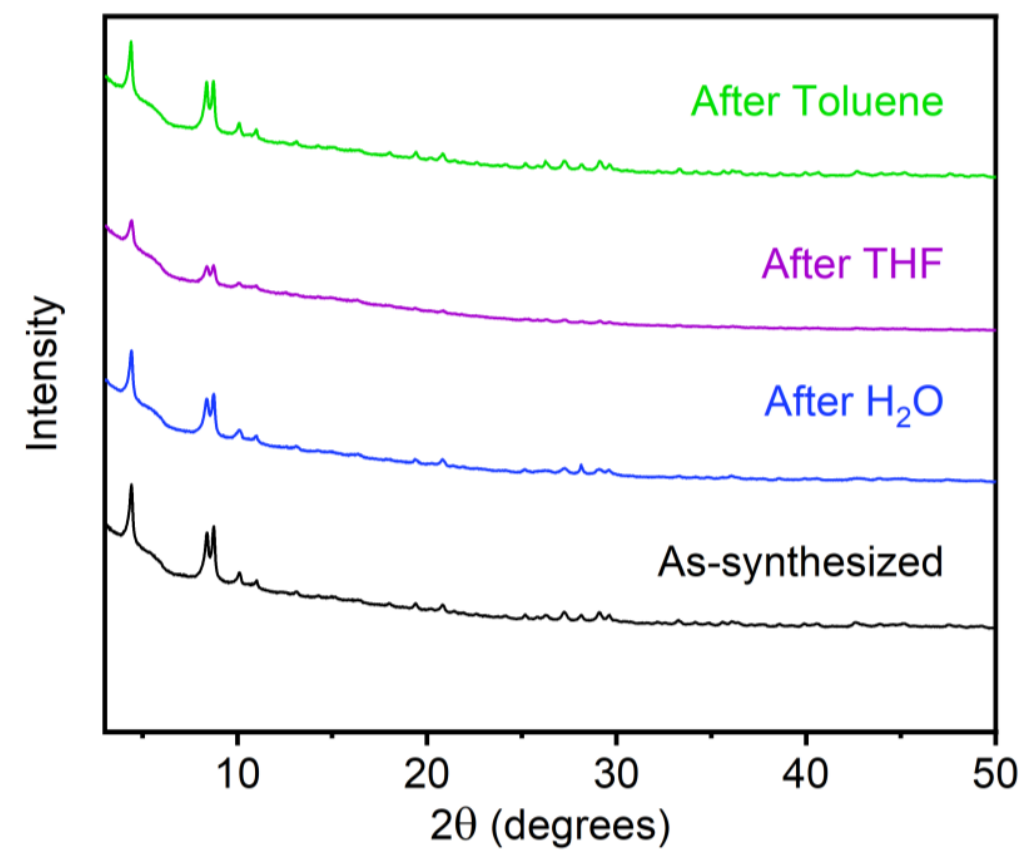

Figure S34. PXRD patterns $(\lambda=1.5406 \AA)$ of MOF-808 upon exposure to various organic solvents and water. Note that MOF-808 was soaked in DMF and $\mathrm{CHCl}_{3}$ during its synthesis as well. A reference pattern of as-synthesized MOF-808 is included.

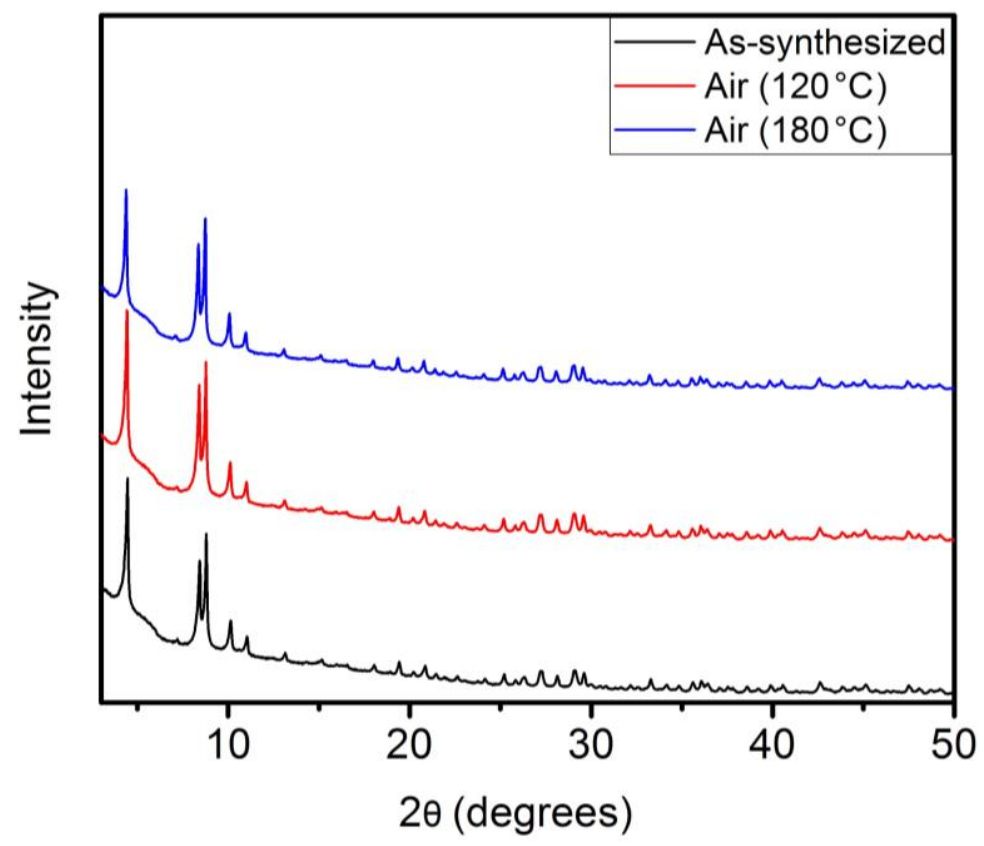

Figure S35. PXRD patterns $(\lambda=1.5406 \AA)$ of MOF-808 upon standing at $120{ }^{\circ} \mathrm{C}$ and $180{ }^{\circ} \mathrm{C}$ in air for $24 \mathrm{~h}$. A reference pattern of as-synthesized MOF-808 is included. 


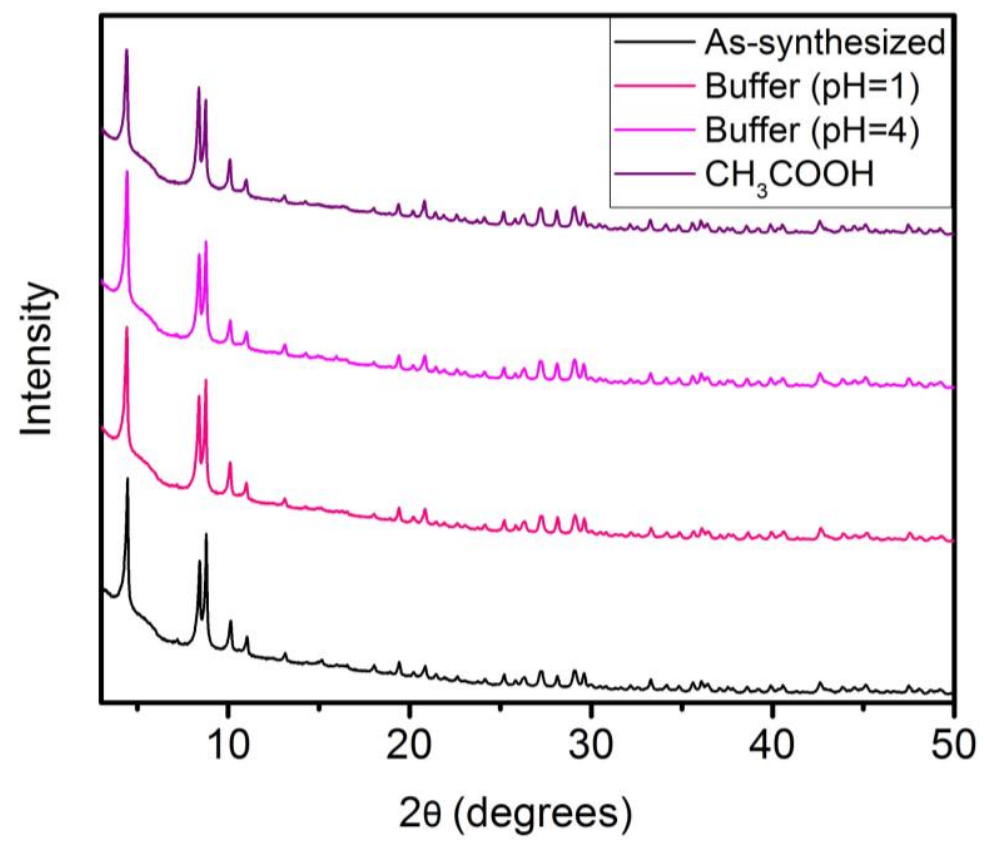

Figure S36. PXRD patterns ( $\lambda=1.5406 \AA)$ of MOF- 808 upon exposure to acids. Exposure tests include aqueous solutions buffered at $\mathrm{pH} 1$ and $\mathrm{pH} 4$ and glacial acetic acid. A reference pattern of as-synthesized MOF-808 is included.

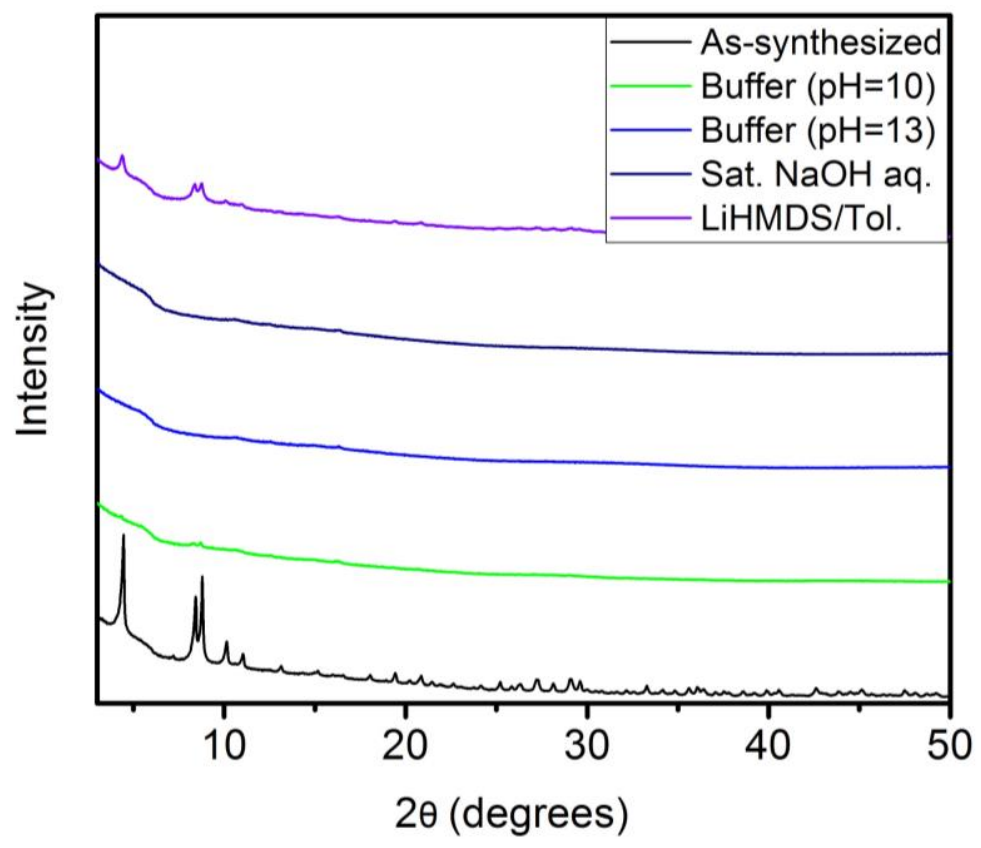

Figure S37. PXRD patterns ( $\lambda=1.5406 \AA$ ) of MOF-808 upon exposure to bases. Exposure tests include aqueous solutions buffered at $\mathrm{pH} 10$ and $\mathrm{pH} 13$, saturated aqueous $\mathrm{NaOH}$, and $1.0 \mathrm{M}$ lithium hexamethyldisilazide (LiHMDS) in toluene. A reference pattern of as-synthesized MOF808 is included. 


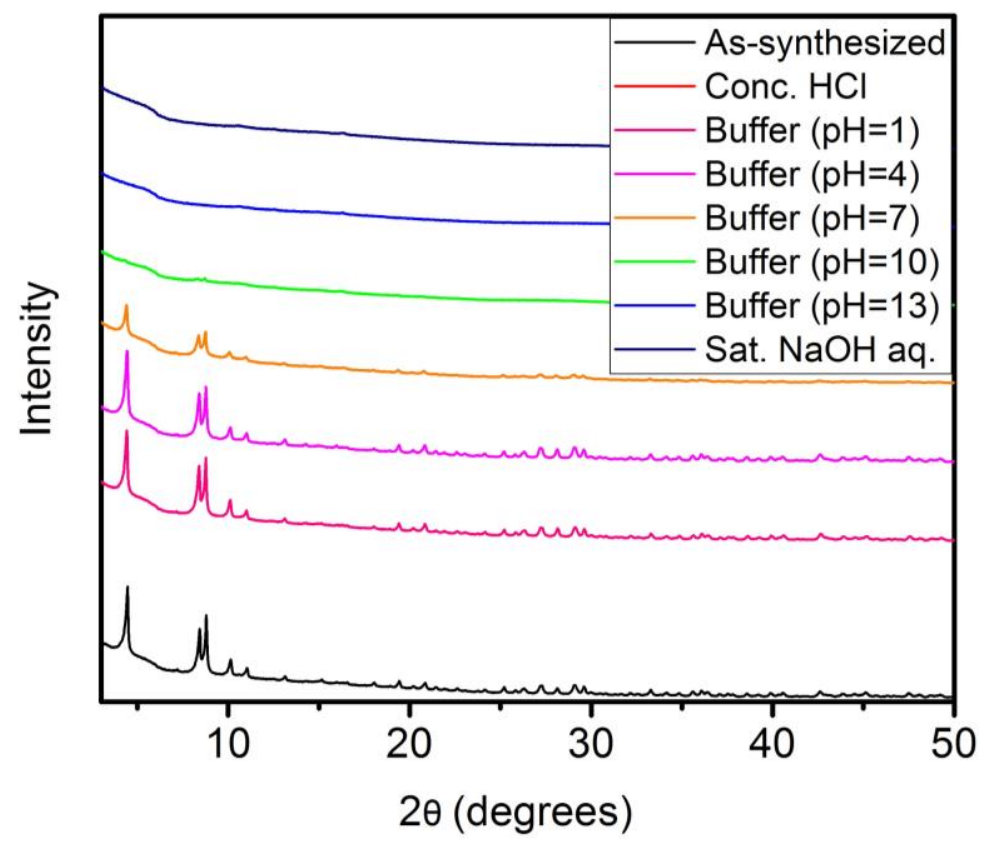

Figure S38. Summary of the PXRD patterns $(\lambda=1.5406 \AA$ ) of MOF- 808 upon exposure to various aqueous conditions. No solid remained after exposure of MOF-808 to concentrated $\mathrm{HCl}$. A reference pattern of as-synthesized MOF-808 is included.

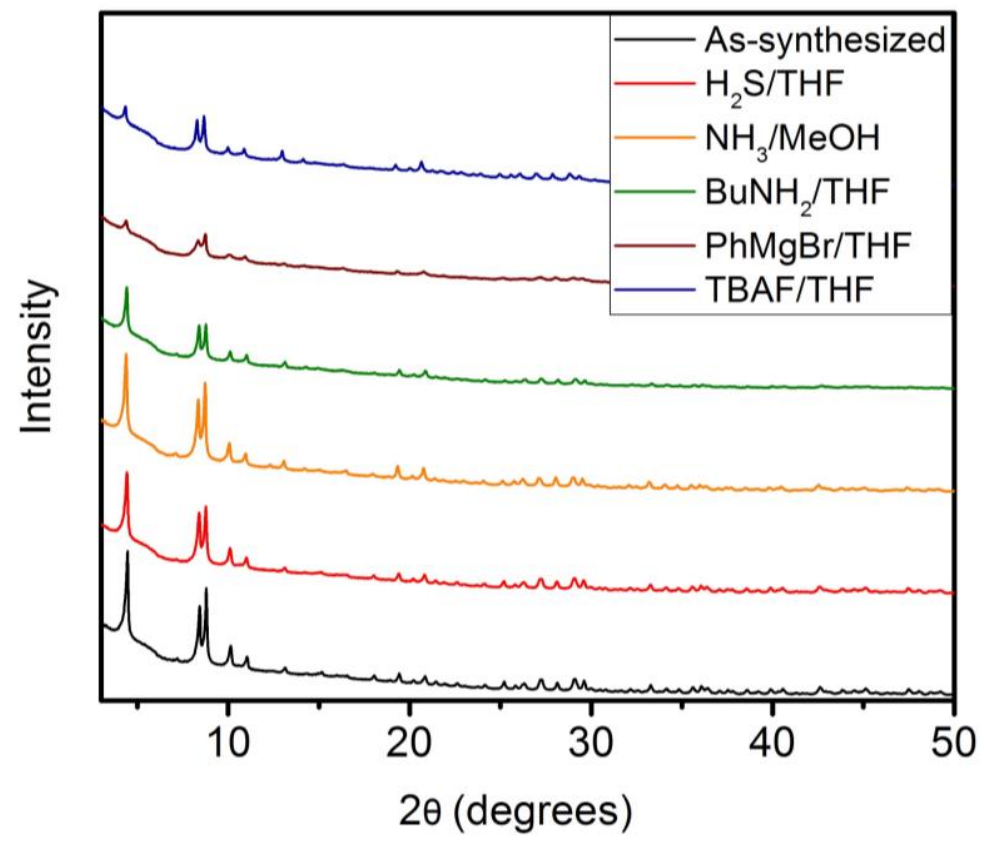

Figure S39. PXRD patterns ( $\lambda=1.5406 \AA$ ) of MOF-808 upon exposure to nucleophiles. Exposure tests include $0.8 \mathrm{M}$ hydrogen sulfide in tetrahydrofuran, $1.0 \mathrm{M}$ ammonia in methanol, $1.0 \mathrm{M} \mathrm{n}$ butylamine in tetrahydrofuran, $1.0 \mathrm{M} \mathrm{PhMgBr}$ in tetrahydrofuran, and $1.0 \mathrm{M}$ tetrabutylammonium fluoride (TBAF) in tetrahydrofuran. A reference pattern of as-synthesized MOF-808 is included. 


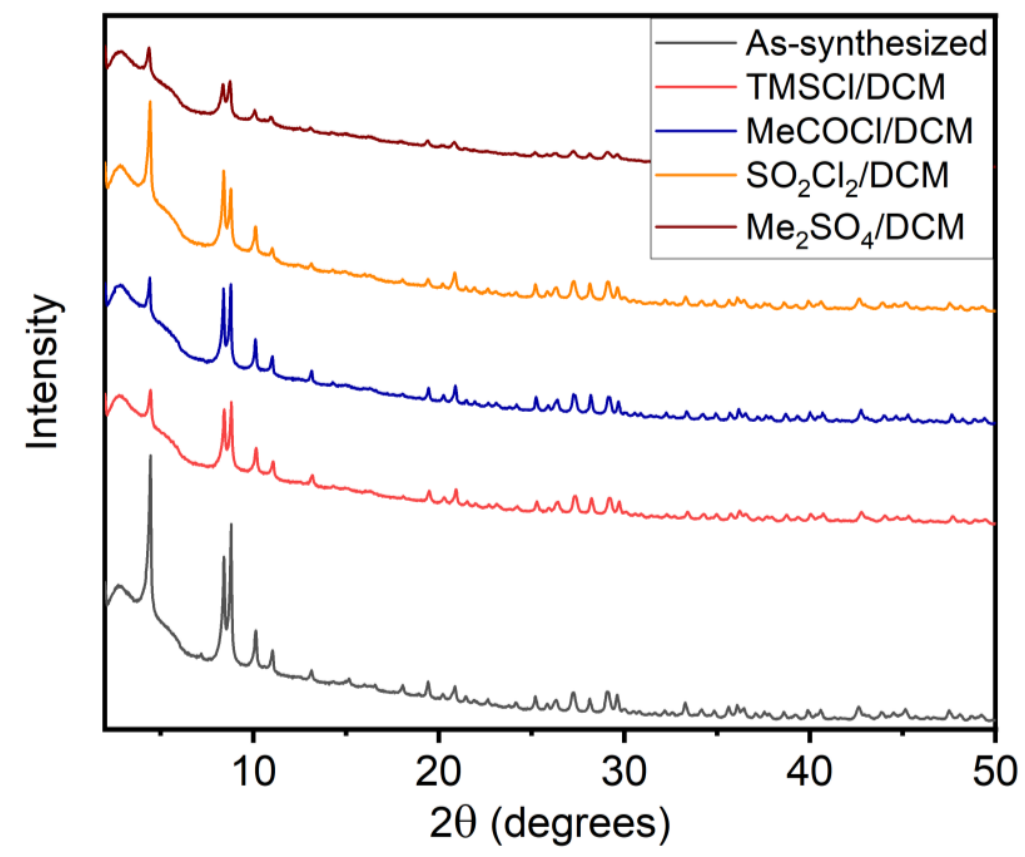

Figure S40. PXRD patterns ( $\lambda=1.5406 \AA$ ) of MOF-808 upon exposure to electrophiles. Exposure tests include $1.0 \mathrm{M}$ chlorotrimethylsilane (TMSCl) in dichloromethane, $1.0 \mathrm{M}$ acetyl chloride in dichloromethane, $1.0 \mathrm{M}$ sulfuryl chloride in dichloromethane, and saturated dimethyl sulfate in dichloromethane. A reference pattern of as-synthesized MOF-808 is included.

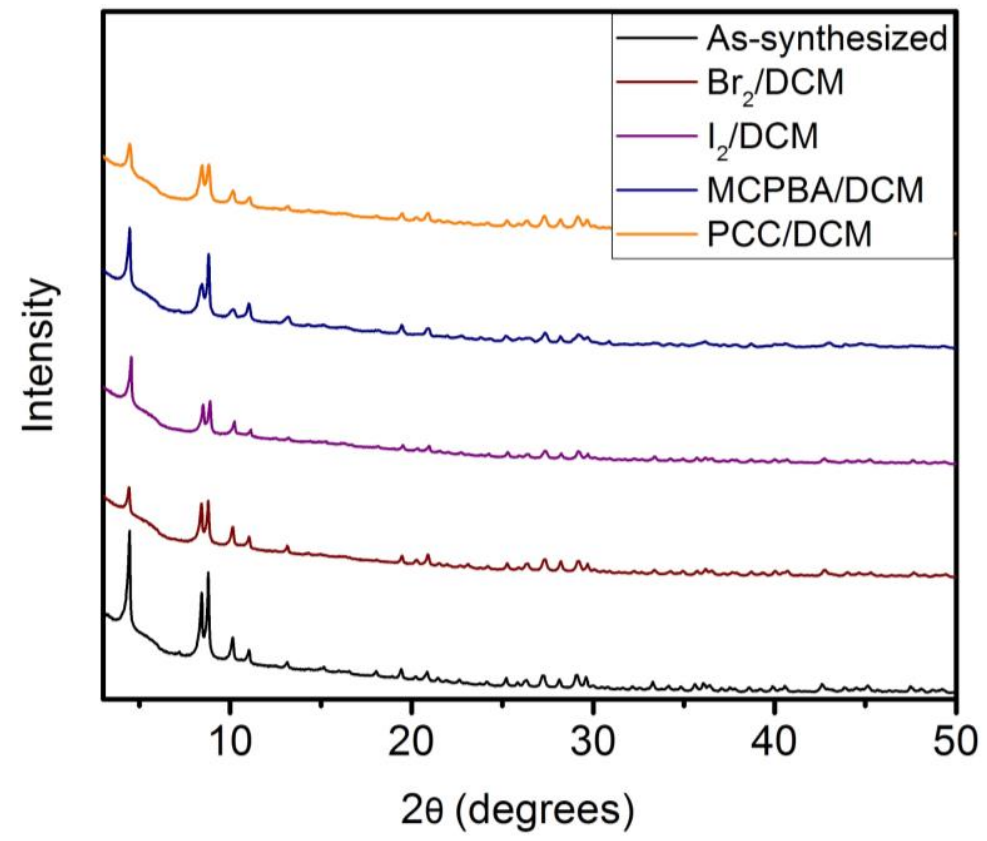

Figure S41. PXRD patterns $(\lambda=1.5406 \AA)$ of MOF-808 upon exposure to oxidants. Exposure tests include $1.0 \mathrm{M}$ bromine in dichloromethane, saturated iodine in dichloromethane, saturated $m$-chloroperoxybenzoic acid (MCPBA) in dichloromethane, and saturated pyridinium chlorochromate (PCC) in dichloromethane. A reference pattern of as-synthesized MOF-808 is included. 


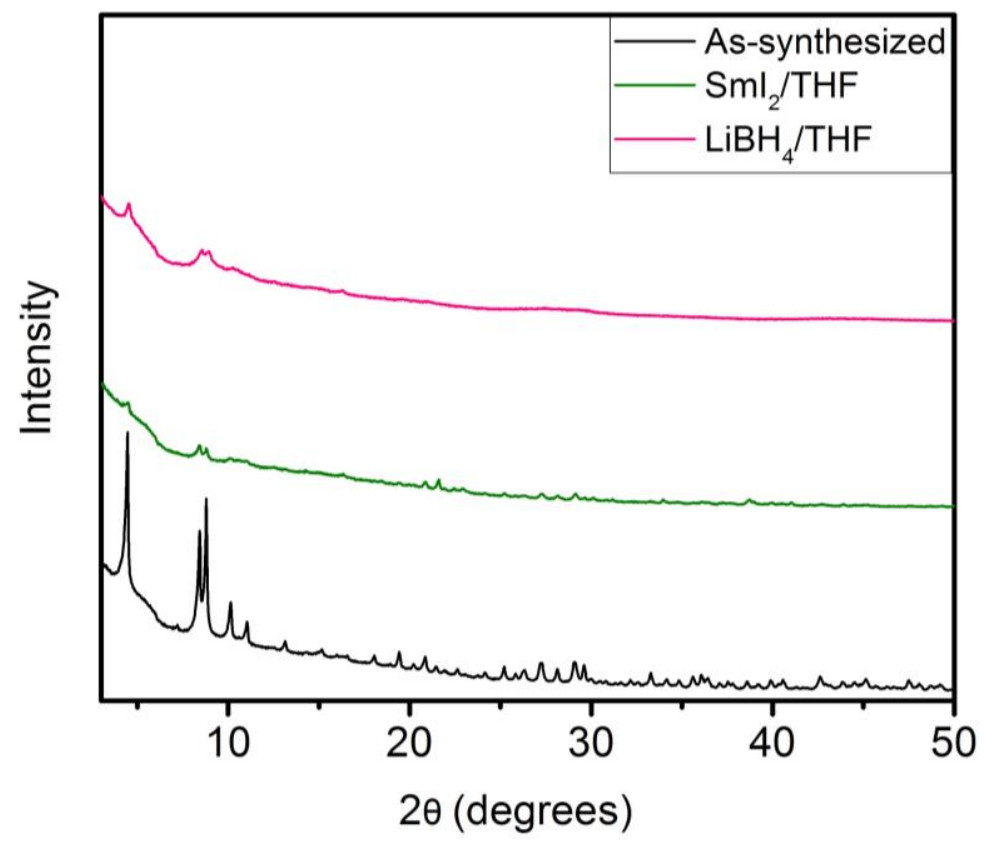

Figure S42. PXRD patterns ( $\lambda=1.5406 \AA)$ of MOF-808 upon exposure to reductants. Exposure tests include $0.1 \mathrm{M}$ samarium iodide in tetrahydrofuran and $1.0 \mathrm{M}$ lithium borohydride in tetrahydrofuran. A reference pattern of as-synthesized MOF-808 is included. 
Table S3. Summary of changes in the full width at half maximum (FWHM) for the $2 \theta=4^{\circ}(\lambda=$ $1.5406 \AA$ ) reflection of MOF-808 under a range of conditions.

\begin{tabular}{|c|c|c|c|c|c|}
\hline Condition & \multicolumn{2}{|c|}{ Result } & Condition & \multicolumn{2}{|c|}{ Result } \\
\hline \multirow{2}{*}{ Initial } & FWHM & 0.15031 & \multirow{2}{*}{ DI water } & FWHM & $0.1805^{a}$ \\
\hline & $\%$ Change & - & & $\%$ Change & $-16^{a}$ \\
\hline \multirow{2}{*}{$120{ }^{\circ} \mathrm{C}$ Air } & FWHM & 0.15103 & \multirow{2}{*}{$\mathrm{BuNH}_{2} / \mathrm{THF}$} & FWHM & 0.14864 \\
\hline & $\%$ Change & 1 & & $\%$ Change & -2 \\
\hline \multirow{2}{*}{$180{ }^{\circ} \mathrm{C}$ Air } & FWHM & 0.14650 & \multirow{2}{*}{$\mathrm{PhMgBr} / \mathrm{THF}$} & FWHM & 0.37331 \\
\hline & $\%$ Change & -3 & & $\%$ Change & 149 \\
\hline \multirow{2}{*}{ Conc. $\mathrm{HCl}$} & FWHM & 0.00000 & \multirow{2}{*}{ TBAF/THF } & FWHM & 0.15507 \\
\hline & $\%$ Change & $x$ & & $\%$ Change & 4 \\
\hline \multirow{2}{*}{$\mathrm{pH}=1$ Buffer } & FWHM & 0.16079 & \multirow{2}{*}{$\mathrm{Me}_{3} \mathrm{SiCl} / \mathrm{CH}_{2} \mathrm{Cl}_{2}$} & FWHM & 0.16010 \\
\hline & $\%$ Change & 7 & & $\%$ Change & 7 \\
\hline \multirow{2}{*}{$\mathrm{pH}=4$ Buffer } & FWHM & 0.17136 & \multirow{2}{*}{$\mathrm{MeCOCl} / \mathrm{CH}_{2} \mathrm{Cl}_{2}$} & FWHM & 0.12743 \\
\hline & $\%$ Change & 15 & & $\%$ Change & -16 \\
\hline \multirow{2}{*}{$\mathrm{pH}=7$ Buffer } & FWHM & 0.15731 & \multirow{2}{*}{$\mathrm{SO}_{2} \mathrm{Cl}_{2} / \mathrm{CH}_{2} \mathrm{Cl}_{2}$} & FWHM & 0.15021 \\
\hline & $\%$ Change & 5 & & $\%$ Change & -1 \\
\hline \multirow{2}{*}{$\mathrm{pH}=10$ Buffer } & FWHM & 0.00000 & \multirow{2}{*}{$\mathrm{Me}_{2} \mathrm{SO}_{4} / \mathrm{CH}_{2} \mathrm{Cl}_{2}$} & FWHM & $0.22004^{a}$ \\
\hline & $\%$ Change & $\times$ & & $\%$ Change & 3 \\
\hline \multirow{2}{*}{$\mathrm{pH}=13$ Buffer } & FWHM & 0.00000 & \multirow{2}{*}{$\mathrm{Br}_{2} / \mathrm{CH}_{2} \mathrm{Cl}_{2}$} & FWHM & 0.14503 \\
\hline & $\%$ Change & $x$ & & $\%$ Change & -4 \\
\hline \multirow{2}{*}{ Sat. $\mathrm{NaOH}$} & FWHM & 0.00000 & \multirow{2}{*}{$\mathrm{I}_{2} / \mathrm{CH}_{2} \mathrm{Cl}_{2}$} & FWHM & 0.14144 \\
\hline & $\%$ Change & $x$ & & $\%$ Change & -6 \\
\hline \multirow{2}{*}{$\mathrm{CH}_{3} \mathrm{COOH}$} & FWHM & 0.16923 & \multirow{2}{*}{$\mathrm{MCPBA} / \mathrm{CH}_{2} \mathrm{Cl}_{2}$} & FWHM & 0.15923 \\
\hline & $\%$ Change & 13 & & $\%$ Change & 6 \\
\hline \multirow{2}{*}{ LiHMDS/Tol } & FWHM & 0.25029 & \multirow{2}{*}{$\mathrm{PCC} / \mathrm{CH}_{2} \mathrm{Cl}_{2}$} & FWHM & 0.17874 \\
\hline & $\%$ Change & 67 & & $\%$ Change & 19 \\
\hline \multirow{2}{*}{$\mathrm{H}_{2} \mathrm{~S} / \mathrm{THF}$} & FWHM & 0.16736 & \multirow{2}{*}{$\mathrm{SmI}_{2} / \mathrm{THF}$} & FWHM & 0.66259 \\
\hline & $\%$ Change & 12 & & $\%$ Change & 341 \\
\hline \multirow{2}{*}{$\mathrm{NH}_{3} / \mathrm{MeOH}$} & FWHM & 0.17443 & \multirow{2}{*}{$\mathrm{LiBH}_{4} / \mathrm{THF}$} & FWHM & 0.26452 \\
\hline & $\%$ Change & 17 & & $\%$ Change & 76 \\
\hline
\end{tabular}

${ }^{\mathrm{a}} \mathrm{A}$ second sample with an initial FWHM of $0.21431^{\circ}$ was used for this assay. 


\section{Synthesis, characterization, and stability assessment of UiO-66.}

Synthesis of UiO-66. A $350 \mathrm{~mL}$ screw-cap high-pressure reaction flask equipped with a stir bar was charged with terephthalic acid (1.23 g, $7.50 \mathrm{mmol}, 1.00$ equiv.), $\mathrm{ZrCl}_{4}$ (1.75 g, 7.50 mmol, 1.00 equiv.), $\mathrm{H}_{2} \mathrm{O}$ ( $0.41 \mathrm{~mL}, 22.5 \mathrm{mmol}, 3.00$ equiv.), and $N, N$-dimethylformamide (150 $\mathrm{mL}$ ). The reaction vessel was sealed and transferred to a silicone oil bath, which was then heated to $120{ }^{\circ} \mathrm{C}$. The reaction mixture was allowed to stir gently $(300 \mathrm{rpm})$ at $120{ }^{\circ} \mathrm{C}$ for $24 \mathrm{~h}$. Upon heating to $120^{\circ} \mathrm{C}$, the reaction mixture became homogeneous prior to precipitation of a white solid from solution. After $24 \mathrm{~h}$, the heterogeneous reaction mixture was allowed to cool to room temperature and $100 \mathrm{~mL}$ of fresh $\mathrm{N}, \mathrm{N}$-dimethylformamide was added. The reaction mixture was allowed to settle and the solvent was decanted. The resulting white solid was transferred to a 500 mL Pyrex jar with $N, N$-dimethylformamide $(250 \mathrm{~mL})$. The jar was allowed to stand for $24 \mathrm{~h}$ at room temperature, at which time the $N, N$-dimethylformamide was decanted and replaced with fresh $N, N$-dimethylformamide $(250 \mathrm{~mL})$. This procedure was repeated two additional times for a total of three $\mathrm{N}, \mathrm{N}$-dimethylformamide soaks. Next, the solid was filtered and returned to the jar with fresh methanol $(250 \mathrm{~mL})$. The solid was soaked in methanol for $24 \mathrm{~h}$ at room temperature three total times following the same procedure as described above. Complete exchange of $\mathrm{N}, \mathrm{N}$ dimethylformamide for methanol was confirmed by IR spectroscopy. The resulting off-white solid was filtered and transferred to a Schlenk flask. The solid was activated under flowing $\mathrm{N}_{2}$ at 150 ${ }^{\circ} \mathrm{C}$ for $4 \mathrm{~h}$, followed by further activation under high vacuum ( $<100 \mathrm{mbar}$ ) at $150{ }^{\circ} \mathrm{C}$ for $24 \mathrm{~h}$. The Schlenk flask was transferred into a $\mathrm{N}_{2}$-filled glovebox, and the activated UiO-66 was transferred into a $20 \mathrm{~mL}$ scintillation vial for long-term storage. A portion of the activated sample was transferred to a pre-tared Micromeritics sample tube equipped with a Sureseal. The tube was removed from the glovebox and the sample was further activated under high vacuum $(<10 \mu \mathrm{bar})$ at $150{ }^{\circ} \mathrm{C}$ for $24 \mathrm{~h}$ prior to gas sorption measurements. 


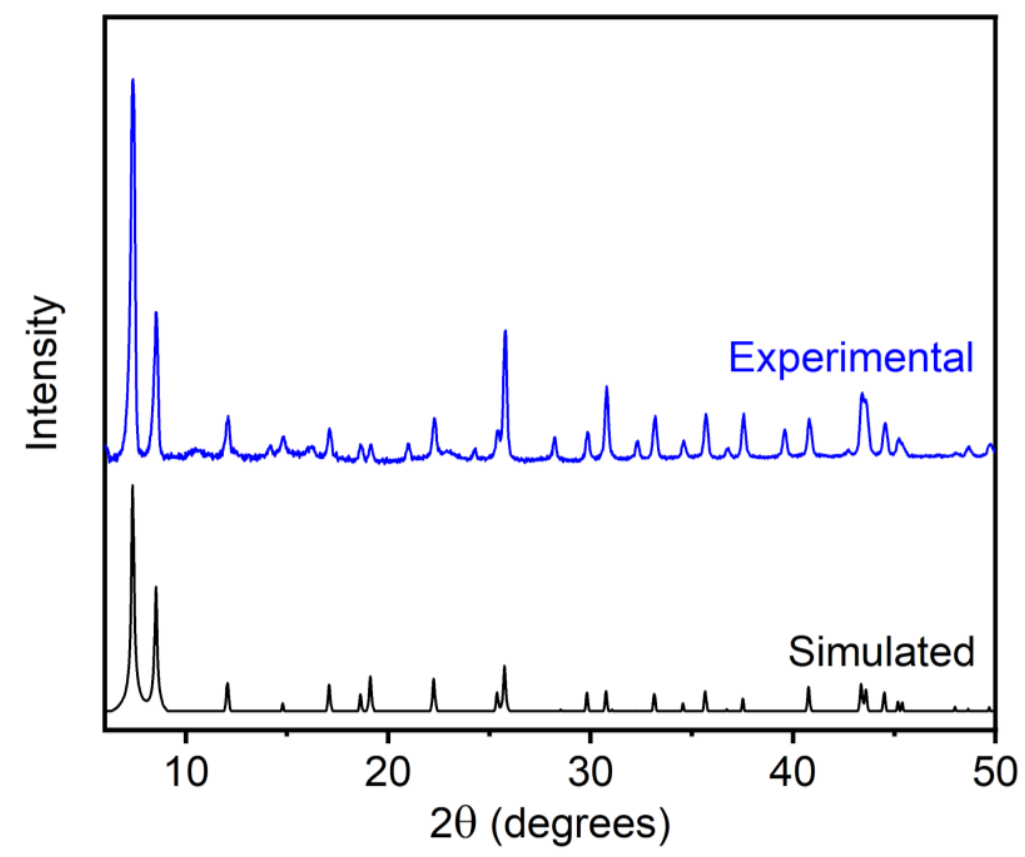

Figure S43. PXRD pattern $(\lambda=1.5406 \AA)$ of THF-solvated UiO-66. The simulated pattern based on the previously reported single-crystal X-ray diffraction structure of UiO-66 is included for reference. ${ }^{18}$ The PXRD pattern of UiO-66 was baseline corrected.

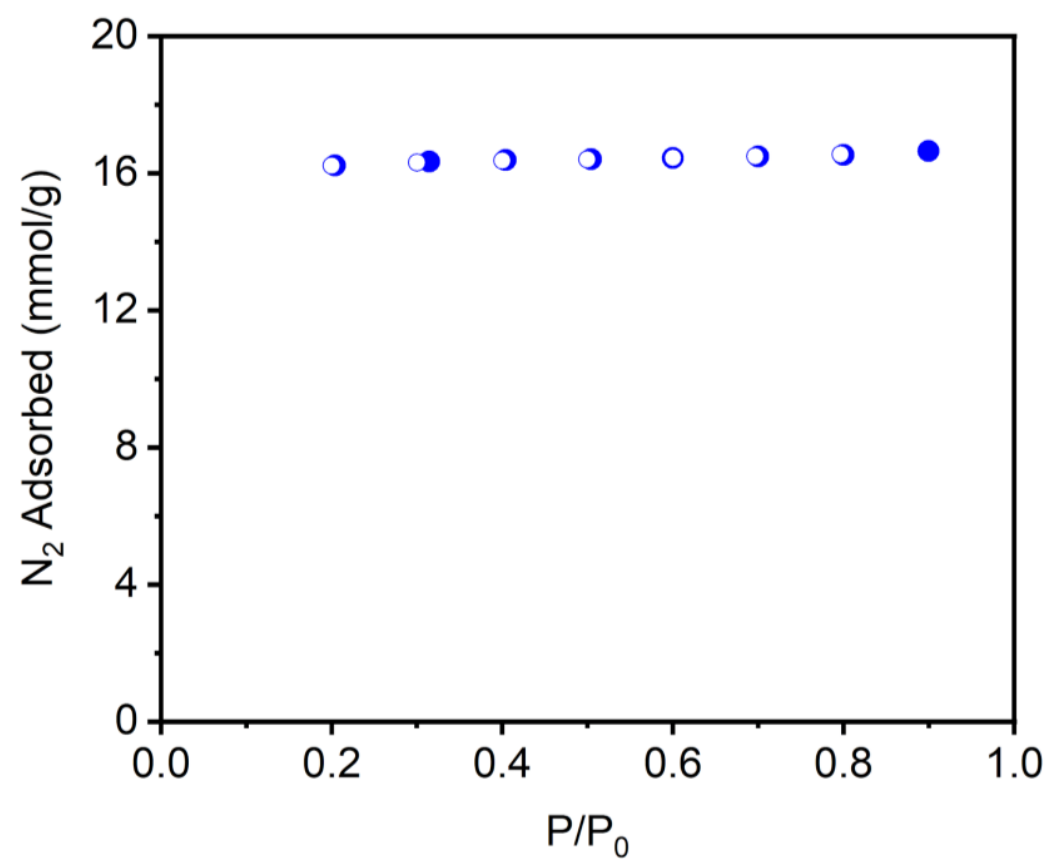

Figure $\mathbf{S 4 4} .77 \mathrm{~K} \mathrm{~N}_{2}$ adsorption (filled circles) and desorption (open circles) isotherm of activated UiO-66. The Langmuir surface area determined from these data is $1615 \pm 1 \mathrm{~m}^{2} / \mathrm{g}$. 


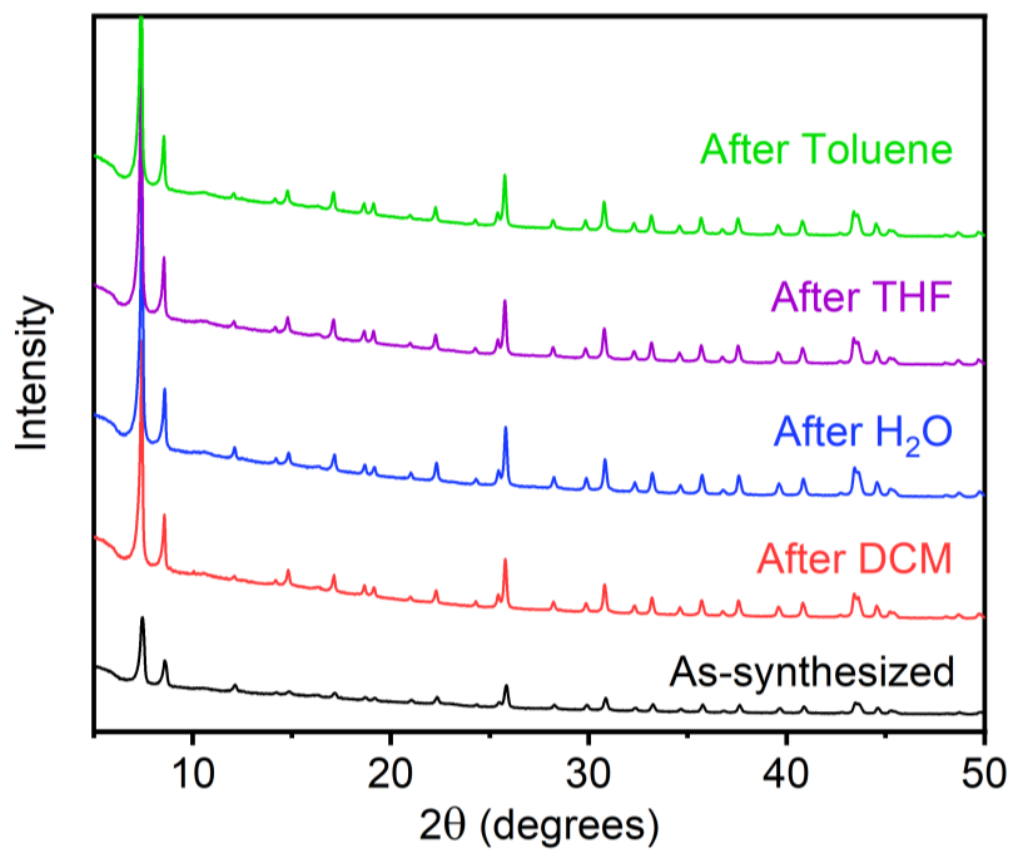

Figure S45. PXRD patterns ( $\lambda=1.5406 \AA$ ) of UiO-66 upon exposure to various organic solvents and water. Note that UiO-66 was soaked in DMF and $\mathrm{MeOH}$ during its synthesis as well. A reference pattern of as-synthesized UiO-66 is included.

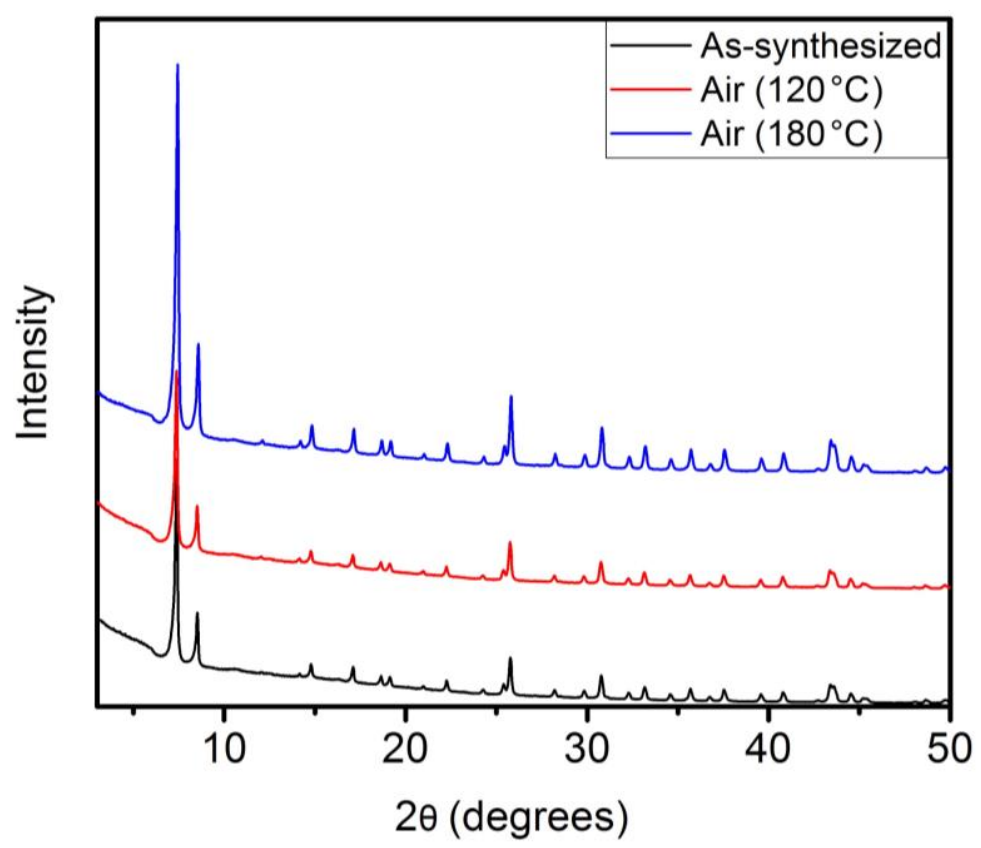

Figure S46. PXRD patterns $(\lambda=1.5406 \AA)$ of UiO-66 upon standing at $120^{\circ} \mathrm{C}$ and $180{ }^{\circ} \mathrm{C}$ in air for $24 \mathrm{~h}$. A reference pattern of as-synthesized UiO-66 is included. 


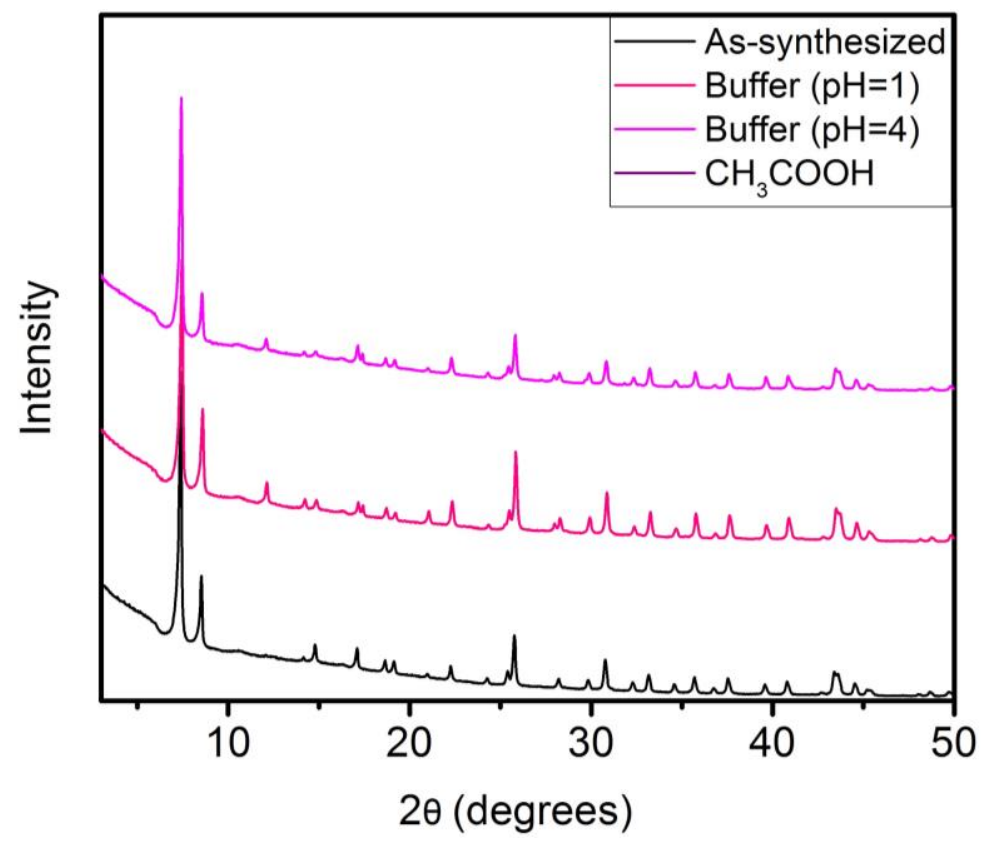

Figure S47. PXRD patterns $(\lambda=1.5406 \AA)$ of UiO-66 upon exposure to acids. Exposure tests include aqueous solutions buffered at $\mathrm{pH} 1$ and $\mathrm{pH} 4$ and glacial acetic acid. No solid remained after exposure of UiO-66 to the glacial acetic acid. A reference pattern of as-synthesized UiO-66 is included.

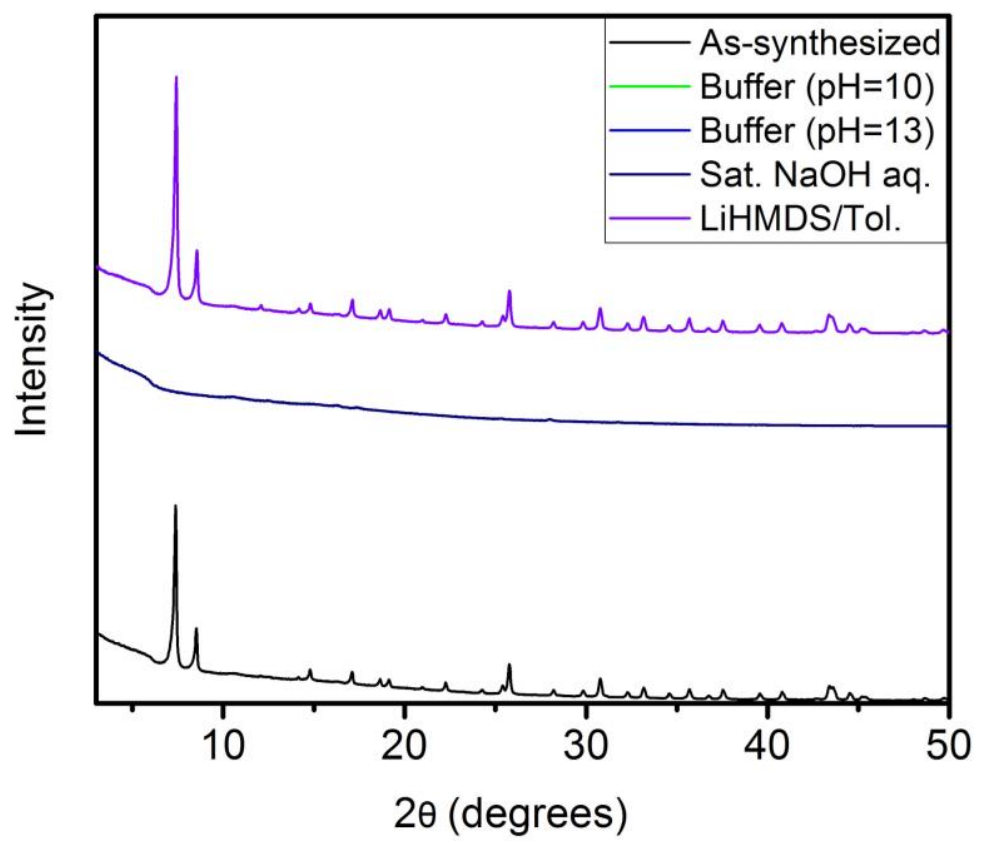

Figure S48. PXRD patterns $(\lambda=1.5406 \AA)$ of UiO-66 upon exposure to bases. Exposure tests include aqueous solutions buffered at $\mathrm{pH} 10$ and $\mathrm{pH} \mathrm{13}$, saturated aqueous $\mathrm{NaOH}$, and $1.0 \mathrm{M}$ lithium hexamethyldisilazide (LiHMDS) in toluene. No solid remained after exposure of UiO-66 to the $\mathrm{pH} 10$ or $\mathrm{pH} 13$ buffer. A reference pattern of as-synthesized UiO-66 is included. 


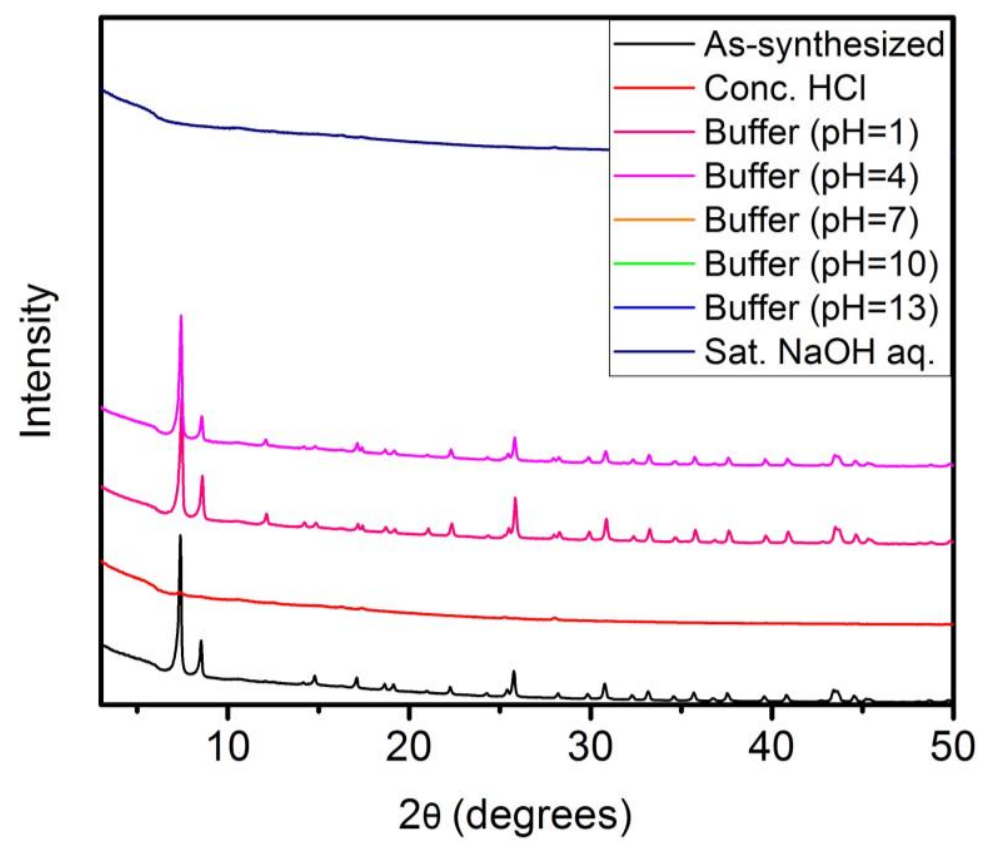

Figure S49. Summary of the PXRD patterns ( $\lambda=1.5406 \AA$ ) of UiO-66 upon exposure to various aqueous conditions. No solid remained after exposure of UiO-66 to the $\mathrm{pH}$ 7, $\mathrm{pH}$ 10, or $\mathrm{pH} 13$ buffers. A reference pattern of as-synthesized UiO-66 is included.

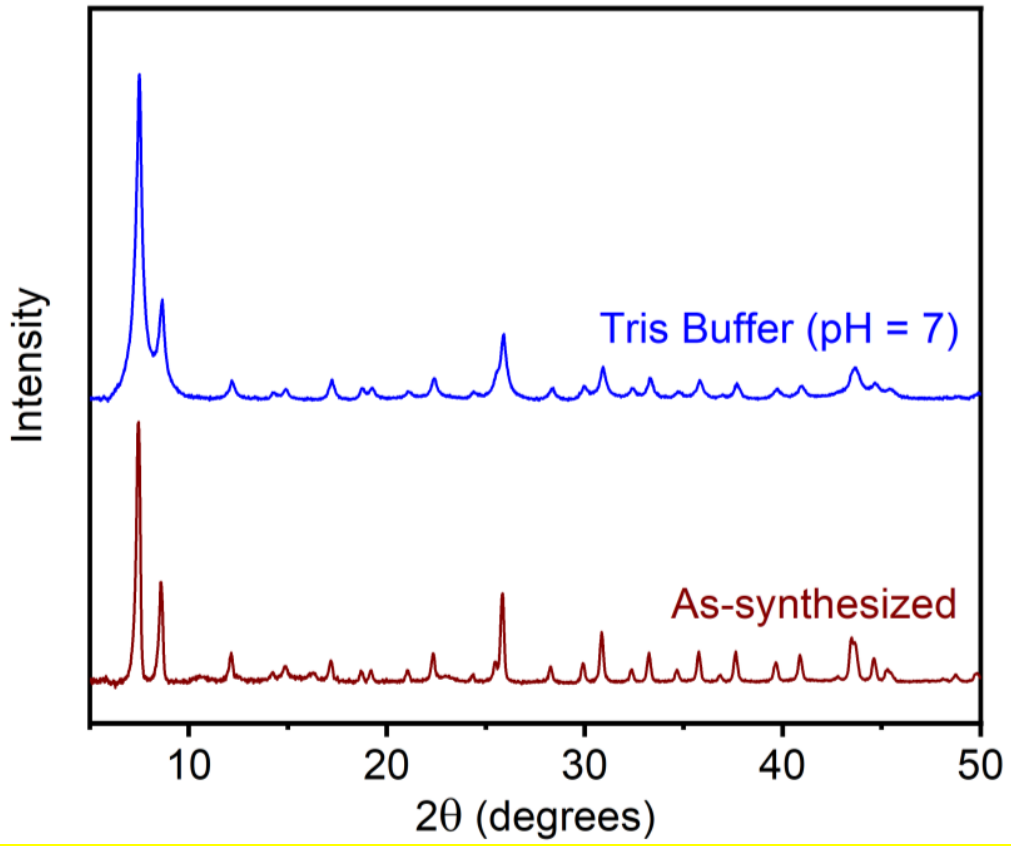

Figure S50. PXRD patterns for UiO-66 before and after exposure to aqueous tris buffer $(\mathrm{pH}=7)$. The initial FWHM for the peak at $2 \theta=7^{\circ}$ was $0.24438^{\circ}$, and the FWHM after exposure to buffer was $0.37967^{\circ}$, resulting in a 55\% change in FWHM after the exposure test. These powder X-ray diffraction patterns were baseline corrected. 


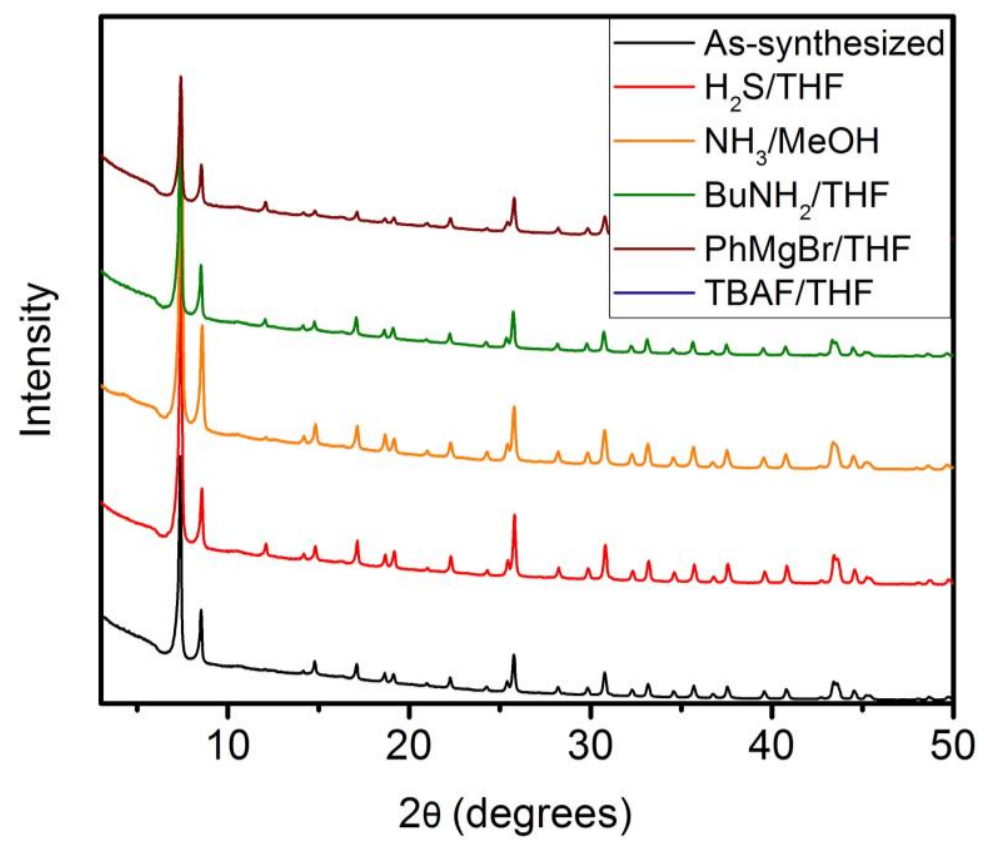

Figure S51. PXRD patterns $(\lambda=1.5406 \AA)$ of UiO-66 upon exposure to nucleophiles. Exposure tests include $0.8 \mathrm{M}$ hydrogen sulfide in tetrahydrofuran, $1.0 \mathrm{M}$ ammonia in methanol, $1.0 \mathrm{M} n$ butylamine in tetrahydrofuran, $1.0 \mathrm{M} \mathrm{PhMgBr}$ in tetrahydrofuran, and $1.0 \mathrm{M}$ tetrabutylammonium fluoride (TBAF) in tetrahydrofuran. No solid remained after exposure of UiO-66 to the TBAF solution. A reference pattern of as-synthesized UiO-66 is included.

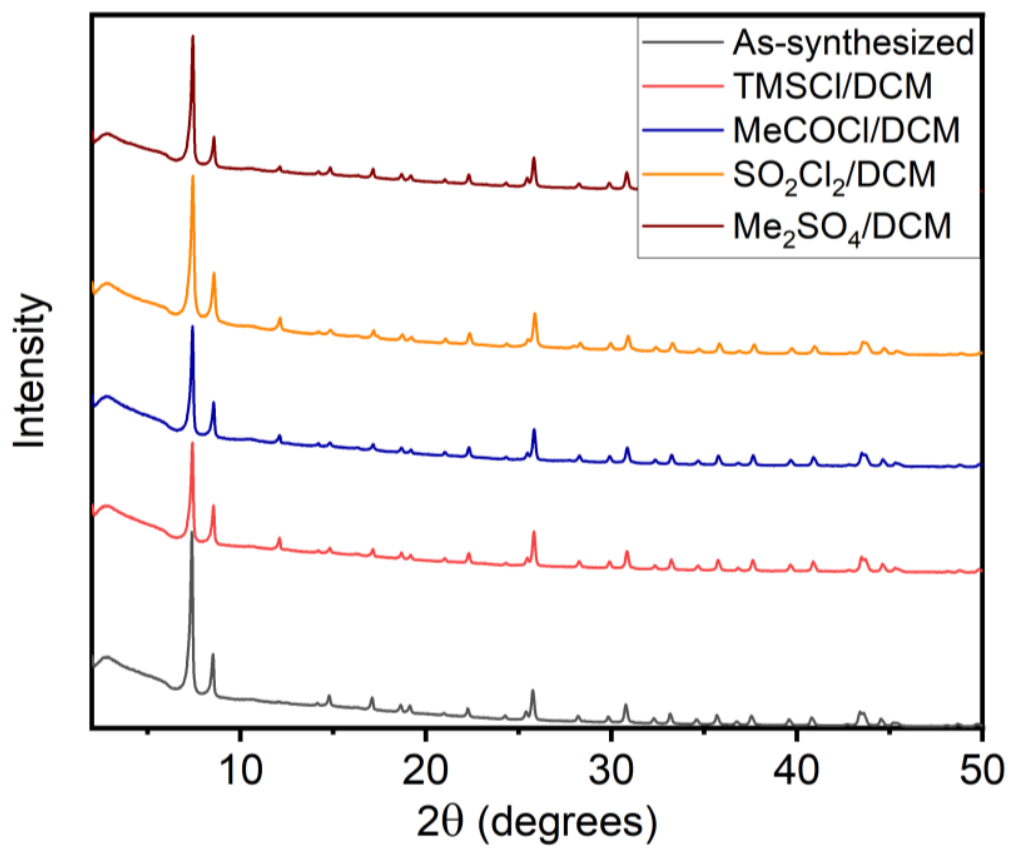

Figure S52. PXRD patterns $(\lambda=1.5406 \AA)$ of UiO-66 upon exposure to electrophiles. Exposure tests include $1.0 \mathrm{M}$ chlorotrimethylsilane (TMSCl) in dichloromethane, $1.0 \mathrm{M}$ acetyl chloride in dichloromethane, saturated sulfuryl chloride in dichloromethane, and $1.0 \mathrm{M}$ dimethyl sulfate in dichloromethane. A reference pattern of as-synthesized UiO-66 is included. 


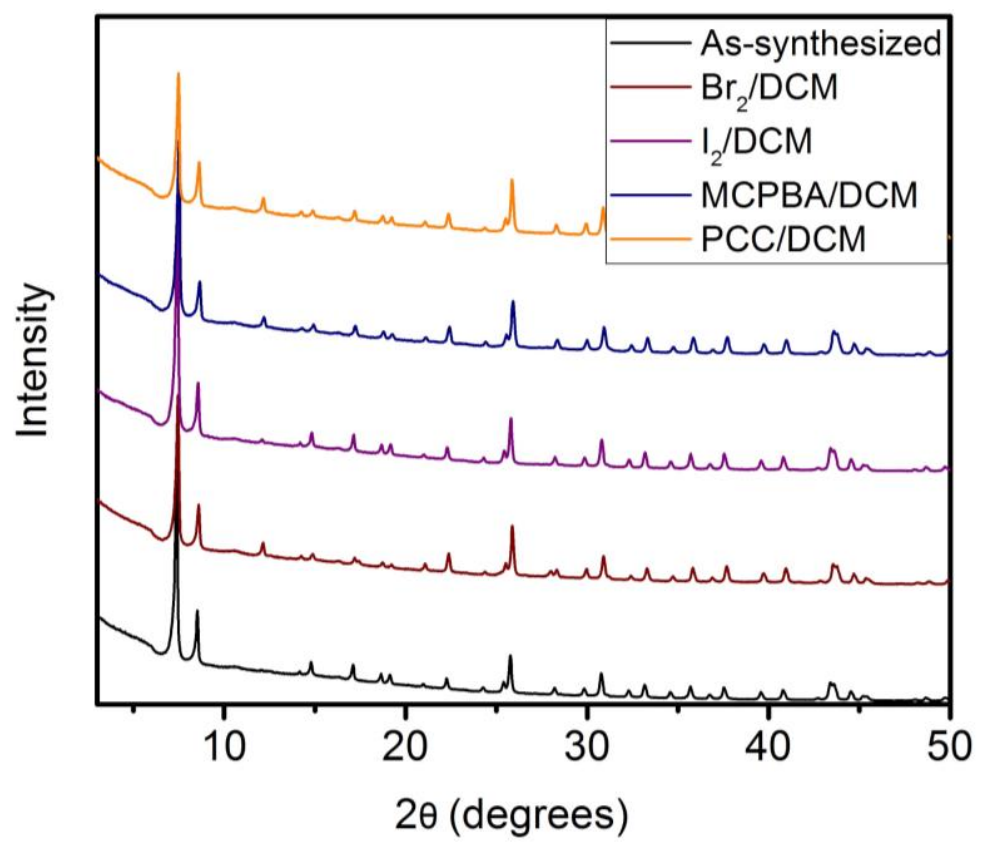

Figure S53. PXRD patterns ( $\lambda=1.5406 \AA$ ) of UiO-66 upon exposure to oxidants. Exposure tests include 1.0 M bromine in dichloromethane, saturated iodine in dichloromethane, saturated $\mathrm{m}$ chloroperoxybenzoic acid (MCPBA) in dichloromethane, and saturated pyridinium chlorochromate (PCC) in dichloromethane. A reference pattern of as-synthesized UiO-66 is included.

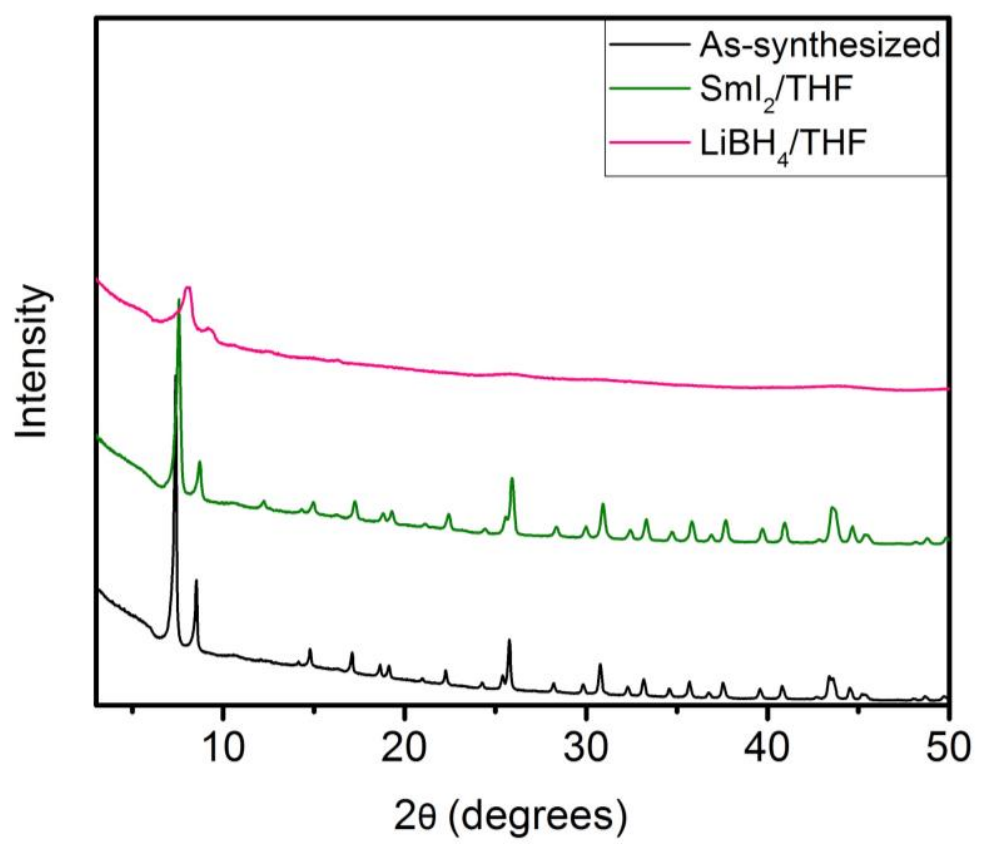

Figure S54. PXRD patterns $(\lambda=1.5406 \AA)$ of UiO-66 upon exposure to reductants. Exposure tests include $0.1 \mathrm{M}$ samarium iodide in tetrahydrofuran and $1.0 \mathrm{M}$ lithium borohydride in tetrahydrofuran. A reference pattern of as-synthesized UiO-66 is included. 
Table S4. Summary of changes in the full width at half maximum (FWHM) for the $2 \theta=7^{\circ}(\lambda=$ $1.5406 \AA$ ) reflection of UIO-66 under a range of conditions.

\begin{tabular}{|c|c|c|c|c|c|}
\hline Condition & \multicolumn{2}{|c|}{ Result } & Condition & \multicolumn{2}{|c|}{ Result } \\
\hline \multirow{2}{*}{ Initial } & FWHM & 0.16105 & \multirow{2}{*}{ DI water } & FWHM & 0.1676 \\
\hline & $\%$ Change & - & & $\%$ Change & 4 \\
\hline \multirow{2}{*}{$120^{\circ} \mathrm{C}$ Air } & FWHM & 0.1626 & \multirow{2}{*}{$\mathrm{BuNH}_{2} / \mathrm{THF}$} & FWHM & 0.15649 \\
\hline & $\%$ Change & 1 & & $\%$ Change & -3 \\
\hline \multirow{2}{*}{$180{ }^{\circ} \mathrm{C}$ Air } & FWHM & 0.16967 & \multirow{2}{*}{$\mathrm{PhMgBr} / \mathrm{THF}$} & FWHM & 0.15478 \\
\hline & $\%$ Change & 6 & & $\%$ Change & -4 \\
\hline \multirow{2}{*}{ Conc. $\mathrm{HCl}$} & FWHM & 0 & \multirow{2}{*}{ TBAF/THF } & FWHM & 0 \\
\hline & $\%$ Change & $x$ & & $\%$ Change & $x$ \\
\hline \multirow{2}{*}{$\mathrm{pH}=1$ Buffer } & FWHM & 0.17245 & \multirow{2}{*}{$\mathrm{Me}_{3} \mathrm{SiCl} / \mathrm{CH}_{2} \mathrm{Cl}_{2}$} & FWHM & 0.15074 \\
\hline & $\%$ Change & 8 & & $\%$ Change & -7 \\
\hline \multirow{2}{*}{$\mathrm{pH}=4$ Buffer } & FWHM & 0.16153 & \multirow{2}{*}{$\mathrm{MeCOCl} / \mathrm{CH}_{2} \mathrm{Cl}_{2}$} & FWHM & 0.14871 \\
\hline & $\%$ Change & 1 & & $\%$ Change & -8 \\
\hline \multirow{2}{*}{$\mathrm{pH}=7$ Buffer $^{a}$} & FWHM & 0 & \multirow{2}{*}{$\mathrm{SO}_{2} \mathrm{Cl}_{2} / \mathrm{CH}_{2} \mathrm{Cl}_{2}$} & FWHM & 0.17288 \\
\hline & $\%$ Change & $x$ & & $\%$ Change & 8 \\
\hline \multirow{2}{*}{$\mathrm{pH}=10$ Buffer } & FWHM & 0 & \multirow{2}{*}{$\mathrm{Me}_{2} \mathrm{SO}_{4} / \mathrm{CH}_{2} \mathrm{Cl}_{2}$} & FWHM & 0.17827 \\
\hline & $\%$ Change & $x$ & & $\%$ Change & 11 \\
\hline \multirow{2}{*}{$\mathrm{pH}=13$ Buffer } & FWHM & 0 & \multirow{2}{*}{$\mathrm{Br}_{2} / \mathrm{CH}_{2} \mathrm{Cl}_{2}$} & FWHM & 0.15231 \\
\hline & $\%$ Change & $x$ & & $\%$ Change & -6 \\
\hline \multirow{2}{*}{ Sat. $\mathrm{NaOH}$} & FWHM & 0 & \multirow{2}{*}{$\mathrm{I}_{2} / \mathrm{CH}_{2} \mathrm{Cl}_{2}$} & FWHM & 0.16301 \\
\hline & $\%$ Change & $x$ & & $\%$ Change & 2 \\
\hline \multirow{2}{*}{$\mathrm{CH}_{3} \mathrm{COOH}$} & FWHM & 0 & \multirow{2}{*}{$\mathrm{MCPBA} / \mathrm{CH}_{2} \mathrm{Cl}_{2}$} & FWHM & 0.18885 \\
\hline & $\%$ Change & $x$ & & $\%$ Change & 18 \\
\hline \multirow{2}{*}{ LiHMDS/Tol } & FWHM & 0.16775 & \multirow{2}{*}{$\mathrm{PCC} / \mathrm{CH}_{2} \mathrm{Cl}_{2}$} & FWHM & 0.16733 \\
\hline & $\%$ Change & 5 & & $\%$ Change & 4 \\
\hline \multirow{2}{*}{$\mathrm{H}_{2} \mathrm{~S} / \mathrm{THF}$} & FWHM & 0.16519 & \multirow{2}{*}{$\mathrm{SmI}_{2} / \mathrm{THF}$} & FWHM & 0.22384 \\
\hline & $\%$ Change & 3 & & $\%$ Change & 39 \\
\hline \multirow{2}{*}{$\mathrm{NH}_{3} / \mathrm{MeOH}$} & FWHM & 0.19208 & \multirow{2}{*}{$\mathrm{LiBH}_{4} / \mathrm{THF}$} & FWHM & 0.46219 \\
\hline & $\%$ Change & 20 & & $\%$ Change & 187 \\
\hline
\end{tabular}

${ }^{a} 55 \%$ reduction in FWHM was observed using aqueous tris buffer $(\mathrm{pH}=7)$. 


\section{Synthesis, characterization, and stability assessment of UiO-67.}

Synthesis of UiO-67. A $350 \mathrm{~mL}$ screw-cap high-pressure reaction flask equipped with a stir bar was charged with 4,4'-biphenyldicarboxylic acid (1.82 g, $7.50 \mathrm{mmol}, 1.00$ equiv.), $\mathrm{ZrCl}_{4}$ (1.75 g, $7.50 \mathrm{mmol}, 1.00$ equiv.), $\mathrm{H}_{2} \mathrm{O}$ (0.41 mL, $22.5 \mathrm{mmol}, 3.00$ equiv.), and $N, N$ dimethylformamide $(150 \mathrm{~mL})$. The reaction vessel was sealed and transferred to a silicone oil bath, which was then heated to $120^{\circ} \mathrm{C}$. The reaction mixture was allowed to stir gently (300 rpm) at 120 ${ }^{\circ} \mathrm{C}$ for $24 \mathrm{~h}$. At no point during this time did the reaction mixture become homogeneous. After 24 $\mathrm{h}$, the heterogeneous reaction mixture was allowed to cool to room temperature and $100 \mathrm{~mL}$ of fresh $N, N$-dimethylformamide was added. The reaction mixture was allowed to settle and the solvent was decanted. The resulting off-white solid was transferred to a $500 \mathrm{~mL}$ Pyrex jar with $\mathrm{N}, \mathrm{N}$-dimethylformamide $(250 \mathrm{~mL})$. The jar was allowed to stand for $24 \mathrm{~h}$ at $100{ }^{\circ} \mathrm{C}$ in an oven, at which time the $N, N$-dimethylformamide was decanted and replaced with fresh $N, N$ dimethylformamide $(250 \mathrm{~mL})$. This procedure was repeated two additional times for a total of three hot $N, N$-dimethylformamide soaks. Note that higher soaking temperatures were employed for this material compared to UiO-66 due to the poor solubility of [1,1'-biphenyl]-4,4'-dicarboxylic acid in $N, N$-dimethylformamide. Next, the solid was filtered and returned to the jar with fresh methanol $(250 \mathrm{~mL})$. The solid was soaked in methanol for $24 \mathrm{~h}$ at $60^{\circ} \mathrm{C}$ in an oven three total times following the same procedure as described above. Complete exchange of $\mathrm{N}, \mathrm{N}$ dimethylformamide for methanol was confirmed by IR spectroscopy. The resulting off-white solid was filtered and transferred to a Schlenk flask. The solid was activated under flowing $\mathrm{N}_{2}$ at 150 ${ }^{\circ} \mathrm{C}$ for $4 \mathrm{~h}$, followed by further activation under high vacuum $(<100 \mathrm{mbar})$ at $150{ }^{\circ} \mathrm{C}$ for $24 \mathrm{~h}$. The Schlenk flask was transferred into a $\mathrm{N}_{2}$-filled glovebox, and the activated UiO-67 was transferred into a $20 \mathrm{~mL}$ scintillation vial for long-term storage. A portion of the activated sample was transferred to a pre-tared Micromeritics sample tube equipped with a Sureseal. The tube was removed from the glovebox and the sample was further activated under high vacuum $(<10 \mu \mathrm{bar})$ at $150{ }^{\circ} \mathrm{C}$ for $24 \mathrm{~h}$ prior to gas sorption measurements. 


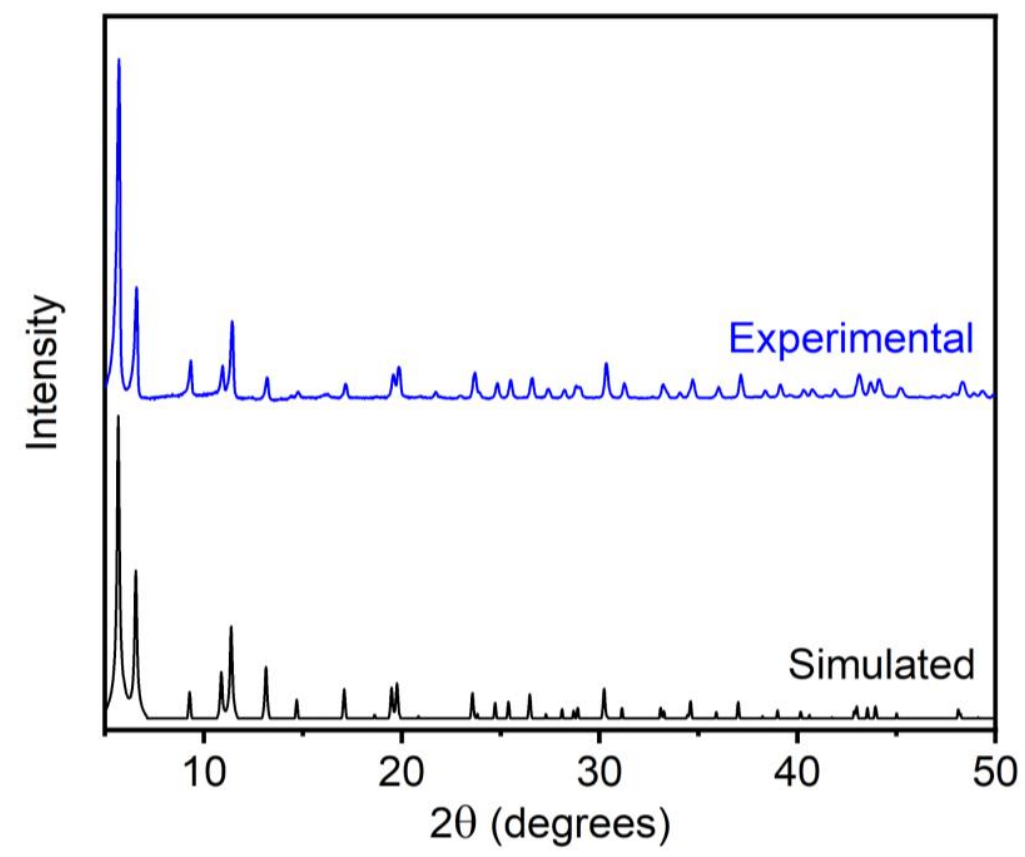

Figure S55. PXRD pattern $(\lambda=1.5406 \AA)$ of THF-solvated UiO-67. The simulated pattern based on the previously reported single-crystal X-ray diffraction structure of UiO-67 is included for reference. ${ }^{19}$ The PXRD pattern of UiO-67 was baseline corrected.

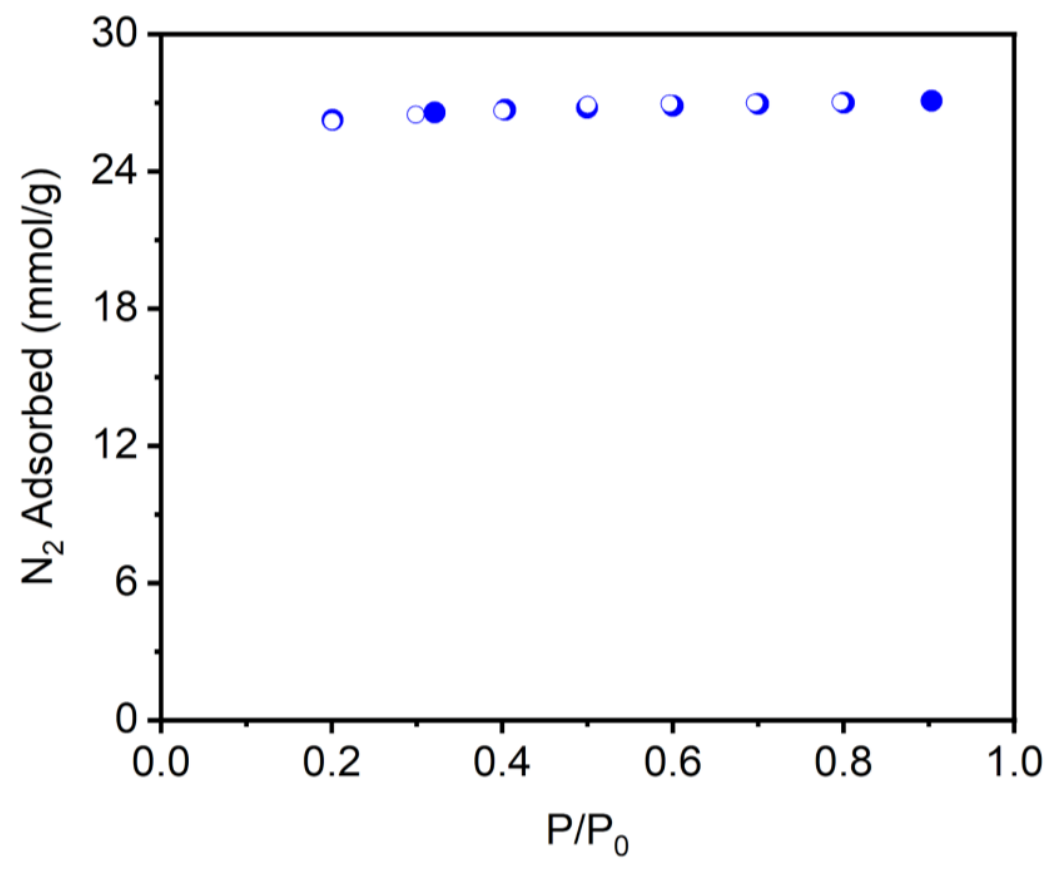

Figure S56. $77 \mathrm{~K} \mathrm{~N}_{2}$ adsorption (filled circles) and desorption (open circles) isotherm of activated UiO-67. The Langmuir surface area determined from these data is $2654 \pm 2 \mathrm{~m}^{2} / \mathrm{g}$. 


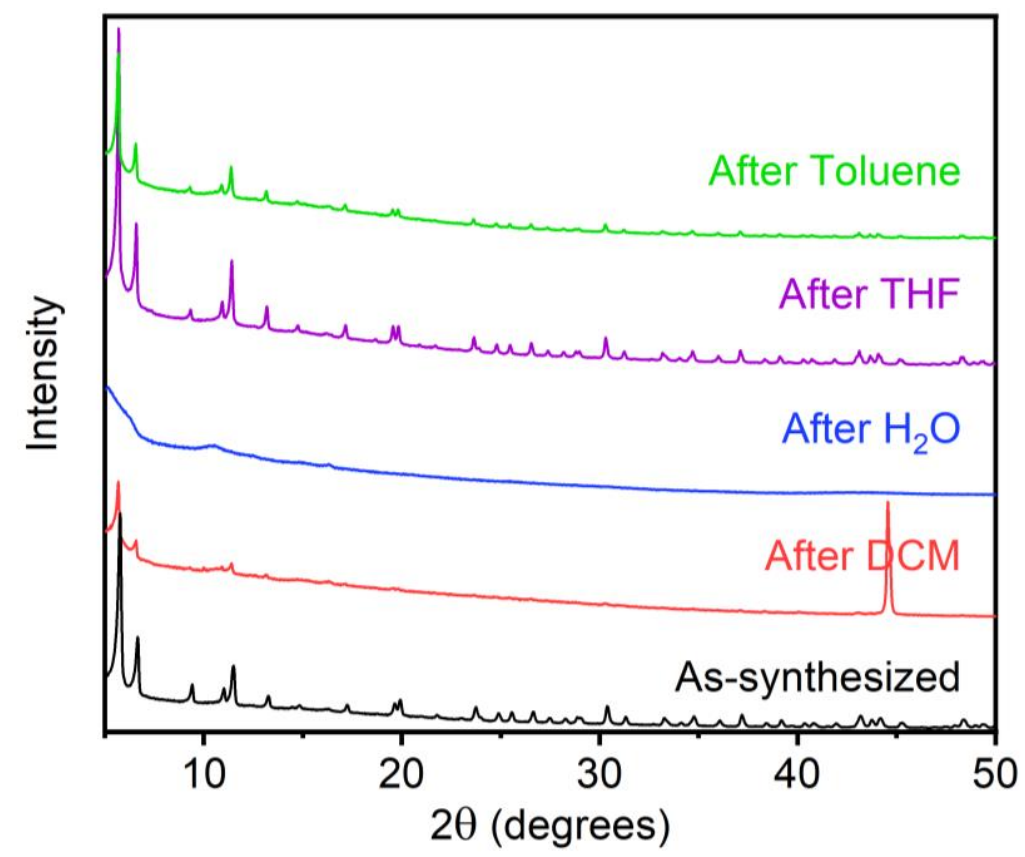

Figure S57. PXRD patterns ( $\lambda=1.5406 \AA$ ) of UiO-67 upon exposure to various organic solvents and water. Note that UiO-67 was soaked in DMF and $\mathrm{MeOH}$ during its synthesis as well. These patterns confirm the poor stability of UiO-67 in water and suggest it undergoes partial degradation in DCM as well. A reference pattern of as-synthesized UiO-67 is included.

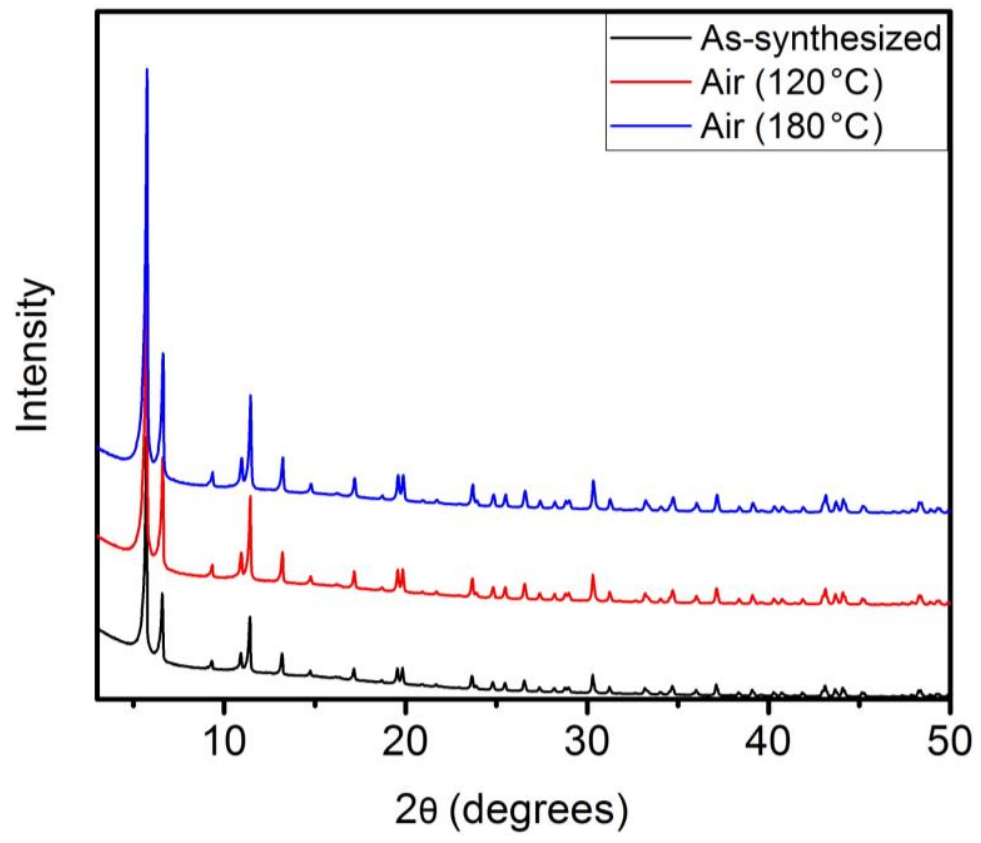

Figure S58. PXRD patterns $(\lambda=1.5406 \AA)$ of UiO-67 upon standing at $120^{\circ} \mathrm{C}$ and $180{ }^{\circ} \mathrm{C}$ in air for $24 \mathrm{~h}$. A reference pattern of as-synthesized UiO-67 is included. 


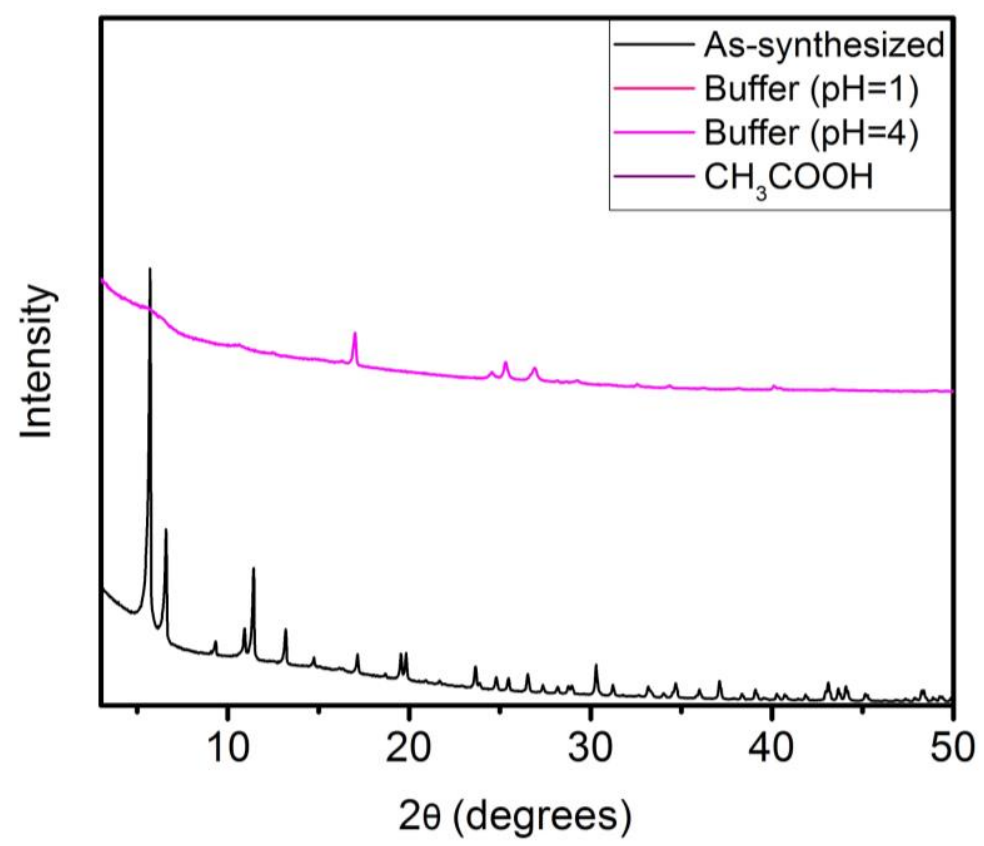

Figure S59. PXRD patterns $(\lambda=1.5406 \AA)$ of UiO-67 upon exposure to acids. Exposure tests include aqueous solutions buffered at $\mathrm{pH} 1$ and $\mathrm{pH} 4$ and glacial acetic acid. No solid material remained after exposure of $\mathrm{UiO}-67$ to the $\mathrm{pH} 1$ buffer or the glacial acetic acid. A reference pattern of as-synthesized UiO-67 is included.

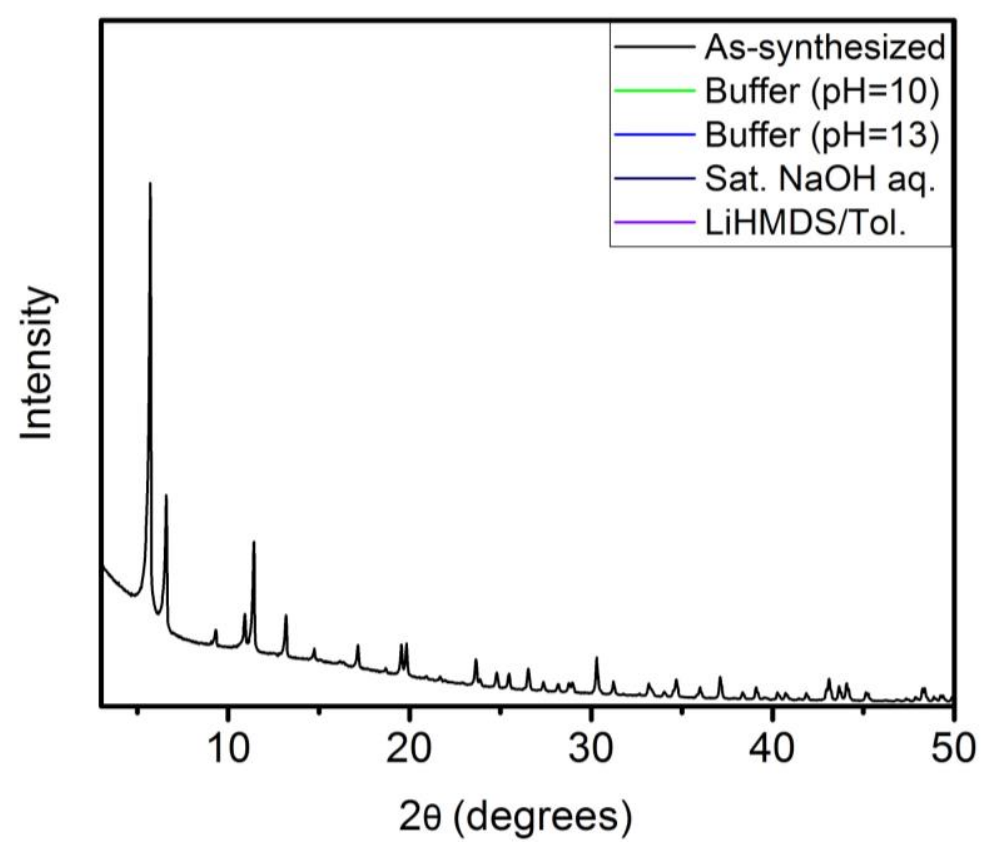

Figure S60. PXRD patterns $(\lambda=1.5406 \AA)$ of UiO-67 upon exposure to bases. Exposure tests include aqueous solutions buffered at $\mathrm{pH} 10$ and $\mathrm{pH} 13$, saturated aqueous $\mathrm{NaOH}$, and $1.0 \mathrm{M}$ lithium hexamethyldisilazide (LiHMDS) in toluene. No solid remained after exposure of UiO-67 to any of the solutions. A reference pattern of as-synthesized UiO-67 is included. 


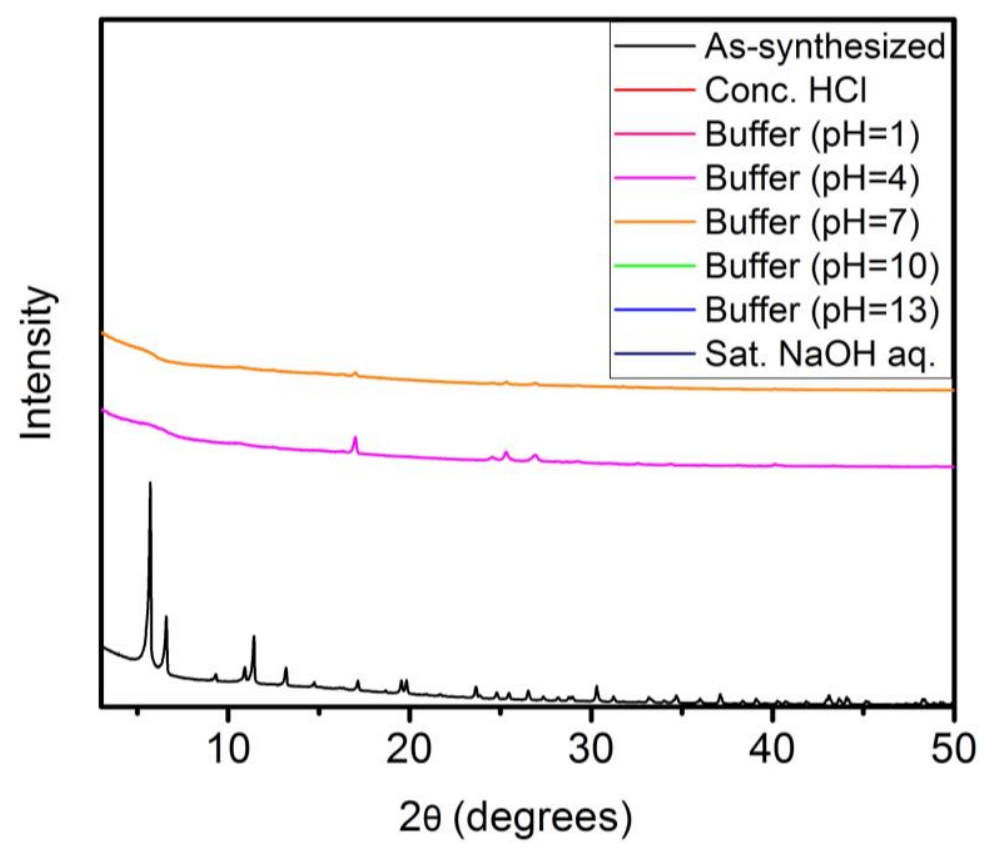

Figure S61. Summary of the PXRD patterns $(\lambda=1.5406 \AA)$ of UiO-67 upon exposure to various aqueous conditions. No solid remained after exposure of UiO-67 to pH 1 buffer, $\mathrm{pH} 10$ buffer, $\mathrm{pH}$ 13 buffer, concentrated $\mathrm{HCl}$, or saturated $\mathrm{NaOH}$ solution. A reference pattern of as-synthesized UiO-67 is included.

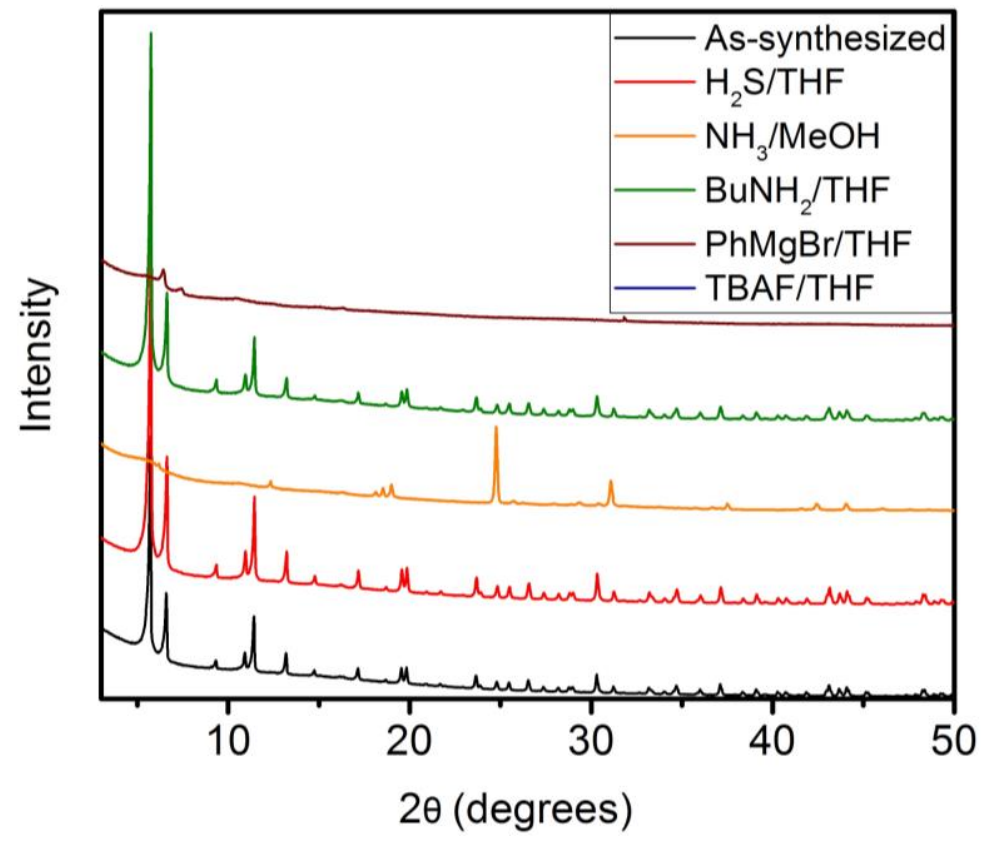

Figure S62. PXRD patterns $(\lambda=1.5406 \AA)$ of UiO-67 upon exposure to nucleophiles. Exposure tests include $0.8 \mathrm{M}$ hydrogen sulfide in tetrahydrofuran, $1.0 \mathrm{M}$ ammonia in methanol, $1.0 \mathrm{M} \mathrm{n}$ butylamine in tetrahydrofuran, $1.0 \mathrm{M} \mathrm{PhMgBr}$ in tetrahydrofuran, and $1.0 \mathrm{M}$ tetrabutylammonium fluoride (TBAF) in tetrahydrofuran. No solid remained after exposure of UiO-67 to the TBAF solution. A reference pattern of as-synthesized UiO-67 is included. 


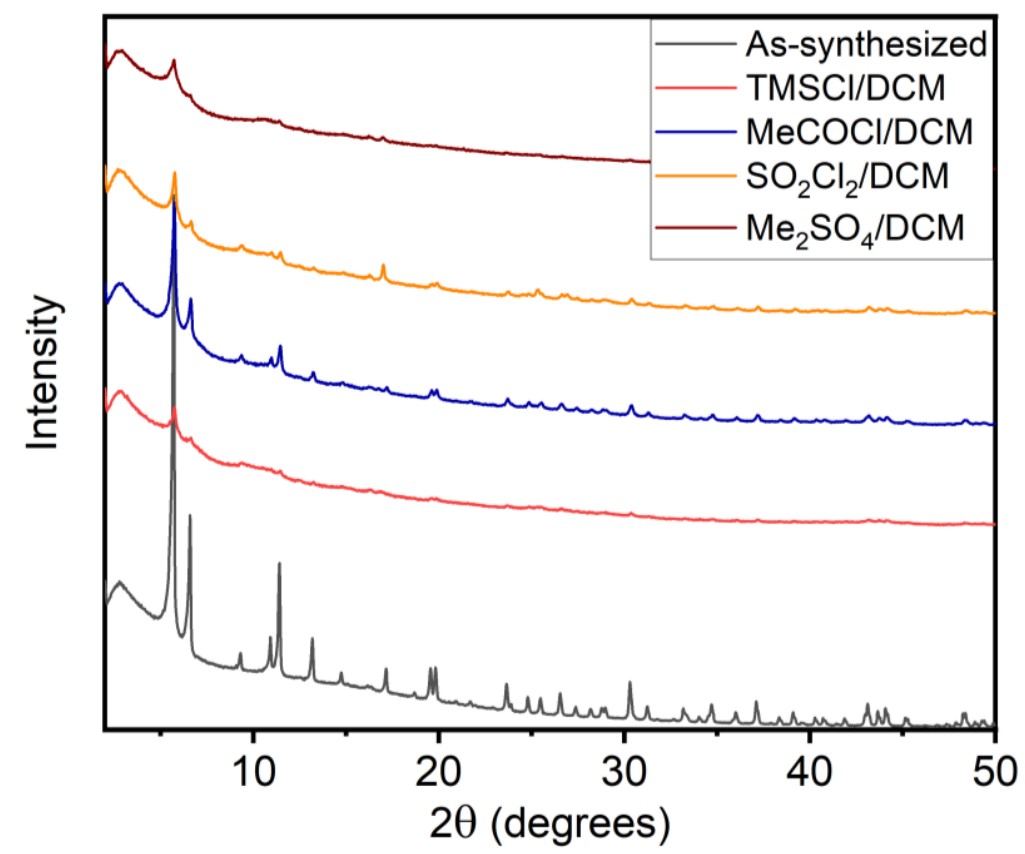

Figure S63. PXRD patterns ( $\lambda=1.5406 \AA)$ of UiO-67 upon exposure to electrophiles. Exposure tests include $1.0 \mathrm{M}$ chlorotrimethylsilane (TMSCl) in dichloromethane, $1.0 \mathrm{M}$ acetyl chloride in dichloromethane, $1.0 \mathrm{M}$ sulfuryl chloride in dichloromethane, and saturated dimethyl sulfate in dichloromethane. A reference pattern of as-synthesized UiO-67 is included.

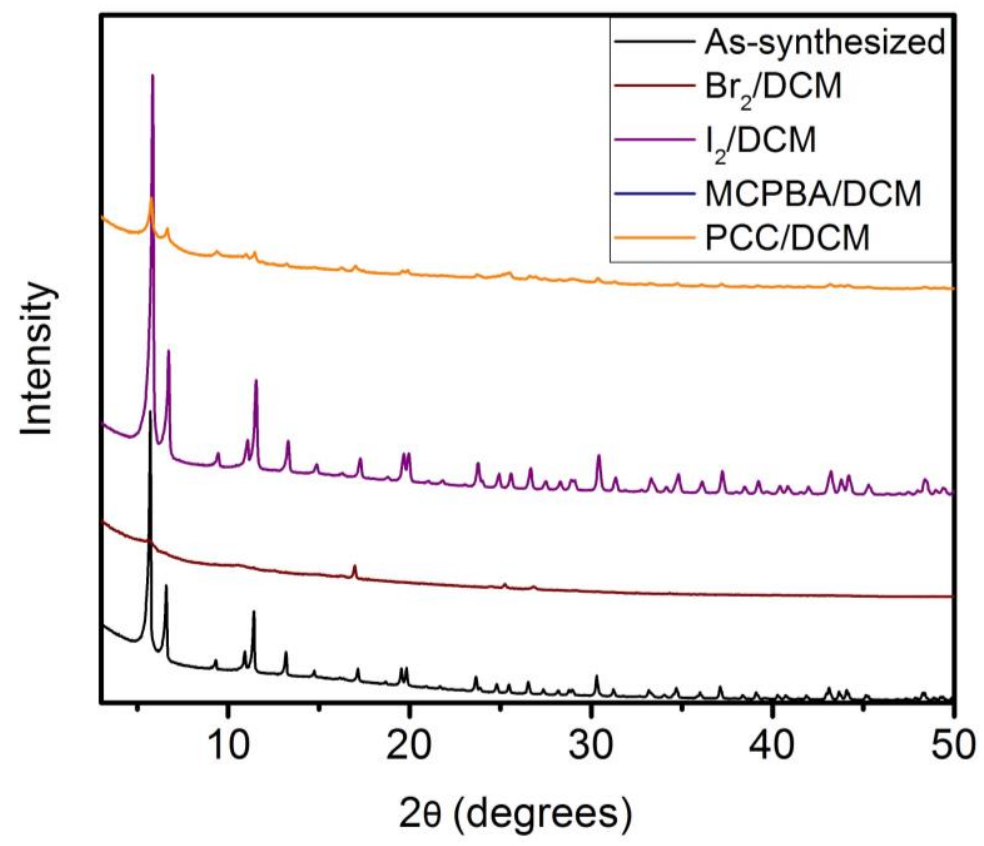

Figure S64. PXRD patterns ( $\lambda=1.5406 \AA$ ) of UiO-67 upon exposure to oxidants. Exposure tests include $1.0 \mathrm{M}$ bromine in dichloromethane, saturated iodine in dichloromethane, saturated $\mathrm{m}$ chloroperoxybenzoic acid (MCPBA) in dichloromethane, and saturated pyridinium chlorochromate (PCC) in dichloromethane. No solid material remained after exposure of UiO-67 to the MCPBA solution. A reference pattern of as-synthesized UiO-67 is included. 


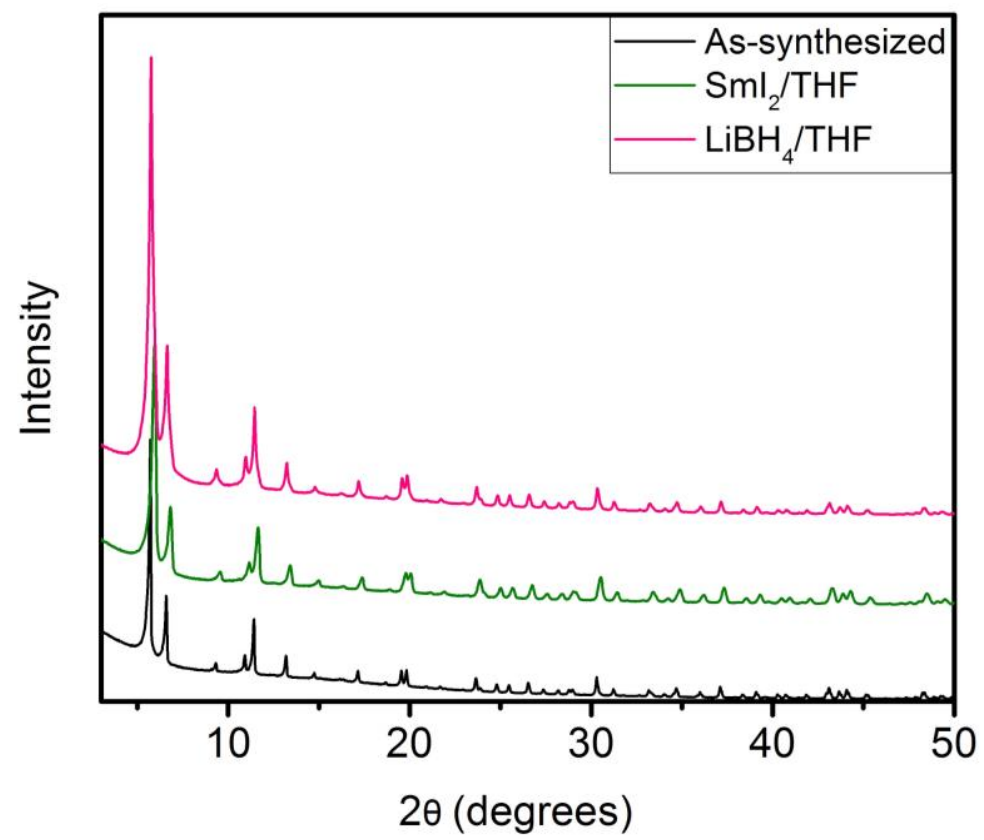

Figure S65. PXRD patterns $(\lambda=1.5406 \AA)$ of UiO-67 upon exposure to reductants. Exposure tests include $0.1 \mathrm{M}$ samarium iodide in tetrahydrofuran and $1.0 \mathrm{M}$ lithium borohydride in tetrahydrofuran. A reference pattern of as-synthesized UiO-67 is included. 
Table S5. Summary of changes in the full width at half maximum (FWHM) for the $2 \theta=6^{\circ}(\lambda=$ $1.5406 \AA$ ) reflection of UIO-67 under a range of conditions.

\begin{tabular}{|c|c|c|c|c|c|}
\hline Condition & \multicolumn{2}{|c|}{ Result } & Condition & \multicolumn{2}{|c|}{ Result } \\
\hline \multirow{2}{*}{ Initial } & FWHM & 0.12079 & \multirow{2}{*}{ DI water } & FWHM & 0 \\
\hline & $\%$ Change & - & & $\%$ Change & $x$ \\
\hline \multirow{2}{*}{$120^{\circ} \mathrm{C}$ Air } & FWHM & 0.12398 & \multirow{2}{*}{$\mathrm{BuNH}_{2} / \mathrm{THF}$} & FWHM & 0.13773 \\
\hline & $\%$ Change & 3 & & $\%$ Change & 15 \\
\hline \multirow{2}{*}{$180{ }^{\circ} \mathrm{C}$ Air } & FWHM & 0.1501 & \multirow{2}{*}{$\mathrm{PhMgBr} / \mathrm{THF}$} & FWHM & 0 \\
\hline & $\%$ Change & 25 & & $\%$ Change & $x$ \\
\hline \multirow{2}{*}{ Conc. $\mathrm{HCl}$} & FWHM & 0 & \multirow{2}{*}{ TBAF/THF } & FWHM & 0 \\
\hline & $\%$ Change & $x$ & & $\%$ Change & $x$ \\
\hline \multirow{2}{*}{$\mathrm{pH}=1$ Buffer } & FWHM & 0 & \multirow{2}{*}{$\mathrm{Me}_{3} \mathrm{SiCl} / \mathrm{CH}_{2} \mathrm{Cl}_{2}$} & FWHM & 0.20308 \\
\hline & $\%$ Change & $x$ & & $\%$ Change & 69 \\
\hline \multirow{2}{*}{$\mathrm{pH}=4$ Buffer } & FWHM & 0 & \multirow{2}{*}{$\mathrm{MeCOCl} / \mathrm{CH}_{2} \mathrm{Cl}_{2}$} & FWHM & 0.17905 \\
\hline & $\%$ Change & $x$ & & $\%$ Change & 49 \\
\hline \multirow{2}{*}{$\mathrm{pH}=7$ Buffer } & FWHM & 0 & \multirow{2}{*}{$\mathrm{SO}_{2} \mathrm{Cl}_{2} / \mathrm{CH}_{2} \mathrm{Cl}_{2}$} & FWHM & 0.20499 \\
\hline & $\%$ Change & $x$ & & $\%$ Change & 70 \\
\hline \multirow{2}{*}{$\mathrm{pH}=10$ Buffer } & FWHM & 0 & \multirow{2}{*}{$\mathrm{Me}_{2} \mathrm{SO}_{4} / \mathrm{CH}_{2} \mathrm{Cl}_{2}$} & FWHM & 0.2628 \\
\hline & $\%$ Change & $x$ & & $\%$ Change & 118 \\
\hline \multirow{2}{*}{$\mathrm{pH}=13$ Buffer } & FWHM & 0 & \multirow{2}{*}{$\mathrm{Br}_{2} / \mathrm{CH}_{2} \mathrm{Cl}_{2}$} & FWHM & 0 \\
\hline & $\%$ Change & $x$ & & $\%$ Change & $\times$ \\
\hline \multirow{2}{*}{ Sat. $\mathrm{NaOH}$} & FWHM & 0 & \multirow{2}{*}{$\mathrm{I}_{2} / \mathrm{CH}_{2} \mathrm{Cl}_{2}$} & FWHM & 0.15045 \\
\hline & $\%$ Change & $x$ & & $\%$ Change & 25 \\
\hline \multirow{2}{*}{$\mathrm{CH}_{3} \mathrm{COOH}$} & FWHM & 0 & \multirow{2}{*}{$\mathrm{MCPBA} / \mathrm{CH}_{2} \mathrm{Cl}_{2}$} & FWHM & 0 \\
\hline & $\%$ Change & $x$ & & $\%$ Change & $\times$ \\
\hline \multirow{2}{*}{ LiHMDS/Tol } & FWHM & 0 & \multirow{2}{*}{$\mathrm{PCC} / \mathrm{CH}_{2} \mathrm{Cl}_{2}$} & FWHM & 0.16381 \\
\hline & $\%$ Change & $\times$ & & $\%$ Change & 36 \\
\hline \multirow{2}{*}{$\mathrm{H}_{2} \mathrm{~S} / \mathrm{THF}$} & FWHM & 0.13469 & \multirow{2}{*}{$\mathrm{SmI}_{2} / \mathrm{THF}$} & FWHM & 0.20066 \\
\hline & $\%$ Change & 12 & & $\%$ Change & 67 \\
\hline \multirow{2}{*}{$\mathrm{NH}_{3} / \mathrm{MeOH}$} & FWHM & 0 & \multirow{2}{*}{$\mathrm{LiBH}_{4} / \mathrm{THF}$} & FWHM & 0.28667 \\
\hline & $\%$ Change & $x$ & & $\%$ Change & 138 \\
\hline
\end{tabular}




\section{Synthesis, characterization, and stability assessment of PCN-128.}

Synthesis of PCN-128. This procedure is adapted from the literature. ${ }^{3}$ A $125 \mathrm{~mL}$ Erlenmeyer flask was charged with 4',4"',4"'",4"'"''-(ethene-1,1,2,2-tetrayl)tetrakis(([1,1'biphenyl]-4-carboxylic acid)) (300 mg, $0.36 \mathrm{mmol}, 1.00$ equiv.), $\mathrm{ZrCl}_{4}(600 \mathrm{mg}, 2.58 \mathrm{mmol}, 7.17$ equiv.), $N, N$-dimethylformamide $(40 \mathrm{~mL})$, and trifluoroacetic acid $(4 \mathrm{~mL})$. The reaction mixture was sonicated for $15 \mathrm{~min}$. The heterogeneous mixture was evenly distributed among twenty $4 \mathrm{~mL}$ scintillation vials $(\sim 2 \mathrm{~mL}$ per vial) with Teflon tape wrapped around the rims. The vials were tightly capped and placed in an aluminum heat block. The heat block was transferred to a dry block heater, which was then heated to $120^{\circ} \mathrm{C}$. The vials were allowed to stand at $120^{\circ} \mathrm{C}$ for $48 \mathrm{~h}$. The vials were allowed to cool to room temperature and filtered, combining the solid from every vial into one batch. The combined solid was transferred to a $500 \mathrm{~mL}$ Pyrex jar filled with $\mathrm{N}, \mathrm{N}$ dimethylformamide $(200 \mathrm{~mL})$. The jar was allowed to stand for $24 \mathrm{~h}$ at room temperature, at which time the $\mathrm{N}, \mathrm{N}$-dimethylformamide was decanted and replaced with fresh $\mathrm{N}, \mathrm{N}$-dimethylformamide $(200 \mathrm{~mL})$. This procedure was repeated two additional times for a total of three $N, N$ dimethylformamide soaks. Next, the solid was filtered and returned to the jar with fresh acetone $(200 \mathrm{~mL})$. The solid was soaked in acetone for $24 \mathrm{~h}$ at room temperature three total times following the same procedure as described above. Robustness assessments were performed using acetonesolvated PCN-128 that was freshly filtered. Some of the resulting pale yellow solid was filtered and transferred to a Schlenk flask. The solid was activated under flowing $\mathrm{N}_{2}$ at $150{ }^{\circ} \mathrm{C}$ for $1 \mathrm{~h}$, followed by further activation under high vacuum ( $<100 \mathrm{mbar})$ at $150{ }^{\circ} \mathrm{C}$ for $24 \mathrm{~h}$. During activation, the solid became more intensely yellow in color. The Schlenk flask was transferred into a $\mathrm{N}_{2}$-filled glovebox, and the activated PCN-128 was transferred into a $20 \mathrm{~mL}$ scintillation vial for long-term storage. A portion of the activated sample was transferred to a pre-tared Micromeritics sample tube equipped with a Sureseal. The tube was removed from the glovebox and the sample was gently heated to $180^{\circ} \mathrm{C}\left(0.1^{\circ} \mathrm{C} / \mathrm{min}\right)$ under high vacuum $(<10 \mu \mathrm{bar})$ and held at $180{ }^{\circ} \mathrm{C}$ under high vacuum $(<10 \mu \mathrm{bar})$ for an additional $24 \mathrm{~h}$ before gas sorption measurements. 


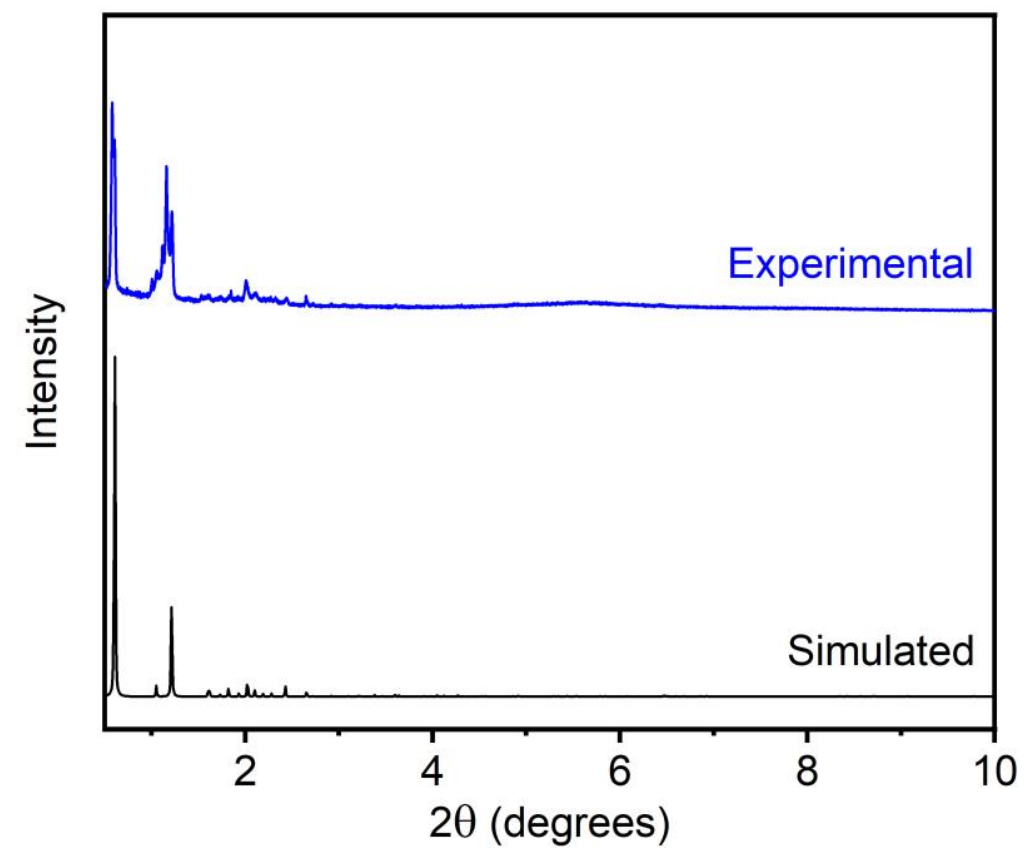

Figure S66. Synchrotron PXRD pattern $(\lambda=0.457897 \AA)$ of acetone-solvated PCN-128. The simulated pattern based on the previously reported electron diffraction structure of PCN-128 is included for reference. ${ }^{3}$

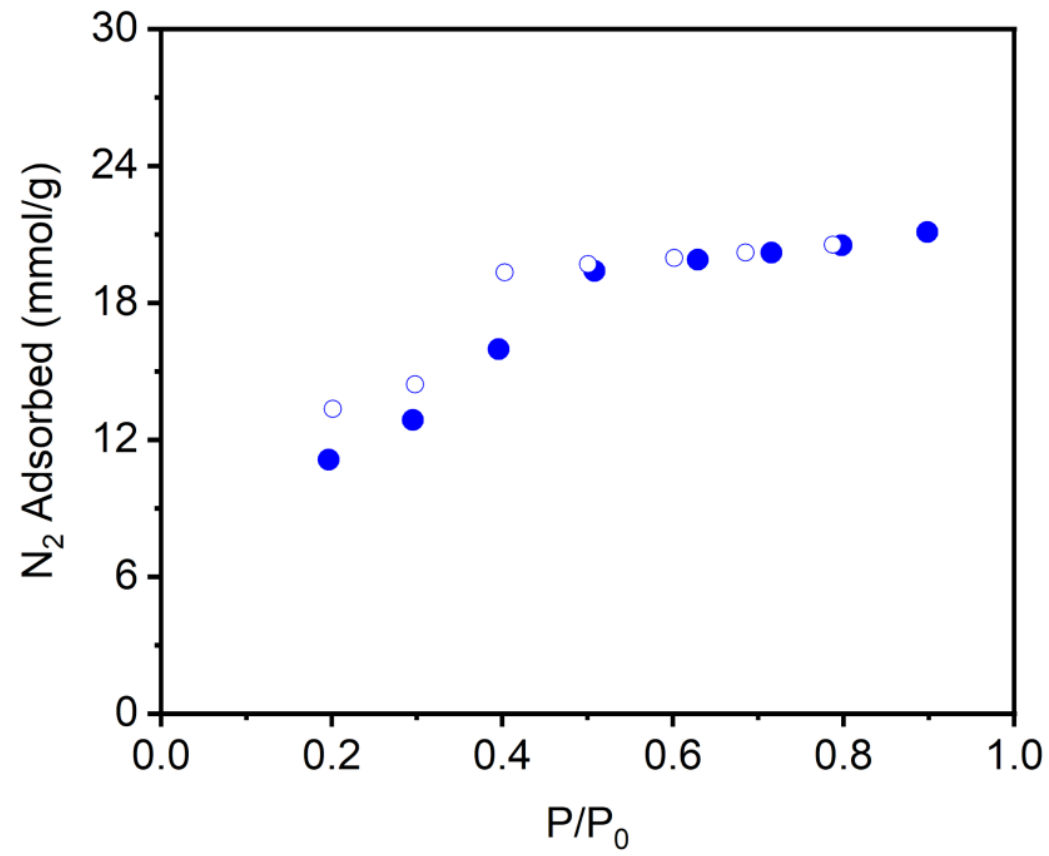

Figure S67. $77 \mathrm{~K} \mathrm{~N}_{2}$ adsorption (filled circles) and desorption (open circles) isotherm of activated PCN-128. The Langmuir surface area determined from these data is $3017 \pm 317 \mathrm{~m}^{2} / \mathrm{g}$. 


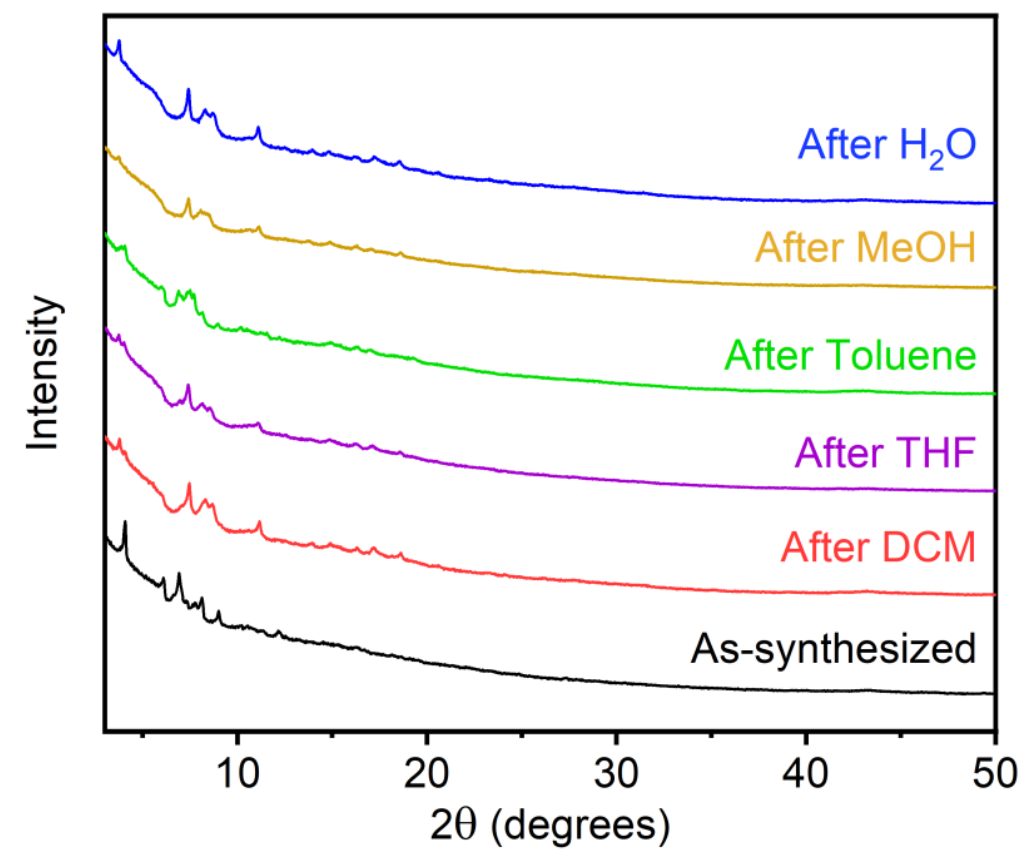

Figure S68. PXRD patterns $(\lambda=1.5406 \AA)$ of PCN-128 upon exposure to various organic solvents and water. Note that PCN-128 was soaked in DMF and acetone during its synthesis as well. A reference pattern of as-synthesized PCN-128 is included.

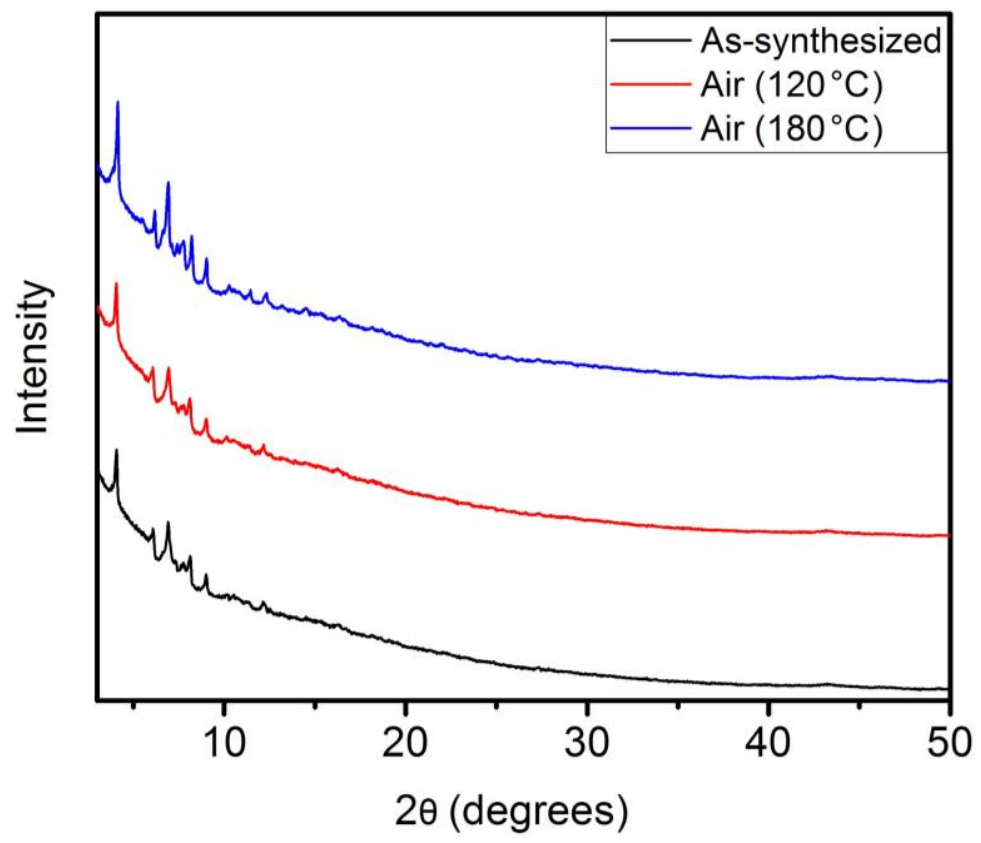

Figure S69. PXRD patterns $(\lambda=1.5406 \AA)$ of PCN-128 upon standing at $120{ }^{\circ} \mathrm{C}$ and $180{ }^{\circ} \mathrm{C}$ in air for $24 \mathrm{~h}$. A reference pattern of as-synthesized PCN-128 is included. 


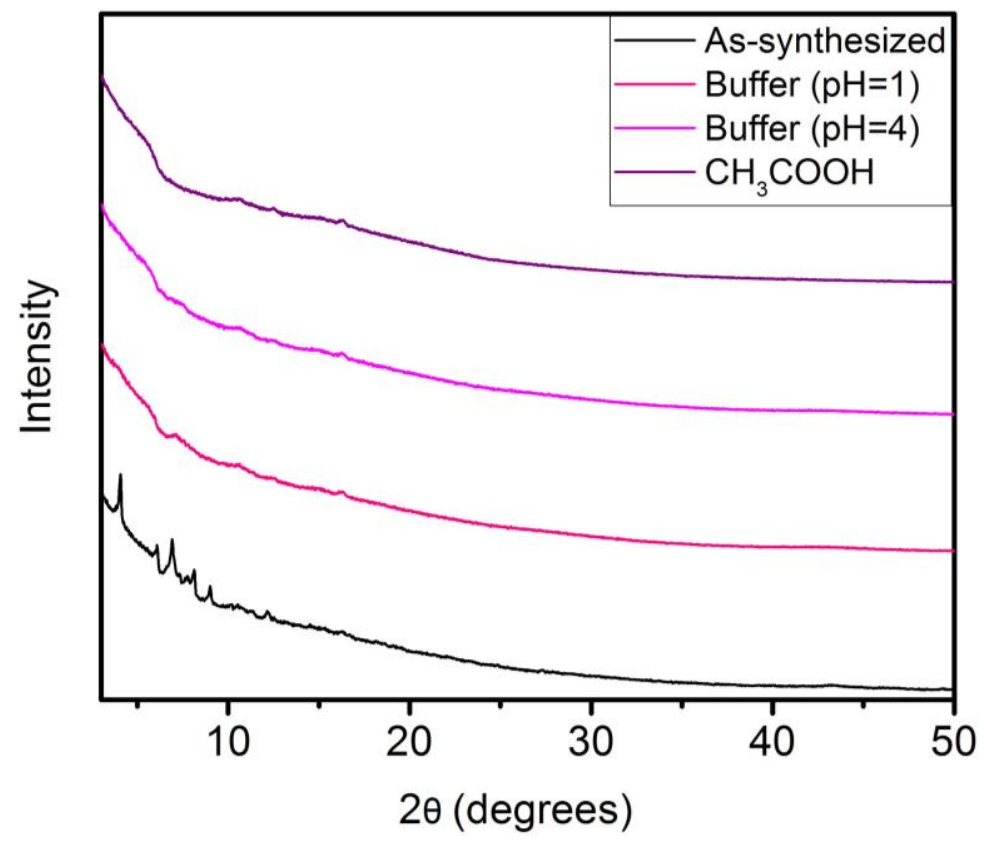

Figure S70. PXRD patterns $(\lambda=1.5406 \AA)$ of PCN-128 upon exposure to acids. Exposure tests include aqueous solutions buffered at $\mathrm{pH} 1$ and $\mathrm{pH} 4$ and glacial acetic acid. A reference pattern of as-synthesized PCN-128 is included.

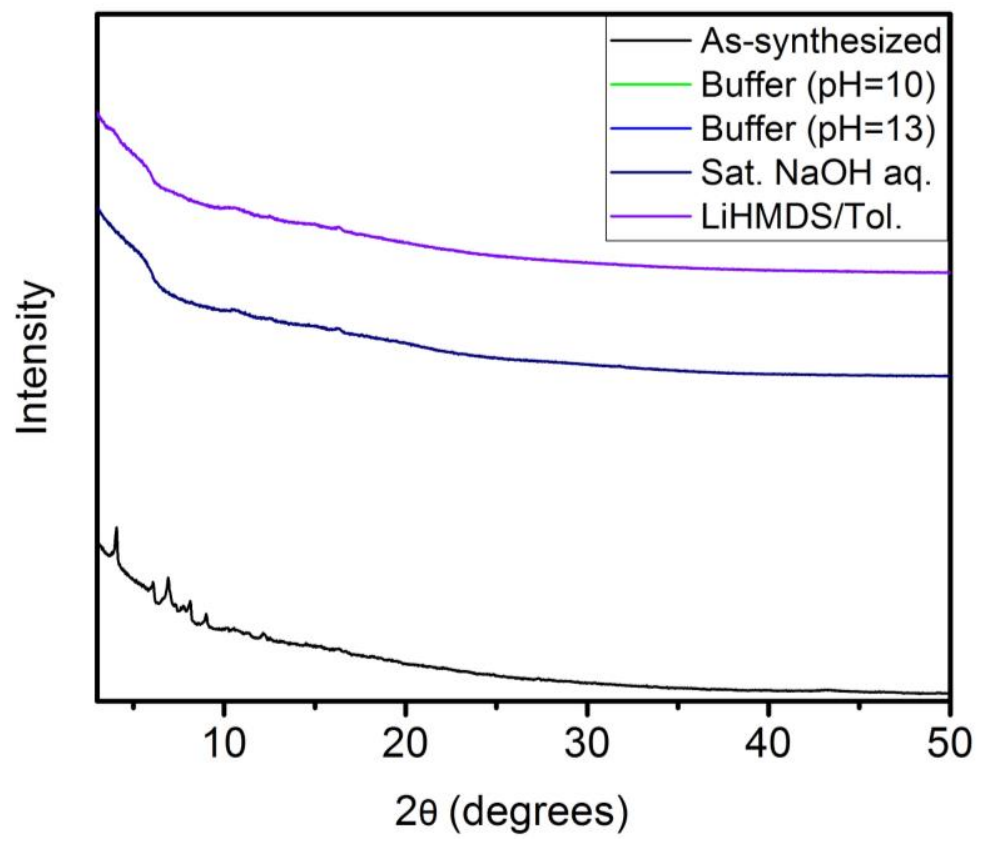

Figure S71. PXRD patterns ( $\lambda=1.5406 \AA)$ of PCN-128 upon exposure to bases. Exposure tests include aqueous solutions buffered at $\mathrm{pH} 10$ and $\mathrm{pH} \mathrm{13}$, saturated aqueous $\mathrm{NaOH}$, and $1.0 \mathrm{M}$ lithium hexamethyldisilazide (LiHMDS) in toluene. No solid remained after exposure of PCN-128 to the $\mathrm{pH} 10$ or $\mathrm{pH} 13$ buffers. A reference pattern of as-synthesized PCN-128 is included. 


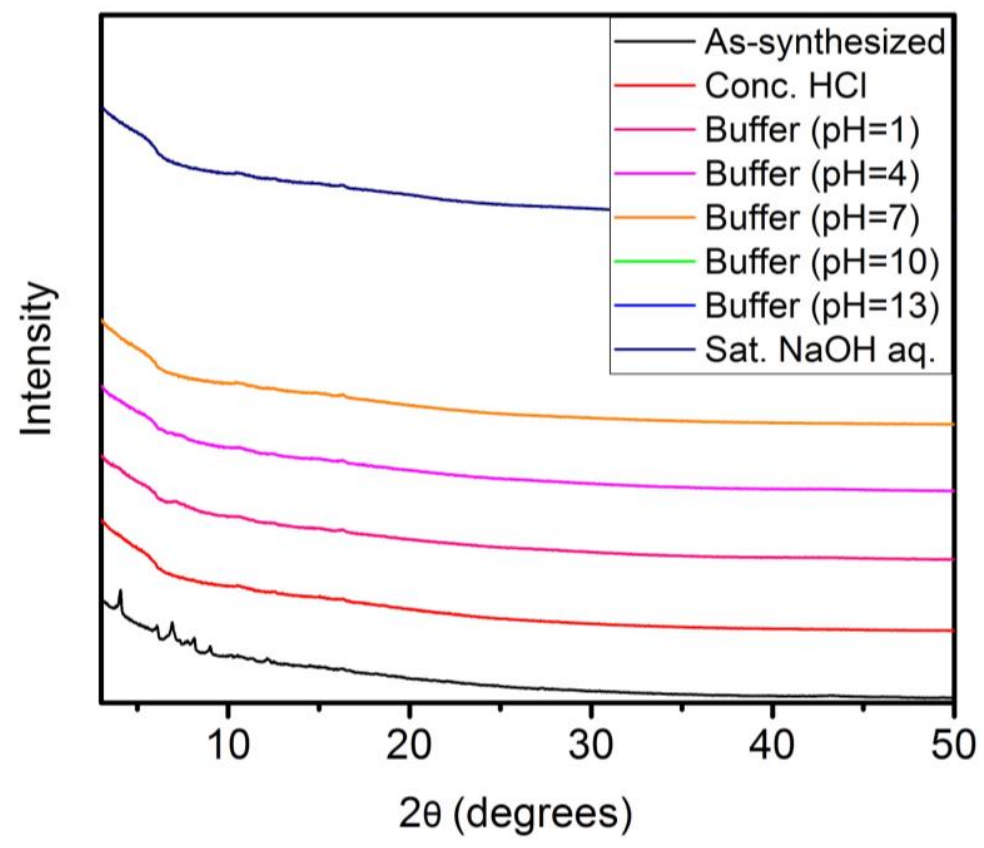

Figure S72. Summary of the PXRD patterns ( $\lambda=1.5406 \AA$ ) of PCN-128 upon exposure to various aqueous conditions. No solid remained after exposure of $\mathrm{PCN}-128$ to the $\mathrm{pH} 10$ or $\mathrm{pH} 13$ buffers. A reference pattern of as-synthesized PCN-128 is included.

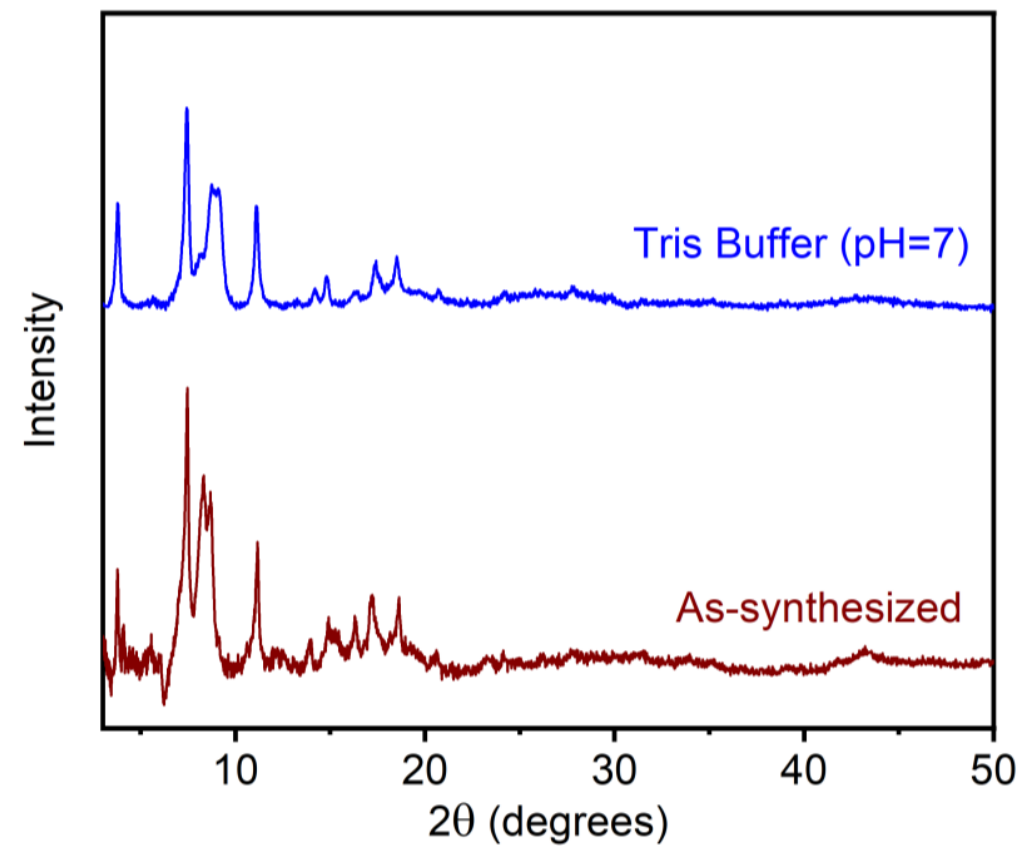

Figure S73. PXRD patterns for PCN-128 before and after exposure to aqueous tris buffer $(\mathrm{pH}=7)$. The initial FWHM for the peak at $2 \theta=7^{\circ}$ was $0.22014^{\circ}$, and the FWHM after exposure to buffer was $0.23573^{\circ}$, resulting in a 7\% change in FWHM after the exposure test. These powder X-ray diffraction patterns were baseline corrected. 


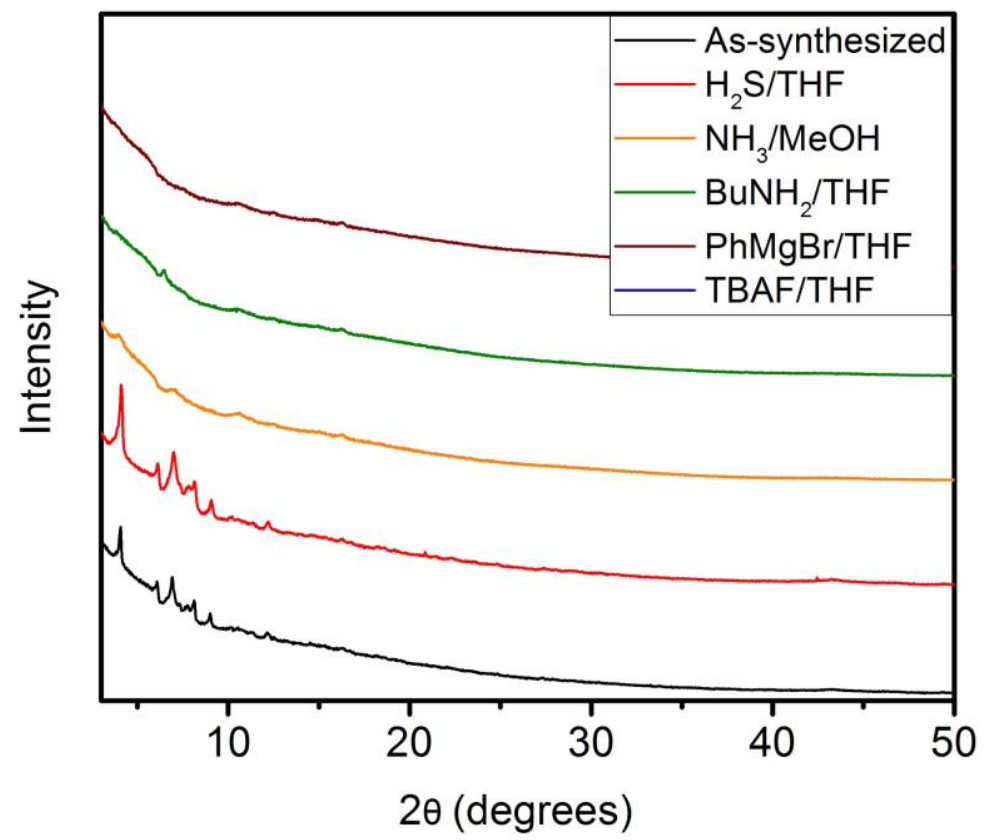

Figure S74. PXRD patterns ( $\lambda=1.5406 \AA$ ) of PCN-128 upon exposure to nucleophiles. Exposure tests include $0.8 \mathrm{M}$ hydrogen sulfide in tetrahydrofuran, $1.0 \mathrm{M}$ ammonia in methanol, $1.0 \mathrm{M} \mathrm{n}$ butylamine in tetrahydrofuran, $1.0 \mathrm{M} \mathrm{PhMgBr}$ in tetrahydrofuran, and $1.0 \mathrm{M}$ tetrabutylammonium fluoride (TBAF) in tetrahydrofuran. No solid remained after exposure of PCN-128 to the TBAF solution. A reference pattern of as-synthesized PCN-128 is included.

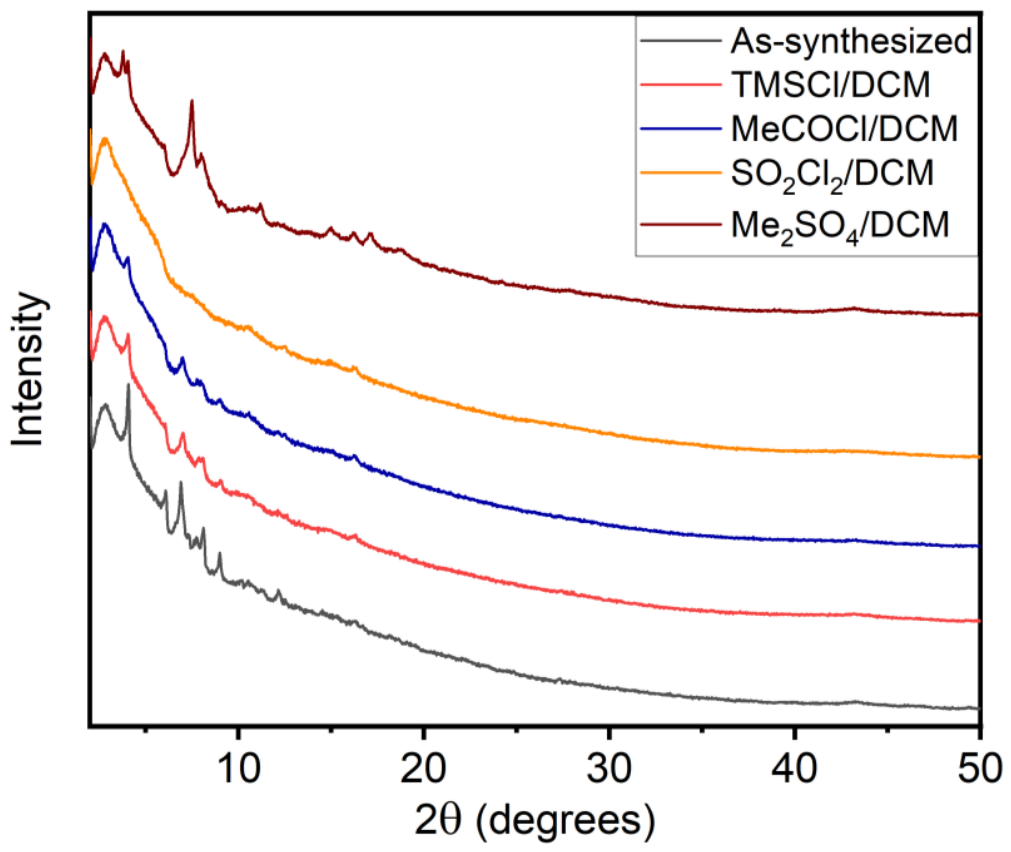

Figure S75. PXRD patterns ( $\lambda=1.5406 \AA$ ) of PCN-128 upon exposure to electrophiles. Exposure tests include $1.0 \mathrm{M}$ chlorotrimethylsilane (TMSCl) in dichloromethane, $1.0 \mathrm{M}$ acetyl chloride in dichloromethane, $1.0 \mathrm{M}$ sulfuryl chloride in dichloromethane, and saturated dimethyl sulfate in dichloromethane. A reference pattern of as-synthesized PCN-128 is included. 


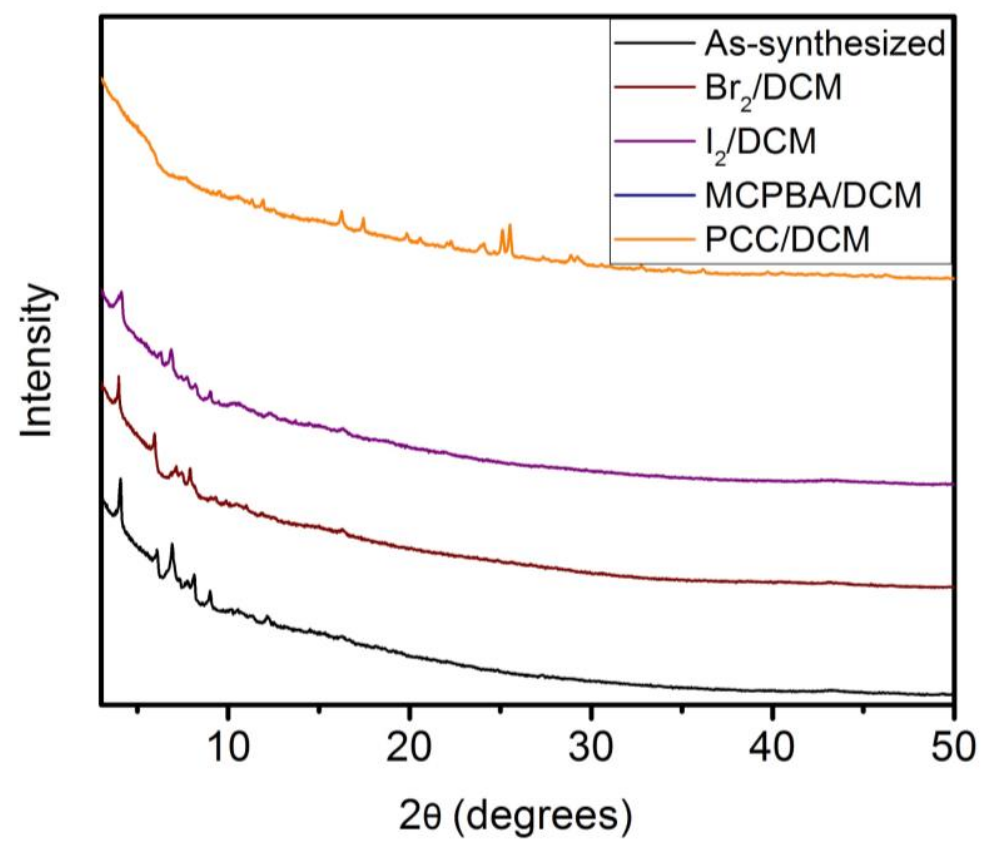

Figure S76. PXRD patterns ( $\lambda=1.5406 \AA$ ) of PCN-128 upon exposure to oxidants. Exposure tests include $1.0 \mathrm{M}$ bromine in dichloromethane, saturated iodine in dichloromethane, saturated $\mathrm{m}$ chloroperoxybenzoic acid (MCPBA) in dichloromethane, and saturated pyridinium chlorochromate (PCC) in dichloromethane. No solid material remained after exposure of PCN128 to the MCPBA solution. A reference pattern of as-synthesized PCN-128 is included.

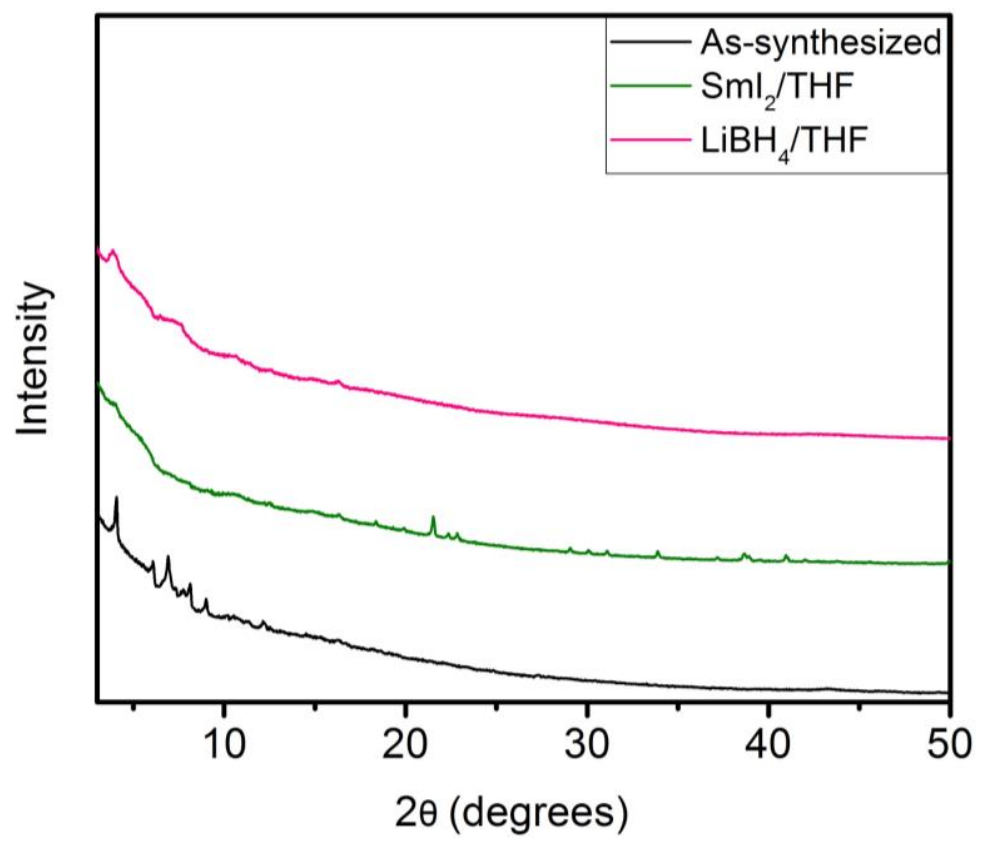

Figure S77. PXRD patterns $(\lambda=1.5406 \AA)$ of PCN-128 upon exposure to reductants. Exposure tests include $0.1 \mathrm{M}$ samarium iodide in tetrahydrofuran and $1.0 \mathrm{M}$ lithium borohydride in tetrahydrofuran. A reference pattern of as-synthesized PCN-128 is included. 
Table S6. Summary of changes in the full width at half maximum (FWHM) for the $2 \theta=4^{\circ}(\lambda=$ $1.5406 \AA$ ) reflection of PCN-128 under a range of conditions.

\begin{tabular}{|c|c|c|c|c|c|}
\hline Condition & \multicolumn{2}{|c|}{ Result } & Condition & \multicolumn{2}{|c|}{ Result } \\
\hline \multirow{2}{*}{ Initial } & FWHM & 0.10845 & \multirow{2}{*}{ DI water } & FWHM & 0.14458 \\
\hline & $\%$ Change & - & & $\%$ Change & 33 \\
\hline \multirow{2}{*}{$120^{\circ} \mathrm{C}$ Air } & FWHM & 0.11478 & \multirow{2}{*}{$\mathrm{BuNH}_{2} / \mathrm{THF}$} & FWHM & 0 \\
\hline & $\%$ Change & 6 & & $\%$ Change & $x$ \\
\hline \multirow{2}{*}{$180^{\circ} \mathrm{C}$ Air } & FWHM & 0.09966 & \multirow{2}{*}{$\mathrm{PhMgBr} / \mathrm{THF}$} & FWHM & 0 \\
\hline & $\%$ Change & -9 & & $\%$ Change & $\times$ \\
\hline \multirow{2}{*}{ Conc. $\mathrm{HCl}$} & FWHM & 0 & \multirow{2}{*}{ TBAF/THF } & FWHM & 0 \\
\hline & $\%$ Change & $x$ & & $\%$ Change & $x$ \\
\hline \multirow{2}{*}{$\mathrm{pH}=1$ Buffer } & FWHM & 0 & \multirow{2}{*}{$\mathrm{Me}_{3} \mathrm{SiCl} / \mathrm{CH}_{2} \mathrm{Cl}_{2}$} & FWHM & 0.12093 \\
\hline & $\%$ Change & $x$ & & $\%$ Change & 12 \\
\hline \multirow{2}{*}{$\mathrm{pH}=4$ Buffer } & FWHM & 0 & \multirow{2}{*}{$\mathrm{MeCOCl} / \mathrm{CH}_{2} \mathrm{Cl}_{2}$} & FWHM & 0.16928 \\
\hline & $\%$ Change & $x$ & & $\%$ Change & 57 \\
\hline \multirow{2}{*}{$\mathrm{pH}=7 \mathrm{Buffer}^{a}$} & FWHM & 0 & \multirow{2}{*}{$\mathrm{SO}_{2} \mathrm{Cl}_{2} / \mathrm{CH}_{2} \mathrm{Cl}_{2}$} & FWHM & 0 \\
\hline & $\%$ Change & $x$ & & $\%$ Change & $x$ \\
\hline \multirow{2}{*}{$\mathrm{pH}=10$ Buffer } & FWHM & 0 & \multirow{2}{*}{$\mathrm{Me}_{2} \mathrm{SO}_{4} / \mathrm{CH}_{2} \mathrm{Cl}_{2}$} & FWHM & 0.13264 \\
\hline & $\%$ Change & $x$ & & $\%$ Change & 22 \\
\hline \multirow{2}{*}{$\mathrm{pH}=13$ Buffer } & FWHM & 0 & \multirow{2}{*}{$\mathrm{Br}_{2} / \mathrm{CH}_{2} \mathrm{Cl}_{2}$} & FWHM & 0.08556 \\
\hline & $\%$ Change & $x$ & & $\%$ Change & -22 \\
\hline \multirow{2}{*}{ Sat. $\mathrm{NaOH}$} & FWHM & 0 & \multirow{2}{*}{$\mathrm{I}_{2} / \mathrm{CH}_{2} \mathrm{Cl}_{2}$} & FWHM & 0.27751 \\
\hline & $\%$ Change & $x$ & & $\%$ Change & 156 \\
\hline \multirow{2}{*}{$\mathrm{CH}_{3} \mathrm{COOH}$} & FWHM & 0 & \multirow{2}{*}{$\mathrm{MCPBA} / \mathrm{CH}_{2} \mathrm{Cl}_{2}$} & FWHM & 0 \\
\hline & $\%$ Change & $x$ & & $\%$ Change & $x$ \\
\hline \multirow{2}{*}{ LiHMDS/Tol } & FWHM & 0 & \multirow{2}{*}{$\mathrm{PCC} / \mathrm{CH}_{2} \mathrm{Cl}_{2}$} & FWHM & 0 \\
\hline & $\%$ Change & $\times$ & & $\%$ Change & $x$ \\
\hline \multirow{2}{*}{$\mathrm{H}_{2} \mathrm{~S} / \mathrm{THF}$} & FWHM & 0.13201 & \multirow{2}{*}{$\mathrm{SmI}_{2} / \mathrm{THF}$} & FWHM & 0 \\
\hline & $\%$ Change & 22 & & $\%$ Change & $x$ \\
\hline \multirow{2}{*}{$\mathrm{NH}_{3} / \mathrm{MeOH}$} & FWHM & 0 & \multirow{2}{*}{$\mathrm{LiBH}_{4} / \mathrm{THF}$} & FWHM & 0.42713 \\
\hline & $\%$ Change & $x$ & & $\%$ Change & 294 \\
\hline
\end{tabular}

${ }^{a} 7 \%$ reduction in FWHM was observed using aqueous tris buffer $(\mathrm{pH}=7)$. 


\section{Synthesis, characterization, and stability assessment of MOF-74 (Mg).}

Synthesis of MOF-74 (Mg). This procedure is adapted from the literature. ${ }^{20}$ A $1 \mathrm{~L}$ round bottom flask equipped with a stir bar and reflux condenser was charged with 2,5dihydroxyterephthalic acid (991 mg, $5.00 \mathrm{mmol}, 1.00$ equiv.), $\mathrm{Mg}\left(\mathrm{NO}_{3}\right)_{2} \bullet 6 \mathrm{H}_{2} \mathrm{O}(3.21 \mathrm{~g}, 12.5 \mathrm{mmol}$, 2.50 equiv.), $\mathrm{H}_{2} \mathrm{O}(25 \mathrm{~mL})$, ethanol $(25 \mathrm{~mL})$, and $N, N$-dimethylformamide $(450 \mathrm{~mL})$. The reaction mixture was transferred to a silicone oil bath and stirred at reflux (700 rpm) for $24 \mathrm{~h}$. Over the course of the reaction, a light brown solid precipitated from solution. After $24 \mathrm{~h}$, the heterogeneous reaction mixture was allowed to cool to room temperature and filtered. The resulting solid was transferred to a $500 \mathrm{~mL}$ Pyrex jar with $N, N$-dimethylformamide $(250 \mathrm{~mL})$. The jar was allowed to stand for $24 \mathrm{~h}$ at $120^{\circ} \mathrm{C}$ in an oven, at which time the $N, N$-dimethylformamide was decanted and replaced with fresh $N, N$-dimethylformamide $(250 \mathrm{~mL})$. This procedure was repeated two additional times for a total of three hot $N, N$-dimethylformamide soaks. Next, the solid was filtered and returned to the jar with fresh methanol $(250 \mathrm{~mL})$. The solid was soaked in methanol for $24 \mathrm{~h}$ at $60{ }^{\circ} \mathrm{C}$ in an oven three total times following the same procedure as described above. Complete exchange of $N, N$-dimethylformamide for methanol was confirmed by IR spectroscopy. The resulting light brown solid was filtered and transferred to a Schlenk flask. The solid was activated under flowing $\mathrm{N}_{2}$ at $180{ }^{\circ} \mathrm{C}$ for $4 \mathrm{~h}$, followed by further activation under high vacuum (<100 mbar) at $180{ }^{\circ} \mathrm{C}$ for $24 \mathrm{~h}$. The Schlenk flask was transferred into a $\mathrm{N}_{2}$-filled glovebox, and the activated MOF-74(Mg) was transferred into a $20 \mathrm{~mL}$ scintillation vial for long-term storage. A portion of the activated sample was transferred to a pre-tared Micromeritics sample tube equipped with a Sureseal. The tube was removed from the glovebox and the sample was further activated under high vacuum $(<10 \mu \mathrm{bar})$ at $180^{\circ} \mathrm{C}$ for $24 \mathrm{~h}$ prior to gas sorption measurements. 


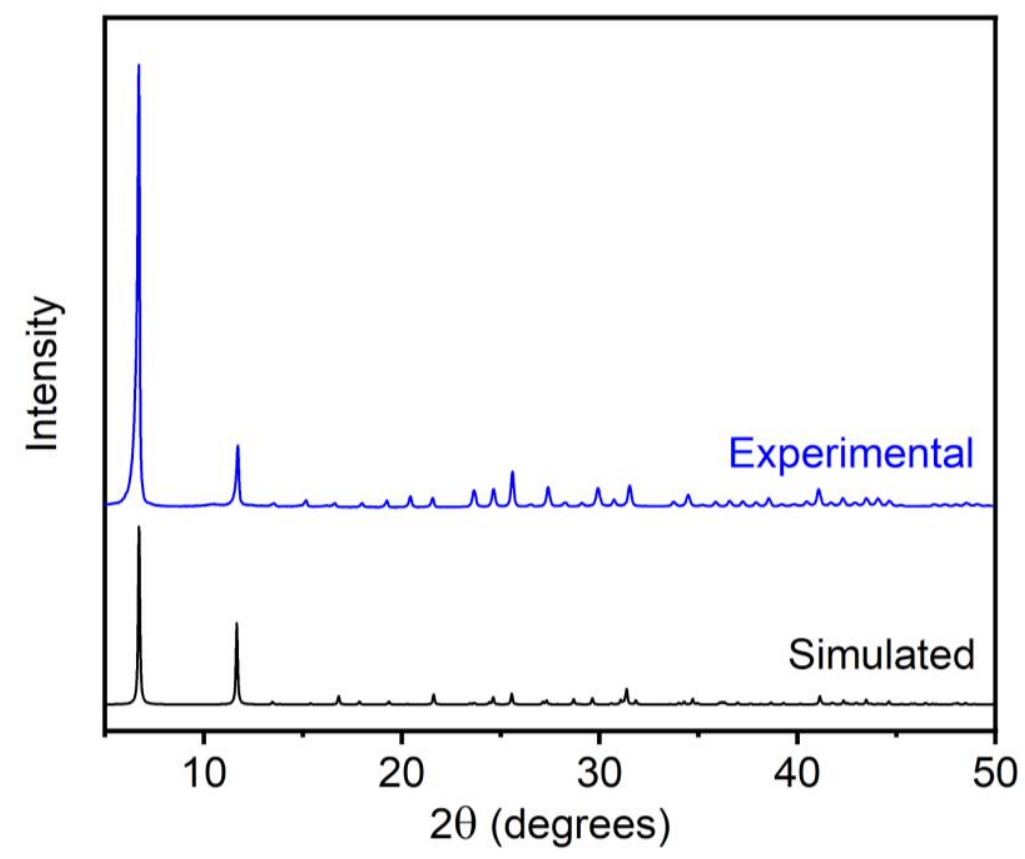

Figure S78. PXRD pattern $(\lambda=1.5406 \AA)$ of methanol-solvated MOF-74 (Mg). The simulated pattern based on the previously reported single-crystal X-ray diffraction structure of the isostructural framework $\mathrm{Zn}_{2}$ (dobdc) is included for reference. ${ }^{21}$ The PXRD pattern of MOF-74 $(\mathrm{Mg})$ was baseline corrected.

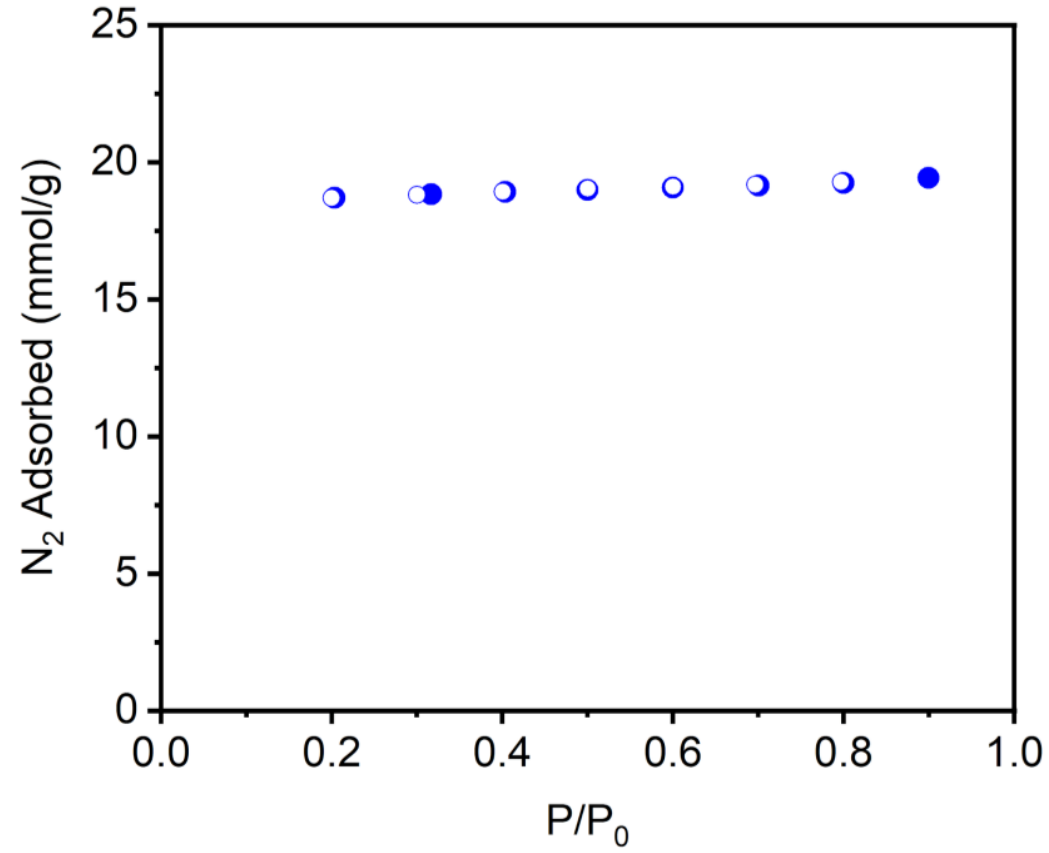

Figure S79. $77 \mathrm{~K} \mathrm{~N}_{2}$ adsorption (filled circles) and desorption (open circles) isotherm of activated MOF-74 (Mg). The Langmuir surface area determined from these data is $1879 \pm 5 \mathrm{~m}^{2} / \mathrm{g}$. 


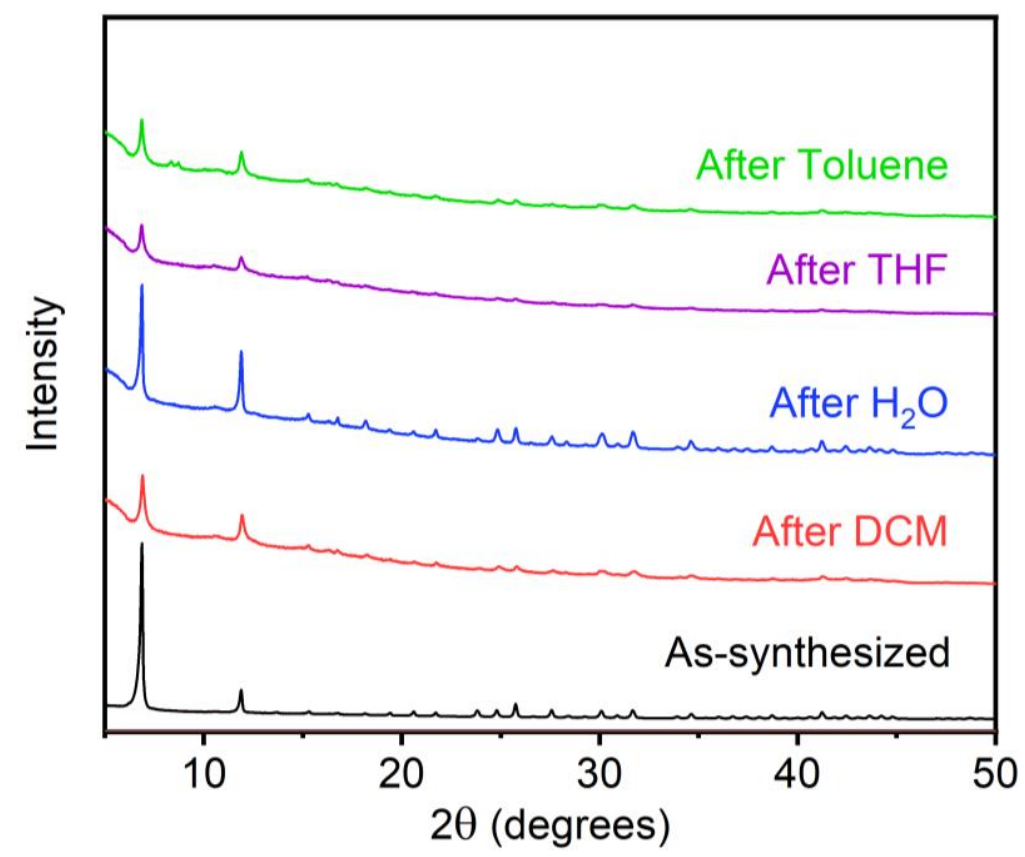

Figure S80. PXRD patterns $(\lambda=1.5406 \AA)$ of MOF-74 $(\mathrm{Mg})$ upon exposure to various organic solvents and water. Note that MOF-74 (Mg) was soaked in DMF and MeOH during its synthesis as well. A reference pattern of as-synthesized MOF-74 (Mg) is included.

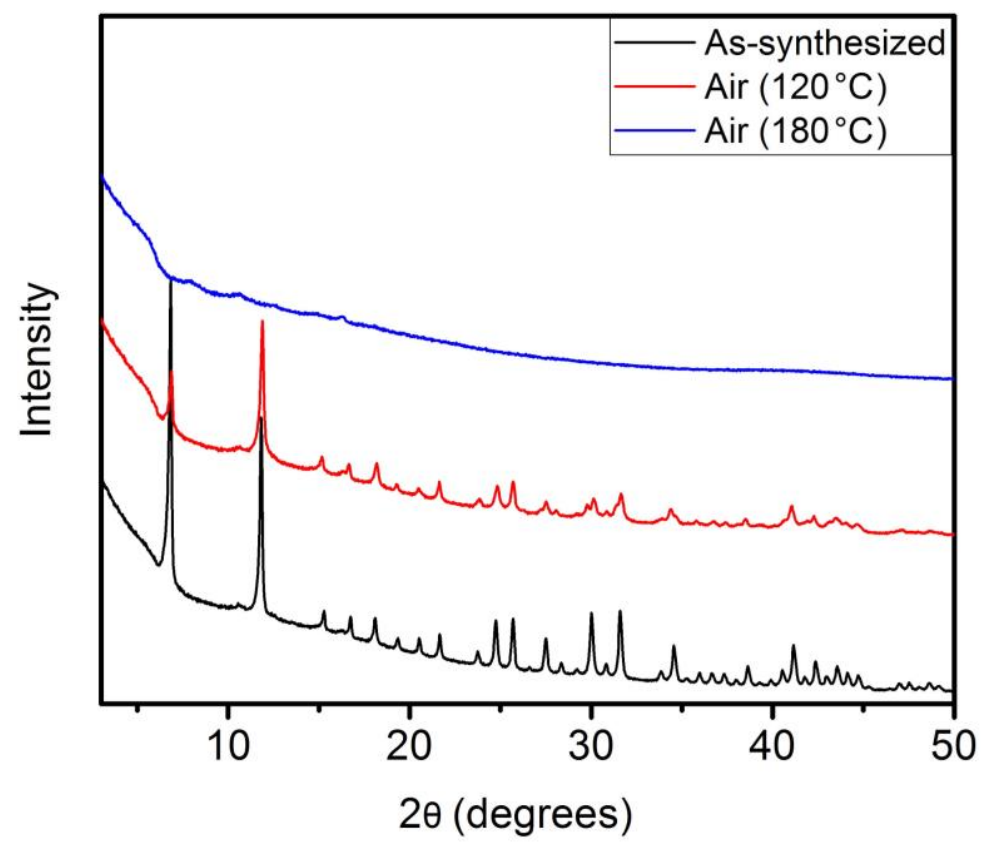

Figure S81. PXRD patterns $(\lambda=1.5406 \AA)$ of MOF-74 (Mg) upon standing at $120^{\circ} \mathrm{C}$ and $180^{\circ} \mathrm{C}$ in air for $24 \mathrm{~h}$. A reference pattern of as-synthesized MOF-74 (Mg) is included. 


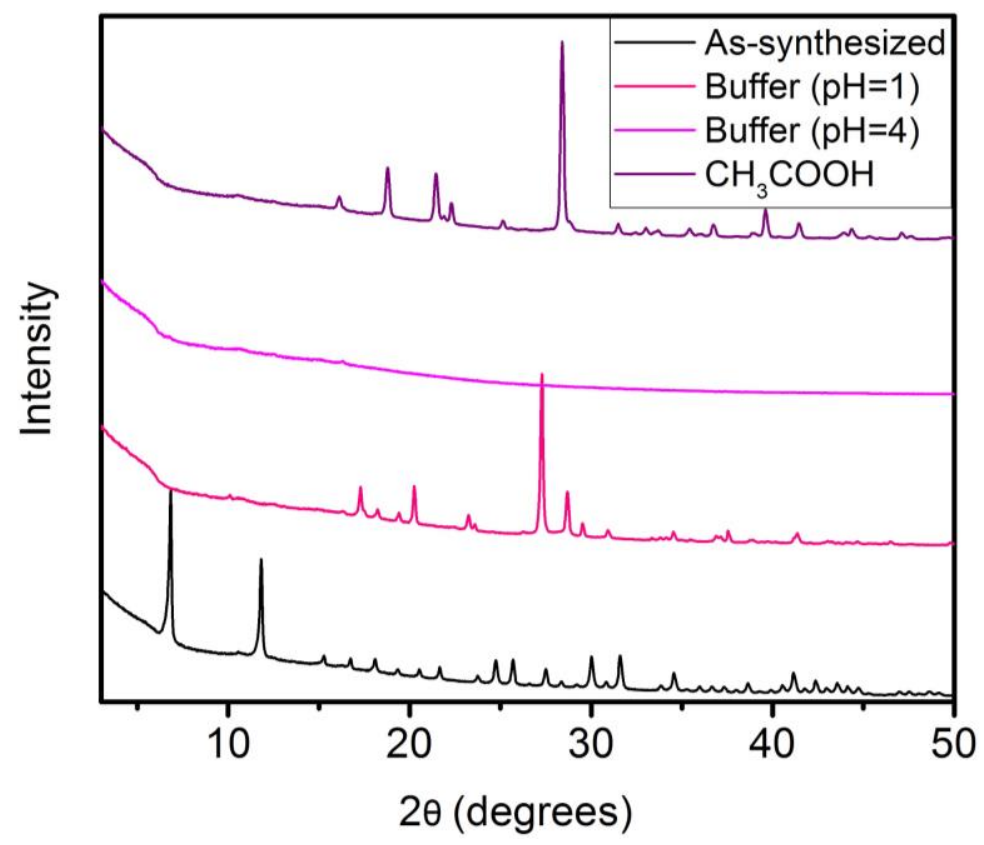

Figure S82. PXRD patterns $(\lambda=1.5406 \AA)$ of MOF-74 $(\mathrm{Mg})$ upon exposure to acids. Exposure tests include aqueous solutions buffered at $\mathrm{pH} 1$ and $\mathrm{pH} 4$ and glacial acetic acid. A reference pattern of as-synthesized MOF-74 (Mg) is included.

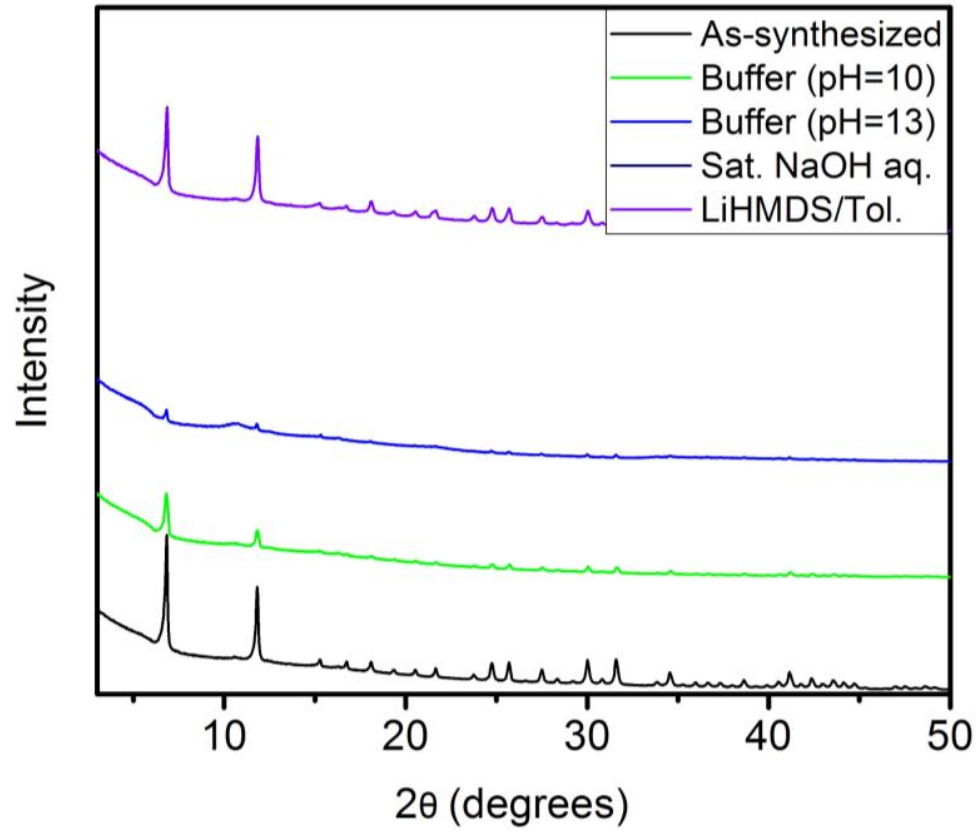

Figure S83. PXRD patterns $(\lambda=1.5406 \AA)$ of MOF-74 $(\mathrm{Mg})$ upon exposure to bases. Exposure tests include aqueous solutions buffered at $\mathrm{pH} 10$ and $\mathrm{pH} 13$, saturated aqueous $\mathrm{NaOH}$, and $1.0 \mathrm{M}$ lithium hexamethyldisilazide (LiHMDS) in toluene. No solid remained after exposure of MOF-74 $(\mathrm{Mg})$ to the saturated $\mathrm{NaOH}$ solution. A reference pattern of as-synthesized MOF-74 $(\mathrm{Mg})$ is included. 


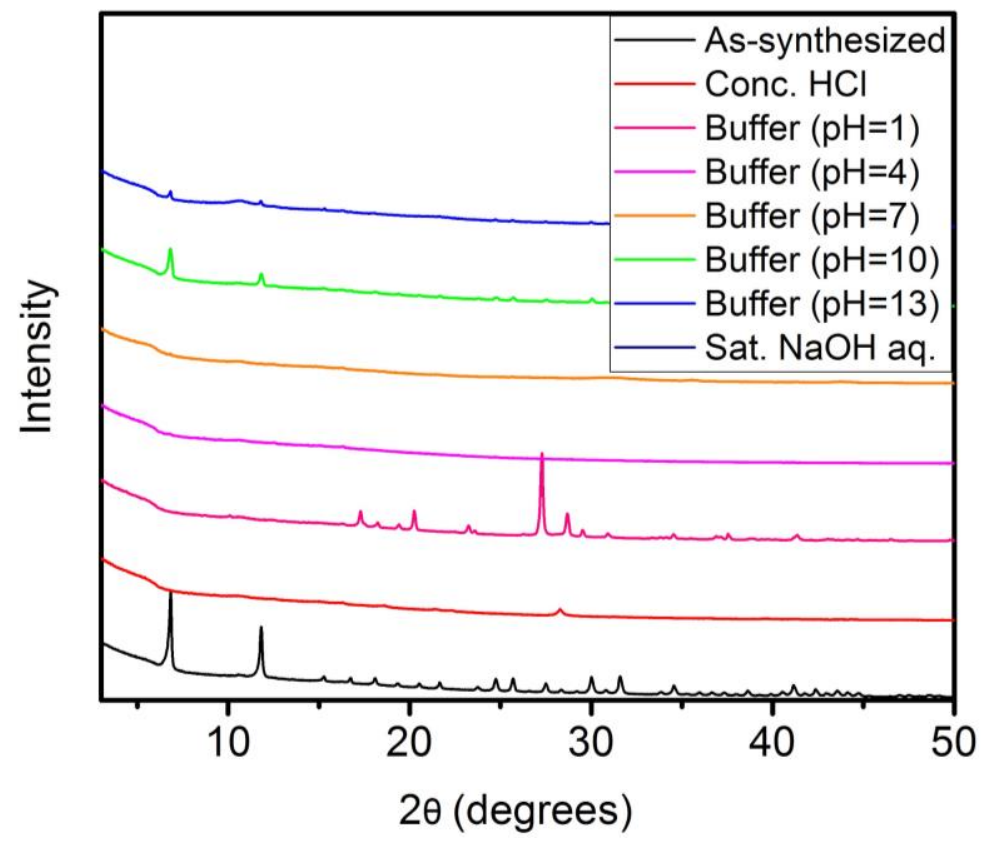

Figure S84. Summary of the PXRD patterns $(\lambda=1.5406 \AA)$ of MOF-74 (Mg) upon exposure to various aqueous conditions. No solid remained after exposure of MOF-74 $(\mathrm{Mg})$ to the saturated $\mathrm{NaOH}$ solution. A reference pattern of as-synthesized MOF-74 (Mg) is included. Notably, MOF$74(\mathrm{Mg})$ was found to completely dissolve in aqueous tris buffer $(\mathrm{pH}=7)$.

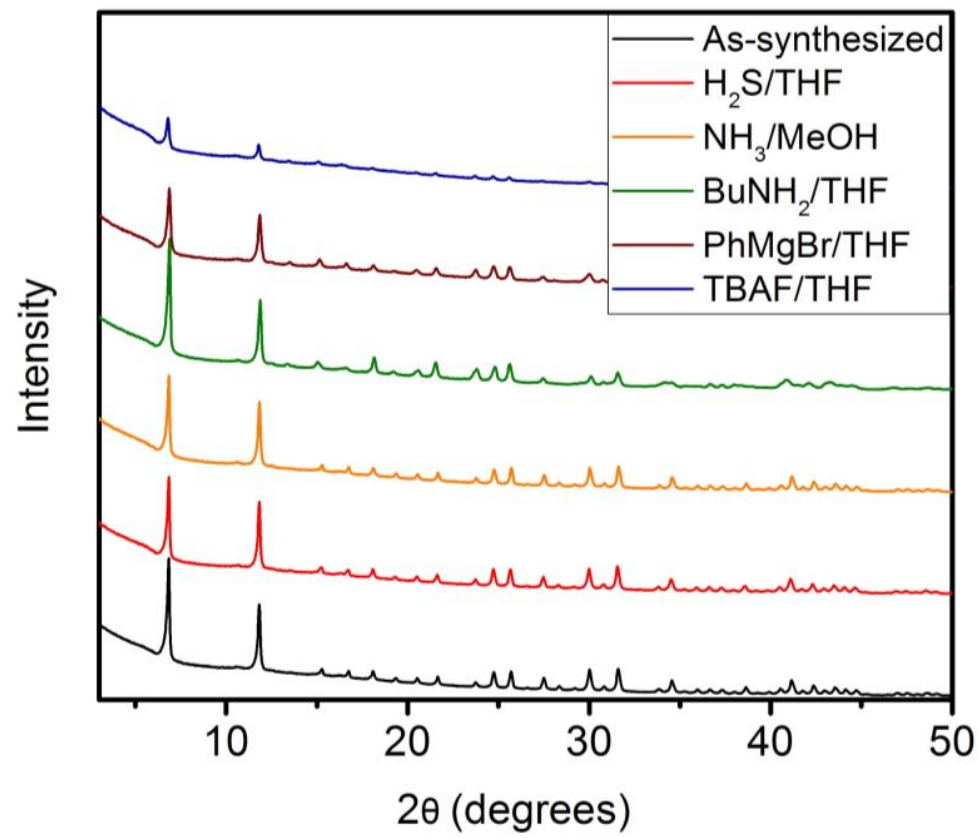

Figure S85. PXRD patterns $(\lambda=1.5406 \AA)$ of MOF-74 $(\mathrm{Mg})$ upon exposure to nucleophiles. Exposure tests include $0.8 \mathrm{M}$ hydrogen sulfide in tetrahydrofuran, $1.0 \mathrm{M}$ ammonia in methanol, 1.0 $\mathrm{M} \mathrm{n}$-butylamine in tetrahydrofuran, $1.0 \mathrm{M} \mathrm{PhMgBr}$ in tetrahydrofuran, and $1.0 \mathrm{M}$ tetrabutylammonium fluoride (TBAF) in tetrahydrofuran. A reference pattern of as-synthesized MOF-74 (Mg) is included. 


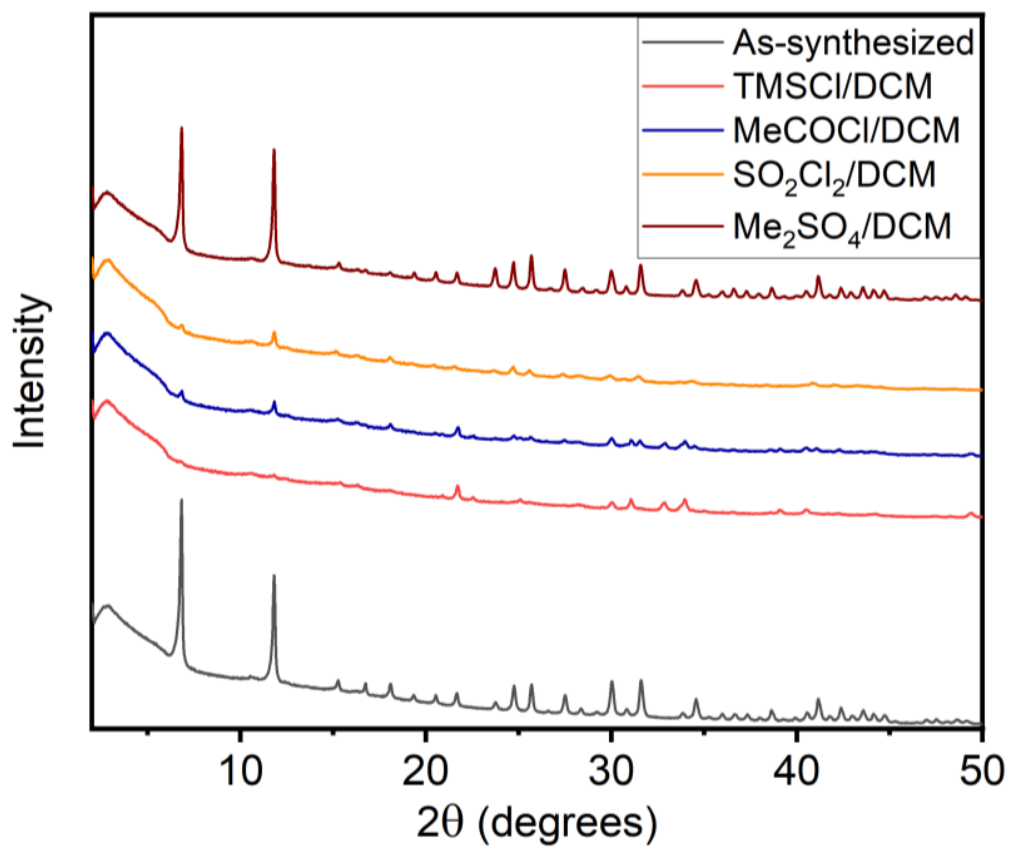

Figure S86. PXRD patterns $(\lambda=1.5406 \AA)$ of MOF-74 $(\mathrm{Mg})$ upon exposure to electrophiles. Exposure tests include $1.0 \mathrm{M}$ chlorotrimethylsilane (TMSCl) in dichloromethane, $1.0 \mathrm{M}$ acetyl chloride in dichloromethane, $1.0 \mathrm{M}$ sulfuryl chloride in dichloromethane, and saturated dimethyl sulfate in dichloromethane. A reference pattern of as-synthesized MOF-74 (Mg) is included.

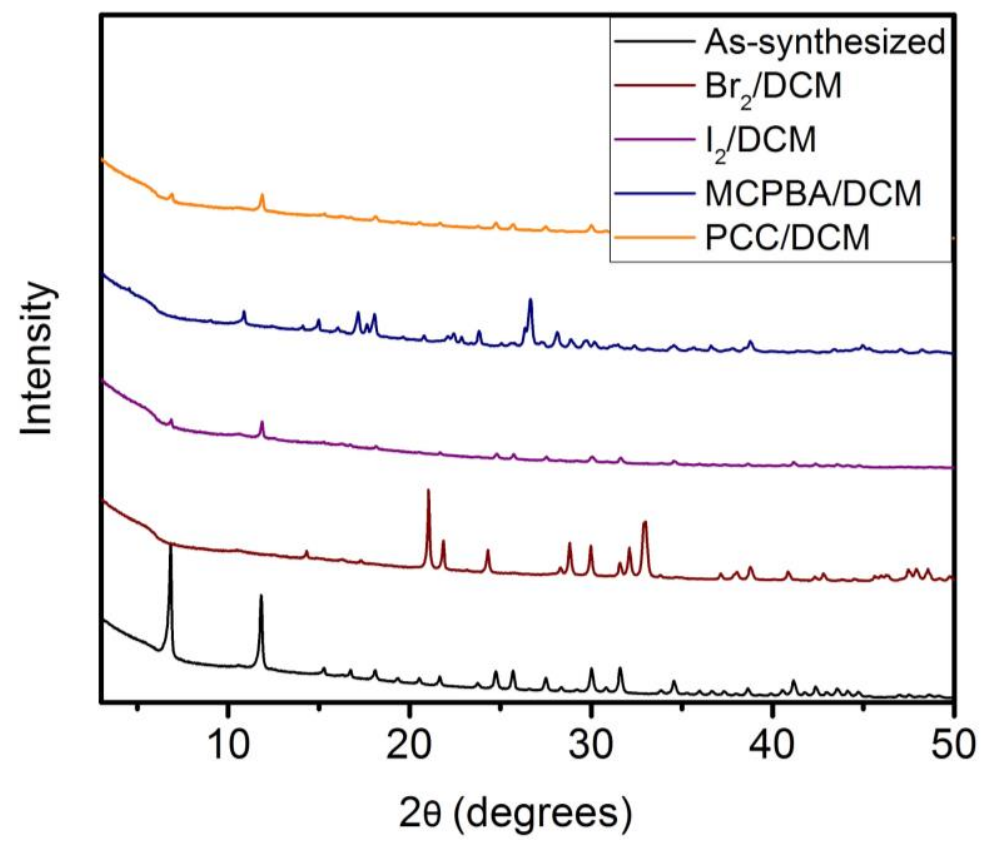

Figure S87. PXRD patterns $(\lambda=1.5406 \AA)$ of MOF-74 $(\mathrm{Mg})$ upon exposure to oxidants. Exposure tests include $1.0 \mathrm{M}$ bromine in dichloromethane, saturated iodine in dichloromethane, saturated $m$-chloroperoxybenzoic acid (MCPBA) in dichloromethane, and saturated pyridinium chlorochromate (PCC) in dichloromethane. No solid material remained after exposure of MOF-74 $(\mathrm{Mg})$ to MCPBA. A reference pattern of as-synthesized MOF-74 (Mg) is included. 


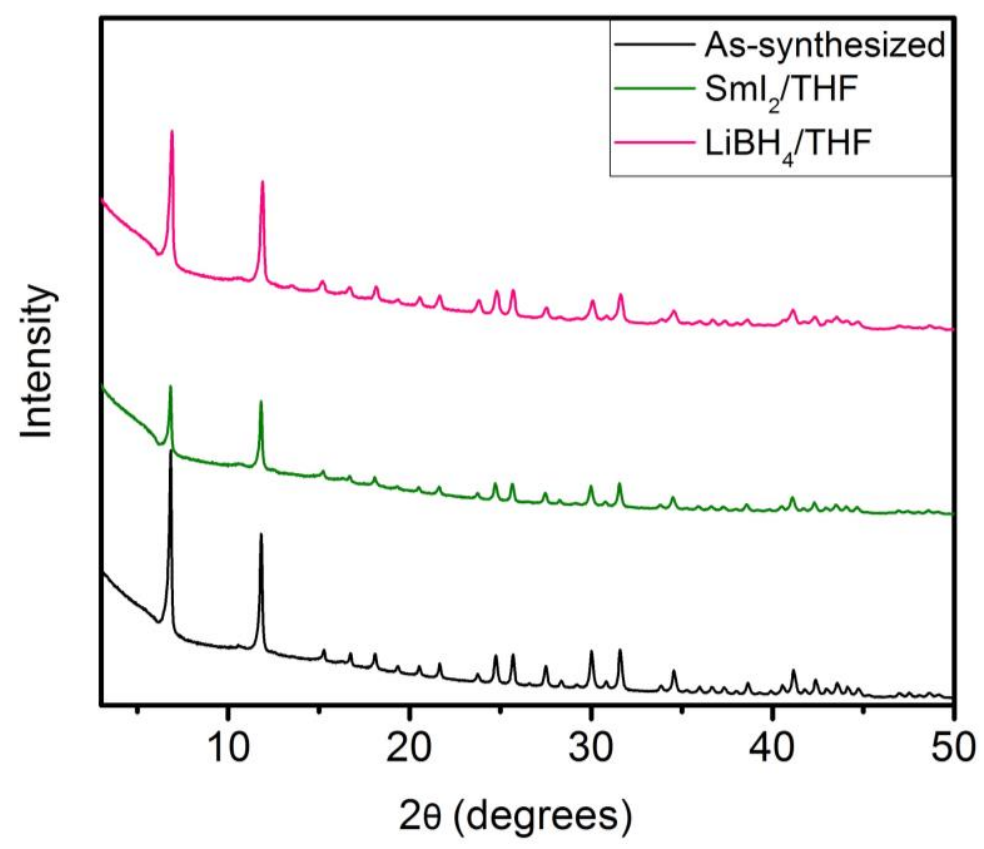

Figure S88. PXRD patterns $(\lambda=1.5406 \AA)$ of MOF-74 $(\mathrm{Mg})$ upon exposure to reductants. Exposure tests include $0.1 \mathrm{M}$ samarium iodide in tetrahydrofuran and $1.0 \mathrm{M}$ lithium borohydride in tetrahydrofuran. A reference pattern of as-synthesized MOF-74 (Mg) is included. 
Table S7. Summary of changes in the full width at half maximum (FWHM) for the $2 \theta=7^{\circ}(\lambda=$ $1.5406 \AA$ ) reflection of MOF-74 (Mg) under a range of conditions.

\begin{tabular}{|c|c|c|c|c|c|}
\hline Condition & \multicolumn{2}{|c|}{ Result } & Condition & \multicolumn{2}{|c|}{ Result } \\
\hline \multirow{2}{*}{ Initial } & FWHM & 0.15210 & \multirow{2}{*}{ DI water } & FWHM & 0.15183 \\
\hline & $\%$ Change & - & & $\%$ Change & 0 \\
\hline \multirow{2}{*}{$120{ }^{\circ} \mathrm{C}$ Air } & FWHM & 0.16455 & \multirow{2}{*}{$\mathrm{BuNH}_{2} / \mathrm{THF}$} & FWHM & 0.16434 \\
\hline & $\%$ Change & 9 & & $\%$ Change & 9 \\
\hline \multirow{2}{*}{$180{ }^{\circ} \mathrm{C}$ Air } & FWHM & 0 & \multirow{2}{*}{$\mathrm{PhMgBr} / \mathrm{THF}$} & FWHM & 0.18993 \\
\hline & $\%$ Change & $x$ & & $\%$ Change & 25 \\
\hline \multirow{2}{*}{ Conc. $\mathrm{HCl}$} & FWHM & 0 & \multirow{2}{*}{ TBAF/THF } & FWHM & 0.16281 \\
\hline & $\%$ Change & $x$ & & $\%$ Change & 8 \\
\hline \multirow{2}{*}{$\mathrm{pH}=1$ Buffer } & FWHM & 0 & \multirow{2}{*}{$\mathrm{Me}_{3} \mathrm{SiCl} / \mathrm{CH}_{2} \mathrm{Cl}_{2}$} & FWHM & 0 \\
\hline & $\%$ Change & $x$ & & $\%$ Change & $x$ \\
\hline \multirow{2}{*}{$\mathrm{pH}=4$ Buffer } & FWHM & 0 & \multirow{2}{*}{$\mathrm{MeCOCl} / \mathrm{CH}_{2} \mathrm{Cl}_{2}$} & FWHM & 0.29755 \\
\hline & $\%$ Change & $x$ & & $\%$ Change & 96 \\
\hline \multirow{2}{*}{$\mathrm{pH}=7$ Buffer $^{a}$} & FWHM & 0 & \multirow{2}{*}{$\mathrm{SO}_{2} \mathrm{Cl}_{2} / \mathrm{CH}_{2} \mathrm{Cl}_{2}$} & FWHM & 0.31238 \\
\hline & $\%$ Change & $x$ & & $\%$ Change & 106 \\
\hline \multirow{2}{*}{$\mathrm{pH}=10$ Buffer } & FWHM & 0.19184 & \multirow{2}{*}{$\mathrm{Me}_{2} \mathrm{SO}_{4} / \mathrm{CH}_{2} \mathrm{Cl}_{2}$} & FWHM & 0.15296 \\
\hline & $\%$ Change & 27 & & $\%$ Change & 1 \\
\hline \multirow{2}{*}{$\mathrm{pH}=13$ Buffer } & FWHM & 0.11947 & \multirow{2}{*}{$\mathrm{Br}_{2} / \mathrm{CH}_{2} \mathrm{Cl}_{2}$} & FWHM & 0 \\
\hline & $\%$ Change & -22 & & $\%$ Change & $x$ \\
\hline \multirow{2}{*}{ Sat. $\mathrm{NaOH}$} & FWHM & 0 & \multirow{2}{*}{$\mathrm{I}_{2} / \mathrm{CH}_{2} \mathrm{Cl}_{2}$} & FWHM & 0.09466 \\
\hline & $\%$ Change & $x$ & & $\%$ Change & -38 \\
\hline \multirow{2}{*}{$\mathrm{CH}_{3} \mathrm{COOH}$} & FWHM & 0 & \multirow{2}{*}{$\mathrm{MCPBA} / \mathrm{CH}_{2} \mathrm{Cl}_{2}$} & FWHM & 0 \\
\hline & $\%$ Change & $\times$ & & $\%$ Change & $\times$ \\
\hline \multirow{2}{*}{ LiHMDS/Tol } & FWHM & 0.15962 & \multirow{2}{*}{$\mathrm{PCC} / \mathrm{CH}_{2} \mathrm{Cl}_{2}$} & FWHM & 0.19478 \\
\hline & $\%$ Change & 5 & & $\%$ Change & 29 \\
\hline \multirow{2}{*}{$\mathrm{H}_{2} \mathrm{~S} / \mathrm{THF}$} & FWHM & 0.14122 & \multirow{2}{*}{$\mathrm{SmI}_{2} / \mathrm{THF}$} & FWHM & 0.1337 \\
\hline & $\%$ Change & -8 & & $\%$ Change & -13 \\
\hline \multirow{2}{*}{$\mathrm{NH}_{3} / \mathrm{MeOH}$} & FWHM & 0.14398 & \multirow{2}{*}{$\mathrm{LiBH}_{4} / \mathrm{THF}$} & FWHM & 0.19005 \\
\hline & $\%$ Change & -6 & & $\%$ Change & 25 \\
\hline
\end{tabular}

${ }^{a} \mathrm{MOF}-74(\mathrm{Mg})$ was found to completely dissolve in aqueous tris buffer $(\mathrm{pH}=7)$. 


\section{Synthesis, characterization, and stability assessment of MOF-74 (Ni).}

Synthesis of MOF-74 (Ni). This procedure is adapted from the literature. ${ }^{22}$ A $350 \mathrm{~mL}$ screw-cap high-pressure reaction flask equipped with a stir bar was charged with $\mathrm{Ni}\left(\mathrm{NO}_{3}\right)_{2} \bullet 6 \mathrm{H}_{2} \mathrm{O}$ (4.65 g, $16.0 \mathrm{mmol}, 2.50$ equiv.), 2,5-dihydroxyterephthalic acid (1.27 g, $6.41 \mathrm{mmol}, 1.00$ eq.), $N, N$-dimethylformamide $(156 \mathrm{~mL})$, and methanol $(19 \mathrm{~mL})$. The reaction mixture was sparged vigorously with $\mathrm{N}_{2}$ for $1 \mathrm{~h}$, sealed, and transferred to a silicone oil bath. The oil bath was heated to $120^{\circ} \mathrm{C}$, and the reaction mixture was allowed to stir $(700 \mathrm{rpm})$ at this temperature for $24 \mathrm{~h}$. Over the course of the reaction, a yellow-brown solid precipitated from solution. Note: when the reaction mixture was not sparged with $\mathrm{N}_{2}$, the reaction mixture became black instead. The reaction mixture was allowed to cool to room temperature, filtered, and washed with $N, N$-dimethylformamide (200 $\mathrm{mL}$ ). The collected solid was transferred to a $500 \mathrm{~mL}$ Pyrex jar filled with $N, N$-dimethylformamide $\left(200 \mathrm{~mL}\right.$ ). The jar was allowed to stand for $24 \mathrm{~h}$ at $120{ }^{\circ} \mathrm{C}$ in an oven, at which time the $\mathrm{N}, \mathrm{N}$ dimethylformamide was decanted and replaced with fresh $N, N$-dimethylformamide $(200 \mathrm{~mL})$. This procedure was repeated two additional times for a total of three $N, N$-dimethylformamide soaks. Next, the solid was filtered and returned to the jar with fresh methanol $(200 \mathrm{~mL})$. The solid was soaked in methanol for $24 \mathrm{~h}$ at $60{ }^{\circ} \mathrm{C}$ in an oven three total times following the same procedure as described above. Complete exchange of $N, N$-dimethylformamide for methanol was confirmed by IR spectroscopy. The yellow-brown solid was filtered and transferred to a Schlenk flask. The solid was activated under flowing $\mathrm{N}_{2}$ at $180^{\circ} \mathrm{C}$ for $4 \mathrm{~h}$, followed by further activation under high vacuum ( $<100 \mathrm{mbar}$ ) at $180{ }^{\circ} \mathrm{C}$ for $24 \mathrm{~h}$. The Schlenk flask was transferred into a $\mathrm{N}_{2}$-filled glovebox, and the activated MOF-74 (Ni) was transferred into a $20 \mathrm{~mL}$ scintillation vial for long-term storage. A portion of the activated sample was transferred to a pre-tared Micromeritics sample tube equipped with a Sureseal. The tube was removed from the glovebox and the sample was further activated under high vacuum $(<10 \mu \mathrm{bar})$ at $180^{\circ} \mathrm{C}$ for $24 \mathrm{~h}$ before gas sorption measurements. 


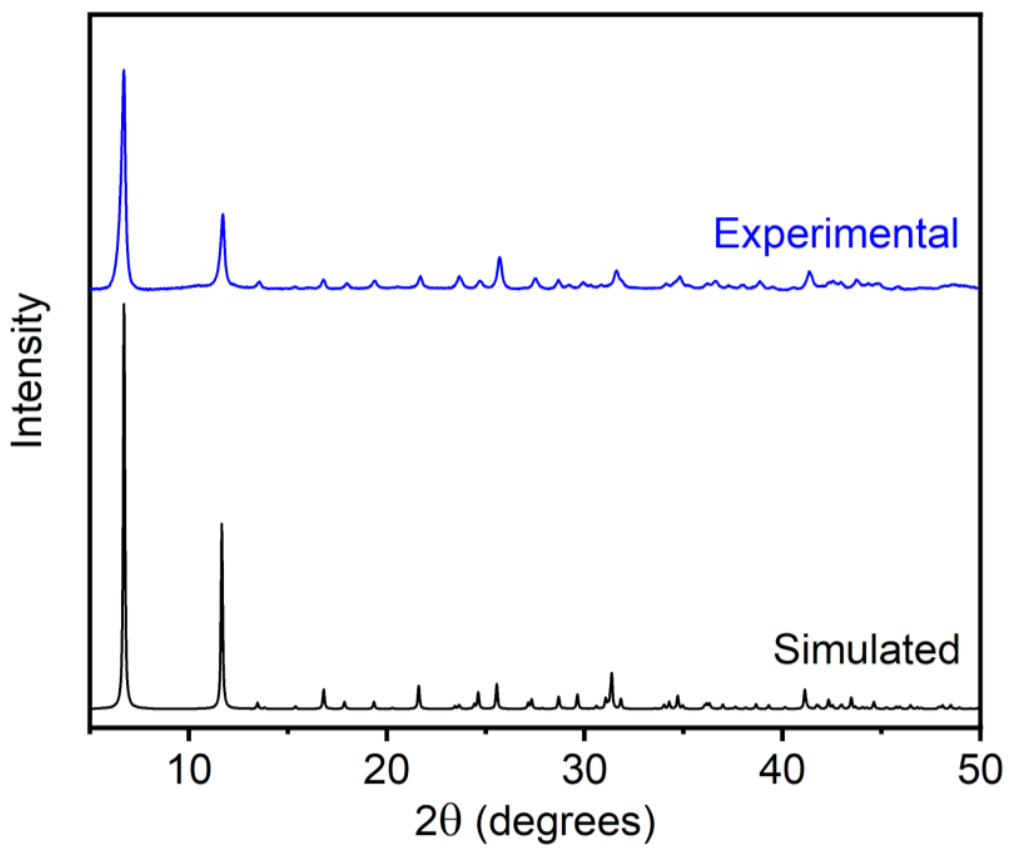

Figure S89. PXRD pattern $(\lambda=1.5406 \AA)$ of methanol-solvated MOF-74 (Ni). The simulated pattern based on the previously reported single-crystal X-ray diffraction structure of the isostructural framework $\mathrm{Zn}_{2}$ (dobdc) is included for reference. ${ }^{21}$ The PXRD pattern of MOF-74 (Ni) was baseline corrected.

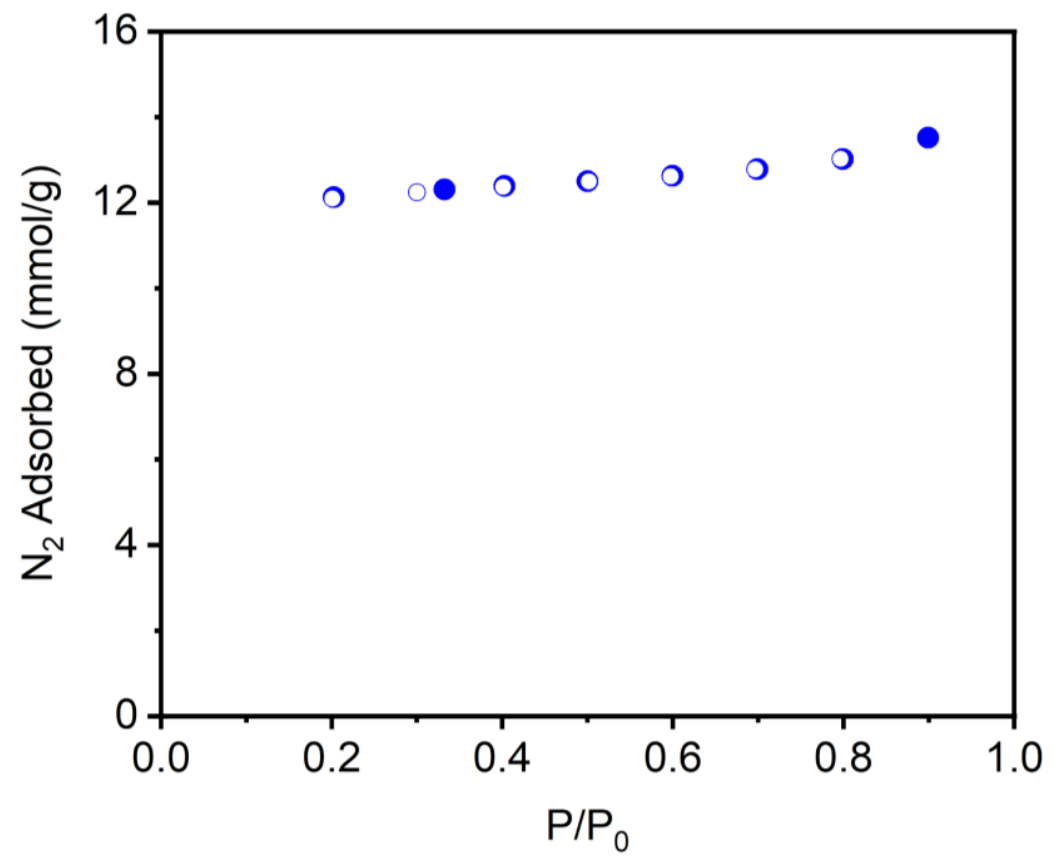

Figure S90. $77 \mathrm{~K} \mathrm{~N}_{2}$ adsorption (filled circles) and desorption (open circles) isotherm of activated MOF-74 (Ni). The Langmuir surface area determined from these data is $1406 \pm 46 \mathrm{~m}^{2} / \mathrm{g}$. 


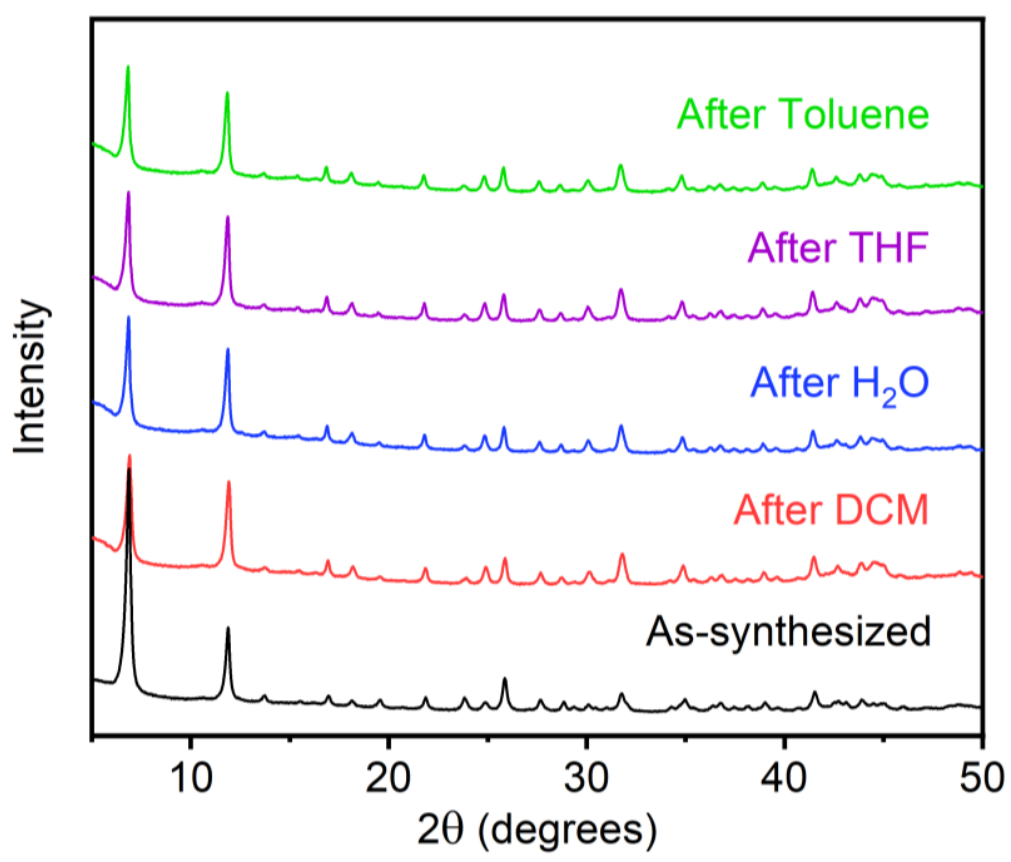

Figure S91. PXRD patterns $(\lambda=1.5406 \AA)$ of MOF-74 (Ni) upon exposure to various organic solvents and water. Note that MOF-74 (Ni) was soaked in DMF and MeOH during its synthesis as well. A reference pattern of as-synthesized MOF-74 (Ni) is included.

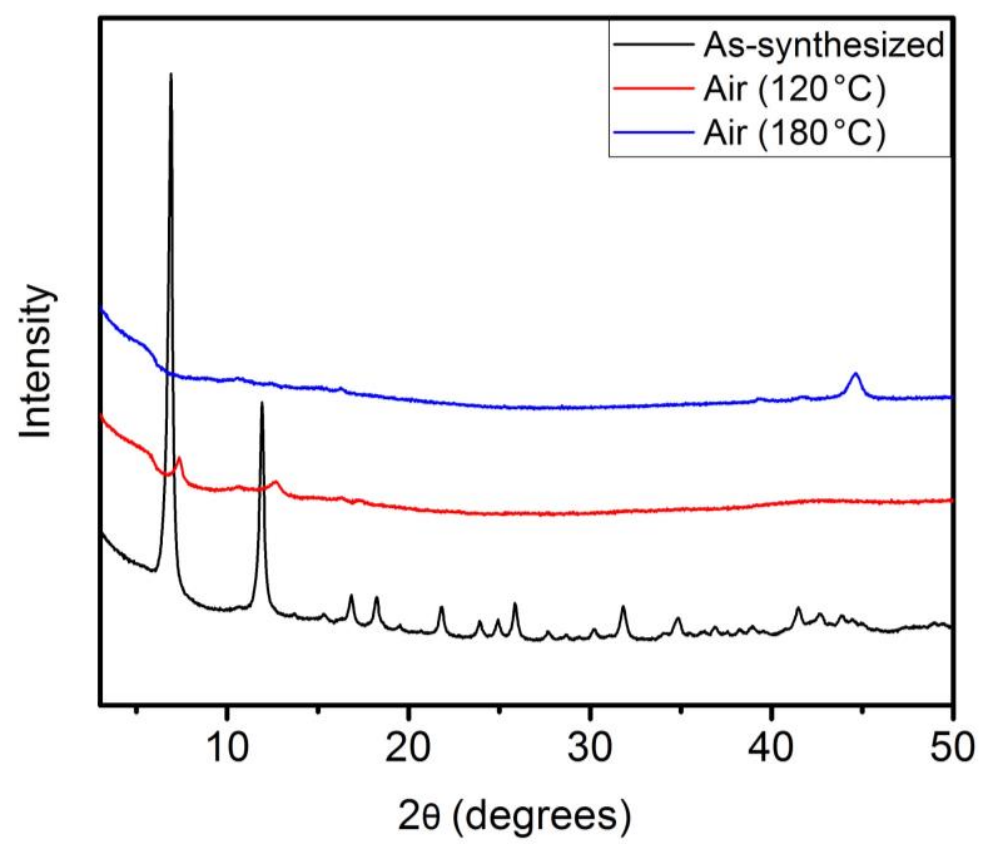

Figure S92. PXRD patterns $(\lambda=1.5406 \AA)$ of MOF-74 (Ni) upon standing at $120{ }^{\circ} \mathrm{C}$ and $180{ }^{\circ} \mathrm{C}$ in air for $24 \mathrm{~h}$. A reference pattern of as-synthesized MOF-74 (Ni) is included. The small reflection remaining at $\sim 45$ degrees after heating in air at $180{ }^{\circ} \mathrm{C}$ is likely due to the formation of $\mathrm{Ni}$ nanoparticles. $^{23}$ 


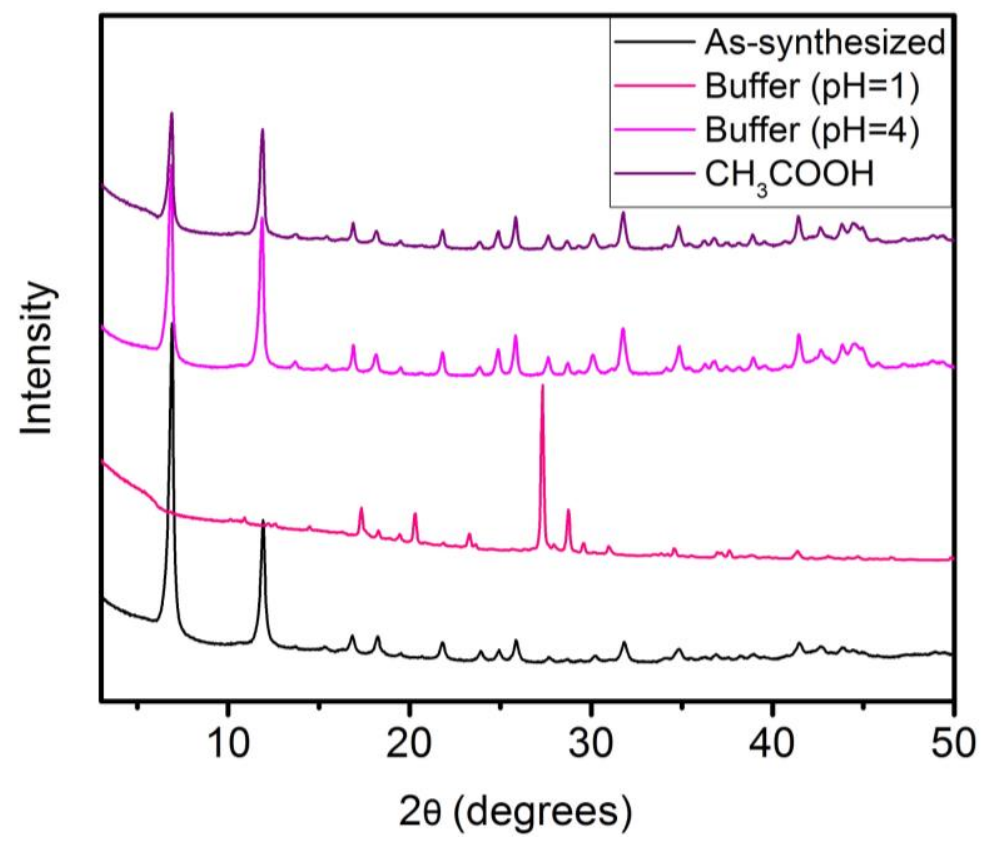

Figure S93. PXRD patterns $(\lambda=1.5406 \AA)$ of MOF-74 (Ni) upon exposure to acids. Exposure tests include aqueous solutions buffered at $\mathrm{pH} 1$ and $\mathrm{pH} 4$ and glacial acetic acid. A reference pattern of as-synthesized MOF-74 (Ni) is included.

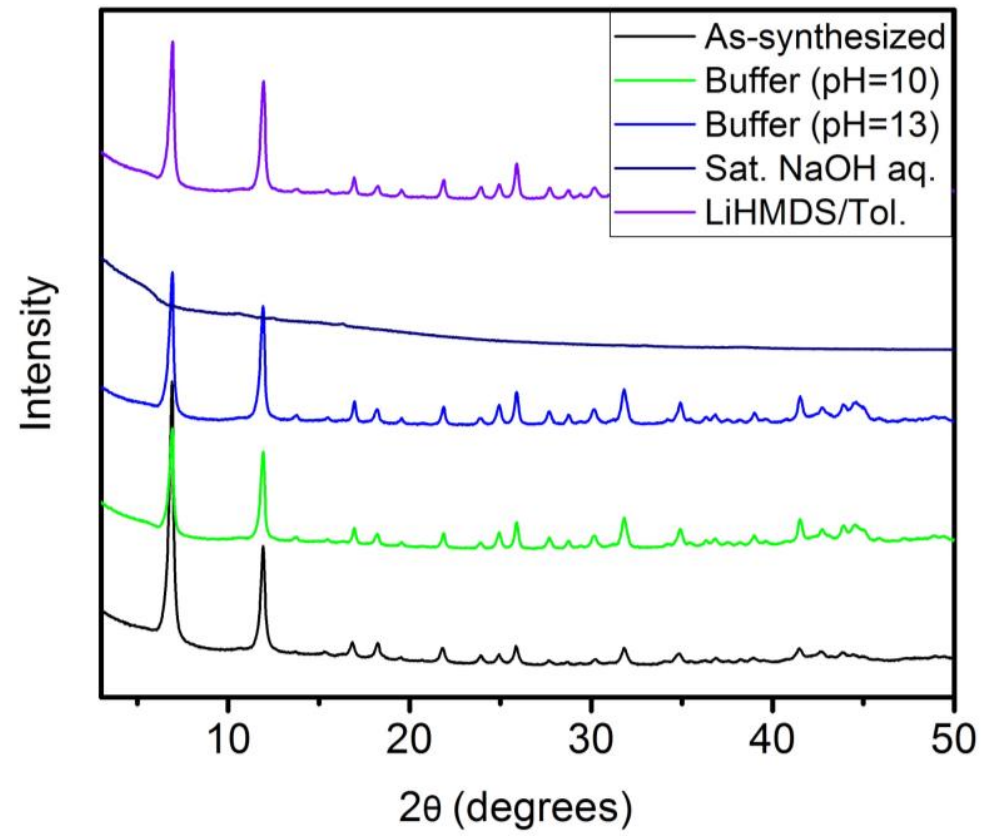

Figure S94. PXRD patterns $(\lambda=1.5406 \AA)$ of MOF-74 (Ni) upon exposure to bases. Exposure tests include aqueous solutions buffered at $\mathrm{pH} 10$ and $\mathrm{pH} 13$, saturated aqueous $\mathrm{NaOH}$, and $1.0 \mathrm{M}$ lithium hexamethyldisilazide (LiHMDS) in toluene. Note that the aqueous $\mathrm{pH} 10$ buffer used for this test was prepared by combining $100 \mathrm{ml}$ of aqueous $0.05 \mathrm{M} \mathrm{NaHCO}_{3}$ and $21.4 \mathrm{ml}$ of aqueous $0.1 \mathrm{M} \mathrm{NaOH}$. A reference pattern of as-synthesized MOF-74 (Ni) is included. 


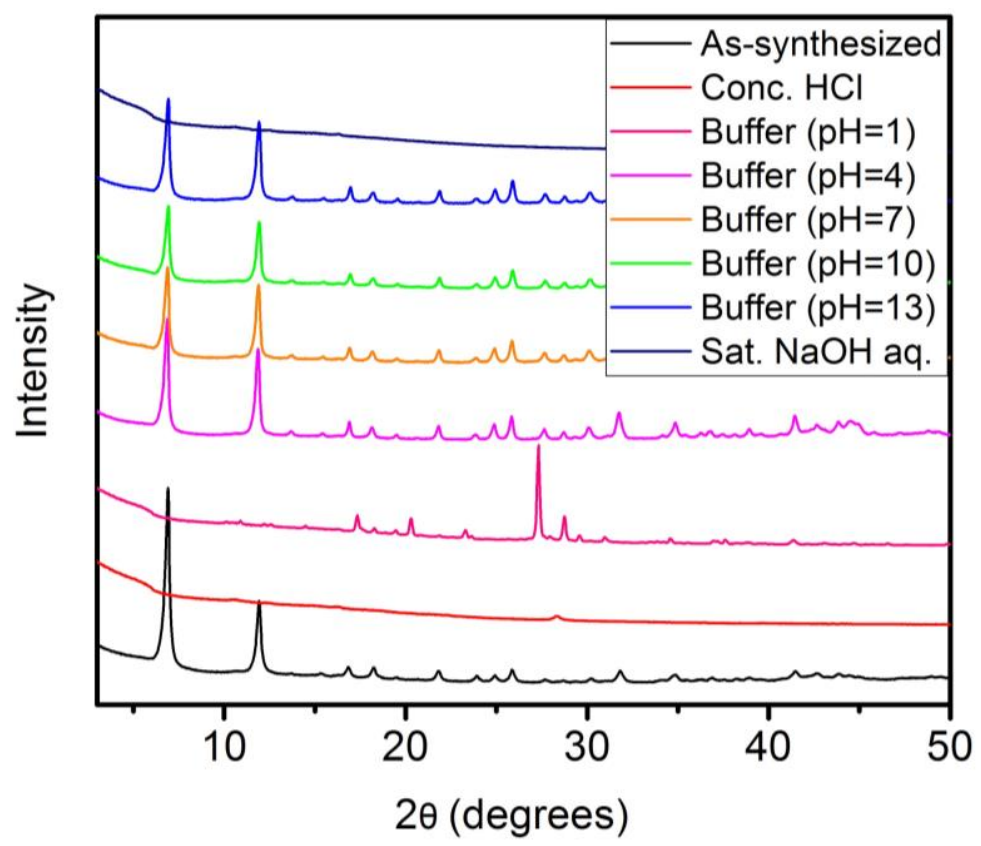

Figure S95. Summary of the PXRD patterns $(\lambda=1.5406 \AA)$ of MOF-74 (Ni) upon exposure to various aqueous conditions. Note that the aqueous $\mathrm{pH} 10$ buffer used for this test was prepared by combining $100 \mathrm{ml}$ of aqueous $0.05 \mathrm{M} \mathrm{NaHCO}_{3}$ and $21.4 \mathrm{ml}$ of aqueous $0.1 \mathrm{M} \mathrm{NaOH}$. A reference pattern of as-synthesized MOF-74 (Ni) is included.

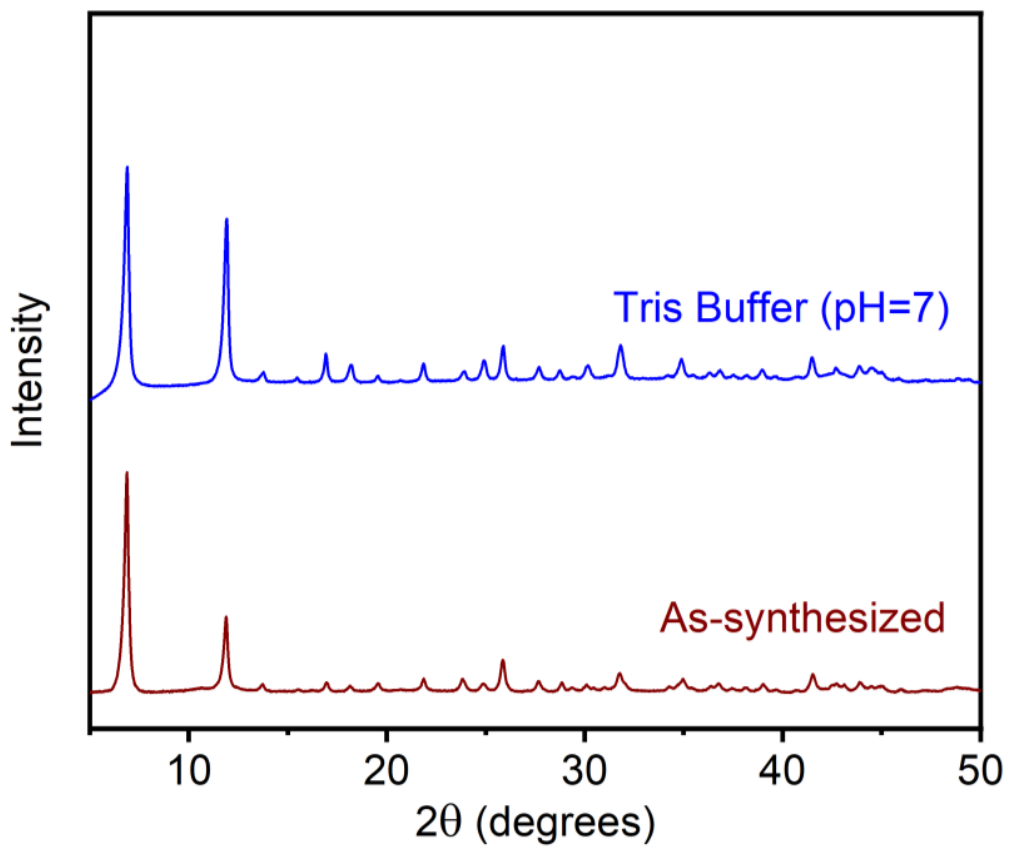

Figure S96. PXRD patterns for MOF-74 (Ni) before and after exposure to aqueous tris buffer $(\mathrm{pH}=7)$. The initial FWHM for the peak at $2 \theta=7^{\circ}$ was $0.29697^{\circ}$, and the FWHM after exposure to buffer was $0.31332^{\circ}$, resulting in a $6 \%$ change in FWHM after the exposure test. 


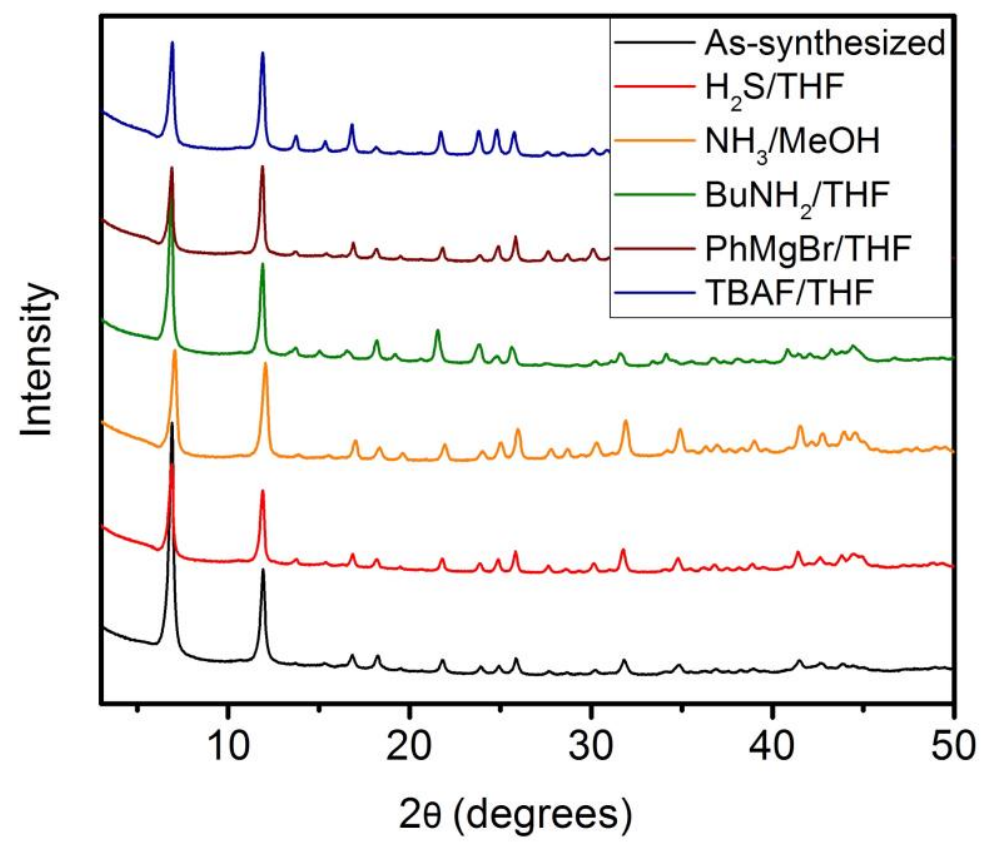

Figure S97. PXRD patterns $(\lambda=1.5406 \AA)$ of MOF-74 (Ni) upon exposure to nucleophiles. Exposure tests include $0.8 \mathrm{M}$ hydrogen sulfide in tetrahydrofuran, $1.0 \mathrm{M}$ ammonia in methanol, 1.0 $\mathrm{M} \mathrm{n}$-butylamine in tetrahydrofuran, $1.0 \mathrm{M} \mathrm{PhMgBr}$ in tetrahydrofuran, and $1.0 \mathrm{M}$ tetrabutylammonium fluoride (TBAF) in tetrahydrofuran. A reference pattern of as-synthesized MOF-74 (Ni) is included.

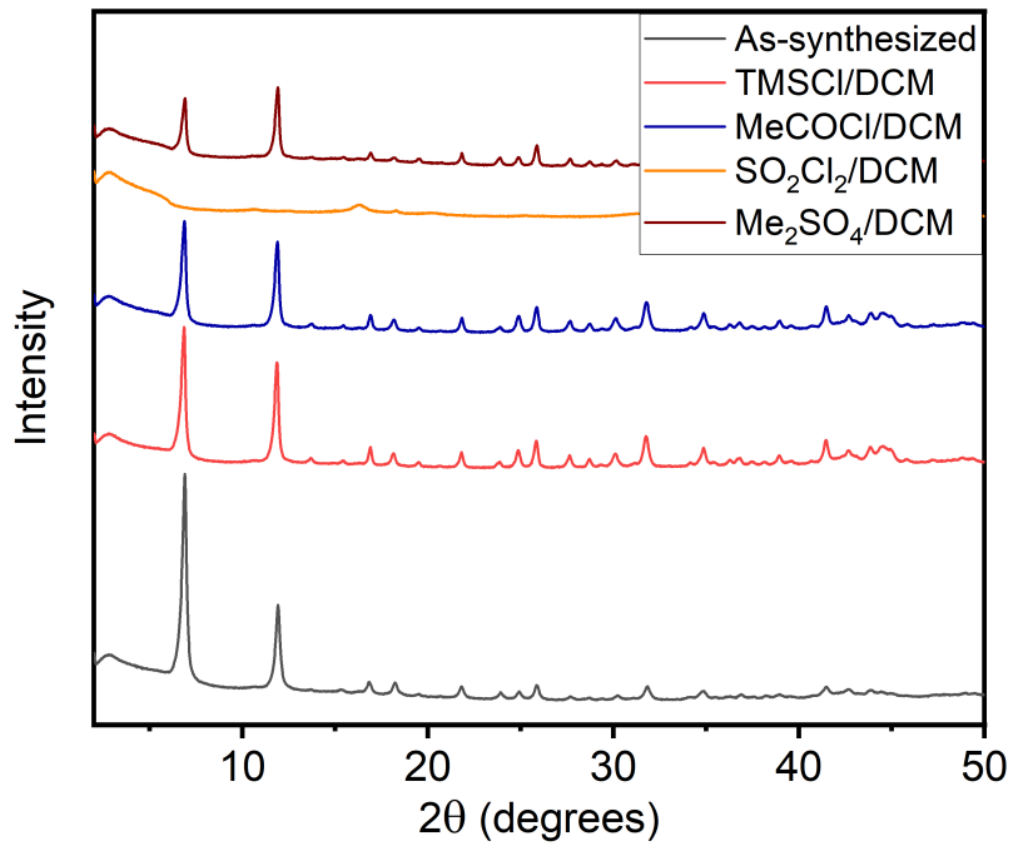

Figure S98. PXRD patterns $(\lambda=1.5406 \AA)$ of MOF-74 (Ni) upon exposure to electrophiles. Exposure tests include $1.0 \mathrm{M}$ chlorotrimethylsilane (TMSCl) in dichloromethane, $1.0 \mathrm{M}$ acetyl chloride in dichloromethane, $1.0 \mathrm{M}$ sulfuryl chloride in dichloromethane, and saturated dimethyl sulfate in dichloromethane. A reference pattern of as-synthesized MOF-74 (Ni) is included. 


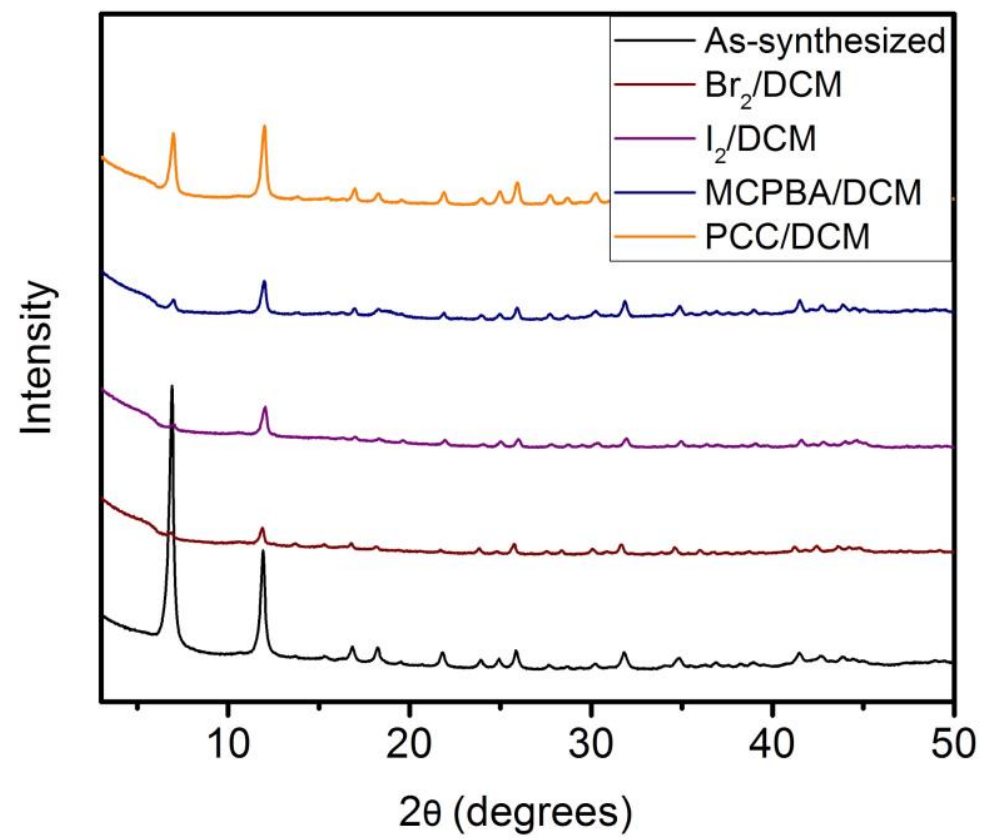

Figure S99. PXRD patterns ( $\lambda=1.5406 \AA$ ) of MOF-74 (Ni) upon exposure to oxidants. Exposure tests include $1.0 \mathrm{M}$ bromine in dichloromethane, saturated iodine in dichloromethane, saturated $m$-chloroperoxybenzoic acid (MCPBA) in dichloromethane, and saturated pyridinium chlorochromate (PCC) in dichloromethane. A reference pattern of as-synthesized MOF-74 (Ni) is included.

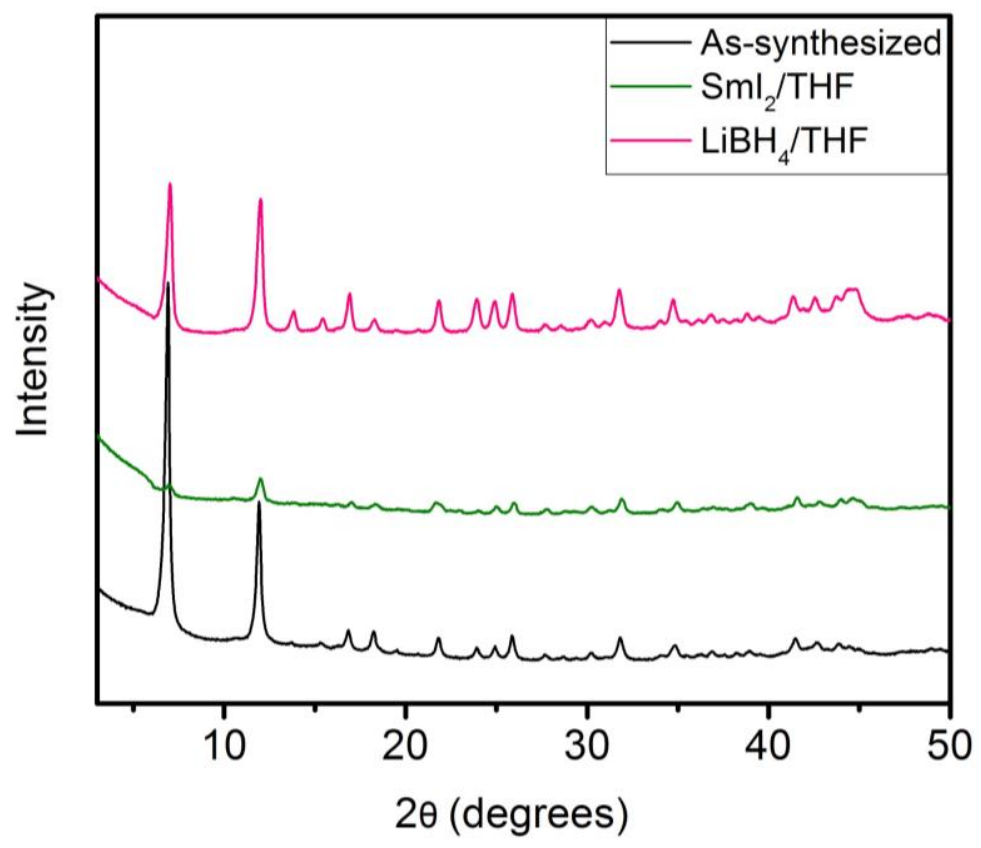

Figure S100. PXRD patterns $(\lambda=1.5406 \AA)$ of MOF-74 (Ni) upon exposure to reductants. Exposure tests include $0.1 \mathrm{M}$ samarium iodide in tetrahydrofuran and $1.0 \mathrm{M}$ lithium borohydride in tetrahydrofuran. A reference pattern of as-synthesized MOF-74 (Ni) is included. 
Table S8. Summary of changes in the full width at half maximum (FWHM) for the $2 \theta=7^{\circ}(\lambda=$ $1.5406 \AA$ ) reflection of MOF-74 (Ni) under a range of conditions.

\begin{tabular}{|c|c|c|c|c|c|}
\hline Condition & \multicolumn{2}{|c|}{ Result } & Condition & \multicolumn{2}{|c|}{ Result } \\
\hline \multirow{2}{*}{ Initial } & FWHM & 0.30437 & \multirow{2}{*}{ DI water } & FWHM & 0.2638 \\
\hline & $\%$ Change & - & & $\%$ Change & 13 \\
\hline \multirow{2}{*}{$120^{\circ} \mathrm{C}$ Air } & FWHM & 0.52215 & \multirow{2}{*}{$\mathrm{BuNH}_{2} / \mathrm{THF}$} & FWHM & 0.26518 \\
\hline & $\%$ Change & 72 & & $\%$ Change & -13 \\
\hline \multirow{2}{*}{$180^{\circ} \mathrm{C}$ Air } & FWHM & 0 & \multirow{2}{*}{$\mathrm{PhMgBr} / \mathrm{THF}$} & FWHM & 0.24452 \\
\hline & $\%$ Change & $x$ & & $\%$ Change & -20 \\
\hline \multirow{2}{*}{ Conc. $\mathrm{HCl}$} & FWHM & 0 & \multirow{2}{*}{ TBAF/THF } & FWHM & 0.28219 \\
\hline & $\%$ Change & $x$ & & $\%$ Change & -8 \\
\hline \multirow{2}{*}{$\mathrm{pH}=1$ Buffer } & FWHM & 0 & \multirow{2}{*}{$\mathrm{Me}_{3} \mathrm{SiCl} / \mathrm{CH}_{2} \mathrm{Cl}_{2}$} & FWHM & 0.28024 \\
\hline & $\%$ Change & $x$ & & $\%$ Change & -8 \\
\hline \multirow{2}{*}{$\mathrm{pH}=4$ Buffer } & FWHM & 0.28813 & \multirow{2}{*}{$\mathrm{MeCOCl} / \mathrm{CH}_{2} \mathrm{Cl}_{2}$} & FWHM & 0.30194 \\
\hline & $\%$ Change & -6 & & $\%$ Change & -1 \\
\hline \multirow{2}{*}{$\mathrm{pH}=7$ Buffer $^{a}$} & FWHM & 0.28931 & \multirow{2}{*}{$\mathrm{SO}_{2} \mathrm{Cl}_{2} / \mathrm{CH}_{2} \mathrm{Cl}_{2}$} & FWHM & 0 \\
\hline & $\%$ Change & -5 & & $\%$ Change & $x$ \\
\hline \multirow{2}{*}{$\mathrm{pH}=10$ Buffer } & FWHM & 0.27449 & \multirow{2}{*}{$\mathrm{Me}_{2} \mathrm{SO}_{4} / \mathrm{CH}_{2} \mathrm{Cl}_{2}$} & FWHM & 0.2515 \\
\hline & $\%$ Change & -10 & & $\%$ Change & -17 \\
\hline \multirow{2}{*}{$\mathrm{pH}=13$ Buffer } & FWHM & 0.28467 & \multirow{2}{*}{$\mathrm{Br}_{2} / \mathrm{CH}_{2} \mathrm{Cl}_{2}$} & FWHM & 0.4315 \\
\hline & $\%$ Change & -7 & & $\%$ Change & 42 \\
\hline \multirow{2}{*}{ Sat. $\mathrm{NaOH}$} & FWHM & 0 & \multirow{2}{*}{$\mathrm{I}_{2} / \mathrm{CH}_{2} \mathrm{Cl}_{2}$} & FWHM & 0.26967 \\
\hline & $\%$ Change & $x$ & & $\%$ Change & -12 \\
\hline \multirow{2}{*}{$\mathrm{CH}_{3} \mathrm{COOH}$} & FWHM & 0.26308 & \multirow{2}{*}{$\mathrm{MCPBA} / \mathrm{CH}_{2} \mathrm{Cl}_{2}$} & FWHM & 0.35575 \\
\hline & $\%$ Change & -14 & & $\%$ Change & 17 \\
\hline \multirow{2}{*}{ LiHMDS/Tol } & FWHM & 0.28459 & \multirow{2}{*}{$\mathrm{PCC} / \mathrm{CH}_{2} \mathrm{Cl}_{2}$} & FWHM & 0.29023 \\
\hline & $\%$ Change & -7 & & $\%$ Change & -5 \\
\hline \multirow{2}{*}{$\mathrm{H}_{2} \mathrm{~S} / \mathrm{THF}$} & FWHM & 0.26936 & \multirow{2}{*}{$\mathrm{SmI}_{2} / \mathrm{THF}$} & FWHM & 0.6522 \\
\hline & $\%$ Change & -12 & & $\%$ Change & 115 \\
\hline \multirow{2}{*}{$\mathrm{NH}_{3} / \mathrm{MeOH}$} & FWHM & 0.32328 & \multirow{2}{*}{$\mathrm{LiBH}_{4} / \mathrm{THF}$} & FWHM & 0.33017 \\
\hline & $\%$ Change & 7 & & $\%$ Change & 9 \\
\hline
\end{tabular}

${ }^{a} 6 \%$ reduction in FWHM was observed using aqueous tris buffer $(\mathrm{pH}=7)$. 


\section{Synthesis, characterization, and stability assessment of $\mathrm{Ni}_{2}(m$-dobdc).}

Synthesis of $\mathrm{Ni}_{2}\left(\boldsymbol{m}\right.$-dobdc). This procedure is adapted from the literature. ${ }^{24}$ A $350 \mathrm{~mL}$ screw-cap high-pressure reaction flask equipped with a stir bar was charged with $\mathrm{NiCl}_{2}(1.17 \mathrm{~g}$, $9.00 \mathrm{mmol}, 2.50$ equiv.), 4,6-dihydoxy-1,3-benzenedicarboxylic acid (720 mg, $3.60 \mathrm{mmol}, 1.00$ eq.), $N, N$-dimethylformamide $(156 \mathrm{~mL})$, and methanol $(84 \mathrm{~mL})$. The reaction flask was sealed and transferred to a silicone oil bath. The oil bath was heated to $120^{\circ} \mathrm{C}$, and the reaction mixture was allowed to stir gently $(300 \mathrm{rpm})$ at this temperature for $24 \mathrm{~h}$. Over the course of the reaction, a bright green solid precipitated from solution. The reaction mixture was allowed to cool to room temperature, filtered, and washed with $N, N$-dimethylformamide $(200 \mathrm{~mL})$. The collected solid was transferred to a $500 \mathrm{~mL}$ Pyrex jar filled with $N, N$-dimethylformamide $(200 \mathrm{~mL})$. The jar was allowed to stand for $24 \mathrm{~h}$ at $120^{\circ} \mathrm{C}$ in an oven, at which time the $N, N$-dimethylformamide was decanted and replaced with fresh $N, N$-dimethylformamide $(200 \mathrm{~mL})$. This procedure was repeated two additional times for a total of three $N, N$-dimethylformamide soaks. Next, the solid was filtered and returned to the jar with fresh methanol $(200 \mathrm{~mL})$. The solid was soaked in methanol for $24 \mathrm{~h}$ at $60{ }^{\circ} \mathrm{C}$ in an oven three total times following the same procedure as described above. Complete exchange of $N, N$-dimethylformamide for methanol was confirmed by IR spectroscopy. The bright green solid was filtered and transferred to a Schlenk flask. The solid was activated under flowing $\mathrm{N}_{2}$ at $180{ }^{\circ} \mathrm{C}$ for $4 \mathrm{~h}$, followed by further activation under high vacuum (<100 mbar) at $180{ }^{\circ} \mathrm{C}$ for $24 \mathrm{~h}$. During the activation procedure, the material changed in color from bright green to brown. The Schlenk flask was transferred into a $\mathrm{N}_{2}$-filled glovebox, and the activated $\mathrm{Ni}_{2}(m$-dobdc) was transferred into a $20 \mathrm{~mL}$ scintillation vial for long-term storage. A portion of the activated sample was transferred to a pre-tared Micromeritics sample tube equipped with a Sureseal. The tube was removed from the glovebox and the sample was further activated under high vacuum $(<10 \mu$ bar $)$ at $180{ }^{\circ} \mathrm{C}$ for $24 \mathrm{~h}$ before gas sorption measurements. 


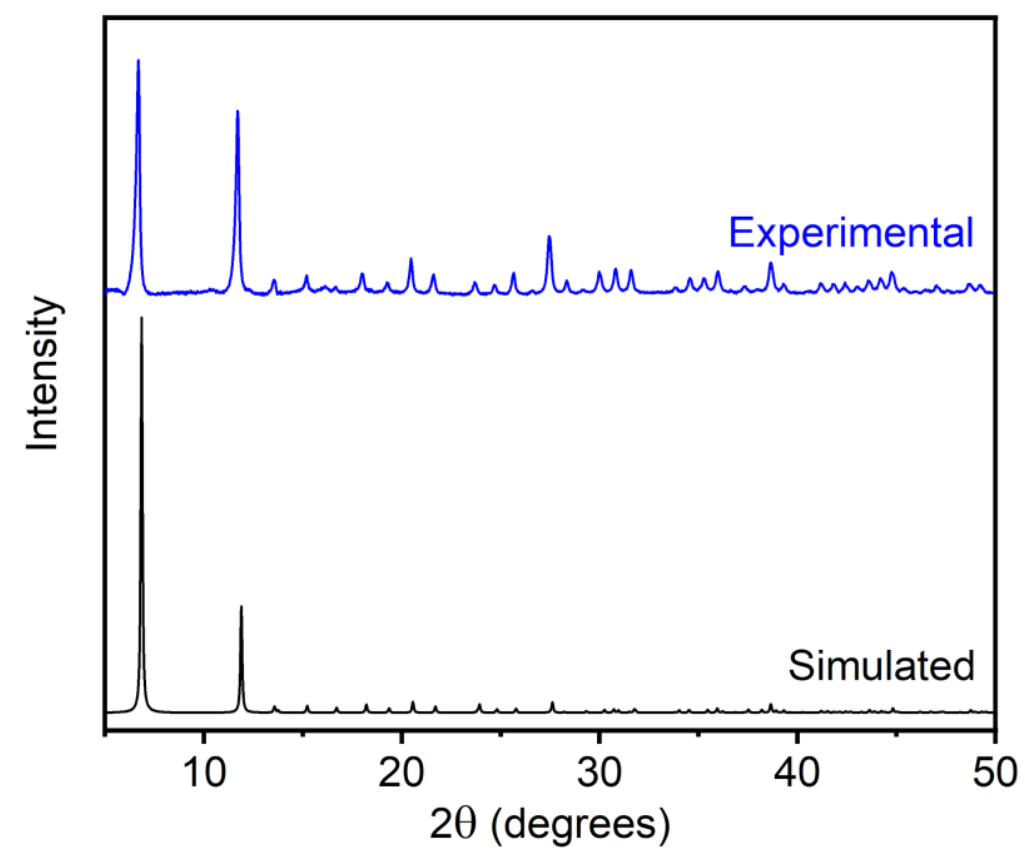

Figure S101. PXRD pattern $(\lambda=1.5406 \AA)$ of methanol-solvated $\mathrm{Ni}_{2}(m$-dobdc). The simulated pattern based on the previously reported single-crystal X-ray diffraction structure of the isostructural framework $\mathrm{Co}_{2}\left(m\right.$-dobdc) is included for reference. ${ }^{25}$ The PXRD pattern of $\mathrm{Ni}_{2}(m-$ dobdc) was baseline corrected.

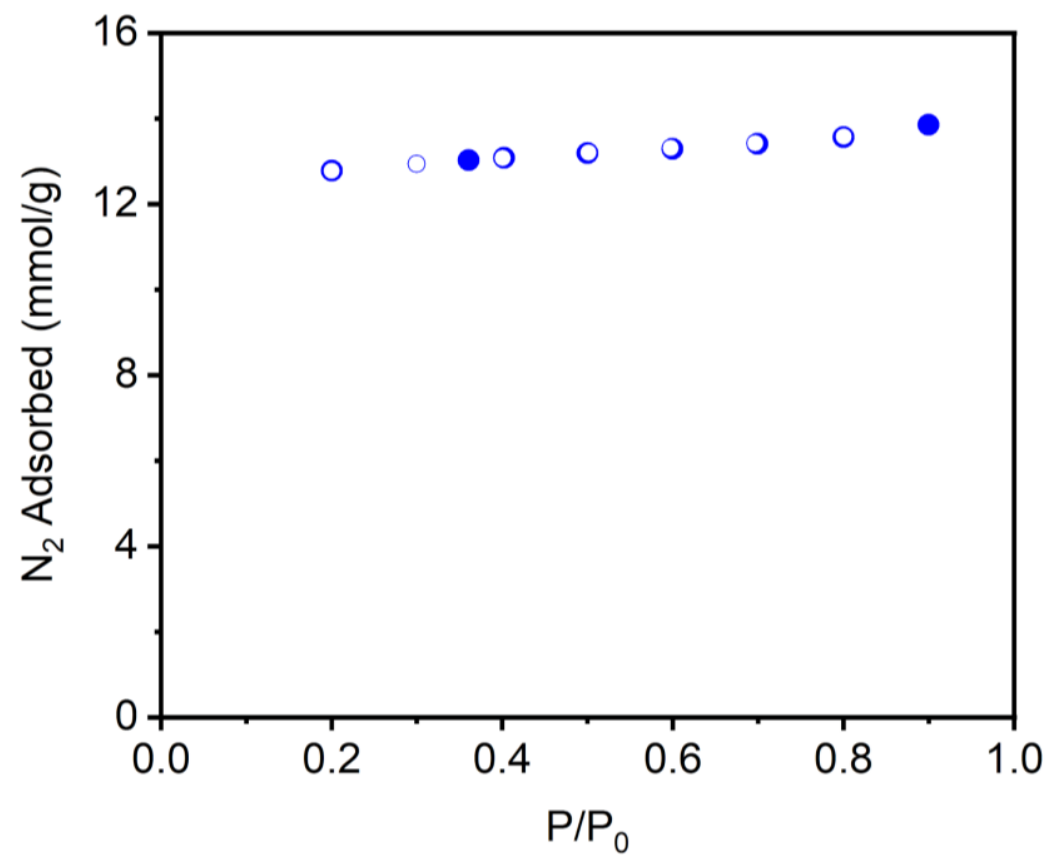

Figure S102. $77 \mathrm{~K} \mathrm{~N}_{2}$ adsorption (filled circles) and desorption (open circles) isotherm of activated $\mathrm{Ni}_{2}(m$-dobdc $)$. The Langmuir surface area determined from these data is $1305 \pm 3 \mathrm{~m}^{2} / \mathrm{g}$. 


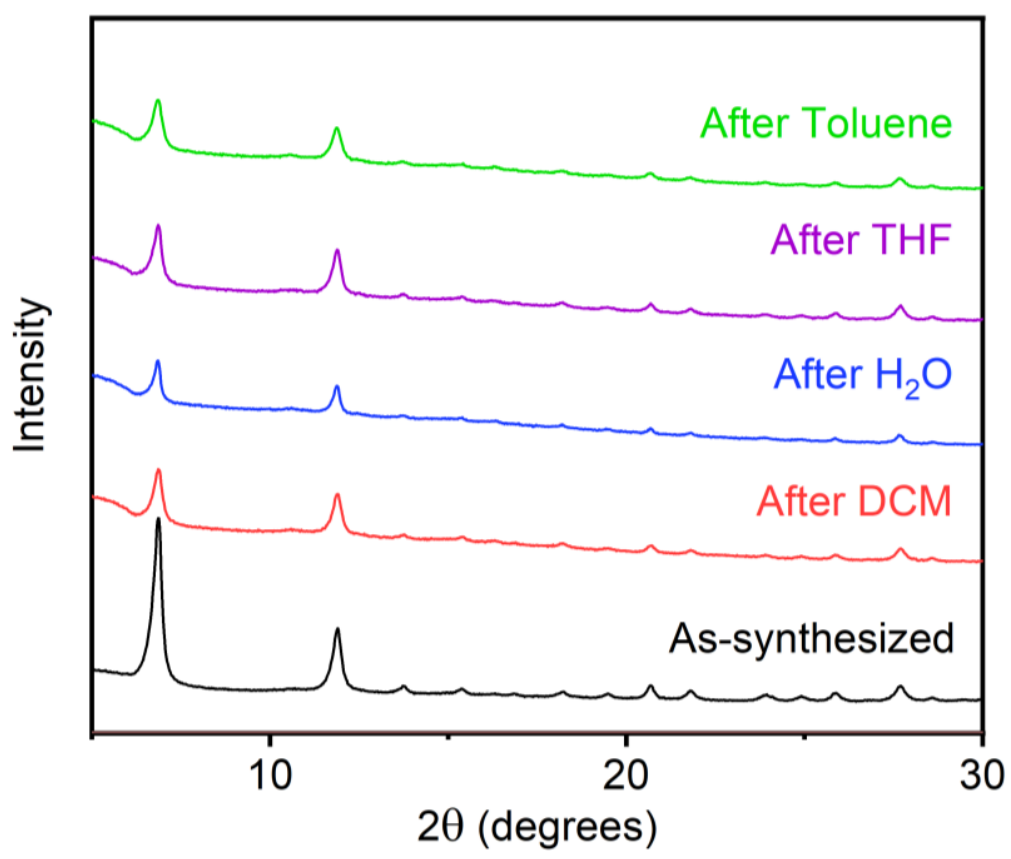

Figure S103. PXRD patterns $(\lambda=1.5406 \AA)$ of $\mathrm{Ni}_{2}(m$-dobdc) upon exposure to various organic solvents and water. Note that $\mathrm{Ni}_{2}(m$-dobdc) was soaked in $\mathrm{DMF}$ and $\mathrm{MeOH}$ during its synthesis as well. A reference pattern of as-synthesized $\mathrm{Ni}_{2}(m$-dobdc $)$ is included.

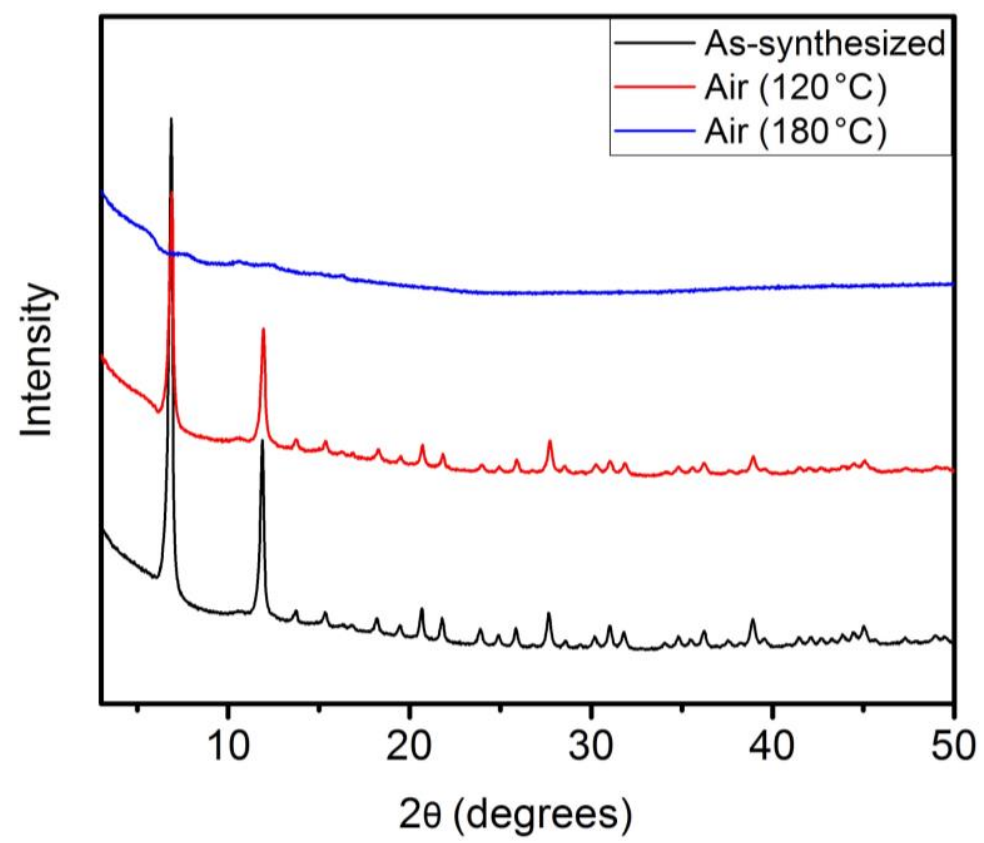

Figure S104. PXRD patterns $(\lambda=1.5406 \AA)$ of $\mathrm{Ni}_{2}$ ( $m$-dobdc) upon standing at $120^{\circ} \mathrm{C}$ and $180{ }^{\circ} \mathrm{C}$ in air for $24 \mathrm{~h}$. A reference pattern of as-synthesized $\mathrm{Ni}_{2}(m$-dobdc) is included. 


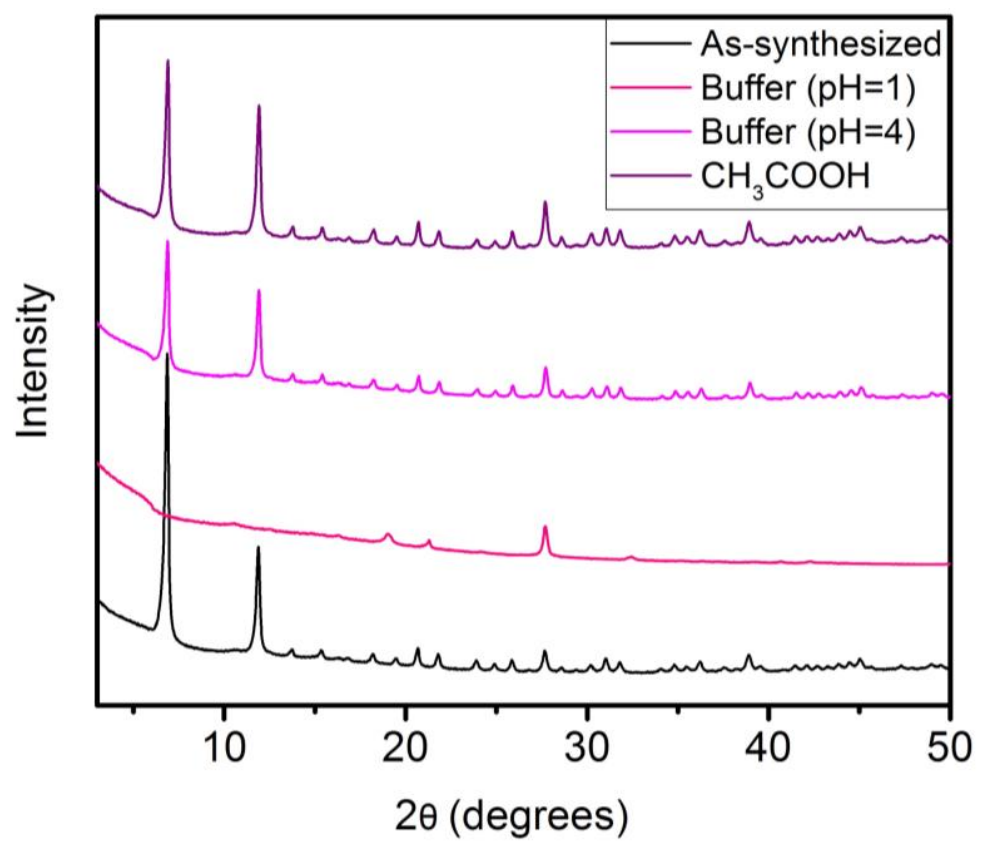

Figure S105. PXRD patterns $(\lambda=1.5406 \AA)$ of $\mathrm{Ni}_{2}(m$-dobdc) upon exposure to acids. Exposure tests include aqueous solutions buffered at $\mathrm{pH} 1$ and $\mathrm{pH} 4$ and glacial acetic acid. A reference pattern of as-synthesized $\mathrm{Ni}_{2}(m$-dobdc) is included.

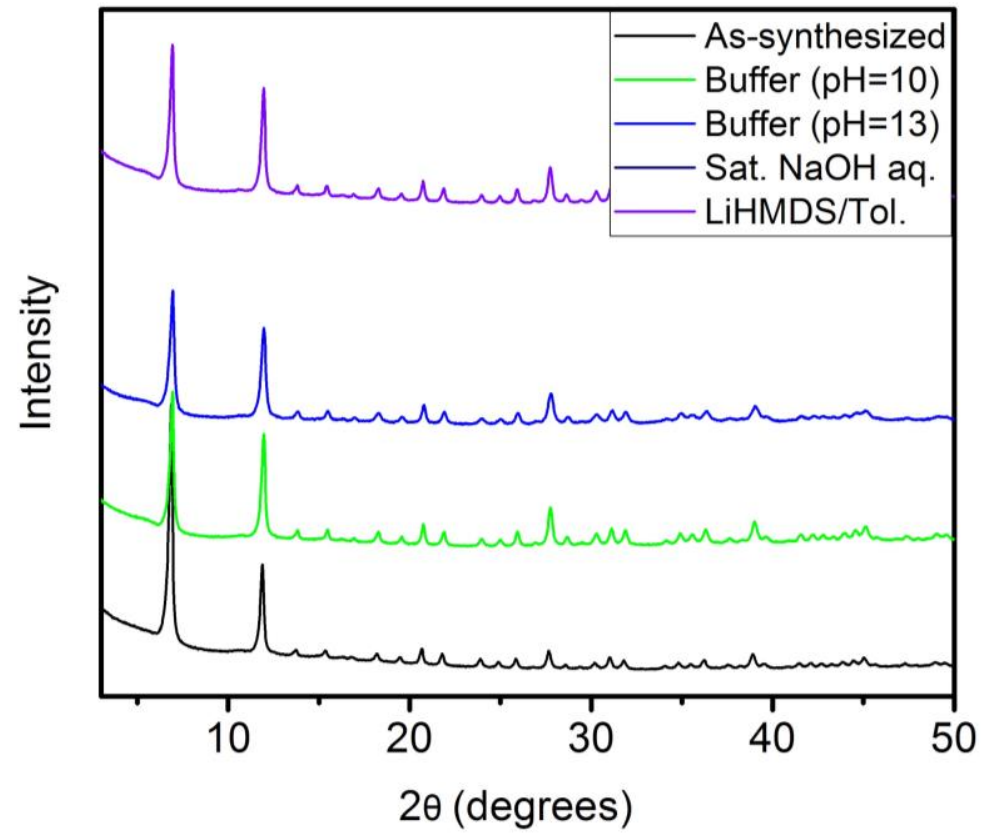

Figure S106. PXRD patterns $(\lambda=1.5406 \AA)$ of $\mathrm{Ni}_{2}(m$-dobdc) upon exposure to bases. Exposure tests include aqueous solutions buffered at $\mathrm{pH} 10$ and $\mathrm{pH} 13$, saturated aqueous $\mathrm{NaOH}$, and $1.0 \mathrm{M}$ lithium hexamethyldisilazide (LiHMDS) in toluene. No solid remained after exposure of $\mathrm{Ni}_{2}(\mathrm{~m}$ dobdc) to the saturated $\mathrm{NaOH}$ solution. Note that the aqueous $\mathrm{pH} 10$ buffer used for this test was prepared by combining $100 \mathrm{ml}$ of aqueous $0.05 \mathrm{M} \mathrm{NaHCO}_{3}$ and $21.4 \mathrm{ml}$ of aqueous $0.1 \mathrm{M} \mathrm{NaOH}$. A reference pattern of as-synthesized $\mathrm{Ni}_{2}(m$-dobdc $)$ is included. 


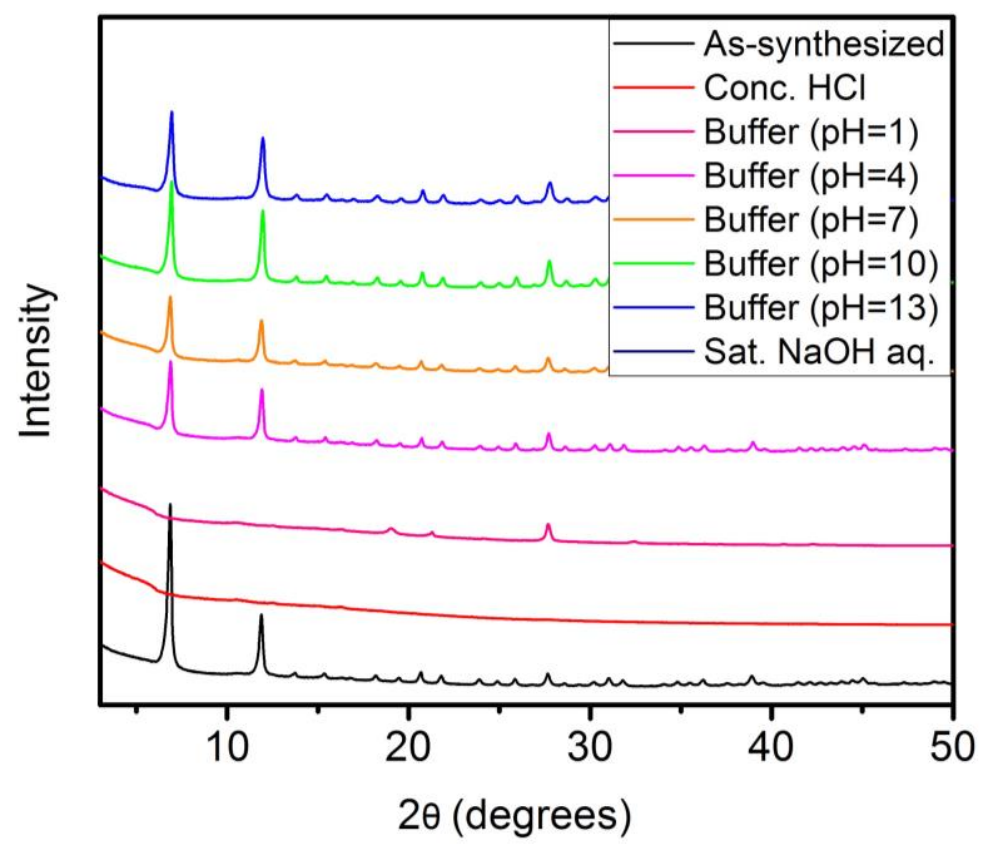

Figure S107. Summary of the PXRD patterns $(\lambda=1.5406 \AA)$ of $\mathrm{Ni}_{2}(m$-dobdc) upon exposure to various aqueous conditions. No solid remained after exposure of $\mathrm{Ni}_{2}(m$-dobdc) to the saturated $\mathrm{NaOH}$ solution. Note that the aqueous $\mathrm{pH} 10$ buffer used for this test was prepared by combining $100 \mathrm{ml}$ of aqueous $0.05 \mathrm{M} \mathrm{NaHCO}_{3}$ and $21.4 \mathrm{ml}$ of aqueous $0.1 \mathrm{M} \mathrm{NaOH}$. A reference pattern of as-synthesized $\mathrm{Ni}_{2}(m$-dobdc) is included.

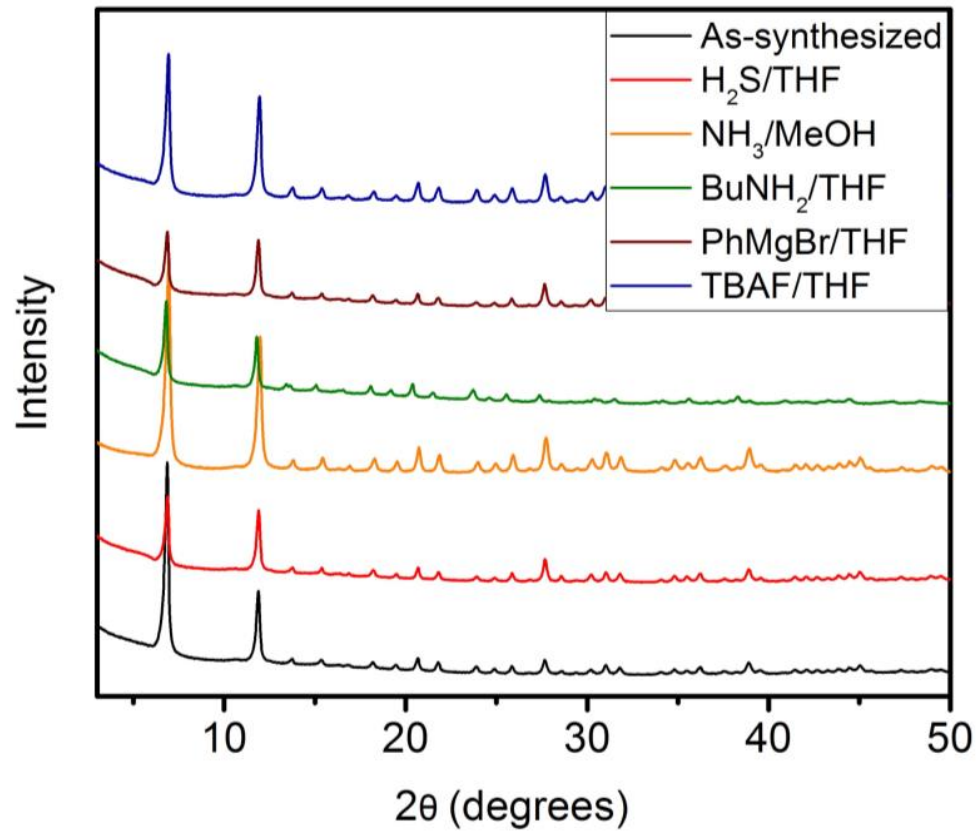

Figure S108. PXRD patterns $(\lambda=1.5406 \AA)$ of $\mathrm{Ni}_{2}$ ( $m$-dobdc) upon exposure to nucleophiles. Exposure tests include $0.8 \mathrm{M}$ hydrogen sulfide in tetrahydrofuran, $1.0 \mathrm{M}$ ammonia in methanol, 1.0 $\mathrm{M} \mathrm{n}$-butylamine in tetrahydrofuran, $1.0 \mathrm{M} \mathrm{PhMgBr}$ in tetrahydrofuran, and $1.0 \mathrm{M}$ tetrabutylammonium fluoride (TBAF) in tetrahydrofuran. A reference pattern of as-synthesized $\mathrm{Ni}_{2}(m$-dobdc $)$ is included. 


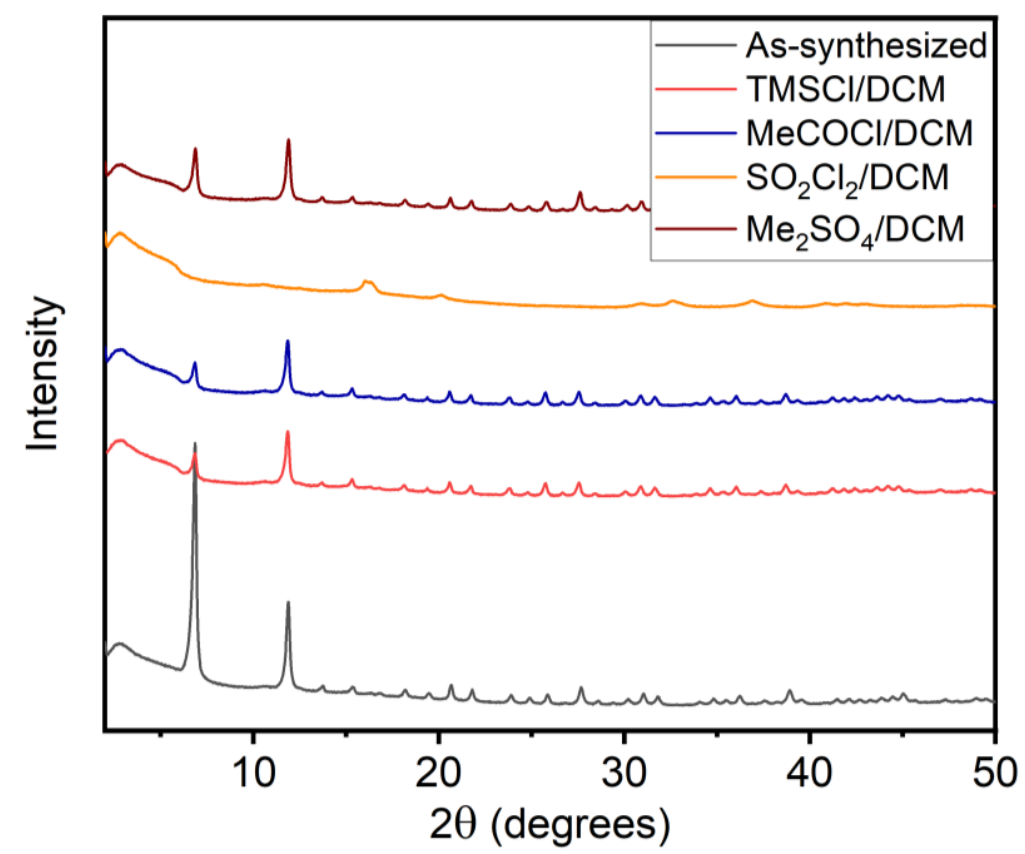

Figure S109. PXRD patterns $(\lambda=1.5406 \AA)$ of $\mathrm{Ni}_{2}(m$-dobdc) upon exposure to electrophiles. Exposure tests include $1.0 \mathrm{M}$ chlorotrimethylsilane (TMSCl) in dichloromethane, $1.0 \mathrm{M}$ acetyl chloride in dichloromethane, $1.0 \mathrm{M}$ sulfuryl chloride in dichloromethane, and saturated dimethyl sulfate in dichloromethane. A reference pattern of as-synthesized $\mathrm{Ni}_{2}(m$-dobdc) is included.

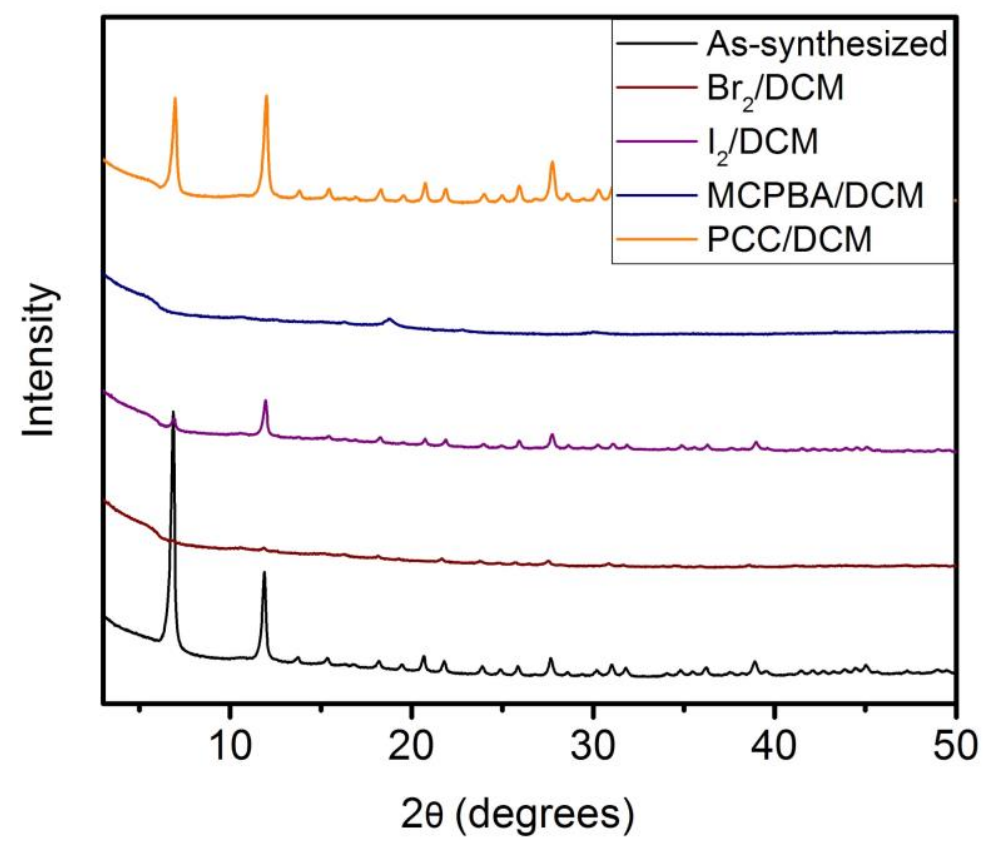

Figure S110. PXRD patterns $(\lambda=1.5406 \AA)$ of $\mathrm{Ni}_{2}(m$-dobdc) upon exposure to oxidants. Exposure tests include $1.0 \mathrm{M}$ bromine in dichloromethane, saturated iodine in dichloromethane, saturated $m$-chloroperoxybenzoic acid (MCPBA) in dichloromethane, and saturated pyridinium chlorochromate (PCC) in dichloromethane. A reference pattern of as-synthesized $\mathrm{Ni}_{2}(m$-dobdc) is included. 


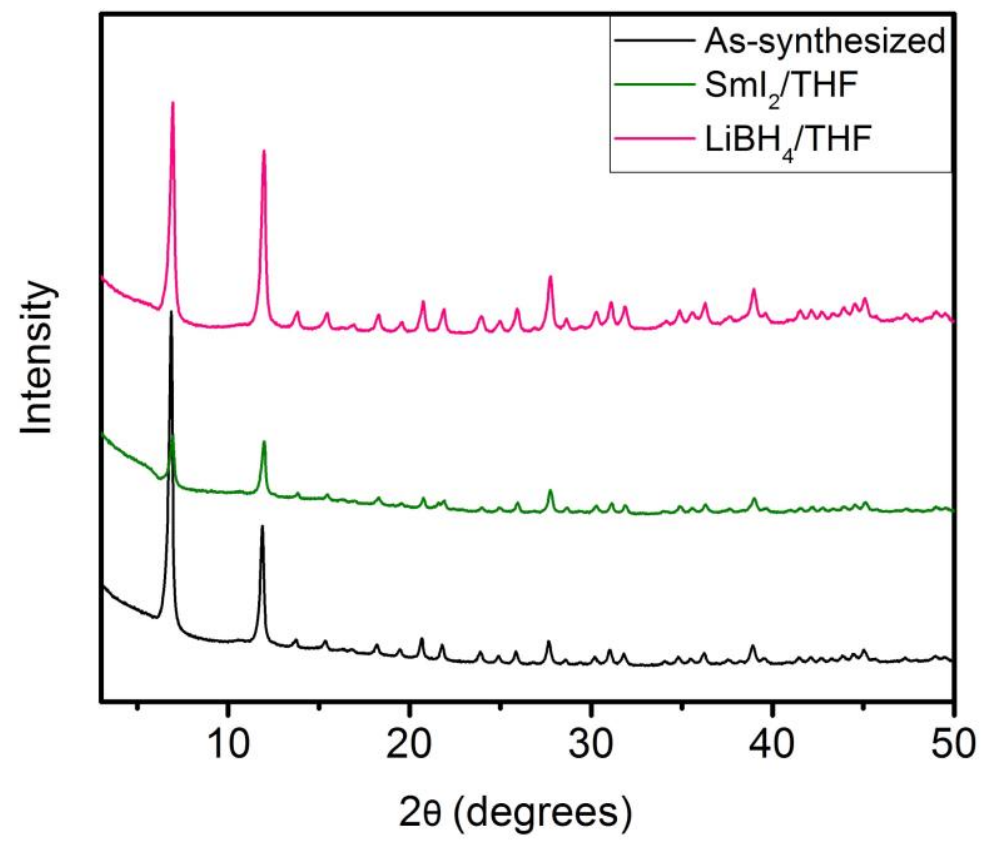

Figure S111. PXRD patterns $(\lambda=1.5406 \AA)$ of $\mathrm{Ni}_{2}(m$-dobdc) upon exposure to reductants. Exposure tests include $0.1 \mathrm{M}$ samarium iodide in tetrahydrofuran and $1.0 \mathrm{M}$ lithium borohydride in tetrahydrofuran. A reference pattern of as-synthesized $\mathrm{Ni}_{2}(m$-dobdc $)$ is included. 
Table S9. Summary of changes in the full width at half maximum (FWHM) for the $2 \theta=7^{\circ}(\lambda=$ $1.5406 \AA$ ) reflection of $\mathrm{Ni}_{2}(m$-dobdc) under a range of conditions.

\begin{tabular}{|c|c|c|c|c|c|}
\hline Condition & \multicolumn{2}{|c|}{ Result } & Condition & \multicolumn{2}{|c|}{ Result } \\
\hline \multirow{2}{*}{ Initial } & FWHM & 0.24503 & \multirow{2}{*}{ DI water } & FWHM & 0.21824 \\
\hline & $\%$ Change & - & & $\%$ Change & 11 \\
\hline \multirow{2}{*}{$120^{\circ} \mathrm{C}$ Air } & FWHM & 0.24288 & \multirow{2}{*}{$\mathrm{BuNH}_{2} / \mathrm{THF}$} & FWHM & 0.22135 \\
\hline & $\%$ Change & -1 & & $\%$ Change & -10 \\
\hline \multirow{2}{*}{$180^{\circ} \mathrm{C}$ Air } & FWHM & 0 & \multirow{2}{*}{$\mathrm{PhMgBr} / \mathrm{THF}$} & FWHM & 0.22625 \\
\hline & $\%$ Change & $x$ & & $\%$ Change & -8 \\
\hline \multirow{2}{*}{ Conc. $\mathrm{HCl}$} & FWHM & 0 & \multirow{2}{*}{ TBAF/THF } & FWHM & 0.26518 \\
\hline & $\%$ Change & $x$ & & $\%$ Change & 9 \\
\hline \multirow{2}{*}{$\mathrm{pH}=1$ Buffer } & FWHM & 0 & \multirow{2}{*}{$\mathrm{Me}_{3} \mathrm{SiCl} / \mathrm{CH}_{2} \mathrm{Cl}_{2}$} & FWHM & 0.18914 \\
\hline & $\%$ Change & $x$ & & $\%$ Change & -23 \\
\hline \multirow{2}{*}{$\mathrm{pH}=4$ Buffer } & FWHM & 0.229 & \multirow{2}{*}{$\mathrm{MeCOCl} / \mathrm{CH}_{2} \mathrm{Cl}_{2}$} & FWHM & 0.20415 \\
\hline & $\%$ Change & -7 & & $\%$ Change & -17 \\
\hline \multirow{2}{*}{$\mathrm{pH}=7$ Buffer } & FWHM & 0.23752 & \multirow{2}{*}{$\mathrm{SO}_{2} \mathrm{Cl}_{2} / \mathrm{CH}_{2} \mathrm{Cl}_{2}$} & FWHM & 0 \\
\hline & $\%$ Change & -4 & & $\%$ Change & $x$ \\
\hline \multirow{2}{*}{$\mathrm{pH}=10$ Buffer } & FWHM & 0.24536 & \multirow{2}{*}{$\mathrm{Me}_{2} \mathrm{SO}_{4} / \mathrm{CH}_{2} \mathrm{Cl}_{2}$} & FWHM & 0.26951 \\
\hline & $\%$ Change & 1 & & $\%$ Change & 10 \\
\hline \multirow{2}{*}{$\mathrm{pH}=13$ Buffer } & FWHM & 0.2769 & \multirow{2}{*}{$\mathrm{Br}_{2} / \mathrm{CH}_{2} \mathrm{Cl}_{2}$} & FWHM & 0 \\
\hline & $\%$ Change & 14 & & $\%$ Change & $x$ \\
\hline \multirow{2}{*}{ Sat. $\mathrm{NaOH}$} & FWHM & 0 & \multirow{2}{*}{$\mathrm{I}_{2} / \mathrm{CH}_{2} \mathrm{Cl}_{2}$} & FWHM & 0.24538 \\
\hline & $\%$ Change & $x$ & & $\%$ Change & 1 \\
\hline \multirow{2}{*}{$\mathrm{CH}_{3} \mathrm{COOH}$} & FWHM & 0.24598 & \multirow{2}{*}{$\mathrm{MCPBA} / \mathrm{CH}_{2} \mathrm{Cl}_{2}$} & FWHM & 0 \\
\hline & $\%$ Change & 1 & & $\%$ Change & $x$ \\
\hline \multirow{2}{*}{ LiHMDS/Tol } & FWHM & 0.24511 & \multirow{2}{*}{$\mathrm{PCC} / \mathrm{CH}_{2} \mathrm{Cl}_{2}$} & FWHM & 0.26078 \\
\hline & $\%$ Change & 1 & & $\%$ Change & 7 \\
\hline \multirow{2}{*}{$\mathrm{H}_{2} \mathrm{~S} / \mathrm{THF}$} & FWHM & 0.22655 & \multirow{2}{*}{$\mathrm{SmI}_{2} / \mathrm{THF}$} & FWHM & 0.22395 \\
\hline & $\%$ Change & -8 & & $\%$ Change & -9 \\
\hline \multirow{2}{*}{$\mathrm{NH}_{3} / \mathrm{MeOH}$} & FWHM & 0.27812 & \multirow{2}{*}{$\mathrm{LiBH}_{4} / \mathrm{THF}$} & FWHM & 0.27514 \\
\hline & $\%$ Change & 14 & & $\%$ Change & 13 \\
\hline
\end{tabular}




\section{Synthesis, characterization, and stability assessment of $\mathrm{Mg}_{2}$ (dobpdc).}

Synthesis of $\mathrm{Mg}_{2}$ (dobpdc). This procedure is adapted from the literature. ${ }^{26}$ A $250 \mathrm{~mL}$ Erlenmeyer flask was charged with $\mathrm{Mg}\left(\mathrm{NO}_{3}\right)_{2} \cdot 6 \mathrm{H}_{2} \mathrm{O}$ (3.48 g, $13.6 \mathrm{mmol}, 2.50$ equiv.), 4,4'dihydroxy-[1,1'-biphenyl]-3,3'-dicarboxylic acid (1.50 g, $5.45 \mathrm{mmol}, 1.00$ eq.), $N, N$ dimethylformamide $(20 \mathrm{~mL})$, and methanol $(24 \mathrm{~mL})$. The reaction mixture was sonicated until all of the solids dissolved. The reaction mixture was filtered through filter paper into a $350 \mathrm{~mL}$ screwcap high-pressure reaction flask equipped with a stir bar. The reaction vessel was sealed and transferred to a silicone oil bath. The oil bath was heated to $120^{\circ} \mathrm{C}$, and the reaction mixture was allowed to stir gently (500 rpm) at this temperature for $14 \mathrm{~h}$. Over the course of the reaction, an off-white solid precipitated from solution. The reaction mixture was allowed to cool to room temperature, filtered, and washed with $N, N$-dimethylformamide $(200 \mathrm{~mL})$. The collected solid was transferred to a $500 \mathrm{~mL}$ Pyrex jar filled with $N, N$-dimethylformamide $(200 \mathrm{~mL})$. The jar was allowed to stand for $3 \mathrm{~h}$ at $60{ }^{\circ} \mathrm{C}$ in an oven, at which time the $N, N$-dimethylformamide was decanted and replaced with fresh $N, N$-dimethylformamide $(200 \mathrm{~mL})$. This procedure was repeated two additional times for a total of three $N, N$-dimethylformamide soaks. Next, the solid was filtered and returned to the jar with fresh methanol $(200 \mathrm{~mL})$. The solid was soaked in methanol for $3 \mathrm{~h}$ at $60{ }^{\circ} \mathrm{C}$ in an oven three total times following the same procedure as described above. Complete exchange of $N, N$-dimethylformamide for methanol was confirmed by IR spectroscopy. Robustness assessments were performed using methanol-solvated $\mathrm{Mg}_{2}$ (dotpdc) that was freshly filtered. Some of the resulting white solid was filtered and transferred to a Schlenk flask. The solid was activated under flowing $\mathrm{N}_{2}$ at $180{ }^{\circ} \mathrm{C}$ for $4 \mathrm{~h}$, followed by further activation under high vacuum (<100 mbar) at $180{ }^{\circ} \mathrm{C}$ for $24 \mathrm{~h}$. The Schlenk flask was transferred into a $\mathrm{N}_{2}$-filled glovebox, and the activated $\mathrm{Mg}_{2}$ (dobpdc) was transferred into a $20 \mathrm{~mL}$ scintillation vial for long-term storage. A portion of the activated sample was transferred to a pre-tared Micromeritics sample tube equipped with a Sureseal. The tube was removed from the glovebox and the sample was gently heated to $180{ }^{\circ} \mathrm{C}$ $\left(0.1^{\circ} \mathrm{C} / \mathrm{min}\right)$ under high vacuum $(<10 \mu \mathrm{bar})$ and held at $180^{\circ} \mathrm{C}$ under high vacuum $(<10 \mu \mathrm{bar})$ for an additional $24 \mathrm{~h}$ before gas sorption measurements. 


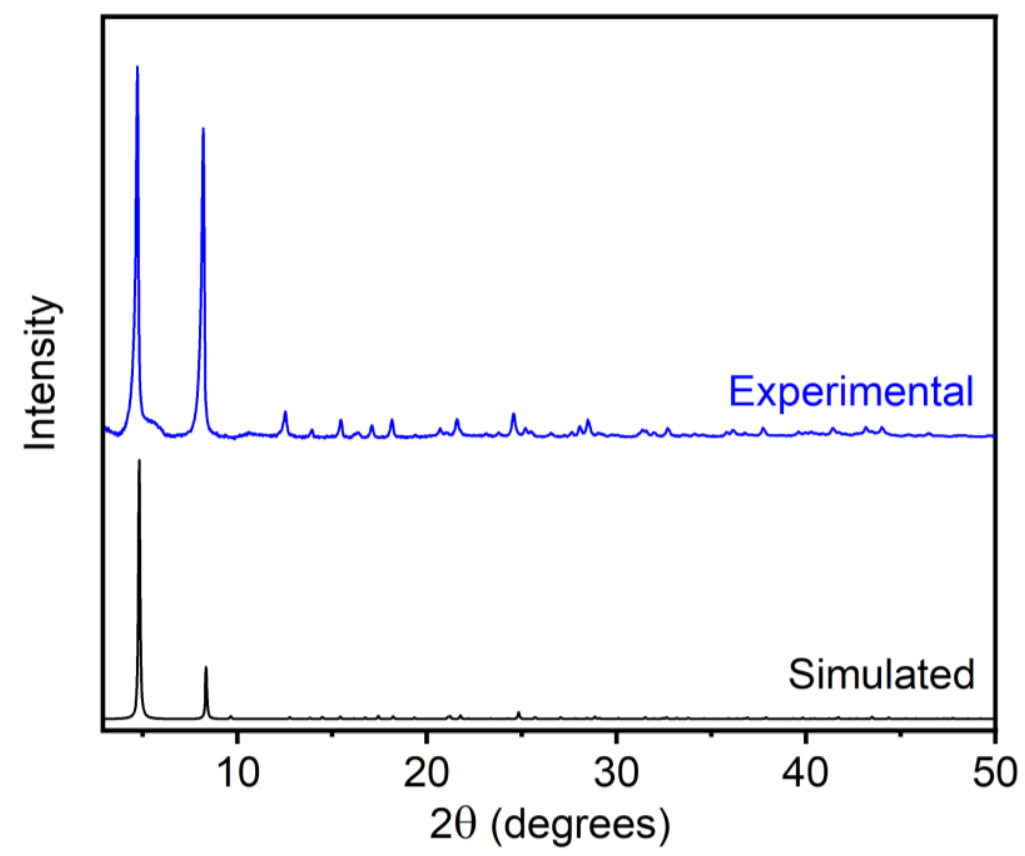

Figure S112. PXRD pattern $(\lambda=1.5406 \AA)$ of methanol-solvated $\mathrm{Mg}_{2}(\mathrm{dobpdc})$. The simulated pattern based on the previously reported single-crystal X-ray diffraction structure of the isostructural framework $\mathrm{Zn}_{2}$ (dobpdc) is included for reference. ${ }^{26}$ The PXRD pattern of $\mathrm{Mg}_{2}$ (dobpdc) was baseline corrected.

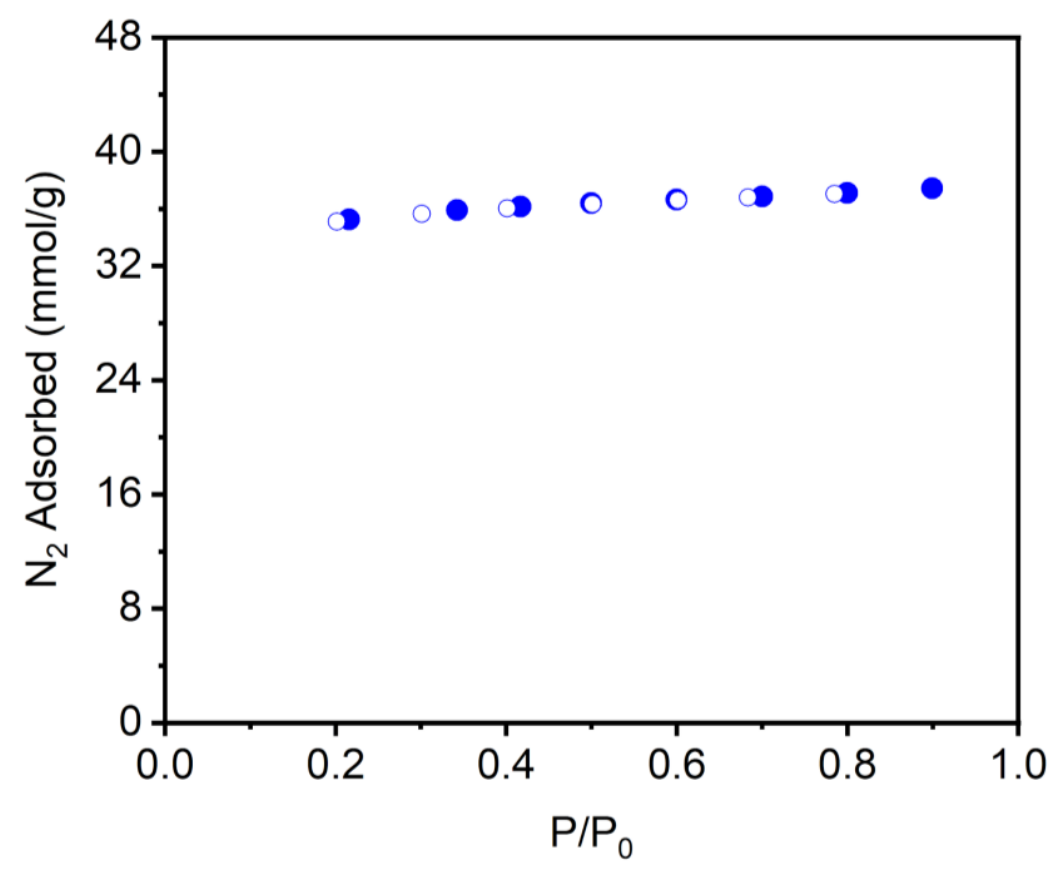

Figure S113. $77 \mathrm{~K} \mathrm{~N}_{2}$ adsorption (filled circles) and desorption (open circles) isotherm of activated $\mathrm{Mg}_{2}$ (dobpdc). The Langmuir surface area determined from these data is $3710 \pm 12 \mathrm{~m}^{2} / \mathrm{g}$. 


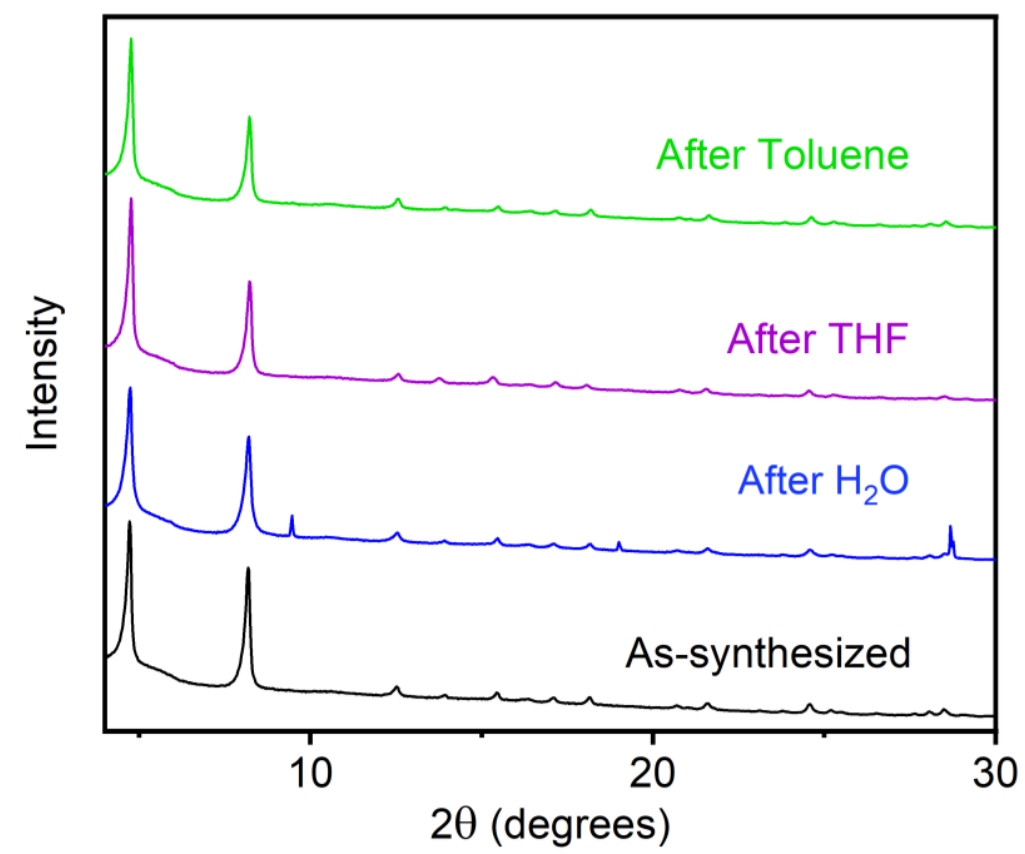

Figure S114. PXRD patterns $(\lambda=1.5406 \AA)$ of $\mathrm{Mg}_{2}$ (dobpdc) upon exposure to various organic solvents and water. Note that $\mathrm{Mg}_{2}$ (dobpdc) was soaked in DMF and $\mathrm{MeOH}$ during its synthesis as well. A reference pattern of as-synthesized $\mathrm{Mg}_{2}$ (dobpdc) is included. These patterns confirm that $\mathrm{Mg}_{2}$ (dobpdc) undergoes partial degradation in neutral water.

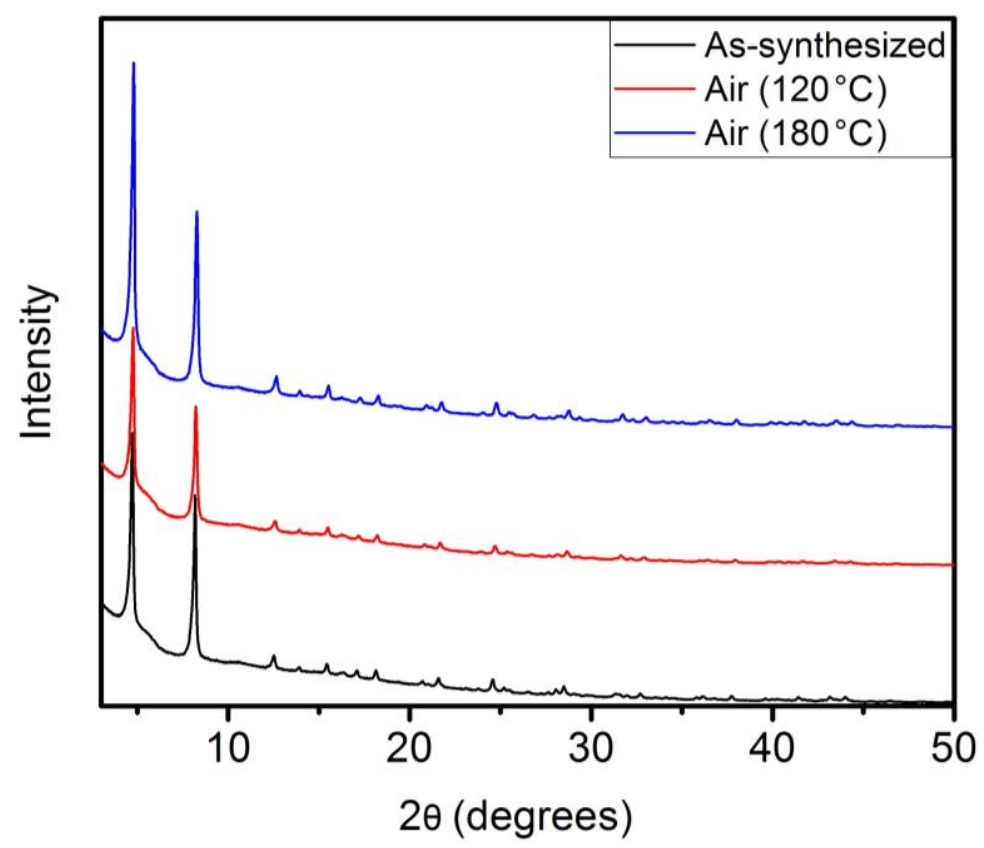

Figure S115. PXRD patterns ( $\lambda=1.5406 \AA$ ) of $\mathrm{Mg}_{2}$ (dobpdc) upon standing at $120^{\circ} \mathrm{C}$ and $180^{\circ} \mathrm{C}$ in air for $24 \mathrm{~h}$. A reference pattern of as-synthesized $\mathrm{Mg}_{2}$ (dobpdc) is included. 


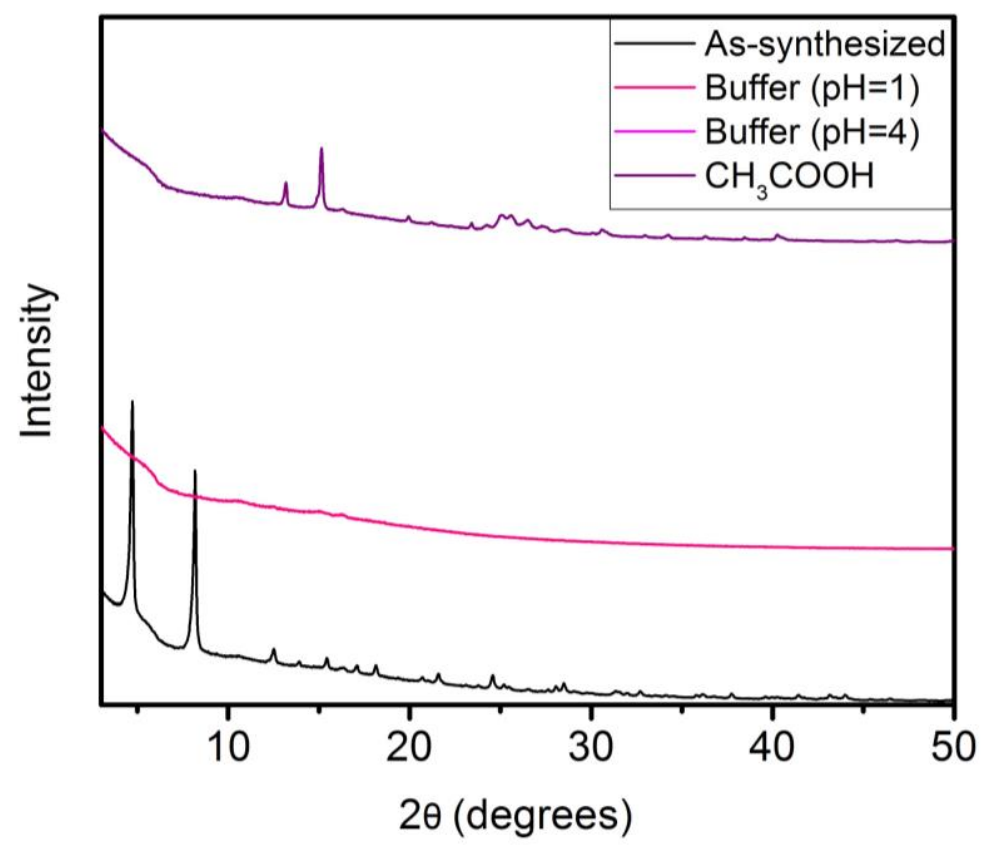

Figure S116. PXRD patterns $(\lambda=1.5406 \AA)$ of $\mathrm{Mg}_{2}$ (dobpdc) upon exposure to acids. Exposure tests include aqueous solutions buffered at $\mathrm{pH} 1$ and $\mathrm{pH} 4$ and glacial acetic acid. No solid remained after exposure of $\mathrm{Mg}_{2}$ (dobpdc) to the $\mathrm{pH} 4$ buffer. A reference pattern of as-synthesized $\mathrm{Mg}_{2}$ (dobpdc) is included.

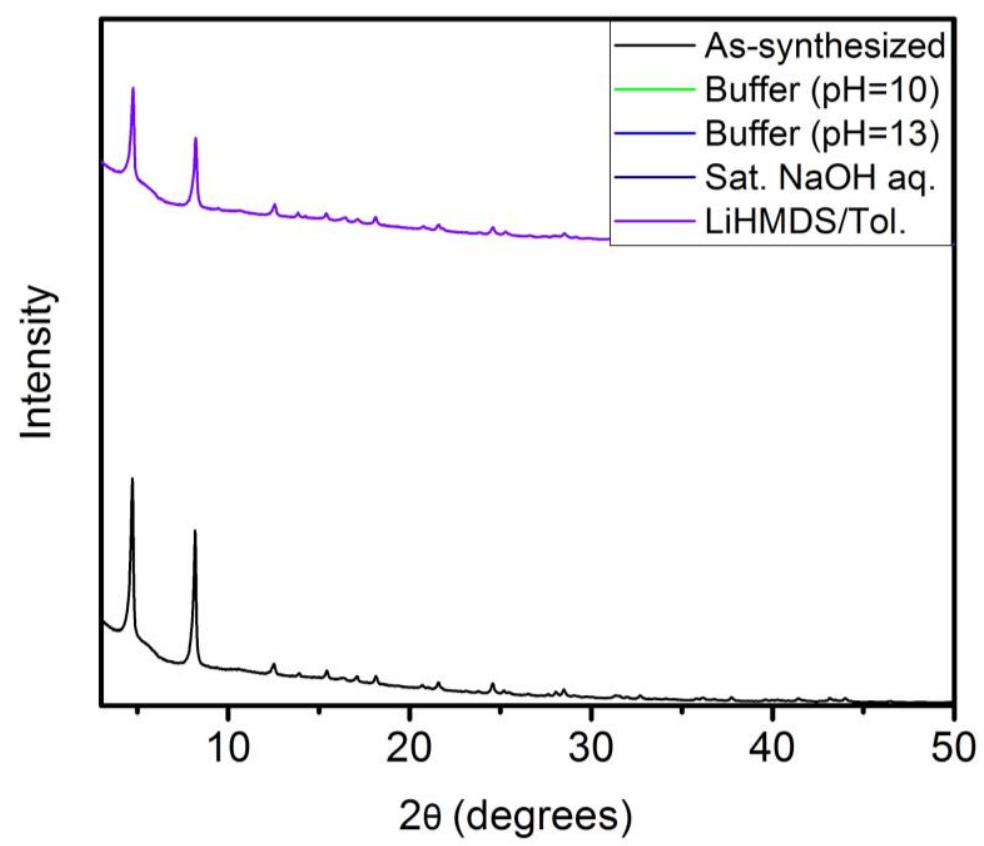

Figure S117. PXRD patterns $\left(\lambda=1.5406 \AA\right.$ ) of $\mathrm{Mg}_{2}$ (dobpdc) upon exposure to bases. Exposure tests include aqueous solutions buffered at $\mathrm{pH} 10$ and $\mathrm{pH} 13$, saturated aqueous $\mathrm{NaOH}$, and $1.0 \mathrm{M}$ lithium hexamethyldisilazide (LiHMDS) in toluene. No solid remained after exposure of $\mathrm{Mg}_{2}$ (dobpdc) to the $\mathrm{pH} 10$ buffer, $\mathrm{pH} 13$ buffer, or the saturated $\mathrm{NaOH}$ solution. A reference pattern of as-synthesized $\mathrm{Mg}_{2}$ (dobpdc) is included. 


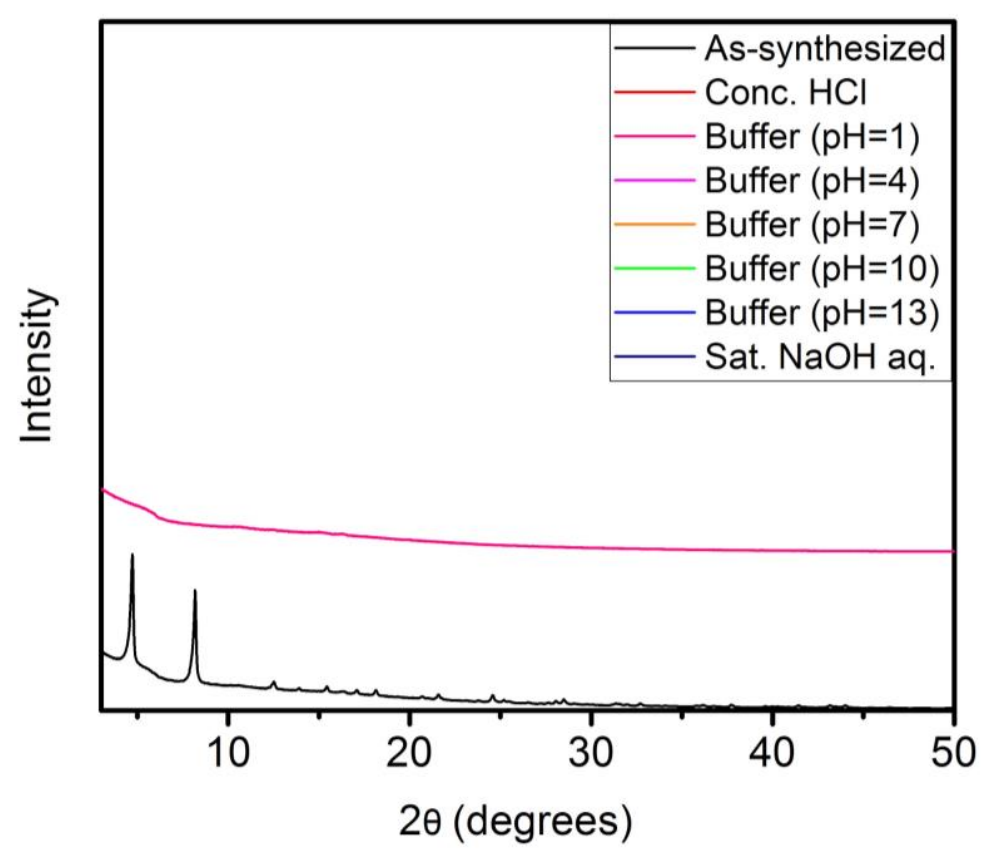

Figure S118. Summary of the PXRD patterns $(\lambda=1.5406 \AA)$ of $\mathrm{Mg}_{2}$ (dobpdc) upon exposure to various aqueous conditions. No solid remained after exposure of $\mathrm{Mg}_{2}$ (dobpdc) to any of the solutions except the $\mathrm{pH} 1$ buffer. A reference pattern of as-synthesized $\mathrm{Mg}_{2}$ (dobpdc) is included. Notably, $\mathrm{Mg}_{2}$ (dobpdc) was followed to completely dissolve in aqueous tris buffer ( $\mathrm{pH}=7$ ).

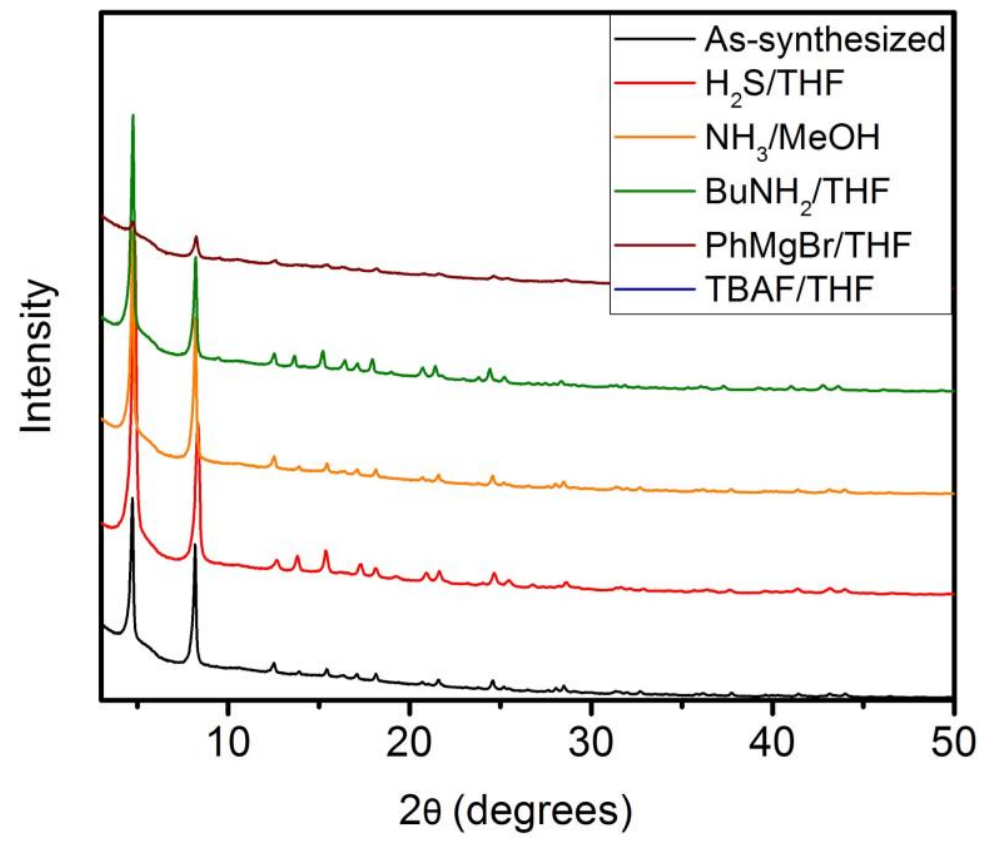

Figure S119. PXRD patterns $(\lambda=1.5406 \AA)$ of $\mathrm{Mg}_{2}$ (dobpdc) upon exposure to nucleophiles. Exposure tests include $0.8 \mathrm{M}$ hydrogen sulfide in tetrahydrofuran, $1.0 \mathrm{M}$ ammonia in methanol, $1.0 \mathrm{M} n$-butylamine in tetrahydrofuran, $1.0 \mathrm{M} \mathrm{PhMgBr}$ in tetrahydrofuran, and $1.0 \mathrm{M}$ tetrabutylammonium fluoride (TBAF) in tetrahydrofuran. No solid remained after exposure of $\mathrm{Mg}_{2}$ (dobpdc) to the TBAF solution. A reference pattern of as-synthesized $\mathrm{Mg}_{2}$ (dobpdc) is included. 


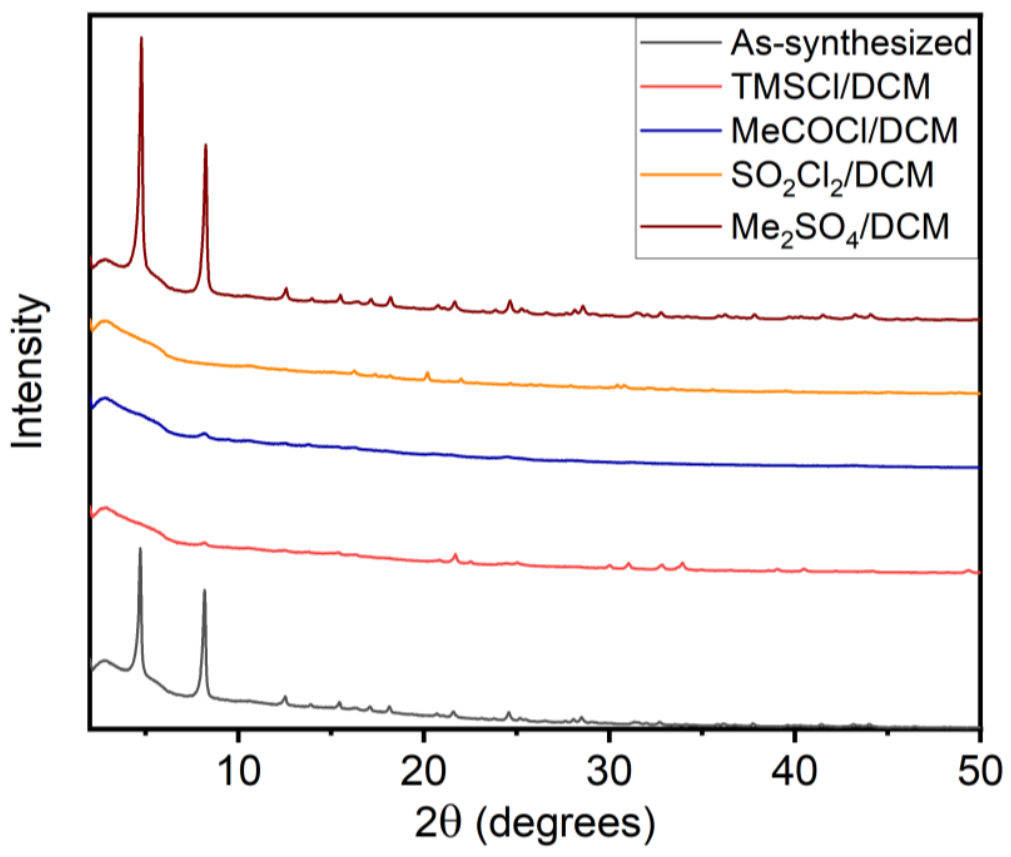

Figure S120. PXRD patterns $(\lambda=1.5406 \AA)$ of $\mathrm{Mg}_{2}$ (dobpdc) upon exposure to electrophiles. Exposure tests include $1.0 \mathrm{M}$ chlorotrimethylsilane (TMSCl) in dichloromethane, $1.0 \mathrm{M}$ acetyl chloride in dichloromethane, 1.0 M sulfuryl chloride in dichloromethane, and saturated dimethyl sulfate in dichloromethane. No solid remained after exposure of $\mathrm{Mg}_{2}$ (dobpdc) to dimethyl sulfate. A reference pattern of as-synthesized $\mathrm{Mg}_{2}$ (dobpdc) is included.

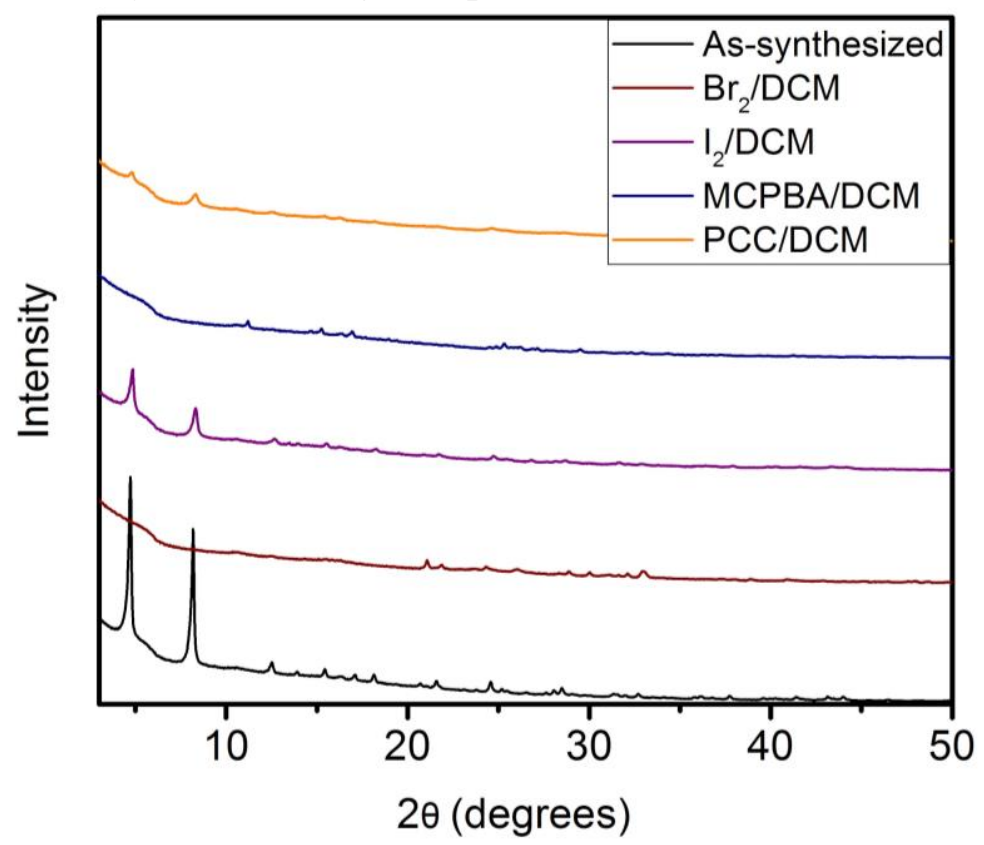

Figure S121. PXRD patterns $(\lambda=1.5406 \AA)$ of $\mathrm{Mg}_{2}$ (dobpdc) upon exposure to oxidants. Exposure tests include 1.0 M bromine in dichloromethane, saturated iodine in dichloromethane, saturated $m$-chloroperoxybenzoic acid (MCPBA) in dichloromethane, and saturated pyridinium chlorochromate (PCC) in dichloromethane. A reference pattern of as-synthesized $\mathrm{Mg}_{2}(\mathrm{dobpdc})$ is included. 


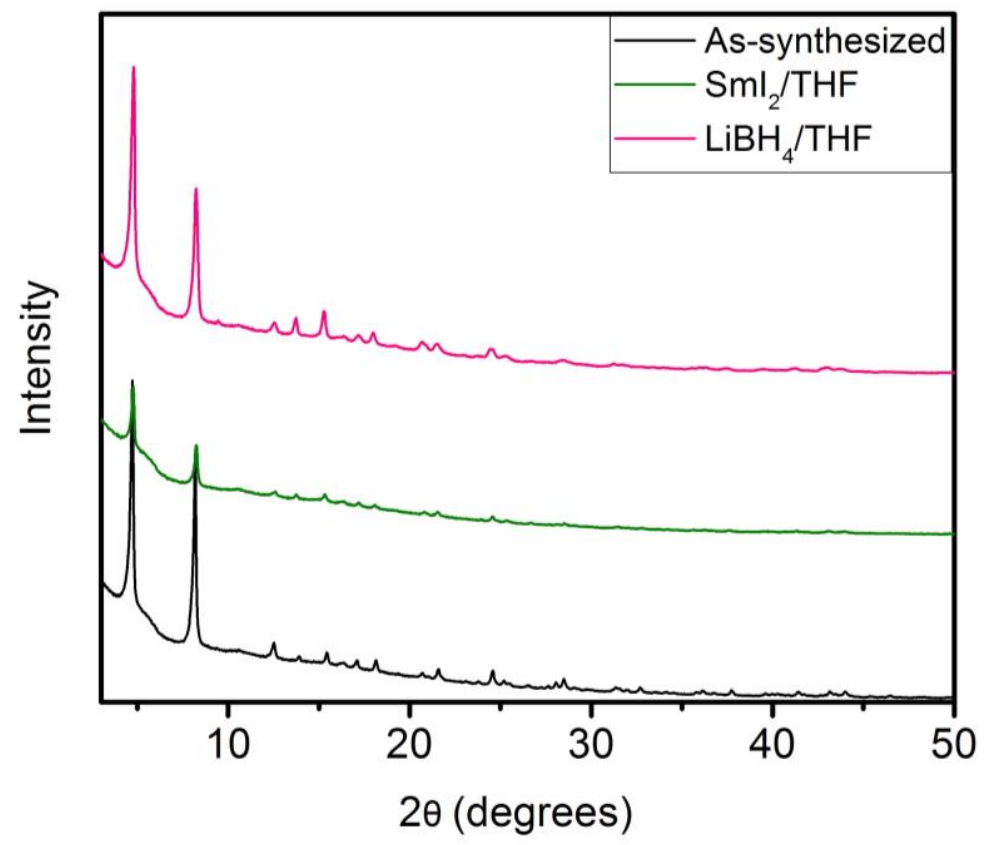

Figure S122. PXRD patterns $(\lambda=1.5406 \AA)$ of $\mathrm{Mg}_{2}$ (dobpdc) upon exposure to reductants. Exposure tests include $0.1 \mathrm{M}$ samarium iodide in tetrahydrofuran and $1.0 \mathrm{M}$ lithium borohydride in tetrahydrofuran. A reference pattern of as-synthesized $\mathrm{Mg}_{2}$ (dobpdc) is included. 
Table S10. Summary of changes in the full width at half maximum (FWHM) for the $2 \theta=4^{\circ}(\lambda=$ $1.5406 \AA$ ) reflection of $\mathrm{Mg}_{2}(\mathrm{dobpdc})$ under a range of conditions.

\begin{tabular}{|c|c|c|c|c|c|}
\hline Condition & \multicolumn{2}{|c|}{ Result } & Condition & \multicolumn{2}{|c|}{ Result } \\
\hline \multirow{2}{*}{ Initial } & FWHM & 0.17694 & \multirow{2}{*}{ DI water } & FWHM & 0.22661 \\
\hline & $\%$ Change & - & & $\%$ Change & $28^{a}$ \\
\hline \multirow{2}{*}{$120{ }^{\circ} \mathrm{C}$ Air } & FWHM & 0.17979 & \multirow{2}{*}{$\mathrm{BuNH}_{2} / \mathrm{THF}$} & FWHM & 0.18979 \\
\hline & $\%$ Change & 2 & & $\%$ Change & 8 \\
\hline \multirow{2}{*}{$180{ }^{\circ} \mathrm{C}$ Air } & FWHM & 0.19716 & \multirow{2}{*}{$\mathrm{PhMgBr} / \mathrm{THF}$} & FWHM & 0.44231 \\
\hline & $\%$ Change & 12 & & $\%$ Change & 150 \\
\hline \multirow{2}{*}{ Conc. $\mathrm{HCl}$} & FWHM & 0 & \multirow{2}{*}{ TBAF/THF } & FWHM & 0 \\
\hline & $\%$ Change & $x$ & & $\%$ Change & $x$ \\
\hline \multirow{2}{*}{$\mathrm{pH}=1$ Buffer } & FWHM & 0 & \multirow{2}{*}{$\mathrm{Me}_{3} \mathrm{SiCl} / \mathrm{CH}_{2} \mathrm{Cl}_{2}$} & FWHM & 0 \\
\hline & $\%$ Change & $x$ & & $\%$ Change & $x$ \\
\hline \multirow{2}{*}{$\mathrm{pH}=4$ Buffer } & FWHM & 0 & \multirow{2}{*}{$\mathrm{MeCOCl} / \mathrm{CH}_{2} \mathrm{Cl}_{2}$} & FWHM & 0 \\
\hline & $\%$ Change & $x$ & & $\%$ Change & $x$ \\
\hline \multirow{2}{*}{$\mathrm{pH}=7 \mathrm{Buffer}^{b}$} & FWHM & 0 & \multirow{2}{*}{$\mathrm{SO}_{2} \mathrm{Cl}_{2} / \mathrm{CH}_{2} \mathrm{Cl}_{2}$} & FWHM & 0 \\
\hline & $\%$ Change & $x$ & & $\%$ Change & $\times$ \\
\hline \multirow{2}{*}{$\mathrm{pH}=10$ Buffer } & FWHM & 0 & \multirow{2}{*}{$\mathrm{Me}_{2} \mathrm{SO}_{4} / \mathrm{CH}_{2} \mathrm{Cl}_{2}$} & FWHM & 0.17372 \\
\hline & $\%$ Change & $x$ & & $\%$ Change & -2 \\
\hline \multirow{2}{*}{$\mathrm{pH}=13$ Buffer } & FWHM & 0 & \multirow{2}{*}{$\mathrm{Br}_{2} / \mathrm{CH}_{2} \mathrm{Cl}_{2}$} & FWHM & 0 \\
\hline & $\%$ Change & $x$ & & $\%$ Change & $\times$ \\
\hline \multirow{2}{*}{ Sat. $\mathrm{NaOH}$} & FWHM & 0 & \multirow{2}{*}{$\mathrm{I}_{2} / \mathrm{CH}_{2} \mathrm{Cl}_{2}$} & FWHM & 0.19306 \\
\hline & $\%$ Change & $x$ & & $\%$ Change & 10 \\
\hline \multirow{2}{*}{$\mathrm{CH}_{3} \mathrm{COOH}$} & FWHM & 0 & \multirow{2}{*}{$\mathrm{MCPBA} / \mathrm{CH}_{2} \mathrm{Cl}_{2}$} & FWHM & 0 \\
\hline & $\%$ Change & $\times$ & & $\%$ Change & $\times$ \\
\hline \multirow{2}{*}{ LiHMDS/Tol } & FWHM & 0.17877 & \multirow{2}{*}{$\mathrm{PCC} / \mathrm{CH}_{2} \mathrm{Cl}_{2}$} & FWHM & 1.5275 \\
\hline & $\%$ Change & 2 & & $\%$ Change & 764 \\
\hline \multirow{2}{*}{$\mathrm{H}_{2} \mathrm{~S} / \mathrm{THF}$} & FWHM & 0.27355 & \multirow{2}{*}{$\mathrm{SmI}_{2} / \mathrm{THF}$} & FWHM & 0.13935 \\
\hline & $\%$ Change & 55 & & $\%$ Change & -22 \\
\hline \multirow{2}{*}{$\mathrm{NH}_{3} / \mathrm{MeOH}$} & FWHM & 0.18196 & \multirow{2}{*}{$\mathrm{LiBH}_{4} / \mathrm{THF}$} & FWHM & 0.2175 \\
\hline & $\%$ Change & 3 & & $\%$ Change & 23 \\
\hline
\end{tabular}

${ }^{a} \mathrm{New}$ reflections observed by PXRD. ${ }^{b} \mathrm{Mg}_{2}$ (dobpdc) was found to completely dissolve in aqueous tris buffer $(\mathrm{pH}=7)$. 


\section{Synthesis, characterization, and stability assessment of $\mathrm{Mg}_{2}$ (dotpdc).}

Synthesis of $\mathbf{M g}_{2}$ (dotpdc). This procedure is adapted from the literature. ${ }^{27}$ A $250 \mathrm{~mL}$ Erlenmeyer flask was charged with 4,4"-dihydroxy-[1,1':4',1"-terphenyl]-3,3"-dicarboxylic acid (420 mg, $1.20 \mathrm{mmol}, 1.00$ equiv.), $\mathrm{Mg}\left(\mathrm{NO}_{3}\right)_{2} \bullet 6 \mathrm{H}_{2} \mathrm{O}$ (769 mg, $3.00 \mathrm{mmol}, 2.50$ equiv.), $N, N-$ dimethylformamide $(60 \mathrm{~mL})$, and methanol $(60 \mathrm{~mL})$. The flask was swirled until the solution was completely homogeneous. The contents of the flask were evenly distributed among twelve $20 \mathrm{~mL}$ scintillation vials $(\sim 10 \mathrm{~mL}$ per vial) with Teflon tape wrapped around the rims. The vials were tightly capped and placed in an aluminum heat block. The heat block was transferred to a dry block heater, which was then heated to $120^{\circ} \mathrm{C}$. The vials were allowed to stand at $120^{\circ} \mathrm{C}$ for $14 \mathrm{~h}$. Over the course of the reaction, an off-white solid precipitated from solution. The vials were allowed to cool to room temperature and filtered, combining the solid from every vial into one batch. The combined solid was transferred to a $500 \mathrm{~mL}$ Pyrex jar filled with $N, N$-dimethylformamide (200 $\mathrm{mL})$. The jar was allowed to stand for $3 \mathrm{~h}$ at $60{ }^{\circ} \mathrm{C}$ in an oven, at which time the $N, N$ dimethylformamide was decanted and replaced with fresh $N, N$-dimethylformamide $(200 \mathrm{~mL})$. This procedure was repeated two additional times for a total of three $N, N$-dimethylformamide soaks. Next, the solid was filtered and returned to the jar with fresh methanol $(200 \mathrm{~mL})$. The solid was soaked in methanol for $3 \mathrm{~h}$ at $60{ }^{\circ} \mathrm{C}$ in an oven three total times following the same procedure as described above. Complete exchange of $N, N$-dimethylformamide for methanol was confirmed by IR spectroscopy. Robustness assessments were performed using methanol-solvated $\mathrm{Mg}_{2}$ (dotpdc) that was freshly filtered. Some of the resulting off-white solid was filtered and transferred to a Schlenk flask. The solid was activated under flowing $\mathrm{N}_{2}$ at $180{ }^{\circ} \mathrm{C}$ for $1 \mathrm{~h}$, followed by further activation under high vacuum (<100 mbar) at $180{ }^{\circ} \mathrm{C}$ for $24 \mathrm{~h}$. The Schlenk flask was transferred into a $\mathrm{N}_{2}$-filled glovebox, and the activated $\mathrm{Mg}_{2}$ (dotpdc) was transferred into a $20 \mathrm{~mL}$ scintillation vial for long-term storage. A portion of the activated sample was transferred to a pre-tared Micromeritics sample tube equipped with a Sureseal. The tube was removed from the glovebox and the sample was gently heated to $180{ }^{\circ} \mathrm{C}\left(0.1^{\circ} \mathrm{C} / \mathrm{min}\right)$ under high vacuum $(<10 \mu \mathrm{bar})$ and held at $180^{\circ} \mathrm{C}$ under high vacuum $(<10 \mu$ bar) for an additional $24 \mathrm{~h}$ before gas sorption measurements. 


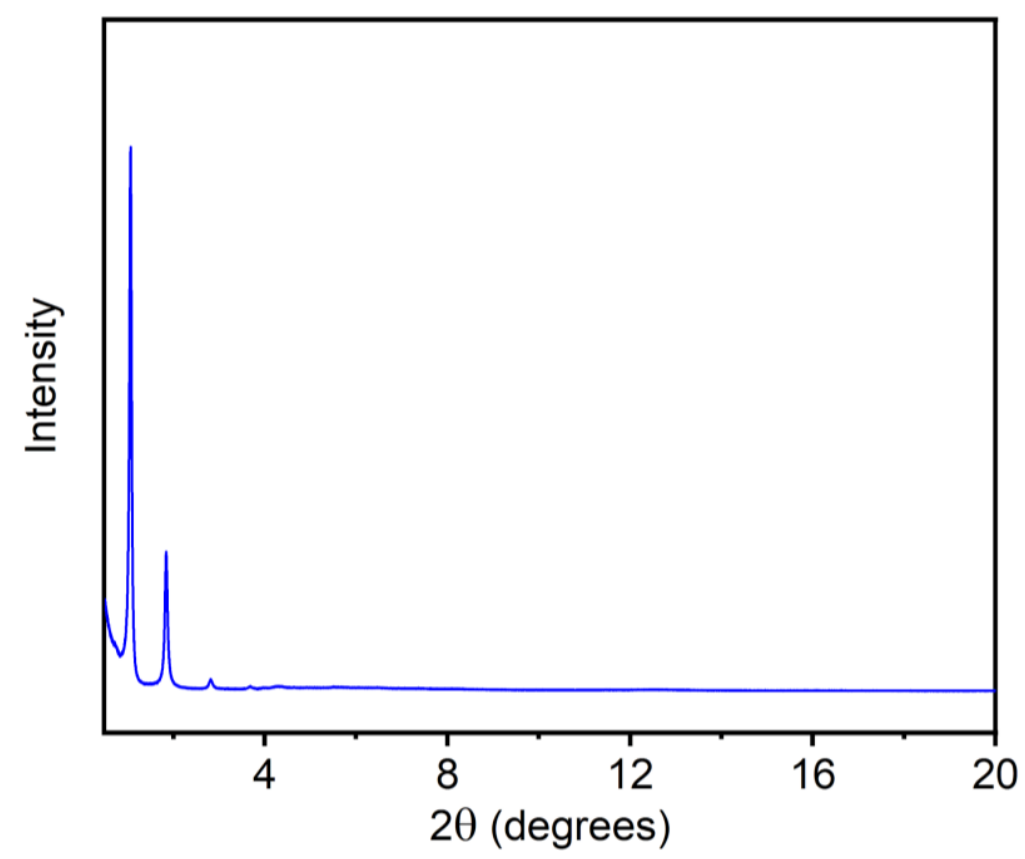

Figure S123. Synchrotron PXRD pattern $(\lambda=0.457897 \AA)$ of methanol-solvated $\operatorname{Mg}_{2}$ (dotpdc). This data is consistent with that reported in the literature. ${ }^{27}$

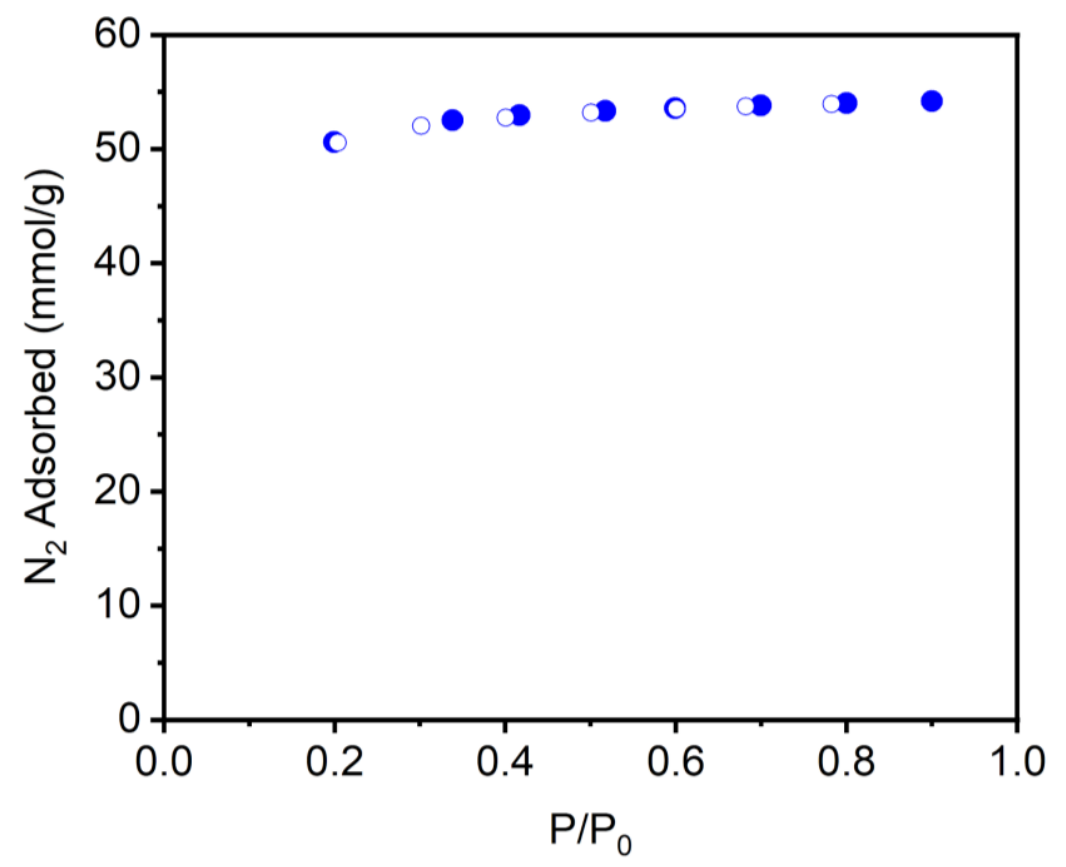

Figure S124. $77 \mathrm{~K} \mathrm{~N}_{2}$ adsorption (filled circles) and desorption (open circles) isotherm of activated $\mathrm{Mg}_{2}$ (dotpdc). The Langmuir surface area determined from these data is $5381 \pm 4 \mathrm{~m}^{2} / \mathrm{g}$. 


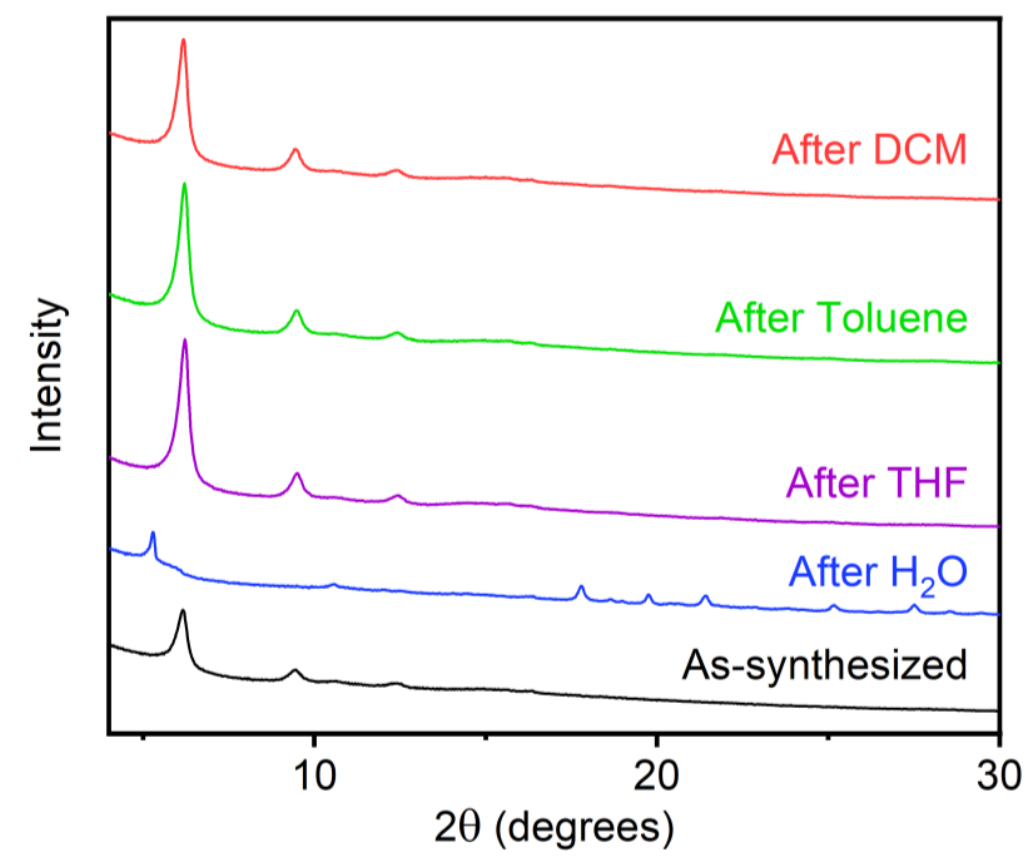

Figure S125. PXRD patterns $(\lambda=1.5406 \AA)$ of $\mathrm{Mg}_{2}$ (dotpdc) upon exposure to various organic solvents and water. Note that $\mathrm{Mg}_{2}$ (dobpdc) was soaked in DMF and $\mathrm{MeOH}$ during its synthesis as well. A reference pattern of as-synthesized $\mathrm{Mg}_{2}(\mathrm{dotpdc})$ is included. These patterns confirm that $\mathrm{Mg}_{2}$ (dotpdc) undergoes degradation in neutral water.

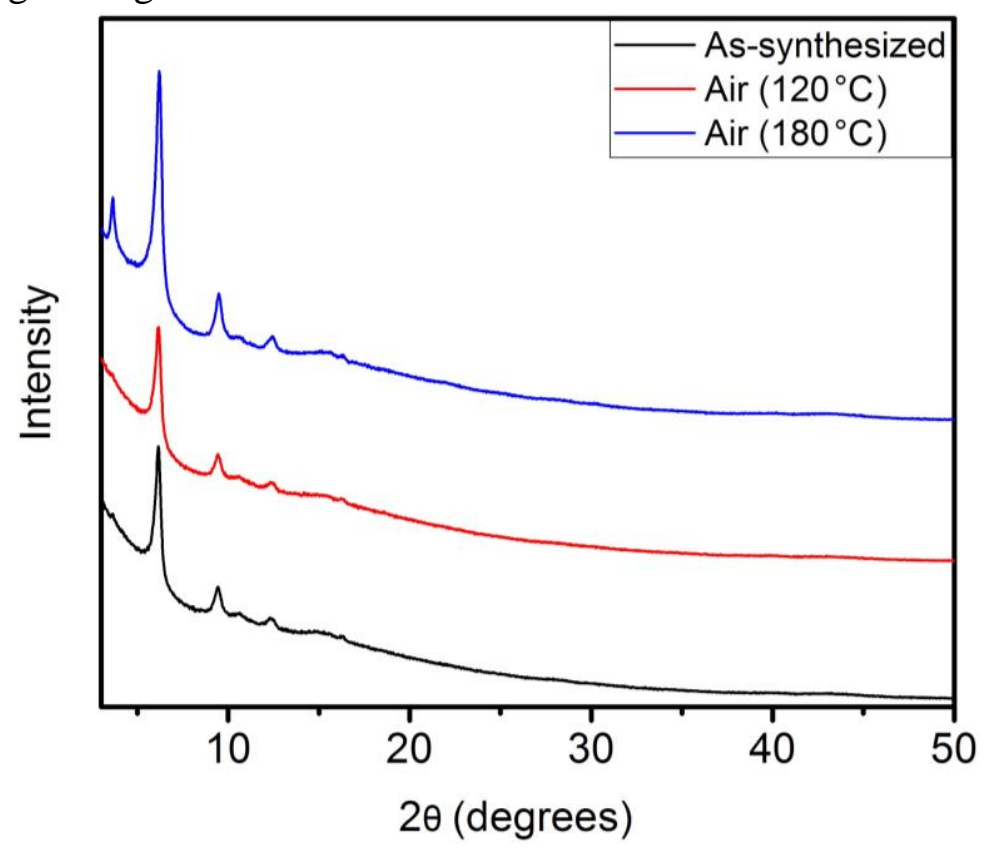

Figure S126. PXRD patterns ( $\lambda=1.5406 \AA$ ) of $\mathrm{Mg}_{2}$ (dotpdc) upon standing at $120^{\circ} \mathrm{C}$ and $180^{\circ} \mathrm{C}$ in air for $24 \mathrm{~h}$. A reference pattern of as-synthesized $\mathrm{Mg}_{2}(\mathrm{dotpdc})$ is included. 


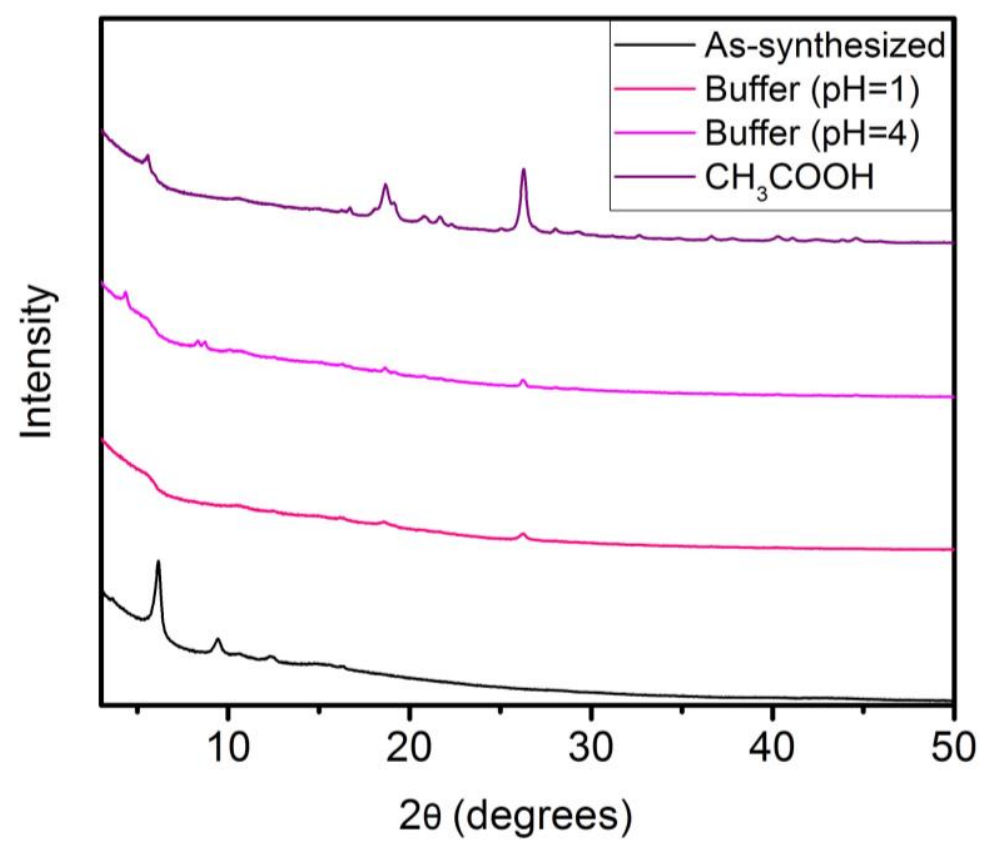

Figure S127. PXRD patterns $(\lambda=1.5406 \AA)$ of $\mathrm{Mg}_{2}$ (dotpdc) upon exposure to acids. Exposure tests include aqueous solutions buffered at $\mathrm{pH} 1$ and $\mathrm{pH} 4$ and glacial acetic acid. A reference pattern of as-synthesized $\mathrm{Mg}_{2}$ (dotpdc) is included.

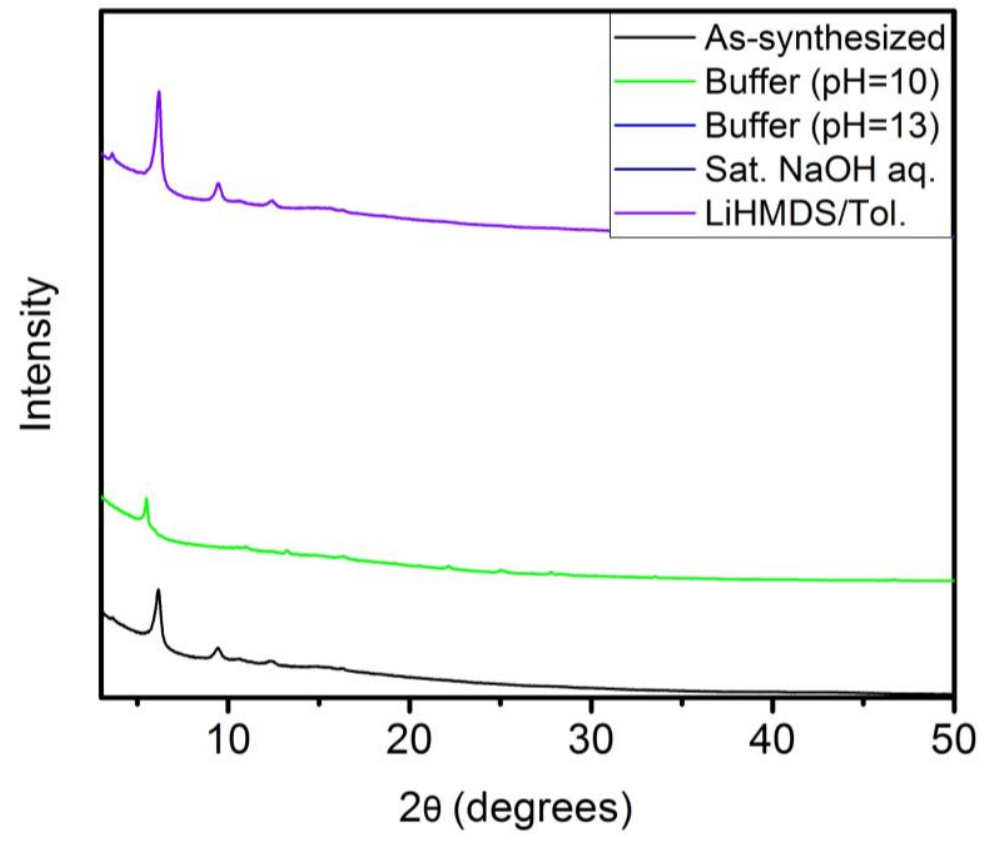

Figure S128. PXRD patterns $\left(\lambda=1.5406 \AA\right.$ ) of $\mathrm{Mg}_{2}$ (dotpdc) upon exposure to bases. Exposure tests include aqueous solutions buffered at $\mathrm{pH} 10$ and $\mathrm{pH} 13$, saturated aqueous $\mathrm{NaOH}$, and $1.0 \mathrm{M}$ lithium hexamethyldisilazide (LiHMDS) in toluene. No solid remained after exposure of $\mathrm{Mg}_{2}$ (dotpdc) to the $\mathrm{pH} 13$ buffer or the saturated $\mathrm{NaOH}$ solution. A reference pattern of assynthesized $\mathrm{Mg}_{2}$ (dotpdc) is included. 


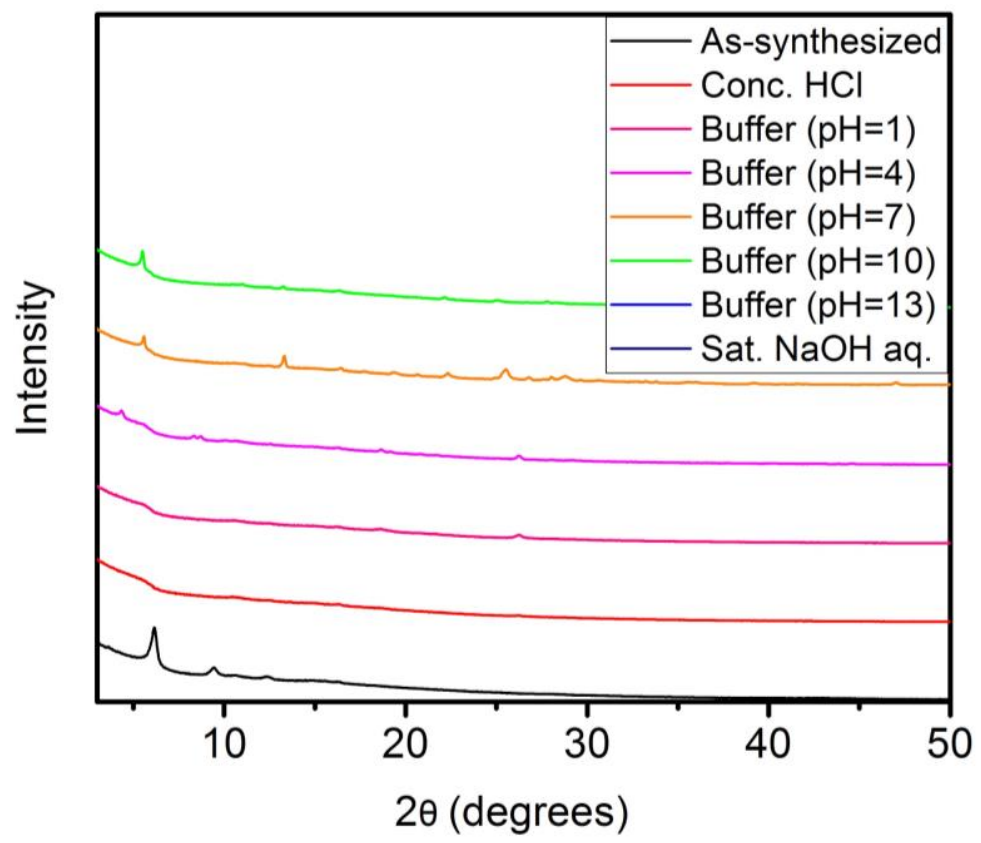

Figure S129. Summary of the PXRD patterns $(\lambda=1.5406 \AA)$ of $\mathrm{Mg}_{2}(\operatorname{dotpdc})$ upon exposure to various aqueous conditions. No solid remained after exposure of $\mathrm{Mg}_{2}$ (dotpdc) to the $\mathrm{pH} 13$ buffer or the saturated $\mathrm{NaOH}$ solution. A reference pattern of as-synthesized $\mathrm{Mg}_{2}$ (dotpdc) is included.

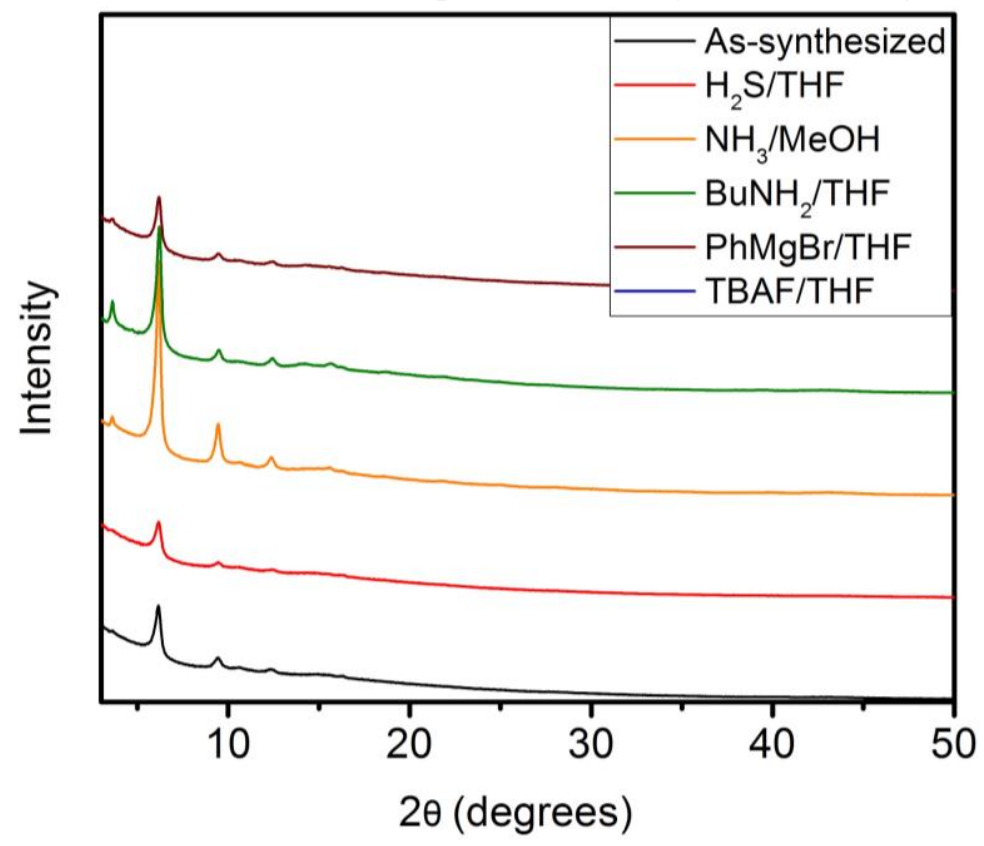

Figure S130. PXRD patterns $(\lambda=1.5406 \AA)$ of $\mathrm{Mg}_{2}(\mathrm{dotpdc})$ upon exposure to nucleophiles. Exposure tests include $0.8 \mathrm{M}$ hydrogen sulfide in tetrahydrofuran, $1.0 \mathrm{M}$ ammonia in methanol, $1.0 \mathrm{M} n$-butylamine in tetrahydrofuran, $1.0 \mathrm{M} \mathrm{PhMgBr}$ in tetrahydrofuran, and $1.0 \mathrm{M}$ tetrabutylammonium fluoride (TBAF) in tetrahydrofuran. No solid remained after exposure of $\mathrm{Mg}_{2}$ (dotpdc) to the TBAF solution. A reference pattern of as-synthesized $\mathrm{Mg}_{2}(\mathrm{dotpdc})$ is included. 


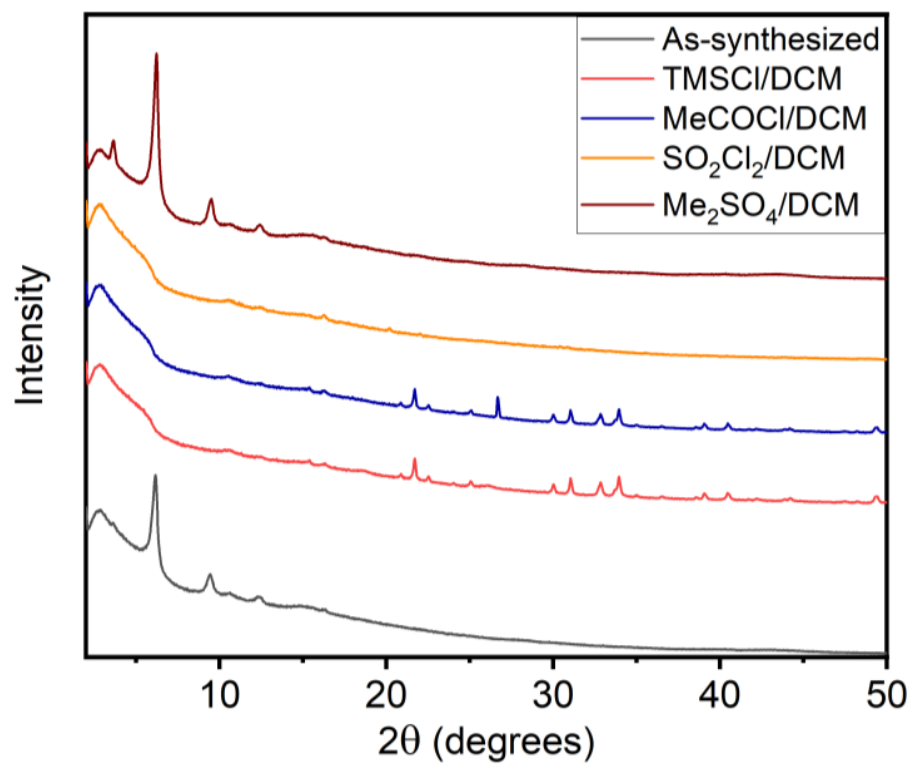

Figure S131. PXRD patterns $(\lambda=1.5406 \AA)$ of $\mathrm{Mg}_{2}$ (dotpdc) upon exposure to electrophiles. Exposure tests include $1.0 \mathrm{M}$ chlorotrimethylsilane (TMSCl) in dichloromethane, $1.0 \mathrm{M}$ acetyl chloride in dichloromethane, 1.0 M sulfuryl chloride in dichloromethane, and saturated dimethyl sulfate in dichloromethane. A reference pattern of as-synthesized $\mathrm{Mg}_{2}$ (dotpdc) is included.

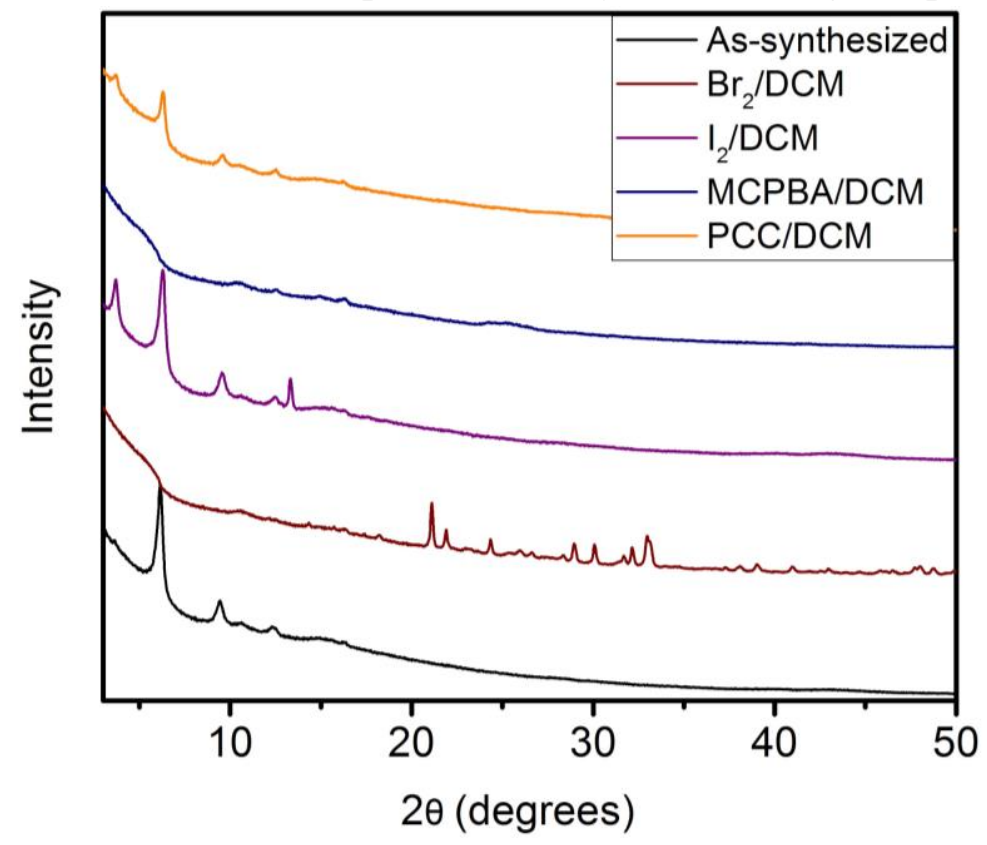

Figure S132. PXRD patterns $\left(\lambda=1.5406 \AA\right.$ ) of $\mathrm{Mg}_{2}$ (dotpdc)upon exposure to oxidants. Exposure tests include 1.0 M bromine in dichloromethane, saturated iodine in dichloromethane, saturated $m$-chloroperoxybenzoic acid (MCPBA) in dichloromethane, and saturated pyridinium chlorochromate (PCC) in dichloromethane. A reference pattern of as-synthesized $\mathrm{Mg}_{2}(\mathrm{dotpdc})$ is included. 


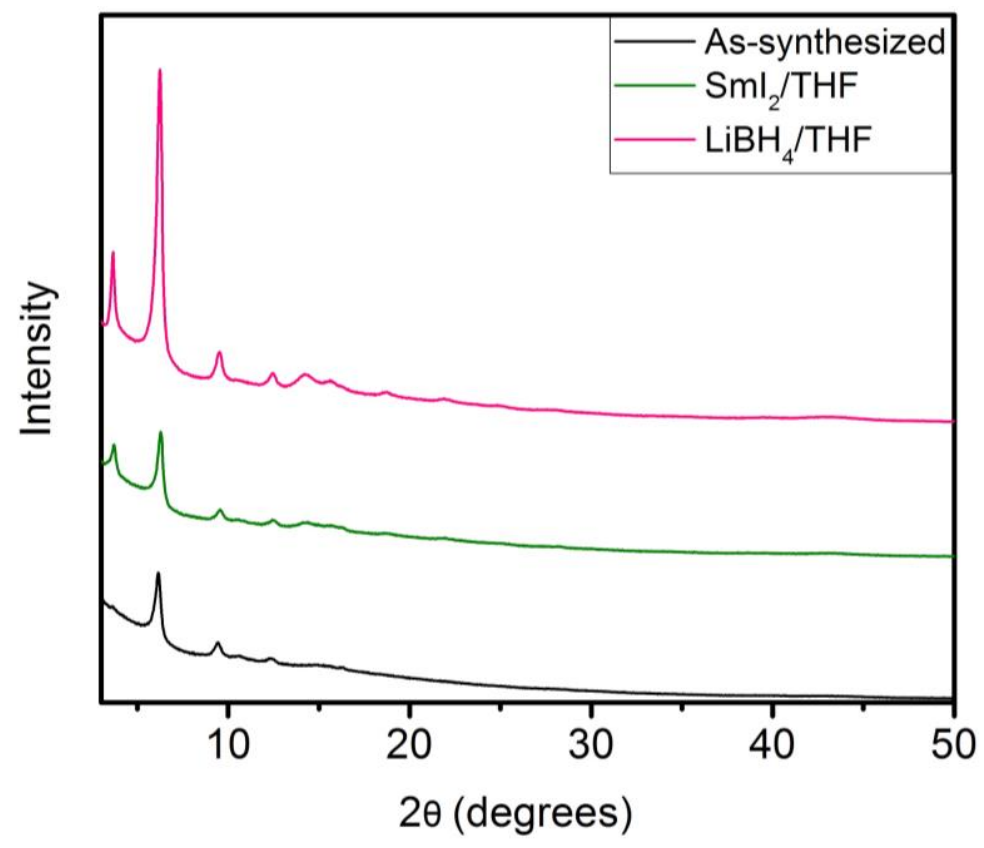

Figure S133. PXRD patterns $(\lambda=1.5406 \AA)$ of $\mathrm{Mg}_{2}$ (dotpdc) upon exposure to reductants. Exposure tests include $0.1 \mathrm{M}$ samarium iodide in tetrahydrofuran and $1.0 \mathrm{M}$ lithium borohydride in tetrahydrofuran. A reference pattern of as-synthesized $\mathrm{Mg}_{2}$ (dotpdc) is included. 
Table S11. Summary of changes in the full width at half maximum (FWHM) for the $2 \theta=6^{\circ}(\lambda=$ $1.5406 \AA$ ) reflection of $\mathrm{Mg}_{2}($ dotpdc) under a range of conditions.

\begin{tabular}{|c|c|c|c|c|c|}
\hline Condition & \multicolumn{2}{|c|}{ Result } & Condition & \multicolumn{2}{|c|}{ Result } \\
\hline \multirow{2}{*}{ Initial } & FWHM & 0.36865 & \multirow{2}{*}{ DI water } & FWHM & 0 \\
\hline & $\%$ Change & - & & $\%$ Change & $x$ \\
\hline \multirow{2}{*}{$120^{\circ} \mathrm{C}$ Air } & FWHM & 0.36102 & \multirow{2}{*}{$\mathrm{BuNH}_{2} / \mathrm{THF}$} & FWHM & 0.31949 \\
\hline & $\%$ Change & -3 & & $\%$ Change & -14 \\
\hline \multirow{2}{*}{$180^{\circ} \mathrm{C}$ Air } & FWHM & 0.35587 & \multirow{2}{*}{$\mathrm{PhMgBr} / \mathrm{THF}$} & FWHM & 0.33437 \\
\hline & $\%$ Change & -4 & & $\%$ Change & -10 \\
\hline \multirow{2}{*}{ Conc. $\mathrm{HCl}$} & FWHM & 0 & \multirow{2}{*}{ TBAF/THF } & FWHM & 0 \\
\hline & $\%$ Change & $x$ & & $\%$ Change & $x$ \\
\hline \multirow{2}{*}{$\mathrm{pH}=1$ Buffer } & FWHM & 0 & \multirow{2}{*}{$\mathrm{Me}_{3} \mathrm{SiCl} / \mathrm{CH}_{2} \mathrm{Cl}_{2}$} & FWHM & 0 \\
\hline & $\%$ Change & $x$ & & $\%$ Change & $x$ \\
\hline \multirow{2}{*}{$\mathrm{pH}=4$ Buffer } & FWHM & 0 & \multirow{2}{*}{$\mathrm{MeCOCl} / \mathrm{CH}_{2} \mathrm{Cl}_{2}$} & FWHM & 0 \\
\hline & $\%$ Change & $x$ & & $\%$ Change & $x$ \\
\hline \multirow{2}{*}{$\mathrm{pH}=7$ Buffer } & FWHM & 0 & \multirow{2}{*}{$\mathrm{SO}_{2} \mathrm{Cl}_{2} / \mathrm{CH}_{2} \mathrm{Cl}_{2}$} & FWHM & 0 \\
\hline & $\%$ Change & $x$ & & $\%$ Change & $x$ \\
\hline \multirow{2}{*}{$\mathrm{pH}=10$ Buffer } & FWHM & 0 & \multirow{2}{*}{$\mathrm{Me}_{2} \mathrm{SO}_{4} / \mathrm{CH}_{2} \mathrm{Cl}_{2}$} & FWHM & 0.34831 \\
\hline & $\%$ Change & $x$ & & $\%$ Change & -5 \\
\hline \multirow{2}{*}{$\mathrm{pH}=13$ Buffer } & FWHM & 0 & \multirow{2}{*}{$\mathrm{Br}_{2} / \mathrm{CH}_{2} \mathrm{Cl}_{2}$} & FWHM & 0 \\
\hline & $\%$ Change & $x$ & & $\%$ Change & $\times$ \\
\hline \multirow{2}{*}{ Sat. $\mathrm{NaOH}$} & FWHM & 0 & \multirow{2}{*}{$\mathrm{I}_{2} / \mathrm{CH}_{2} \mathrm{Cl}_{2}$} & FWHM & 0.33401 \\
\hline & $\%$ Change & $x$ & & $\%$ Change & -10 \\
\hline \multirow{2}{*}{$\mathrm{CH}_{3} \mathrm{COOH}$} & FWHM & 0 & \multirow{2}{*}{$\mathrm{MCPBA} / \mathrm{CH}_{2} \mathrm{Cl}_{2}$} & FWHM & 0 \\
\hline & $\%$ Change & $\times$ & & $\%$ Change & $\times$ \\
\hline \multirow{2}{*}{ LiHMDS/Tol } & FWHM & 0.3207 & \multirow{2}{*}{$\mathrm{PCC} / \mathrm{CH}_{2} \mathrm{Cl}_{2}$} & FWHM & 0.29654 \\
\hline & $\%$ Change & -14 & & $\%$ Change & -20 \\
\hline \multirow{2}{*}{$\mathrm{H}_{2} \mathrm{~S} / \mathrm{THF}$} & FWHM & 0.34183 & \multirow{2}{*}{$\mathrm{SmI}_{2} / \mathrm{THF}$} & FWHM & 0.34578 \\
\hline & $\%$ Change & -8 & & $\%$ Change & -7 \\
\hline \multirow{2}{*}{$\mathrm{NH}_{3} / \mathrm{MeOH}$} & FWHM & 0.31085 & \multirow{2}{*}{$\mathrm{LiBH}_{4} / \mathrm{THF}$} & FWHM & 0.36237 \\
\hline & $\%$ Change & -16 & & $\%$ Change & -2 \\
\hline
\end{tabular}




\section{Synthesis, characterization, and stability assessment of ZIF-8.}

Synthesis of ZIF-8. This procedure is adapted from the literature. ${ }^{28}$ A $350 \mathrm{~mL}$ screw-cap high-pressure reaction flask equipped with a stir bar was charged with 2-methylimidazole ( $\mathrm{H} 2 \mathrm{mim}$, $0.84 \mathrm{~g}, 10.0 \mathrm{mmol}, 1.00$ equiv.), $\mathrm{Zn}\left(\mathrm{NO}_{3}\right)_{2} \cdot 6 \mathrm{H}_{2} \mathrm{O}$ (3.35 g, $10.0 \mathrm{mmol}, 1.00$ equiv.), and $N, N$ dimethylformamide $(250 \mathrm{~mL})$. The reaction mixture was stirred for $20 \mathrm{~min}$ and then sonicated for 20 min to dissolve all reagents. The vessel was sealed and transferred to a silicone oil bath, which was then heated to $140^{\circ} \mathrm{C}$. The reaction mixture was allowed to stir $(700 \mathrm{rpm})$ at $140{ }^{\circ} \mathrm{C}$ for $24 \mathrm{~h}$. After $24 \mathrm{~h}$, the heterogeneous reaction mixture was allowed to cool to room temperature. The reaction mixture was filtered. The resulting white solid was transferred to a $500 \mathrm{~mL}$ Pyrex jar with $\mathrm{N}, \mathrm{N}$-dimethylformamide $(250 \mathrm{~mL})$. The jar was allowed to stand for $24 \mathrm{~h}$ at room temperature, at which time the $\mathrm{N}, \mathrm{N}$-dimethylformamide was decanted and replaced with fresh $\mathrm{N}, \mathrm{N}$ dimethylformamide $(250 \mathrm{~mL})$. This procedure was repeated two additional times for a total of three $N, N$-dimethylformamide soaks. Next, the solid was filtered and returned to the jar with fresh methanol $(250 \mathrm{~mL})$. The solid was soaked in methanol for $24 \mathrm{~h}$ at room temperature three total times following the same procedure as described above. Complete exchange of $\mathrm{N}, \mathrm{N}$ dimethylformamide for methanol was confirmed by IR spectroscopy. The resulting white solid was filtered and transferred to a Schlenk flask. The solid was activated under flowing $\mathrm{N}_{2}$ at 150 ${ }^{\circ} \mathrm{C}$ for $4 \mathrm{~h}$, followed by further activation under high vacuum ( $<100 \mathrm{mbar}$ ) at $150{ }^{\circ} \mathrm{C}$ for $24 \mathrm{~h}$. The Schlenk flask was transferred into a $\mathrm{N}_{2}$-filled glovebox, and the activated ZIF-8 was transferred into a $20 \mathrm{~mL}$ scintillation vial for long-term storage. A portion of the activated sample was transferred to a pre-tared Micromeritics sample tube equipped with a Sureseal. The tube was removed from the glovebox and the sample was further activated under high vacuum $(<10 \mu \mathrm{bar})$ at $150{ }^{\circ} \mathrm{C}$ for $24 \mathrm{~h}$ prior to gas sorption measurements. 


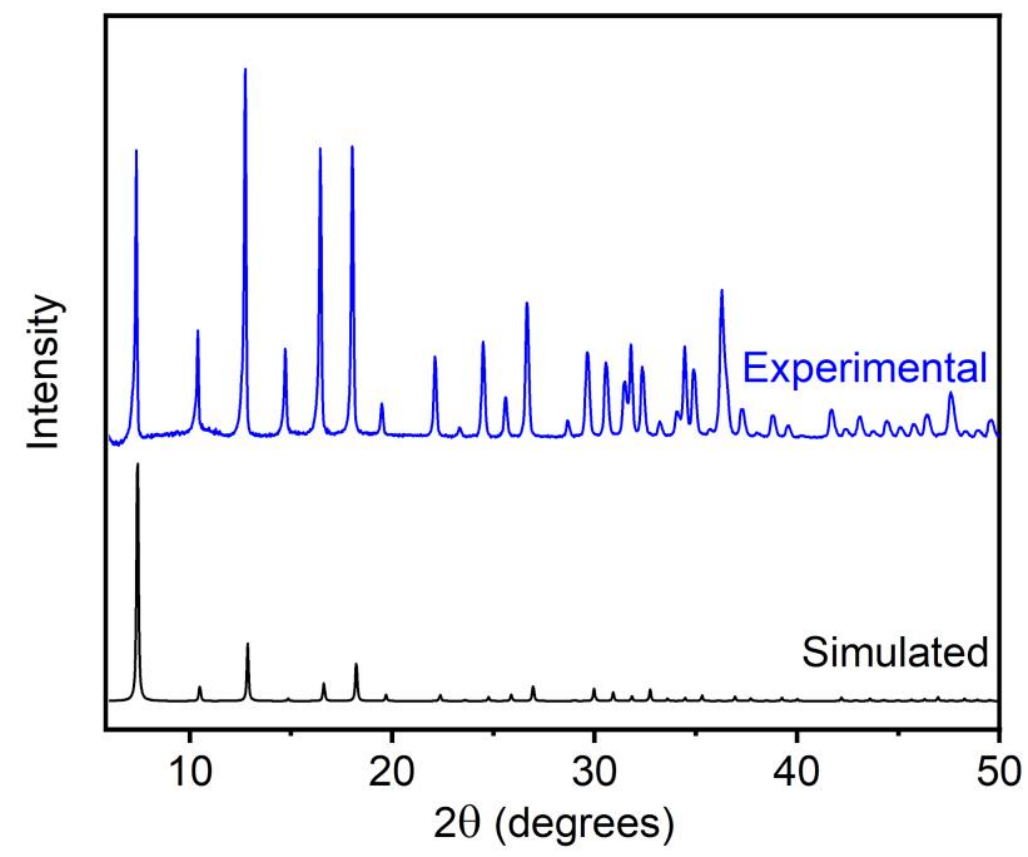

Figure S134. PXRD pattern $(\lambda=1.5406 \AA)$ of methanol-solvated ZIF- 8 . The simulated pattern based on the previously reported single-crystal X-ray diffraction structure of ZIF-8 is included for reference. ${ }^{29}$ The PXRD pattern of ZIF-8 was baseline corrected.

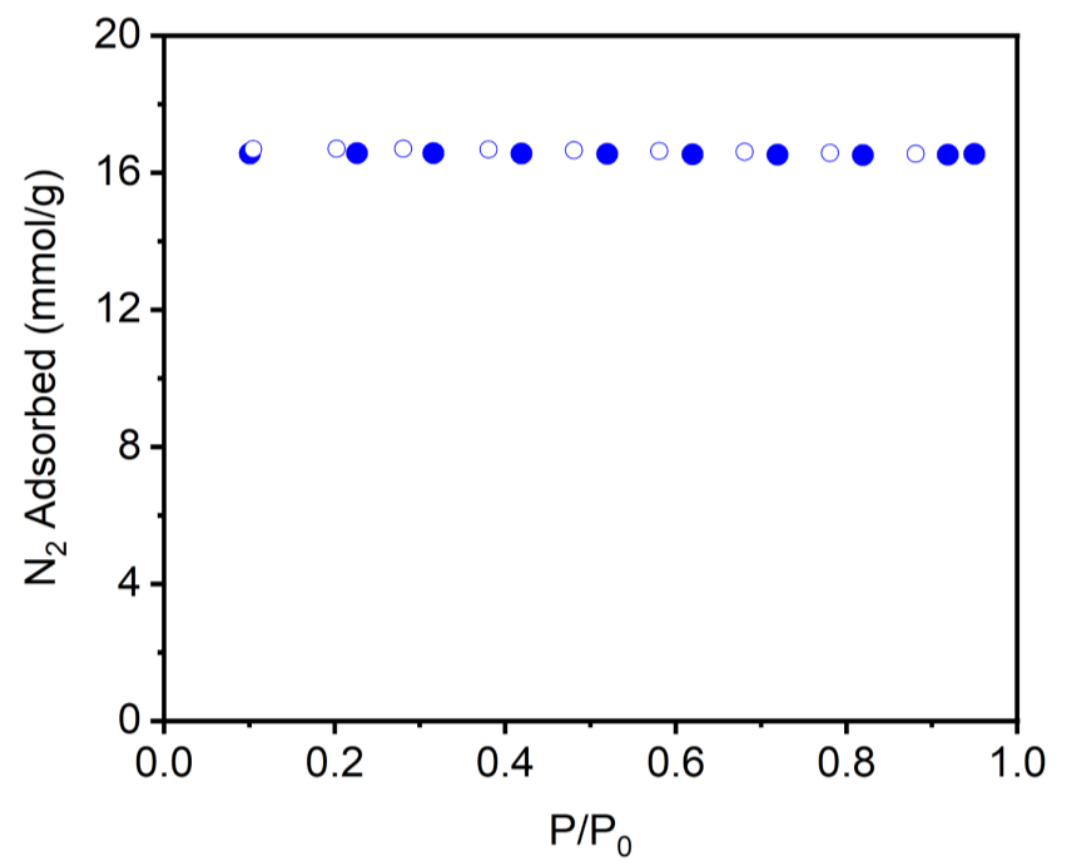

Figure S135. $77 \mathrm{~K} \mathrm{~N}_{2}$ adsorption (filled circles) and desorption (open circles) isotherm of activated ZIF-8. The Langmuir surface area determined from these data is $1609 \pm 1 \mathrm{~m}^{2} / \mathrm{g}$. 


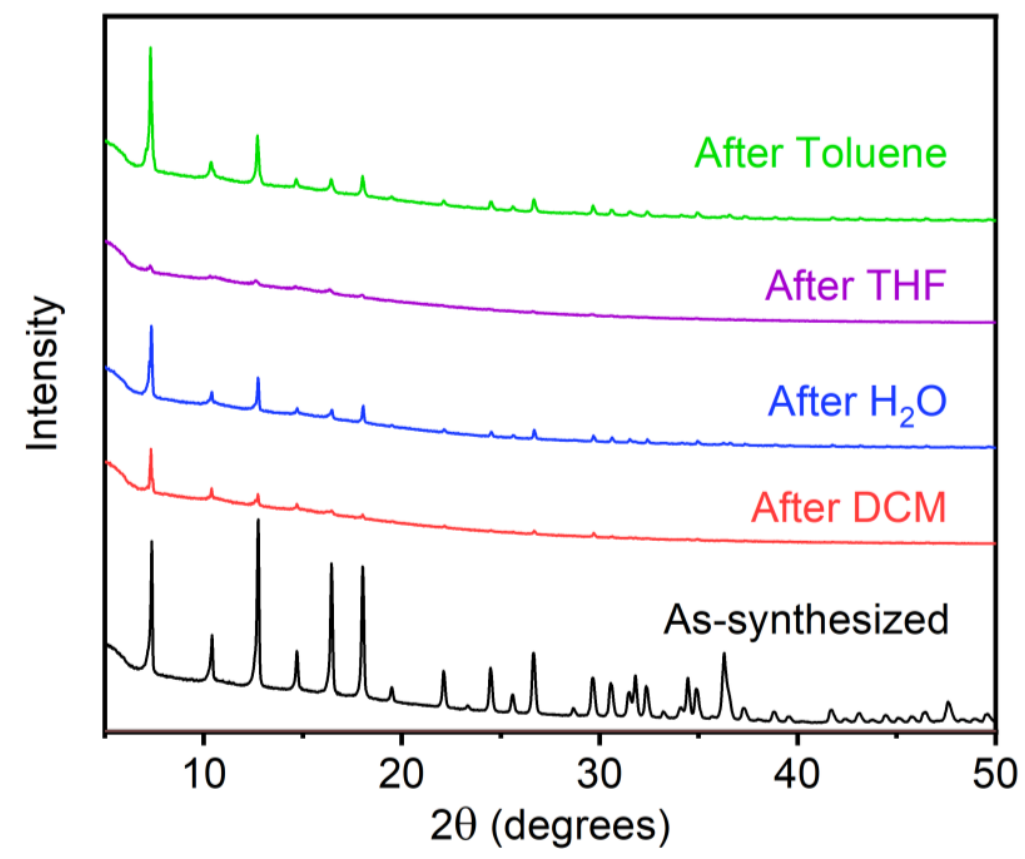

Figure S136. PXRD patterns $(\lambda=1.5406 \AA)$ of ZIF-8 upon exposure to various organic solvents and water. Note that ZIF-8 was soaked in DMF and MeOH during its synthesis as well. A reference pattern of as-synthesized ZIF-8 is included.

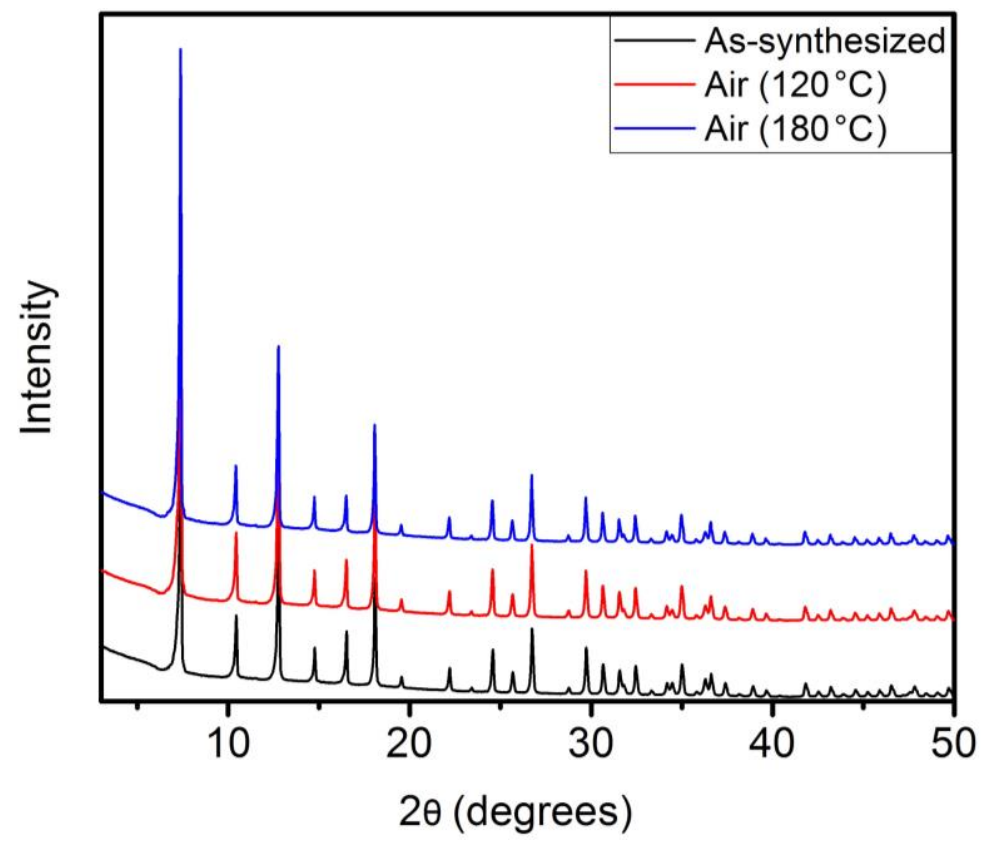

Figure S137. PXRD patterns $(\lambda=1.5406 \AA)$ of ZIF-8 upon standing at $120{ }^{\circ} \mathrm{C}$ and $180{ }^{\circ} \mathrm{C}$ in air for $24 \mathrm{~h}$. A reference pattern of as-synthesized ZIF-8 is included. 


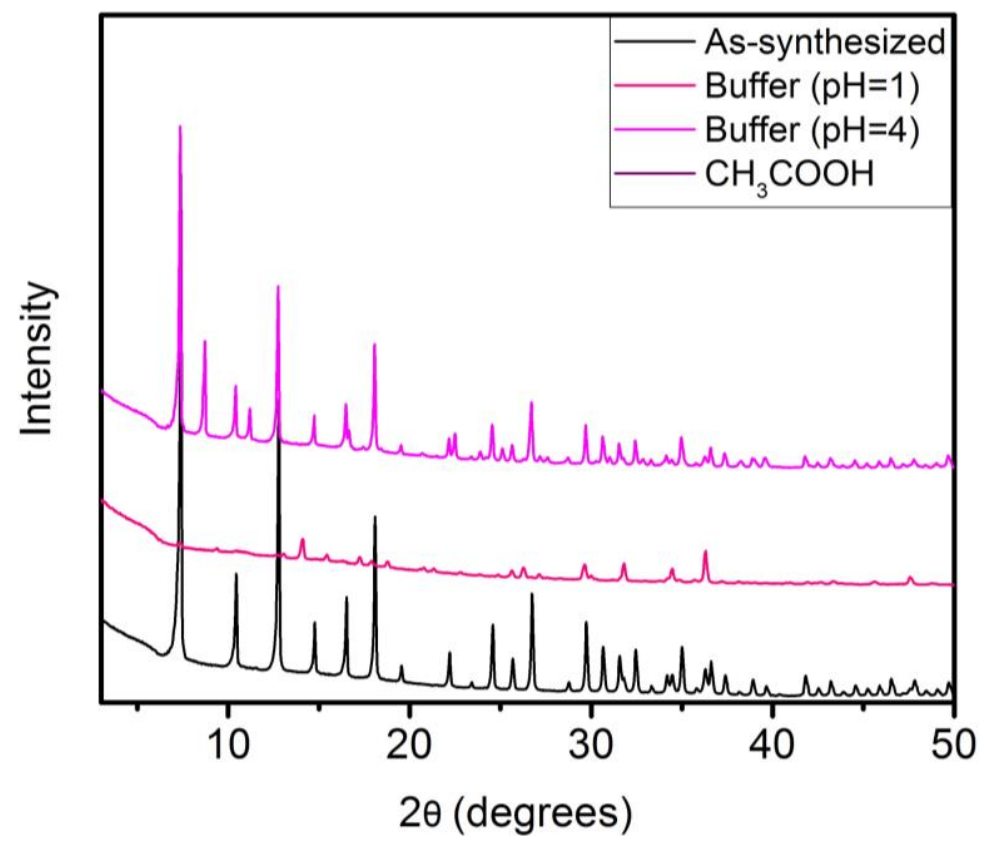

Figure S138. PXRD patterns $(\lambda=1.5406 \AA)$ of ZIF- 8 upon exposure to acids. Exposure tests include aqueous solutions buffered at $\mathrm{pH} 1$ and $\mathrm{pH} 4$ and glacial acetic acid. No solid remained after exposure to ZIF-8 to glacial acetic acid. A reference pattern of as-synthesized ZIF-8 is included.

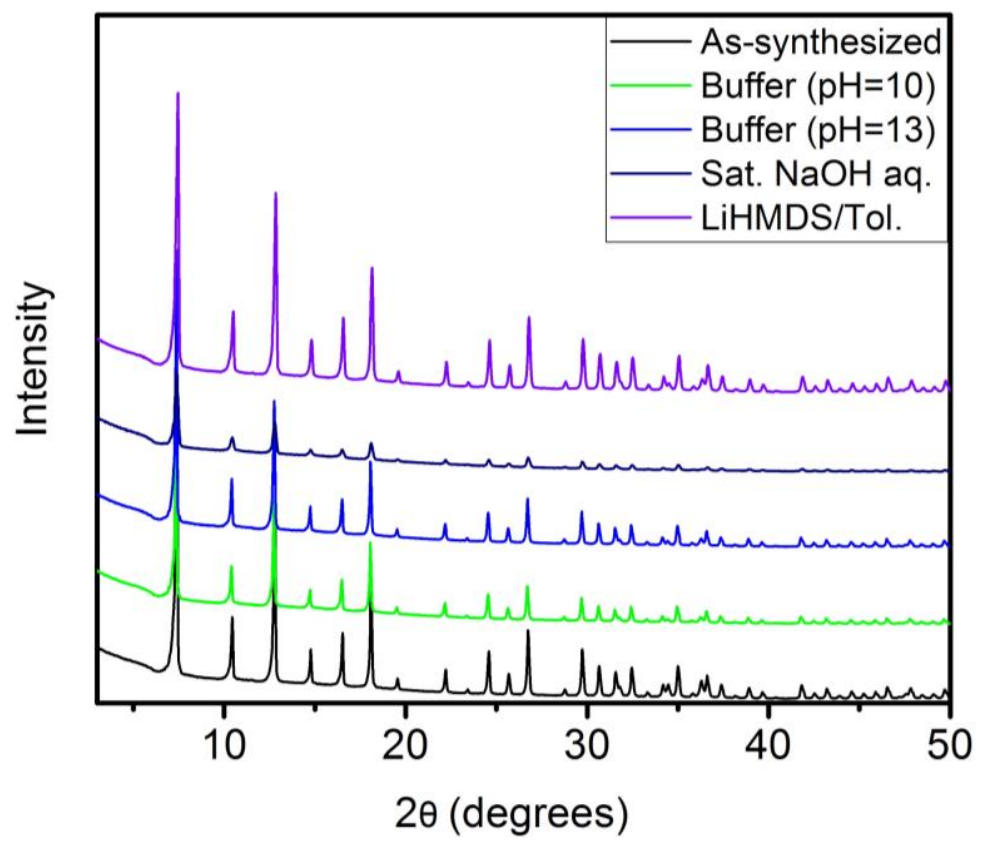

Figure S139. PXRD patterns $(\lambda=1.5406 \AA)$ of ZIF-8 upon exposure to bases. Exposure tests include aqueous solutions buffered at $\mathrm{pH} 10$ and $\mathrm{pH} 13$, saturated aqueous $\mathrm{NaOH}$, and $1.0 \mathrm{M}$ lithium hexamethyldisilazide (LiHMDS) in toluene. A reference pattern of as-synthesized ZIF-8 is included. 


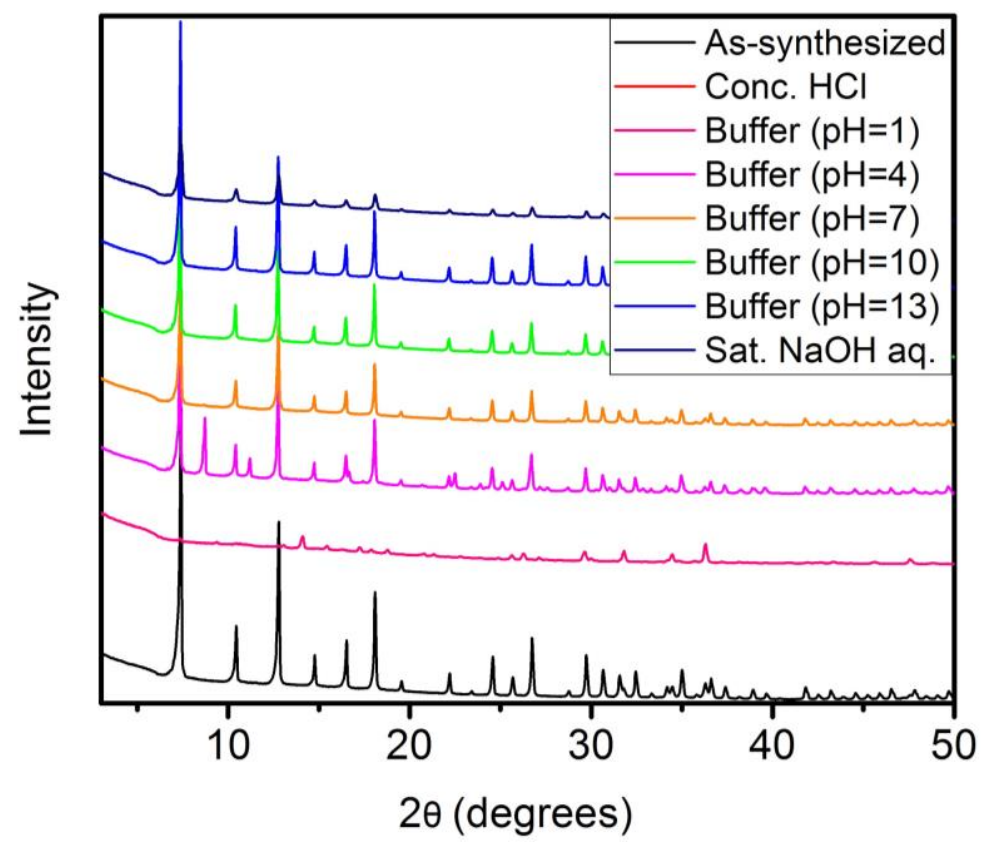

Figure S140. Summary of the PXRD patterns $(\lambda=1.5406 \AA)$ of ZIF-8 upon exposure to various aqueous conditions. No solid remained after exposure of ZIF-8 to the concentrated $\mathrm{HCl}$ solution. A reference pattern of as-synthesized ZIF-8 is included.

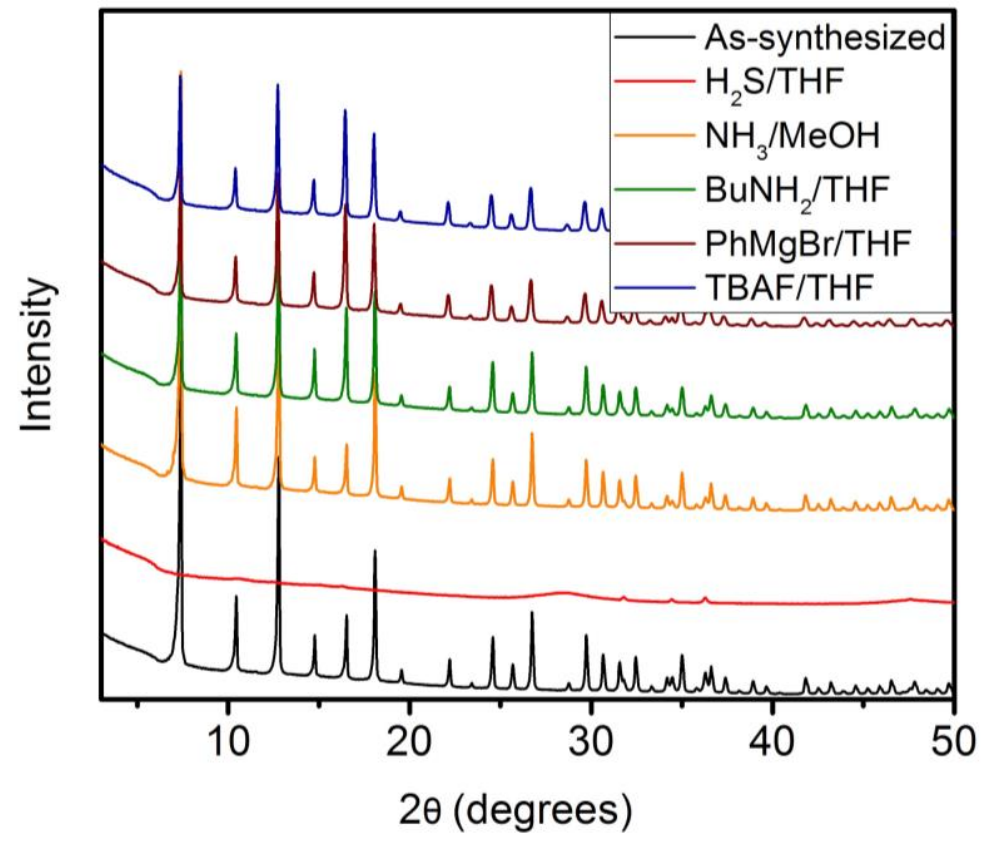

Figure S141. PXRD patterns $(\lambda=1.5406 \AA)$ of ZIF-8 upon exposure to nucleophiles. Exposure tests include $0.8 \mathrm{M}$ hydrogen sulfide in tetrahydrofuran, $1.0 \mathrm{M}$ ammonia in methanol, $1.0 \mathrm{M} \mathrm{n}$ butylamine in tetrahydrofuran, $1.0 \mathrm{M} \mathrm{PhMgBr}$ in tetrahydrofuran, and $1.0 \mathrm{M}$ tetrabutylammonium fluoride (TBAF) in tetrahydrofuran. A reference pattern of as-synthesized ZIF-8 is included 


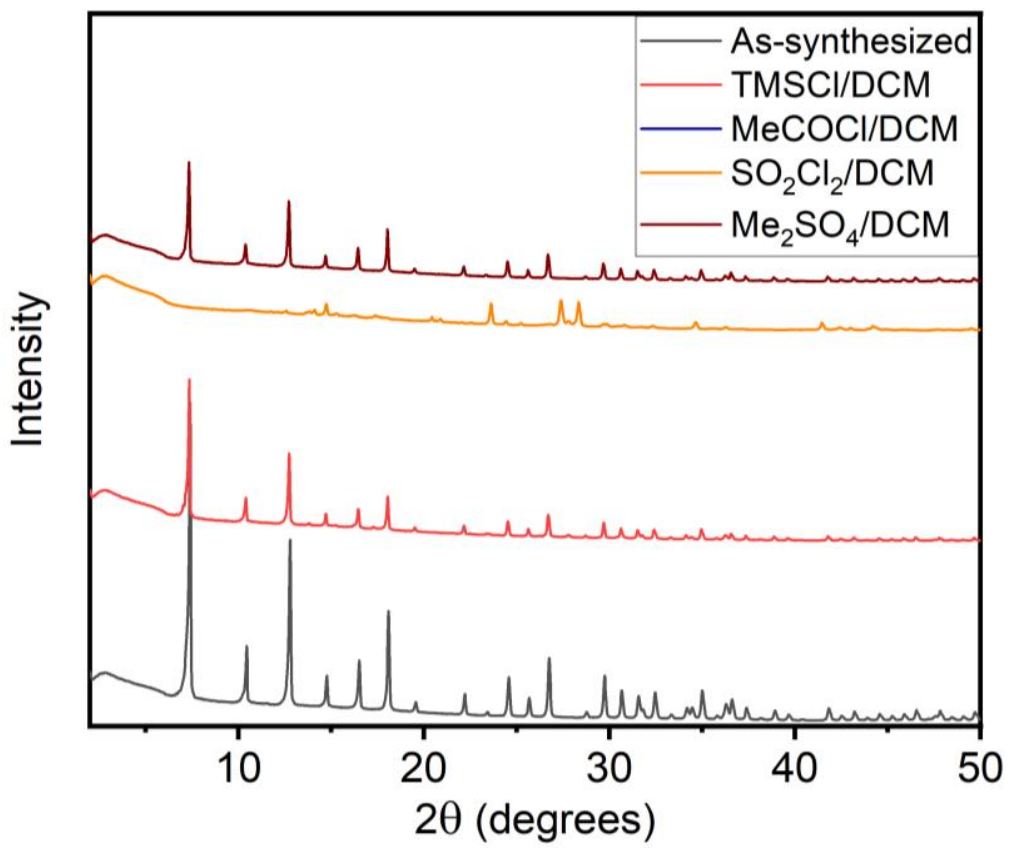

Figure S142. PXRD patterns ( $\lambda=1.5406 \AA)$ of ZIF-8 upon exposure to electrophiles. Exposure tests include $1.0 \mathrm{M}$ chlorotrimethylsilane (TMSCl) in dichloromethane, $1.0 \mathrm{M}$ acetyl chloride in dichloromethane, 1.0 M sulfuryl chloride in dichloromethane, and saturated dimethyl sulfate in dichloromethane. No solid material remained after exposure of ZIF-8 to the acetyl chloride solution. A reference pattern of as-synthesized ZIF-8 is included.

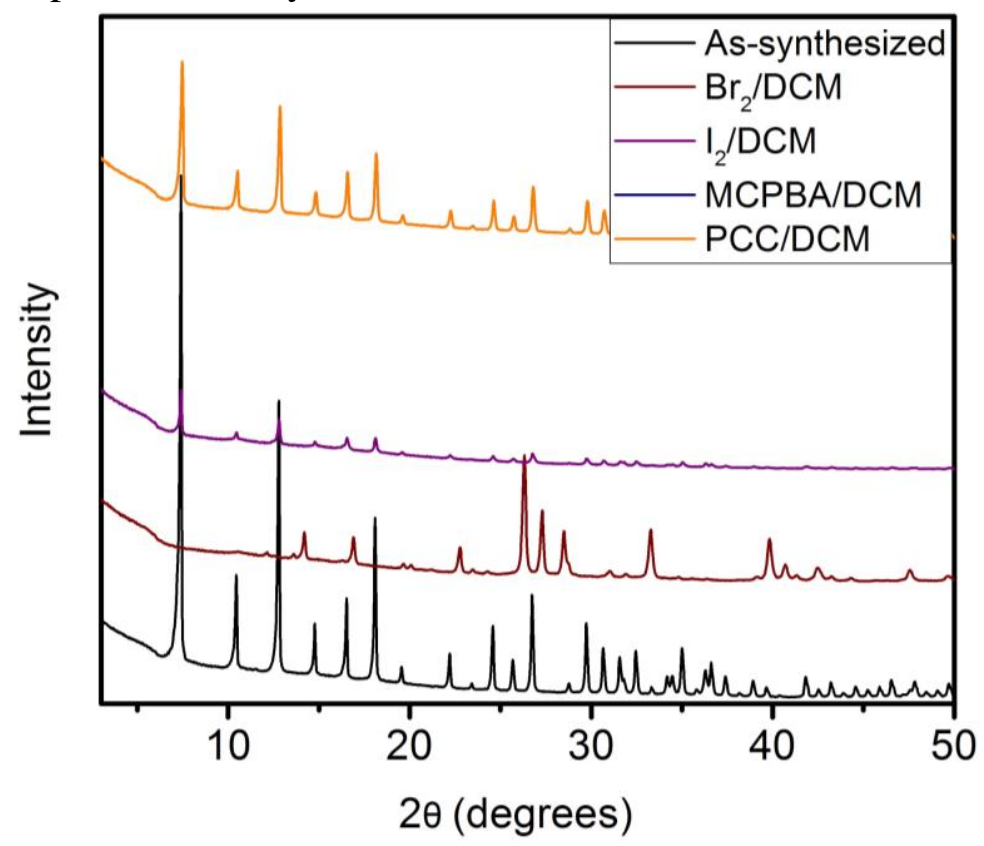

Figure S143. PXRD patterns $(\lambda=1.5406 \AA)$ of ZIF-8 upon exposure to oxidants. Exposure tests include $1.0 \mathrm{M}$ bromine in dichloromethane, saturated iodine in dichloromethane, saturated $\mathrm{m}$ chloroperoxybenzoic acid (MCPBA) in dichloromethane, and saturated pyridinium chlorochromate (PCC) in dichloromethane. No solid material remained after exposure of ZIF-8 to the MCPBA solution. A reference pattern of as-synthesized ZIF-8 is included. 


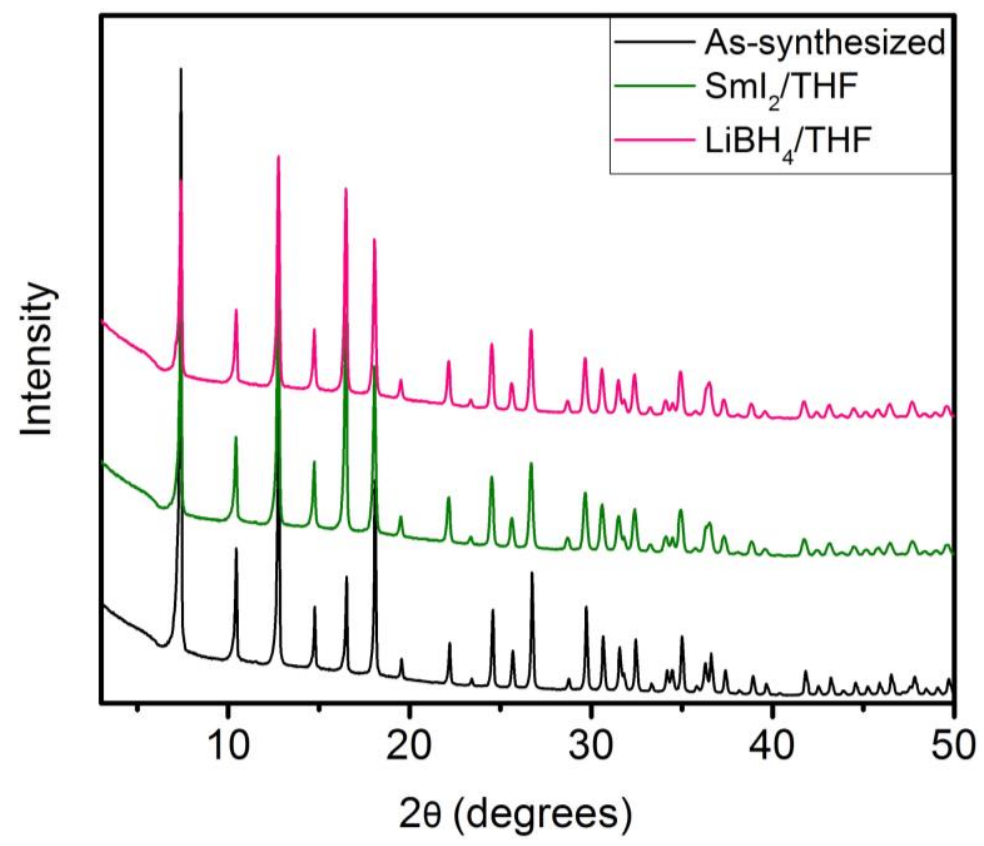

Figure S144. PXRD patterns ( $\lambda=1.5406 \AA$ ) of ZIF-8 upon exposure to reductants. Exposure tests include $0.1 \mathrm{M}$ samarium iodide in tetrahydrofuran and $1.0 \mathrm{M}$ lithium borohydride in tetrahydrofuran. A reference pattern of as-synthesized ZIF-8 is included. 
Table S12. Summary of changes in the full width at half maximum (FWHM) for the $2 \theta=7^{\circ}(\lambda=$ $1.5406 \AA$ ) reflection of ZIF-8 under a range of conditions.

\begin{tabular}{|c|c|c|c|c|c|}
\hline Condition & \multicolumn{2}{|c|}{ Result } & Condition & \multicolumn{2}{|c|}{ Result } \\
\hline \multirow{2}{*}{ Initial } & FWHM & 0.10680 & \multirow{2}{*}{ DI water } & FWHM & 0.11625 \\
\hline & $\%$ Change & - & & $\%$ Change & 9 \\
\hline \multirow{2}{*}{$120{ }^{\circ} \mathrm{C}$ Air } & FWHM & 0.11183 & \multirow{2}{*}{$\mathrm{BuNH}_{2} / \mathrm{THF}$} & FWHM & 0.10801 \\
\hline & $\%$ Change & 5 & & $\%$ Change & 2 \\
\hline \multirow{2}{*}{$180{ }^{\circ} \mathrm{C}$ Air } & FWHM & 0.10076 & \multirow{2}{*}{$\mathrm{PhMgBr} / \mathrm{THF}$} & FWHM & 0.10988 \\
\hline & $\%$ Change & -6 & & $\%$ Change & 3 \\
\hline \multirow{2}{*}{ Conc. $\mathrm{HCl}$} & FWHM & 0 & \multirow{2}{*}{ TBAF/THF } & FWHM & 0.10852 \\
\hline & $\%$ Change & $x$ & & $\%$ Change & 2 \\
\hline \multirow{2}{*}{$\mathrm{pH}=1$ Buffer } & FWHM & 0 & \multirow{2}{*}{$\mathrm{Me}_{3} \mathrm{SiCl} / \mathrm{CH}_{2} \mathrm{Cl}_{2}$} & FWHM & 0.09164 \\
\hline & $\%$ Change & $x$ & & $\%$ Change & -15 \\
\hline \multirow{2}{*}{$\mathrm{pH}=4$ Buffer } & FWHM & 0.09923 & \multirow{2}{*}{$\mathrm{MeCOCl} / \mathrm{CH}_{2} \mathrm{Cl}_{2}$} & FWHM & 0 \\
\hline & $\%$ Change & $-8^{a}$ & & $\%$ Change & $x$ \\
\hline \multirow{2}{*}{$\mathrm{pH}=7$ Buffer } & FWHM & 0.09864 & \multirow{2}{*}{$\mathrm{SO}_{2} \mathrm{Cl}_{2} / \mathrm{CH}_{2} \mathrm{Cl}_{2}$} & FWHM & 0 \\
\hline & $\%$ Change & -8 & & $\%$ Change & $x$ \\
\hline \multirow{2}{*}{$\mathrm{pH}=10$ Buffer } & FWHM & 0.11681 & \multirow{2}{*}{$\mathrm{Me}_{2} \mathrm{SO}_{4} / \mathrm{CH}_{2} \mathrm{Cl}_{2}$} & FWHM & 0.10389 \\
\hline & $\%$ Change & 10 & & $\%$ Change & -3 \\
\hline \multirow{2}{*}{$\mathrm{pH}=13$ Buffer } & FWHM & 0.10301 & \multirow{2}{*}{$\mathrm{Br}_{2} / \mathrm{CH}_{2} \mathrm{Cl}_{2}$} & FWHM & 0 \\
\hline & $\%$ Change & -4 & & $\%$ Change & $x$ \\
\hline \multirow{2}{*}{ Sat. $\mathrm{NaOH}$} & FWHM & 0.19761 & \multirow{2}{*}{$\mathrm{I}_{2} / \mathrm{CH}_{2} \mathrm{Cl}_{2}$} & FWHM & 0.08849 \\
\hline & $\%$ Change & 86 & & $\%$ Change & -18 \\
\hline \multirow{2}{*}{$\mathrm{CH}_{3} \mathrm{COOH}$} & FWHM & 0 & \multirow{2}{*}{$\mathrm{MCPBA} / \mathrm{CH}_{2} \mathrm{Cl}_{2}$} & FWHM & 0 \\
\hline & $\%$ Change & $\times$ & & $\%$ Change & $x$ \\
\hline \multirow{2}{*}{ LiHMDS/Tol } & FWHM & 0.16015 & \multirow{2}{*}{$\mathrm{PCC} / \mathrm{CH}_{2} \mathrm{Cl}_{2}$} & FWHM & 0.15358 \\
\hline & $\%$ Change & 50 & & $\%$ Change & 44 \\
\hline \multirow{2}{*}{$\mathrm{H}_{2} \mathrm{~S} / \mathrm{THF}$} & FWHM & 0 & \multirow{2}{*}{$\mathrm{SmI}_{2} / \mathrm{THF}$} & FWHM & 0.12591 \\
\hline & $\%$ Change & $\times$ & & $\%$ Change & 18 \\
\hline \multirow{2}{*}{$\mathrm{NH}_{3} / \mathrm{MeOH}$} & FWHM & 0.10484 & \multirow{2}{*}{$\mathrm{LiBH}_{4} / \mathrm{THF}$} & FWHM & 0.12639 \\
\hline & $\%$ Change & -2 & & $\%$ Change & 19 \\
\hline
\end{tabular}

${ }^{a}$ New reflections observed by PXRD. 


\section{Synthesis, characterization, and stability assessment of $\mathrm{Ni}_{2} \mathrm{Cl}_{2}$ (btdd).}

Synthesis of $\mathbf{N i}_{2} \mathbf{C l}_{\mathbf{2}}$ (btdd). This procedure is adapted from the literature. ${ }^{30}$ Three $1 \mathrm{~L}$ Pyrex jars were each charged with bis(1H-1,2,3-triazolo[4,5-b],[4',5'-i])dibenzo[1,4]dioxin) ( $\mathrm{H}_{2}$ btdd, $0.30 \mathrm{~g}, 1.13 \mathrm{mmol}, 1.00$ equiv.) and $N, N$-dimethylformamide $(300 \mathrm{~mL})$. The jars were sealed and placed in an oven that had been pre-heated to $100{ }^{\circ} \mathrm{C}$. Once the solutions became homogeneous they were removed from the oven and allowed to cool to room temperature. Separately, three separate solutions of $\mathrm{NiCl}_{2} \cdot 6 \mathrm{H}_{2} \mathrm{O}(0.59 \mathrm{~g}, 2.48 \mathrm{mmol}, 2.20$ equiv.) dissolved in methanol ( $300 \mathrm{~mL})$ and concentrated aq. $\mathrm{HCl}(192 \mathrm{~mL})$ were prepared. The three $\mathrm{NiCl}_{2} \bullet 6 \mathrm{H}_{2} \mathrm{O}$ solutions were added separately to the three Pyrex jars. The jars were sealed and returned to the oven. The jars were allowed to stand at $100{ }^{\circ} \mathrm{C}$ for $2 \mathrm{~d}$. At this time, the jars were removed from the oven. The heterogeneous reaction mixtures were filtered, combining the solid from all three jars into one sample. The resulting solid was transferred to a $1 \mathrm{~L}$ Pyrex jar with $N, N$-dimethylformamide (500 $\mathrm{mL}$ ). The jar was allowed to stand for $24 \mathrm{~h}$ at room temperature, at which time the $N, N$ dimethylformamide was decanted and replaced with fresh $N, N$-dimethylformamide $(500 \mathrm{~mL})$. This procedure was repeated two additional times for a total of three $N, N$-dimethylformamide soaks. Next, the solid was filtered and returned to the jar with fresh methanol $(500 \mathrm{~mL})$. The solid was soaked in methanol for $24 \mathrm{~h}$ at room temperature three total times following the same procedure described above. The heterogeneous mixture was filtered, and the resulting solid was transferred to a Schlenk flask. The solid was activated under flowing $\mathrm{N}_{2}$ at $150^{\circ} \mathrm{C}$ for $4 \mathrm{~h}$, followed by further activation under high vacuum ( $<100$ mbar) at $150{ }^{\circ} \mathrm{C}$ for $24 \mathrm{~h}$, during which time the $\mathrm{Ni}_{2} \mathrm{Cl}_{2}$ (btdd) became brown in color. The Schlenk flask was transferred into a $\mathrm{N}_{2}$-filled glovebox, and the activated $\mathrm{Ni}_{2} \mathrm{Cl}_{2}$ (btdd) was transferred into a $20 \mathrm{~mL}$ scintillation vial for long-term storage. A portion of the activated sample was transferred to a pre-tared Micromeritics sample tube equipped with a Sureseal. The tube was removed from the glovebox and the sample was further activated under high vacuum $(<10 \mu \mathrm{bar})$ at $150^{\circ} \mathrm{C}$ for $24 \mathrm{~h}$ prior to gas sorption measurements. 


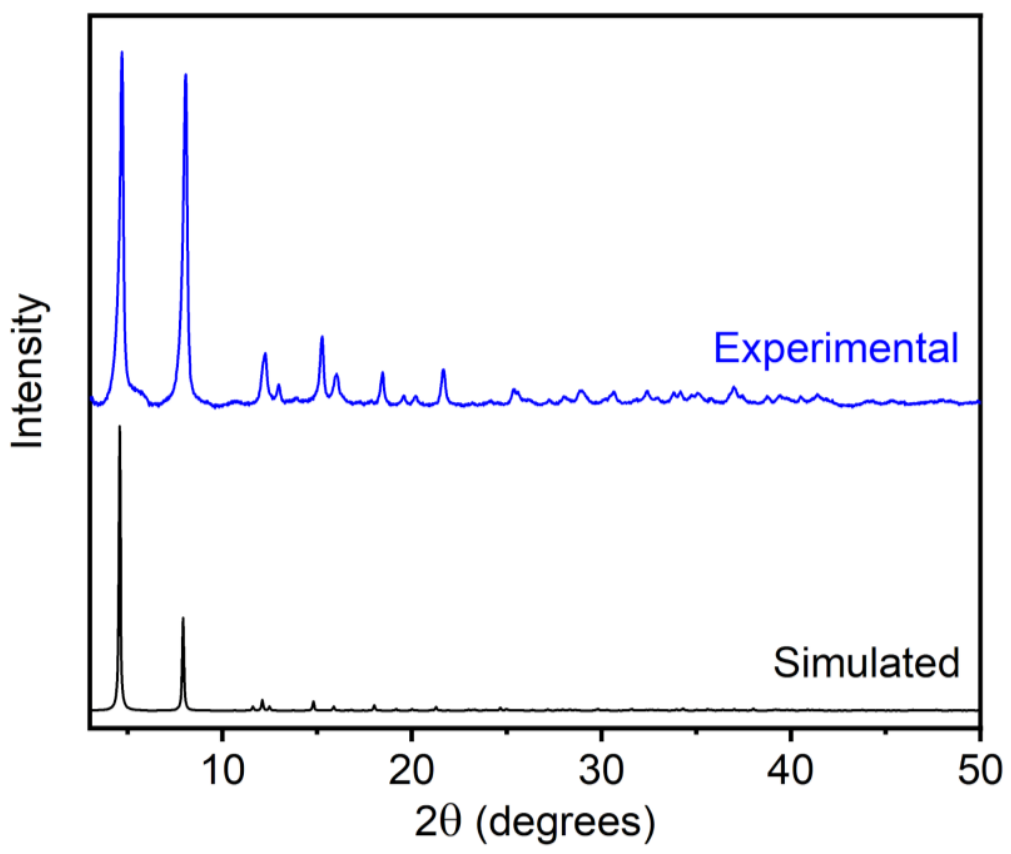

Figure S145. PXRD pattern $(\lambda=1.5406 \AA)$ of methanol-solvated $\mathrm{Ni}_{2} \mathrm{Cl}_{2}$ (btdd). The simulated pattern based on the previously reported single-crystal X-ray diffraction structure of the isostructural framework $\mathrm{Mn}_{2} \mathrm{Cl}_{2}$ (btdd) is included for reference. ${ }^{31}$ The PXRD pattern of $\mathrm{Ni}_{2} \mathrm{Cl}_{2}$ (btdd) was baseline corrected.

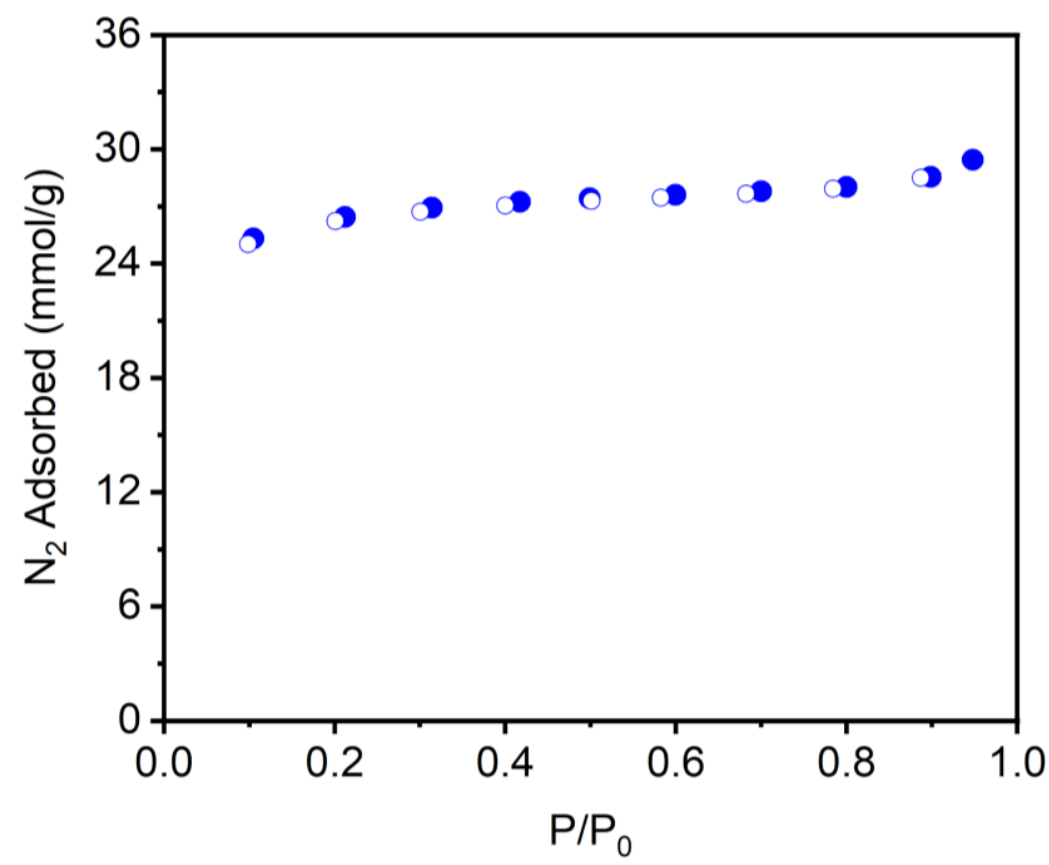

Figure S146. $77 \mathrm{~K} \mathrm{~N}_{2}$ adsorption (filled circles) and desorption (open circles) isotherm of activated $\mathrm{Ni}_{2} \mathrm{Cl}_{2}$ (btdd). The Langmuir surface area determined from these data is $2791 \pm 12 \mathrm{~m} / \mathrm{g}$. 


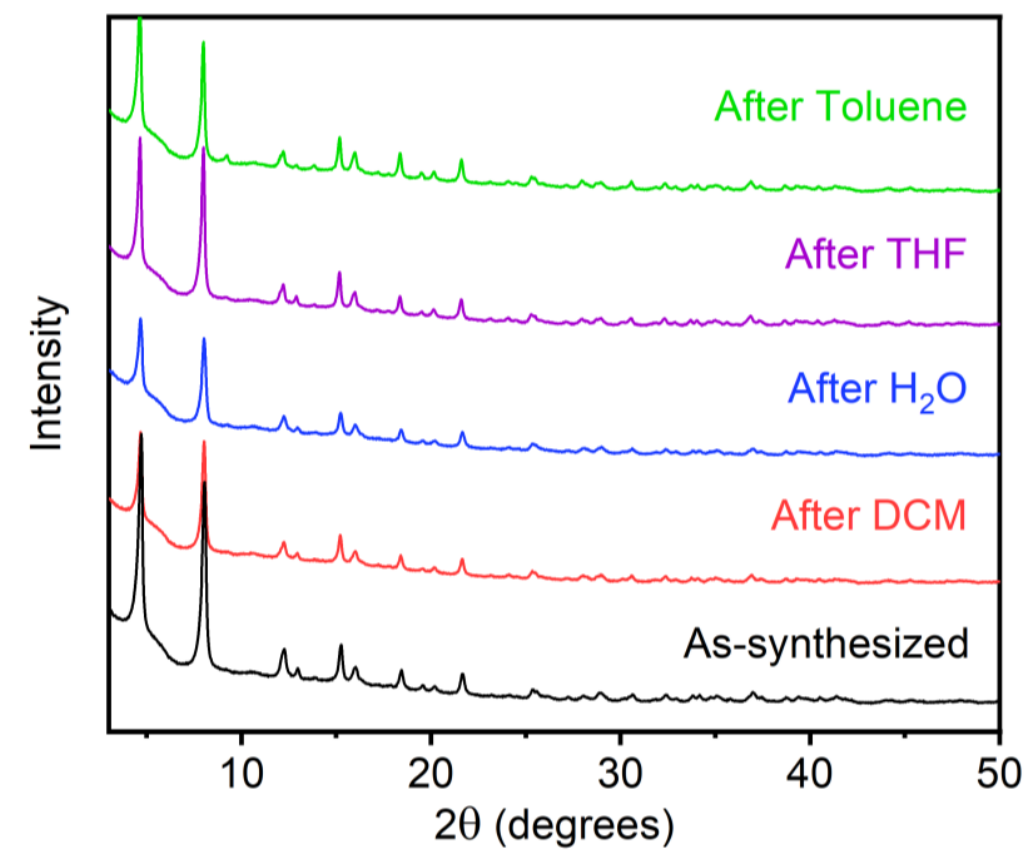

Figure S147. PXRD patterns $(\lambda=1.5406 \AA)$ of $\mathrm{Ni}_{2} \mathrm{Cl}_{2}$ (btdd) upon exposure to various organic solvents and water. Note that $\mathrm{Ni}_{2} \mathrm{Cl}_{2}$ (btdd) was soaked in DMF and $\mathrm{MeOH}$ during its synthesis as well. A reference pattern of as-synthesized $\mathrm{Ni}_{2} \mathrm{Cl}_{2}$ (btdd) is included.

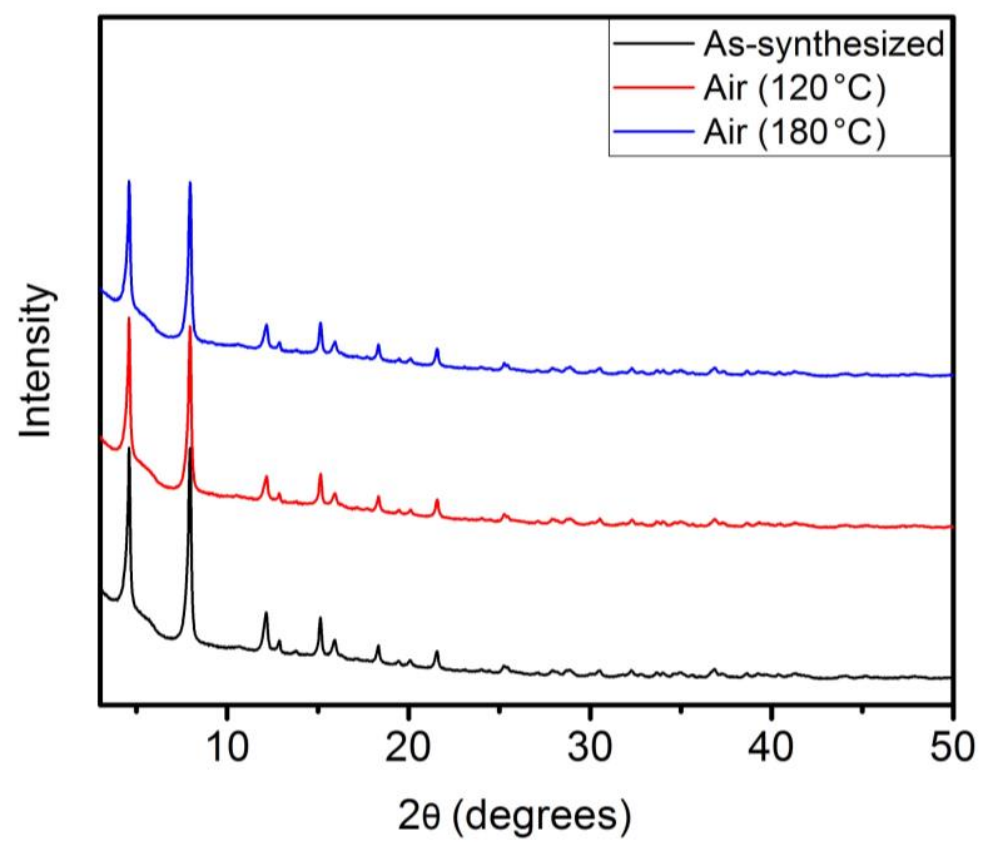

Figure S148. PXRD patterns ( $\lambda=1.5406 \AA$ ) of $\mathrm{Ni}_{2} \mathrm{Cl}_{2}$ (btdd) upon standing at $120{ }^{\circ} \mathrm{C}$ and $180{ }^{\circ} \mathrm{C}$ in air for $24 \mathrm{~h}$. A reference pattern of as-synthesized $\mathrm{Ni}_{2} \mathrm{Cl}_{2}$ (btdd) is included. 


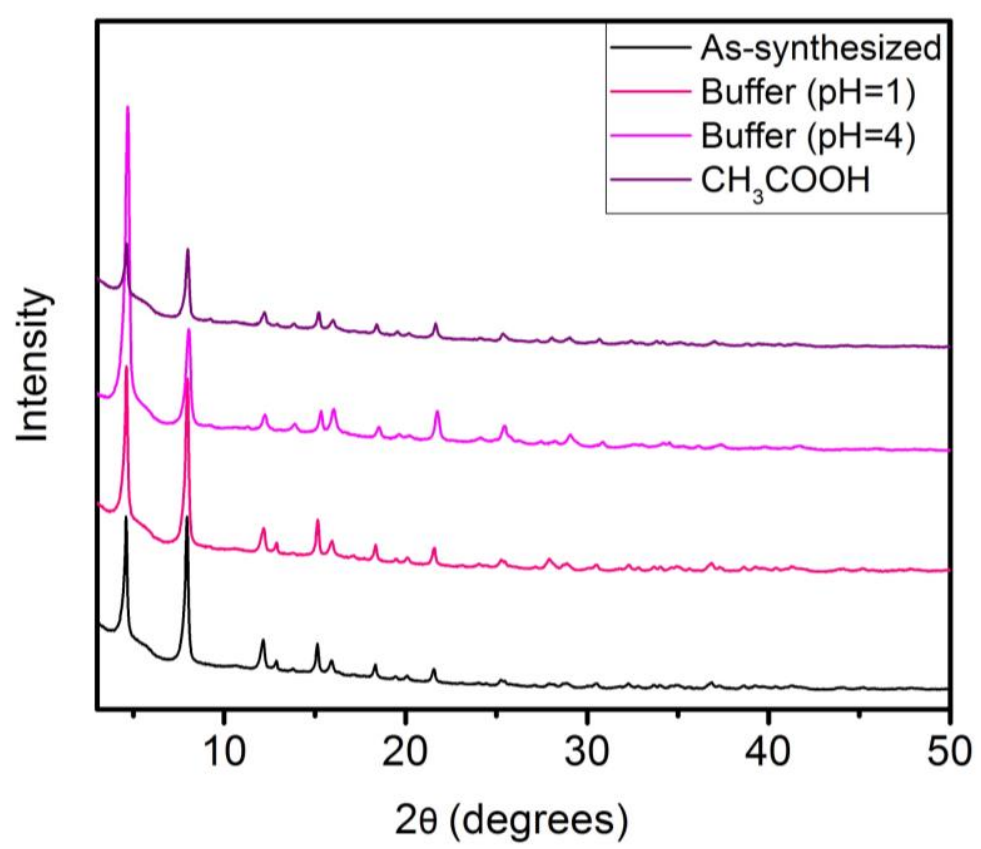

Figure S149. PXRD patterns $(\lambda=1.5406 \AA)$ of $\mathrm{Ni}_{2} \mathrm{Cl}_{2}$ (btdd) upon exposure to acids. Exposure tests include aqueous solutions buffered at $\mathrm{pH} 1$ and $\mathrm{pH} 4$ and glacial acetic acid. A reference pattern of as-synthesized $\mathrm{Ni}_{2} \mathrm{Cl}_{2}$ (btdd) is included.

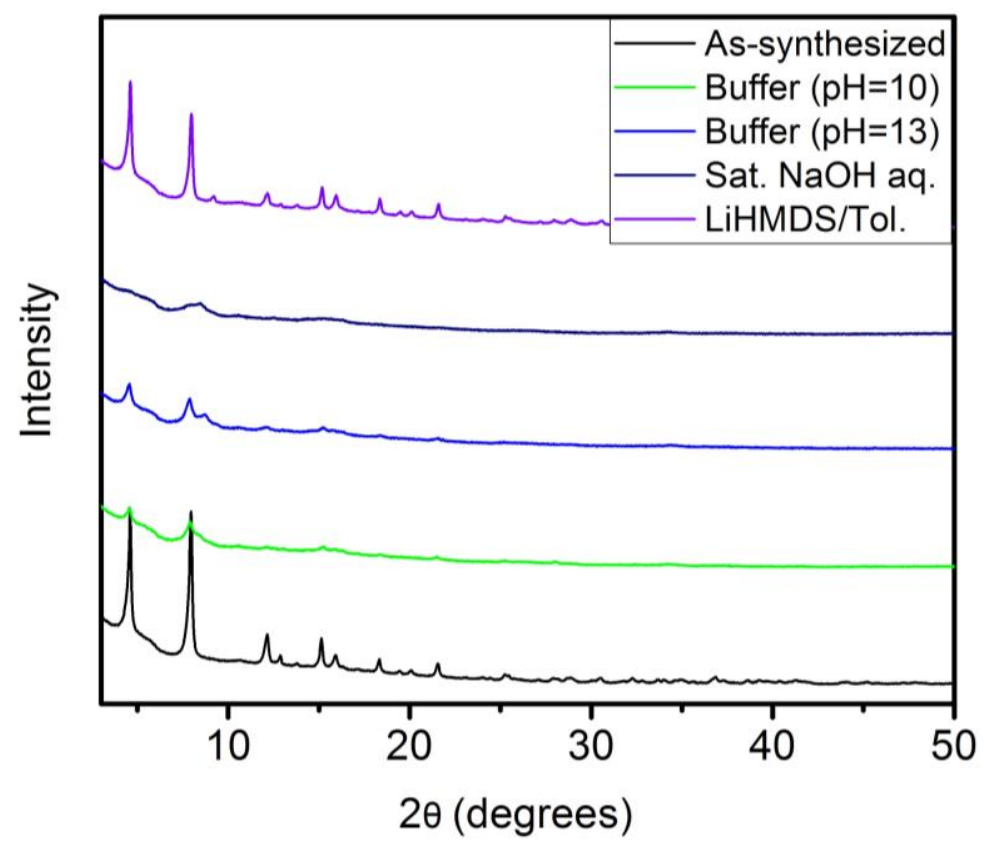

Figure S150. PXRD patterns $(\lambda=1.5406 \AA)$ of $\mathrm{Ni}_{2} \mathrm{Cl}_{2}$ (btdd) upon exposure to bases. Exposure tests include aqueous solutions buffered at $\mathrm{pH} 10$ and $\mathrm{pH} 13$, saturated aqueous $\mathrm{NaOH}$, and $1.0 \mathrm{M}$ lithium hexamethyldisilazide (LiHMDS) in toluene. A reference pattern of as-synthesized $\mathrm{Ni}_{2} \mathrm{Cl}_{2}$ (btdd) is included. 


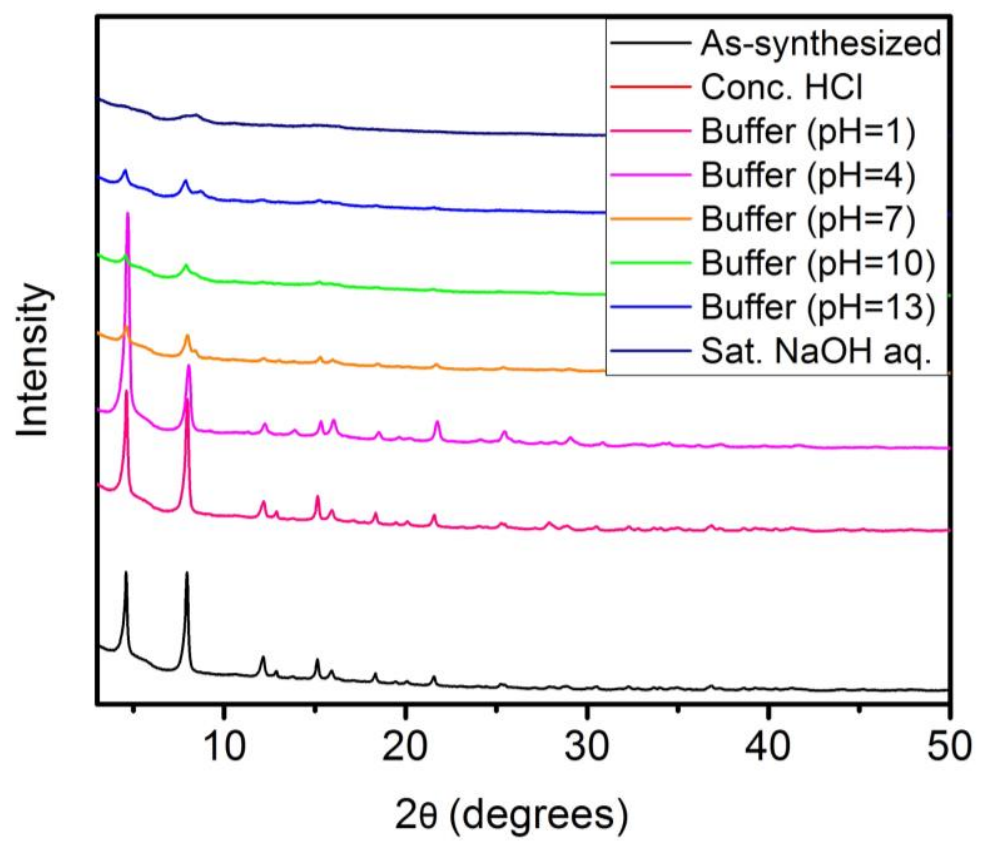

Figure S151. Summary of the PXRD patterns $(\lambda=1.5406 \AA)$ of $\mathrm{Ni}_{2} \mathrm{Cl}_{2}$ (btdd) upon exposure to various aqueous conditions. A reference pattern of as-synthesized $\mathrm{Ni}_{2} \mathrm{Cl}_{2}$ (btdd) is included.

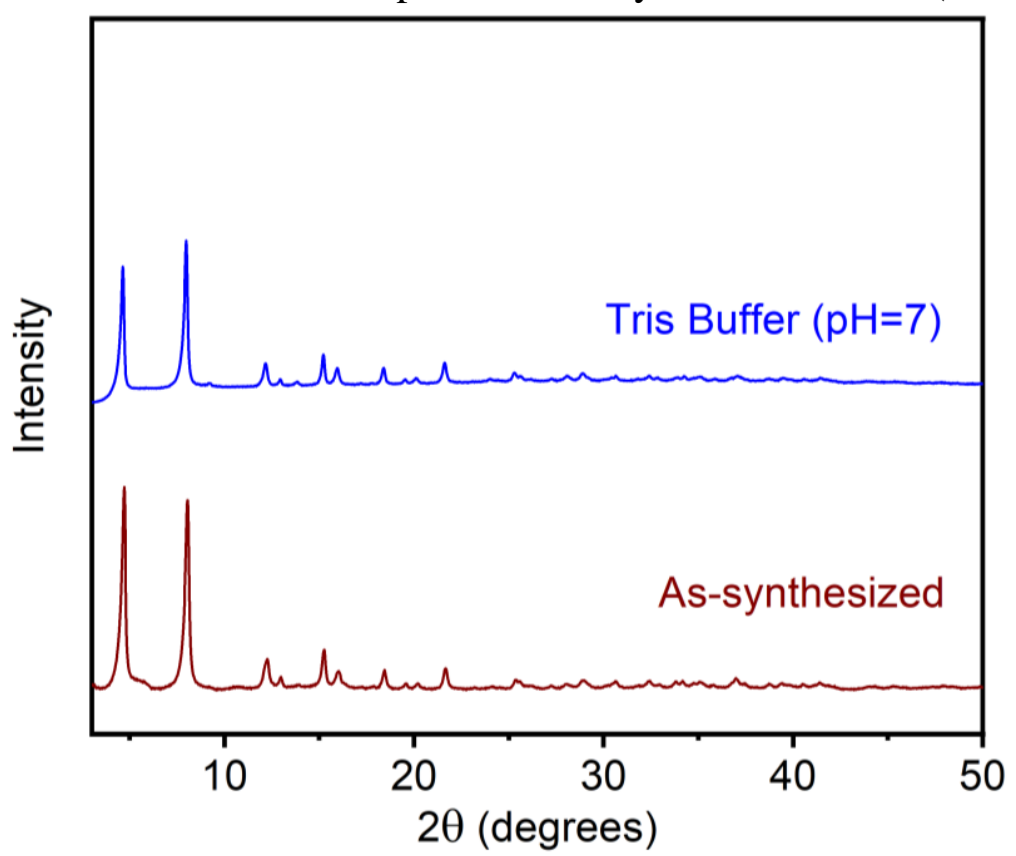

Figure S152. PXRD patterns for $\mathrm{Ni}_{2} \mathrm{Cl}_{2}$ (btdd) before and after exposure to aqueous tris buffer $(\mathrm{pH}=7)$. The initial FWHM for the peak at $2 \theta=4^{\circ}$ was $0.27458^{\circ}$, and the FWHM after exposure to buffer was $0.24743^{\circ}$, resulting in a $-10 \%$ change in FWHM after the exposure test. 


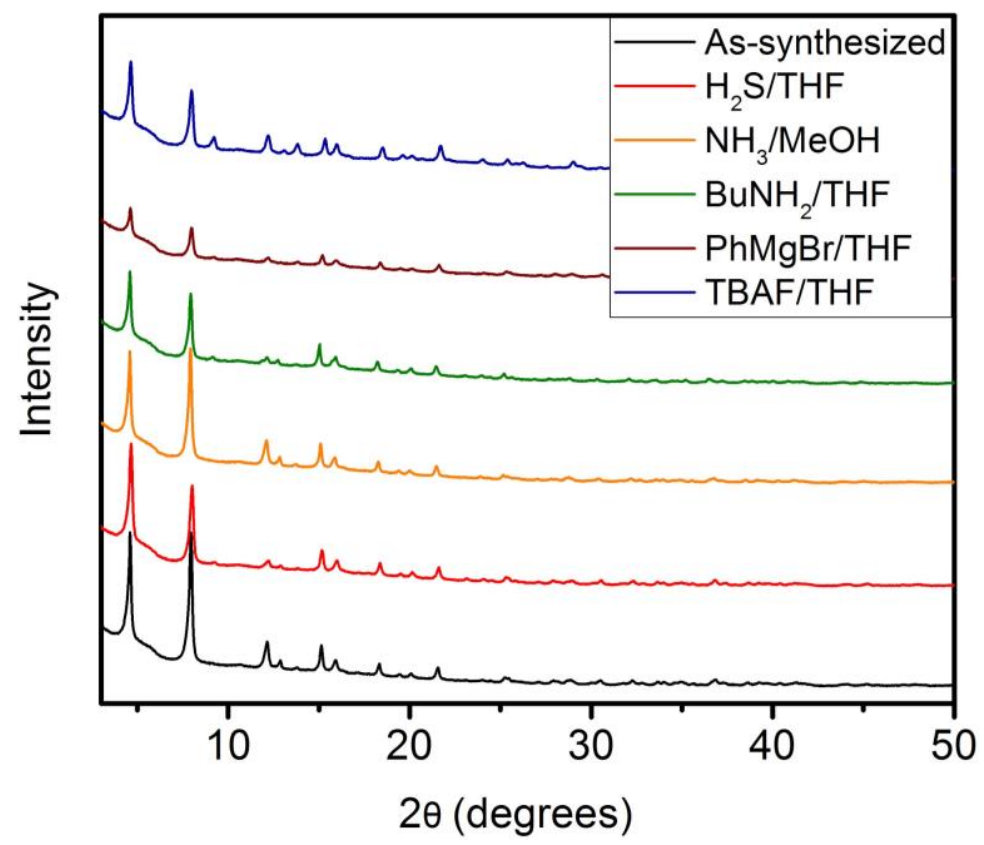

Figure S153. PXRD patterns $(\lambda=1.5406 \AA)$ of $\mathrm{Ni}_{2} \mathrm{Cl}_{2}$ (btdd) upon exposure to nucleophiles. Exposure tests include $0.8 \mathrm{M}$ hydrogen sulfide in tetrahydrofuran, $1.0 \mathrm{M}$ ammonia in methanol, $1.0 \mathrm{M} n$-butylamine in tetrahydrofuran, $1.0 \mathrm{M} \mathrm{PhMgBr}$ in tetrahydrofuran, and $1.0 \mathrm{M}$ tetrabutylammonium fluoride (TBAF) in tetrahydrofuran. A reference pattern of as-synthesized $\mathrm{Ni}_{2} \mathrm{Cl}_{2}$ (btdd) is included.

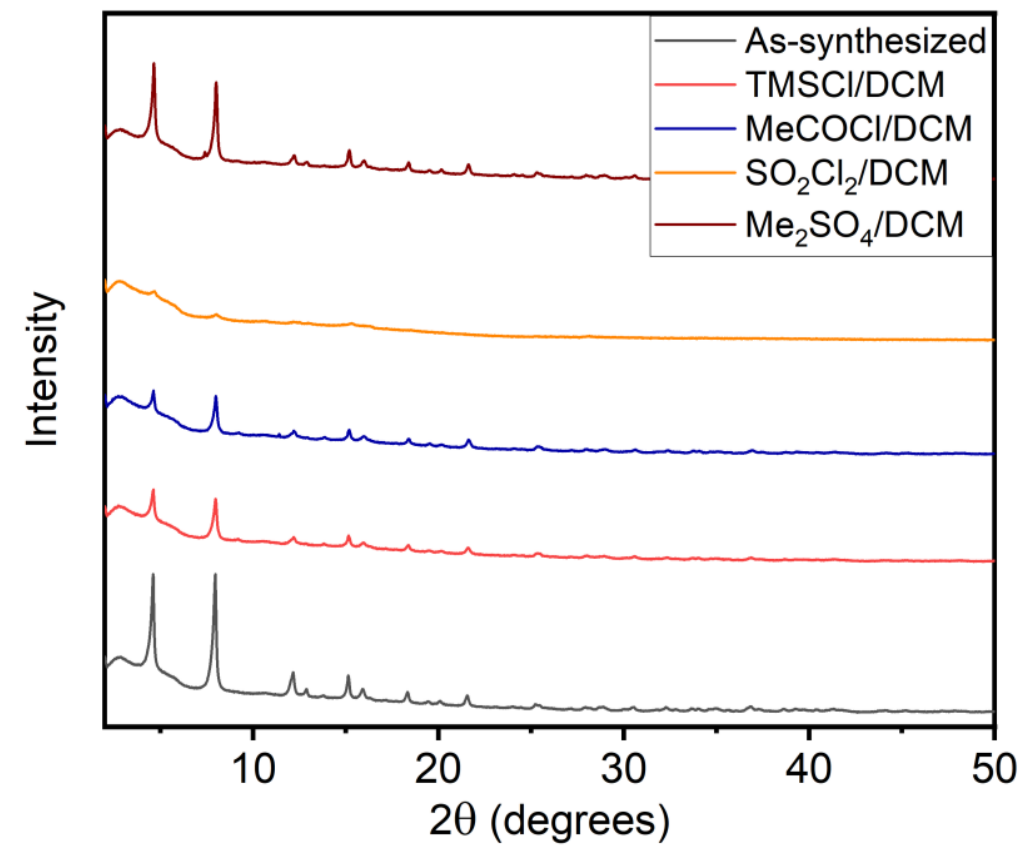

Figure S154. PXRD patterns $(\lambda=1.5406 \AA)$ of $\mathrm{Ni}_{2} \mathrm{Cl}_{2}(\mathrm{btdd})$ upon exposure to electrophiles. Exposure tests include $1.0 \mathrm{M}$ chlorotrimethylsilane (TMSCl) in dichloromethane, $1.0 \mathrm{M}$ acetyl chloride in dichloromethane, $1.0 \mathrm{M}$ sulfuryl chloride in dichloromethane, and saturated dimethyl sulfate in dichloromethane. A reference pattern of as-synthesized $\mathrm{Ni}_{2} \mathrm{Cl}_{2}$ (btdd) is included. 


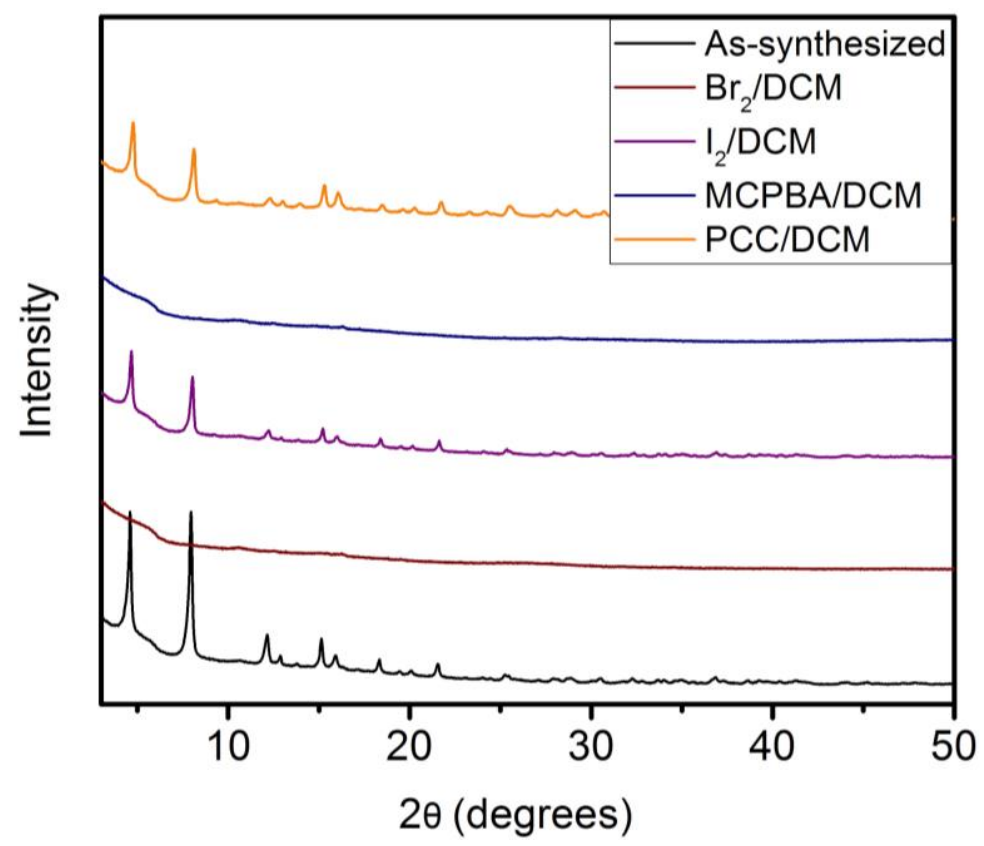

Figure S155. PXRD patterns $(\lambda=1.5406 \AA)$ of $\mathrm{Ni}_{2} \mathrm{Cl}_{2}$ (btdd) upon exposure to oxidants. Exposure tests include $1.0 \mathrm{M}$ bromine in dichloromethane, saturated iodine in dichloromethane, saturated $m$-chloroperoxybenzoic acid (MCPBA) in dichloromethane, and saturated pyridinium chlorochromate (PCC) in dichloromethane. A reference pattern of as-synthesized $\mathrm{Ni}_{2} \mathrm{Cl}_{2}$ (btdd) is included.

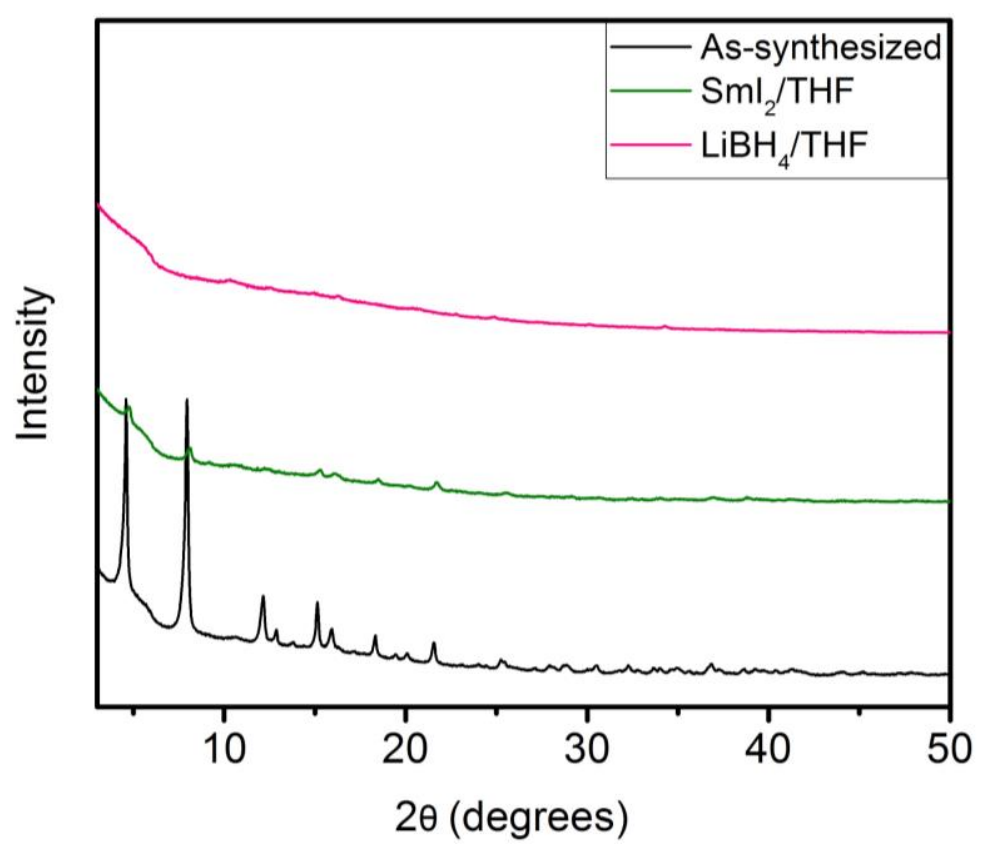

Figure S156. PXRD patterns $(\lambda=1.5406 \AA)$ of $\mathrm{Ni}_{2} \mathrm{Cl}_{2}(\mathrm{btdd})_{2}$ upon exposure to reductants. Exposure tests include $0.1 \mathrm{M}$ samarium iodide in tetrahydrofuran and $1.0 \mathrm{M}$ lithium borohydride in tetrahydrofuran. A reference pattern of as-synthesized $\mathrm{Ni}_{2} \mathrm{Cl}_{2}$ (btdd) is included. 
Table S13. Summary of changes in the full width at half maximum (FWHM) for the $2 \theta=4^{\circ}(\lambda=$ $1.5406 \AA$ ) reflection of $\mathrm{Ni}_{2} \mathrm{Cl}_{2}$ (btdd) under a range of conditions.

\begin{tabular}{|c|c|c|c|c|c|}
\hline Condition & \multicolumn{2}{|c|}{ Result } & Condition & \multicolumn{2}{|c|}{ Result } \\
\hline \multirow{2}{*}{ Initial } & FWHM & 0.21190 & \multirow{2}{*}{ DI water } & FWHM & 0.24349 \\
\hline & $\%$ Change & - & & $\%$ Change & 15 \\
\hline \multirow{2}{*}{$120^{\circ} \mathrm{C}$ Air } & FWHM & 0.20227 & \multirow{2}{*}{$\mathrm{BuNH}_{2} / \mathrm{THF}$} & FWHM & 0.20279 \\
\hline & $\%$ Change & -5 & & $\%$ Change & -5 \\
\hline \multirow{2}{*}{$180^{\circ} \mathrm{C}$ Air } & FWHM & 0.20365 & \multirow{2}{*}{$\mathrm{PhMgBr} / \mathrm{THF}$} & FWHM & 0.2124 \\
\hline & $\%$ Change & -4 & & $\%$ Change & 1 \\
\hline \multirow{2}{*}{ Conc. $\mathrm{HCl}$} & FWHM & 0 & \multirow{2}{*}{ TBAF/THF } & FWHM & 0.2278 \\
\hline & $\%$ Change & $x$ & & $\%$ Change & 8 \\
\hline \multirow{2}{*}{$\mathrm{pH}=1$ Buffer } & FWHM & 0.21342 & \multirow{2}{*}{$\mathrm{Me}_{3} \mathrm{SiCl} / \mathrm{CH}_{2} \mathrm{Cl}_{2}$} & FWHM & 0.22097 \\
\hline & $\%$ Change & 1 & & $\%$ Change & 5 \\
\hline \multirow{2}{*}{$\mathrm{pH}=4$ Buffer } & FWHM & 0.28565 & \multirow{2}{*}{$\mathrm{MeCOCl} / \mathrm{CH}_{2} \mathrm{Cl}_{2}$} & FWHM & 0.19852 \\
\hline & $\%$ Change & 35 & & $\%$ Change & -7 \\
\hline \multirow{2}{*}{$\mathrm{pH}=7$ Buffer } & FWHM & 0.25888 & \multirow{2}{*}{$\mathrm{SO}_{2} \mathrm{Cl}_{2} / \mathrm{CH}_{2} \mathrm{Cl}_{2}$} & FWHM & 1.28625 \\
\hline & $\%$ Change & $23^{a}$ & & $\%$ Change & 508 \\
\hline \multirow{2}{*}{$\mathrm{pH}=10$ Buffer } & FWHM & 0.23492 & \multirow{2}{*}{$\mathrm{Me}_{2} \mathrm{SO}_{4} / \mathrm{CH}_{2} \mathrm{Cl}_{2}$} & FWHM & 0.20081 \\
\hline & $\%$ Change & $11^{b}$ & & $\%$ Change & -5 \\
\hline \multirow{2}{*}{$\mathrm{pH}=13$ Buffer } & FWHM & 0.28265 & \multirow{2}{*}{$\mathrm{Br}_{2} / \mathrm{CH}_{2} \mathrm{Cl}_{2}$} & FWHM & 0 \\
\hline & $\%$ Change & $34^{b}$ & & $\%$ Change & $x$ \\
\hline \multirow{2}{*}{ Sat. $\mathrm{NaOH}$} & FWHM & 0 & \multirow{2}{*}{$\mathrm{I}_{2} / \mathrm{CH}_{2} \mathrm{Cl}_{2}$} & FWHM & 0.21053 \\
\hline & $\%$ Change & $x$ & & $\%$ Change & -1 \\
\hline \multirow{2}{*}{$\mathrm{CH}_{3} \mathrm{COOH}$} & FWHM & 0.21062 & \multirow{2}{*}{$\mathrm{MCPBA} / \mathrm{CH}_{2} \mathrm{Cl}_{2}$} & FWHM & 0 \\
\hline & $\%$ Change & -1 & & $\%$ Change & $x$ \\
\hline \multirow{2}{*}{ LiHMDS/Tol } & FWHM & 0.20679 & \multirow{2}{*}{$\mathrm{PCC} / \mathrm{CH}_{2} \mathrm{Cl}_{2}$} & FWHM & 0.22993 \\
\hline & $\%$ Change & -3 & & $\%$ Change & 9 \\
\hline \multirow{2}{*}{$\mathrm{H}_{2} \mathrm{~S} / \mathrm{THF}$} & FWHM & 0.22022 & \multirow{2}{*}{$\mathrm{SmI}_{2} / \mathrm{THF}$} & FWHM & 0.55661 \\
\hline & $\%$ Change & 4 & & $\%$ Change & 163 \\
\hline \multirow{2}{*}{$\mathrm{NH}_{3} / \mathrm{MeOH}$} & FWHM & 0.20342 & \multirow{2}{*}{$\mathrm{LiBH}_{4} / \mathrm{THF}$} & FWHM & 0 \\
\hline & $\%$ Change & -5 & & $\%$ Change & $x$ \\
\hline
\end{tabular}

${ }^{a}-10 \%$ reduction in FWHM was observed using aqueous tris buffer $(\mathrm{pH}=7) .{ }^{b} \mathrm{New}$ reflections observed by PXRD. 


\section{Synthesis, characterization, and stability assessment of $\mathrm{Ni}_{3}(\mathrm{btp})_{2}$.}

Synthesis of $\mathbf{N i}_{3}(\mathbf{b t p})_{2}$. This procedure is adapted from the literature. ${ }^{10}$ A $350 \mathrm{~mL}$ screwcap high-pressure reaction flask equipped with a stir bar was charged with 1,3,5-tri(1H-pyrazol-4yl)benzene ( $\mathrm{H}_{3} \mathrm{btp}, 500 \mathrm{mg}, 1.81 \mathrm{mmol}, 1.00$ equiv.) and $N, N$-dimethylformamide $(50 \mathrm{~mL})$. The flask was transferred to a silicone oil bath that had been pre-heated to $60{ }^{\circ} \mathrm{C}$, and the reaction mixture was allowed to stir vigorously $(700 \mathrm{rpm})$ at this temperature for $5 \mathrm{~min}$. At this time, $\mathrm{Ni}(\mathrm{OAc})_{2} \bullet 4 \mathrm{H}_{2} \mathrm{O}(676 \mathrm{mg}, 2.72 \mathrm{mmol}, 1.50$ equiv.) was added in one portion, and the flask was rinsed with additional $\mathrm{N}, \mathrm{N}$-dimethylformamide $(5 \mathrm{~mL})$. The reaction vessel was sealed and the silicone oil bath was heated to $130{ }^{\circ} \mathrm{C}$. The reaction mixture was allowed to vigorously stir (700 $\mathrm{rpm}$ ) at $130{ }^{\circ} \mathrm{C}$ for $24 \mathrm{~h}$. At this time, the heterogeneous reaction mixture was allowed to cool to room temperature and filtered. The resulting dark green solid was transferred to a $500 \mathrm{~mL}$ Pyrex jar with $N, N$-dimethylformamide $(250 \mathrm{~mL})$. The jar was allowed to stand for $24 \mathrm{~h}$ at $120{ }^{\circ} \mathrm{C}$ in an oven, at which time the $N, N$-dimethylformamide was decanted and replaced with fresh $N, N$ dimethylformamide $(250 \mathrm{~mL})$. This procedure was repeated two additional times for a total of three hot $N, N$-dimethylformamide soaks. Next, the solid was filtered and returned to the jar with fresh methanol $(200 \mathrm{~mL})$. The solid was soaked in methanol for $24 \mathrm{~h}$ at $60{ }^{\circ} \mathrm{C}$ in an oven three total times following the same procedure as described above. Complete exchange of $N, N$ dimethylformamide for methanol was confirmed by IR spectroscopy. The resulting dark green solid was filtered and transferred to a Schlenk flask. The solid was activated under flowing $\mathrm{N}_{2}$ at $180{ }^{\circ} \mathrm{C}$ for $4 \mathrm{~h}$, followed by further activation under high vacuum $(<100 \mathrm{mbar})$ at $180{ }^{\circ} \mathrm{C}$ for $24 \mathrm{~h}$. During the activation procedure, the material changed in color from dark green to brown. The Schlenk flask was transferred into a $\mathrm{N}_{2}$-filled glovebox, and the activated $\mathrm{Ni}_{3}$ (btp) 2 was transferred into a $20 \mathrm{~mL}$ scintillation vial for long-term storage. A portion of the activated sample was transferred to a pre-tared Micromeritics sample tube equipped with a Sureseal. The tube was removed from the glovebox and the sample was further activated under high vacuum $(<10 \mu$ bar $)$ at $180{ }^{\circ} \mathrm{C}$ for $24 \mathrm{~h}$ prior to gas sorption measurements.

A second sample with an initial FWHM of $0.18742^{\circ}$ was prepared following the same procedure. 


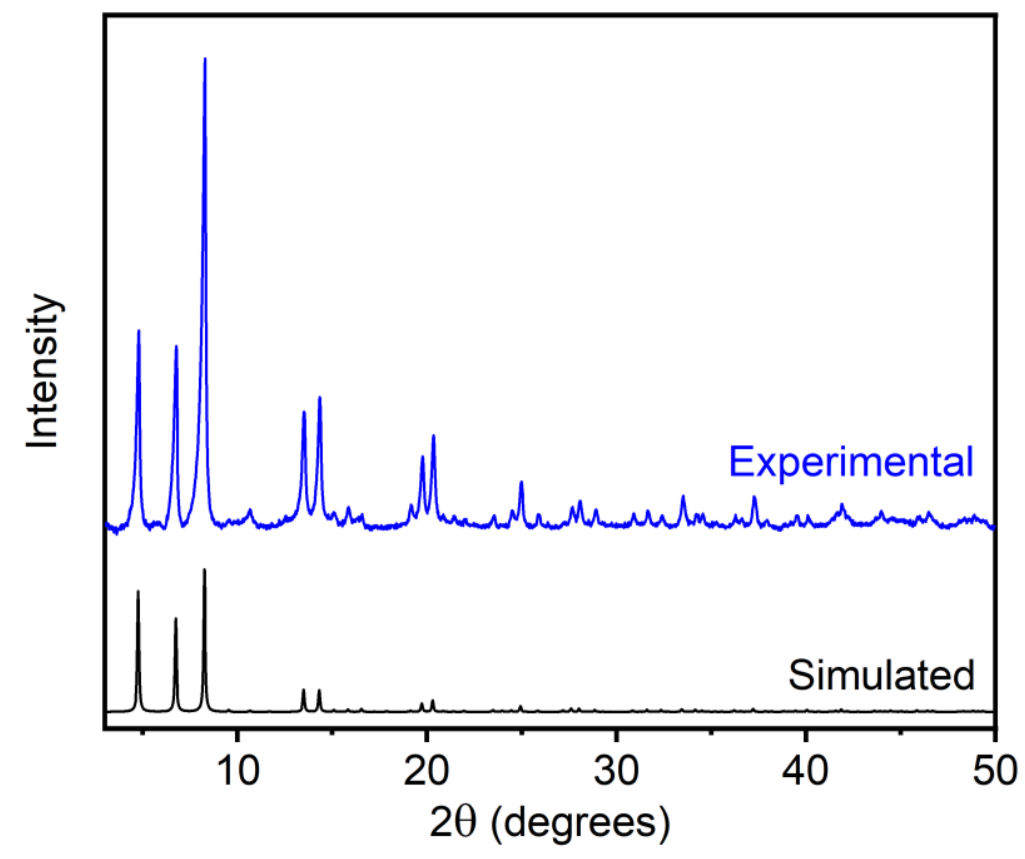

Figure S157. PXRD pattern $(\lambda=1.5406 \AA)$ of methanol-solvated $\mathrm{Ni}_{3}(\mathrm{btp})_{2}$. The simulated pattern based on the previously reported powder X-ray diffraction structure of $\mathrm{Ni}_{3}(\mathrm{btp})_{2}$ is included for reference. ${ }^{10}$ The PXRD pattern of $\mathrm{Ni}_{3}(\mathrm{btp})_{2}$ was baseline corrected.

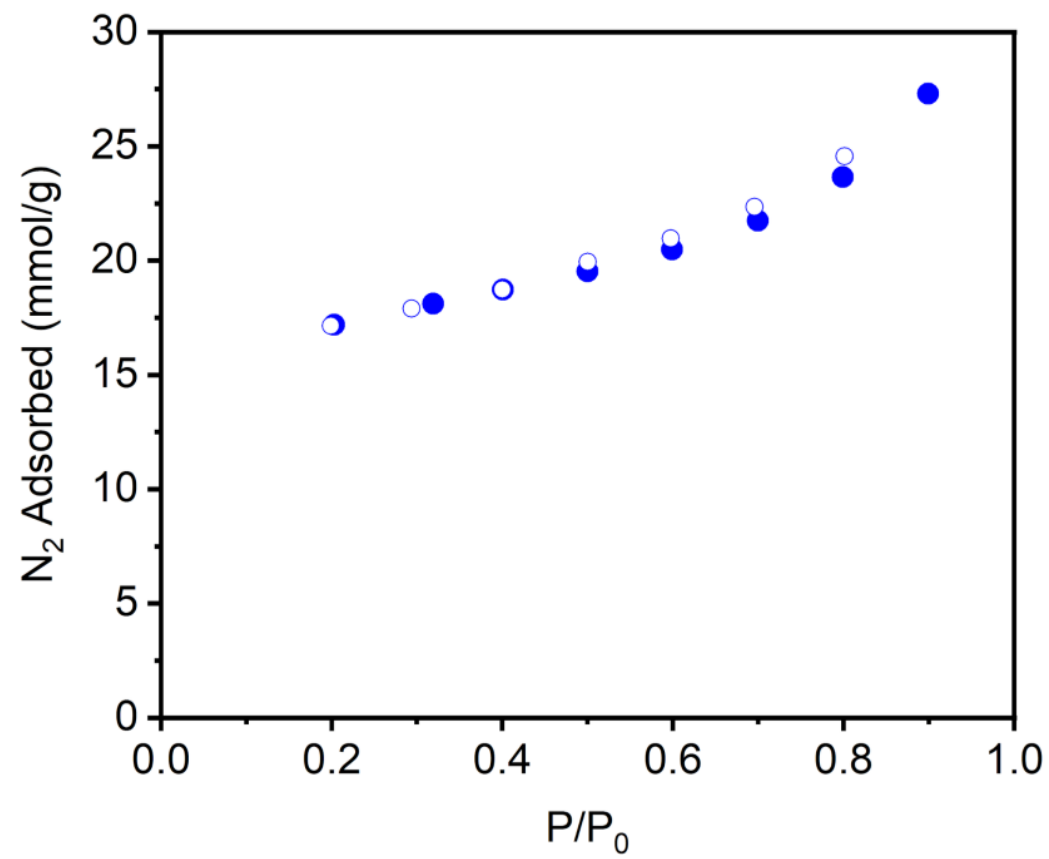

Figure S158. $77 \mathrm{~K} \mathrm{~N}_{2}$ adsorption (filled circles) and desorption (open circles) isotherm of activated $\mathrm{Ni}_{3}(\mathrm{btp})_{2}$. The Langmuir surface area determined from these data is $2008 \pm 45 \mathrm{~m}^{2} / \mathrm{g}$. 


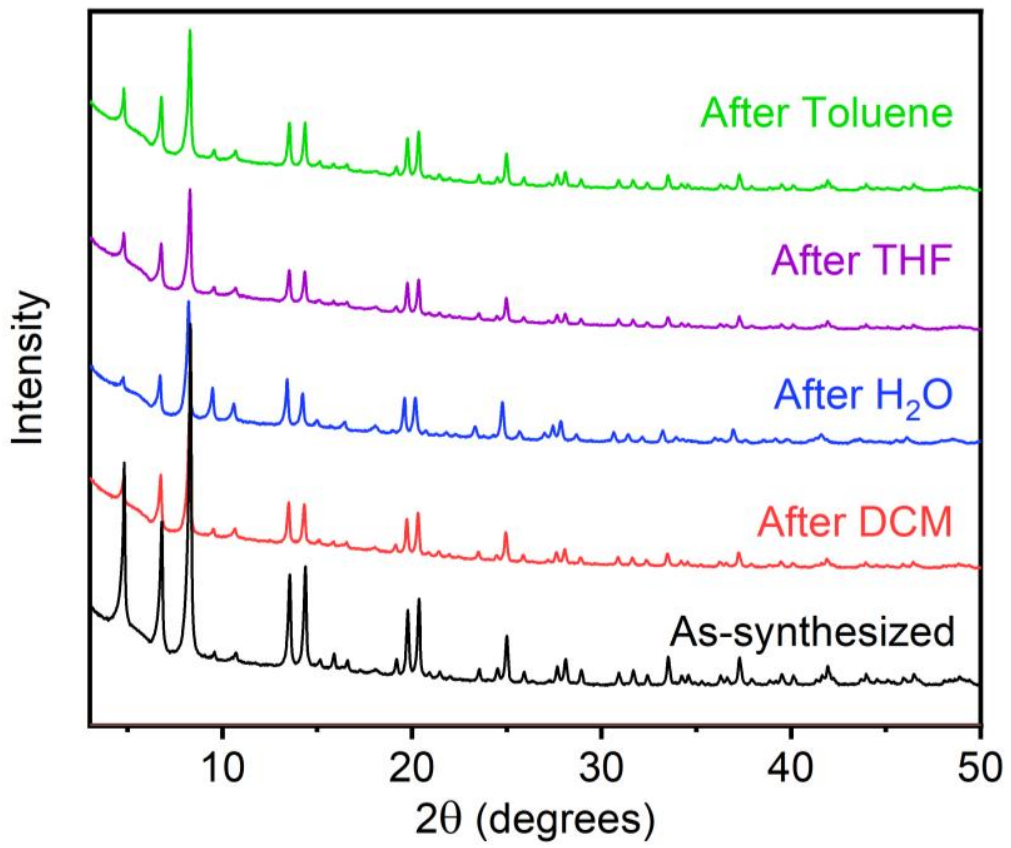

Figure S159. PXRD patterns $(\lambda=1.5406 \AA)$ of $\mathrm{Ni}_{3}(\mathrm{btp})_{2}$ upon exposure to various organic solvents and water. Note that $\mathrm{Ni}_{3}(\mathrm{btp})_{2}$ was soaked in $\mathrm{DMF}$ and $\mathrm{MeOH}$ during its synthesis as well. A reference pattern of as-synthesized $\mathrm{Ni}_{3}(\mathrm{btp})_{2}$ is included.

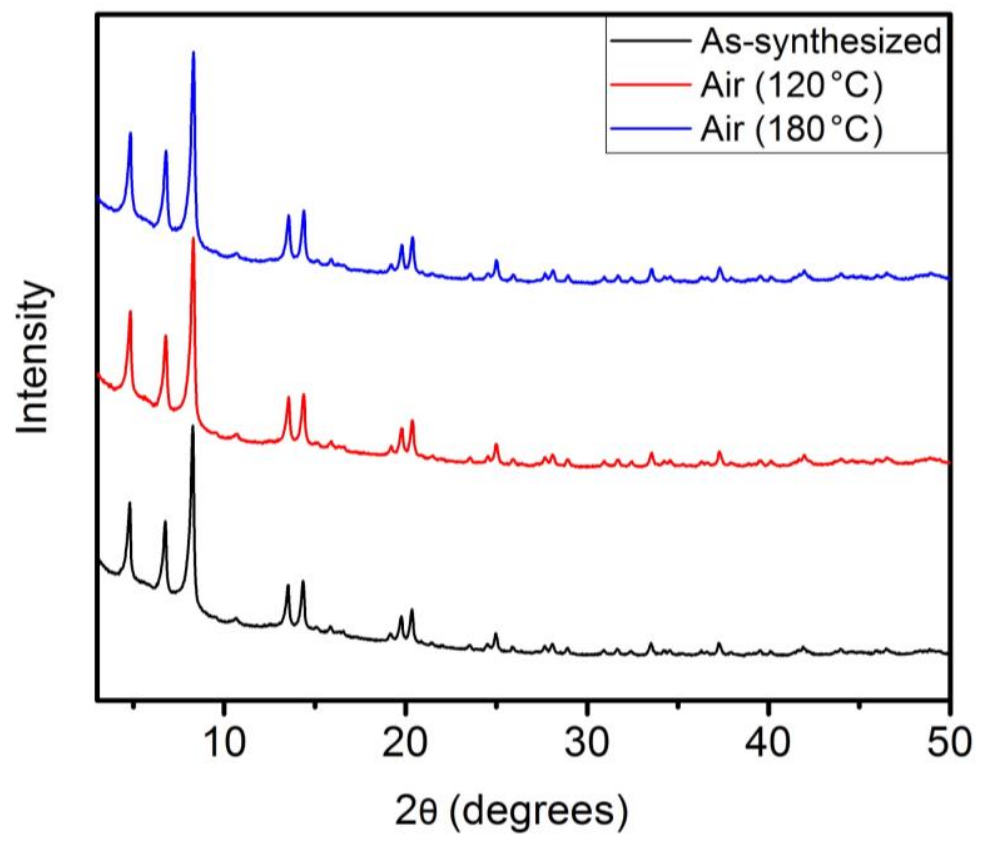

Figure S160. PXRD patterns $(\lambda=1.5406 \AA)$ of $\mathrm{Ni}_{3}(\mathrm{btp})_{2}$ upon standing at $120{ }^{\circ} \mathrm{C}$ and $180{ }^{\circ} \mathrm{C}$ in air for $24 \mathrm{~h}$. A reference pattern of as-synthesized $\mathrm{Ni}_{3}(\mathrm{btp})_{2}$ is included. 


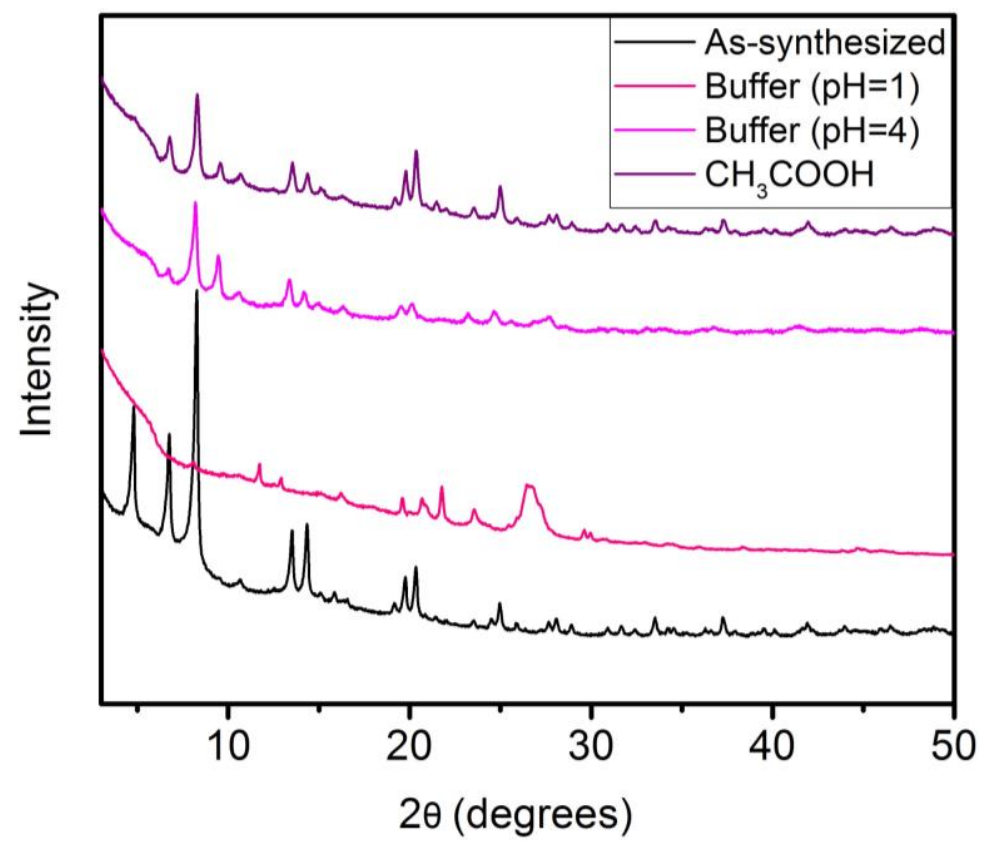

Figure S161. PXRD patterns $(\lambda=1.5406 \AA)$ of $\mathrm{Ni}_{3}(\mathrm{btp})_{2}$ upon exposure to acids. Exposure tests include aqueous solutions buffered at $\mathrm{pH} 1$ and $\mathrm{pH} 4$ and glacial acetic acid. A reference pattern of as-synthesized $\mathrm{Ni}_{3}(\mathrm{btp})_{2}$ is included.

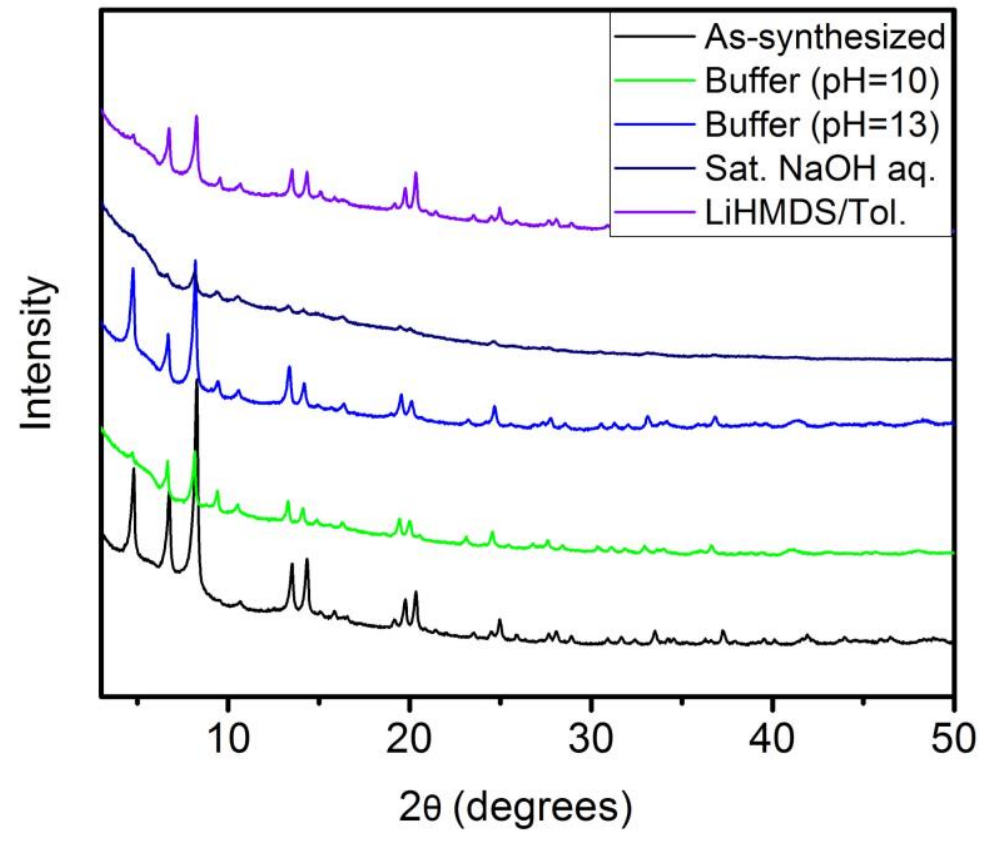

Figure S162. PXRD patterns $(\lambda=1.5406 \AA)$ of $\mathrm{Ni}_{3}(\mathrm{btp})_{2}$ upon exposure to bases. Exposure tests include aqueous solutions buffered at $\mathrm{pH} 10$ and $\mathrm{pH} \mathrm{13}$, saturated aqueous $\mathrm{NaOH}$, and $1.0 \mathrm{M}$ lithium hexamethyldisilazide (LiHMDS) in toluene. A reference pattern of as-synthesized $\mathrm{Ni}_{3}(\mathrm{btp})_{2}$ is included. 


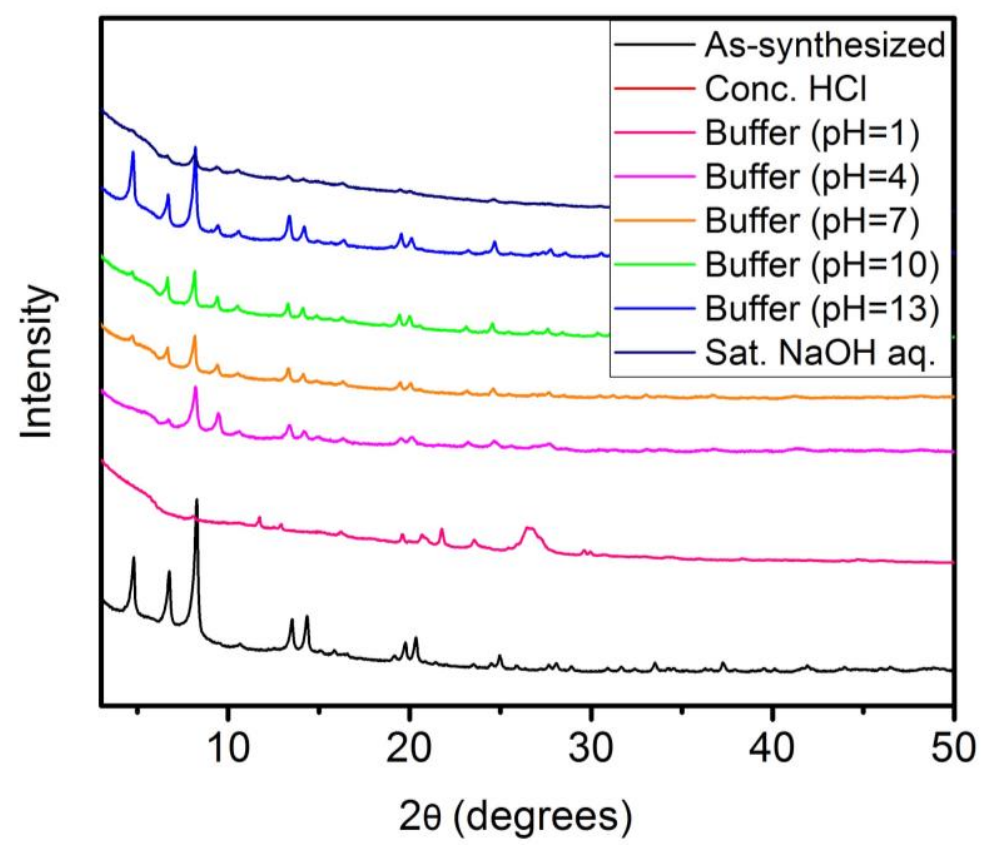

Figure S163. Summary of the PXRD patterns $(\lambda=1.5406 \AA)$ of $\mathrm{Ni}_{3}(\mathrm{btp})_{2}$ upon exposure to various aqueous conditions. A reference pattern of as-synthesized $\mathrm{Ni}_{3}(\mathrm{btp})_{2}$ is included.

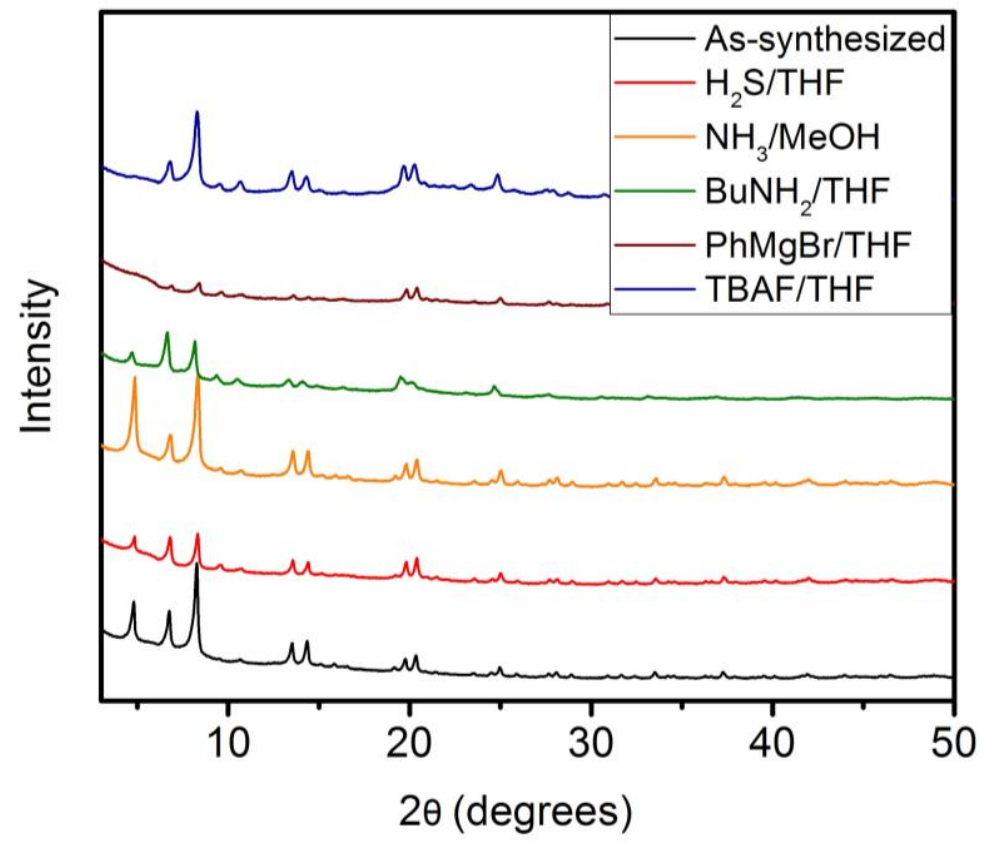

Figure S164. PXRD patterns $(\lambda=1.5406 \AA)$ of $\mathrm{Ni}_{3}(\mathrm{btp})_{2}$ upon exposure to nucleophiles. Exposure tests include $0.8 \mathrm{M}$ hydrogen sulfide in tetrahydrofuran, $1.0 \mathrm{M}$ ammonia in methanol, $1.0 \mathrm{M} n$ butylamine in tetrahydrofuran, $1.0 \mathrm{M} \mathrm{PhMgBr}$ in tetrahydrofuran, and $1.0 \mathrm{M}$ tetrabutylammonium fluoride (TBAF) in tetrahydrofuran. A reference pattern of as-synthesized $\mathrm{Ni}_{3}(\mathrm{btp})_{2}$ is included. 


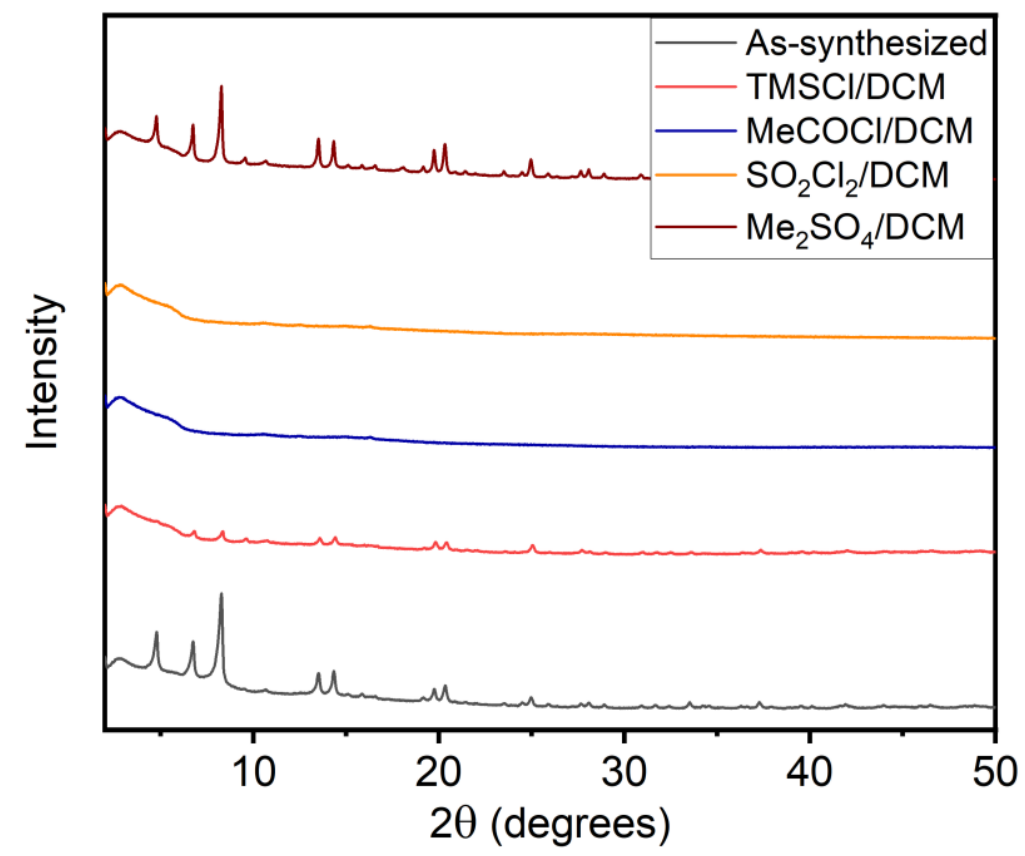

Figure S165. PXRD patterns $(\lambda=1.5406 \AA)$ of $\mathrm{Ni}_{3}(\mathrm{btp})_{2}$ upon exposure to electrophiles. Exposure tests include $1.0 \mathrm{M}$ chlorotrimethylsilane (TMSCl) in dichloromethane, $1.0 \mathrm{M}$ acetyl chloride in dichloromethane, $1.0 \mathrm{M}$ sulfuryl chloride in dichloromethane, and saturated dimethyl sulfate in dichloromethane. A reference pattern of as-synthesized $\mathrm{Ni}_{3}(\mathrm{btp})_{2}$ is included.

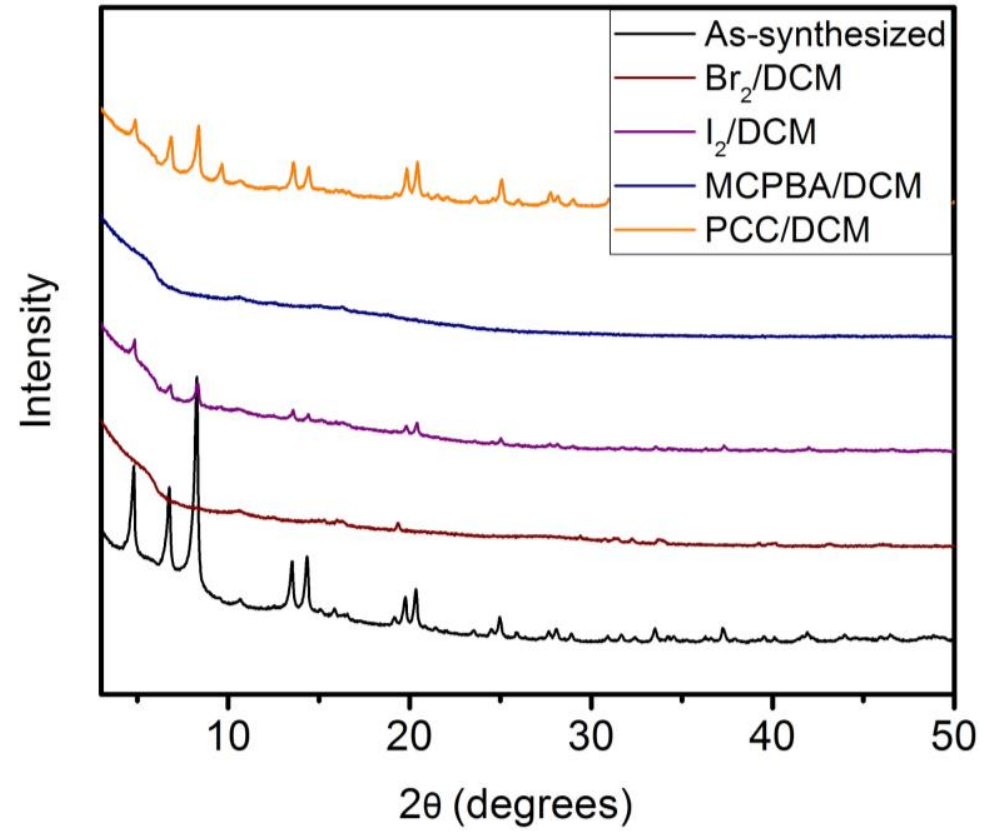

Figure S166. PXRD patterns $(\lambda=1.5406 \AA)$ of $\mathrm{Ni}_{3}(\mathrm{btp})_{2}$ upon exposure to oxidants. Exposure tests include $1.0 \mathrm{M}$ bromine in dichloromethane, saturated iodine in dichloromethane, saturated $m$-chloroperoxybenzoic acid (MCPBA) in dichloromethane, and saturated pyridinium chlorochromate (PCC) in dichloromethane. A reference pattern of as-synthesized $\mathrm{Ni}_{3}(\mathrm{btp})_{2}$ is included. 


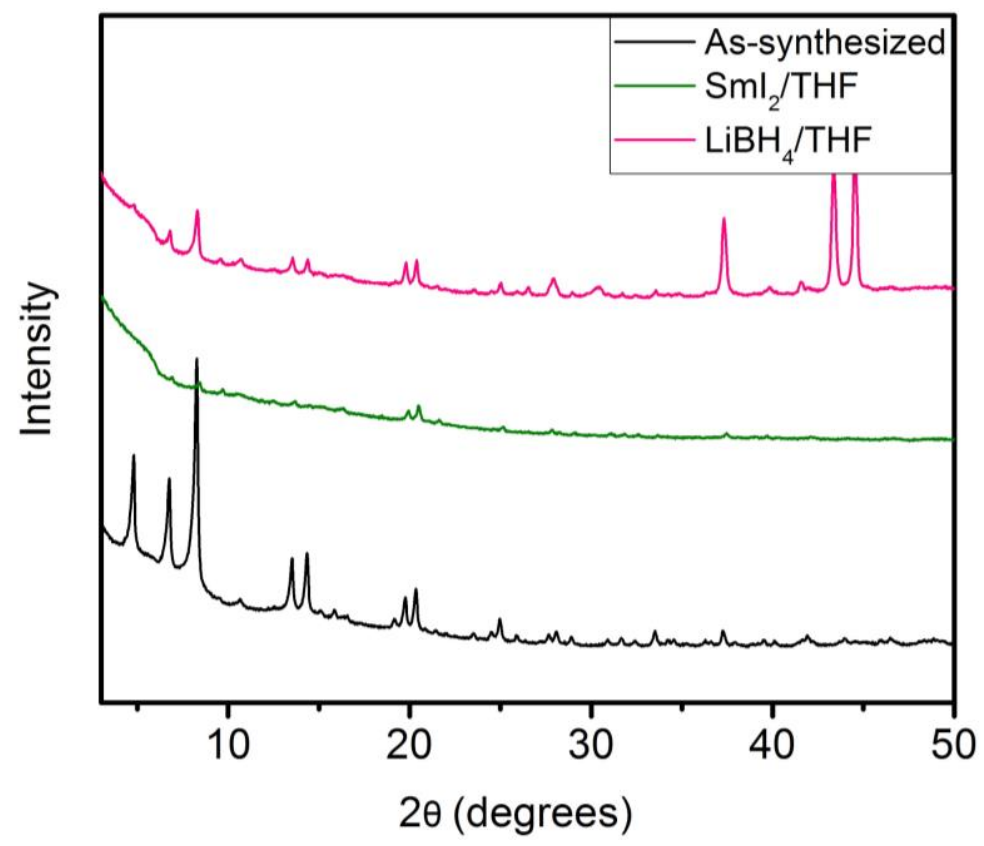

Figure S167. PXRD patterns $(\lambda=1.5406 \AA)$ of $\mathrm{Ni}_{3}(\mathrm{btp})_{2}$ upon exposure to reductants. Exposure tests include $0.1 \mathrm{M}$ samarium iodide in tetrahydrofuran and $1.0 \mathrm{M}$ lithium borohydride in tetrahydrofuran. A reference pattern of as-synthesized $\mathrm{Ni}_{3}(\mathrm{btp})_{2}$ is included. 
Table S14. Summary of changes in the full width at half maximum (FWHM) for the $2 \theta=8^{\circ}(\lambda=$ $1.5406 \AA$ ) reflection of $\mathrm{Ni}_{3}$ (btp) $)_{2}$ under a range of conditions.

\begin{tabular}{|c|c|c|c|c|c|}
\hline Condition & \multicolumn{2}{|c|}{ Result } & Condition & \multicolumn{2}{|c|}{ Result } \\
\hline \multirow{2}{*}{ Initial } & FWHM & 0.24125 & \multirow{2}{*}{ DI water } & FWHM & $0.19633^{a}$ \\
\hline & $\%$ Change & - & & $\%$ Change & $5^{a}$ \\
\hline \multirow{2}{*}{$120{ }^{\circ} \mathrm{C}$ Air } & FWHM & 0.24189 & \multirow{2}{*}{$\mathrm{BuNH}_{2} / \mathrm{THF}$} & FWHM & 0.21378 \\
\hline & $\%$ Change & 1 & & $\%$ Change & -12 \\
\hline \multirow{2}{*}{$180{ }^{\circ} \mathrm{C}$ Air } & FWHM & 0.24218 & \multirow{2}{*}{$\mathrm{PhMgBr} / \mathrm{THF}$} & FWHM & 0.22305 \\
\hline & $\%$ Change & 1 & & $\%$ Change & -8 \\
\hline \multirow{2}{*}{ Conc. $\mathrm{HCl}$} & FWHM & 0 & \multirow{2}{*}{ TBAF/THF } & FWHM & 0.2639 \\
\hline & $\%$ Change & $x$ & & $\%$ Change & 10 \\
\hline \multirow{2}{*}{$\mathrm{pH}=1$ Buffer } & FWHM & 0 & \multirow{2}{*}{$\mathrm{Me}_{3} \mathrm{SiCl} / \mathrm{CH}_{2} \mathrm{Cl}_{2}$} & FWHM & 0.17551 \\
\hline & $\%$ Change & $x$ & & $\%$ Change & -28 \\
\hline \multirow{2}{*}{$\mathrm{pH}=4$ Buffer } & FWHM & 0.26052 & \multirow{2}{*}{$\mathrm{MeCOCl} / \mathrm{CH}_{2} \mathrm{Cl}_{2}$} & FWHM & 0 \\
\hline & $\%$ Change & 8 & & $\%$ Change & $x$ \\
\hline \multirow{2}{*}{$\mathrm{pH}=7$ Buffer } & FWHM & 0.21311 & \multirow{2}{*}{$\mathrm{SO}_{2} \mathrm{Cl}_{2} / \mathrm{CH}_{2} \mathrm{Cl}_{2}$} & FWHM & 0 \\
\hline & $\%$ Change & -12 & & $\%$ Change & $\times$ \\
\hline \multirow{2}{*}{$\mathrm{pH}=10$ Buffer } & FWHM & 0.19146 & \multirow{2}{*}{$\mathrm{Me}_{2} \mathrm{SO}_{4} / \mathrm{CH}_{2} \mathrm{Cl}_{2}$} & FWHM & $0.17741^{a}$ \\
\hline & $\%$ Change & -21 & & $\%$ Change & $-5^{a}$ \\
\hline \multirow{2}{*}{$\mathrm{pH}=13$ Buffer } & FWHM & 0.22075 & \multirow{2}{*}{$\mathrm{Br}_{2} / \mathrm{CH}_{2} \mathrm{Cl}_{2}$} & FWHM & 0 \\
\hline & $\%$ Change & -9 & & $\%$ Change & $\times$ \\
\hline \multirow{2}{*}{ Sat. $\mathrm{NaOH}$} & FWHM & 0.30253 & \multirow{2}{*}{$\mathrm{I}_{2} / \mathrm{CH}_{2} \mathrm{Cl}_{2}$} & FWHM & 0.17743 \\
\hline & $\%$ Change & 26 & & $\%$ Change & -27 \\
\hline \multirow{2}{*}{$\mathrm{CH}_{3} \mathrm{COOH}$} & FWHM & 0.26005 & \multirow{2}{*}{$\mathrm{MCPBA} / \mathrm{CH}_{2} \mathrm{Cl}_{2}$} & FWHM & 0 \\
\hline & $\%$ Change & 8 & & $\%$ Change & $\times$ \\
\hline \multirow{2}{*}{ LiHMDS/Tol } & FWHM & 0.19679 & \multirow{2}{*}{$\mathrm{PCC} / \mathrm{CH}_{2} \mathrm{Cl}_{2}$} & FWHM & 0.19041 \\
\hline & $\%$ Change & -19 & & $\%$ Change & -22 \\
\hline \multirow{2}{*}{$\mathrm{H}_{2} \mathrm{~S} / \mathrm{THF}$} & FWHM & 0.20328 & \multirow{2}{*}{$\mathrm{SmI}_{2} / \mathrm{THF}$} & FWHM & 0.40399 \\
\hline & $\%$ Change & -16 & & $\%$ Change & 68 \\
\hline \multirow{2}{*}{$\mathrm{NH}_{3} / \mathrm{MeOH}$} & FWHM & 0.25607 & \multirow{2}{*}{$\mathrm{LiBH}_{4} / \mathrm{THF}$} & FWHM & 0.19221 \\
\hline & $\%$ Change & 7 & & $\%$ Change & -21 \\
\hline
\end{tabular}

${ }^{\mathrm{a}} \mathrm{A}$ second sample with an initial FWHM of $0.18742^{\circ}$ was used for this assay. 


\section{Synthesis, characterization, and stability assessment of $\mathrm{Zn}(\mathrm{bdp})$.}

Synthesis of $\mathbf{Z n}(\mathbf{b d p})$. This procedure is adapted from the literature. ${ }^{32}$ A $350 \mathrm{~mL}$ screwcap high-pressure reaction flask equipped with a stir bar was charged with 1,4-di(1H-pyrazol-4yl)benzene ( $\mathrm{H}_{2}$ bdp, $841 \mathrm{mg}, 4.00 \mathrm{mmol}, 1.00$ equiv.) and $N, N$-dimethylformamide $(80 \mathrm{~mL})$. The flask was transferred to a silicone oil bath that had been pre-heated to $60{ }^{\circ} \mathrm{C}$, and the reaction mixture was allowed to stir vigorously $(700 \mathrm{rpm})$ at this temperature for $5 \mathrm{~min}$. At this time, $\mathrm{Zn}(\mathrm{OAc})_{2} \cdot 2 \mathrm{H}_{2} \mathrm{O}$ (878 $\mathrm{mg}, 4.00 \mathrm{mmol}, 1.00$ equiv.) was added in small portions. The reaction vessel was sealed and the silicone oil bath was heated to $150{ }^{\circ} \mathrm{C}$. The reaction mixture was allowed to vigorously stir $(700 \mathrm{rpm})$ at $150{ }^{\circ} \mathrm{C}$ for $24 \mathrm{~h}$. Note: vigorous stirring is required to obtain highly crystalline $\mathrm{Zn}(\mathrm{bdp})$ in high yield. After $24 \mathrm{~h}$, the heterogeneous reaction mixture was allowed to cool to room temperature and filtered. The resulting off-white solid was transferred to a $500 \mathrm{~mL}$ Pyrex jar with $N, N$-dimethylformamide $(250 \mathrm{~mL})$. The jar was allowed to stand for $24 \mathrm{~h}$ at $120{ }^{\circ} \mathrm{C}$, at which time the $N, N$-dimethylformamide was decanted and replaced with fresh $N, N$ dimethylformamide $(250 \mathrm{~mL})$. This procedure was repeated two additional times for a total of three $N, N$-dimethylformamide soaks. Next, the solid was filtered and returned to the jar with fresh dichloromethane $(250 \mathrm{~mL})$. The solid was soaked in dichloromethane for $24 \mathrm{~h}$ at room temperature three total times following the same procedure as described above. The resulting off-white solid was filtered and transferred to a Schlenk flask. The solid was activated under flowing $\mathrm{N}_{2}$ at 150 ${ }^{\circ} \mathrm{C}$ for $4 \mathrm{~h}$, followed by further activation under high vacuum ( $<100 \mathrm{mbar}$ ) at $150{ }^{\circ} \mathrm{C}$ for $24 \mathrm{~h}$. The Schlenk flask was transferred into a $\mathrm{N}_{2}$-filled glovebox, and the activated $\mathrm{Zn}$ (bdp) was transferred into a $20 \mathrm{~mL}$ scintillation vial for long-term storage. A portion of the activated sample was transferred to a pre-tared Micromeritics sample tube equipped with a Sureseal. The tube was removed from the glovebox and the sample was further activated under high vacuum $(<10 \mu$ bar $)$ at $150{ }^{\circ} \mathrm{C}$ for $24 \mathrm{~h}$ prior to gas sorption measurements. 


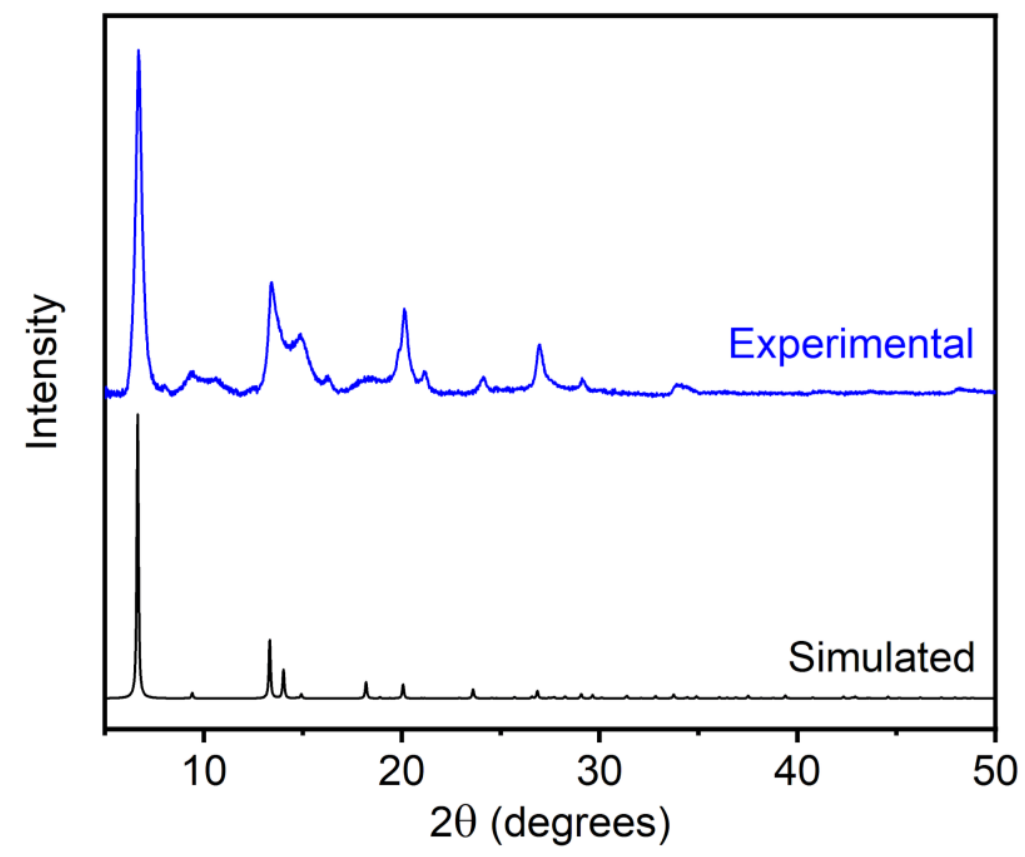

Figure S168. PXRD pattern $(\lambda=1.5406 \AA)$ of $\mathrm{CH}_{2} \mathrm{Cl}_{2}$-solvated $\mathrm{Zn}(\mathrm{bdp})$. The simulated pattern based on the previously reported powder X-ray diffraction structure of the isostructural framework $\mathrm{Co}(\mathrm{bdp})$ is included for reference. ${ }^{33}$ The PXRD pattern of $\mathrm{Zn}(\mathrm{bdp})$ was baseline corrected.

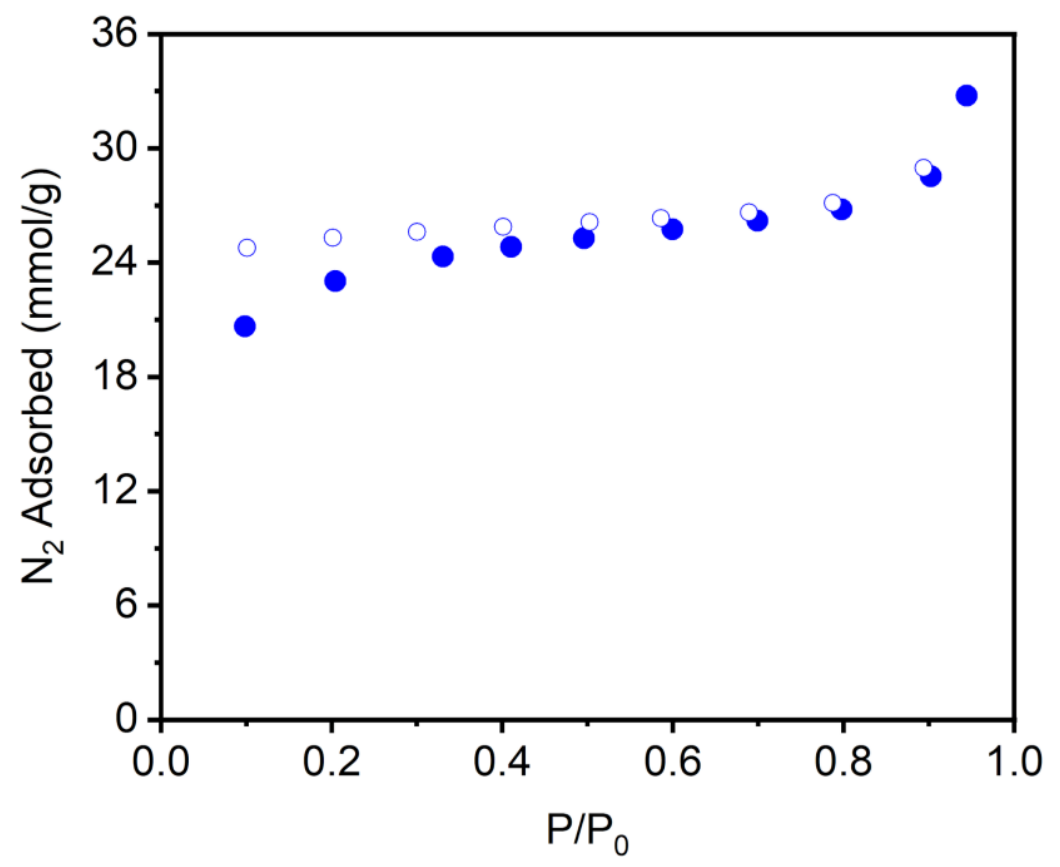

Figure S169. $77 \mathrm{~K} \mathrm{~N}_{2}$ adsorption (filled circles) and desorption (open circles) isotherm of activated $\mathrm{Zn}$ (bdp). The Langmuir surface area determined from these data is $2761 \pm 35 \mathrm{~m}^{2} / \mathrm{g}$. 


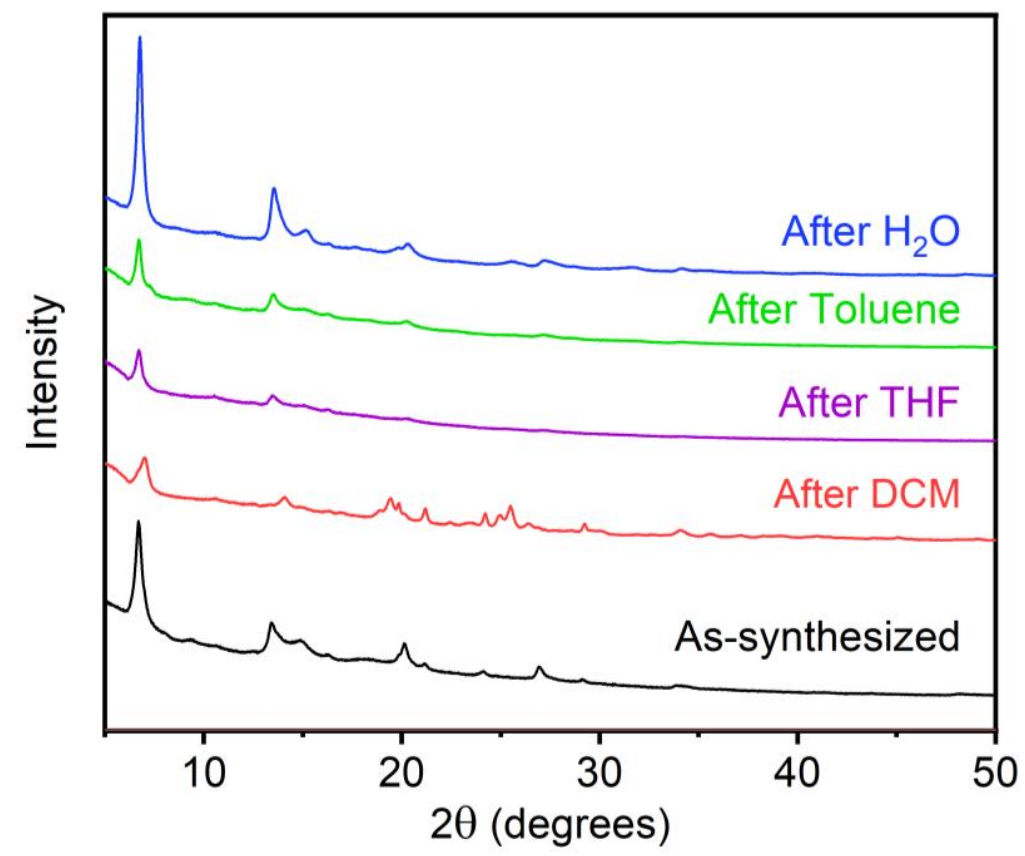

Figure S170. PXRD patterns $(\lambda=1.5406 \AA)$ of $\mathrm{Zn}(\mathrm{bdp})$ upon exposure to various organic solvents and water. Note that $\mathrm{Zn}(\mathrm{bdp})$ was soaked in DMF and $\mathrm{CH}_{2} \mathrm{Cl}_{2}$ during its synthesis as well. A reference pattern of as-synthesized $\mathrm{Zn}(\mathrm{bdp})$ is included.

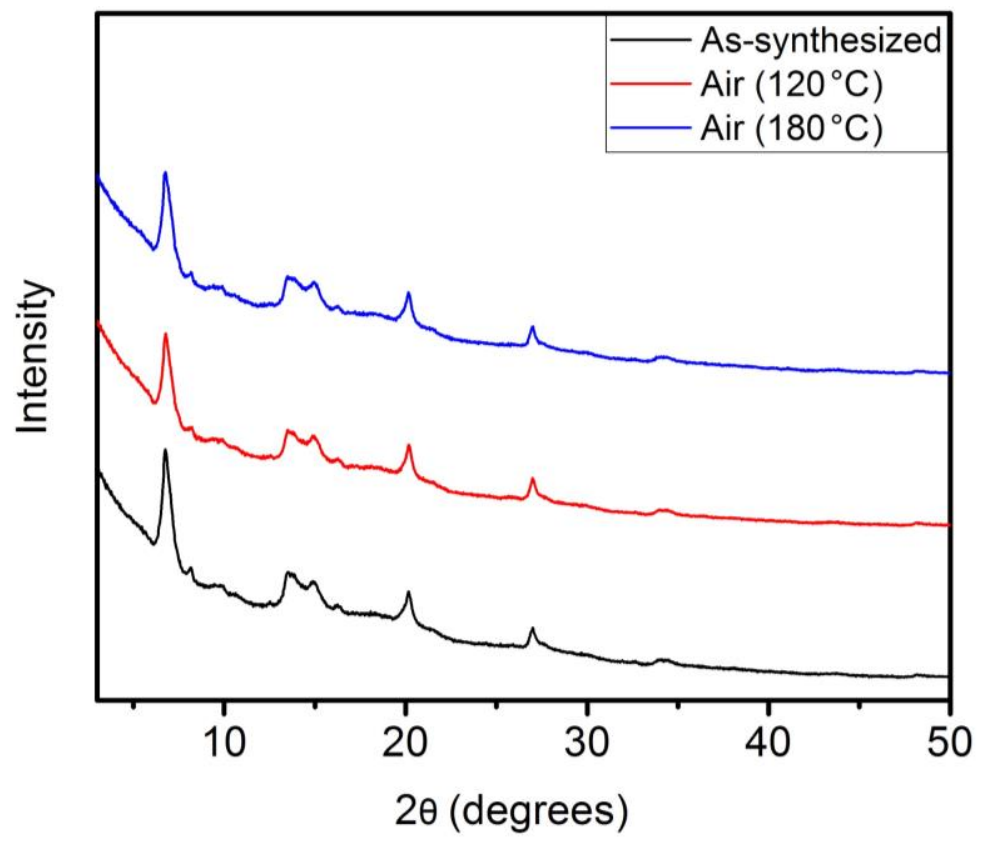

Figure S171. PXRD patterns $(\lambda=1.5406 \AA)$ of $\mathrm{Zn}(\mathrm{bdp})$ upon standing at $120{ }^{\circ} \mathrm{C}$ and $180{ }^{\circ} \mathrm{C}$ in air for $24 \mathrm{~h}$. A reference pattern of as-synthesized $\mathrm{Zn}(\mathrm{bdp})$ is included. 


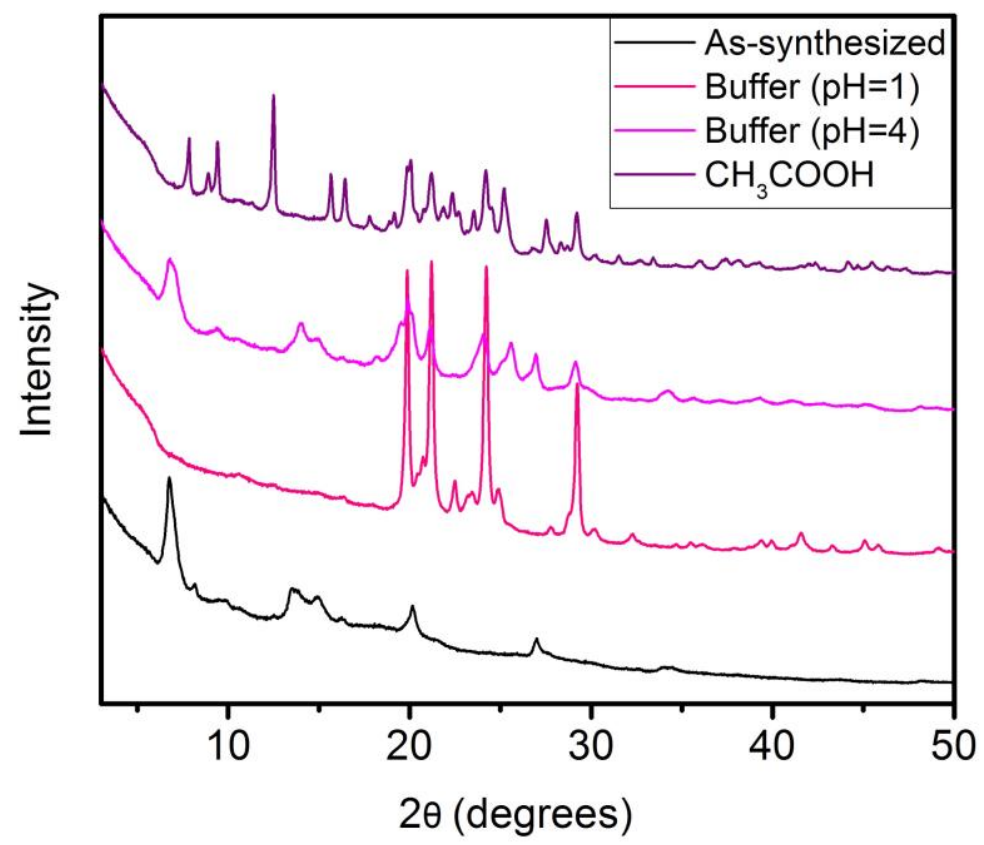

Figure S172. PXRD patterns $(\lambda=1.5406 \AA)$ of $\mathrm{Zn}(\mathrm{bdp})$ upon exposure to acids. Exposure tests include aqueous solutions buffered at $\mathrm{pH} 1$ and $\mathrm{pH} 4$ and glacial acetic acid. A reference pattern of as-synthesized $\mathrm{Zn}(\mathrm{bdp})$ is included.

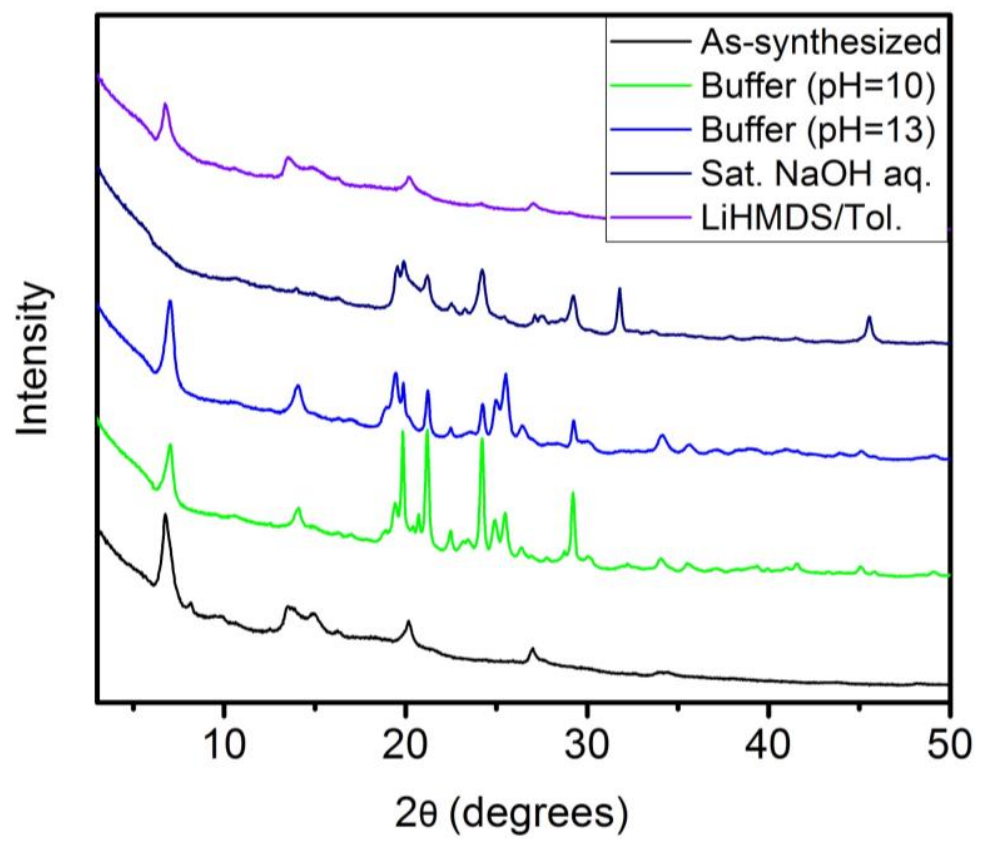

Figure S173. PXRD patterns ( $\lambda=1.5406 \AA$ ) of $\mathrm{Zn}(\mathrm{bdp})$ upon exposure to bases. Exposure tests include aqueous solutions buffered at $\mathrm{pH} 10$ and $\mathrm{pH}$ 13, saturated aqueous $\mathrm{NaOH}$, and $1.0 \mathrm{M}$ lithium hexamethyldisilazide (LiHMDS) in toluene. A reference pattern of as-synthesized $\mathrm{Zn}$ (bdp) is included. 


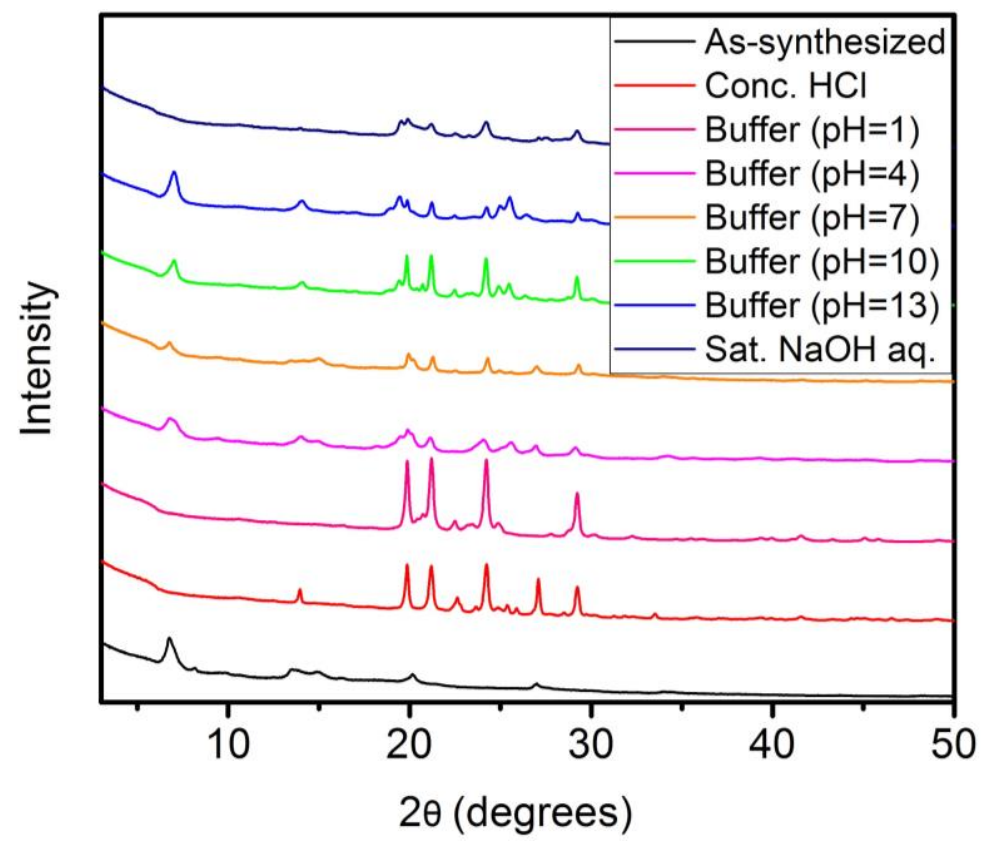

Figure S174. Summary of the PXRD patterns ( $\lambda=1.5406 \AA$ ) of $Z n(b d p)$ upon exposure to various aqueous conditions. A reference pattern of as-synthesized $\mathrm{Zn}(\mathrm{bdp})$ is included.

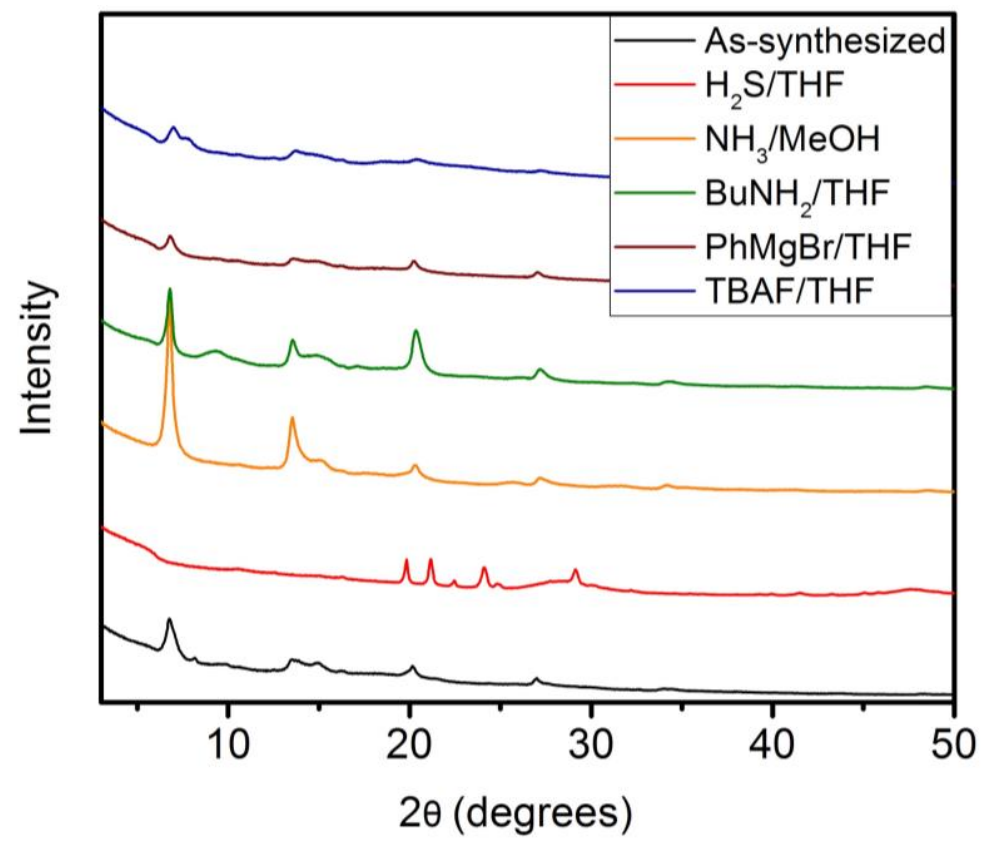

Figure S175. PXRD patterns ( $\lambda=1.5406 \AA$ ) of $Z n(b d p)$ upon exposure to nucleophiles. Exposure tests include $0.8 \mathrm{M}$ hydrogen sulfide in tetrahydrofuran, $1.0 \mathrm{M}$ ammonia in methanol, $1.0 \mathrm{M} \mathrm{n}$ butylamine in tetrahydrofuran, $1.0 \mathrm{M} \mathrm{PhMgBr}$ in tetrahydrofuran, and $1.0 \mathrm{M}$ tetrabutylammonium fluoride (TBAF) in tetrahydrofuran. A reference pattern of as-synthesized $\mathrm{Zn}(\mathrm{bdp}$ ) is included. 


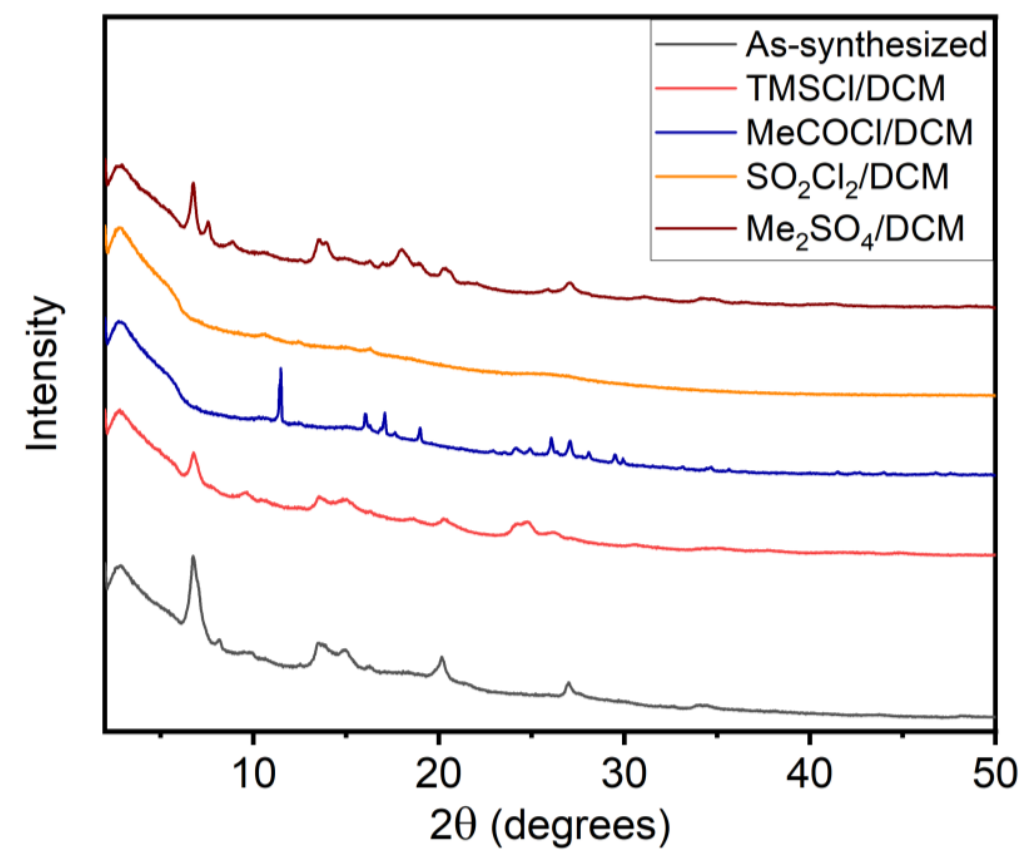

Figure S176. PXRD patterns ( $\lambda=1.5406 \AA$ ) of $Z n(b d p)$ upon exposure to electrophiles. Exposure tests include $1.0 \mathrm{M}$ chlorotrimethylsilane (TMSCl) in dichloromethane, $1.0 \mathrm{M}$ acetyl chloride in dichloromethane, $1.0 \mathrm{M}$ sulfuryl chloride in dichloromethane, and saturated dimethyl sulfate in dichloromethane. A reference pattern of as-synthesized $\mathrm{Zn}(\mathrm{bdp})$ is included.

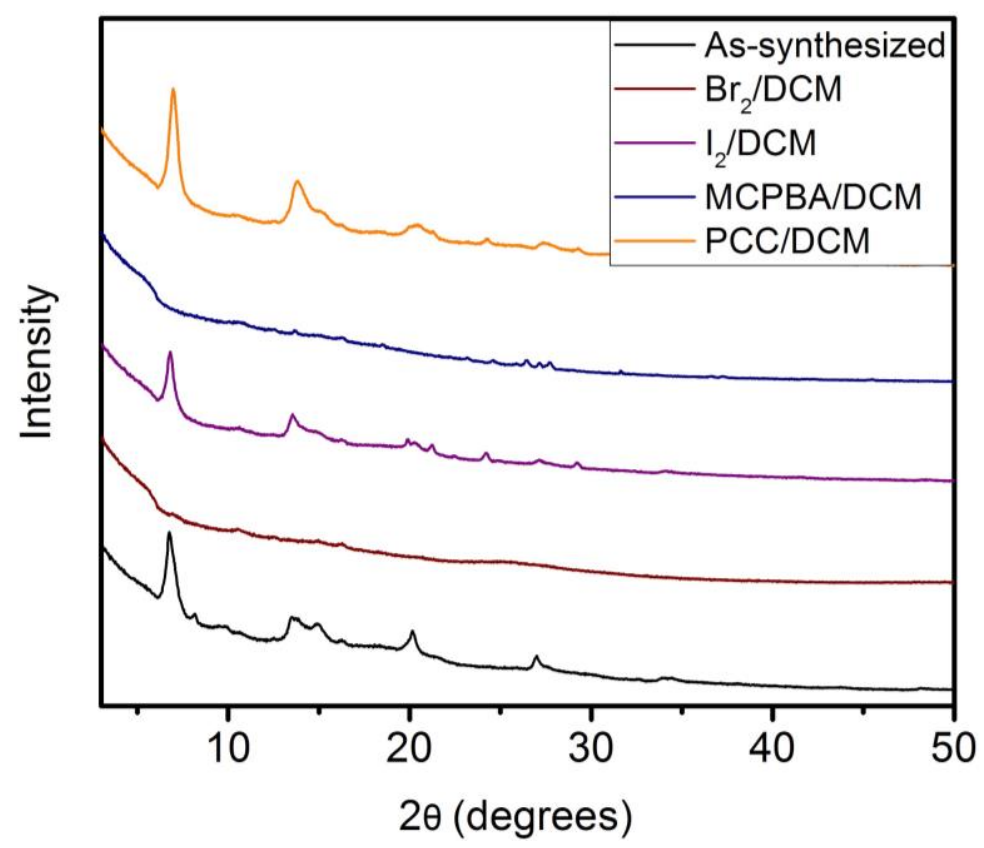

Figure S177. PXRD patterns $(\lambda=1.5406 \AA)$ of $Z n(b d p)$ upon exposure to oxidants. Exposure tests include $1.0 \mathrm{M}$ bromine in dichloromethane, saturated iodine in dichloromethane, saturated $\mathrm{m}$ chloroperoxybenzoic acid (MCPBA) in dichloromethane, and saturated pyridinium chlorochromate (PCC) in dichloromethane. A reference pattern of as-synthesized $\mathrm{Zn}$ (bdp) is included. 


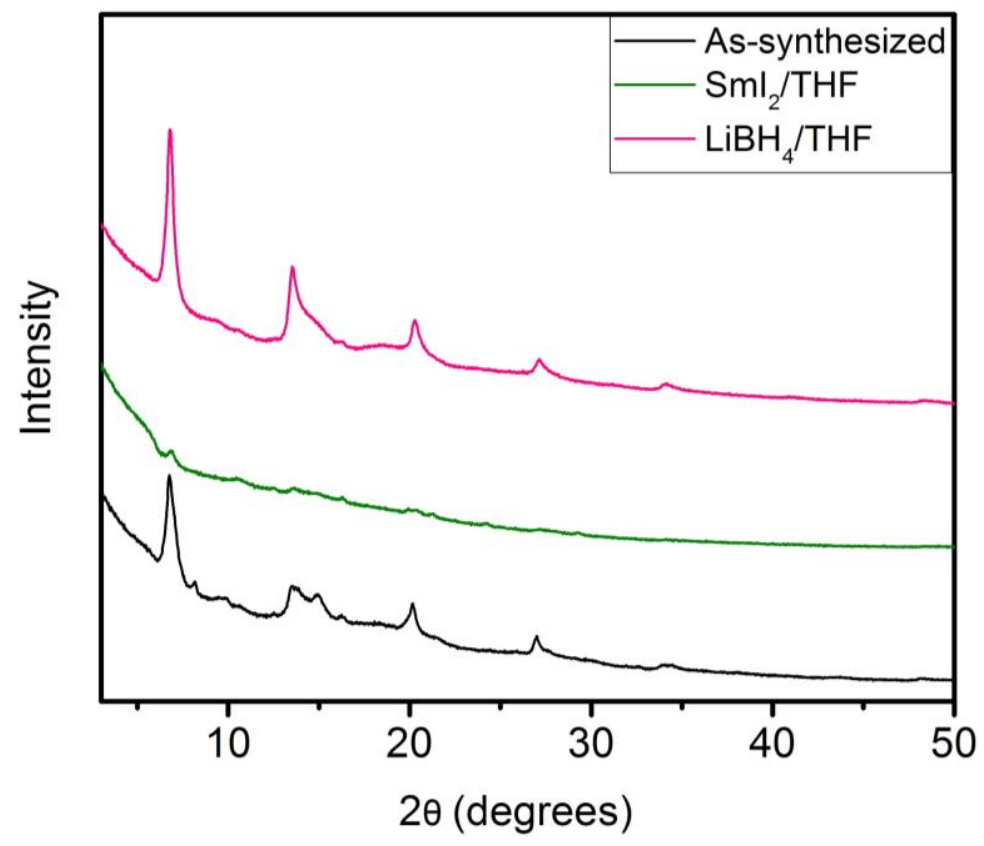

Figure S178. PXRD patterns $(\lambda=1.5406 \AA)$ of $Z n(b d p)$ upon exposure to reductants. Exposure tests include $0.1 \mathrm{M}$ samarium iodide in tetrahydrofuran and $1.0 \mathrm{M}$ lithium borohydride in tetrahydrofuran. A reference pattern of as-synthesized $\mathrm{Zn}(\mathrm{bdp})$ is included. 
Table S15. Summary of changes in the full width at half maximum (FWHM) for the $2 \theta=7^{\circ}(\lambda=$ $1.5406 \AA$ ) reflection of $\mathrm{Zn}(\mathrm{bdp})$ under a range of conditions.

\begin{tabular}{|c|c|c|c|c|c|}
\hline Condition & \multicolumn{2}{|c|}{ Result } & Condition & \multicolumn{2}{|c|}{ Result } \\
\hline \multirow{2}{*}{ Initial } & FWHM & 0.66455 & \multirow{2}{*}{ DI water } & FWHM & 0.37011 \\
\hline & \% Change & - & & $\%$ Change & -44 \\
\hline \multirow{2}{*}{$120^{\circ} \mathrm{C}$ Air } & FWHM & 0.67694 & \multirow{2}{*}{$\mathrm{BuNH}_{2} / \mathrm{THF}$} & FWHM & 0.39477 \\
\hline & $\%$ Change & 2 & & $\%$ Change & $-41^{a}$ \\
\hline \multirow{2}{*}{$180^{\circ} \mathrm{C}$ Air } & FWHM & 0.69702 & \multirow{2}{*}{$\mathrm{PhMgBr} / \mathrm{THF}$} & FWHM & 0.84545 \\
\hline & $\%$ Change & 5 & & $\%$ Change & 28 \\
\hline \multirow{2}{*}{ Conc. $\mathrm{HCl}$} & FWHM & 0 & \multirow{2}{*}{ TBAF/THF } & FWHM & 0.53762 \\
\hline & $\%$ Change & $x$ & & $\%$ Change & $-20^{a}$ \\
\hline \multirow{2}{*}{$\mathrm{pH}=1$ Buffer } & FWHM & 0 & \multirow{2}{*}{$\mathrm{Me}_{3} \mathrm{SiCl} / \mathrm{CH}_{2} \mathrm{Cl}_{2}$} & FWHM & 0.57701 \\
\hline & $\%$ Change & $x$ & & $\%$ Change & $-14^{a}$ \\
\hline \multirow{2}{*}{$\mathrm{pH}=4$ Buffer } & FWHM & 0.98352 & \multirow{2}{*}{$\mathrm{MeCOCl} / \mathrm{CH}_{2} \mathrm{Cl}_{2}$} & FWHM & 0 \\
\hline & $\%$ Change & $48^{a}$ & & $\%$ Change & $x$ \\
\hline \multirow{2}{*}{$\mathrm{pH}=7$ Buffer } & FWHM & 0.88251 & \multirow{2}{*}{$\mathrm{SO}_{2} \mathrm{Cl}_{2} / \mathrm{CH}_{2} \mathrm{Cl}_{2}$} & FWHM & 0 \\
\hline & $\%$ Change & $33^{a}$ & & $\%$ Change & $x$ \\
\hline \multirow{2}{*}{$\mathrm{pH}=10$ Buffer } & FWHM & 0.54342 & \multirow{2}{*}{$\mathrm{Me}_{2} \mathrm{SO}_{4} / \mathrm{CH}_{2} \mathrm{Cl}_{2}$} & FWHM & 0.30122 \\
\hline & $\%$ Change & $-19^{a}$ & & $\%$ Change & -55 \\
\hline \multirow{2}{*}{$\mathrm{pH}=13$ Buffer } & FWHM & 0.51783 & \multirow{2}{*}{$\mathrm{Br}_{2} / \mathrm{CH}_{2} \mathrm{Cl}_{2}$} & FWHM & 0 \\
\hline & $\%$ Change & $-23^{a}$ & & $\%$ Change & $x$ \\
\hline \multirow{2}{*}{ Sat. $\mathrm{NaOH}$} & FWHM & 0 & \multirow{2}{*}{$\mathrm{I}_{2} / \mathrm{CH}_{2} \mathrm{Cl}_{2}$} & FWHM & 0.58382 \\
\hline & $\%$ Change & $x$ & & $\%$ Change & -13 \\
\hline \multirow{2}{*}{$\mathrm{CH}_{3} \mathrm{COOH}$} & FWHM & 0 & \multirow{2}{*}{$\mathrm{MCPBA} / \mathrm{CH}_{2} \mathrm{Cl}_{2}$} & FWHM & 0 \\
\hline & $\%$ Change & $x$ & & $\%$ Change & $x$ \\
\hline \multirow{2}{*}{ LiHMDS/Tol } & FWHM & 0.57994 & \multirow{2}{*}{$\mathrm{PCC} / \mathrm{CH}_{2} \mathrm{Cl}_{2}$} & FWHM & 0.52618 \\
\hline & $\%$ Change & -13 & & $\%$ Change & -21 \\
\hline \multirow{2}{*}{$\mathrm{H}_{2} \mathrm{~S} / \mathrm{THF}$} & FWHM & 0 & \multirow{2}{*}{$\mathrm{SmI}_{2} / \mathrm{THF}$} & FWHM & 0 \\
\hline & $\%$ Change & $x$ & & $\%$ Change & $x$ \\
\hline \multirow{2}{*}{$\mathrm{NH}_{3} / \mathrm{MeOH}$} & FWHM & 0.43849 & \multirow{2}{*}{$\mathrm{LiBH}_{4} / \mathrm{THF}$} & FWHM & 0.51658 \\
\hline & $\%$ Change & -35 & & $\%$ Change & -23 \\
\hline
\end{tabular}

${ }^{a}$ New reflections observed by PXRD. 


\section{Synthesis, characterization, and stability assessment of $\mathrm{Ni}(\mathrm{bdp})$.}

Synthesis of $\mathbf{N i ( b d p ) . ~ T h i s ~ p r o c e d u r e ~ i s ~ a d a p t e d ~ f r o m ~ t h e ~ l i t e r a t u r e . ~}{ }^{32}$ Attempts to prepare $\mathrm{Ni}(\mathrm{bdp})$ on large scale led to poorly crystalline material or a different phase, and thus a bulk sample was prepared by combining the products from multiple small-scale reactions. Twelve $15 \mathrm{~mL}$ screw-cap Pyrex reaction tubes equipped with stir bars were each charged with 1,4-di( $1 \mathrm{H}$-pyrazol4-yl)benzene ( $\mathrm{H}_{2} \mathrm{bdp}, 52.5 \mathrm{mg}, 0.25 \mathrm{mmol}, 1.00$ equiv.) and $N, N$-dimethylformamide $(5 \mathrm{~mL})$. The tubes were sealed and placed in a silicone oil bath. The oil bath was heated to $60{ }^{\circ} \mathrm{C}$ and the reaction mixtures were allowed to stir vigorously $(700 \mathrm{rpm})$ until homogeneous. $\mathrm{Next}, \mathrm{Ni}(\mathrm{OAc})_{2} \bullet 4 \mathrm{H}_{2} \mathrm{O}$ (62.3 $\mathrm{mg}, 0.25 \mathrm{mmol}, 1.00$ equiv.) was added to each tube. The tubes were re-sealed and the temperature of the silicone oil bath was increased to $150{ }^{\circ} \mathrm{C}$. The reaction mixtures were allowed to stir vigorously $(700 \mathrm{rpm})$ at $150{ }^{\circ} \mathrm{C}$ for $5 \mathrm{~h}$. During the reaction, a color change from green to orange (the color of the final product) was observed; a color change to black (typically observed with longer reaction times) indicates that the reaction has failed. Note: vigorous stirring is required to obtain highly crystalline $\mathrm{Ni}(\mathrm{bdp})$ in high yield. After $5 \mathrm{~h}$, the tubes were allowed to cool to room temperature. The heterogeneous reaction mixtures were filtered, combining the solid from all twelve tubes into one sample. The resulting orange solid was transferred to a $500 \mathrm{~mL}$ Pyrex jar with $N, N$-dimethylformamide $(250 \mathrm{~mL})$. The jar was allowed to stand for $24 \mathrm{~h}$ at $120^{\circ} \mathrm{C}$, at which time the $N, N$-dimethylformamide was decanted and replaced with fresh $N, N$-dimethylformamide $(250 \mathrm{~mL})$. This procedure was repeated two additional times for a total of three $N, N$ dimethylformamide soaks. Next, the solid was filtered and returned to the jar with fresh dichloromethane $(200 \mathrm{~mL})$. The solid was soaked in dichloromethane for $24 \mathrm{~h}$ at room temperature three total times following the same procedure as described above. The resulting orange solid was filtered and transferred to a Schlenk flask. The solid was activated under flowing $\mathrm{N}_{2}$ at $150{ }^{\circ} \mathrm{C}$ for $4 \mathrm{~h}$, followed by further activation under high vacuum ( $<100 \mathrm{mbar}$ ) at $150{ }^{\circ} \mathrm{C}$ for $24 \mathrm{~h}$. The Schlenk flask was transferred into a $\mathrm{N}_{2}$-filled glovebox, and the activated $\mathrm{Ni}$ (bdp) was transferred into a 20 $\mathrm{mL}$ scintillation vial for long-term storage. A portion of the activated sample was transferred to a pre-tared Micromeritics sample tube equipped with a Sureseal. The tube was removed from the glovebox and the sample was further activated under high vacuum $(<10 \mu \mathrm{bar})$ at $150{ }^{\circ} \mathrm{C}$ for $24 \mathrm{~h}$ prior to gas sorption measurements. 


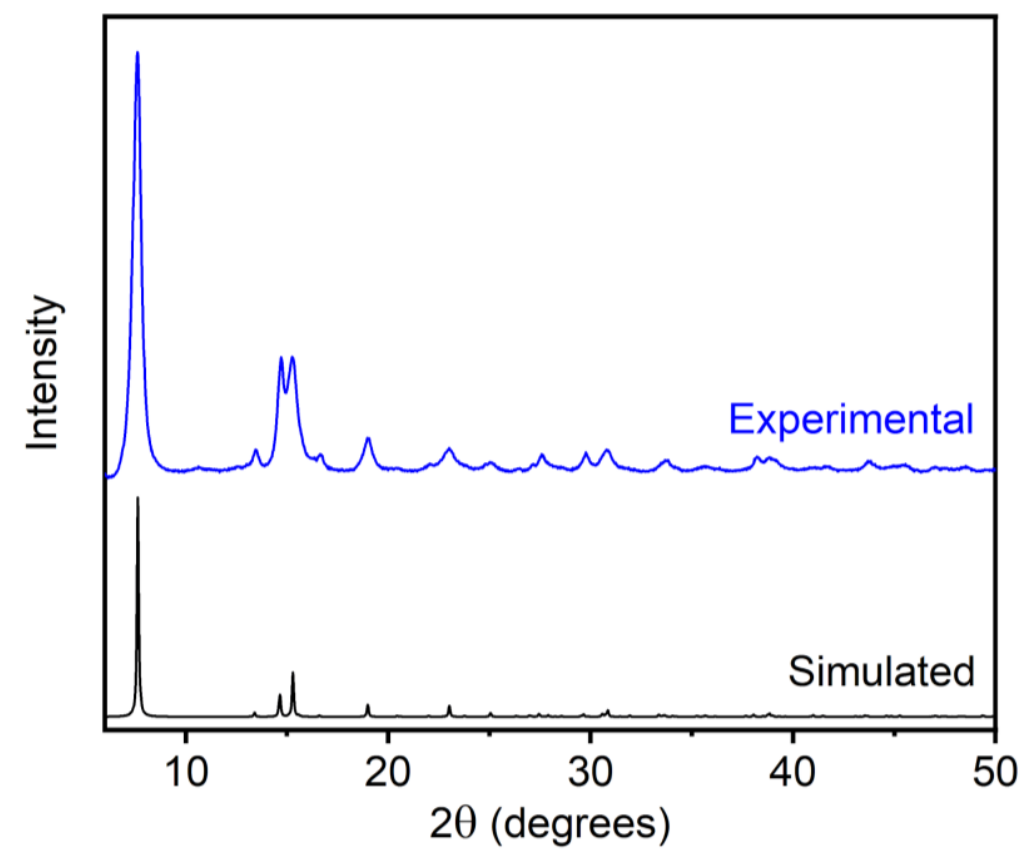

Figure S179. PXRD pattern $(\lambda=1.5406 \AA)$ of $\mathrm{CH}_{2} \mathrm{Cl}_{2}$-solvated $\mathrm{Ni}(\mathrm{bdp})$. The simulated pattern based on the previously reported powder X-ray diffraction structure of $\mathrm{Ni}(\mathrm{bdp})$ is included for reference. ${ }^{34}$ The PXRD pattern of $\mathrm{Ni}(\mathrm{bdp})$ was baseline corrected.

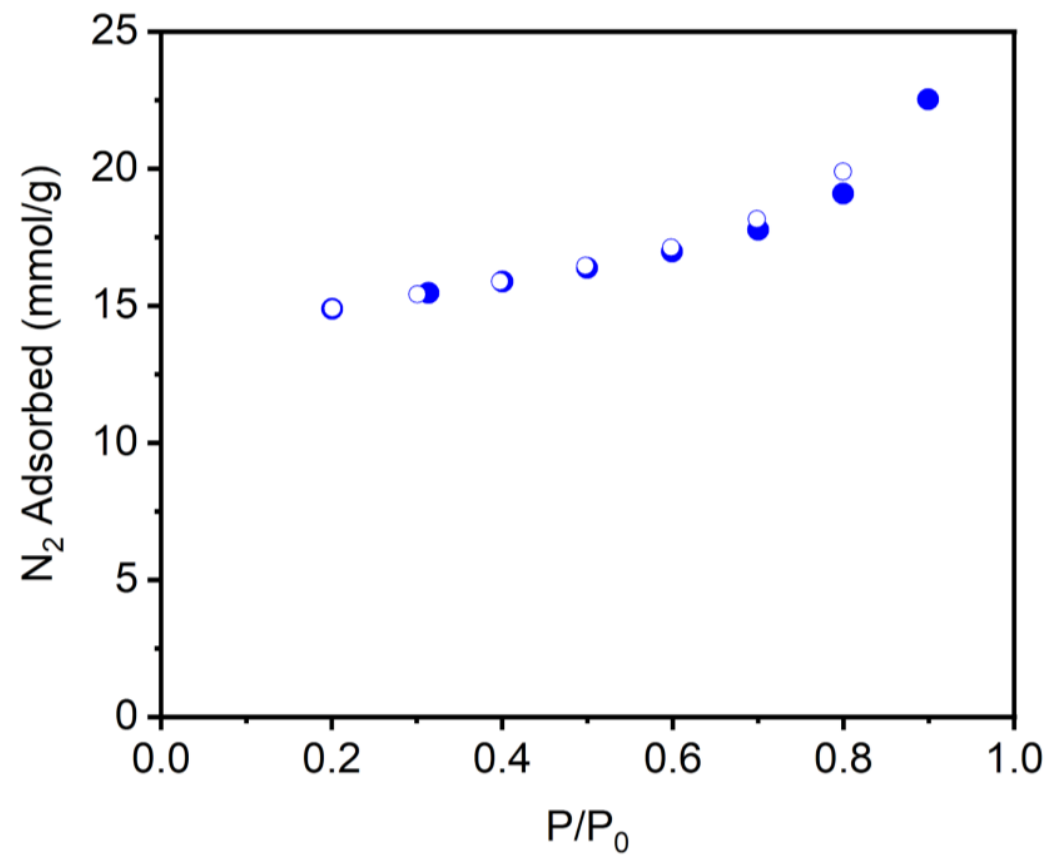

Figure S180. $77 \mathrm{~K} \mathrm{~N}_{2}$ adsorption (filled circles) and desorption (open circles) isotherm of activated $\mathrm{Ni}$ (bdp). The Langmuir surface area determined from these data is $1661 \pm 26 \mathrm{~m}^{2} / \mathrm{g}$. 


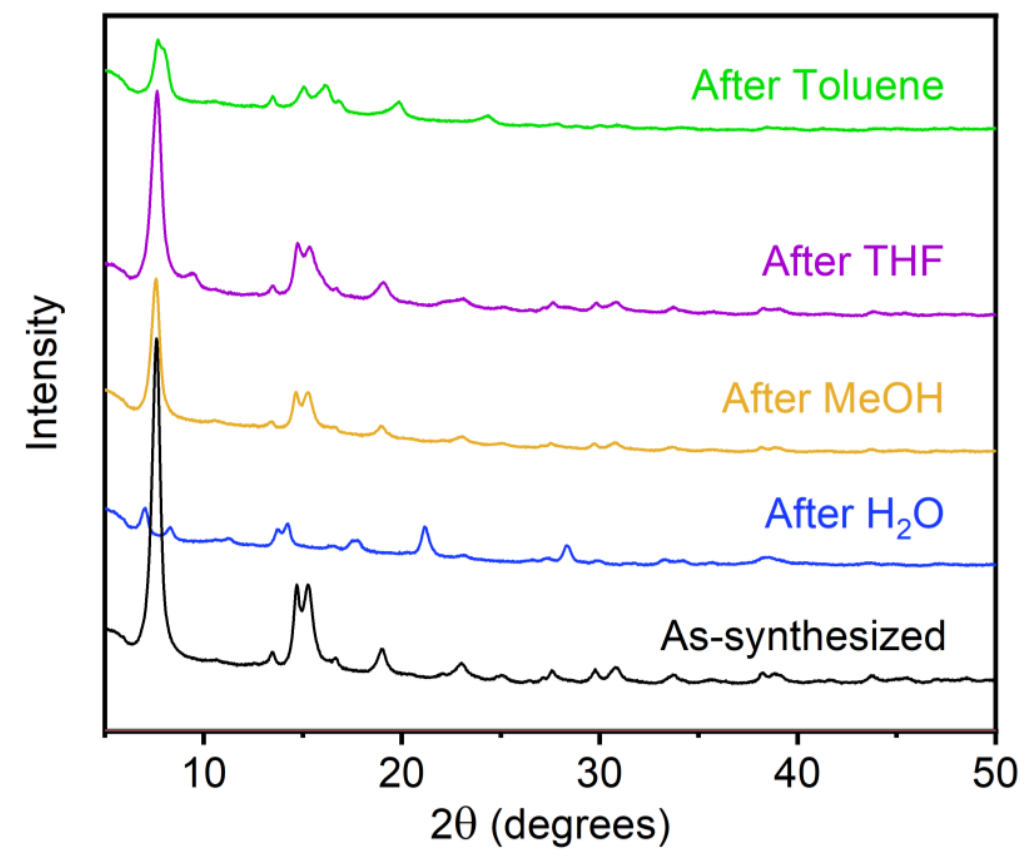

Figure S181. PXRD patterns $(\lambda=1.5406 \AA)$ of $\mathrm{Ni}(\mathrm{bdp})$ upon exposure to various organic solvents and water. Note that $\mathrm{Ni}(\mathrm{bdp})$ was soaked in $\mathrm{DMF}$ and $\mathrm{MeOH}$ during its synthesis as well. A reference pattern of as-synthesized $\mathrm{Ni}(\mathrm{bdp})$ is included. These patterns suggest that $\mathrm{Ni}(\mathrm{bdp})$ undergoes a phase change upon submersion in water.

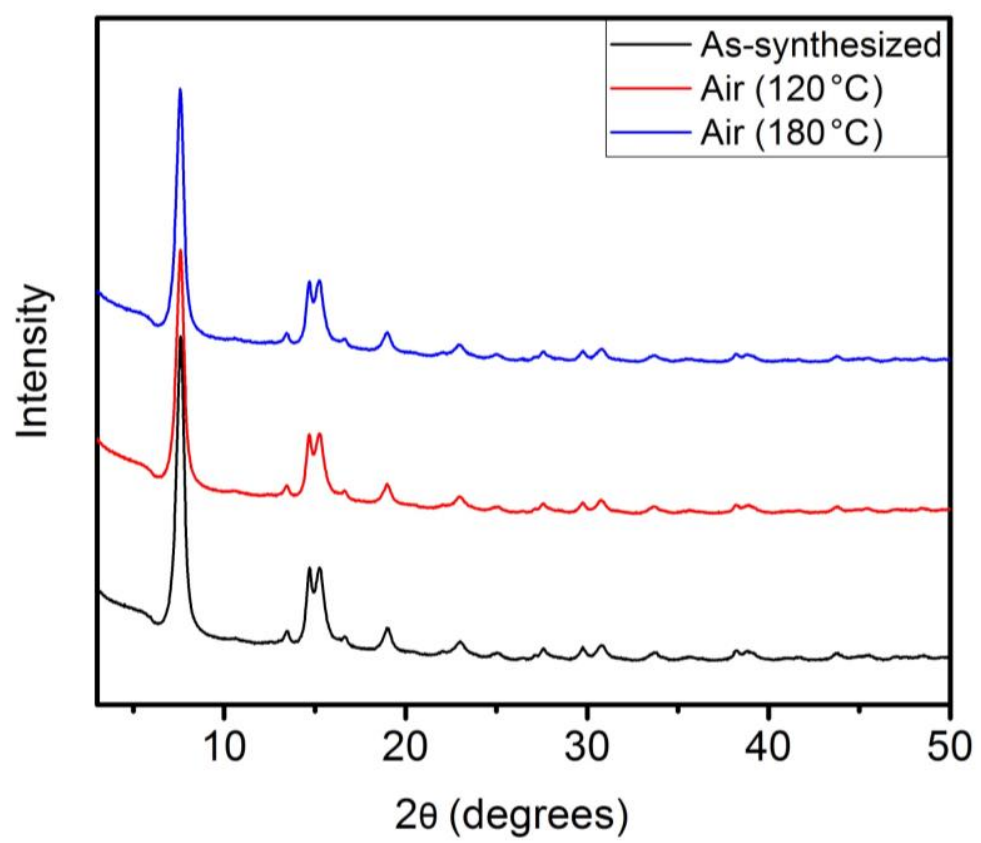

Figure S182. PXRD patterns $(\lambda=1.5406 \AA)$ of $\mathrm{Ni}(\mathrm{bdp})$ upon standing at $120^{\circ} \mathrm{C}$ and $180{ }^{\circ} \mathrm{C}$ in air for $24 \mathrm{~h}$. A reference pattern of as-synthesized $\mathrm{Ni}$ (bdp) is included. 


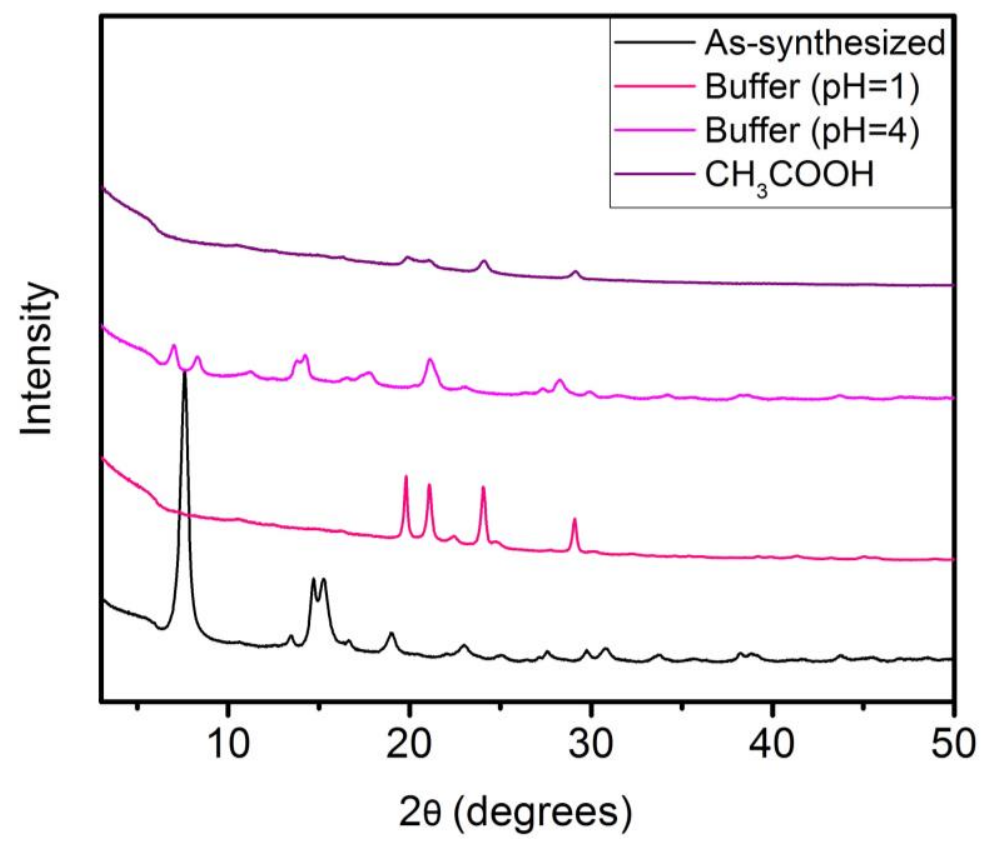

Figure S183. PXRD patterns $(\lambda=1.5406 \AA)$ of $\mathrm{Ni}(\mathrm{bdp})$ upon exposure to acids. Exposure tests include aqueous solutions buffered at $\mathrm{pH} 1$ and $\mathrm{pH} 4$ and glacial acetic acid. A reference pattern of as-synthesized $\mathrm{Ni}(\mathrm{bdp})$ is included.

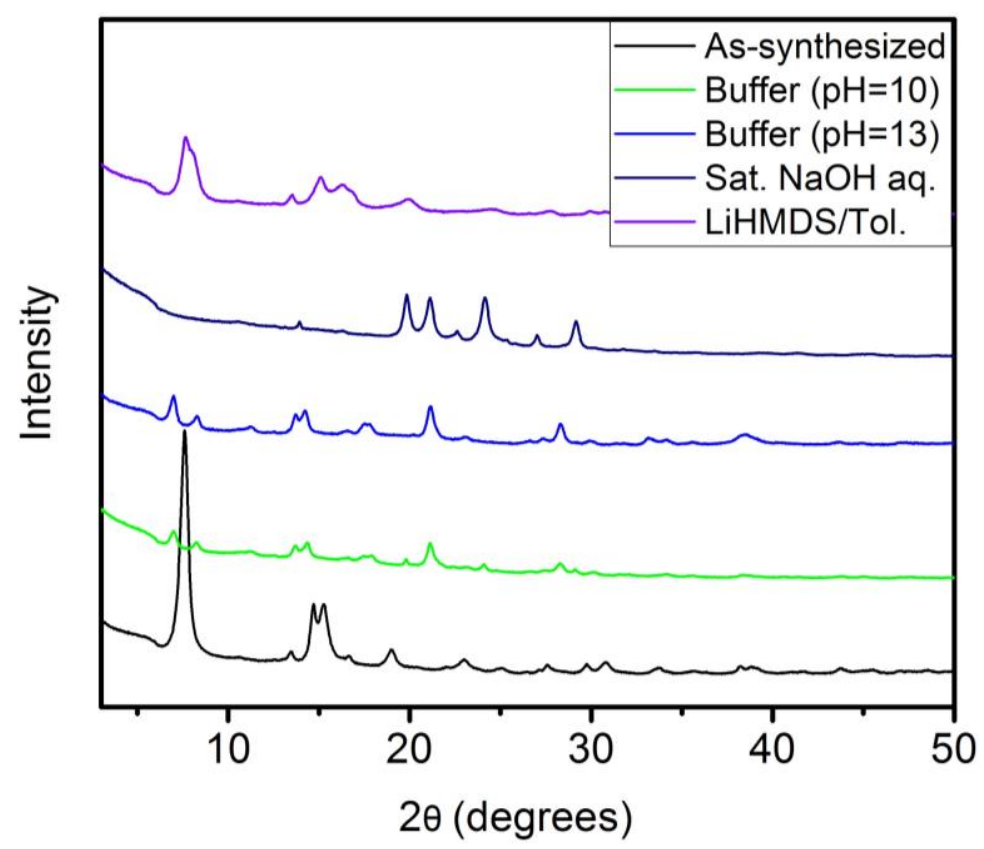

Figure S184. PXRD patterns $(\lambda=1.5406 \AA)$ of $\mathrm{Ni}(\mathrm{bdp})$ upon exposure to bases. Exposure tests include aqueous solutions buffered at $\mathrm{pH} 10$ and $\mathrm{pH}$ 13, saturated aqueous $\mathrm{NaOH}$, and $1.0 \mathrm{M}$ lithium hexamethyldisilazide (LiHMDS) in toluene. A reference pattern of as-synthesized Ni(bdp) is included. 


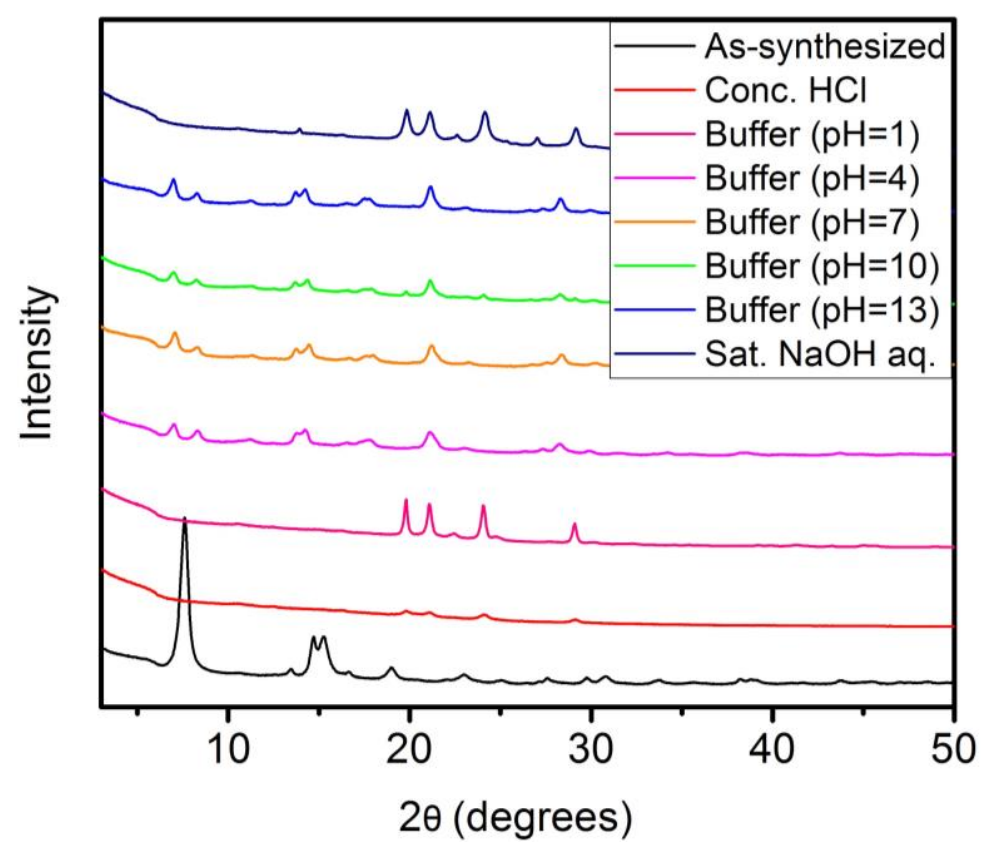

Figure S185. Summary of the PXRD patterns $(\lambda=1.5406 \AA)$ of $\mathrm{Ni}(\mathrm{bdp})$ upon exposure to various aqueous conditions. A reference pattern of as-synthesized $\mathrm{Ni}(\mathrm{bdp})$ is included.

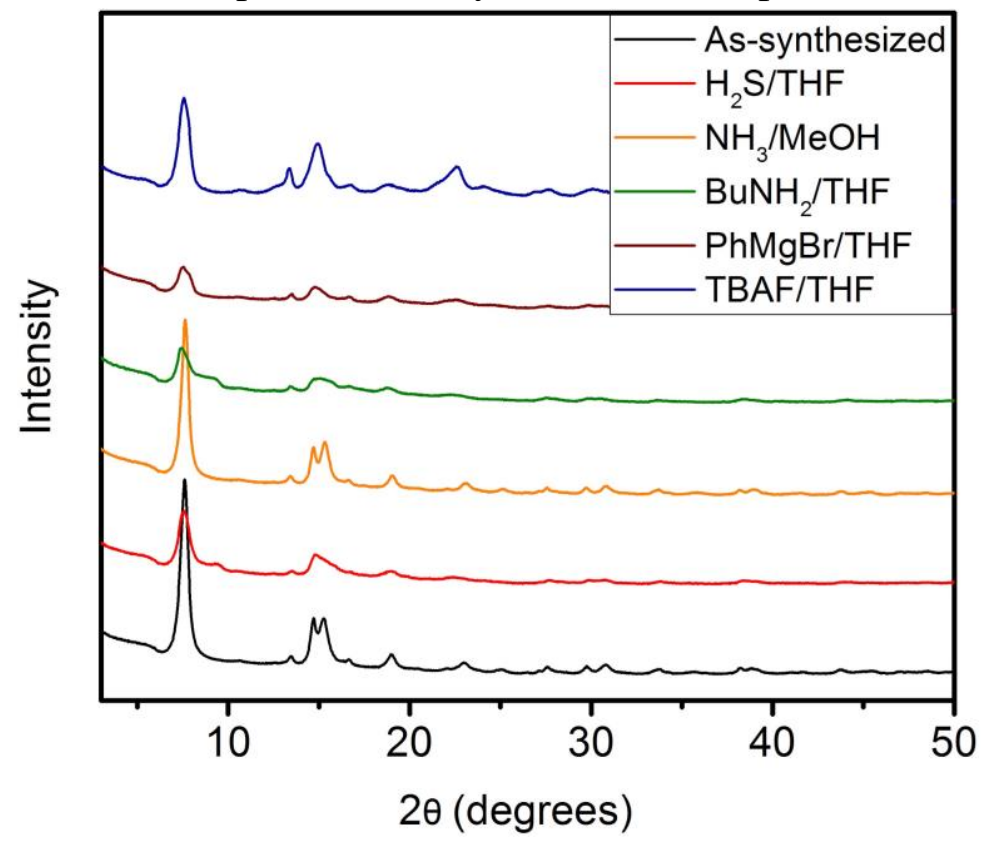

Figure S186. PXRD patterns $(\lambda=1.5406 \AA$ ) of Ni(bdp) upon exposure to nucleophiles. Exposure tests include $0.8 \mathrm{M}$ hydrogen sulfide in tetrahydrofuran, $1.0 \mathrm{M}$ ammonia in methanol, $1.0 \mathrm{M} n$ butylamine in tetrahydrofuran, 1.0 M PhMgBr in tetrahydrofuran, and $1.0 \mathrm{M}$ tetrabutylammonium fluoride (TBAF) in tetrahydrofuran. A reference pattern of as-synthesized Ni(bdp) is included. 


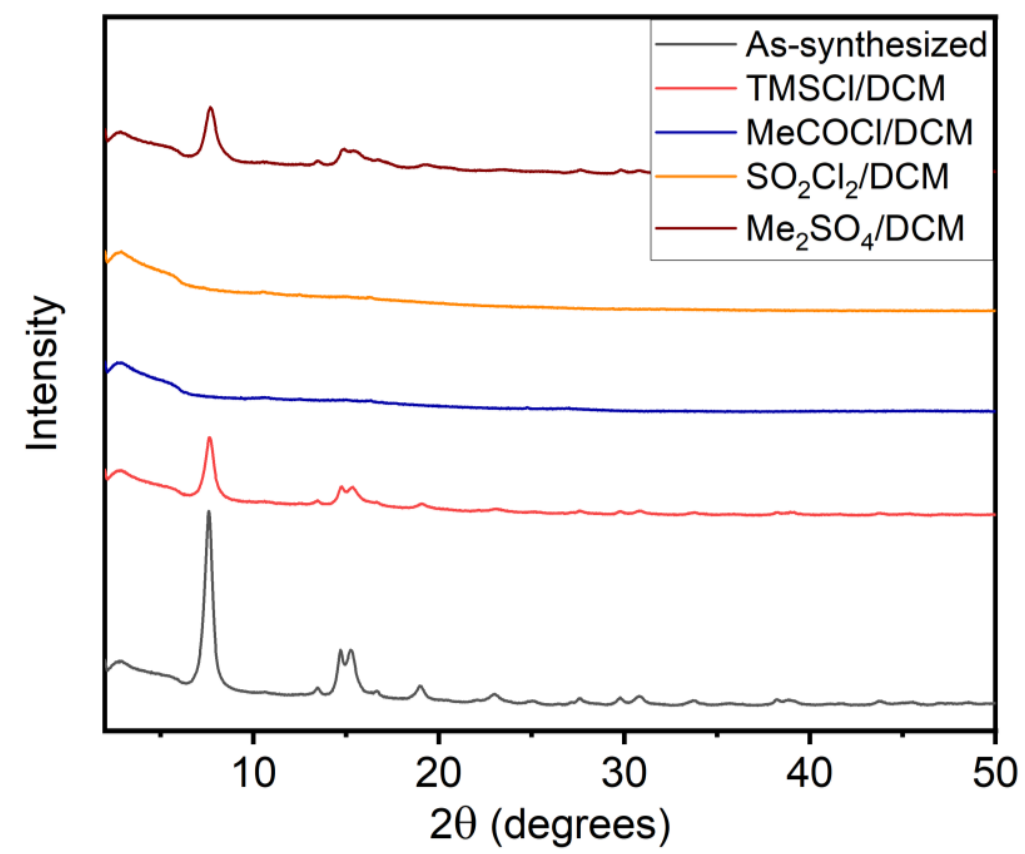

Figure S187. PXRD patterns ( $\lambda=1.5406 \AA$ ) of Ni(bdp) upon exposure to electrophiles. Exposure tests include $1.0 \mathrm{M}$ chlorotrimethylsilane (TMSCl) in dichloromethane, $1.0 \mathrm{M}$ acetyl chloride in dichloromethane, $1.0 \mathrm{M}$ sulfuryl chloride in dichloromethane, and saturated dimethyl sulfate in dichloromethane. A reference pattern of as-synthesized Ni(bdp) is included.

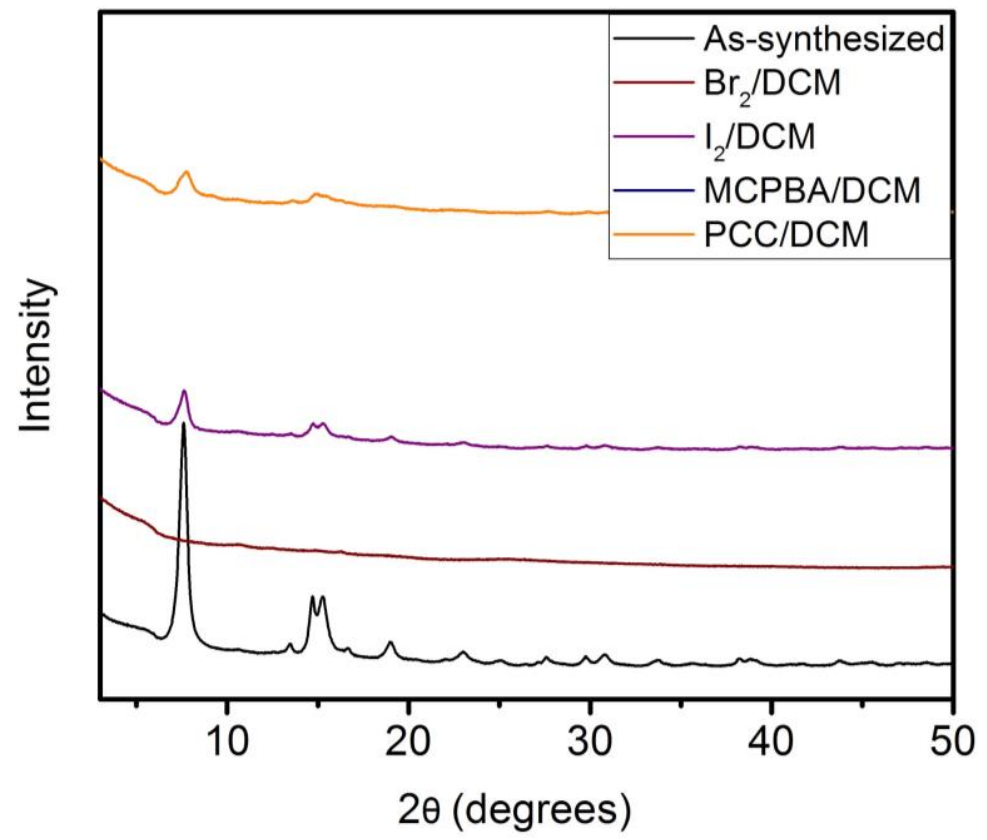

Figure S188. PXRD patterns $(\lambda=1.5406 \AA$ ) of Ni(bdp) upon exposure to oxidants. Exposure tests include $1.0 \mathrm{M}$ bromine in dichloromethane, saturated iodine in dichloromethane, saturated $\mathrm{m}$ chloroperoxybenzoic acid (MCPBA) in dichloromethane, and saturated pyridinium chlorochromate (PCC) in dichloromethane. No solid material remained after exposure of $\mathrm{Ni}(\mathrm{bdp})$ to the MCPBA solution. A reference pattern of as-synthesized Ni(bdp) is included. 


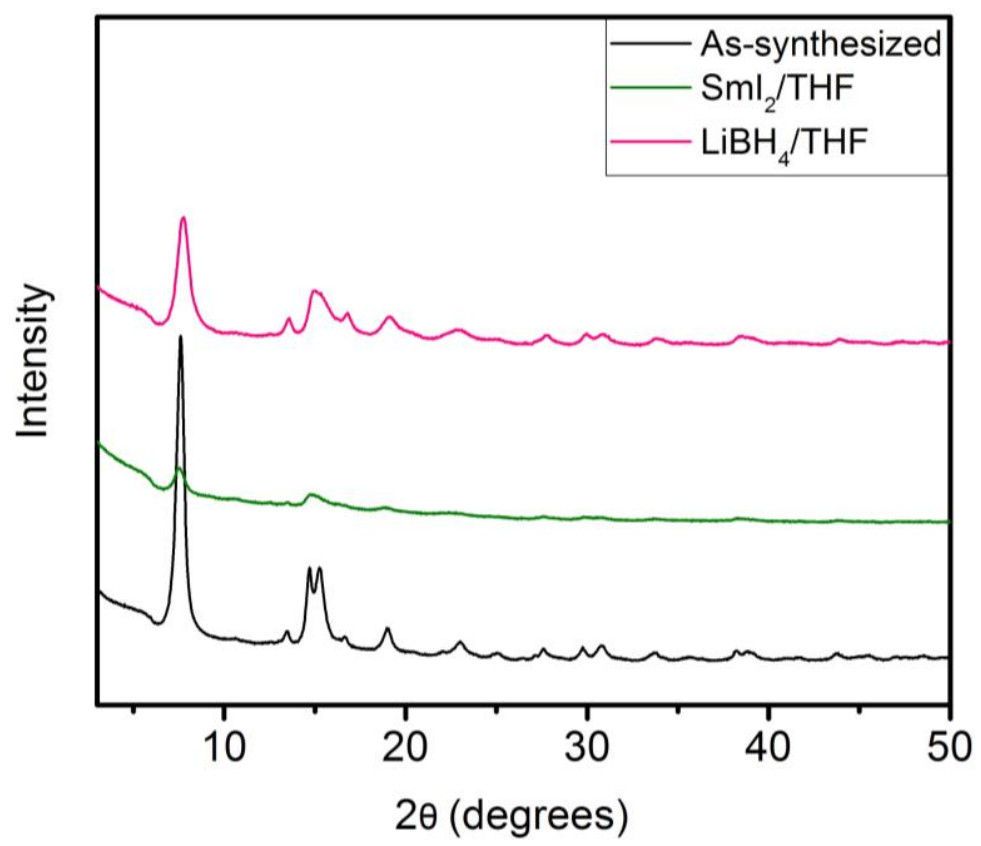

Figure S189. PXRD patterns $(\lambda=1.5406 \AA)$ of $\mathrm{Ni}(\mathrm{bdp})$ upon exposure to reductants. Exposure tests include $0.1 \mathrm{M}$ samarium iodide in tetrahydrofuran and $1.0 \mathrm{M}$ lithium borohydride in tetrahydrofuran. A reference pattern of as-synthesized $\mathrm{Ni}(\mathrm{bdp})$ is included. 
Table S16. Summary of changes in the full width at half maximum (FWHM) for the $2 \theta=7^{\circ}(\lambda=$ $1.5406 \AA$ ) reflection of $\mathrm{Ni}(\mathrm{bdp})$ under a range of conditions.

\begin{tabular}{|c|c|c|c|c|c|}
\hline Condition & \multicolumn{2}{|c|}{ Result } & Condition & \multicolumn{2}{|c|}{ Result } \\
\hline \multirow{2}{*}{ Initial } & FWHM & 0.50718 & \multirow{2}{*}{ DI water } & FWHM & 0.436 \\
\hline & $\%$ Change & - & & $\%$ Change & $-14^{a}$ \\
\hline \multirow{2}{*}{$120{ }^{\circ} \mathrm{C}$ Air } & FWHM & 0.50609 & \multirow{2}{*}{$\mathrm{BuNH}_{2} / \mathrm{THF}$} & FWHM & 0.65842 \\
\hline & $\%$ Change & -1 & & $\%$ Change & 30 \\
\hline \multirow{2}{*}{$180{ }^{\circ} \mathrm{C}$ Air } & FWHM & 0.50302 & \multirow{2}{*}{$\mathrm{PhMgBr} / \mathrm{THF}$} & FWHM & 0.87333 \\
\hline & $\%$ Change & -1 & & $\%$ Change & 73 \\
\hline \multirow{2}{*}{ Conc. $\mathrm{HCl}$} & FWHM & 0 & \multirow{2}{*}{ TBAF/THF } & FWHM & 0.70836 \\
\hline & $\%$ Change & $x$ & & $\%$ Change & 40 \\
\hline \multirow{2}{*}{$\mathrm{pH}=1$ Buffer } & FWHM & 0 & \multirow{2}{*}{$\mathrm{Me}_{3} \mathrm{SiCl} / \mathrm{CH}_{2} \mathrm{Cl}_{2}$} & FWHM & 0.58782 \\
\hline & $\%$ Change & $x$ & & $\%$ Change & 16 \\
\hline \multirow{2}{*}{$\mathrm{pH}=4$ Buffer } & FWHM & 0.3755 & \multirow{2}{*}{$\mathrm{MeCOCl} / \mathrm{CH}_{2} \mathrm{Cl}_{2}$} & FWHM & 0 \\
\hline & $\%$ Change & $-26^{a}$ & & $\%$ Change & $x$ \\
\hline \multirow{2}{*}{$\mathrm{pH}=7$ Buffer } & FWHM & 0.41168 & \multirow{2}{*}{$\mathrm{SO}_{2} \mathrm{Cl}_{2} / \mathrm{CH}_{2} \mathrm{Cl}_{2}$} & FWHM & 0 \\
\hline & $\%$ Change & $-19^{a}$ & & $\%$ Change & $x$ \\
\hline \multirow{2}{*}{$\mathrm{pH}=10$ Buffer } & FWHM & 0.46875 & \multirow{2}{*}{$\mathrm{Me}_{2} \mathrm{SO}_{4} / \mathrm{CH}_{2} \mathrm{Cl}_{2}$} & FWHM & 0.62502 \\
\hline & $\%$ Change & $-8^{a}$ & & $\%$ Change & 23 \\
\hline \multirow{2}{*}{$\mathrm{pH}=13$ Buffer } & FWHM & 0.42034 & \multirow{2}{*}{$\mathrm{Br}_{2} / \mathrm{CH}_{2} \mathrm{Cl}_{2}$} & FWHM & 0 \\
\hline & $\%$ Change & $-18^{a}$ & & $\%$ Change & $x$ \\
\hline \multirow{2}{*}{ Sat. $\mathrm{NaOH}$} & FWHM & 0 & \multirow{2}{*}{$\mathrm{I}_{2} / \mathrm{CH}_{2} \mathrm{Cl}_{2}$} & FWHM & 0.64596 \\
\hline & $\%$ Change & $x$ & & $\%$ Change & 28 \\
\hline \multirow{2}{*}{$\mathrm{CH}_{3} \mathrm{COOH}$} & FWHM & 0 & \multirow{2}{*}{$\mathrm{MCPBA} / \mathrm{CH}_{2} \mathrm{Cl}_{2}$} & FWHM & 0 \\
\hline & $\%$ Change & $x$ & & $\%$ Change & $x$ \\
\hline \multirow{2}{*}{ LiHMDS/Tol } & FWHM & 0.97897 & \multirow{2}{*}{$\mathrm{PCC} / \mathrm{CH}_{2} \mathrm{Cl}_{2}$} & FWHM & 0.8055 \\
\hline & $\%$ Change & 94 & & $\%$ Change & 59 \\
\hline \multirow{2}{*}{$\mathrm{H}_{2} \mathrm{~S} / \mathrm{THF}$} & FWHM & 0.6741 & \multirow{2}{*}{$\mathrm{SmI}_{2} / \mathrm{THF}$} & FWHM & 0.77772 \\
\hline & $\%$ Change & 33 & & $\%$ Change & 54 \\
\hline \multirow{2}{*}{$\mathrm{NH}_{3} / \mathrm{MeOH}$} & FWHM & 0.49663 & \multirow{2}{*}{$\mathrm{LiBH}_{4} / \mathrm{THF}$} & FWHM & 0.7546 \\
\hline & $\%$ Change & -3 & & $\%$ Change & 49 \\
\hline
\end{tabular}

${ }^{a}$ New reflections observed by PXRD. 


\section{Synthesis, characterization, and stability assessment of $\mathrm{Fe}_{2}(\mathrm{bdp})_{3}$.}

Synthesis of $\mathbf{F e}_{2}$ (bdp) 3. This procedure is adapted from the literature. ${ }^{35}$ A $100 \mathrm{~mL}$ Schlenk flask equipped with a stir bar was charged with 1,4-di(1H-pyrazol-4-yl)benzene $\left(\mathrm{H}_{2} \mathrm{bdp}, 600 \mathrm{mg}\right.$, 2.86 mmol, 1.00 equiv.) and $\mathrm{Fe}(\mathrm{acac})_{3}(3.02 \mathrm{~g}, 8.56 \mathrm{mmol}, 3.00$ equiv.). The flask was placed under high vacuum and back-filled with $\mathrm{N}_{2}$. This process was repeated a total of three times. Next, degassed $N, N$-dimethylformamide $(40 \mathrm{~mL})$ was added under a positive pressure of $\mathrm{N}_{2}$, and the Schlenk flask was transferred to a silicone oil bath that was then heated to $150{ }^{\circ} \mathrm{C}$. The reaction mixture was vigorously stirred $(700 \mathrm{rpm})$ at $150{ }^{\circ} \mathrm{C}$ under $\mathrm{N}_{2}$ for $18 \mathrm{~h}$. Note: vigorous stirring is required to obtain highly crystalline $\mathrm{Fe}_{2}(\mathrm{bdp})_{3}$ in high yield. After the reaction was complete, the heterogeneous reaction mixture was allowed to cool to room temperature and filtered. The resulting black solid was transferred to a $500 \mathrm{~mL}$ Pyrex jar with dimethyl sulfoxide $(100 \mathrm{~mL})$. The jar was allowed to stand for $8 \mathrm{~h}$ at $100{ }^{\circ} \mathrm{C}$ in an oven, at which time the dimethyl sulfoxide was decanted and replaced with fresh dimethyl sulfoxide $(100 \mathrm{~mL})$. This procedure was repeated two additional times for a total of three hot dimethyl sulfoxide soaks. Next, the solid was filtered and returned to the jar with fresh $N, N$-dimethylformamide $(100 \mathrm{~mL})$. The solid was soaked in $N, N$ dimethylformamide for $8 \mathrm{~h}$ at $100{ }^{\circ} \mathrm{C}$ in an oven three total times following the same procedure as described above. Next, the solid was filtered and returned to the jar with fresh dichloromethane $(100 \mathrm{~mL})$. The solid was soaked in dichloromethane for $8 \mathrm{~h}$ at room temperature three total times following the same procedure as described above. The resulting black solid was filtered and transferred to a Schlenk flask. The solid was activated under flowing $\mathrm{N}_{2}$ at $180{ }^{\circ} \mathrm{C}$ for $4 \mathrm{~h}$, followed by further activation under high vacuum (<100 mbar) at $180{ }^{\circ} \mathrm{C}$ for $24 \mathrm{~h}$. The Schlenk flask was transferred into a $\mathrm{N}_{2}$-filled glovebox, and the activated $\mathrm{Fe}_{2}(\mathrm{bdp})_{3}$ was transferred into a $20 \mathrm{~mL}$ scintillation vial for long-term storage. A portion of the activated sample was transferred to a pretared Micromeritics sample tube equipped with a Sureseal. The tube was removed from the glovebox and the sample was further activated under high vacuum $(<10 \mu \mathrm{bar})$ at $180{ }^{\circ} \mathrm{C}$ for $24 \mathrm{~h}$ prior to gas sorption measurements. 


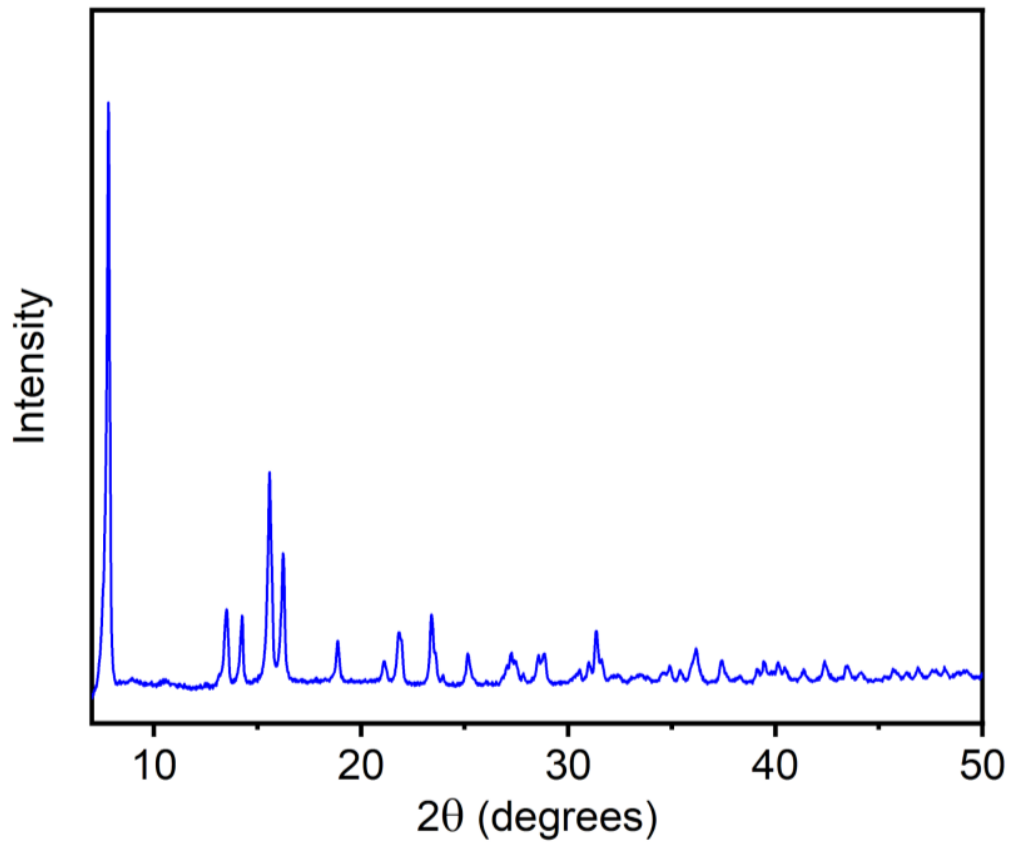

Figure S190. PXRD pattern $(\lambda=1.5406 \AA)$ of $\mathrm{CH}_{2} \mathrm{Cl}_{2}$-solvated $\mathrm{Fe}_{2}(\mathrm{bdp})_{3}$. This data is consistent with that reported in the literature. ${ }^{35}$ The PXRD pattern of $\mathrm{Fe}_{2}(\mathrm{bdp})_{3}$ was baseline corrected.

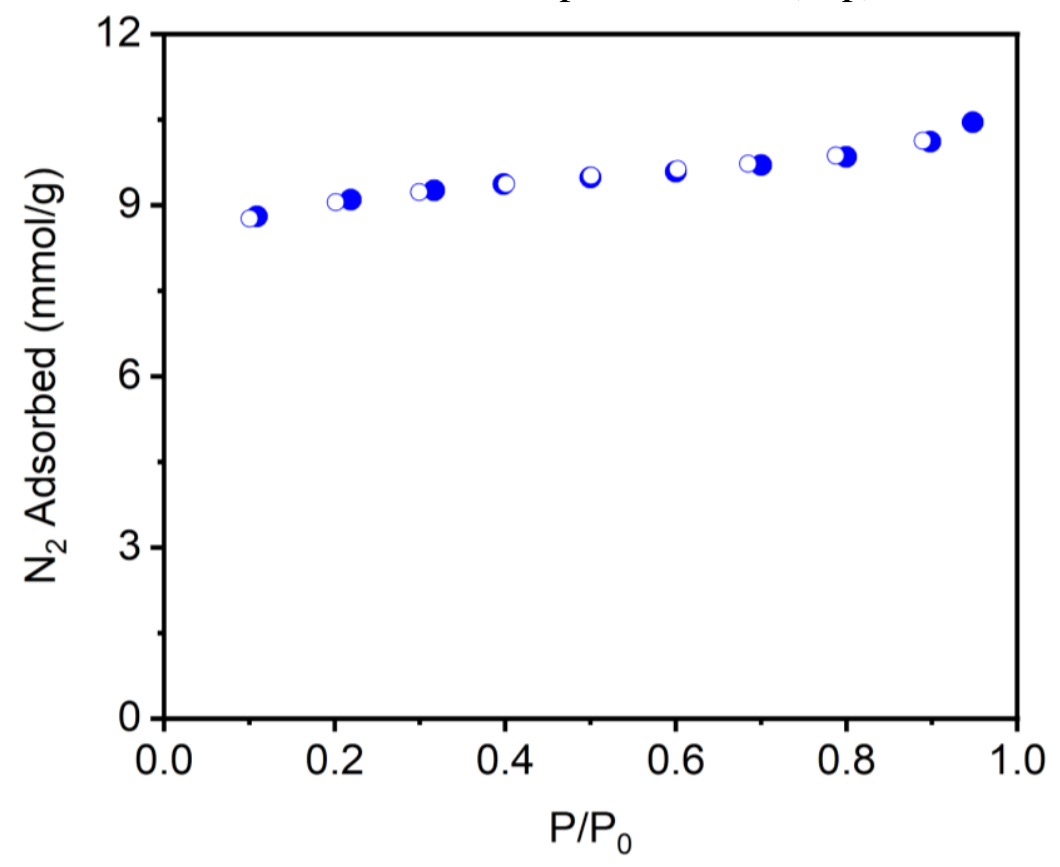

Figure S191. $77 \mathrm{~K} \mathrm{~N}_{2}$ adsorption (filled circles) and desorption (open circles) isotherm of activated $\mathrm{Fe}_{2}(\mathrm{bdp})_{3}$. The Langmuir surface area determined from these data is $989 \pm 9 \mathrm{~m}^{2} / \mathrm{g}$. 


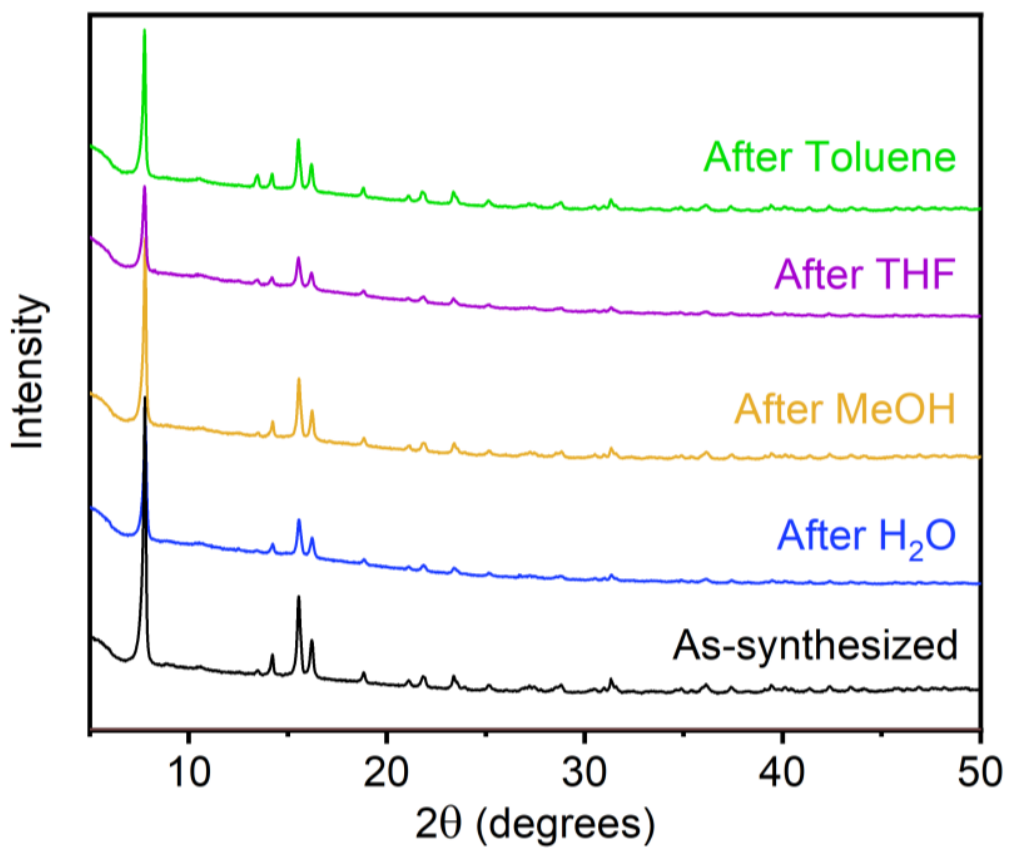

Figure S192. PXRD patterns $(\lambda=1.5406 \AA)$ of $\mathrm{Fe}_{2}(\mathrm{bdp})_{3}$ upon exposure to various organic solvents and water. Note that $\mathrm{Fe}_{2}(\mathrm{bdp})_{3}$ was soaked in DMF, DMSO, and $\mathrm{CH}_{2} \mathrm{Cl}_{2}$ during its synthesis as well. A reference pattern of as-synthesized $\mathrm{Fe}_{2}(\mathrm{bdp})_{3}$ is included.

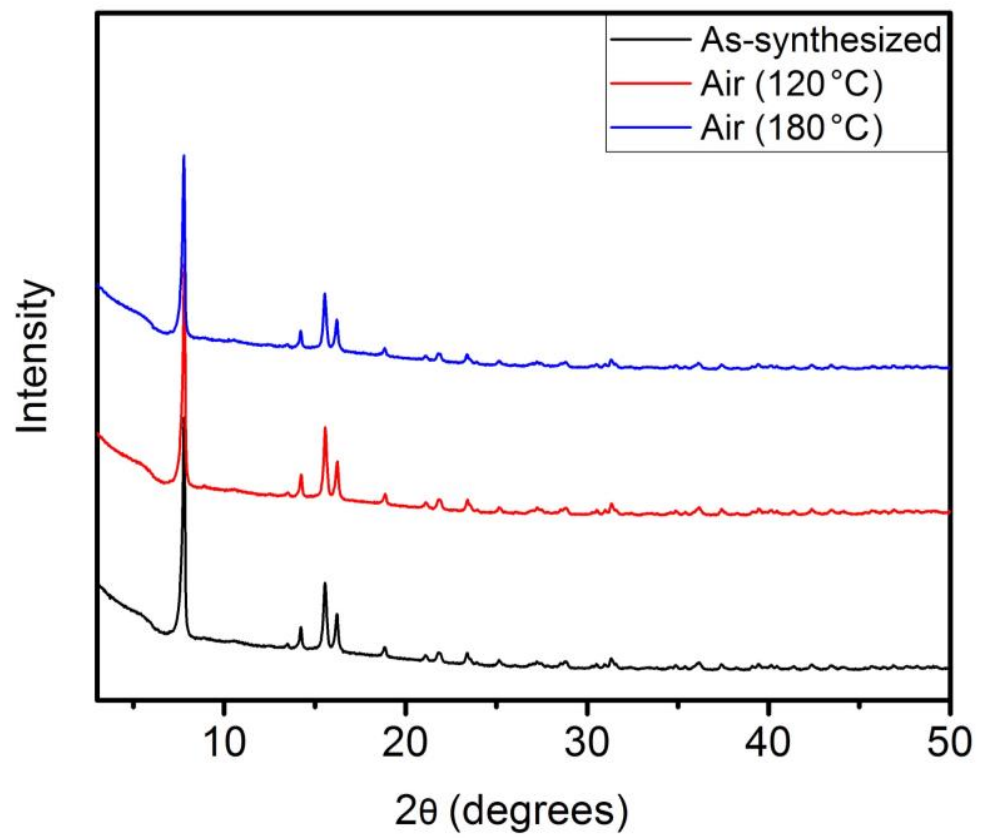

Figure S193. PXRD patterns $(\lambda=1.5406 \AA)$ of $\mathrm{Fe}_{2}(\mathrm{bdp})_{3}$ upon standing at $120{ }^{\circ} \mathrm{C}$ and $180{ }^{\circ} \mathrm{C}$ in air for $24 \mathrm{~h}$. A reference pattern of as-synthesized $\mathrm{Fe}_{2}(\mathrm{bdp})_{3}$ is included. 


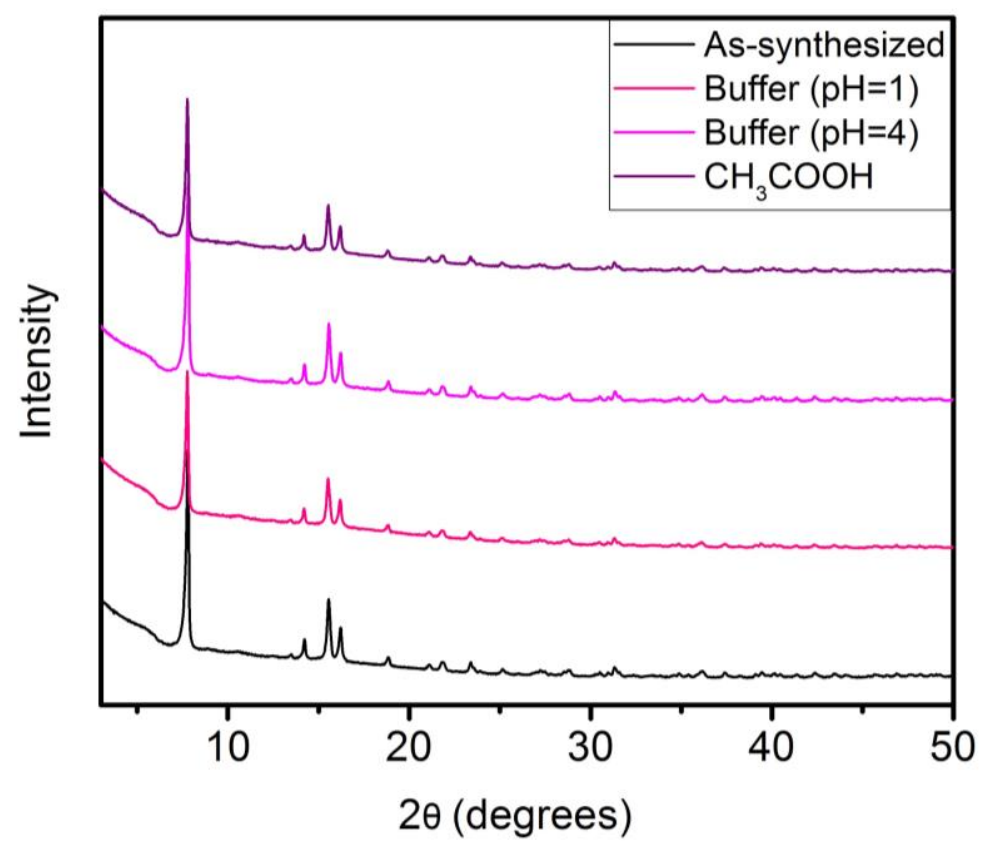

Figure S194. PXRD patterns $(\lambda=1.5406 \AA)$ of $\mathrm{Fe}_{2}(\mathrm{bdp})_{3}$ upon exposure to acids. Exposure tests include aqueous solutions buffered at $\mathrm{pH} 1$ and $\mathrm{pH} 4$ and glacial acetic acid. A reference pattern of as-synthesized $\mathrm{Fe}_{2}(\mathrm{bdp})_{3}$ is included.

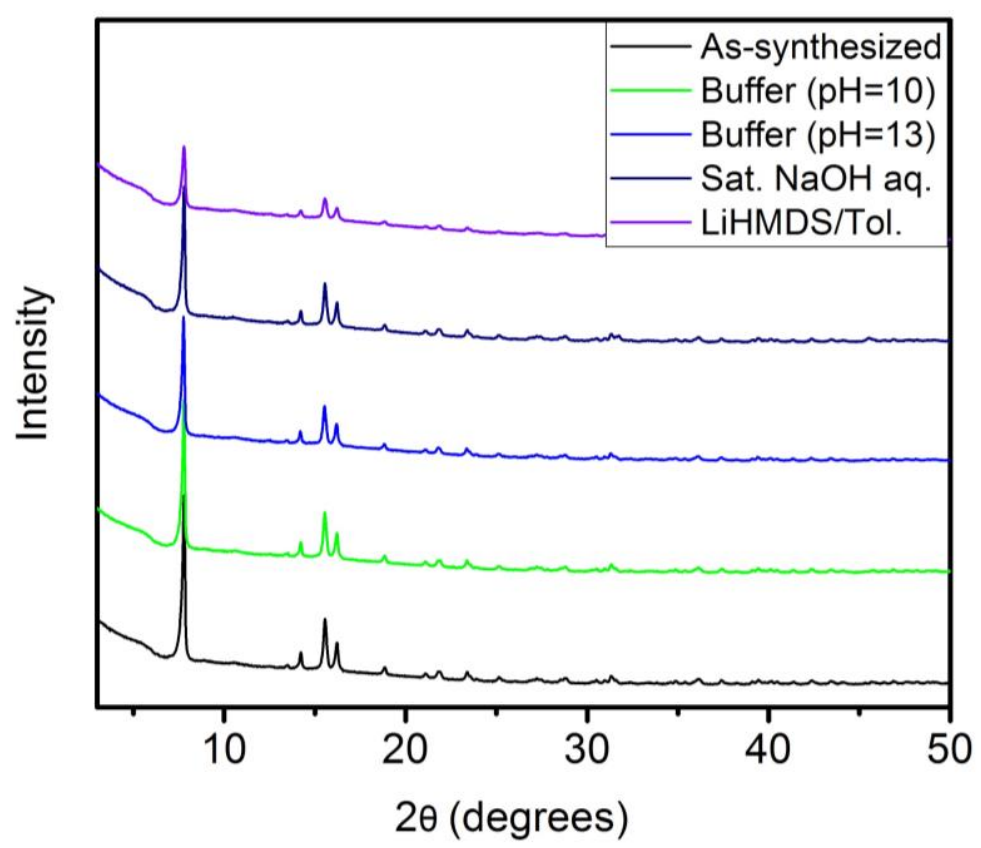

Figure S195. PXRD patterns $(\lambda=1.5406 \AA)$ of $\mathrm{Fe}_{2}(\mathrm{bdp})_{3}$ upon exposure to bases. Exposure tests include aqueous solutions buffered at $\mathrm{pH} 10$ and $\mathrm{pH} 13$, saturated aqueous $\mathrm{NaOH}$, and $1.0 \mathrm{M}$ lithium hexamethyldisilazide (LiHMDS) in toluene. A reference pattern of as-synthesized $\mathrm{Fe}_{2}(\mathrm{bdp})_{3}$ is included. 


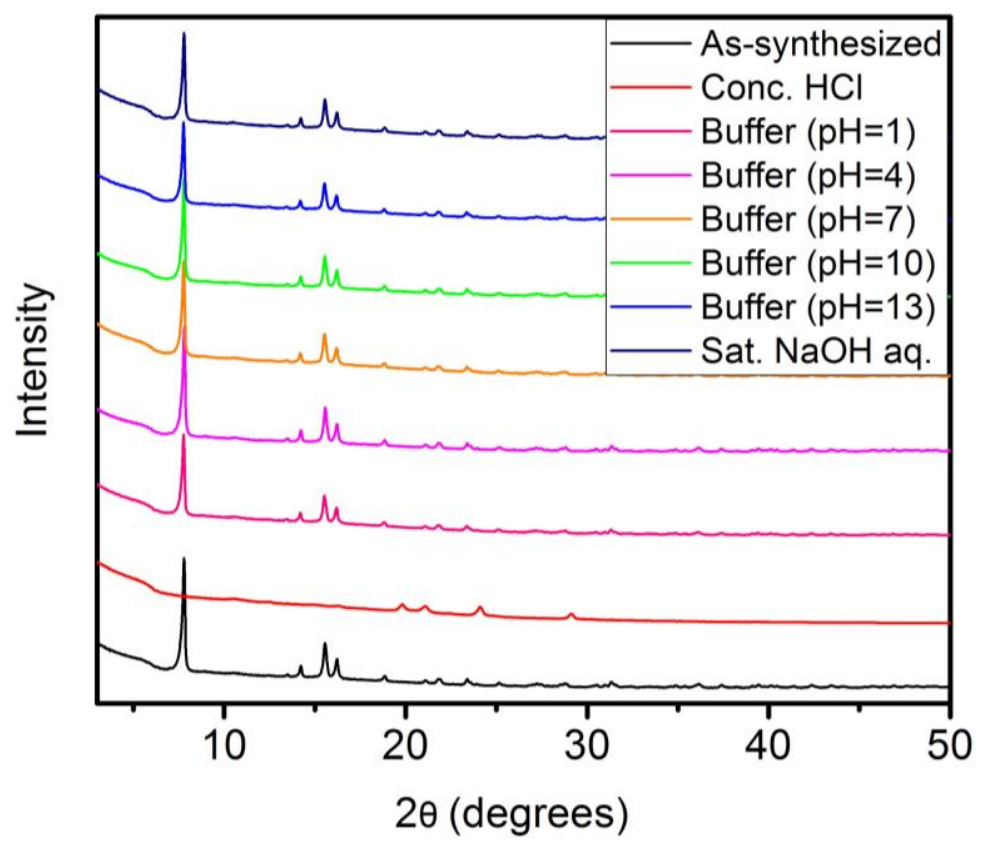

Figure S196. Summary of the PXRD patterns $(\lambda=1.5406 \AA)$ of $\mathrm{Fe}_{2}(\mathrm{bdp})_{3}$ upon exposure to various aqueous conditions. A reference pattern of as-synthesized $\mathrm{Fe}_{2}(\mathrm{bdp})_{3}$ is included.

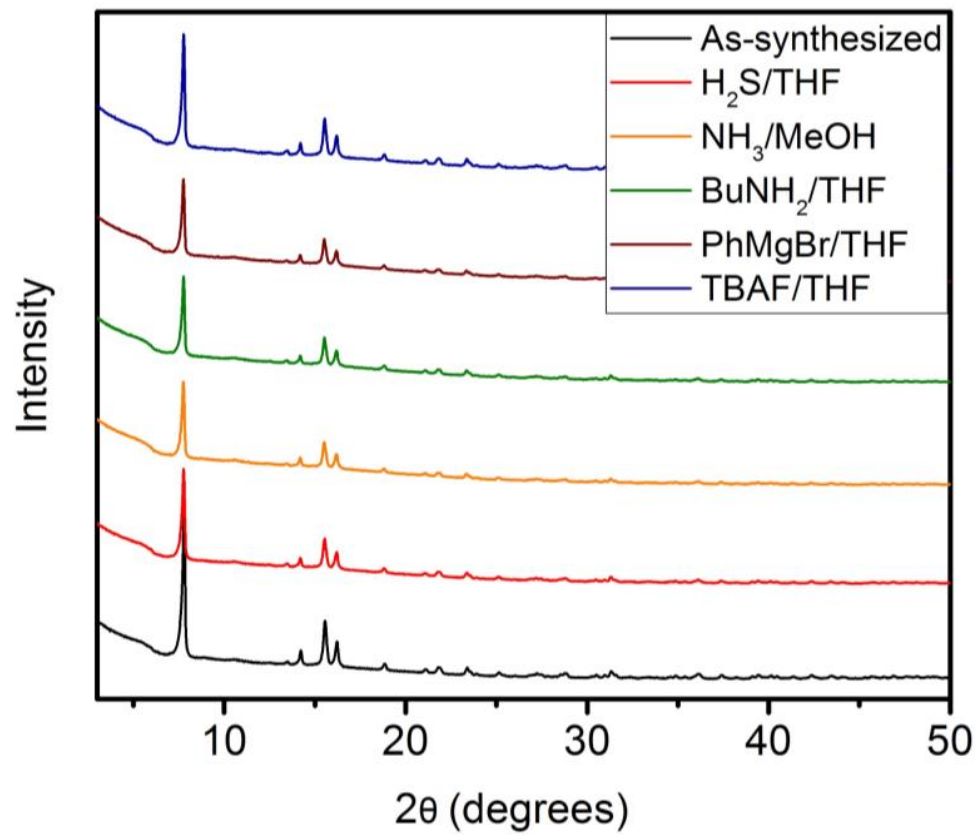

Figure S197. PXRD patterns $(\lambda=1.5406 \AA)$ of $\mathrm{Fe}_{2}(\mathrm{bdp})_{3}$ upon exposure to nucleophiles. Exposure tests include $0.8 \mathrm{M}$ hydrogen sulfide in tetrahydrofuran, $1.0 \mathrm{M}$ ammonia in methanol, $1.0 \mathrm{M} \mathrm{n}$ butylamine in tetrahydrofuran, $1.0 \mathrm{M} \mathrm{PhMgBr}$ in tetrahydrofuran, and $1.0 \mathrm{M}$ tetrabutylammonium fluoride (TBAF) in tetrahydrofuran. A reference pattern of as-synthesized $\mathrm{Fe}_{2}(\mathrm{bdp})_{3}$ is included. 


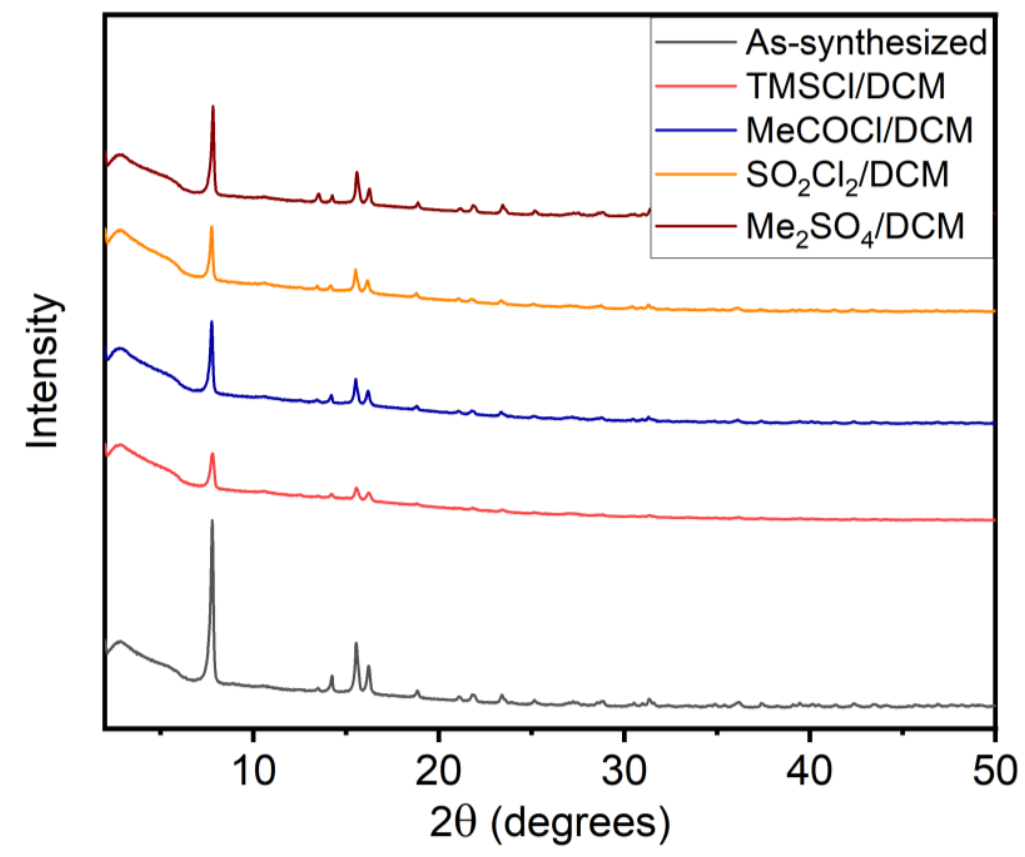

Figure S198. PXRD patterns $(\lambda=1.5406 \AA)$ of $\mathrm{Fe}_{2}(\mathrm{bdp})_{3}$ upon exposure to electrophiles. Exposure tests include $1.0 \mathrm{M}$ chlorotrimethylsilane (TMSCl) in dichloromethane, $1.0 \mathrm{M}$ acetyl chloride in dichloromethane, $1.0 \mathrm{M}$ sulfuryl chloride in dichloromethane, and saturated dimethyl sulfate in dichloromethane. A reference pattern of as-synthesized $\mathrm{Fe}_{2}(\mathrm{bdp})_{3}$ is included.

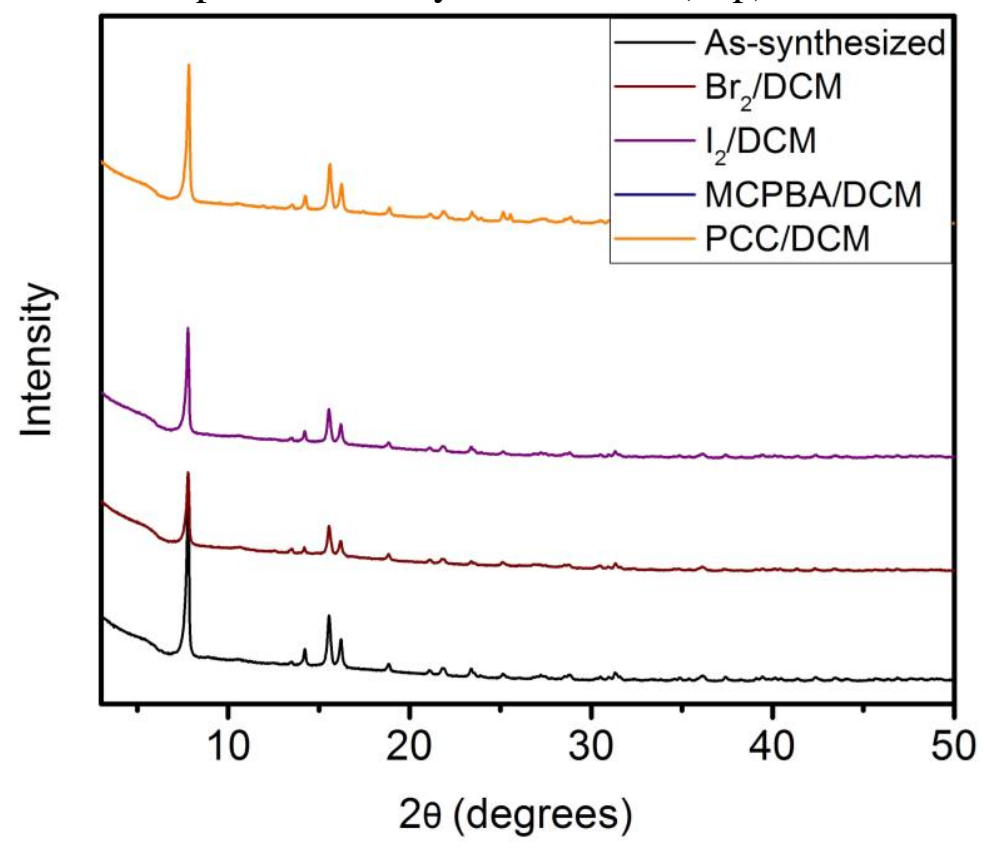

Figure S199. PXRD patterns $(\lambda=1.5406 \AA)$ of $\mathrm{Fe}_{2}(\mathrm{bdp})_{3}$ upon exposure to oxidants. Exposure tests include 1.0 M bromine in dichloromethane, saturated iodine in dichloromethane, saturated $m$-chloroperoxybenzoic acid (MCPBA) in dichloromethane, and saturated pyridinium chlorochromate (PCC) in dichloromethane. No solid material remained after exposure of $\mathrm{Fe}_{2}(\mathrm{bdp})_{3}$ to the MCPBA. A reference pattern of as-synthesized $\mathrm{Fe}_{2}(\mathrm{bdp})_{3}$ is included. 


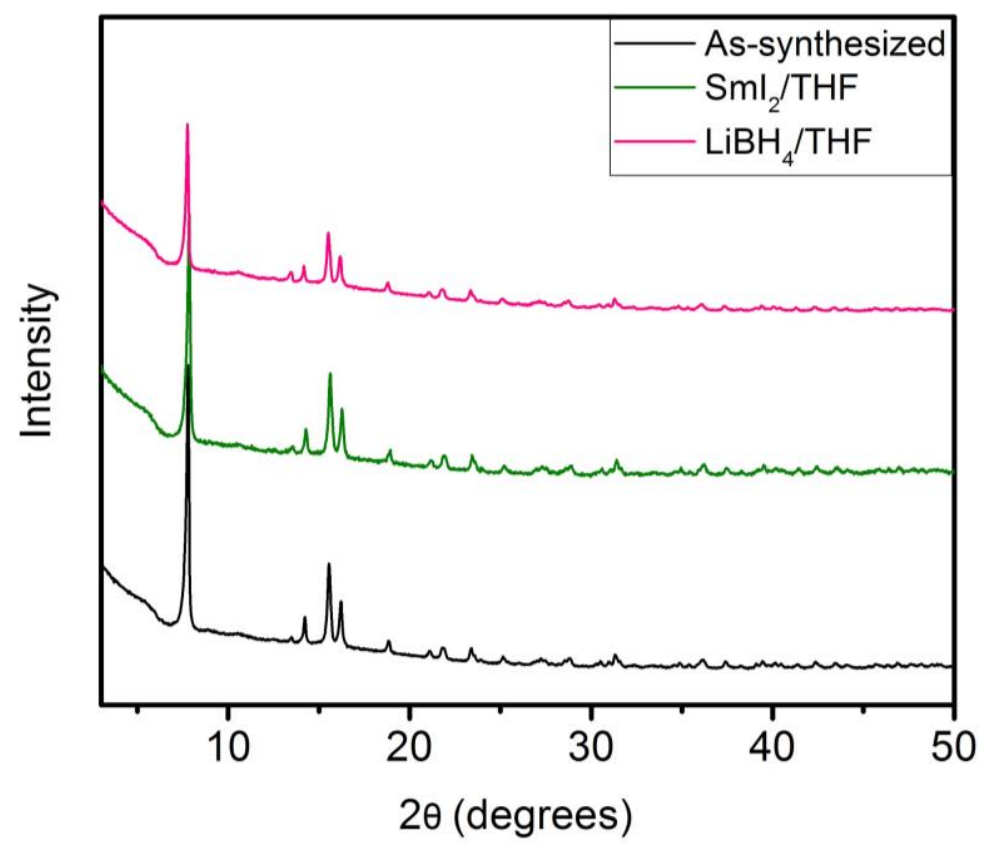

Figure S200. PXRD patterns $(\lambda=1.5406 \AA)$ of $\mathrm{Fe}_{2}(\mathrm{bdp})_{3}$ upon exposure to reductants. Exposure tests include $0.1 \mathrm{M}$ samarium iodide in tetrahydrofuran and $1.0 \mathrm{M}$ lithium borohydride in tetrahydrofuran. A reference pattern of as-synthesized $\mathrm{Fe}_{2}(\mathrm{bdp})_{3}$ is included. 
Table S17. Summary of changes in the full width at half maximum (FWHM) for the $2 \theta=8^{\circ}(\lambda=$ $1.5406 \AA$ ) reflection of $\mathrm{Fe}_{2}(\mathrm{bdp})_{3}$ under a range of conditions.

\begin{tabular}{|c|c|c|c|c|c|}
\hline Condition & \multicolumn{2}{|c|}{ Result } & Condition & \multicolumn{2}{|c|}{ Result } \\
\hline \multirow{2}{*}{ Initial } & FWHM & 0.1865 & \multirow{2}{*}{ DI water } & FWHM & 0.19774 \\
\hline & $\%$ Change & - & & $\%$ Change & 6 \\
\hline \multirow{2}{*}{$120^{\circ} \mathrm{C}$ Air } & FWHM & 0.18206 & \multirow{2}{*}{$\mathrm{BuNH}_{2} / \mathrm{THF}$} & FWHM & 0.18424 \\
\hline & $\%$ Change & -3 & & $\%$ Change & -2 \\
\hline \multirow{2}{*}{$180^{\circ} \mathrm{C}$ Air } & FWHM & 0.1764 & \multirow{2}{*}{$\mathrm{PhMgBr} / \mathrm{THF}$} & FWHM & 0.18068 \\
\hline & $\%$ Change & -6 & & $\%$ Change & -4 \\
\hline \multirow{2}{*}{ Conc. $\mathrm{HCl}$} & FWHM & 0 & \multirow{2}{*}{ TBAF/THF } & FWHM & 0.18014 \\
\hline & $\%$ Change & $x$ & & $\%$ Change & -4 \\
\hline \multirow{2}{*}{$\mathrm{pH}=1$ Buffer } & FWHM & 0.18116 & \multirow{2}{*}{$\mathrm{Me}_{3} \mathrm{SiCl} / \mathrm{CH}_{2} \mathrm{Cl}_{2}$} & FWHM & 0.23593 \\
\hline & $\%$ Change & -3 & & $\%$ Change & 27 \\
\hline \multirow{2}{*}{$\mathrm{pH}=4$ Buffer } & FWHM & 0.19087 & \multirow{2}{*}{$\mathrm{MeCOCl} / \mathrm{CH}_{2} \mathrm{Cl}_{2}$} & FWHM & 0.18106 \\
\hline & $\%$ Change & 3 & & $\%$ Change & -3 \\
\hline \multirow{2}{*}{$\mathrm{pH}=7$ Buffer } & FWHM & 0.1859 & \multirow{2}{*}{$\mathrm{SO}_{2} \mathrm{Cl}_{2} / \mathrm{CH}_{2} \mathrm{Cl}_{2}$} & FWHM & 0.18259 \\
\hline & $\%$ Change & -1 & & $\%$ Change & -3 \\
\hline \multirow{2}{*}{$\mathrm{pH}=10$ Buffer } & FWHM & 0.17957 & \multirow{2}{*}{$\mathrm{Me}_{2} \mathrm{SO}_{4} / \mathrm{CH}_{2} \mathrm{Cl}_{2}$} & FWHM & 0.1777 \\
\hline & $\%$ Change & -4 & & $\%$ Change & -5 \\
\hline \multirow{2}{*}{$\mathrm{pH}=13$ Buffer } & FWHM & 0.17902 & \multirow{2}{*}{$\mathrm{Br}_{2} / \mathrm{CH}_{2} \mathrm{Cl}_{2}$} & FWHM & 0.18887 \\
\hline & $\%$ Change & -5 & & $\%$ Change & 2 \\
\hline \multirow{2}{*}{ Sat. $\mathrm{NaOH}$} & FWHM & 0.1852 & \multirow{2}{*}{$\mathrm{I}_{2} / \mathrm{CH}_{2} \mathrm{Cl}_{2}$} & FWHM & 0.18361 \\
\hline & $\%$ Change & -1 & & $\%$ Change & -2 \\
\hline \multirow{2}{*}{$\mathrm{CH}_{3} \mathrm{COOH}$} & FWHM & 0.18069 & \multirow{2}{*}{$\mathrm{MCPBA} / \mathrm{CH}_{2} \mathrm{Cl}_{2}$} & FWHM & 0 \\
\hline & $\%$ Change & -4 & & $\%$ Change & $x$ \\
\hline \multirow{2}{*}{ LiHMDS/Tol } & FWHM & 0.21763 & \multirow{2}{*}{$\mathrm{PCC} / \mathrm{CH}_{2} \mathrm{Cl}_{2}$} & FWHM & 0.19615 \\
\hline & $\%$ Change & 17 & & $\%$ Change & 6 \\
\hline \multirow{2}{*}{$\mathrm{H}_{2} \mathrm{~S} / \mathrm{THF}$} & FWHM & 0.18238 & \multirow{2}{*}{$\mathrm{SmI}_{2} / \mathrm{THF}$} & FWHM & 0.20826 \\
\hline & $\%$ Change & -3 & & $\%$ Change & 12 \\
\hline \multirow{2}{*}{$\mathrm{NH}_{3} / \mathrm{MeOH}$} & FWHM & 0.17709 & \multirow{2}{*}{$\mathrm{LiBH}_{4} / \mathrm{THF}$} & FWHM & 0.18024 \\
\hline & $\%$ Change & -6 & & $\%$ Change & -4 \\
\hline
\end{tabular}




\section{Comparison of Langmuir surface areas to literature values.}

Table S18. Langmuir surface areas of MOFs prepared as part of this work compared to representative surface areas from the literature.

\begin{tabular}{|c|c|c|}
\hline MOF & $\begin{array}{c}77 \mathrm{~K} \mathrm{~N}_{2} \text { Langmuir Surface } \\
\text { Area }\left(\mathrm{m}^{2} / \mathrm{g}\right) \text { (this work) }\end{array}$ & $\begin{array}{c}77 \mathrm{~K} \mathrm{~N}_{2} \text { Langmuir Surface } \\
\text { Area }\left(\mathrm{m}^{2} / \mathrm{g}\right) \text { (lit.) }\end{array}$ \\
\hline MIL-100 (Fe) & $2387 \pm 15$ & $2831^{36}$ \\
\hline MIL-100 (Cr) & $2449 \pm 100$ & $3100^{16}$ \\
\hline MOF-808 & $1743 \pm 3$ & $2390^{17}$ \\
\hline UiO-66 & $1615 \pm 1$ & $1187^{37}$ \\
\hline UiO-67 & $2654 \pm 2$ & $2772^{38}$ \\
\hline $\mathrm{PCN}-128$ & $3017 \pm 317$ & $4774^{3}$ \\
\hline MOF-74 (Mg) & $1879 \pm 5$ & $1957^{39}$ \\
\hline MOF-74 (Ni) & $1406 \pm 46$ & $1574^{39}$ \\
\hline $\mathrm{Ni}_{2}(m$-dobdc) & $1305 \pm 3$ & $1592^{24}$ \\
\hline $\mathrm{Mg}_{2}(\mathrm{dobpdc})$ & $3710 \pm 12$ & $3780^{27}$ \\
\hline $\mathrm{Mg}_{2}($ dotpdc $)$ & $5381 \pm 4$ & $5840^{27}$ \\
\hline ZIF-8 & $1609 \pm 1$ & $1810^{40}$ \\
\hline $\mathrm{Ni}_{2} \mathrm{Cl}_{2}$ (btdd) & $2791 \pm 12$ & $1762(\mathrm{BET})^{31}$ \\
\hline $\mathrm{Ni}_{3}(\mathrm{btp})_{2}$ & $2008 \pm 45$ & $1900^{10}$ \\
\hline $\mathrm{Zn}(\mathrm{bdp})$ & $2761 \pm 35$ & $2857^{32}$ \\
\hline $\mathrm{Ni}(\mathrm{bdp})$ & $1661 \pm 26$ & $1350^{32}$ \\
\hline $\mathrm{Fe}_{2}(\mathrm{bdp})_{3}$ & $989 \pm 9$ & $1230(\mathrm{BET})^{35}$ \\
\hline
\end{tabular}




\section{Additional stability assays for $\mathrm{Fe}_{2}(\mathrm{bdp})_{3}$.}

TBAF. Approximately $50 \mathrm{mg}$ of activated $\mathrm{Fe}_{2}(\mathrm{bdp})_{3}$ was submerged in $5 \mathrm{~mL}$ of $1.0 \mathrm{M}$ TBAF in THF in a $20 \mathrm{~mL}$ scintillation vial. The suspension was allowed to stand at room temperature for $24 \mathrm{~h}$. The mixture was filtered, and the resulting black solid was rinsed thoroughly with THF (50 $\mathrm{mL}$ ). The black solid was transferred to a $20 \mathrm{~mL}$ scintillation vial filled with THF (20 mL) and allowed to stand at room temperature for $24 \mathrm{~h}$. The THF was decanted and replaced with fresh FHF. This process was repeated for a total of three THF soaks. Next, the vial was filled with $\mathrm{CH}_{2} \mathrm{Cl}_{2}(20 \mathrm{~mL})$ and the solid was soaked in $\mathrm{CH}_{2} \mathrm{Cl}_{2}$ at room temperature for $24 \mathrm{~h}$. The $\mathrm{CH}_{2} \mathrm{Cl}_{2}$ was decanted and replaced with fresh $\mathrm{CH}_{2} \mathrm{Cl}_{2}$. This process was repeated for a total of three room temperature $\mathrm{CH}_{2} \mathrm{Cl}_{2}$ soaks. The mixture was filtered, and the black solid was transferred to a Micromeritics sample tube equipped with a Sureseal. The sample was reactivated under high vacuum $(<10 \mu \mathrm{bar})$ at $180^{\circ} \mathrm{C}$ for $24 \mathrm{~h}$ prior to gas adsorption measurements.

Lithium borohydride. Approximately $50 \mathrm{mg}$ of activated $\mathrm{Fe}_{2}(\mathrm{bdp})_{3}$ was submerged in $5 \mathrm{~mL}$ of 2.0 $\mathrm{M} \mathrm{LiBH}_{4}$ in THF in a $20 \mathrm{~mL}$ scintillation vial. The suspension was allowed to stand at room temperature for $24 \mathrm{~h}$. The mixture was filtered, and the resulting black solid was rinsed thoroughly with THF $(50 \mathrm{~mL})$. The mother liquor was quenched with isopropanol to destroy any remaining $\mathrm{LiBH}_{4}$. The black solid was transferred to a $100 \mathrm{~mL}$ Pyrex jar filled with DMSO $(50 \mathrm{~mL})$ and allowed to stand at $100{ }^{\circ} \mathrm{C}$ for $24 \mathrm{~h}$. The DMSO was decanted and replaced with fresh DMSO. This process was repeated for a total of three hot DMSO soaks. Next, the jar was filled with $\mathrm{CH}_{2} \mathrm{Cl}_{2}$ (50 mL) and the solid was soaked in $\mathrm{CH}_{2} \mathrm{Cl}_{2}$ at room temperature for $24 \mathrm{~h}$. The $\mathrm{CH}_{2} \mathrm{Cl}_{2}$ was decanted and replaced with fresh $\mathrm{CH}_{2} \mathrm{Cl}_{2}$. This process was repeated for a total of three room temperature $\mathrm{CH}_{2} \mathrm{Cl}_{2}$ soaks. The mixture was filtered, and the black solid was transferred to a Micromeritics sample tube equipped with a Sureseal. The sample was reactivated under high vacuum $(<10 \mu \mathrm{bar})$ at $180^{\circ} \mathrm{C}$ for $24 \mathrm{~h}$ prior to gas adsorption measurements. 


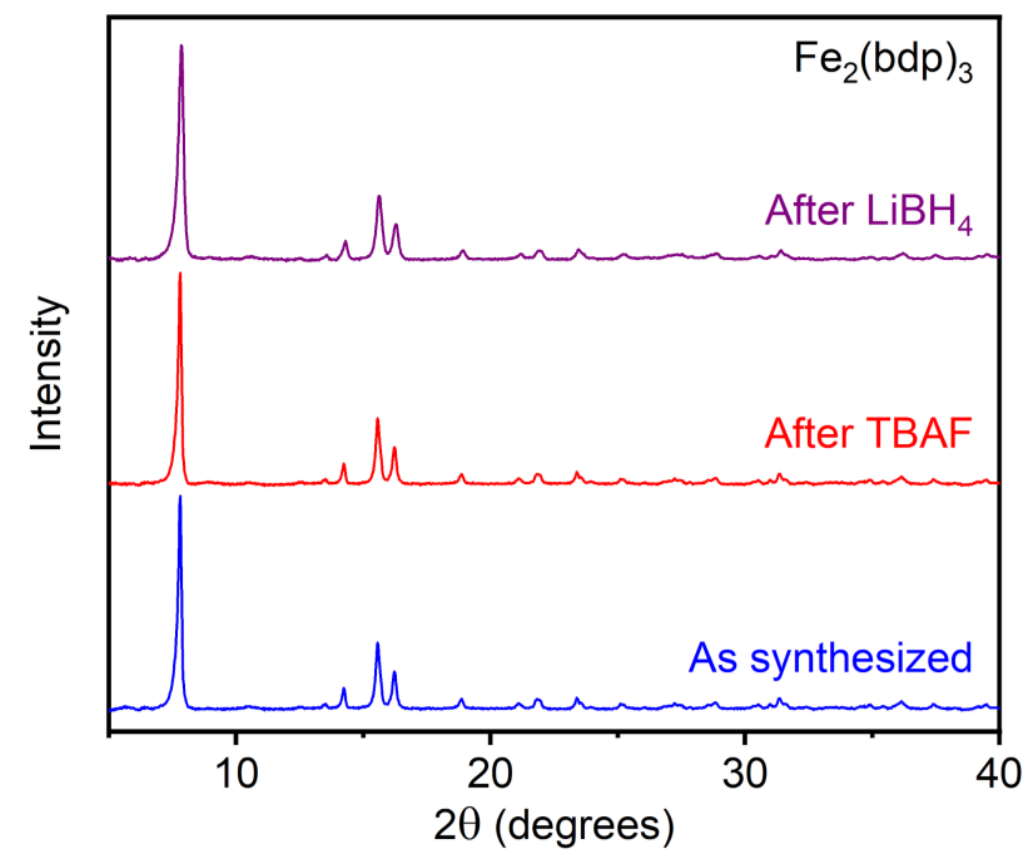

Figure S201. PXRD patterns of $\mathrm{Fe}_{2}(\mathrm{bdp})_{3}$ before and after representative stability assays.

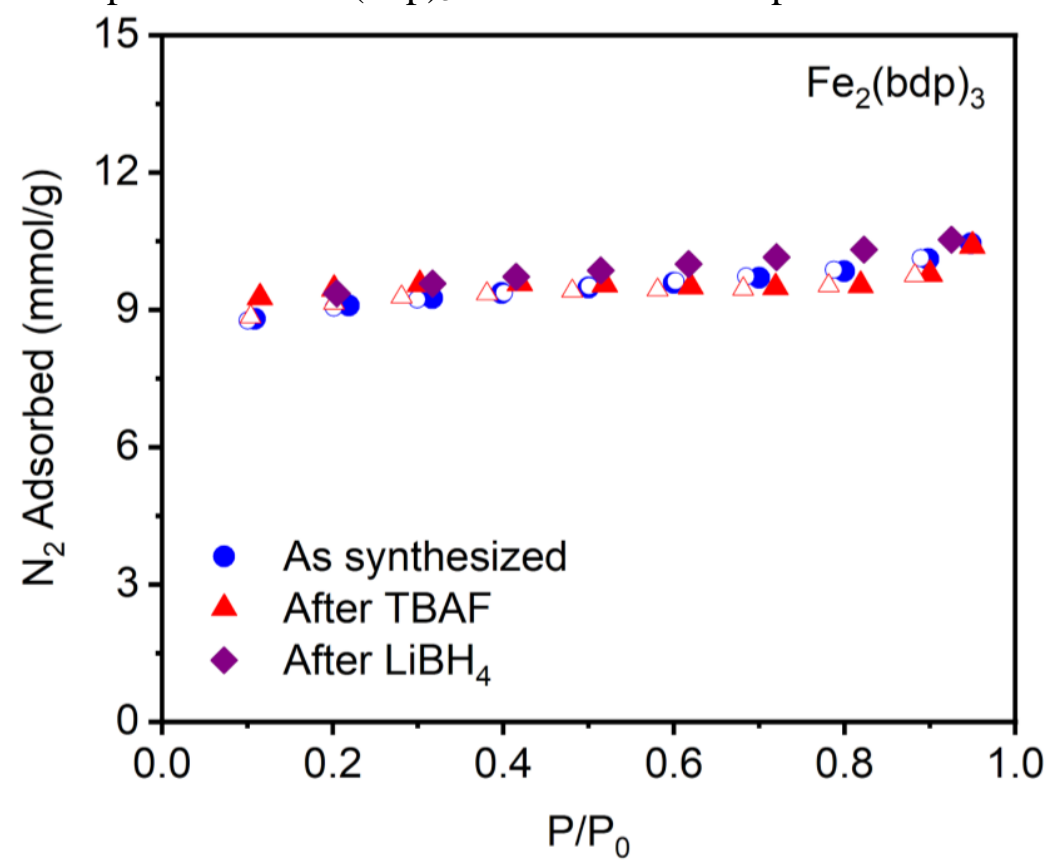

Figure S202. $77 \mathrm{~K} \mathrm{~N}_{2}$ adsorption (filled circles) and desorption (open circles) isotherms of $\mathrm{Fe}_{2}(\mathrm{bdp})_{3}$ before and after representative stability assays. The Langmuir surface areas determined from these data are included in Table S18. 
Table S19. Langmuir surface areas and pore valumes of $\mathrm{Fe}_{2}(\mathrm{bdp})_{3}$ before and after representative stability assays.

\begin{tabular}{|c|c|c|}
\hline Condition & Langmuir Surface Area $\left(\mathrm{m}^{2} / \mathrm{g}\right)$ & $\begin{array}{c}\text { Pore Volume at } P / P_{0} \approx 0.9 \\
\left(\mathrm{~cm}^{3} / \mathrm{g}\right)\end{array}$ \\
\hline As-synthesized & $989 \pm 9$ & 0.3204 \\
\hline TBAF & $920 \pm 4$ & 0.3389 \\
\hline $\mathrm{LiBH}_{4}$ & $986 \pm 7$ & 0.3655 \\
\hline
\end{tabular}

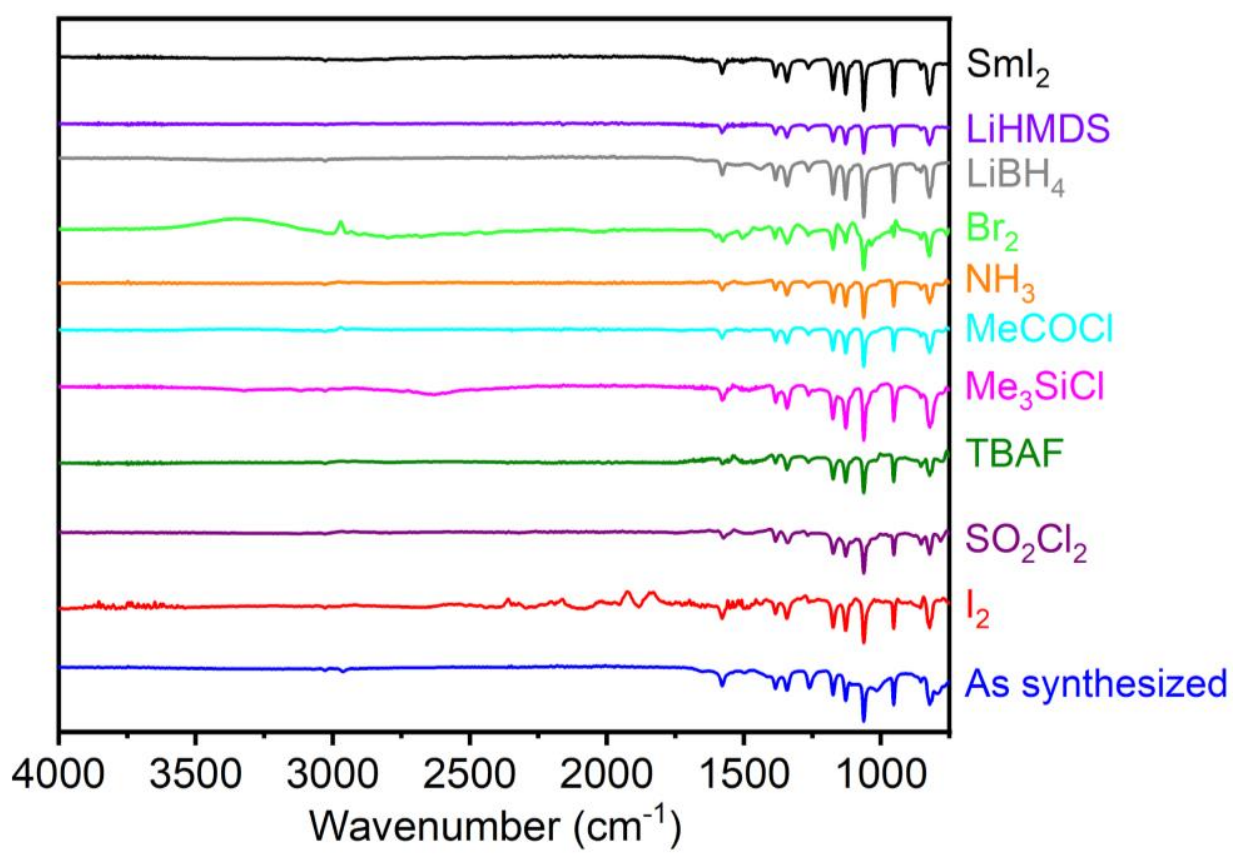

Figure S203. IR spectra of $\mathrm{Fe}_{2}(\mathrm{bdp})_{3}$ before and after representative successful stability assays.

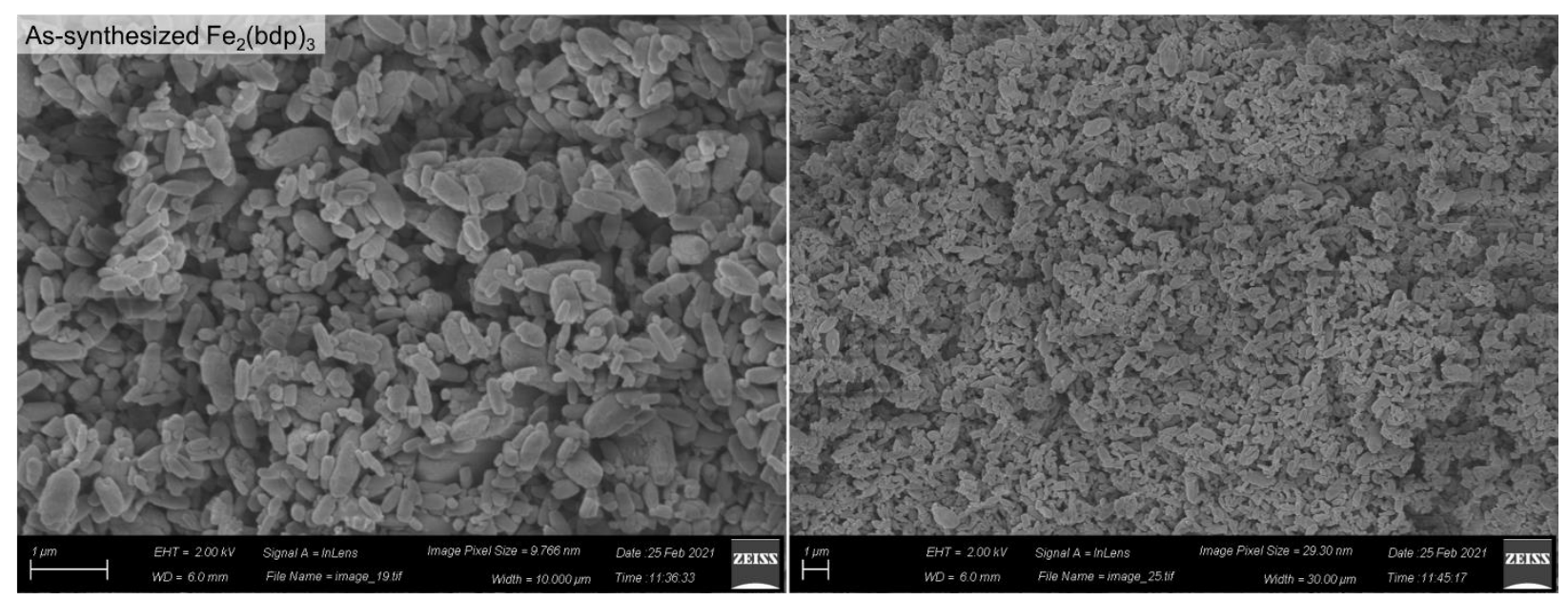

Figure S204. SEM images of as-synthesized $\mathrm{Fe}_{2}(\mathrm{bdp})_{3}$. 


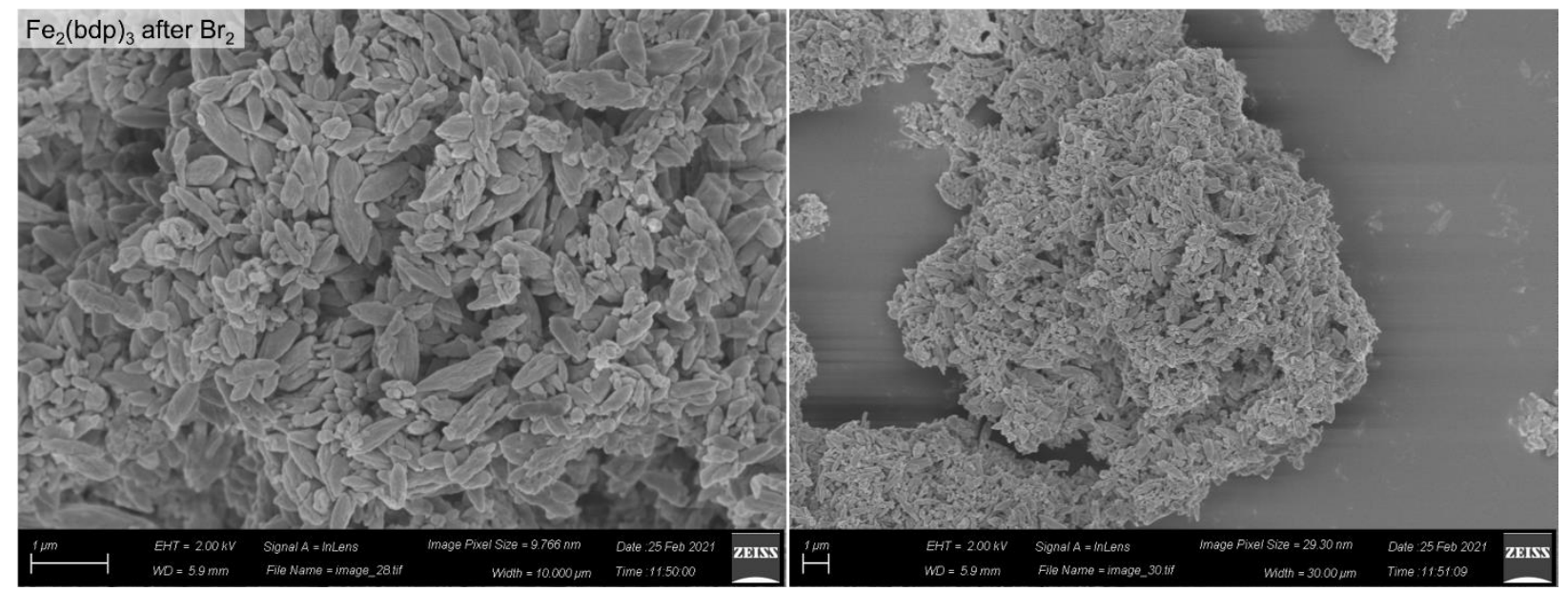

Figure S205. SEM images of $\mathrm{Fe}_{2}(\mathrm{bdp})_{3}$ after treatment with $\mathrm{Br}_{2}$, confirming the retention of welldefined crystallites.

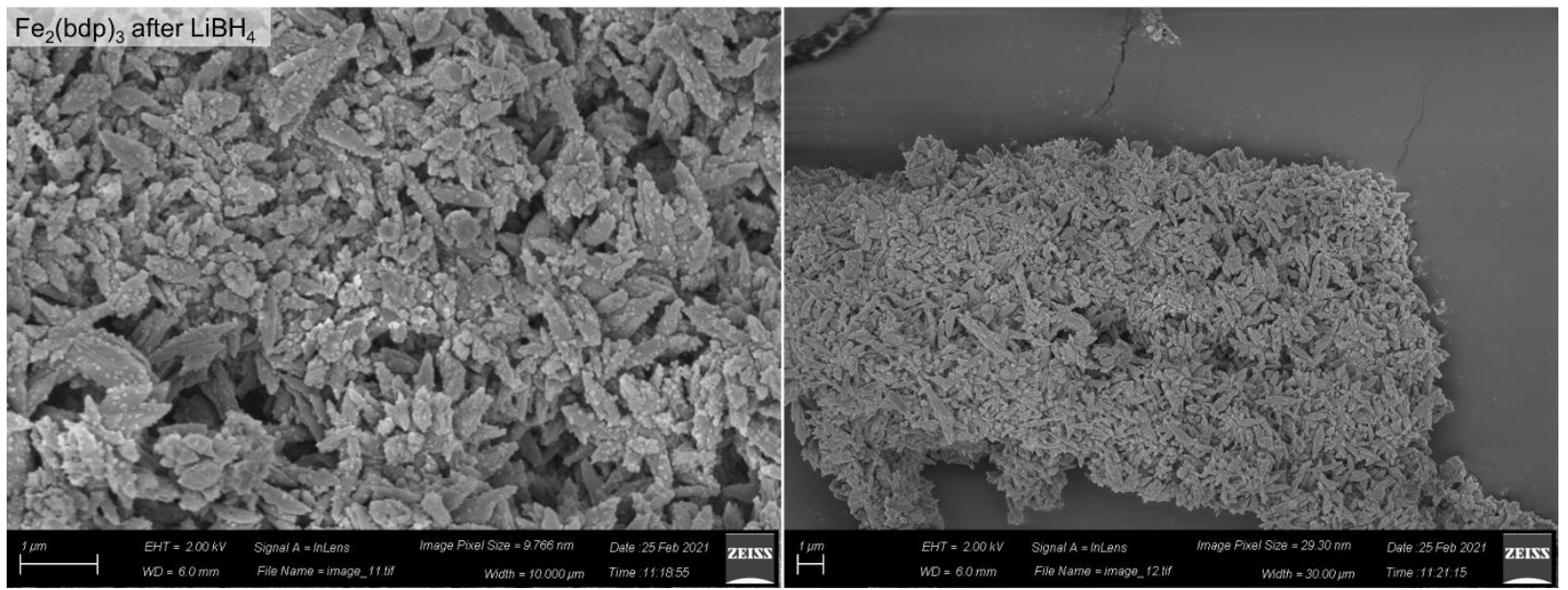

Figure S206. SEM images of $\mathrm{Fe}_{2}(\mathrm{bdp})_{3}$ after treatment with $\mathrm{LiBH}_{4}$, confirming the retention of well-defined crystallites. The presence of additional particles on the surface of the crystallites is evident, which may be due to residual Li-containing salts in the sample.

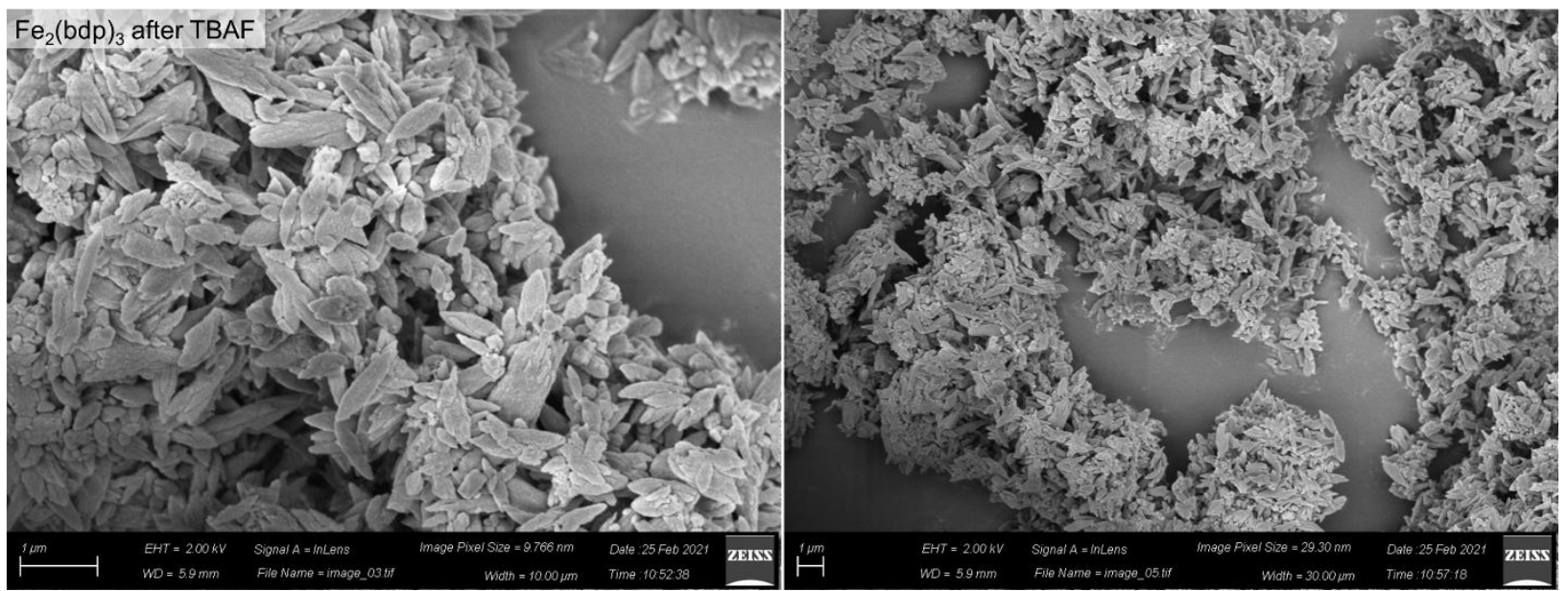

Figure S207. SEM images of $\mathrm{Fe}_{2}(\mathrm{bdp})_{3}$ after treatment with $\mathrm{Br}_{2}$, confirming the retention of welldefined crystallites. 


\section{Additional stability assays for MOF-808.}

$\boldsymbol{n B u N H}$. Approximately $75 \mathrm{mg}$ of activated MOF-808 was submerged in $5 \mathrm{~mL}$ of a freshly prepared $1.0 \mathrm{M}$ solution of $n \mathrm{BuNH}_{2}$ in THF in a $20 \mathrm{~mL}$ scintillation vial. The suspension was allowed to stand at room temperature for $24 \mathrm{~h}$. The mixture was filtered, and the resulting white solid was rinsed thoroughly with THF. The white solid was transferred to a $20 \mathrm{~mL}$ scintillation vial filled with THF (20 mL) and allowed to stand at room temperature for $24 \mathrm{~h}$. The THF was decanted and replaced with fresh THF. This process was repeated for a total of three room temperature THF soaks. The mixture was filtered, and the white solid was transferred to a Micromeritics sample tube equipped with a Sureseal. The sample was reactivated under high vacuum $(<10 \mu$ bar $)$ at $120{ }^{\circ} \mathrm{C}$ for $24 \mathrm{~h}$ prior to gas adsorption measurements.

PCC. Approximately $75 \mathrm{mg}$ of activated MOF-808 was submerged in $5 \mathrm{~mL}$ of a saturated solution of PCC in $\mathrm{CH}_{2} \mathrm{Cl}_{2}$ in a $20 \mathrm{~mL}$ scintillation vial. The suspension was allowed to stand at room temperature for $24 \mathrm{~h}$. The mixture was filtered, and the resulting brown solid was rinsed thoroughly with $\mathrm{CH}_{2} \mathrm{Cl}_{2}$. The brown solid was transferred to a $20 \mathrm{~mL}$ scintillation vial filled with $\mathrm{CH}_{2} \mathrm{Cl}_{2}(20$ $\mathrm{mL}$ ) and allowed to stand at room temperature for $24 \mathrm{~h}$. The $\mathrm{CH}_{2} \mathrm{Cl}_{2}$ was decanted and replaced with fresh $\mathrm{CH}_{2} \mathrm{Cl}_{2}$. This process was repeated for a total of three room temperature $\mathrm{CH}_{2} \mathrm{Cl}_{2}$ soaks. The mixture was filtered, and the brown solid was transferred to a Micromeritics sample tube equipped with a Sureseal. The sample was reactivated under high vacuum $(<10 \mu \mathrm{bar})$ at $120{ }^{\circ} \mathrm{C}$ for $24 \mathrm{~h}$ prior to gas adsorption measurements. After activation, the MOF changed from brown to blue in color, suggesting the presence of residual chromium species within the sample.

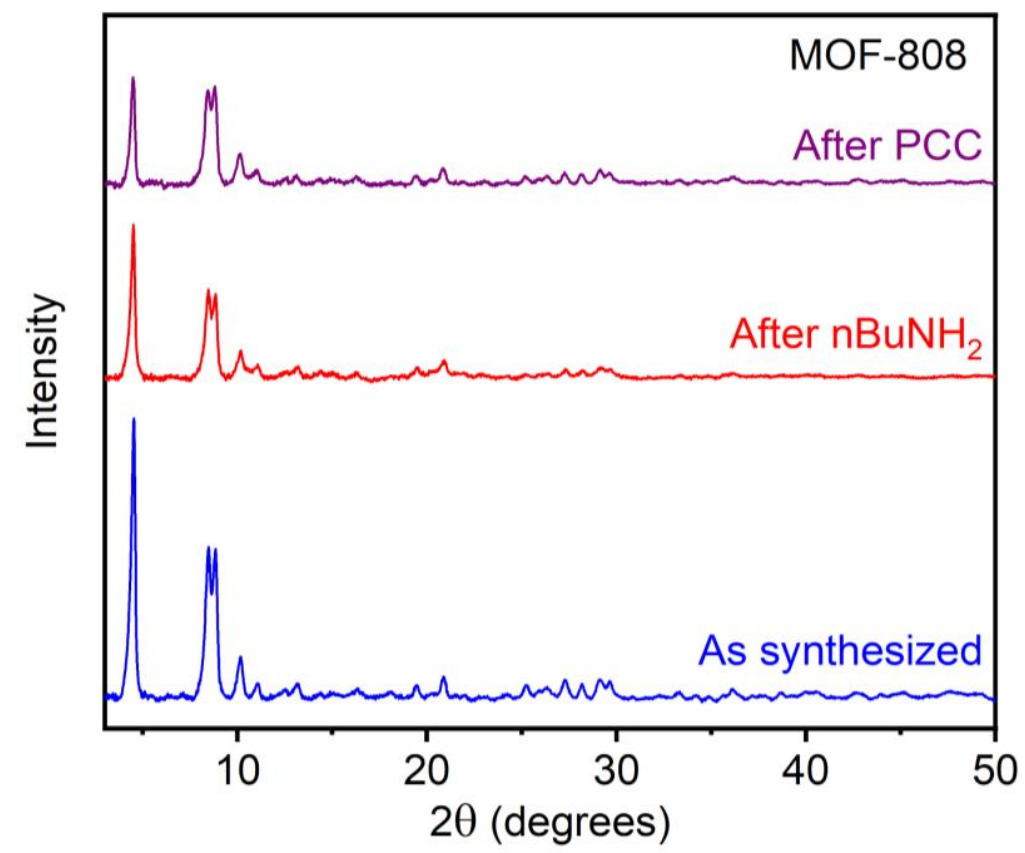

Figure S208. PXRD patterns of MOF-808 before and after representative stability assays. 


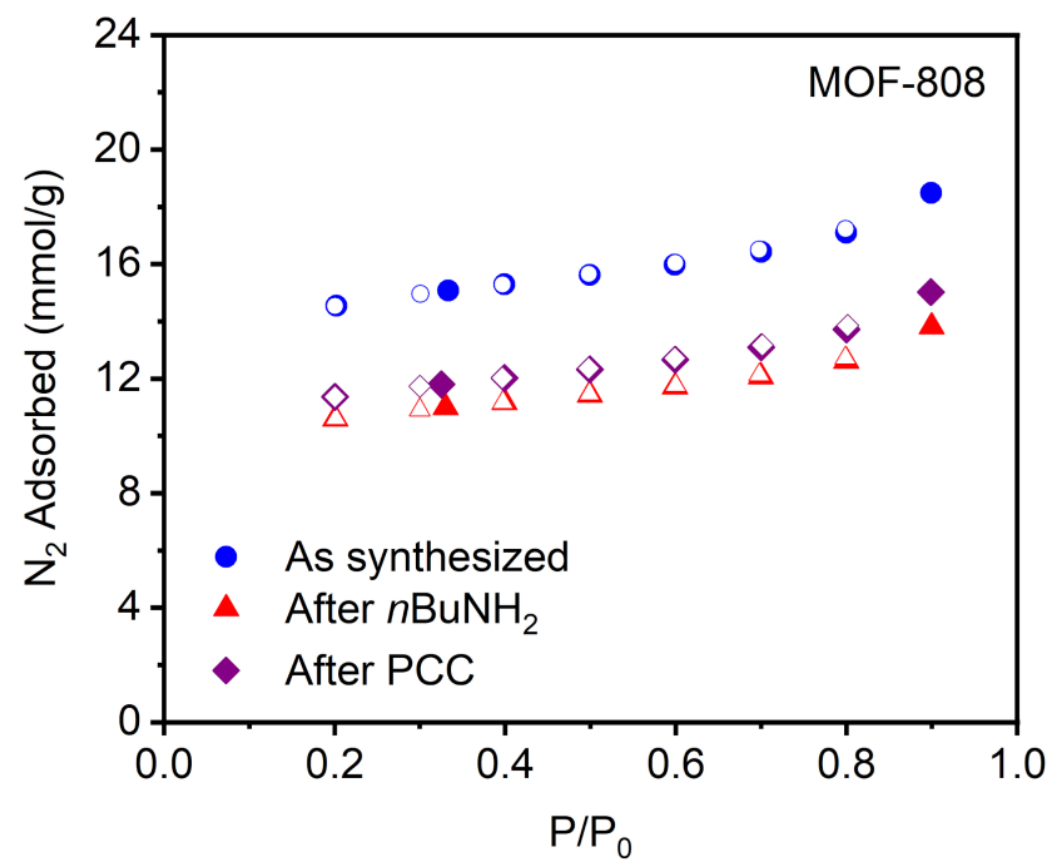

Figure S209. $77 \mathrm{~K} \mathrm{~N}_{2}$ adsorption (filled circles) and desorption (open circles) isotherms of MOF808 before and after representative stability assays. The Langmuir surface areas determined from these data are included in Table S19.

Table S20. Langmuir surface areas and pore volumes of MOF-808 before and after representative stability assays.

\begin{tabular}{|c|c|c|}
\hline Condition & Langmuir Surface Area $\left(\mathrm{m}^{2} / \mathrm{g}\right)$ & $\begin{array}{c}\text { Pore Volume at } P / P_{0} \approx 0.9 \\
\left(\mathrm{~cm}^{3} / \mathrm{g}\right)\end{array}$ \\
\hline As-synthesized & $1574 \pm 14$ & 0.6413 \\
\hline$n \mathrm{BuNH}_{2}$ & $1152 \pm 12$ & 0.5214 \\
\hline $\mathrm{PCC}$ & $1245 \pm 14$ & 0.4794 \\
\hline
\end{tabular}




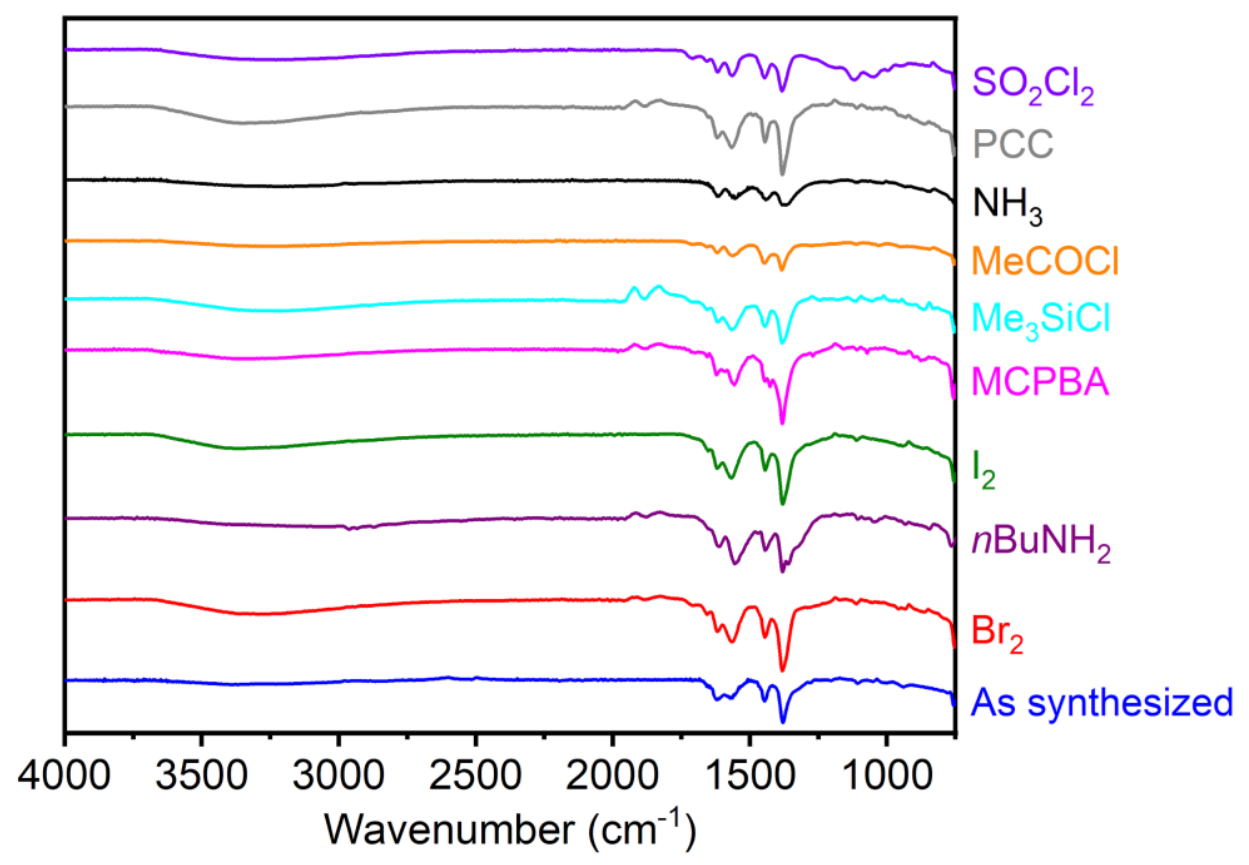

Figure S210. ATR IR spectra of MOF-808 before and after representative successful stability assays. 


\section{Additional stability assays for MOF-74 (Ni).}

I2. Approximately $50 \mathrm{mg}$ of activated MOF-74 (Ni) was submerged in $5 \mathrm{~mL}$ of $1.0 \mathrm{M} \mathrm{I}_{2}$ in $\mathrm{CH}_{2} \mathrm{Cl}_{2}$ in a $20 \mathrm{~mL}$ scintillation vial. The suspension was allowed to stand at room temperature for $24 \mathrm{~h}$. The mixture was filtered, and the resulting black solid was rinsed thoroughly with $\mathrm{CH}_{2} \mathrm{Cl}_{2}$. The brown solid was transferred to a $20 \mathrm{~mL}$ scintillation vial filled with $\mathrm{CH}_{2} \mathrm{Cl}_{2}(20 \mathrm{~mL})$ and allowed to stand at room temperature for $24 \mathrm{~h}$. The $\mathrm{CH}_{2} \mathrm{Cl}_{2}$ was decanted and replaced with fresh $\mathrm{CH}_{2} \mathrm{Cl}_{2}$. This process was repeated every day until the $\mathrm{CH}_{2} \mathrm{Cl}_{2}$ was colorless. At this time, the $\mathrm{CH}_{2} \mathrm{Cl}_{2}$ was decanted and methanol $(20 \mathrm{~mL})$ was added. The suspension was allowed to stand at room temperature for $24 \mathrm{~h}$. The methanol was decanted and replaced with fresh methanol. This process was repeated for a total of three room temperature methanol soaks. The mixture was filtered, and the brown solid was transferred to a Micromeritics sample tube equipped with a Sureseal. The sample was reactivated under high vacuum $(<10 \mu \mathrm{bar})$ at $180^{\circ} \mathrm{C}$ for $24 \mathrm{~h}$ prior to gas adsorption measurements.

Acetic acid. Approximately $50 \mathrm{mg}$ of activated MOF-74 (Ni) was submerged in $5 \mathrm{~mL}$ of glacial acetic acid in a $20 \mathrm{~mL}$ scintillation vial. The suspension was allowed to stand at room temperature for $24 \mathrm{~h}$. The mixture was filtered, and the resulting brown solid was rinsed thoroughly with THF and $\mathrm{CH}_{2} \mathrm{Cl}_{2}$. The brown solid was transferred to a $20 \mathrm{~mL}$ scintillation vial filled with $\mathrm{CH}_{2} \mathrm{Cl}_{2}$ (20 $\mathrm{mL}$ ) and allowed to stand at room temperature for $24 \mathrm{~h}$. The $\mathrm{CH}_{2} \mathrm{Cl}_{2}$ was decanted and replaced with fresh $\mathrm{CH}_{2} \mathrm{Cl}_{2}$. This process was repeated for a total of three room temperature $\mathrm{CH}_{2} \mathrm{Cl}_{2}$ soaks. The mixture was filtered, and the brown solid was transferred to a Micromeritics sample tube equipped with a Sureseal. The sample was reactivated under high vacuum $(<10 \mu \mathrm{bar})$ at $180{ }^{\circ} \mathrm{C}$ for $24 \mathrm{~h}$ prior to gas adsorption measurements. 


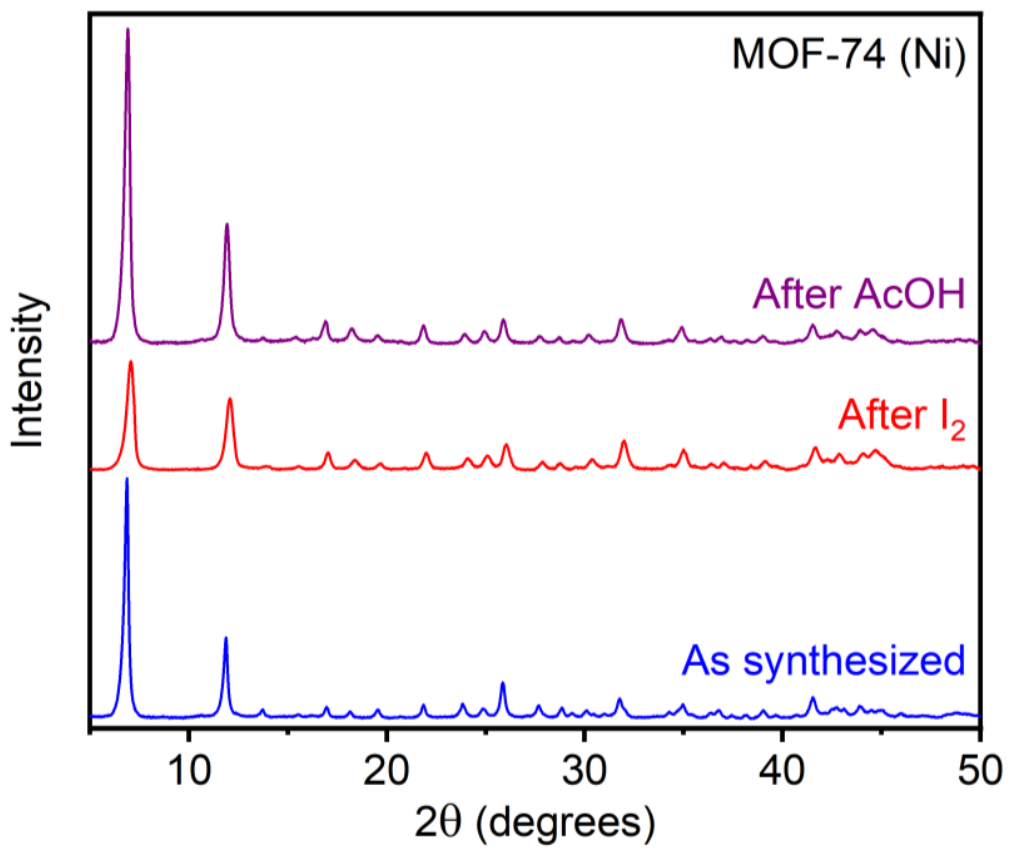

Figure S211. PXRD patterns $(\lambda=1.5406 \AA)$ of MOF-74 (Ni) before and after representative stability assays. The PXRD patterns were baseline-corrected.

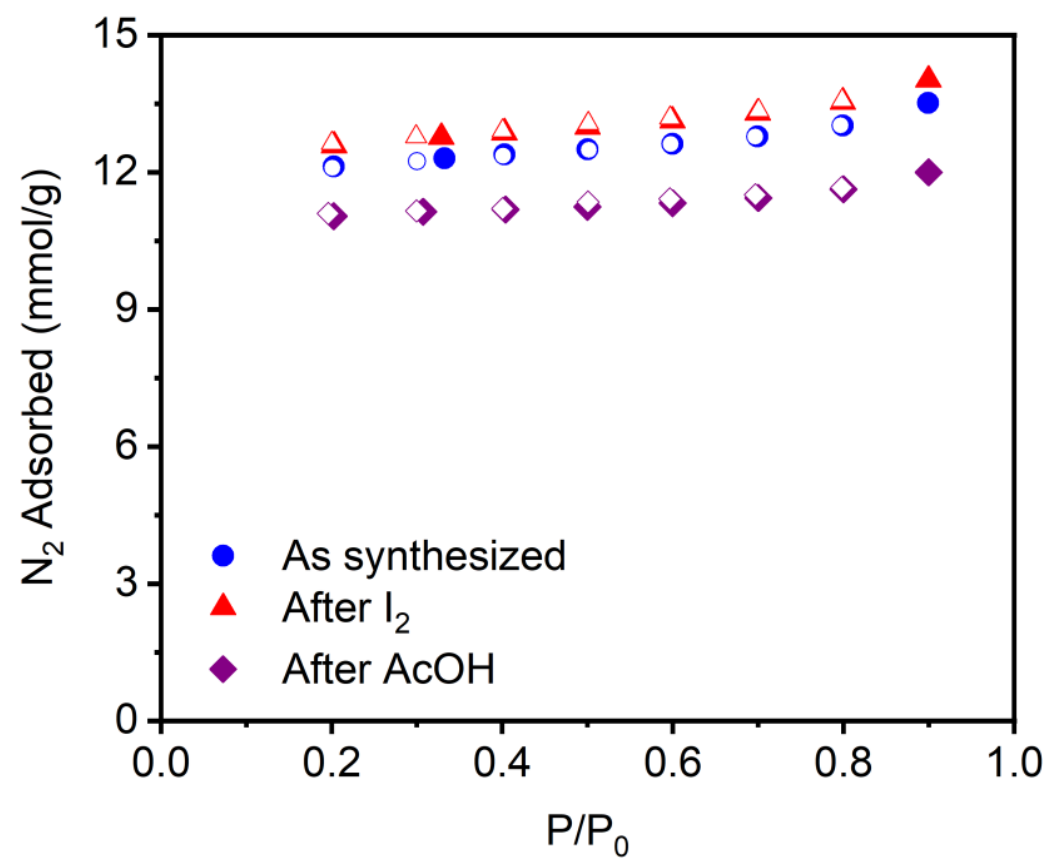

Figure S212. $77 \mathrm{~K} \mathrm{~N}_{2}$ adsorption (filled) and desorption (open) isotherms of MOF-74 (Ni) before and after representative stability assays. The Langmuir surface areas determined from these data are included in Table S20. 
Table S21. Langmuir surface areas and pore volumes of MOF-74 (Ni) before and after representative stability assays.

\begin{tabular}{|c|c|c|}
\hline Condition & Langmuir Surface Area $\left(\mathrm{m}^{2} / \mathrm{g}\right)$ & $\begin{array}{c}\text { Pore Volume at } P / P_{0} \approx 0.9 \\
\left(\mathrm{~cm}^{3} / \mathrm{g}\right)\end{array}$ \\
\hline As-synthesized & $1406 \pm 46$ & 0.4691 \\
\hline After $\mathrm{I}_{2}$ & $1352 \pm 17$ & 0.4862 \\
\hline After AcOH & $1106 \pm 1$ & 0.4164 \\
\hline
\end{tabular}

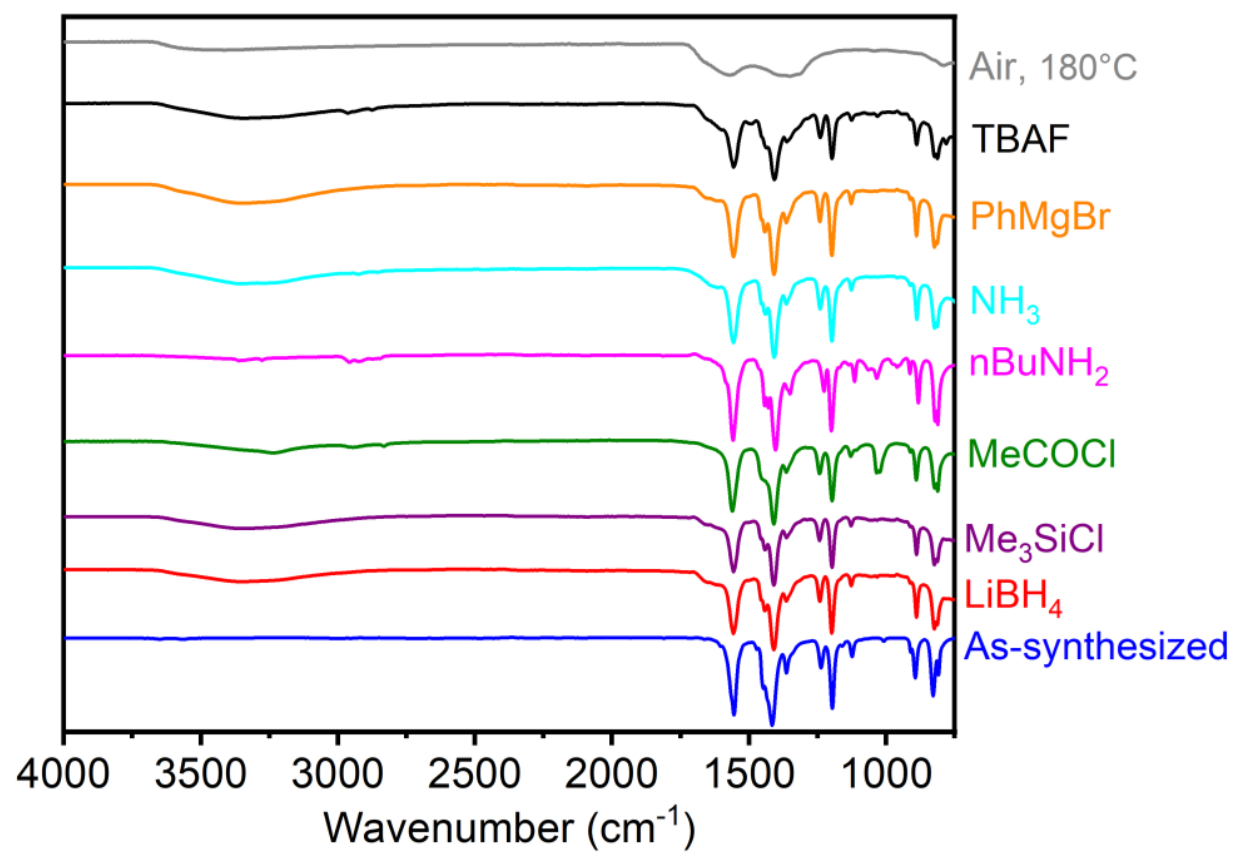

Figure S213. ATR IR spectra of MOF-74 (Ni) before and after representative successful stability assays. 


\section{Stability assessments of defect-rich UiO-66 and UiO-67.}

Synthesis of defect-rich UiO-66. This procedure is adapted from the literature. ${ }^{41}$ A 500 $\mathrm{mL}$ roundbottom flask equipped with a stir bar was charged with $\mathrm{ZrCl}_{4}(1.25 \mathrm{~g}, 5.37 \mathrm{mmol}, 1.00$ equiv.), concentrated hydrochloric acid $(10 \mathrm{~mL})$, and DMF $(50 \mathrm{~mL})$. The mixture was sonicated for $20 \mathrm{~min}$ to fully dissolve the $\mathrm{Zr}$ salts. Next, terephthalic acid (1.23 g, $7.41 \mathrm{mmol}, 1.38$ equiv.) was added along with additional DMF $(100 \mathrm{~mL})$. The flask was sealed with a septum and transferred to a silicone oil bath, which was then heated to $80^{\circ} \mathrm{C}$. The reaction mixture was allowed to stir gently $(300 \mathrm{rpm})$ at $80{ }^{\circ} \mathrm{C}$ for $24 \mathrm{~h}$. During this time, the reaction mixture became homogeneous, followed by precipitation of a white solid from solution. After $24 \mathrm{~h}$, the heterogeneous reaction mixture was allowed to cool to room temperature and filtered. The resulting white solid was transferred to a $500 \mathrm{~mL}$ Pyrex jar with $N, N$-dimethylformamide (250 $\mathrm{mL}$ ). The jar was allowed to stand for $24 \mathrm{~h}$ at room temperature, at which time the $N, N$ dimethylformamide was decanted and replaced with fresh $N, N$-dimethylformamide $(250 \mathrm{~mL})$. This procedure was repeated two additional times for a total of three $N, N$-dimethylformamide soaks. Next, the solid was filtered and returned to the jar with fresh methanol $(250 \mathrm{~mL})$. The solid was soaked in methanol for $24 \mathrm{~h}$ at room temperature three total times following the same procedure as described above. Complete exchange of $N, N$-dimethylformamide for methanol was confirmed by IR spectroscopy. The resulting white solid was filtered and transferred to a Schlenk flask. The solid was activated under flowing $\mathrm{N}_{2}$ at $150{ }^{\circ} \mathrm{C}$ for $4 \mathrm{~h}$, followed by further activation under high vacuum (<100 mbar) at $150{ }^{\circ} \mathrm{C}$ for $24 \mathrm{~h}$. The Schlenk flask was transferred into a $\mathrm{N}_{2}$-filled glovebox, and the activated defect-rich UiO-66 was transferred into a $20 \mathrm{~mL}$ scintillation vial for long-term storage. A portion of the activated sample was transferred to a pre-tared Micromeritics sample tube equipped with a Sureseal. The tube was removed from the glovebox and the sample was further activated under high vacuum $(<10 \mu \mathrm{bar})$ at $150{ }^{\circ} \mathrm{C}$ for $24 \mathrm{~h}$ prior to gas sorption

measurements. The highly defective nature of this material was confirmed by its higher surface area compared to the material prepared without acid modulator. 


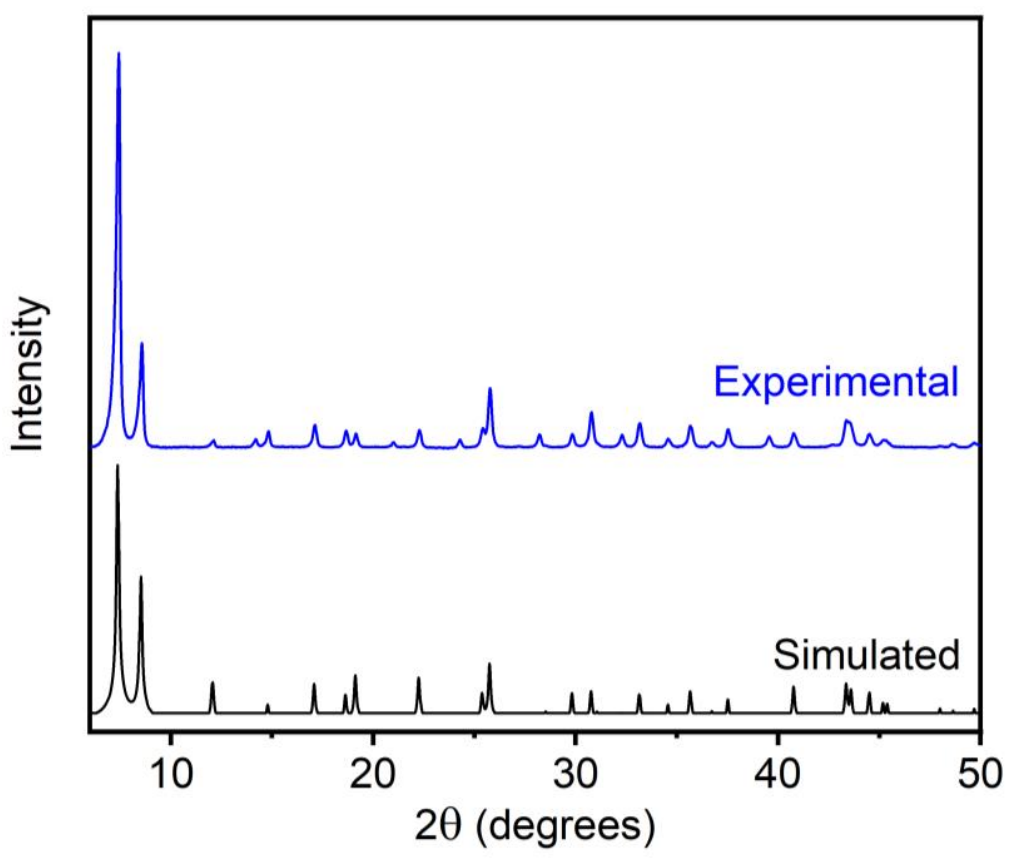

Figure S214. PXRD pattern $(\lambda=1.5406 \AA)$ of methanol-solvated defect-rich UiO-66. The simulated pattern based on the previously reported single-crystal X-ray diffraction structure of UiO-66 is included for reference. ${ }^{18}$ The PXRD pattern of UiO-66 was baseline corrected.

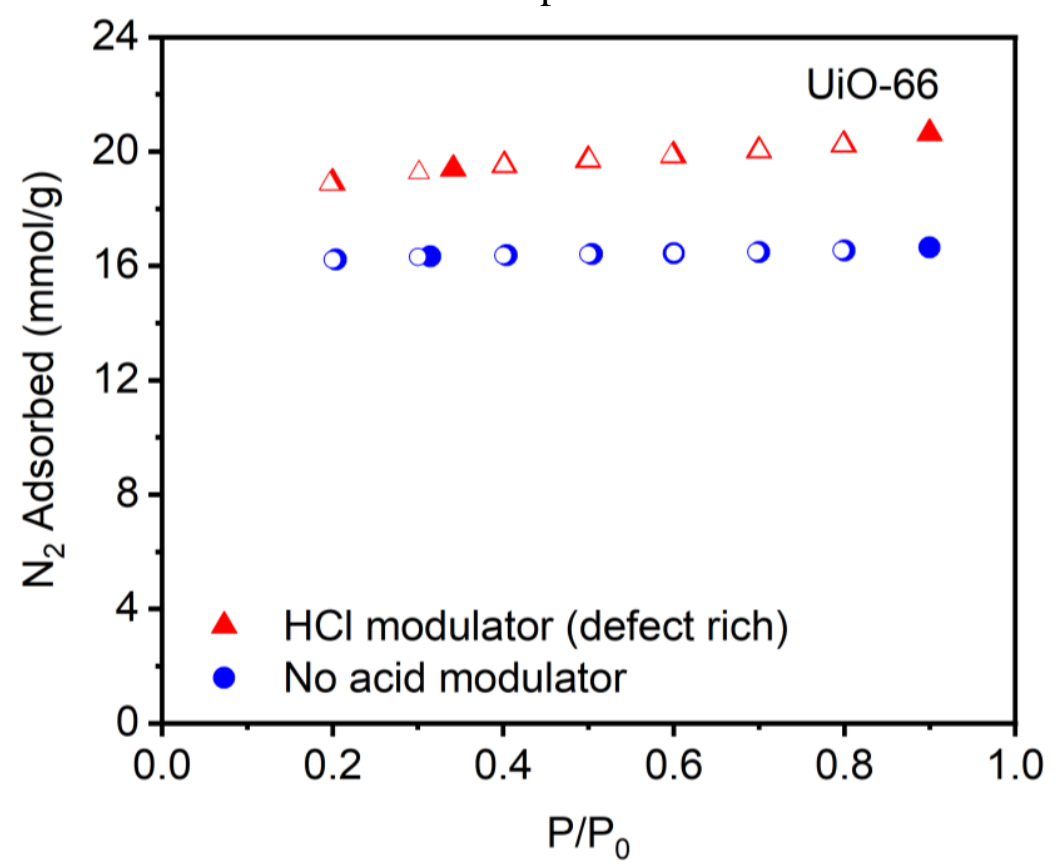

Figure S215. $77 \mathrm{~K} \mathrm{~N}_{2}$ adsorption (filled circles) and desorption (open circles) isotherm of activated, defect-rich UiO-66 (red triangles) compared to material prepared without an acid modulator (blue circles). The Langmuir surface area determined for the defect-rich material is $1988 \pm 8 \mathrm{~m}^{2} / \mathrm{g}$ (compared to $1615 \pm 1 \mathrm{~m}^{2} / \mathrm{g}$ for the material prepared without an acid modulator). The higher surface area of the material prepared using $\mathrm{HCl}$ is due to a higher prevalence of missing linker defects. ${ }^{41}$ 


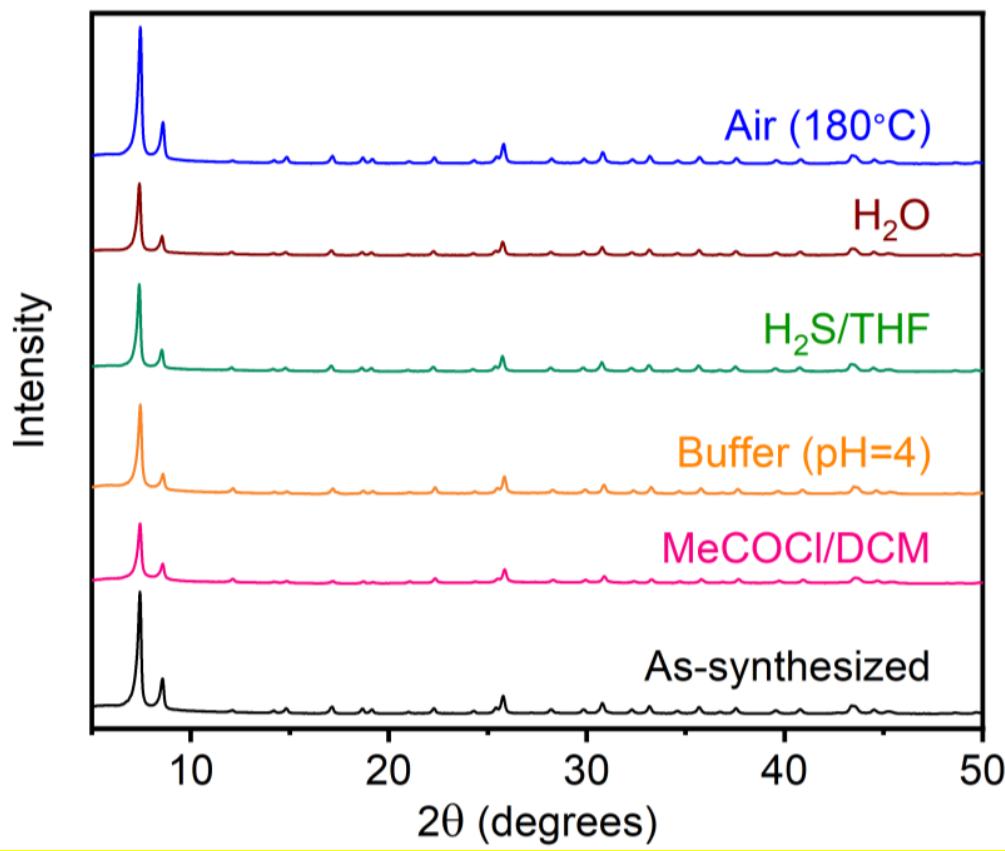

Figure S216. PXRD patterns ( $\lambda=1.5406 \AA)$ of defect-rich UiO-66 upon exposure to representative conditions. Exposure tests include standing in air at $180^{\circ} \mathrm{C}$ for $24 \mathrm{~h}$, deionized water, $0.8 \mathrm{M} \mathrm{H}_{2} \mathrm{~S}$ in THF, aqueous solution buffered at $\mathrm{pH}=4$, and $1.0 \mathrm{M}$ acetyl chloride in dichloromethane. A reference pattern of as-synthesized defect-rich UiO-66 is included.

Table S22. Comparison of robustness assay results for UiO-66 (prepared without an acid modulator) and defect-rich UiO-66 (prepared using $\mathrm{HCl}$ as modulator).

\begin{tabular}{|c|c|c|}
\hline Assay & $\begin{array}{c}\text { UiO-66 } \\
\text { \% Change FWHM }\end{array}$ & $\begin{array}{c}\text { Defect-rich UiO-66 } \\
\text { \% Change FWHM }\end{array}$ \\
\hline $180{ }^{\circ} \mathrm{C}$ Air & 6 & 2 \\
\hline $\mathrm{DI} \mathrm{H}_{2} \mathrm{O}$ & 4 & -1 \\
\hline $\mathrm{pH}=4$ aqueous buffer & 1 & 4 \\
\hline $0.8 \mathrm{M} \mathrm{H}_{2} \mathrm{~S} / \mathrm{THF}$ & 3 & -4 \\
\hline $1.0 \mathrm{M} \mathrm{MeCOCl} / \mathrm{DCM}$ & -8 & 7 \\
\hline
\end{tabular}

These results indicate that UiO-66 prepared without an acid modulator and defect-rich UiO-66 prepared using hydrochloric acid as a modulator likely possess similar robustness towards air, water, acids, nucleophiles, and electrophiles.

Synthesis of defect-rich UiO-67. This procedure is adapted from the literature. ${ }^{41}$ A 500 $\mathrm{mL}$ roundbottom flask equipped with a stir bar was charged with $\mathrm{ZrCl}_{4}(670 \mathrm{mg}, 2.88 \mathrm{mmol}, 1.00$ equiv.), concentrated hydrochloric acid $(5 \mathrm{~mL})$, and DMF $(50 \mathrm{~mL})$. The mixture was sonicated for $20 \mathrm{~min}$ to fully dissolve the Zr salts. Next, 4,4'-biphenyldicarboxylic acid (900 mg, $3.72 \mathrm{mmol}$, 1.29 equiv.) was added along with additional DMF $(100 \mathrm{~mL})$. The flask was sealed with a septum and transferred to a silicone oil bath, which was then heated to $80^{\circ} \mathrm{C}$. The reaction mixture was 
allowed to stir gently $(300 \mathrm{rpm})$ at $80{ }^{\circ} \mathrm{C}$ for $24 \mathrm{~h}$. At no point did the reaction mixture become homogeneous. After $24 \mathrm{~h}$, the heterogeneous reaction mixture was allowed to cool to room temperature and filtered. The resulting off-white solid was transferred to a $500 \mathrm{~mL}$ Pyrex jar with $N, N$-dimethylformamide $(250 \mathrm{~mL})$. The jar was allowed to stand for $24 \mathrm{~h}$ at $100{ }^{\circ} \mathrm{C}$ in an oven, at which time the $N, N$-dimethylformamide was decanted and replaced with fresh $N, N$ dimethylformamide $(250 \mathrm{~mL})$. This procedure was repeated two additional times for a total of three hot $\mathrm{N}, \mathrm{N}$-dimethylformamide soaks. Next, the solid was filtered and returned to the jar with fresh methanol $(250 \mathrm{~mL})$. The solid was soaked in methanol for $24 \mathrm{~h}$ at $60{ }^{\circ} \mathrm{C}$ in an oven three total times following the same procedure as described above. Complete exchange of $N, N$ dimethylformamide for methanol was confirmed by IR spectroscopy. The resulting white solid was filtered and transferred to a Schlenk flask. The solid was activated under flowing $\mathrm{N}_{2}$ at 150 ${ }^{\circ} \mathrm{C}$ for $4 \mathrm{~h}$, followed by further activation under high vacuum ( $\left.<100 \mathrm{mbar}\right)$ at $150{ }^{\circ} \mathrm{C}$ for $24 \mathrm{~h}$. The Schlenk flask was transferred into a $\mathrm{N}_{2}$-filled glovebox, and the activated defect-rich UiO-67 was transferred into a $20 \mathrm{~mL}$ scintillation vial for long-term storage. A portion of the activated sample was transferred to a pre-tared Micromeritics sample tube equipped with a Sureseal. The tube was removed from the glovebox and the sample was further activated under high vacuum $(<10 \mu$ bar $)$ at $150{ }^{\circ} \mathrm{C}$ for $24 \mathrm{~h}$ prior to gas sorption measurements. The highly defective nature of this material was confirmed by its higher surface area compared to the material prepared without acid modulator.

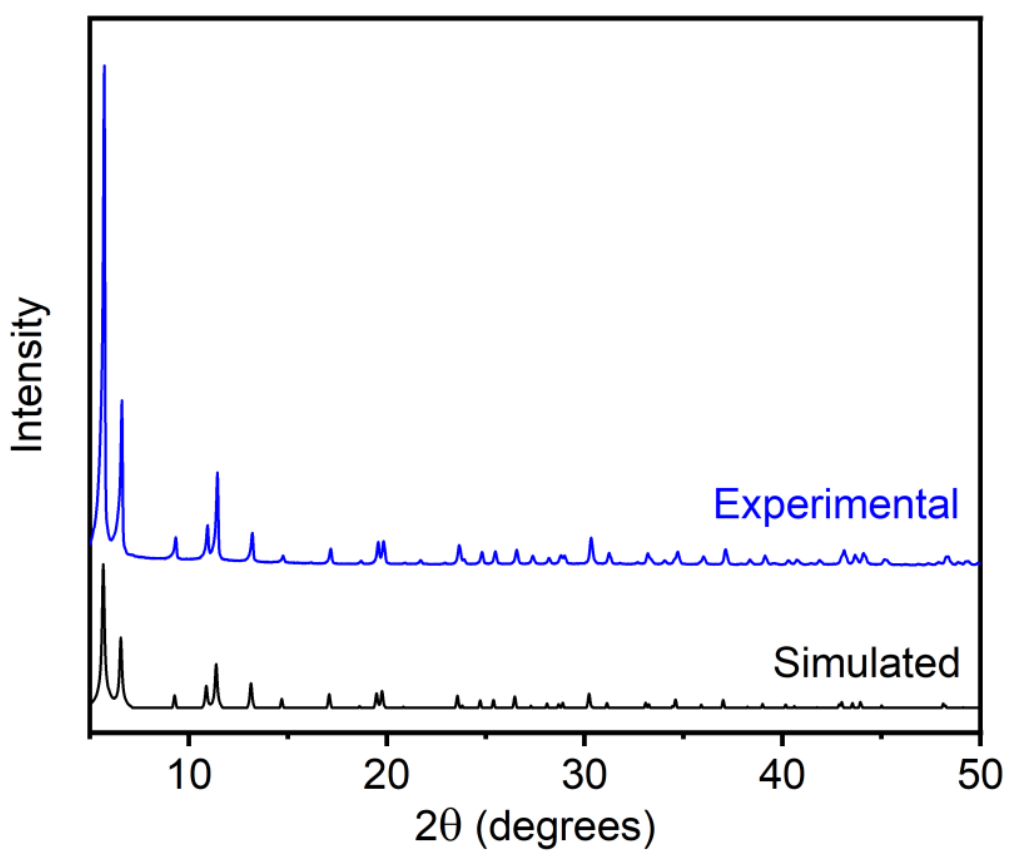

Figure S217. PXRD pattern $(\lambda=1.5406 \AA)$ of methanol-solvated, defect-rich UiO-67. The simulated pattern based on the previously reported single-crystal X-ray diffraction structure of UiO-67 is included for reference. ${ }^{19}$ 


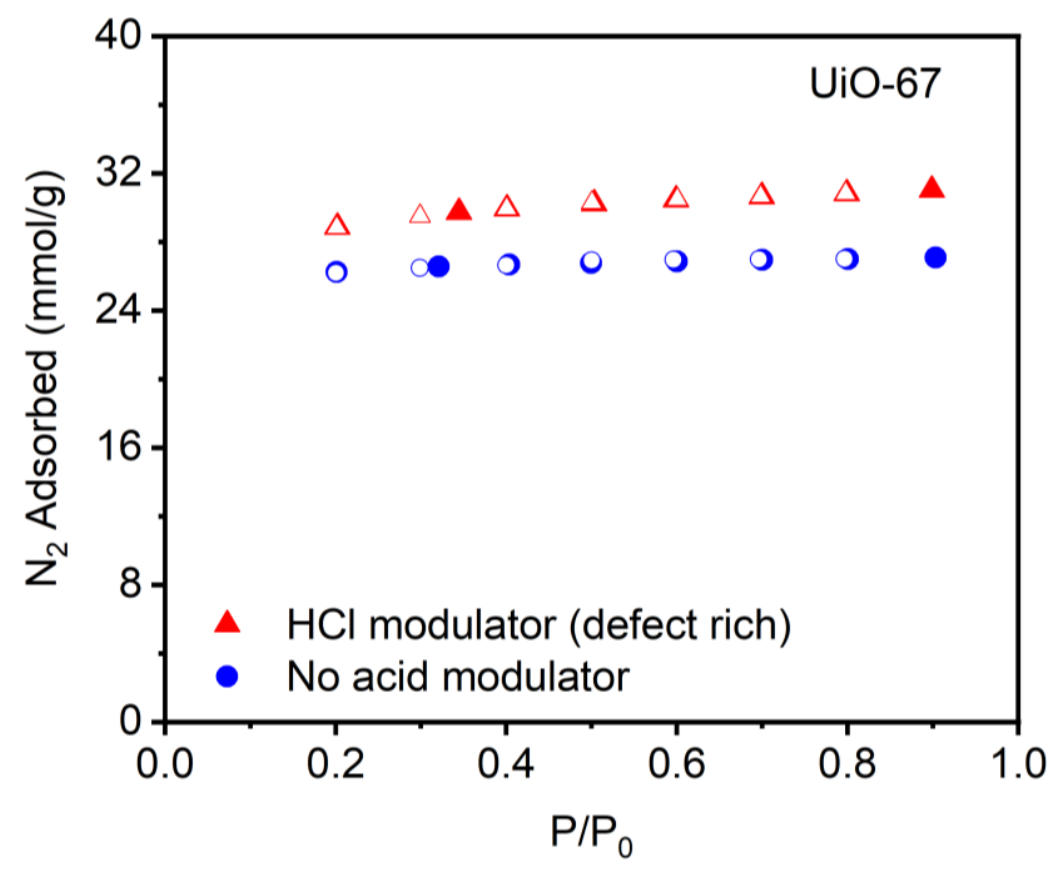

Figure S218. $77 \mathrm{~K} \mathrm{~N}_{2}$ adsorption (filled circles) and desorption (open circles) isotherm of activated, defect-rich UiO-67 (red triangles) compared to material prepared without an acid modulator (blue circles). The Langmuir surface area determined for the defect-rich material is $3056 \pm 9 \mathrm{~m}^{2} / \mathrm{g}$ (compared to $2654 \pm 2$ for the material prepared without an acid modulator). The higher surface area of the material prepared using $\mathrm{HCl}$ is due to a higher prevalence of missing linker defects. ${ }^{41}$ 


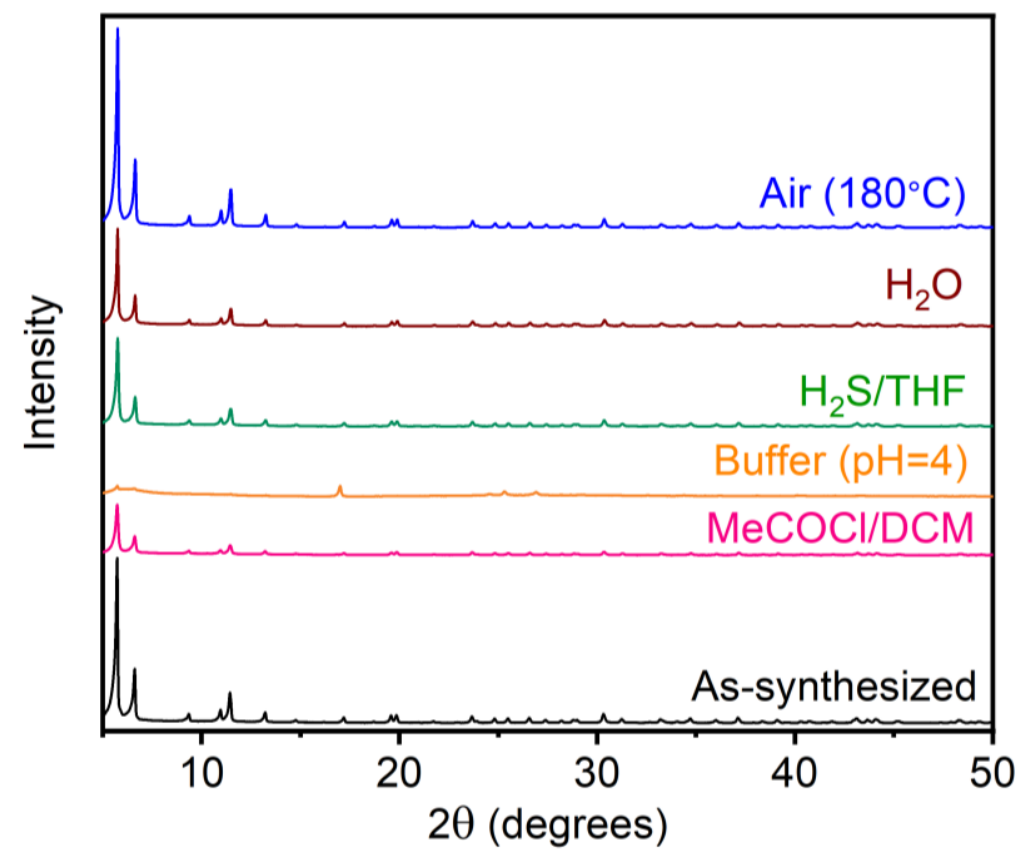

Figure S219. PXRD patterns ( $\lambda=1.5406 \AA)$ of defect-rich UiO-67 upon exposure to representative conditions. Exposure tests include standing in air at $180{ }^{\circ} \mathrm{C}$ for $24 \mathrm{~h}$, deionized water, $0.8 \mathrm{M} \mathrm{H}_{2} \mathrm{~S}$ in THF, aqueous solution buffered at $\mathrm{pH}=4$, and $1.0 \mathrm{M}$ acetyl chloride in dichloromethane. A reference pattern of as-synthesized defect-rich UiO-67 is included.

Table S23. Comparison of robustness assay results for UiO-67 (prepared without an acid modulator) and defect-rich $\mathrm{UiO}-67$ (prepared using $\mathrm{HCl}$ as modulator).

\begin{tabular}{|c|c|c|}
\hline Assay & $\begin{array}{c}\text { UiO-67 } \\
\text { \% Change FWHM }\end{array}$ & $\begin{array}{c}\text { Defect-rich UiO-67 } \\
\text { \% Change FWHM }\end{array}$ \\
\hline $180^{\circ} \mathrm{C}$ Air & 25 & 4 \\
\hline $\mathrm{DI} \mathrm{H}_{2} \mathrm{O}$ & $\times$ & 3 \\
\hline $\mathrm{pH}=4$ aqueous buffer & $\times$ & $\times$ \\
\hline $0.8 \mathrm{M} \mathrm{H}_{2} \mathrm{~S} / \mathrm{THF}$ & 12 & 19 \\
\hline $1.0 \mathrm{M} \mathrm{MeCOCl} / \mathrm{DCM}$ & 49 & 32 \\
\hline
\end{tabular}

These results indicate that defect-rich UiO-67 prepared using hydrochloric acid as a modulator likely possesses similar or even superior robustness compared to UiO-67 prepared without an acid modulator. The improved robustness of defect-rich UiO-67 maybe due to its significantly greater degree of crystallinity. 


\section{References.}

(1) Sun, Z.; Li, Y.; Chen, L.; Jing, X.; Xie, Z. Fluorescent Hydrogen-Bonded Organic Framework for Sensing of Aromatic Compounds. Cryst. Growth Des. 2015, 15 (2), 542-545. https://doi.org/10.1021/cg501652r.

(2) Schultz, A.; Laschat, S.; Diele, S.; Nimtz, M. Tetraphenylethene-Derived Columnar Liquid Crystals and Their Oxidative Photocyclization. Eur. J. Org. Chem. 2003, 2003 (15), 28292839. https://doi.org/10.1002/ejoc.200300118.

(3) Zhang, Q.; Su, J.; Feng, D.; Wei, Z.; Zou, X.; Zhou, H.-C. Piezofluorochromic MetalOrganic Framework: A Microscissor Lift. J. Am. Chem. Soc. 2015, 137 (32), 10064-10067. https://doi.org/10.1021/jacs.5b04695.

(4) Gonzalez, M. I.; Kapelewski, M. T.; Bloch, E. D.; Milner, P. J.; Reed, D. A.; Hudson, M. R.; Mason, J. A.; Barin, G.; Brown, C. M.; Long, J. R. Separation of Xylene Isomers through Multiple Metal Site Interactions in Metal-Organic Frameworks. J. Am. Chem. Soc. 2018, 140 (9), 3412-3422. https://doi.org/10.1021/jacs.7b13825.

(5) Xiao, D. J.; Oktawiec, J.; Milner, P. J.; Long, J. R. Pore Environment Effects on Catalytic Cyclohexane Oxidation in Expanded $\mathrm{Fe}_{2}$ (dobdc) Analogues. J. Am. Chem. Soc. 2016, 138 (43), 14371-14379. https://doi.org/10.1021/jacs.6b08417.

(6) Lundvall, F.; Vajeeston, P.; Wragg, D. S.; Dietzel, P. D. C.; Fjellvåg, H. Two New Series of Coordination Polymers and Evaluation of Their Properties by Density Functional Theory. Cryst. Growth Des. 2016, 16 (1), 339-346. https://doi.org/10.1021/acs.cgd.5b01302.

(7) Gygi, D.; Bloch, E. D.; Mason, J. A.; Hudson, M. R.; Gonzalez, M. I.; Siegelman, R. L.; Darwish, T. A.; Queen, W. L.; Brown, C. M.; Long, J. R. Hydrogen Storage in the Expanded Pore Metal-Organic Frameworks $\mathrm{M}_{2}$ (dobpdc) $(\mathrm{M}=\mathrm{Mg}, \mathrm{Mn}, \mathrm{Fe}, \mathrm{Co}, \mathrm{Ni}, \mathrm{Zn})$. Chem. Mater. 2016, 28 (4), 1128-1138. https://doi.org/10.1021/acs.chemmater.5b04538.

(8) Denysenko, D.; Grzywa, M.; Tonigold, M.; Streppel, B.; Krkljus, I.; Hirscher, M.; Mugnaioli, E.; Kolb, U.; Hanss, J.; Volkmer, D. Elucidating Gating Effects for Hydrogen Sorption in MFU-4-Type Triazolate-Based Metal-Organic Frameworks Featuring Different Pore Sizes. Chem. Eur. J. 2011, 17 (6), 1837-1848. https://doi.org/10.1002/chem.201001872.

(9) Chichak, K.; Jacquemard, U.; Branda, N. R. The Construction of (Salophen)Ruthenium(II) Assemblies Using Axial Coordination. Eur. J. Inog. Chem. 2002, 2002 (2), 357-368. https://doi.org/10.1002/1099-0682(20022)2002:2<357::AID-EJIC357>3.0.CO;2-T.

(10) Colombo, V.; Galli, S.; Choi, H. J.; Han, G. D.; Maspero, A.; Palmisano, G.; Masciocchi, N.; Long, J. R. High Thermal and Chemical Stability in Pyrazolate-Bridged Metal-Organic Frameworks with Exposed Metal Sites. Chem. Sci. 2011, 2 (7), 1311. https://doi.org/10.1039/c1sc00136a.

(11) Kershaw Cook, L. J.; Kearsey, R.; Lamb, J. V.; Pace, E. J.; Gould, J. A. Efficient and Chromatography-Free Methodology for the Modular Synthesis of Oligo-(1 H -Pyrazol-4-Y1)Arenes with Controllable Size, Shape and Steric Bulk. Tetrahedron Lett. 2016, 57 (8), 895898. https://doi.org/10.1016/j.tetlet.2016.01.043.

(12) Jeremias, F.; Henninger, S. K.; Janiak, C. Ambient Pressure Synthesis of MIL-100(Fe) MOF from Homogeneous Solution Using a Redox Pathway. Dalton Trans. 2016, 45 (20), 86378644. https://doi.org/10.1039/C6DT01179A.

(13) Seo, Y.-K.; Yoon, J. W.; Lee, J. S.; Lee, U.-H.; Hwang, Y. K.; Jun, C.-H.; Horcajada, P.; Serre, C.; Chang, J.-S. Large Scale Fluorine-Free Synthesis of Hierarchically Porous Iron(III) 
Trimesate MIL-100(Fe) with a Zeolite MTN Topology. Microporous Mesoporous Mater. 2012, 157, 137-145. https://doi.org/10.1016/j.micromeso.2012.02.027.

(14) Horcajada, P.; Surblé, S.; Serre, C.; Hong, D.-Y.; Seo, Y.-K.; Chang, J.-S.; Grenèche, J.-M.; Margiolaki, I.; Férey, G. Synthesis and Catalytic Properties of MIL-100(Fe), an Iron(III) Carboxylate with Large Pores. Chem. Commun. 2007, No. 27, 2820-2822. https://doi.org/10.1039/B704325B.

(15) Mao, Y.; Qi, H.; Ye, G.; Han, L.; Zhou, W.; Xu, W.; Sun, Y. Green and Time-Saving Synthesis of MIL-100(Cr) and Its Catalytic Performance. Microporous Mesoporous Mater. 2019, 274, 70-75. https://doi.org/10.1016/j.micromeso.2018.07.026.

(16) Férey, G.; Serre, C.; Mellot-Draznieks, C.; Millange, F.; Surblé, S.; Dutour, J.; Margiolaki, I. A Hybrid Solid with Giant Pores Prepared by a Combination of Targeted Chemistry, Simulation, and Powder Diffraction. Angew. Chem. Int. Ed. 2004, 43 (46), 6296-6301. https://doi.org/10.1002/anie.200460592.

(17) Furukawa, H.; Gándara, F.; Zhang, Y.-B.; Jiang, J.; Queen, W. L.; Hudson, M. R.; Yaghi, O. M. Water Adsorption in Porous Metal-Organic Frameworks and Related Materials. J. Am. Chem. Soc. 2014, 136 (11), 4369-4381. https://doi.org/10.1021/ja500330a.

(18) Øien, S.; Wragg, D.; Reinsch, H.; Svelle, S.; Bordiga, S.; Lamberti, C.; Lillerud, K. P. Detailed Structure Analysis of Atomic Positions and Defects in Zirconium Metal-Organic Frameworks. Cryst. Growth Des. 2014, $14 \quad$ (11), 5370-5372. https://doi.org/10.1021/cg501386j.

(19) Marshall, R. J.; Richards, T.; Hobday, C. L.; Murphie, C. F.; Wilson, C.; Moggach, S. A.; Bennett, T. D.; Forgan, R. S. Postsynthetic Bromination of UiO-66 Analogues: Altering Linker Flexibility and Mechanical Compliance. Dalton Trans. 2016, 45 (10), 4132-4135. https://doi.org/10.1039/C5DT03178H.

(20) Zick, M. E.; Lee, J.-H. Fluoroarene Separations in Metal-Organic Frameworks with Two Proximal $\mathrm{Mg}^{2+}$ Coordination Sites. J. Am. Chem. Soc. 2021, 143 (4), 1948-1958. https://doi.org/10.1021/jacs.0c11530

(21) Dietzel, P. D. C.; Johnsen, R. E.; Fjellvåg, H.; Bordiga, S.; Groppo, E.; Chavan, S.; Blom, R. Adsorption Properties and Structure of $\mathrm{CO}_{2}$ Adsorbed on Open Coordination Sites of MetalOrganic Framework $\mathrm{Ni}_{2}$ (dhtp) from Gas Adsorption, IR Spectroscopy and X-Ray Diffraction. Chem. Commun. 2008, No. 41, 5125. https://doi.org/10.1039/b810574j.

(22) Mason, J. A.; Veenstra, M.; Long, J. R. Evaluating Metal-Organic Frameworks for Natural Gas Storage. Chem. Sci. 2014, 5 (1), 32-51. https://doi.org/10.1039/C3SC52633J.

(23) Tayal, A.; Chen, Y.; Song, C.; Hiroi, S.; Kumara, L. S. R.; Palina, N.; Seo, O.; Mukoyoshi, M.; Kobayashi, H.; Kitagawa, H.; Sakata, O. Local Geometry and Electronic Properties of Nickel Nanoparticles Prepared via Thermal Decomposition of Ni-MOF-74. Inorg. Chem. 2018, 57 (16), 10072-10080. https://doi.org/10.1021/acs.inorgchem.8b01230.

(24) Kapelewski, M. T.; Geier, S. J.; Hudson, M. R.; Stück, D.; Mason, J. A.; Nelson, J. N.; Xiao, D. J.; Hulvey, Z.; Gilmour, E.; FitzGerald, S. A.; Head-Gordon, M.; Brown, C. M.; Long, J. R. $\mathrm{M}_{2}(m$-dobdc) $(\mathrm{M}=\mathrm{Mg}, \mathrm{Mn}, \mathrm{Fe}, \mathrm{Co}, \mathrm{Ni})$ Metal-Organic Frameworks Exhibiting Increased Charge Density and Enhanced $\mathrm{H}_{2}$ Binding at the Open Metal Sites. J. Am. Chem. Soc. 2014, 136 (34), 12119-12129. https://doi.org/10.1021/ja506230r.

(25) Bachman, J. E.; Kapelewski, M. T.; Reed, D. A.; Gonzalez, M. I.; Long, J. R. M2(m -dobdc) $(\mathrm{M}=\mathrm{Mn}, \mathrm{Fe}, \mathrm{Co}, \mathrm{Ni})$ Metal-Organic Frameworks as Highly Selective, High-Capacity Adsorbents for Olefin/Paraffin Separations. J. Am. Chem. Soc. 2017, 139 (43), 15363-15370. https://doi.org/10.1021/jacs.7b06397. 
(26) Siegelman, R. L.; McDonald, T. M.; Gonzalez, M. I.; Martell, J. D.; Milner, P. J.; Mason, J. A.; Berger, A. H.; Bhown, A. S.; Long, J. R. Controlling Cooperative $\mathrm{CO}_{2}$ Adsorption in Diamine-Appended $\mathrm{Mg}_{2}$ (dobpdc) Metal-Organic Frameworks. J. Am. Chem. Soc. 2017, 139 (30), 10526-10538. https://doi.org/10.1021/jacs.7b05858.

(27) Milner, P. J.; Martell, J. D.; Siegelman, R. L.; Gygi, D.; Weston, S. C.; Long, J. R. Overcoming Double-Step $\mathrm{CO}_{2}$ Adsorption and Minimizing Water Co-Adsorption in Bulky Diamine-Appended Variants of $\mathrm{Mg}_{2}$ (dobpdc). Chem. Sci. 2018, 9 (1), 160-174. https://doi.org/10.1039/C7SC04266C.

(28) Lee, Y.-R.; Jang, M.-S.; Cho, H.-Y.; Kwon, H.-J.; Kim, S.; Ahn, W.-S. ZIF-8: A Comparison of Synthesis Methods. Chem. Eng. J. 2015, 271, 276-280. https://doi.org/10.1016/j.cej.2015.02.094.

(29) Morris, W.; Stevens, C. J.; Taylor, R. E.; Dybowski, C.; Yaghi, O. M.; Garcia-Garibay, M. A. NMR and X-Ray Study Revealing the Rigidity of Zeolitic Imidazolate Frameworks. J. Phys. Chem. C 2012, 116 (24), 13307-13312. https://doi.org/10.1021/jp303907p.

(30) Rieth, A. J.; Wright, A. M.; Skorupskii, G.; Mancuso, J. L.; Hendon, C. H.; Dincă, M. RecordSetting Sorbents for Reversible Water Uptake by Systematic Anion Exchanges in MetalOrganic Frameworks. J. Am. Chem. Soc. 2019, 141 (35), 13858-13866. https://doi.org/10.1021/jacs.9b06246.

(31) Rieth, A. J.; Tulchinsky, Y.; Dincă, M. High and Reversible Ammonia Uptake in Mesoporous Azolate Metal-Organic Frameworks with Open Mn, Co, and Ni Sites. J. Am. Chem. Soc. 2016, 138 (30), 9401-9404. https://doi.org/10.1021/jacs.6b05723.

(32) Colombo, V.; Montoro, C.; Maspero, A.; Palmisano, G.; Masciocchi, N.; Galli, S.; Barea, E.; Navarro, J. A. R. Tuning the Adsorption Properties of Isoreticular Pyrazolate-Based MetalOrganic Frameworks through Ligand Modification. J. Am. Chem. Soc. 2012, 134 (30), 12830-12843. https://doi.org/10.1021/ja305267m.

(33) Choi, H. J.; Dincă, M.; Long, J. R. Broadly Hysteretic H 2 Adsorption in the Microporous Metal-Organic Framework Co(1,4-Benzenedipyrazolate). J. Am. Chem. Soc. 2008, 130 (25), 7848-7850. https://doi.org/10.1021/ja8024092.

(34) Galli, S.; Masciocchi, N.; Colombo, V.; Maspero, A.; Palmisano, G.; López-Garzón, F. J.; Domingo-García, M.; Fernández-Morales, I.; Barea, E.; Navarro, J. A. R. Adsorption of Harmful Organic Vapors by Flexible Hydrophobic Bis-Pyrazolate Based MOFs. Chem. Mater. 2010, 22 (5), 1664-1672. https://doi.org/10.1021/cm902899t.

(35) Herm, Z. R.; Wiers, B. M.; Mason, J. A.; van Baten, J. M.; Hudson, M. R.; Zajdel, P.; Brown, C. M.; Masciocchi, N.; Krishna, R.; Long, J. R. Separation of Hexane Isomers in a MetalOrganic Framework with Triangular Channels. Science 2013, 340 (6135), 960-964. https://doi.org/10.1126/science.1234071.

(36) Peng, J.; Xian, S.; Xiao, J.; Huang, Y.; Xia, Q.; Wang, H.; Li, Z. A Supported Cu(I)@MIL100(Fe) Adsorbent with High CO Adsorption Capacity and CO/ $\mathrm{N}_{2}$ Selectivity. Chem. Eng. J. 2015, 270, 282-289. https://doi.org/10.1016/j.cej.2015.01.126.

(37) Cavka, J. H.; Jakobsen, S.; Olsbye, U.; Guillou, N.; Lamberti, C.; Bordiga, S.; Lillerud, K. P. A New Zirconium Inorganic Building Brick Forming Metal Organic Frameworks with Exceptional Stability. J. Am. Chem. Soc. 2008, 130 (42), 13850-13851. https://doi.org/10.1021/ja8057953.

(38) Gonzalez, M. I.; Bloch, E. D.; Mason, J. A.; Teat, S. J.; Long, J. R. Single-Crystal-to-SingleCrystal Metalation of a Metal-Organic Framework: A Route toward Structurally Well- 
Defined Catalysts. Inorg. Chem. 2015, $54 \quad$ (6), 2995-3005. https://doi.org/10.1021/acs.inorgchem.5b00096.

(39) Queen, W. L.; Hudson, M. R.; Bloch, E. D.; Mason, J. A.; Gonzalez, M. I.; Lee, J. S.; Gygi, D.; Howe, J. D.; Lee, K.; Darwish, T. A.; James, M.; Peterson, V. K.; Teat, S. J.; Smit, B.; Neaton, J. B.; Long, J. R.; Brown, C. M. Comprehensive Study of Carbon Dioxide Adsorption in the Metal-Organic Frameworks $\mathrm{M}_{2}$ (dobdc) $(\mathrm{M}=\mathrm{Mg}, \mathrm{Mn}, \mathrm{Fe}, \mathrm{Co}, \mathrm{Ni}, \mathrm{Cu}, \mathrm{Zn})$. Chem. Sci. 2014, 5 (12), 4569-4581. https://doi.org/10.1039/C4SC02064B.

(40) Park, K. S.; Ni, Z.; Cote, A. P.; Choi, J. Y.; Huang, R.; Uribe-Romo, F. J.; Chae, H. K.; O'Keeffe, M.; Yaghi, O. M. Exceptional Chemical and Thermal Stability of Zeolitic Imidazolate Frameworks. Proc. Natl. Acad. Sci. 2006, 103 (27), 10186-10191. https://doi.org/10.1073/pnas.0602439103.

(41) Katz, M. J.; Brown, Z. J.; Colón, Y. J.; Siu, P. W.; Scheidt, K. A.; Snurr, R. Q.; Hupp, J. T.; Farha, O. K. A Facile Synthesis of UiO-66, UiO-67 and Their Derivatives. Chem. Commun. 2013, 49 (82), 9449. https://doi.org/10.1039/c3cc46105j. 